\author{
RECEIVED \\ OCT 201995 \\ OSTI
}

INEL-95/0013

Revision 0

June 1995

\title{
Waste Management Facilities Cost Information for Low-Level Waste
}

David Shropshire Michael Sherick Chuck Biagi 
INEL-95/0013

Revision 0

\section{Waste Management Facilities Cost Information for Low-Level Waste}

David Shropshire

Michael Sherick

Chuck Biagi

Published June 1995

\section{Idaho National Engineering Laboratory \\ Lockheed Martin Idaho Technologies \\ Radioactive Waste Technical Support Program \\ Idaho Falls, Idaho 83415}

Prepared for the

U.S. Department of Energy Office of Environmental Management Under DOE Idaho Operations Office Contract DE-AC07-94ID13223 


\section{DISCLAIMER}

Portions of this document may be illegible in electronic image products. Images are produced from the best available original document. 
Waste Management Facilities Cost Information for Low-Level Waste

INEL-95/0013

Prepared by:
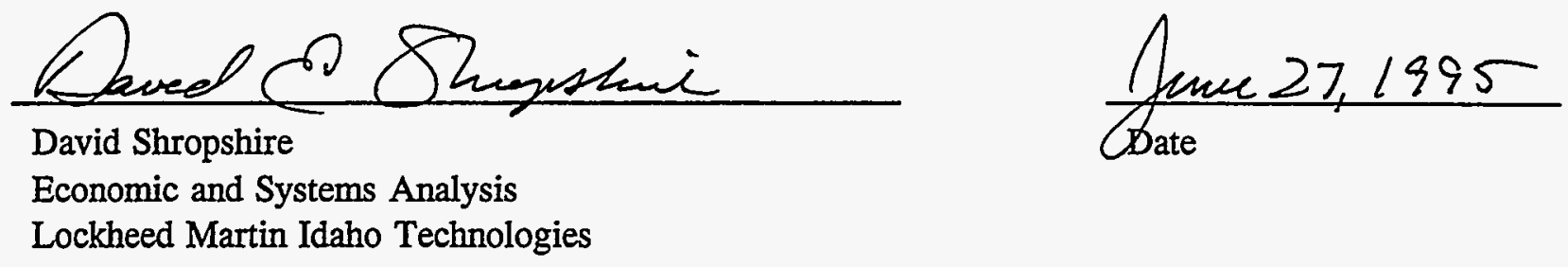

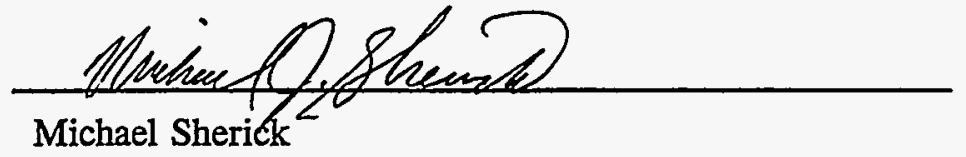

Economic and Systems Analysis

Lockheed Martin Idaho Technologies

Chuck Bragi

Chuck Bragi

Environmental Services Division

Morrison Knudsen Corporation

Reviewed by:

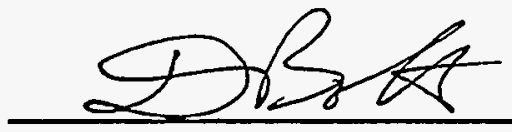

Derek Bolton

Environmental Services Division

Morrison Knudsen Corporation

Reviewed and approved by:

LEa whens

R. Eric Williams, Manager

Radioactive Waste Technical Support Program

Lockheed Martin Idaho Technologies

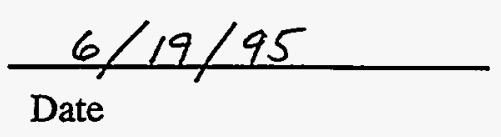

$\frac{6-16-95}{\text { Date }}$
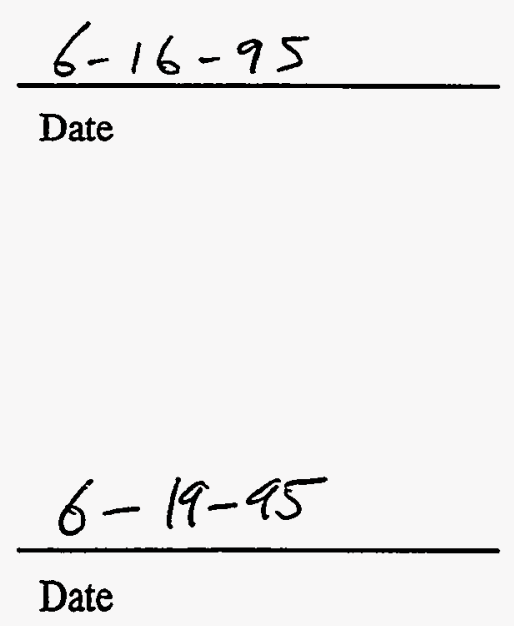


\begin{abstract}
This report contains preconceptual designs and planning level life-cycle cost estimates for managing low-level waste. The report's information on treatment, storage, and disposal modules can be integrated to develop total lifecycle costs for various waste management options. A procedure to guide the U.S. Department of Energy and its contractor personnel in the use of cost estimation data is also summarized in this report.
\end{abstract}


- 


\section{CONTENTS}

ABSTRACT $\ldots \ldots \ldots \ldots \ldots \ldots \ldots \ldots \ldots \ldots \ldots \ldots \ldots \ldots \ldots \ldots \ldots \ldots \ldots$

ACRONYMS $\ldots \ldots \ldots \ldots \ldots \ldots \ldots \ldots \ldots \ldots \ldots \ldots \ldots \ldots \ldots \ldots \ldots \ldots \ldots \ldots$

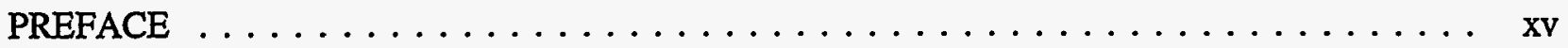

1. INTRODUCTION AND SUMMARY $\ldots \ldots \ldots \ldots \ldots \ldots \ldots \ldots \ldots$

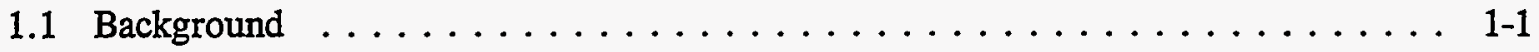

1.2 Waste Management Facility Cost Information Task Participants . . . . . . . . . 1-1

1.3 Modules and Unit Operations $\ldots \ldots \ldots \ldots \ldots \ldots \ldots \ldots \ldots \ldots \ldots \ldots \ldots$

1.4 Technical and Cost Estimate Bases and Assumptions . . . . . . . . . . . . . . . 1-2

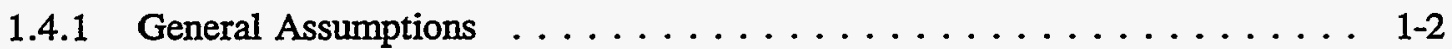

1.4 .2 Facility Operation Assumptions . . . . . . . . . . . . . . 1-3

1.4.3 Mass Flow Rate Calculations ................. 1-3

1.4 .4 Cost Bases . . . . . . . . . . . . . . . . . . . 1-3

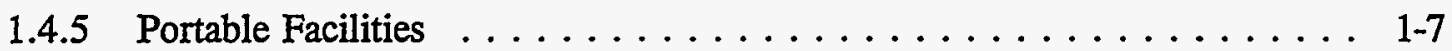

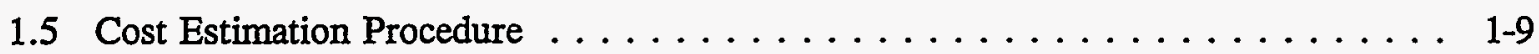

1.6 Cost Assessment Activities . . . . . . . . . . . . . . . 1-9

1.7 Limitations . . . . . . . . . . . . . . . . . . . 1-10

2. TREATMENT ADMINISTRATION (MODULE TADMN) . . . . . . . . 2-1

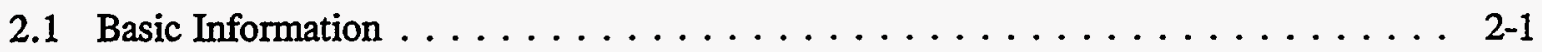

2.2 Technical Bases and Assumptions . . . . . . . . . . . . . . 2-1

2.2.1 Function and Operation of Large Generator Modules . . . . . . . . 2-1

2.2.2 Integration of Large Generator Modules . . . . . . . . . . . 2-1

2.2.3 Small Generator and Portable Modules . . . . . . . . . . . . . 2-1

2.3 Cost Bases, Assumptions, and Results . . . . . . . . . . . . . 2-1

3. RECEIVING AND INSPECTION (MODULE RCINS) $\ldots \ldots \ldots \ldots \ldots \ldots \ldots$

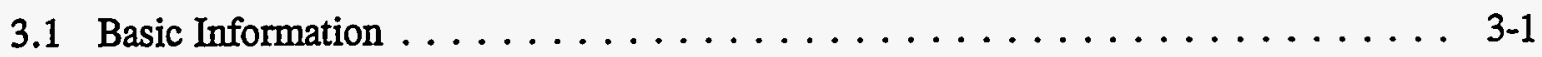

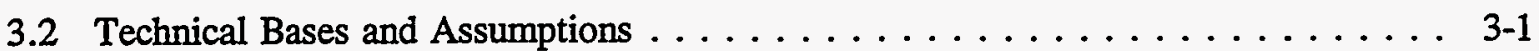


3.2.1 Function and Operation of Large Generator Modules . . . . . . . . . 3-1

3.2.2 Integration of Large Generator Modules . . . . . . . . . . . . . 3-2

3.2 .3 Small Generator Fixed Module $\ldots \ldots \ldots \ldots \ldots \ldots \ldots$. . . . . . . .

3.3 Cost Bases, Assumptions, and Results . . . . . . . . . . . . . . 3-2

4. SMALL GENERATOR FRONT-END AND BACK-END SUPPORT (MODULE

FBSPT) $\ldots \ldots \ldots \ldots \ldots \ldots \ldots \ldots \ldots \ldots \ldots \ldots \ldots \ldots \ldots \ldots \ldots \ldots \ldots \ldots$

4.1 Basic Information $\ldots \ldots \ldots \ldots \ldots \ldots \ldots \ldots \ldots \ldots \ldots \ldots$

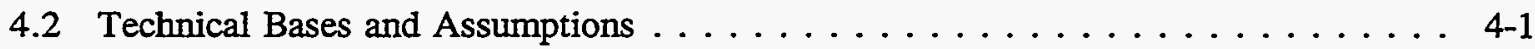

4.2.1 Function and Operation of the Module .............. 4-1

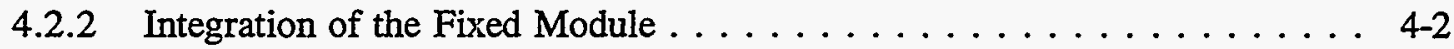

4.3 Cost Bases, Assumptions, and Results . . . . . . . . . . . . . 4-2

5. OPEN, DUMP, AND SORT (MODULE OSORT) $\ldots \ldots \ldots \ldots \ldots \ldots$

5.1 Basic Information $\ldots \ldots \ldots \ldots \ldots \ldots \ldots \ldots \ldots \ldots \ldots \ldots \ldots \ldots$

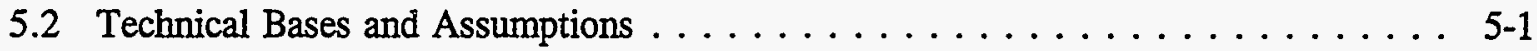

5.2.1 Function and Operation of Large Generator Modules . . . . . . . . . . 5-1

5.2.2 Integration of Large Generator Modules . . . . . . . . . . . . 5-2

5.2.3 Small Generator Fixed and Portable Module . . . . . . . . . . . . . 5-2

5.3 Cost Bases, Assumptions, and Results . . . . . . . . . . . . 5-2

6. MAINTENANCE (MODULE MAINT) $\ldots \ldots \ldots \ldots \ldots \ldots \ldots \ldots$

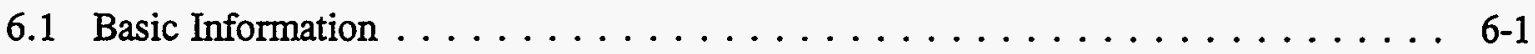

6.2 Technical Bases and Assumptions . . . . . . . . . . . . 6-1

6.2.1 Function and Operation of Large Generator Modules . . . . . . . . . 6-1

6.2 .2 Integration of Large Generator Modules . . . . . . . . . . . . 6-1

6.2 .3 Small Generator Module ................... 6-1

6.3 Cost Bases, Assumptions, and Results . . . . . . . . . . . . . 6 6-1

7. INCINERATION (MODULE INCIN) $\ldots \ldots \ldots \ldots \ldots \ldots \ldots \ldots \ldots$

7.1 Basic Information . . . . . . . . . . . . . . . .

7.2 Technical Bases and Assumptions . . . . . . . . . . . . . 7-1 
7.2.1 Function and Operation of Large Generator Modules . . . . . . . . 7-1

7.2.2 Integration of Large Generator Modules . . . . . . . . . . . .

7.2.3 Function and Operation of Small Generator Fixed Module in a New or Existing Building $\ldots \ldots \ldots \ldots \ldots \ldots \ldots \ldots \ldots \ldots \ldots \ldots \ldots \ldots \ldots$

7.2.4 Integration of Small Generator Fixed Module in a New or Existing

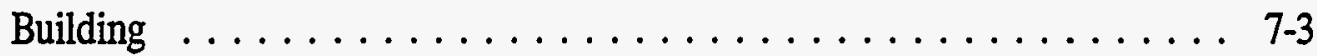

7.2.5 Function and Operation of Portable Module $\ldots \ldots \ldots \ldots \ldots \ldots$ 7-3

7.3 Cost Bases, Assumptions, and Results $\ldots \ldots \ldots \ldots \ldots \ldots \ldots \ldots \ldots$ 7-3

8. METAL MELTING (MODULE MMELT) $\ldots \ldots \ldots \ldots \ldots \ldots \ldots$ 8-1

8.1 Basic Information $\ldots \ldots \ldots \ldots \ldots \ldots \ldots \ldots \ldots \ldots \ldots \ldots \ldots \ldots$

8.2 Technical Bases and Assumptions . . . . . . . . . . . . . . 8-1

8.2.1 Function and Operation of the Module $\ldots \ldots \ldots \ldots \ldots \ldots \ldots$ 8 1

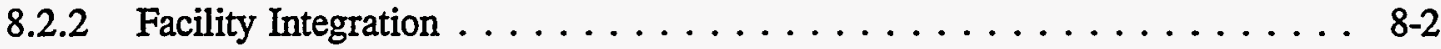

8.3 Cost Bases, Assumptions, and Results $\ldots \ldots \ldots \ldots \ldots \ldots \ldots \ldots$. $8-2$

9. SPECIAL WASTE PROCESSING (MODULE SPECL) $\ldots \ldots \ldots \ldots \ldots \ldots .9 .1$

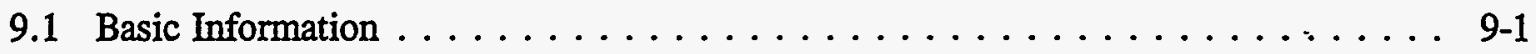

9.2 Technical Bases and Assumptions . . . . . . . . . . . . . . . 9-1

9.2.1 Function and Operation of the Module $\ldots \ldots \ldots \ldots \ldots \ldots \ldots$ 9-1

9.2.2 Integration of the Module . . . . . . . .

9.3 Cost Bases, Assumptions, and Results $\ldots \ldots \ldots \ldots \ldots \ldots \ldots \ldots$ 9-1

10. METAL SIZING/DECONTAMINATION FACILITY (MODULE DECON) $\ldots \ldots \ldots$ 10-1

10.1 Basic Information $\ldots \ldots \ldots \ldots \ldots \ldots \ldots \ldots \ldots \ldots \ldots \ldots \ldots \ldots \ldots \ldots$

10.2 Technical Bases and Assumptions . . . . . . . . . . . . .

10.2.1 Function and Operation of the Module $\ldots \ldots \ldots \ldots \ldots \ldots \ldots$ 10-1

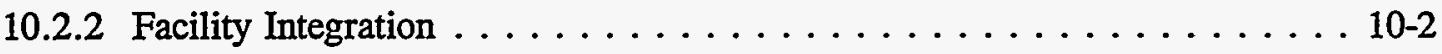

10.3 Cost Summaries . . . . . . . . . . . . . . . . . . . . . 10-3

11. NEUTRALIZATION (MODULE NEUTR) $\ldots \ldots \ldots \ldots \ldots \ldots \ldots \ldots \ldots \ldots \ldots \ldots$

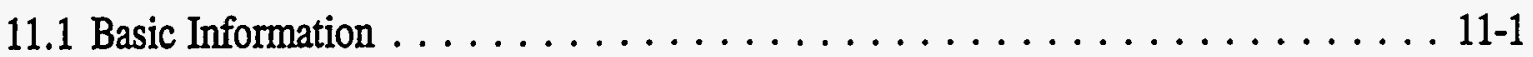




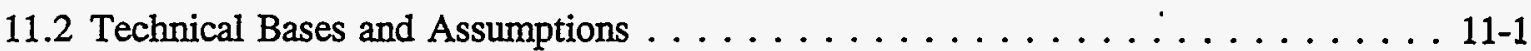

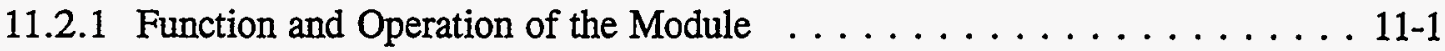

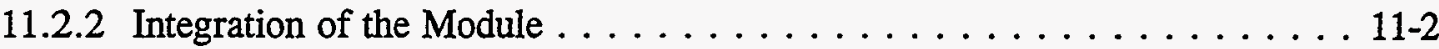

11.3 Cost Bases, Assumptions, and Results $\ldots \ldots \ldots \ldots \ldots \ldots \ldots \ldots \ldots \ldots \ldots \ldots .2$

12. GROUT STABILIZATION (MODULE GROUT) $\ldots \ldots \ldots \ldots \ldots \ldots \ldots \ldots \ldots$ 12-1

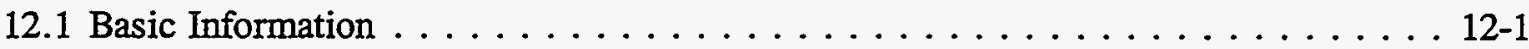

12.2 Technical Bases and Assumptions $\ldots \ldots \ldots \ldots \ldots \ldots \ldots \ldots \ldots \ldots \ldots \ldots \ldots \ldots \ldots .12-1$

12.2.1 Function and Operation of Large Generator Modules . . . . . . . 12-1

12.2.2 Integration of Large Generator Modules . . . . . . . . . . . 12-2

12.2.3 Function and Operation of Small Generator Fixed Module Installed in a

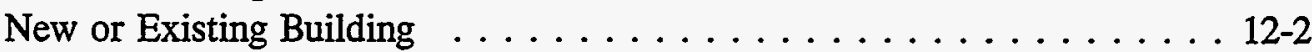

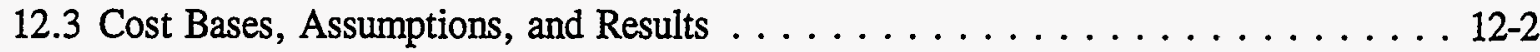

13. POLYMER STABILIZATION (MODULE PLYMR) $\ldots \ldots \ldots \ldots \ldots \ldots \ldots . \ldots \ldots$

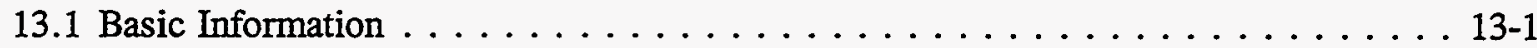

13.2 Technical Bases and Assumptions . . . . . . . . . . . . . . 13-1

13.2.1 Function and Operation of Large Generator Modules . . . . . . . 13-1

13.2.2 Integration of Large Generator Modules . . . . . . . . . . 13-1

13.2.3 Function and Operation of Small Generator Fixed Module in a New or Existing Building . . . . . . . . . 13-2

13.2.4 Integration of Small Generator Fixed Module in a New or Existing

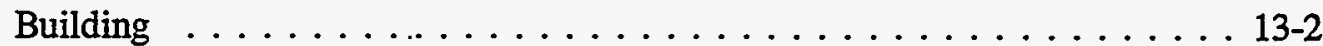

13.2.5 Function and Operation of Portable Module . . . . . . . . 13-2

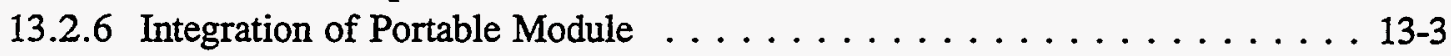

13.3 Cost Bases, Assumptions, and Results $\ldots \ldots \ldots \ldots \ldots \ldots \ldots \ldots \ldots$. . . . . . . . .

14. VITRIFICATION (MODULE VITRF) $\ldots \ldots \ldots \ldots \ldots \ldots \ldots \ldots \ldots \ldots \ldots$ 14-1

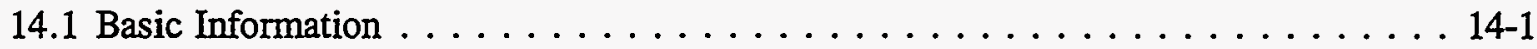

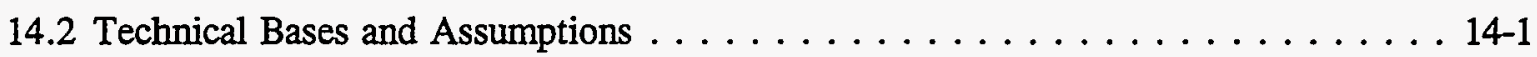

14.2.1 Function and Operation of Large Generator Modules . . . . . . . 14-1 14.2.2 Integration of Large Generator Modules . . . . . . . . . . . 14-1

14.3 Cost Bases, Assumptions, and Results . . . . . . . . . . . . 14-2 


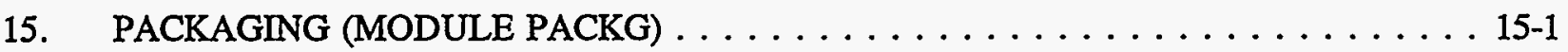

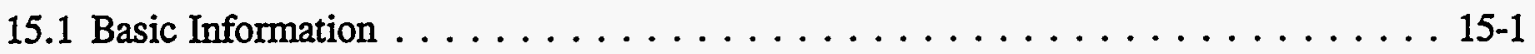

15.2 Technical Bases and Assumptions . . . . . . . . . . . . . . .

15.2.1 Function and Operation of the Module $\ldots \ldots \ldots \ldots \ldots \ldots \ldots$ 15-1

15.2.2 Integration of the Module . . . . . . . . . . . . .

15.3 Cost Bases, Assumptions, and Results . . . . . . . . . . . 15-1

16. SHREDDING AND COMPACTION (MODULE CMPCT) . . . . . . . . . . 16-1

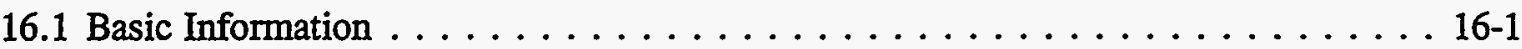

16.2 Technical Bases and Assumptions . . . . . . . . . . . . . . 16-1

16.2.1 Function and Operation of Large Generator Module . . . . . . . . 16-1

16.2.2 Integration of Large Generator Module . . . . . . . . . . 16-1

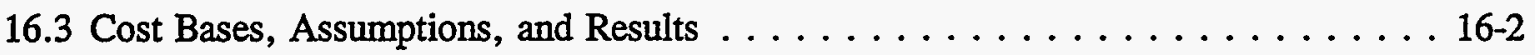

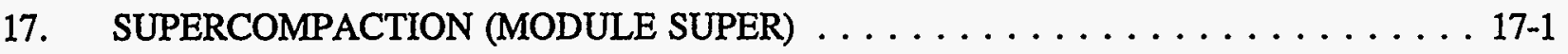

17.1 Basic Information $\ldots \ldots \ldots \ldots \ldots \ldots \ldots \ldots \ldots \ldots \ldots \ldots \ldots \ldots \ldots \ldots \ldots \ldots .17$

17.2 Technical Bases and Assumptions . . . . . . . . . . . . . 17-1

17.2.1 Function and Operation of the Module $\ldots \ldots \ldots \ldots \ldots \ldots \ldots \ldots$ 17-1

17.3 Cost Bases, Assumptions, and Assessments $\ldots \ldots \ldots \ldots \ldots \ldots \ldots \ldots$ 17-1

18. CERTIFICATION AND SHIPPING (MODULE CSHIP) $\ldots \ldots \ldots \ldots \ldots \ldots$ 18-1

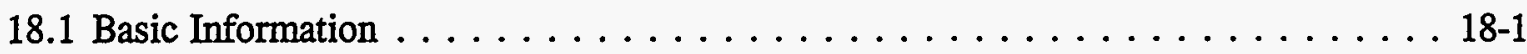

18.2 Technical Bases and Assumptions . . . . . . . . . . . . . . 18-1

18.2.1 Function and Operation of Large Generator Modules $\ldots \ldots \ldots \ldots \ldots$ 18-1

18.2.2 Integration of Large Generator Modules . . . . . . . . . . 18-2

18.2.3 Small Generator Fixed and Portable Module . . . . . . . . . 18-2

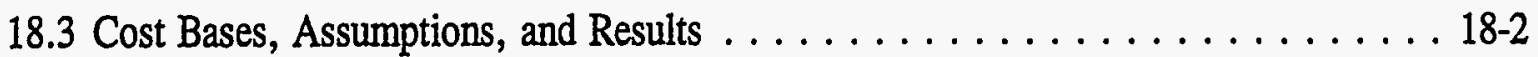

19. STORAGE ADMINISTRATION (MODULE SADMN) $\ldots \ldots \ldots \ldots \ldots \ldots$ 19-1

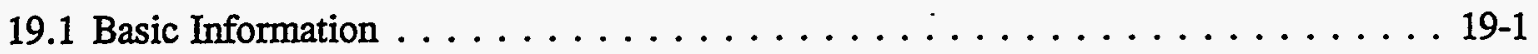


19.2 Technical Bases and Requirements $\ldots \ldots \ldots \ldots \ldots \ldots \ldots \ldots \ldots$ 19-1

19.2.1 Function and Operation of the Modules . . . . . . . . . . . 19-1

19.2.2 Integration of the Modules . . . . . . . . . . . . . 19-1

19.3 Cost Bases, Assumptions, and Results . . . . . . . . . . . . . 19-1

20. STORAGE RECEIVING AND SHIPPING (MODULE SRCSH) $\ldots \ldots \ldots \ldots \ldots$ 20-1

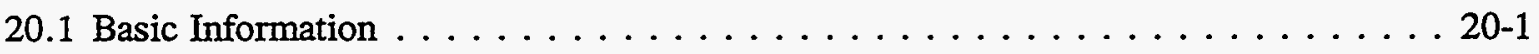

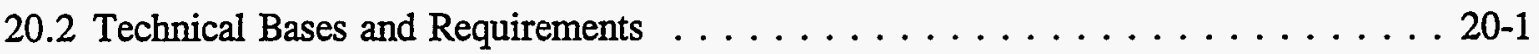

20.2.1 Function and Operation of the Module $\ldots \ldots \ldots \ldots \ldots \ldots \ldots \ldots . \ldots \ldots$

20.2.2 Integration of the Module . . . . . . . . . .

20.3 Cost Bases, Assumptions, and Results . . . . . . . . . . . 20-1

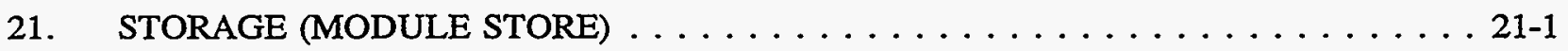

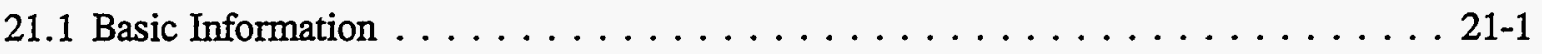

21.2 Technical Bases and Assumptions $\ldots \ldots \ldots \ldots \ldots \ldots \ldots \ldots \ldots \ldots \ldots \ldots \ldots \ldots \ldots .1$

21.2.1 Function and Operation of the Module $\ldots \ldots \ldots \ldots \ldots \ldots \ldots .21-1$

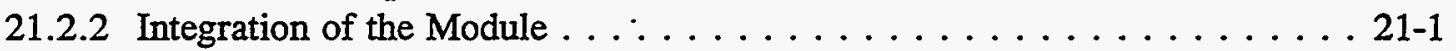

21.3 Cost Bases, Assumptions, and Results . . . . . . . . . . . 21-1

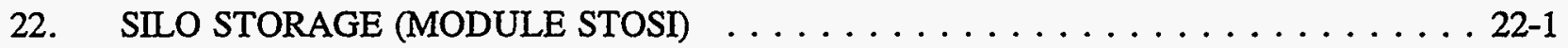

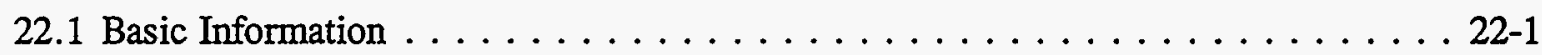

22.2 Technical Bases and Assumptions $\ldots \ldots \ldots \ldots \ldots \ldots \ldots \ldots \ldots \ldots \ldots \ldots \ldots \ldots \ldots .1$

22.2.1 Function and Operation of the Module $\ldots \ldots \ldots \ldots \ldots \ldots \ldots .22-1$

22.2.2 Integration of the Module $\ldots \ldots \ldots \ldots \ldots \ldots \ldots \ldots \ldots \ldots \ldots \ldots \ldots \ldots \ldots .22-1$

22.3 Cost Bases, Assumptions and Results $\ldots \ldots \ldots \ldots \ldots \ldots \ldots \ldots .22-2$

23. DISPOSAL ADMINISTRATION (MODULE DADMN) $\ldots \ldots \ldots \ldots \ldots \ldots .23-1$

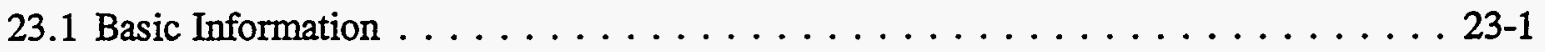

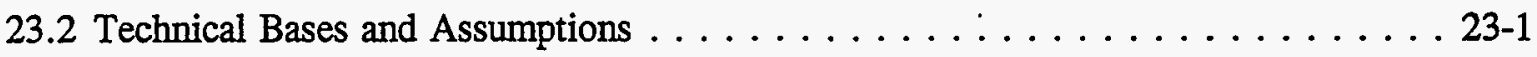

23.2.1 Function and Operation of the Modules $\ldots \ldots \ldots \ldots \ldots \ldots \ldots$ 23-1 


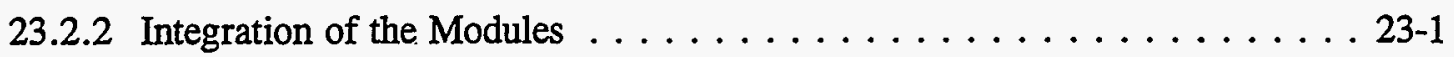

23.3 Cost Bases, Assumptions, and Results $\ldots \ldots \ldots \ldots \ldots \ldots \ldots \ldots \ldots \ldots \ldots \ldots$

24. DISPOSAL RECEIVING (MODULE DRECV) $\ldots \ldots \ldots \ldots \ldots \ldots \ldots . \ldots \ldots . \ldots \ldots$

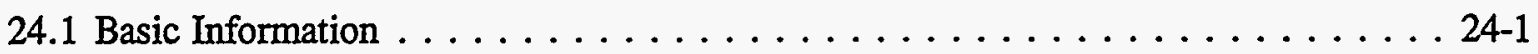

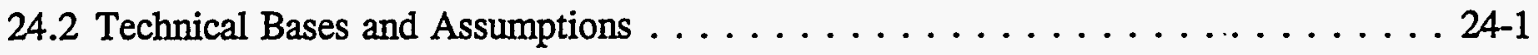

24.2.1 Function and Operation of Large Generator Modules . . . . . . . 24-1

24.2.2 Integration of Large Generator Modules . . . . . . . . . . 24-2

24.3 Cost Bases, Assumptions, and Results $\ldots \ldots \ldots \ldots \ldots \ldots \ldots \ldots \ldots \ldots \ldots \ldots \ldots \ldots .24$

25. ENGINEERED DISPOSAL (MODULE AGDSP) $\ldots \ldots \ldots \ldots \ldots \ldots \ldots \ldots \ldots \ldots \ldots$

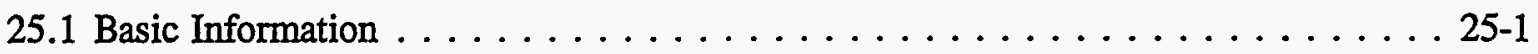

25.2 Technical Bases and Assumptions . . . . . . . . . . . . . 25-1

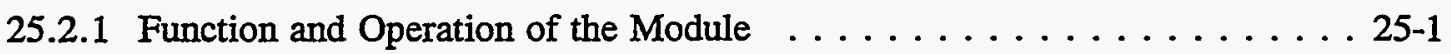

25.2.2 Integration of the Modules . . . . . . . . . . . . . 25-2

25.3 Cost Bases, Assumptions, and Results . . . . . . . . . . . 25-2

26. SHALLOW LAND DISPOSAL (MODULE SLDSP) $\ldots \ldots \ldots \ldots \ldots \ldots . \ldots \ldots$ 26-1

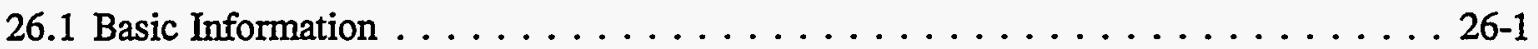

26.2 Technical Bases and Assumptions . . . . . . . . . . . . . . 26-1

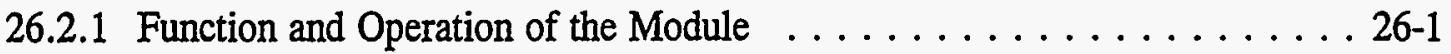

26.2.2 Integration of the Module . . . . . . . . . . . . . . 26-1

26.3 Cost Bases, Assumptions, and Assessments $\ldots \ldots \ldots \ldots \ldots \ldots \ldots . \ldots \ldots$ 26-1

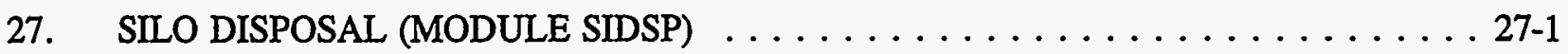

27.1 Basic Information $\ldots \ldots \ldots \ldots \ldots \ldots \ldots \ldots \ldots \ldots \ldots \ldots \ldots \ldots \ldots \ldots \ldots \ldots .27-1$

27.2 Technical Bases and Assumptions $\ldots \ldots \ldots \ldots \ldots \ldots \ldots \ldots \ldots \ldots \ldots \ldots \ldots \ldots .1$

27.2.1 Function and Operation of the Module $\ldots \ldots \ldots \ldots \ldots \ldots \ldots . \ldots \ldots .27-1$

27.2.2 Integration of the Module $\ldots \ldots \ldots \ldots \ldots \ldots \ldots \ldots \ldots \ldots \ldots \ldots \ldots \ldots \ldots .27-1$

27.3 Cost Bases, Assumptions, and Results . . . . . . . . . . . 27-1 
28. BOREHOLE DISPOSAL (MODULE BHDSP) . . . . . . . . . . . . . 28-1

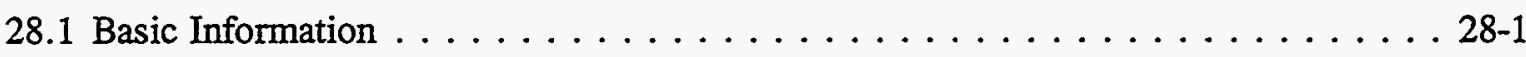

28.2 Technical Bases and Assumptions . . . . . . . . . . . . 28-1

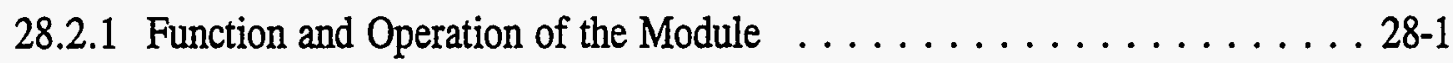

28.2.2 Integration of the Module . . . . . . . . . . . . . 28-1

28.3 Cost Bases, Assumptions, and Results . . . . . . . . . . . . . 28-1

29. COST ESTIMATION PROCEDURE . . . . . . . . . . . . . . . . . . . . . . 29-1

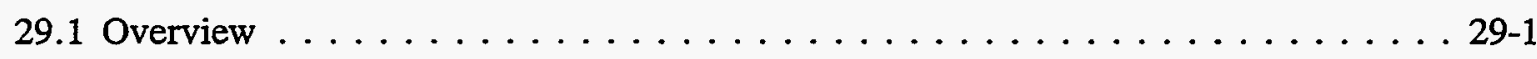

29.2 Waste Loads Definition . . . . . . . . . . . . . . . . . . . . . 29-1

29.2.1 Large Generator Facility Treatment Waste Loads . . . . . . . . . . . . . 29-2

29.2.2 Small Generator Facility and Portable Treatment Waste Loads . . . . . . 29-3

29.2.3 Storage and Disposal Waste Loads . . . . . . . . . . . . . . . . . 29-3

29.3 Estimating TSD Facility Costs and FTEs . . . . . . . . . . . . 29-3

29.4 Transportation Costs . . . . . . . . . . . . . . . . . . 29-4

30. REFERENCES . . . . . . . . . . . . . . . . . . . . . . 30-1

FIGURES

1-1. Integrated waste management facility $\ldots \ldots \ldots \ldots \ldots \ldots \ldots \ldots \ldots$

1-2. PLCC cost estimating steps $\ldots \ldots \ldots \ldots \ldots \ldots \ldots \ldots \ldots \ldots \ldots \ldots \ldots$

2-1. FTE workers versus capacity for the treatment administration (TADMN) module . . . 2-3

2-2. PLCC versus capacity for the treatment administration (TADMN) module . . . . . . . 2-4

2-3. PLCC versus capacity including unit rates for the treatment administration (TADMN) module . . . . . . . . . . . . . . . . . . . . . 2-5

3-1. Equipment layout for the receiving and inspection (RCINS) module . . . . . . . . . 3-3

3-2. Process flow diagram for the receiving and inspection (RCINS) module $\ldots \ldots \ldots$

3-3. FTE workers versus capacity for the nonalpha receiving and inspection (B-RCINS) module .............................. 3-5 
3-4. FTE workers versus capacity for the alpha and RH receiving and inspection

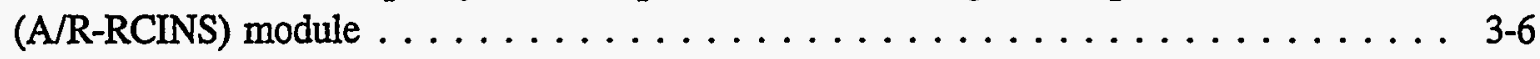

3-5. PLCC versus capacity for the nonalpha receiving and inspection

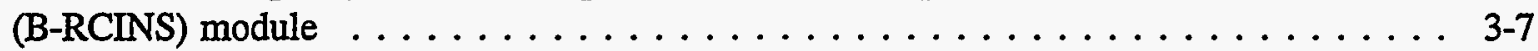

3-6. PLCC versus capacity for the alpha and $\mathrm{RH}$ receiving and inspection

(A/R-RCINS) module $\ldots \ldots \ldots \ldots \ldots \ldots \ldots \ldots \ldots \ldots \ldots \ldots \ldots \ldots$

3-7. PLCC versus capacity including unit rates for the receiving and inspection

(RCINS) module . . . . . . . . . . . . . . . . . . . . 3-9

4-1. Equipment layout for the front-end and back-end support (FBSPT) module $\ldots \ldots \ldots$ 4-5

4-2. Process flow diagram for the front-end and back-end support

(FBSPT) module $\ldots \ldots \ldots \ldots \ldots \ldots \ldots \ldots \ldots \ldots \ldots \ldots \ldots \ldots \ldots$

5-1. Equipment layout for the open, dump, and sort (OSORT) module $\ldots \ldots \ldots \ldots$ 5-3

5-2. Process flow diagram for the open, dump, and sort (OSORT) module $\ldots \ldots \ldots \ldots$ 5-4

5-3. FTE workers versus capacity for the nonalpha open, dump, and sort

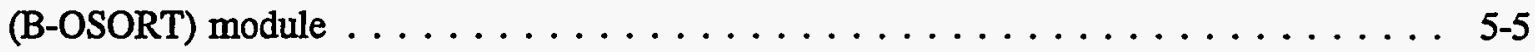

5-4. FTE workers versus capacity for the alpha open, dump, and sort

(A-OSORT) module . . . . . . . . . . . . . . $\ldots \ldots \ldots \ldots \ldots$

5-5. FTE workers versus capacity for the RH open, dump, and sort (R-OSORT) module . . . . . . . . . . . . . . . . . . . . . 5-7

5-6. PLCC versus capacity for the nonalpha open, dump, and sort (B-OSORT) module $\ldots \ldots \ldots \ldots \ldots \ldots \ldots \ldots \ldots \ldots \ldots \ldots \ldots \ldots$. 5.8

5-7. PLCC versus capacity for the alpha open, dump, and sort (A-OSORT) module . . . . . . . . . . . . . . . . . . . . . . . . 5-9

5-8. PLCC versus capacity for the RH open, dump, and sort (R-OSORT) module $\ldots \ldots \ldots$ 5-10

5-9. PLCC versus capacity including unit rates for the open, dump, and sort (OSORT) module . . . . . . . . . . . . . . . . . . . 5 - 11

6-1. FTE workers versus capacity for the nonalpha maintenance (B-MAINT)

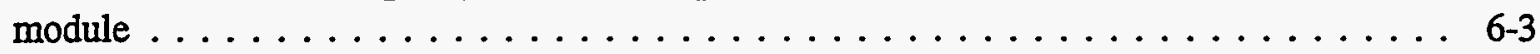

6-2. FTE workers versus capacity for the alpha and $\mathrm{RH}$ maintenance (A/R-MAINT) module $\ldots \ldots \ldots \ldots \ldots \ldots \ldots \ldots \ldots \ldots \ldots \ldots \ldots \ldots \ldots \ldots$ 
6-3. PLCC versus capacity for the nonalpha maintenance (B-MAINT) module $\ldots \ldots \ldots$. . . 6-5

6-4. PLCC versus capacity for the alpha and RH maintenance (A/R-MAINT) module . . . . . 6-6

6-5. PLCC versus capacity including unit rates for the maintenance (MAINT) module . . . . . . . . . . . . . . . . . . . . . . . . 6-7

7-1. Equipment layout for the incineration (INCIN) module $\ldots \ldots \ldots \ldots \ldots$

7-2. Process flow diagram for the incineration (INCIN) module $\ldots \ldots \ldots \ldots \ldots$

7-3. FTE workers versus capacity for the nonalpha incineration (B-INCIN) module . . . . . . . . . . . . . . . . . . . . . 7-7

7-4. FTE workers versus capacity for the alpha incineration (A-INCIN) module . . . . . . . . . . . . . . . . . . . . . . . 7-8

7-5. FTE workers versus capacity for the RH incineration (R-INCIN) module $\ldots \ldots \ldots$. . 7-9

7-6. PLCC versus capacity for the nonalpha incineration (B-INCIN) module $\ldots \ldots \ldots$. . . 7-10

7-7. PLCC versus capacity for the alpha waste incineration (A-INCIN) module $\ldots \ldots \ldots$. . . 7-11

7-8. PLCC versus capacity for the RH incineration (R-INCIN) module $\ldots \ldots \ldots \ldots \ldots$. . . . . .

7-9. PLCC versus capacity including unit rates for the incineration

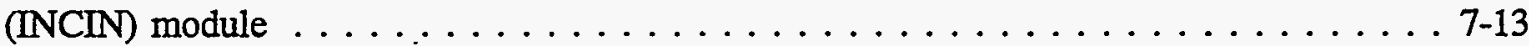

8-1. Equipment layout for the metal melting (MMELT) module $\ldots \ldots \ldots \ldots \ldots$. . . . . 8

8-2. Process flow diagram for the metal melting (MMELT) module $\ldots \ldots \ldots \ldots . \ldots . . .4$

8-3. FTE workers versus capacity for the nonalpha metal melting (B-MMELT) module . . . . . . . . . . . . . . . . . . . . . . 8-5

8-4. FTE workers versus capacity for the alpha metal melting (A-MMELT) module . . . . . 8-6

8-5. FTE workers versus capacity for the RH metal melting (R-MMELT) module . . . . . . 8-7

8-6. PLCC versus capacity for the nonalpha metal melting (B-MMELT) module $\ldots \ldots \ldots$. . . 8-8

8-7. PLCC versus capacity for the alpha metal melting (A-MMELT) module . . . . . . . . 8-9

8-8. PLCC versus capacity for the RH metal melting (R-MMELT) module . . . . . . . 8 8-10

8-9. PLCC versus capacity including unit rates for the metal melting (MMELT) module . . . . . . . . . . . . . . . . . . . . . . 8 8-11 
9-1. Equipment layout for the special waste processing (SPECL) module $\ldots \ldots \ldots \ldots$. . . $9-2$

9-2. Process flow diagram for the special waste processing (SPECL) module . . . . . . . 9-3

9-3. FTE workers versus capacity for the special waste processing (SPECL) module . . . . . . . . . . . . . . . . . . . . . . . 9-4

9-4. PLCC versus capacity for the special waste processing (SPECL) module . . . . . . . 9-5

9-5. PLCC versus capacity including unit rates for the special waste processing (SPECL) module . . . . . . . . . . . . . . . . . . . . . . 9-6

10-1. Equipment layout for large generator metal sizing/decontamination (DECON) module . . . . . . . . . . . . . . . . . . 10-5

10-2. Equipment layout for portable, small-, and medium-sized metal sizing/decontamination (DECON) module . . . . . . . . . . . . . . . . . . . 10-6

10-3. Process flow diagram for the metal sizing/decontamination (DECON) module $\ldots . . .10-7$

10-4. FTE workers versus capacity for the nonalpha metal sizing/decontamination

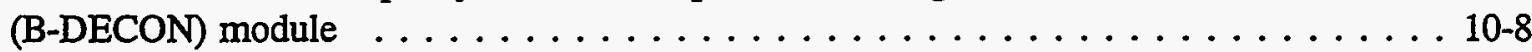

10-5. FTE workers versus capacity for the alpha metal sizing/decontamination (A-DECON) module . . . . . . . . . . . . . . . . . . . 10-9

10-6. FTE workers versus capacity for the RH metal sizing/decontamination (R-DECON) module

10-7. PLCC versus capacity for the nonalpha metal sizing/decontamination (B-DECON) module

10-8. PLCC versus capacity for the alpha metal sizing/decontamination (A-DECON) module

10-9. PLCC versus capacity for the RH metal sizing/decontamination (R-DECON) module

10-10. PLCC versus capacity including unit rates for the metal sizing/decontamination (DECON) module $10-14$

11-1. Equipment layout for the neutralization (NEUTR) module $\ldots \ldots \ldots \ldots \ldots \ldots$

11-2. Process flow diagram for the neutralization (NEUTR) module $\ldots \ldots \ldots \ldots \ldots$

11-3. FTE workers versus capacity for the nonalpha neutralization (B-NEUTR) module 
11-4. FTE workers versus capacity for the alpha neutralization (A-NEUTR)

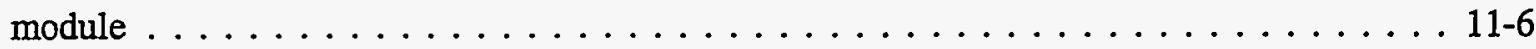

11-5. FTE workers versus capacity for the RH neutralization (R-NEUTR) module $\ldots \ldots \ldots$ 11-7

11-6. PLCC versus capacity for the nonalpha neutralization (B-NEUTR) module $\ldots \ldots \ldots$ 11-8

11-7. PLCC versus capacity for the alpha neutralization (A-NEUTR) module $\ldots \ldots \ldots \ldots \ldots$. . . . .9

11-8. PLCC versus capacity for the RH neutralization (R-NEUTR) module $\ldots \ldots \ldots \ldots$. . . .10

11-9. PLCC versus capacity including unit rates for the neutralization (NEUTR) module

12-1. Equipment layout for the grout stabilization (GROUT) module $\ldots \ldots \ldots \ldots \ldots$ 12-3

12-2. Process flow diagram for the grout stabilization (GROUT) module $\ldots \ldots \ldots \ldots \ldots$

12-3. FTE workers versus capacity for the nonalpha grout stabilization

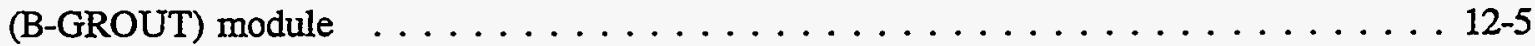

12-4. FTE workers versus capacity for the alpha grout stabilization

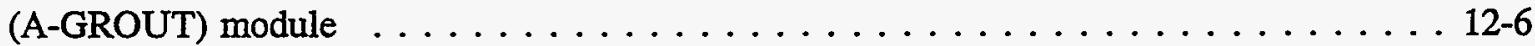

12-5. FTE workers versus capacity for the RH grout stabilization (R-GROUT) module

12-6. PLCC versus capacity for the nonalpha grout stabilization (B-GROUT) module

12-7. PLCC versus capacity for the alpha grout stabilization (A-GROUT) module

12-8. PLCC versus capacity for the RH grout stabilization (R-GROUT) module $\ldots \ldots \ldots$ 12-10

12-9. PLCC versus capacity including unit rates for the grout stabilization (GROUT) module

13-1. Equipment layout for the polymer stabilization (PLYMR) module $\ldots \ldots \ldots \ldots \ldots$ 13-5

13-2. Equipment layout for the portable polymer stabilization (PLYMR) module $\ldots \ldots \ldots$ 13-6

13-3. Process flow diagram for the large generator polymer stabilization (PLYMR) module

13-4. Process flow diagram for the small generator polymer stabilization (PLYMR) module 
13-5. FTE workers versus capacity for the nonalpha polymer stabilization (B-PLYMR) module . . . . . . . . . . . . . . . . . . . . . . . . 13-9

13-6. FTE workers versus capacity for the alpha polymer stabilization

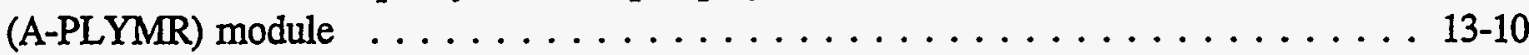

13-7. FTE workers versus capacity for the RH polymer stabilization (R-PLYMR) module

13-8. PLCC versus capacity for the nonalpha polymer stabilization

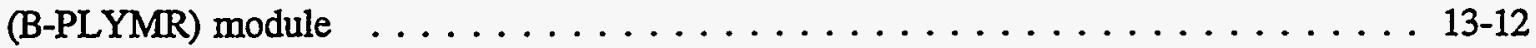

13-9. PLCC versus capacity for the alpha polymer stabilization (A-PLYMR) module

13-10. PLCC versus capacity for the RH polymer stabilization (R-PLYMR) module . . . . . . . . . . . . . . . . . . . . . . . . 13-14

13-11. PLCC versus capacity including unit rates for the polymer stabilization (PLYMR) module

14-1. Equipment layout for the vitrification (VITRF) module $\ldots \ldots \ldots \ldots \ldots \ldots$ 14-3

14-2. Process flow diagram for the vitrification (VITRF) module $\ldots \ldots \ldots \ldots \ldots \ldots$ 14-4

14-3. FTE workers capacity for the nonalpha vitrification (B-VITRF) module $\ldots \ldots \ldots$ 14-5

14-4. FTE workers versus capacity for the alpha vitrification (A-VITRF)

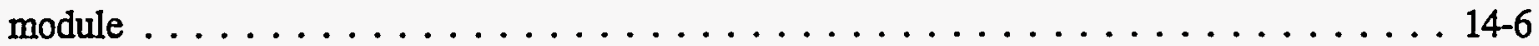

14-5. FTE workers versus capacity for the RH vitrification (R-VITRF) module $\ldots \ldots \ldots$ 14-7

14-6. PLCC versus capacity for the nonalpha vitrification (B-VITRF) module $\ldots \ldots \ldots \ldots$ 14-8

14-7. PLCC versus capacity for the alpha vitrification (A-VITRF) module $\ldots \ldots \ldots \ldots \ldots$ 14-9

14-8. PLCC versus capacity for the RH vitrification (R-VITRF) module $\ldots \ldots \ldots \ldots \ldots$ 14-10

14-9. PLCC versus capacity including unit rates for the vitrification (VITRF) module . . . . . . . . . . . . . . . . . . $\ldots \ldots \ldots$

15-1. Equipment layout for the packaging (PACKG) module $\ldots \ldots \ldots \ldots \ldots \ldots$ 15-2

15-2. Process flow diagram for the packaging (PACKG) module $\ldots \ldots \ldots \ldots \ldots \ldots$ 15-3

15-3. FTE workers versus capacity for the nonalpha waste packaging

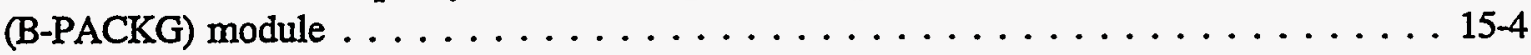

xvii 
15-4. FTE workers versus capacity for the alpha packaging (A-PACKG) module

15-5. FTE workers versus capacity for the remote-handled packaging

(R-PACKG) module . . . . . . . . . . . . . . . . . . . . . . 15-6

15-6. PLCC versus capacity for the nonalpha packaging (B-PACKG) module . . . . . . . . 15-7

15-7. PLCC versus capacity for the alpha packaging (A-PACKG) module $\ldots \ldots \ldots \ldots$. . . . 15-8

15-8. PLCC versus capacity for the RH packaging (R-PACKG) module . . . . . . . . . 15-9

15-9. PLCC versus capacity including unit rates for the packaging (PACKG) module

16-1. Equipment layout for the shredding and compaction (CMPCT) module . . . . . . . 16-3

16-2. Process flow diagram for the shredding and compaction (CMPCT) module $\ldots \ldots \ldots 16-4$

16-3. FTE workers capacity for the nonalpha shredding and compaction (B-CMPCT) module . . . . . . . . . . . . . . . . . . . 16-5

16-4. FTE workers versus capacity for the alpha and RH shredding and compaction

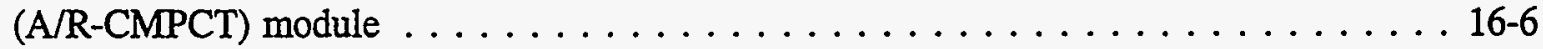

16-5. PLCC versus capacity for the nonalpha shredding and compaction (B-CMPCT) module

16-6. PLCC versus capacity for the alpha and RH shredding and compaction (A/R-CMPCT) module

16-7. PLCC versus capacity including unit rates for the shredding and compaction (CMPCT) module

17-1. Equipment layout for the supercompaction (SUPER) module $\ldots \ldots \ldots \ldots \ldots$. . . . . . .

17-2. Process flow diagram for the supercompaction (SUPER) module $\ldots \ldots \ldots \ldots \ldots$

17-3. FTE workers versus capacity for the nonalpha supercompaction (B-SUPER) module $17-4$

17-4. FTE workers versus capacity for the alpha and RH supercompaction (A/R-SUPER) module

17-5. PLCC versus capacity for the nonalpha supercompaction (B-SUPER) module . . . . . . 17-6

17-6. PLCC versus capacity for the alpha and RH supercompaction (A/R-SUPER) module 
17-7. PLCC versus capacity including unit rates for the supercompaction

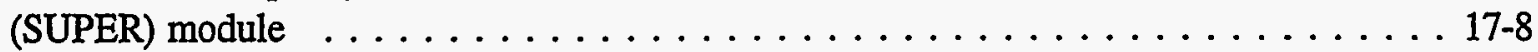

18-1. Equipment layout for the certification and shipping (CSHIP) module $\ldots \ldots \ldots$. . . 18-3

18-2. Process flow diagram for the certification and shipping (CSHIP) module $\ldots \ldots \ldots \ldots$

18-3. FTE workers versus capacity for the certification and shipping (CSHIP) module . . . . . . . . . . . . . . . . . . . . 18-5

18-4. PLCC versus capacity for the certification and shipping (CSHIP) module $\ldots \ldots$. . . 18-6

18-5. PLCC versus capacity including unit rates for the certification and shipping (CSHIP) module $\ldots \ldots \ldots \ldots \ldots \ldots \ldots \ldots \ldots \ldots$. . . . . . . . . . . . $\ldots$

19-1. FTE workers versus capacity for the storage administration

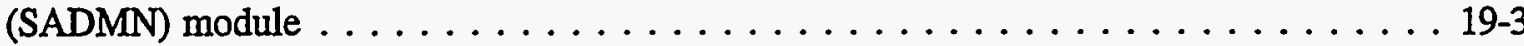

19-2. PLCC versus capacity for the storage administration (SADMN) module . . . . . . . . 19-4

19-3. PLCC versus capacity plus unit rates for the storage administration (SADMN) module

20-1. FTE workers versus capacity for the storage receiving and shipping (SRCSH) module

20-2. PLCC versus capacity for the storage receiving and shipping (SRCSH) module

20-3. PLCC versus capacity plus unit rates for the storage receiving and shipping (SRCSH) module

21-1. Equipment layout for the storage (STORE) module $\ldots \ldots \ldots \ldots \ldots \ldots \ldots$

21-2. FTE workers versus capacity for the nonalpha storage (B-STORE) module $\ldots \ldots \ldots$ 21-3

21-3. FTE workers versus capacity for the alpha and RH storage

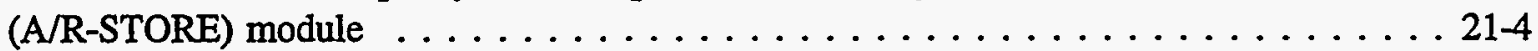

21-4. PLCC versus capacity for the nonalpha storage (B-STORE) module . . . . . . . . 21-5

21-5. PLCC versus capacity for the alpha and RH storage (A/R-STORE) module $\ldots \ldots \ldots$. . . 21-6

21-6. PLCC versus capacity including unit rates for the storage (STORE) module . . . . . . . . . . . . . . . . . . . . . . . . . 21-7

22-1. Equipment layout for the silo storage (STOSI) module $\ldots \ldots \ldots \ldots \ldots \ldots$ 
22-2. Process flow diagram for the silo storage (STOSI) module . . . . . . . . . . . . 22-4

22-3. FTE workers versus capacity for the RH silo storage facility

(R-STOSI) module . . . . . . . . . . . . . . . . . . . . 22-5

22-4. PLCC versus capacity for the RH silo storage facility (R-STOSI) module . . . . . . . 22-6

22-5. PLCC versus capacity including unit rates for the $\mathrm{RH}$ silo storage facility

(R-STOSI) module . . . . . . . . . . . . . . . . . . . 22-7

23-1. FTE workers versus capacity for the disposal administration

(DADMN) module . . . . . . . . . . . . . . . . . . 23-3

23-2. PLCC versus capacity for the disposal administration (DADMN) module $\ldots \ldots$. . . . 23-4

23-3. PLCC versus capacity plus unit rates for the disposal administration

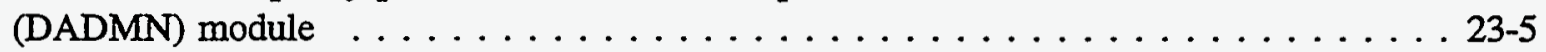

24-1. Equipment layout for the disposal receiving (DRECV) module . . . . . . . . . . . 24-3

24-2. Process flow diagram for the disposal receiving (DRECV) module $\ldots \ldots \ldots$. . . . 24-4

24-3. FTE workers versus capacity for the disposal receiving (DRECV) module . . . . . . 24-5

24-4. PLCC versus capacity for the disposal receiving (DRECV) module . . . . . . . . . 24-6

24-5. PLCC versus capacity including unit rates for the disposal receiving (DRECV) module . . . . . . . . . . . . . . . . . . . . 24-7

25-1. Equipment layout for the engineered disposal (AGDSP) module $\ldots \ldots \ldots \ldots$. . . . . 25-3

25-2. Process flow diagram for the engineered disposal (AGDSP) module . . . . . . . . . 25-4

25-3. FTE workers versus capacity for the engineered disposal (AGDSP) module . . . . . . 25-5

25-4. PLCC versus capacity for the engineered disposal (AGDSP) module $\ldots \ldots \ldots$. . . . 25-6

25-5. PLCC versus capacity including unit rates for the engineered disposal (AGDSP) module . . . . . . . . . . . . . . . . . . . . . . 25-7

26-1. FTE workers versus capacity for the shallow land disposal (SLDSP) module . . . . . . . . . . . . . . . . . . . . . . . 26-2

26-2. PLCC versus capacity for the shallow land disposal (SLDSP) module . . . . . . . . . 26-3

26-3. PLCC versus capacity including unit rates for the shallow land disposal (SLDSP) module . . . . . . . . . . . . . . . . . . . . 26-4 
27-1. Equipment layout for the silo disposal (SIDSP) module . . . . . . . . . . . . 27-2

27-2. Process flow diagram for the silo disposal (SIDSP) module $\ldots \ldots \ldots \ldots \ldots$. . . . . 27-3

27-3. FTE workers versus capacity for the silo disposal (SIDSP) module . . . . . . . . . 27-4

27-4. PLCC versus capacity for the silo disposal (SIDSP) module $\ldots \ldots \ldots \ldots$. . . . . . 27-5

27-5. PLCC versus capacity including unit rates for silo disposal (SIDSP) module . . . . . . . . . . . . . . . . . 27-6

28-1. Equipment layout for the borehole disposal (BHDSP) module $\ldots \ldots \ldots \ldots$. . . . . 28-3

29-1. Layout for integrated treatment facility based on a minimum treatment

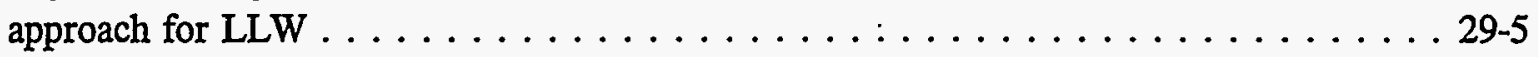

29-2. Layout of an integrated facility designed to achieve maximum volume

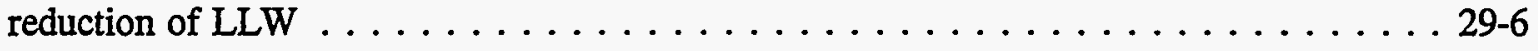

29-3. Layout of an integrated facility that combines maximum volume reduction with vitrification to produce a more robust final waste form . . . . . . . . . . . . 29-7

29-4. Treatment waste load data sheet for the large generator facility . . . . . . . . . . 29-8

29-5. Treatment waste load data sheet for the small generator facility $\ldots \ldots \ldots \ldots$. . . . 29-9

29-6. Storage and disposal waste load data sheet . . . . . . . . . . . . . . . . . 29-10

\section{TÁBLES}

1-1. Capacity ranges of modules developed for low-level waste . . . . . . . . . . . . 1-11

1-2. Sample PLCC estimate summary for the small generator incineration module . . . . . . 1-13

2-1. Plan dimensions of treatment administration (TADMN) module $\ldots \ldots \ldots \ldots$. . . . 2-2

4-1. FTE workers for the small generator front-end and back-end support module . . . . . 4-4

4-2. PLCC $(\$ 1,000)$ for the small generator front-end and back-end support module $\ldots . . .44$

6-1. Plan dimensions of the maintenance (MAINT) module $\ldots \ldots \ldots \ldots \ldots \ldots$. . . . . . $6-2$

7-1. FTE workers for the small generator incineration module $\ldots \ldots \ldots \ldots \ldots$

7-2. PLCC $(\$ 1,000)$ for the small generator incineration module $\ldots \ldots \ldots \ldots \ldots$

10-1. FTE workers for the small generator metal sizing and decontamination module $\ldots . . .10-4$ 
10-2. PLCC $(\$ 1,000)$ for the small generator metal sizing and decontamination module $\ldots$. . 10-4.

13-1. FTE workers for the small generator polymer stabilization (PLYMR) module . . . . . . 13-4

13-2. PLCC $(\$ 1,000)$ for the small generator polymer stabilization (PLYMR) module $\ldots \ldots$. . 13-4

19-1. Plan dimensions of the storage administration (SADMN) module $\ldots \ldots \ldots \ldots$. . . . .

20-1. Plan dimensions of storage receiving and shipping (SRCSH) module $\ldots \ldots \ldots$. . . . 20-2

23-1. Plan dimensions of disposal administration (DADMN) module $\ldots \ldots \ldots \ldots$. . . . . 23-2

28-1. FTE workers and PLCC $(\$ 1,000)$ per excavation for the borehole disposal module . . . 28-2 


\section{ACRONYMS}

\begin{tabular}{|c|c|}
\hline$D \& D$ & decontamination and decommissioning \\
\hline DOE & U.S. Department of Energy \\
\hline FFCA & Federal Facilities Compliance Act \\
\hline FTE & full-time equivalent \\
\hline HEPA & high-efficiency particulate air \\
\hline INEL & Idaho National Engineering Laboratory \\
\hline LLW & low-level waste \\
\hline MK & Morrison Knudsen Corporation, Environmental Services Division \\
\hline MWIR & Mixed Waste Inventory Report \\
\hline NEPA & National Environmental Policy Act \\
\hline NRC & Nuclear Regulatory Commission \\
\hline O\&M & operations and maintenance \\
\hline PAN & passive/active neutron \\
\hline PEIS & Programmatic Environmental Impact Statement \\
\hline PFD & process flow diagram \\
\hline PLCC & planning level life-cycle cost \\
\hline PTM & portable treatment module \\
\hline RCRA & Resource Conservation and Recovery Act \\
\hline $\mathrm{RH}$ & remote-handled \\
\hline RTR & real-time radiography \\
\hline S\&M & surveillance and maintenance \\
\hline SGS & segmented gamma scanning \\
\hline $\mathrm{CA}$ & Toxic Substance Control Act \\
\hline
\end{tabular}


treatment, storage, and disposal

WMFCI

Waste Management Facilities Cost Information 


\section{PREFACE}

This report was prepared for use in the U.S. Department of Energy's Programmatic Environmental Impact Statement Project. It provides a readily useable catalog of developed cost information.

The cost and full-time equivalent information presented in the report has been standardized to a format that is consistent with the Waste Management Facilities Cost Information Reports for Hazardous Waste (Shropshire et al. 1995a), Mixed Low-Level Waste (Shropshire et al. 1995b), and Transuranic Waste (Shropshire et al. 1995c).

The method presented in this report is for planning level life-cycle cost estimates (accuracy of plus or minus 30\%). Estimates based on this report are useful for comparative evaluation of alternatives. However, the cost information is not site-specific, and any alternative selection based on the estimates derived from this method would warrant further study. Therefore, these estimates should not be used to determine funding requirements.

This report is organized according to distinct modules that can be assembled in various ways to create different types of treatment, storage, and disposal facilities. Each module is represented by an abbreviation that is repeated throughout the discussion of the module. For the reader's convenience, these abbreviations are printed on the section tabs. 


\section{Waste Management Facilities Cost Information for Low-Level Waste}

\section{INTRODUCTION AND SUMMARY}

\subsection{Background}

The purpose of this report is to profile cost information on U.S. Department of Energy (DOE) complex waste streams that are being addressed by DOE in the Environmental Management Programmatic Environmental Impact Statement (PEIS). This report describes treatment, storage, and disposal (TSD) modules that will be needed for the management of nonalpha, alpha, ${ }^{a}$ and remotehandled (RH) low-level waste (LLW) streams.

This report describes the cost information for the alternatives involving TSD modules needed for managing nonalpha, alpha, and RH LLW. These modules are designed to be part of an integrated treatment facility. The report contains cost information for the following four applications: (a) large waste generator modules, (b) small waste generator modules using new buildings and equipment, (c) small waste generator modules placing new equipment in existing buildings, and (d) portable treatment equipment.

\subsection{Waste Management Facility Cost Information Task Participants}

The Waste Management Facility Cost Information (WMFCD) task was performed by a project team from Lockheed Martin Idaho Technologies (formerly EG\&G Idaho) and the Environmental Services Division of Morrison Knudsen Corporation (MK). Lockheed Martin and MK were selected for this task because of their combined expertise in design, construction, and operation of waste management TSD facilities for DOE sites and for the nuclear industry.

\subsection{Modules and Unit Operations}

For cost estimating flexibility, the TSD facility has been divided into several distinct modules. Figure 1-1 shows the TSD facility as a whole. The modules can be assembled in various ways to create different types of integrated TSD facilities. In addition, each TSD module is broken down into several distinct functions, referred to as unit operations. Each unit operation consists of all buildings, equipment, and accessories needed to accomplish a given function.

The estimator must know the appropriate modules for the particular waste stream. The selection of the modules may be determined by use of the Federal Facilities Compliance Act (FFCA) Treatment

a. Alpha LLW is LLW containing transuranic nuclides at concentrations between 10 and $100 \mathrm{nCi} / \mathrm{gm}$.

b. Technologies used in the treatment modules presented in this report are based on commercially available equipment selected for the purpose of developing typical costs of treating various waste streams analyzed by the PEIS. This is not to be construed as adoption of a given technology for DOE installations. Others will select the technology for treating LLW stored at, or generated by, various DOE installations. 
Technology Selection Guide or with knowledge of site-specific processing requirements. Section 29 provides more information on which modules are appropriate for a specific waste matrix category.

\subsection{Technical and Cost Estimate Bases and Assumptions}

For larger production-oriented waste generator facilities, modules with at least three different capacities were cost estimated to generate a cost versus capacity curve. In addition, small generator modules were configured for installation at typical DOE research and development (nonproduction oriented) laboratories. Modules for small generator sites can be constructed in the following three ways:

- As a module enclosed within a new building

- As a module constructed within an existing building

- As portable modules.

Modules for small generator sites are provided only for selected treatment options (see Table 1-1). Costs have been estimated for the modules indicated in the table. Modules are stationary (fixed) unless stated as portable. Portable modules have been provided only for selected treatment options.

Costs have not been provided for commercial treatment or low-volume treatment (research and development scale, treatability studies). Costs are not applicable to high-level radioactive wastes.

\subsubsection{General Assumptions}

Facility construction and ownership. It is assumed that all facility equipment will be new and placed within either totally new structures or modified existing structures. Modified structures will be upgraded to house equipment required for processing alpha and nonalpha waste. The upgrades will include construction of interior walls, roof modifications, secondary containment, and other improvements that are necessary to meet all technical and regulatory standards applicable to each treatment facility. Site development costs such as utilities and road work are included only within $30 \mathrm{~m}(100 \mathrm{ft})$ of the facility. Site infrastructure costs are not included. All facilities are assumed to be government owned and contractor operated.

Throughput. For large generator facilities, a broad capacity range is selected to cover the requirements of the PEIS alternatives. The small capacities generally correspond to facilities needed for a decentralized approach, while the large capacities generally correspond to facilities needed for a regionalized or centralized approach.

Modular facility. The planning level life-cycle cost (PLCC) estimates in the WMFCI reports are based on a set of facility modules; each of which may be used alone or in combination with others. 
Technology availability. Cost information in this report is based on available technologies. The basic rule employed in using the technologies is that at least one vendor must commercially offer the given technology without incurring upfront basic research and developmental costs. Information and data used in this report are based on the best available knowledge about waste processing requirements, technology availability, and cost data. The information in this report may require updating when additional information is obtained.

Cost bases. Estimates for new facility construction are based on conditions at Idaho National Engineering Laboratory (INEL), including utility, labor, and the related design, construction, operation, and management factors. The INEL costs are considered to represent the mid-range costs within the DOE complex. Site-specific evaluations should be performed to improve the cost estimating accuracy.

Escalation rates. The PLCC estimates are developed based on 1994 dollars. The time value of money or escalation for expenditures occurring at different time frames has not been considered in the estimates. The costs have been summarized by major program elements [i.e., preoperation, construction, operations and maintenance (O\&M), and decontamination and decommissioning (D\&D)] so that the user can apply appropriate escalation rates to represent the specific schedule requirements.

\subsubsection{Facility Operation Assumptions}

For large generator facilities, the PLCC estimates are based on the assumption that the operating period of the facility is 20 years. New facilities would have a total operational life of 30 years. During this period, the facility may operate a maximum of 24 hours/day, 240 days/year, and at $70 \%$ availability during operation. This is equivalent to 168 days/year or 4,032 hours/year of operation. To compensate for the over-capacity of the small generator alpha and nonalpha waste treatment modules, it is assumed that the operations will be performed on a batch basis. Batch operation provides flexibility to handle variations in capacity and waste characteristics.

This report assumes that alpha-contaminated waste is handled only at large generator facilities. This is due to the complex and therefore expensive handling techniques and equipment required. All modules applicable to small generators or portable equipment are designed and costed assuming that they will process only nonalpha contaminated waste.

\subsubsection{Mass Flow Rate Calculations}

In order to facilitate variations in the waste type and quantities, all processing mass flow rates used in this report are uniformly calculated based on $45 \mathrm{~kg}(100 \mathrm{lb})$ of input waste. This information, which is presented in the process flow diagrams (PFDs), may be used to calculate the site-specific mass-flow rates.

\subsubsection{Cost Bases}

Figure 1-2 shows a block diagram of the steps used in the estimating process. Whenever possible, the baseline capacities were selected to be the same as those of an existing facility or one 
estimated earlier in the WMFCI task. This approach, referred to as anchoring, ${ }^{c}$ provided a reference point that could be used as the basis for estimating the various cost elements. Furthermore, anchoring provides a comparison of the estimates in this report with either the actual costs incurred by an operating facility or estimates of facilities that are in an advanced state of design and construction. Data from the study is based on "bottom-up" cost estimates of three different facility sizes: small, medium, and large. Whenever possible, the baseline capacities are the same as at an existing facility.

Using the given capacities, a preconceptual design package for each facility is used as the basis for the PLCC estimates. Each preconceptual design package includes a PFD with mass flow rates, a layout, and a summary of functional and operational requirements. The PFD and layout drawings identify necessary unit operations. After unit operations are defined, major equipment lists and building configurations are shown for each of these operations. The design packages are based as much as possible on data from existing or planned commercial and DOE (anchor) facilities. New designs were generated only when existing data were not available.

The PLCC estimate for each facility was divided into six elements (see Figure 1-2). Costs for the first and second elements (studies and bench-scale tests, and demonstration) were obtained by estimating research manpower and equipment needs.

The third cost element (facility construction) consists of two key subelements: major equipment costs and building costs. Cost estimates for major equipment were obtained either from a similar facility, from an anchor facility, by soliciting costs from the suppliers, or by making engineering judgments. Building costs were estimated either by multiplying building unit costs by the square footage allocated to each unit operation in the layouts, or by developing building material and labor requirements and multiplying them by the appropriate unit rates. Building costs for modifications to existing structures were estimated by developing material and labor requirements for building cost elements. It is assumed that modifying an existing facility will not require the site preparation and superstructure construction necessary for a new facility. All other building cost elements will be identical to that of a new facility.

Once the equipment and building costs were estimated for each facility, they were totalled and multiplied by a factor to allow for the construction contractor's indirect costs. The sum of the equipment, building, and indirect costs were then multiplied by applicable factors to allow for design, inspection, construction management, and project management costs. Allowances were also included for management reserve and contingencies.

The fourth cost element (operations-budget-funded activities) includes conceptual design, safety assurance, National Environmental Policy Act (NEPA) compliance efforts, permitting, preparation for

c. In this report, the term anchor facility denotes reference facilities that are either operating or are in advanced stages of design and construction. Anchoring denotes using technical data and capital, operating, and maintenance costs incurred by an anchor facility as a yardstick in the development of the PLCC estimates.

Before comparing costs from an anchor facility, they were adjusted to account for any differences in technical requirements and cost escalation. The manual Construction Cost Trends, published by the Bureau of Reclamation, U.S. Department of Interior, was used as the basis for escalation data. 
operation, and project management costs. ${ }^{d}$ All other subelements of the cost of operations-budgetfunded activities were estimated as a percentage of the construction cost.

The fifth cost element (O\&M) consists of four subelements: operating labor, utilities, consumable material, and maintenance (parts, equipment, and labor). The first three subelements were estimated by analyzing the requirements of each facility at the unit operations level. The maintenance costs were estimated as a percentage of the original equipment installed at the facility. Allowances were also included for management reserve and contingencies.

The sixth cost element (D\&D at facility closure) was estimated by multiplying a D\&D unit rate by the facility square footage.

The total facility PLCC estimates were obtained by taking the sum of the six cost elements.

Cost estimating backup data for the modules are provided in Shropshire et al. 1995.'

1.4.4.1 Cost Curve Development Approach. For large generator facilities, unique parametric cost equations were developed for the preoperations, facility construction, $O \& M$, and $D \& D$ cost elements of each module. These equations were developed based on the baseline WMFCI bottom-up estimates regressed over a range of facility capacities for each cost module. There are about 400 equations that describe costs and FTEs for nonalpha LLW, alpha LLW, and RH LLW.

Linear and nonlinear approaches were used to provide the best fit cost curves. The curves were developed to represent the full range of facility costs over the estimated capacity range. Costs should not be extrapolated for facilities outside the defined range of capacities.

1.4.4.2 Cost Curve Applications. Cost curves have been provided for the majority of cost modules to describe the major manpower (FTE) components, cost elements, total life-cycle costs, and total life-cycle unit costs. Separate FTE and cost curves are provided for alpha and nonalpha facilities (as applicable). ${ }^{f}$

As many as seven FTE and cost-figures may be presented for each module, as follows:

1. Full-time equivalent workers versus capacity for nonalpha LLW

d. Please note that NEPA costs of $\$ 6$ million are included in only the receiving and inspection module (RCINS) for the large facility cost estimates. The NEPA and safety assurance costs for the small generator are included in only the front-end and back-end support module (FBSPT).

e. Shropshire, D., M. Sherick, and C. Biagi, 1995, Waste Management Facilities Cost Information Estimating Data for Low-Level Waste, INEL-95/0299, in preparation.

f. Separate cost figures are only provided for nonalpha LLW, alpha LLW, and RH LLW when there is a significant difference in FTEs or cost. When no significant difference is noted, the cost figures are combined for each of the LLW types. 
2. Full-time equivalent workers versus capacity for alpha LLW (as applicable)

3. Full-time equivalent workers versus capacity for RH LLW (as applicable)

4. Planning life-cycle cost versus capacity for nonalpha LLW

5. Planning life-cycle cost versus capacity for alpha LLW (as applicable)

6. Planning life-cycle cost versus capacity for $\mathrm{RH}$ LLW (as applicable)

7. Planning life-cycle cost versus capacity including unit rates for nonalpha, alpha, and RH LLW.

The curves in the first four of these figures were developed to represent only the major FTE and cost elements. These cost figures can be used to derive the four primary costs required to estimate the individual module costs. The six estimated cost elements listed in Section 1.4.4 were simplified. and reduced to four cost elements. These four cost elements and the manner in which they were combined are described below.

1. Preoperations. The preoperations cost element includes the first (studies and bench-scale test), second (demonstration), and fourth (operation-budget-funded activities) cost elements listed in Section 1.4.4. These cost elements were combined because the first and second cost elements are relatively small and would be completed on or about the same schedule as the fourth cost element. Graphically, the small FTE and cost values for the first and second cost elements do not fall on a common scale with the other cost elements.

2. Facility construction. The facility construction cost element is identical to the third cost element listed in Section 1.4.4. This cost element requires capital equipment and line item funding.

3. Operations and maintenance. The O\&M cost element would be equivalent to the fifth cost element listed in Section 1.4.4. The estimated cost and FTE figures are based on one year of O\&M. The estimator may need to multiply the number of FTEs or costs from the curves by the appropriate number of years of O\&M to derive a specific estimate.

4. Decontamination and decommissioning. The D\&D costs are identical to the sixth cost element listed in Section 1.4.4. For disposal modules, these costs include surveillance and monitoring (S\&M).

These four cost elements should be used to determine the required module costs. Existing facility costs would only require the O\&M and D\&D costs. New facilities will include all preoperation, facility construction and equipment, $O \& M$, and $D \& D$ costs. The O\&M costs can be factored from the cost curves to obtain operating costs for periods other than one year.

The fifth cost figure (PLCC versus capacity including unit rates for nonalpha, alpha, and RH LLW) provides the total life-cycle cost curve including preoperation, facility construction, O\&M, and D\&D. The total life-cycle unit cost curve is also provided in Metric (e.g., $\$ / \mathrm{kg}, \$ / \mathrm{m}^{3}$ ) and English 
units (e.g., $\$ / \mathrm{lb}, \$ / \mathrm{ft}^{3}$ ) for maximum utility. These summary level curves should only be used when the O\&M period of 20 years is required.

The capacity units of measure for the WMFCI modules have been provided in terms of processing rates $\left(\mathrm{kg} / \mathrm{hr}, \mathrm{m}^{3} / \mathrm{hr}\right)$ for the administration, treatment, shipping and receiving modules. The capacity units of measure for the storage and disposal modules have been provided in terms of total capacity (total $\mathrm{m}^{3}$ ). Table 1-2 shows an example of a module cost estimate data sheet and top-level elements of a typical estimate. This table illustrates the major Work Breakdown Structure cost elements including the simplified version (reduction from six to four cost elements).

\subsubsection{Portable Facilities}

1.4.5.1 General Assumptions. The portable facility will consist of one or more trailermounted treatment modules that can be dispatched to DOE laboratory installations to treat their waste.

Facility and waste type. The portable, small-sized facility is designed to treat minimal quantities of waste generated at DOE laboratory installations. The portable treatment modules (PTMs) are most suitable for treatment of waste streams that are not generated on a regular basis. They can also be used to augment available existing treatment processes. High-temperature portable thermal treatment processes were considered only for certain processes because of inherent technical difficulties in licensing such PTMs for treating radioactive waste.

Facility construction and ownership. The PTMs are for nonalpha waste only. They consist of equipment mounted in enclosed 8 - by 40 -ft trailers. These modules will be stored at a central location and moved to a DOE installation to treat stored waste. Once on site, PTMs will be set up on existing pads that are equipped with secondary containment. It is assumed that the PTMs will be government owned and contractor operated.

Throughput. Portable treatment module use is on a campaign basis. Campaigns are planned activities necessary to treat an accumulated quantity set at $2.5 \mathrm{~m}^{3}\left(88.3 \mathrm{ft}^{3}\right)$ of waste. It is estimated that each campaign will require a total of 14 days to transport, mobilize, set up, process the waste, decontaminate, disassemble, and demobilize. Each PTM is assumed to complete 12 campaigns per year.

Mobilization and startup. The PTM will be dispatched from the storage site to the desired DOE installation by a licensed commercial firm with drivers certified for interstate travel. The total loaded trailer weight will not exceed the legal highway weight limit of $29,500 \mathrm{~kg}(65,000 \mathrm{lb})$. Once at a treatment site, PTMs will be interconnected to form an integrated treatment facility, and utilities such as service water and electrical power will be connected. Preoperational checkout and safety checks will then be performed to ensure operation readiness of the integrated treatment facility.

Interface availability. It is assumed that the host site will provide the space, utilities (water and electrical power), and other services (i.e., a paved operating pad with secondary containment) needed for operating the PTMs.

Decontamination. At the end of each campaign, the module will be decontaminated by treating all waste through the facility and completely flushing and draining each piece of equipment that has 
been in contact with waste. Waste generated during decontamination will be treated and disposed as required. After decontamination, the interior and exterior of PTMs will be assayed and inspected before disassembly and removal from the treatment site.

Demobilization. After decontamination, the trailers will be disassembled, all flexible lines will be disconnected, loose components will be tied down, and the trailer doors will be locked. A radiological survey of the trailers will be performed and the shipment certification and manifest documents will be prepared. Truck tractors will be connected to the trailers, and the modules will be shipped back to their storage locations. A one-way distance of 500 miles is assumed between the treatment site and the module storage location.

Maintenance. General maintenance will be performed at the storage location on a routine basis.

1.4.5.2 Facility Operation Assumptions. All operations will be done on a batch basis to compensate for the over-capacity of the PTMs and to accommodate differences in treatment capacity requirements at each treatment site. The PLCC estimates are based on the assumption that the operating life of all PTMs and control trailers is five years. The PTMs are assumed to complete 12 campaigns per year or 60 campaigns during the total life of the facility. Safety assurance, NEPA compliance efforts, and permitting are assumed to be part of the location activities and have not been included in the cost estimates.

1.4.5.3 Cost Estimating Methods. The general technical and cost estimate assumptions and the PLCC estimating methods used for the portable minimum modules are the same as for the new minimum facility described earlier in this document. The methods for estimating the first and second elements also remain the same.

The third element (facility construction) consists of only one key subelement: major equipment. Buildings are not required since the equipment is mounted in fully enclosed trailers. Cost estimates for major equipment were obtained from vendors that supplied PTMs and by making engineering judgments. Trailer costs were obtained from suppliers and were adjusted to account for special process requirements.

Once the equipment costs (including trailers) were estimated for each facility, they were totalled and multiplied by a factor to allow for the construction contractor's indirect costs. The sum of the equipment, trailer, and indirect costs were further multiplied by appropriate factors to allow for design, inspection, construction management, and project management costs. Allowances were also included for management reserve and contingencies.

The fourth cost element (operation-budget-funded activities) includes conceptual design, preparation for operation, and project cost. The NEPA compliance and permitting costs are not included.

The fifth cost element (O\&M) is the same as for the new, small-sized facility (except for frontend and back-end support, which is part of normal installation operation), with additional costs for transporting the trailers to and from a location and decontaminating the module before it leaves the treatment location. It is also assumed that (a) utilities are available at the installation and only tie-ins 
are necessary, (b) a parking pad within a secondary containment area is available; and (c) administrative support is provided by the host DOE installation.

The sixth cost element (D\&D at the end of module life) was estimated by multiplying a D\&D unit rate by the trailer's total square footage.

The total facility PLCC estimates for the portable minimum-sized facility were obtained by adding the six elements. Campaign costs were determined based upon 12 campaigns per year for five years of operation.

\subsection{Cost Estimation Procedure}

A detailed cost estimation procedure along with waste load data sheets are presented in Section 29 of this report. Applying estimates in this report requires the following basic steps:

1. Define the treatment process selection based on the waste stream requirements (waste type), TSD requirements, final waste form, and operating parameters. Utilize integrated flow sheets containing modules. Define required support module requirements.

2. Define the total capacity requirements for each module (define if new or existing facility). (Refer to Figures 29-4, 29-5, and 29-6.)

3. Prepare cost estimates for each module required to provide TSD for the waste stream, using the module cost curves.

4. Add the individual module costs to obtain a total waste stream cost.

5. Add transportation costs for offsite shipments to obtain the total option cost.

Estimators preparing costs for the FFCA draft site treatment plans should refer to specific FFCA cost guidance instructions and worksheets for those plans.

\subsection{Cost Assessment Activities}

To the extent possible, equipment costs for each module were compared with data from anchor facilities to establish a cost confidence level within the boundaries established for the PLCC estimates. Both the DOE and the commercial nuclear industry are now planning or operating similar facilities. These facilities were surveyed to obtain capacity, cost data, and other information needed to support the WMFCI data. Before using these costs, the data were adjusted to account for capacity differences and escalation.

Additional assessment activities have included a review of existing DOE facility capital and operating costs for comparison with the WMFCI. Existing DOE facilities that have been evaluated include the Waste Experimental Reduction Facility (incineration, shredding, and compaction) at INEL; the Controlled Air Incinerator at Los Alamos National Laboratory; the Toxic Substances Control Act (TSCA) Incinerator at Oak Ridge National Laboratory; the Supercompactor and 
Repackaging Facility at Rocky Flats; the Radioactive Waste Management Complex (low-level waste disposal) at INEL; and the Transportable Waste Water Treatment Unit from the Uranium Mill Tailings Remedial Action Project. Planned DOE facility costs at INEL were also evaluated for the Radioactive Waste Storage Facility, the Waste Characterization Facility, the Idaho Waste Processing Facility, and the Mixed Low-Level Waste Treatment Facility.

Other facilities evaluated include the Illinois Compact Low-Level Waste Engineered Disposal Facility and the Commonwealth of Massachusetts Low-Level Radioactive Waste Disposal Facility.

\subsection{Limitations}

This section and Appendix A of the WMFCI report (Feizollahi and Shropshire 1992) can be consulted regarding limitations and qualifications that apply to development of PLCC estimates. To apply cost data from this report, the reader must ensure that the treatment front-end and back-end common function modules and any linked treatment modules (e.g., stabilization and neutralization modules required for secondary waste) are currently available at the installation. If they are not available, the PLCC estimates for new modules, as presented in this report, must be incorporated in the overall facility estimates. When using existing facilities, the appropriate operating and maintenance costs must be added to the overall facility costs. 
Table 1-1. Capacity ranges of modules developed for low-level waste.

\begin{tabular}{|c|c|c|c|c|c|c|c|c|}
\hline \multirow[b]{3}{*}{ Module name } & \multirow{3}{*}{$\begin{array}{c}\text { Module } \\
\text { abbreviations }\end{array}$} & \multirow[b]{3}{*}{ Units } & \multicolumn{2}{|c|}{ Small generator module } & \multirow[b]{3}{*}{ Portable } & \multirow{2}{*}{\multicolumn{3}{|c|}{ Large generator module }} \\
\hline & & & \multirow{2}{*}{$\begin{array}{c}\begin{array}{c}\text { In new } \\
\text { building }\end{array} \\
\text { Alpha } \\
\end{array}$} & \multirow{2}{*}{$\begin{array}{c}\begin{array}{c}\text { In existing } \\
\text { building }\end{array} \\
\text { Nonalpha } \\
\end{array}$} & & & & \\
\hline & & & & & & Alpha & Nonalpha & Remote-Handled \\
\hline \multicolumn{9}{|l|}{ Treatment front-end common functions } \\
\hline Treatment administration & TADMN & $\mathrm{kg} / \mathrm{hr}$ & - & - & - & $91-5,670$ & $91-5,670$ & $91-5,670$ \\
\hline Receiving and inspection & RCINS & $\mathrm{kg} / \mathrm{hr}$ & - & - & - & $680-5,670$ & $680-5,670$ & $680-5,670$ \\
\hline Front-end and back-end support & FBSPT & $\mathrm{kg} / \mathrm{hr}$ & 36 & 36 & - & - & - & - \\
\hline Open, dump, and sort & OSORT & $\mathrm{kg} / \mathrm{hr}$ & - & - & - & $408-5,670$ & $91-5,670$ & $408-5,670$ \\
\hline Maintenance & MAINT & $\mathrm{kg} / \mathrm{hr}$ & - & - & - & $204-8,255$ & $204-8,255$ & $204-8,255$ \\
\hline \multicolumn{9}{|l|}{ Primary treatment } \\
\hline Incineration & INCIN & $\mathrm{kg} / \mathrm{hr}$ & 18 & 18 & - & $45-907$ & $45-907$ & 45-907 \\
\hline Metal melting & MMELT & $\mathrm{kg} / \mathrm{hr}$ & - & - & - & $18-227$ & $18-227$ & $18-227$ \\
\hline Special waste processing & SPECL & $\mathrm{kg} / \mathrm{hr}$ & - & - & - & $14-113$ & $14-113$ & $14-113$ \\
\hline Metal sizing/decontamination & DECON & $\mathrm{kg} / \mathrm{hr}$ & 18 & 18 & 18 & $18-227$ & $18-227$ & $18-227$ \\
\hline Neutralization & NEUTR & $\mathrm{kg} / \mathrm{hr}$ & - & - & - & $69-1,179$ & $9-1,179$ & $39-1,179$ \\
\hline \multicolumn{9}{|l|}{ Secondary treatment and stabilization } \\
\hline Shredding and compaction & CMPCT & $\mathrm{kg} / \mathrm{hr}$ & - & - & - & $136-1,814$ & $136-1,814$ & $136-1,814$ \\
\hline Supercompaction & SUPER & $\mathrm{kg} / \mathrm{hr}$ & - & - & - & $136-1,814$ & $136-1,814$ & $136-1,814$ \\
\hline Grout stabilization & GROUT & $\mathrm{kg} / \mathrm{hr}$ & $9^{2}$ & $9^{2}$ & $9^{2}$ & $181-1,814$ & $181-1,814$ & $181-1,814$ \\
\hline Polymer stabilization & PLYMR & $\mathrm{kg} / \mathrm{hr}$ & $9^{2}$ & $9^{\prime}$ & $9^{2}$ & $23-272$ & $9-113$ & $23-272$ \\
\hline Vitrification & VITRF & $\mathrm{kg} / \mathrm{hr}$ & - & - & - & $18-454$ & $23-454$ & $18-454$ \\
\hline Packaging & PACKG & $\mathrm{kg} / \mathrm{hr}$ & - & - & - & $77-3,629$ & $77-3,629$ & $77-771$ \\
\hline \multicolumn{9}{|l|}{ Treatment back-end common functions } \\
\hline Certification and shipping & CSHIP & $\mathrm{kg} / \mathrm{hr}$ & - & - & - & $204-8,255$ & $204-8,255$ & $204-8,255$ \\
\hline
\end{tabular}


Table 1-1. (continued).

\begin{tabular}{|c|c|c|c|c|c|c|c|c|}
\hline \multirow[b]{3}{*}{ Module name } & \multirow{3}{*}{$\begin{array}{c}\begin{array}{c}\text { Module } \\
\text { abbreviations }\end{array} \\
\end{array}$} & \multirow[b]{3}{*}{ Units } & \multicolumn{2}{|c|}{ Small generator module } & \multirow[b]{3}{*}{ Portable } & \multirow{2}{*}{\multicolumn{3}{|c|}{ Large generator module }} \\
\hline & & & \multirow{2}{*}{$\begin{array}{c}\begin{array}{c}\text { In new } \\
\text { building }\end{array} \\
\text { Alpha } \\
\end{array}$} & \multirow{2}{*}{$\begin{array}{c}\text { In existing } \\
\text { building }\end{array}$} & & & & \\
\hline & & & & & & Alpha & Nonalpha & Remote-Handled \\
\hline \multicolumn{9}{|l|}{ Storage } \\
\hline Storage administration & SADMN & $\mathrm{m}^{3} / \mathrm{hr}$ & - & - & - & $0-2$ & $0-2$ & $0-2$ \\
\hline Storage receiving and shipping & SRCSH & $\mathrm{m}^{3} / \mathrm{hr}$ & - & - & - & $0-2$ & $0-2$ & $0-2$ \\
\hline Storage $^{b}$ & STORE & $\mathrm{m}^{3}$ & - & - & - & $11,419-198,688$ & $11,419-198,688$ & $11,419-198,688$ \\
\hline Silo storage ${ }^{b}$ & STOSI & $\mathrm{m}^{3}$ & - & - & - & - & - & $46-13,474$ \\
\hline \multicolumn{9}{|l|}{ Disposal } \\
\hline Disposal administration & DADMN & $\mathrm{m}^{3} / \mathrm{hr}$ & - & - & - & $1-4$ & $1-4$ & $1-4$ \\
\hline Disposal receiving & DRECV & $\mathrm{m}^{3} / \mathrm{hr}$ & - & - & - & $1-4$ & $1-4$ & $1-4$ \\
\hline Engineered disposal ${ }^{b}$ & AGDSP & $\mathrm{m}^{3}$ & - & - & - & $41,108-287,755$ & $41,108-287,755$ & $41,108-287,755$ \\
\hline Shallow land disposal ${ }^{b}$ & SLDSP & $\mathrm{m}^{3}$ & - & - & - & $41,108-287,755$ & $41,108-287,755$ & $41,108-287,755$ \\
\hline Silo disposal ${ }^{b}$ & SIDSP & $\mathrm{m}^{3}$ & - & - & - & $3,289-13,474$ & $3,289-13,474$ & $3,289-13,474$ \\
\hline Borehole disposal $^{b}$ & BHDSP & $\mathbf{m}^{3}$ & 1 & 1 & - & - & - & - \\
\hline
\end{tabular}

a. For small generator modules, grout and polymer stabilization unit operations are combined into a single module.

b. Capacity for storage and disposal modules are 20-year life cycle capacities (in $\mathrm{m}^{3}$ ). 
Table 1-2. Sample PLCC estimate summary for the small generator incineration module.

Module name: Incin

Option name: Example

Waste type:

D MLLK

( HLW

D $M-T R U$

Dalpha

non-alpha

contact-handled

LLW

$\square$ remote-handled

Module location: Example

Module status:

0 Existing
On-Site

0 New

C Small generator

D Portable

$\square$ Commercial

Large generator

Reference capacity requirement: $\quad 2.000 \mathrm{lb} / \mathrm{hr}$

WBS Element

$(\$ \times 1,000)$

$(\$ \times 1,000)$

Sub $\$$

Element \$

1.0 Pre-Operations

1.1 Studies and Bench Sca le Test Costs

$\$ 1,031$

1.2 Demonstration Costs

1.3 Operations Budget Funded Activities

1.3.1 Conceptual Design

1.3.2 Safety Assurance Documentation

1.3.3 Pemitting

$\$ 5,611$

1.3 .4

Preparation for Operations

$\$ \quad 0$

1.3 .5

Project Management

$\$ \quad 999$

$\$ \quad 0$

$\$ 5,793$

$\$ \quad 746$

Total pre-operations

$\$ 14,846$

2.0 Facility Construction Costs

2.1 . Design (Title I and II)

2.2 Inspection

$\$ 4,149$

2.3 Project Management

$\$ 2,420$

$\$ 3,457$

2.4 Building Construction (includes indirect)

$\$ 11,663$

2.5 Equipment (includes indirect)

$\$ 15,136$

2.6 Construction Management

$\$ 5,912$

2.7 Other (includes reserve and contingency)

$\$ 16,084$

Total facility construction costs

$\$ 66,593$

3.0 Operations and Ma intenance

3.1 Annua 1 Operating Labor

3.2 Annual Utilities

3.3 Annual Materials

$\$ 2,940$

3.4 Annual Haintenance

$\$ \quad 190$

$\$ 1,416$

3.5 Annual Other (includes reserve and

$\$ 1,159$

contingency)

Total annual 084

$x$ number of years of operation

$\$ 5,793$

$\times 10$ yrs

Total operations and maintenance

$\$ 57.930$

4.0 Decontamination and Decommissioning

4.1 Facility $0 \& D$

4.2 - Closure, Post-Closure, Monitoring

$\$ 6,259$

$\$ \quad 0$

Total decontamination and decommissioning

Total cost for: Incin module

(1994 dollars)

$\$ 145,628$ 


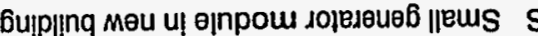

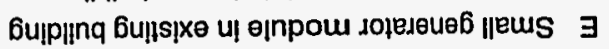

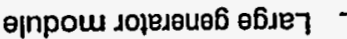

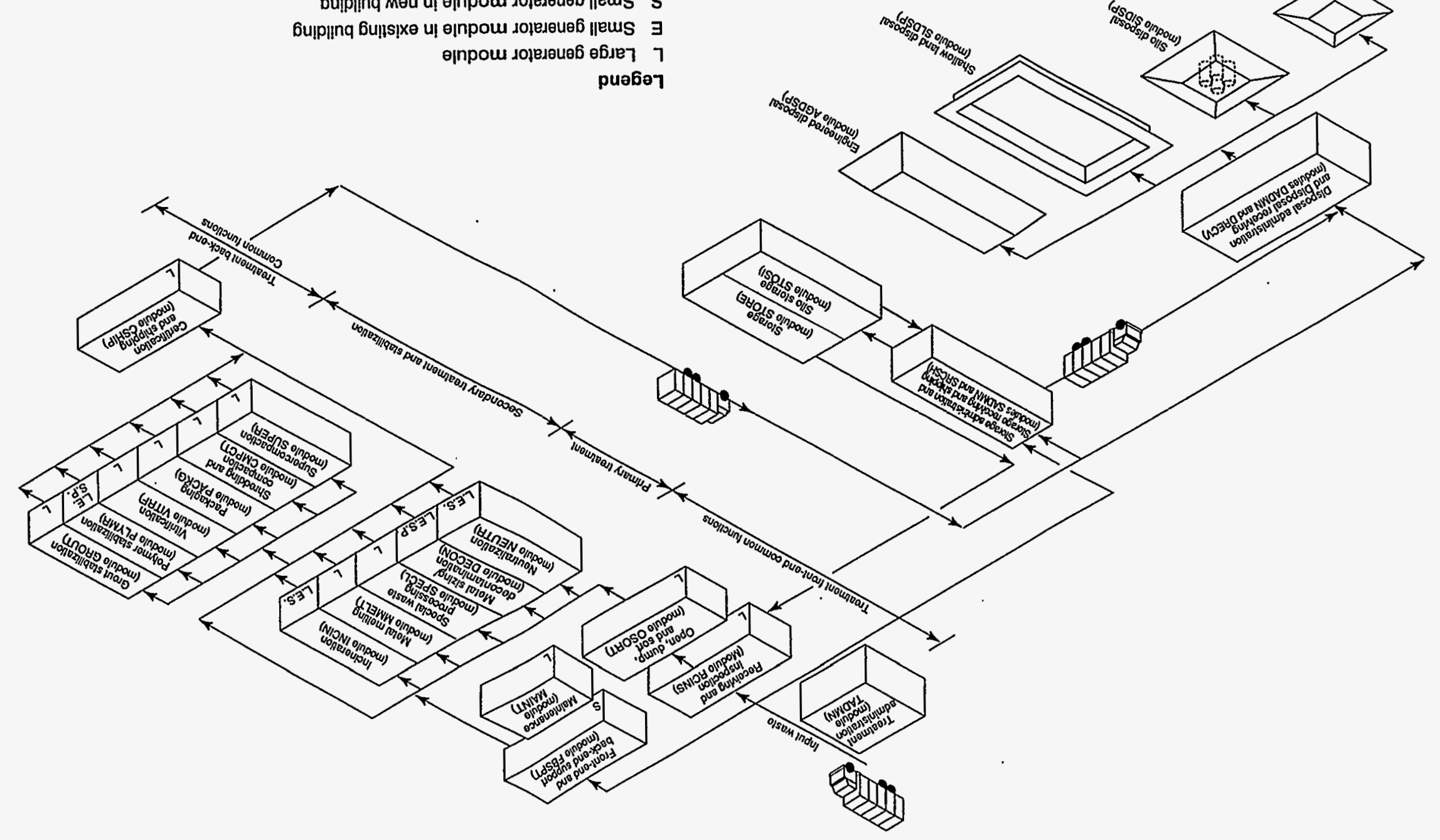




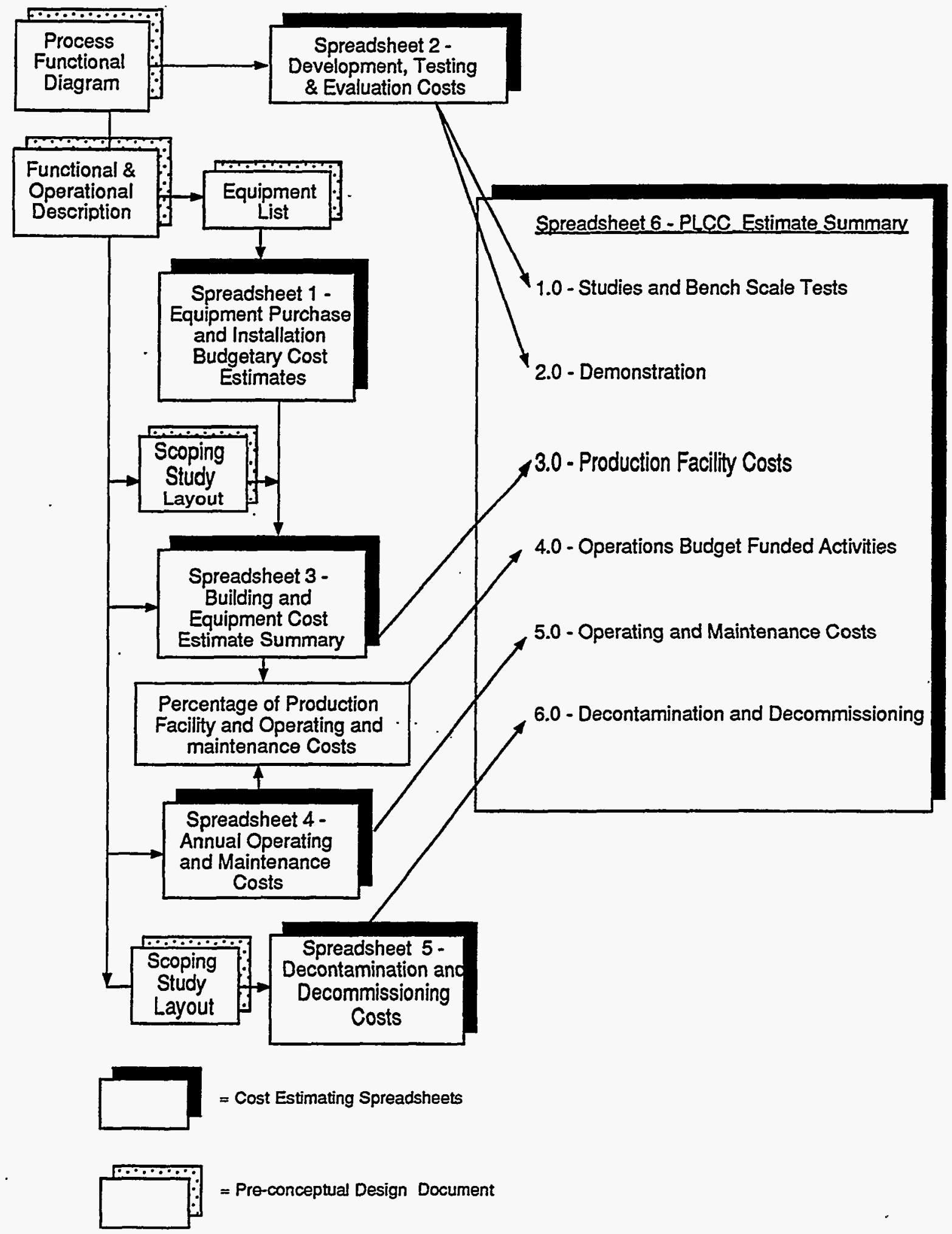

Figure 1-2. PLCC cost estimating steps. 


\section{TREATMENT ADMINISTRATION (MODULE TADMN)}

\subsection{Basic Information}

The treatment administration module includes all administrative and laboratory buildings required for large generator waste management support functions. The treatment administration module is essentially the same for all treatment facilities regardless of their capacity. Treatment administration should be used whenever a new treatment facility is planned.

\subsection{Technical Bases and Assumptions}

\subsubsection{Function and Operation of Large Generator Modules}

The treatment administration module incorporates all technical and administrative support functions needed to manage the operation of a waste management facility. These functions include security, access control including personnel decontamination (radioactive and hazardous), maintenance of uncontaminated areas and equipment, health physics and radiation badges, facility access control, sanitary facilities, work control and personnel support, internal and external (public relations) communications, spill or emergency response provisions (hazardous and radioactive), analytical laboratory, environmental field sampling, environmental regulatory reporting, and records management.

\subsubsection{Integration of Large Generator Modules}

The treatment administration module maintains general interfaces with all treatment modules. The O\&M consumables include analytical supplies, office supplies, sanitary supplies, and personal protective equipment, which all must be purchased.

\subsubsection{Small Generator and Portable Modules}

No separate fixed small generator module has been developed. The treatment front-end support functions for such a facility have been combined with the back-end support functions into a front-end/back-end support module in module FBSPT (Section 4).

\subsection{Cost Bases, Assumptions, and Results}

The treatment administration module is the same for alpha and nonalpha waste. Major equipment capital cost items are laboratory analytical equipment. A $\$ 1$ million allowance is made for analytical instruments and components needed for a mixed-waste laboratory. ${ }^{8}$ Table 2-1 lists the plan dimensions of the module. Figure 2-1 shows the relationship between estimated FTE workers and the capacity of the module. Figures 2-2 and 2-3 show the relationship between PLCC and capacity.

g. . The mixed waste laboratory has been sized to support a $10 \%$ sampling and analysis capability. These costs should be modified if less or more sampling is expected to be required. 
The treatment administration module should be sized based on the total waste capacities to be treated in all treatment modules.

Table 2-1. Plan dimensions of treatment administration (TADMN) module.

\begin{tabular}{ccccccc}
\hline & \multicolumn{2}{c}{$\begin{array}{c}\text { Dimensions } \\
(\mathrm{ft})\end{array}$} & & \multicolumn{2}{c}{$\begin{array}{c}\text { Dimensions } \\
(\mathrm{m})\end{array}$} \\
\cline { 2 - 3 } \cline { 6 - 6 } Module size & Width & Length & & Width & Length \\
\hline Large generator & & & & & \\
Small & 100 & 92.5 & & 30.5 & 28.2 \\
Medium & 100 & 172.5 & & 30.5 & 52.6 \\
Large & 100 & 265.0 & & 30.5 & 80.8 \\
Small generator & - & - & & - & - \\
\hline
\end{tabular}




\section{TREATMENT ADMINISTRATION}

FTE by Work Breakdown Structure Element

Module: TADMN Waste Type: Alpha, Nonalpha, and Remote Handled LLW

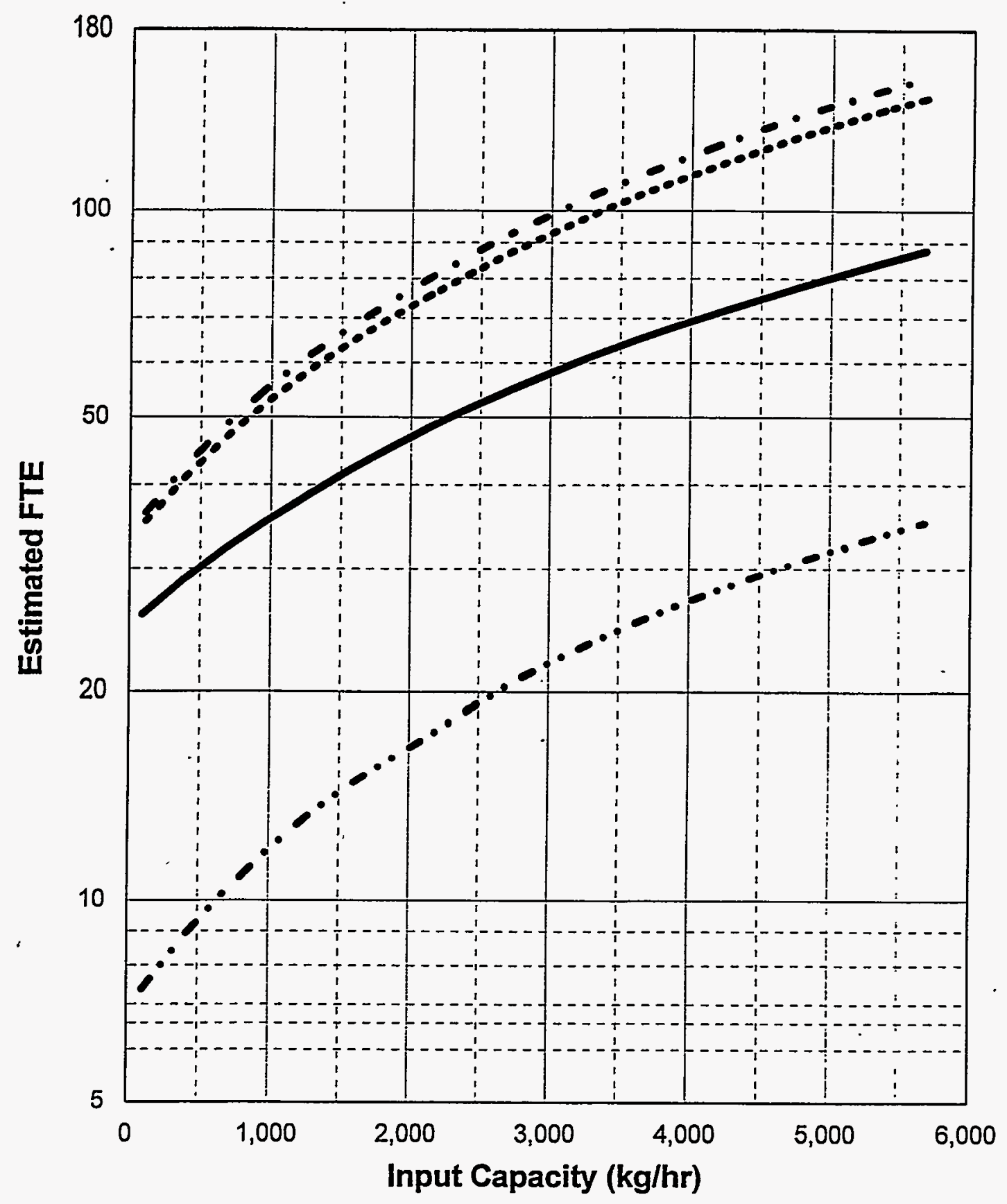

Pre-Operations Construction O\&M (1year) D\&D
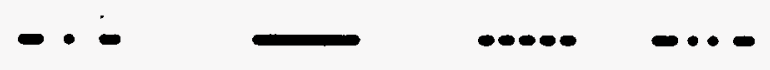

Figure 2-1. FTE workers versus capacity for the treatment administration (TADMN) module. 


\section{TREATMENT ADMINISTRATION}

Costs by Work Breakdown Structure Element Module: TADMN Waste Type: Alpha, Nonalpha, and Remote Handled LLW

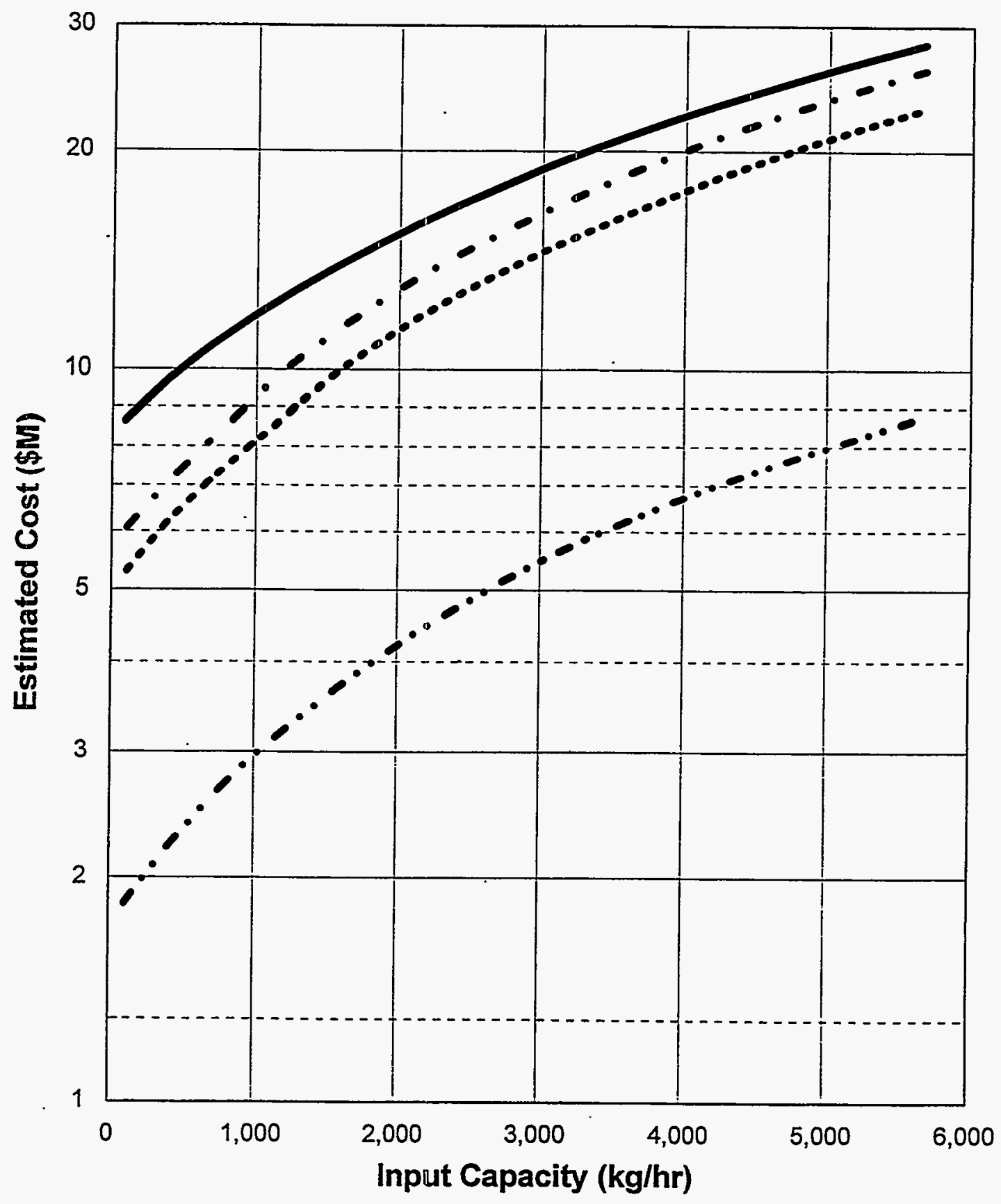

Pre-Operations Construction O\&M (1year) D\&D

Figure 2-2. PLCC versus capacity for the treatment administration (TADMN) module. 


\section{TREATMENT ADMINISTRATION}

Total Life Cycle Costs

Module: TADMN Waste Type: Alpha, Nonalpha, and Remote Handled LLW

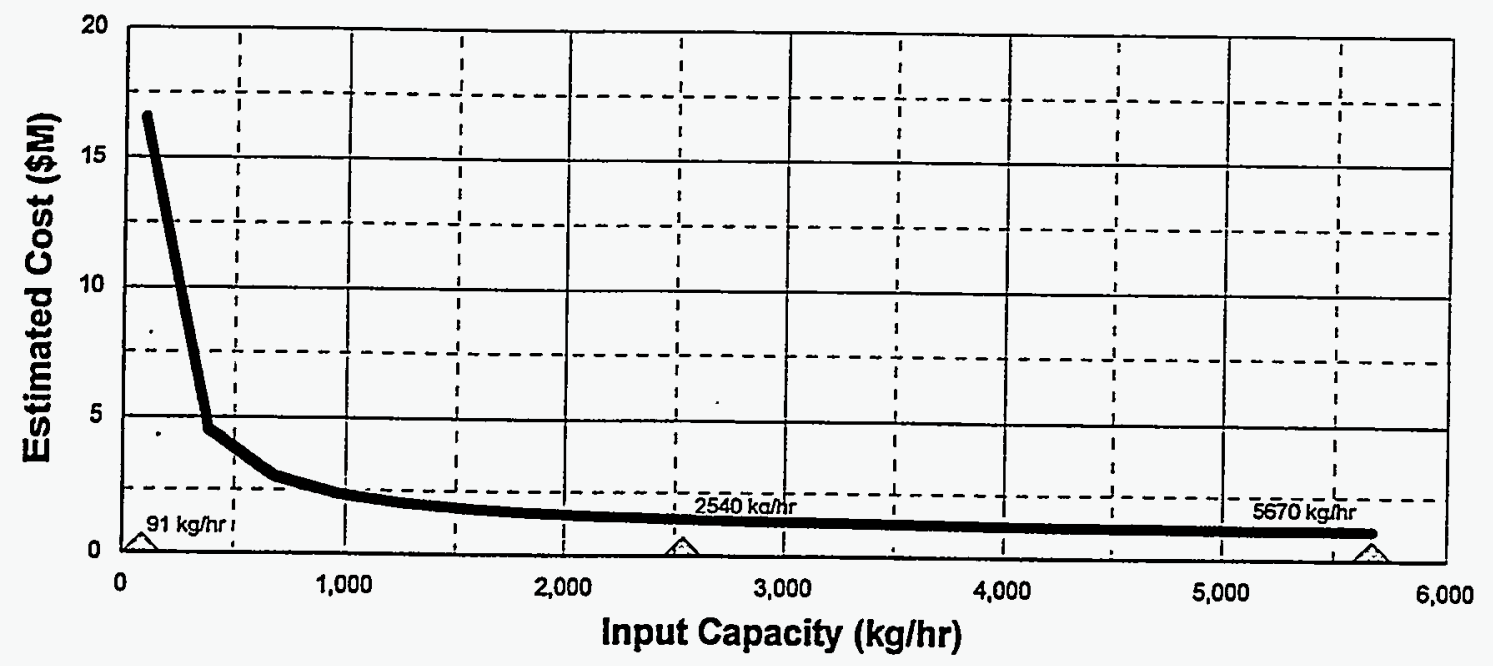

Alpha, Nonalpha, Remote Handled

NOTE: Basis includes 20 years O\&M

Triangles indicate where detailed cost estimates were developed.

\section{TREATMENT ADMINISTRATION}

Total Life Cycle Unit Costs

Module: TADMN Waste Type: Alpha, Nonalpha, and Remote Handled LLW

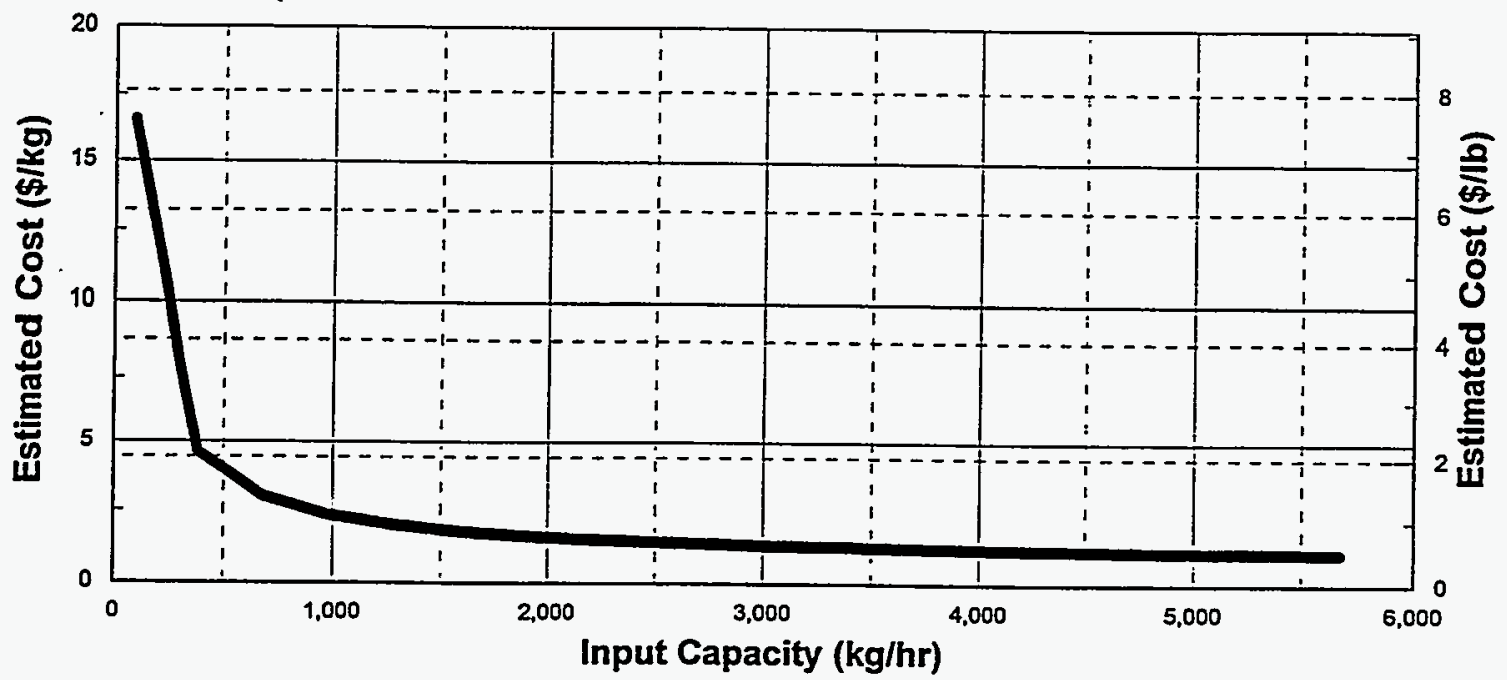

Alpha, Nonalpha, Remote Handled

NOTE; Basis indudes 20 years O\&M

Figure 2-3. PLCC versus capacity including unit rates for the treatment administration (TADMN) module. 


\section{RECEIVING AND INSPECTION (MODULE RCINS)}

\subsection{Basic Information}

The receiving and inspection module, shown in Figure 3-1, is effectively the same for nonaipha, alpha, and RH waste. There are minor differences in the assay and inspection equipment that are negligible at a PLCC estimate level. Unit operations are shown in the PFD in Figure 3-2.

The receiving and inspection module is intended to be contiguous with the open, dump, sort module and the waste treatment modules. It consists of two unit operations: (a) unload and stage, and (b) inspect and assay. The containers of waste (in drums, boxes, and metal bins) arrive at the receiving and inspection module on a transport vehicle. Containers are removed from the transport vehicle and placed in a staging or storage area. The containers are visually examined, labeled, logged, recorded, and sent to inspection and assay.

The purpose of the inspect and assay unit operation is to physically and radiologically characterize the waste to allow segregation of the containers. Based on the inspection and assay results, the waste containers are grouped according to their processing needs. The inspect and assay unit operation also identifies a special waste category that applies to any containerized waste requiring special processing operations.

The receiving and unloading area is equipped with a bridge crane and a forklift truck. It is designed to receive and unload containers from flat-bed trailers or van trucks. Containers brought in large overpacks, for example, transportation transuranic package transporter (TRUPAC II) type containers, can also be unloaded.

\subsection{Technical Bases and Assumptions}

\subsubsection{Function and Operation of Large Generator Modules}

Transportation vehicles are used to ship the containers (in overpacks, if necessary) from the generators to the receiving and inspection module. These vehicles are not included in the module. In the unloading and staging unit operation, the transportation vehicles are unloaded, and containers are placed in the staging area. Surge storage is also provided. Containers may be moved within the unloading, staging, and surge storage areas and transported to and from the various interfacing unit operations.

Containers are unloaded in an enclosed truck bay and placed in an indoor staging area. The area is large enough to maneuver the containers and provide sufficient surge storage capacity to meet the desired operational reliability.

The inspect and assay unit operation determines the radioactivity, physical properties, and other parameters needed to categorize the containerized waste before processing in accordance with the criteria established for the processing unit operations. Various devices, such as passive/active neutron (PAN) counting instruments, may be used. Containers holding waste classified as other than alpha and nonalpha LLW are returned to the generator. 
Waste containers are also examined to allow classification by gamma radioactivity (in accordance with the criteria established for the processing unit operations), to ensure that they are suitable for contact handling (less than 200 milliRems per hour on surface), and for treatment by the given process units. Various devices, such as segmented gamma scanning (SGS), instruments, could be used. Containerized waste that does not meet the criteria is either handled as special waste or returned to the generator.

After the containers are examined, they are weighed and measured to determine waste density. Contents (categorized as metal, paper, glass, sludge, gas cylinders, and liquids) are determined by nondestructive examination. At a minimum, each container is examined using a nondestructive assay unit equipped with a real-time radiography (RTR) device. Ultrasonic devices are also used. After examination, each container is labeled and the properties of its contents are logged and entered into a computerized database.

To allow year-round operations and to minimize the effects of a potential spill, it is assumed that the unloading and staging operations will take place indoors.

\subsubsection{Integration of Large Generator Modules}

In addition to general interfaces typical for all modules, waste from generator facilities becomes input to the receiving and inspection module. The O\&M consumables, including personal protective equipment, must be purchased. Module output consists of containers of alpha and nonalpha waste that are moved to the open, dump, and sort module or to treatment modules.

\subsubsection{Small Generator Fixed Module}

The receiving and inspection functions for a portable or small generator fixed module are performed by the back-end support (FBSPT) module.

\subsection{Cost Bases, Assumptions, and Results}

Cost bases and assumptions were derived from a variety of sources. Major equipment capital cost items for this module include alpha assay, gamma assay, 20-ton bridge crane, and RTR units. The crane cost is based on vendor quotations. The inspection and assay units are based on conceptual designs and cost estimates for a radiological and hazardous material measurement system provided by Lockheed Martin. Budget estimate for an inspection and assay system is $\$ 2$ million. Figures 3-3 and 3-4 show the relationships between estimated FTE workers and capacity of the module. Figures 3-5, 3-6, and 3-7 show the relationship between PLCC and capacity. 


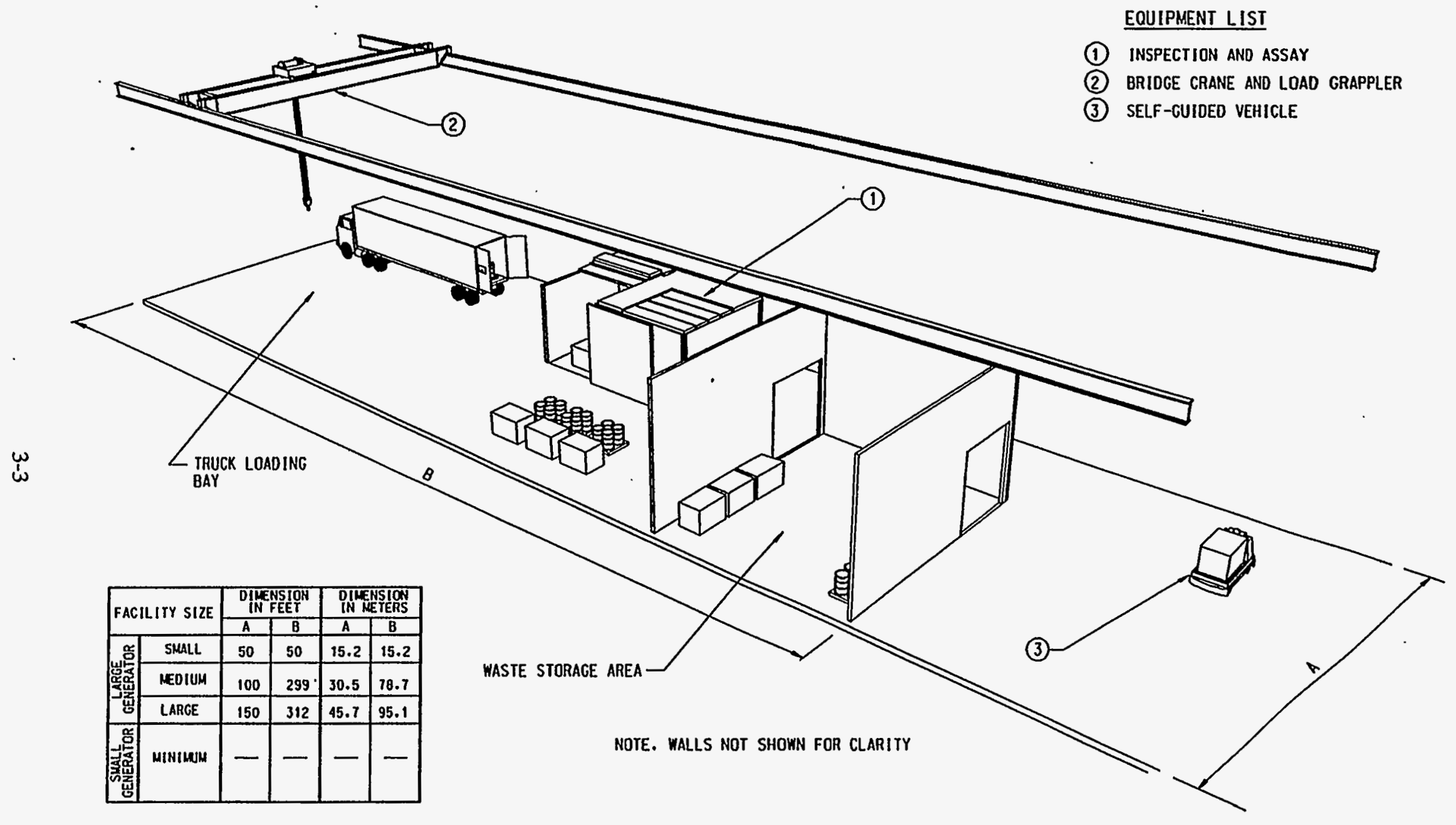

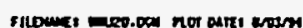

Figure 3-1. Equipment layout for the receiving and inspection (RCINS) module. 


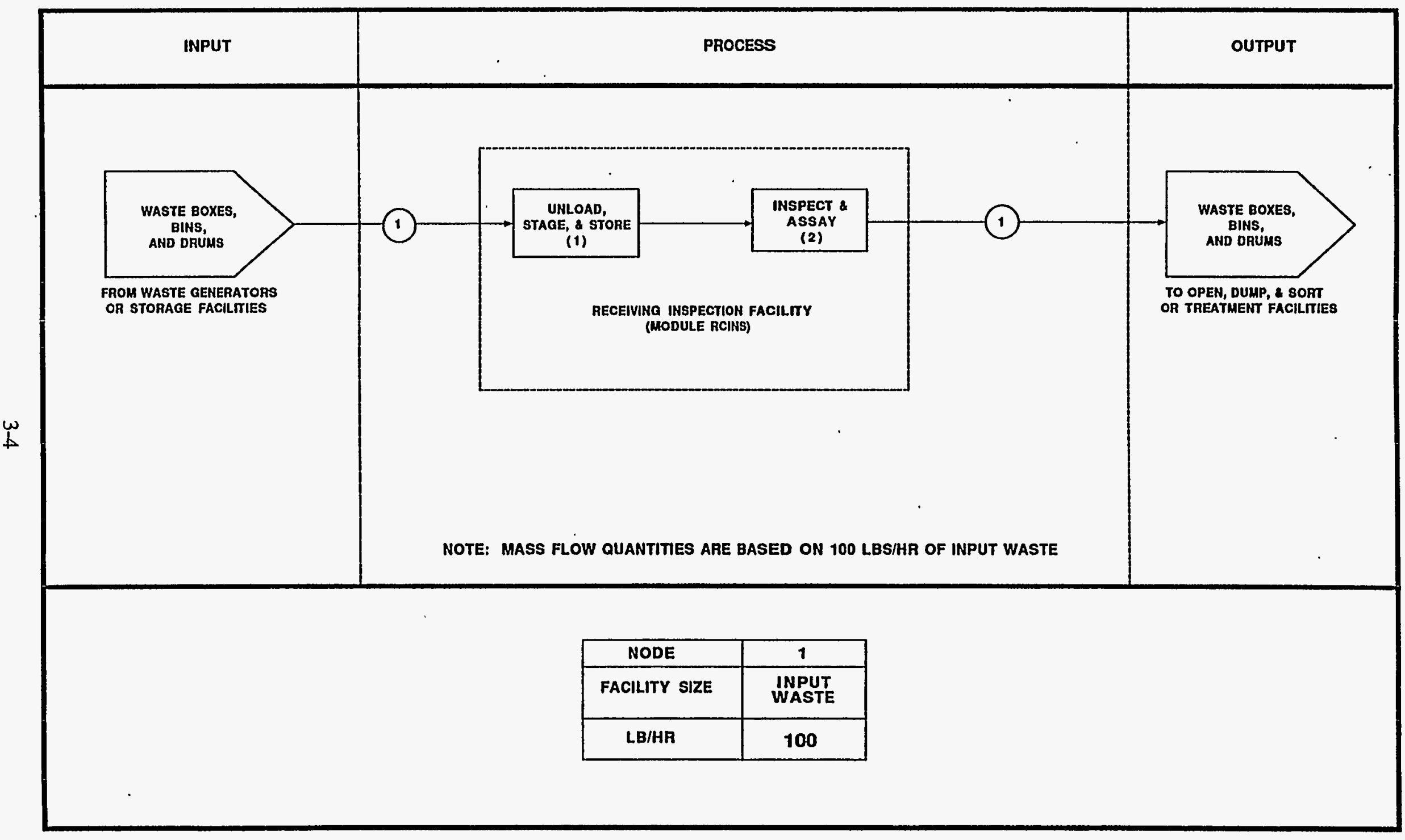

Figure 3-2. Process flow diagram for the receiving and inspection (RCINS) module. 


\section{RECEIVING AND INSPECTION}

FTE by Work Breakdown Structure Element

Module: RCINS Waste Type: Nonalpha LLW

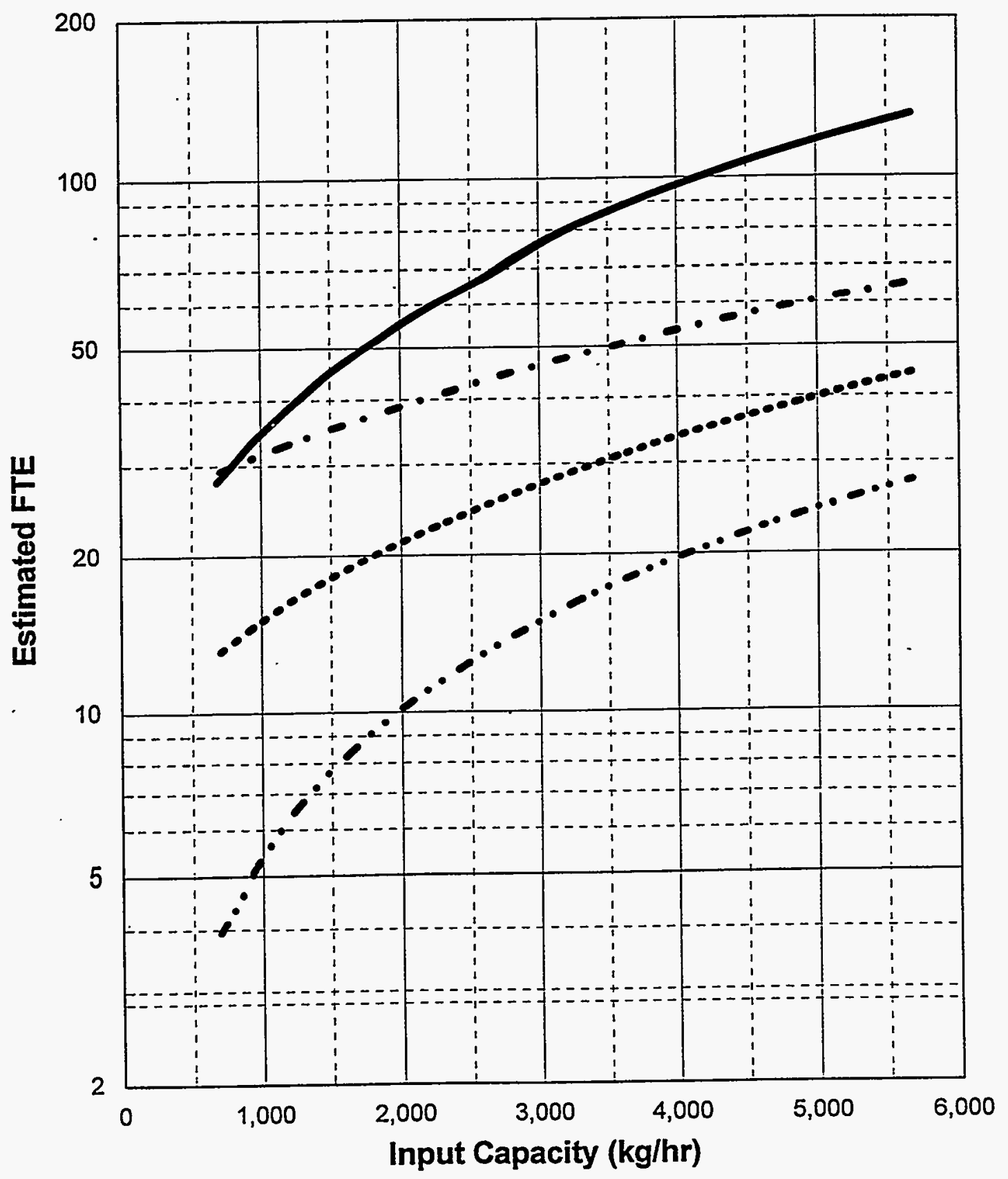

Pre-Operations Construction O\&M (1year) D\&D

Figure 3-3. FTE workers versus capacity for the nonalpha receiving and inspection (B-RCINS) module. 


\section{RECEIVING AND INSPECTION}

FTE by Work Breakdown Structure Element

Module: RCINS Waste Type: Alpha and Remote Handled LLW

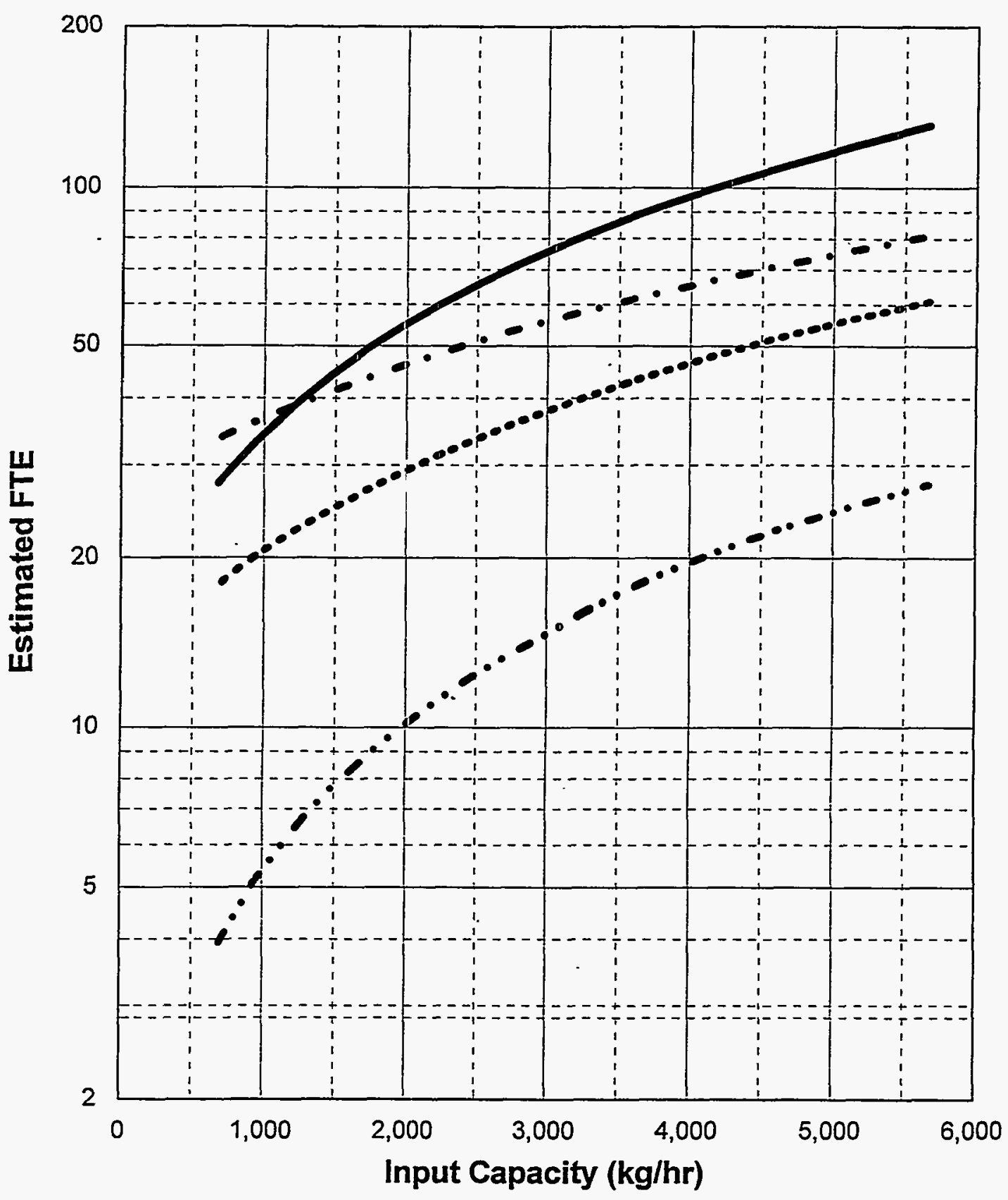

Pre-Operations Construction O\&M (1year) D\&D

Figure 3-4. FTE workers versus capacity for the alpha and RH receiving and inspection (A/R-RCINS) module. 
RECEIVING AND INSPECTION

Cost by Work Breakdown Structure Element Module: RCINS Waste Type: Nonalpha LLW

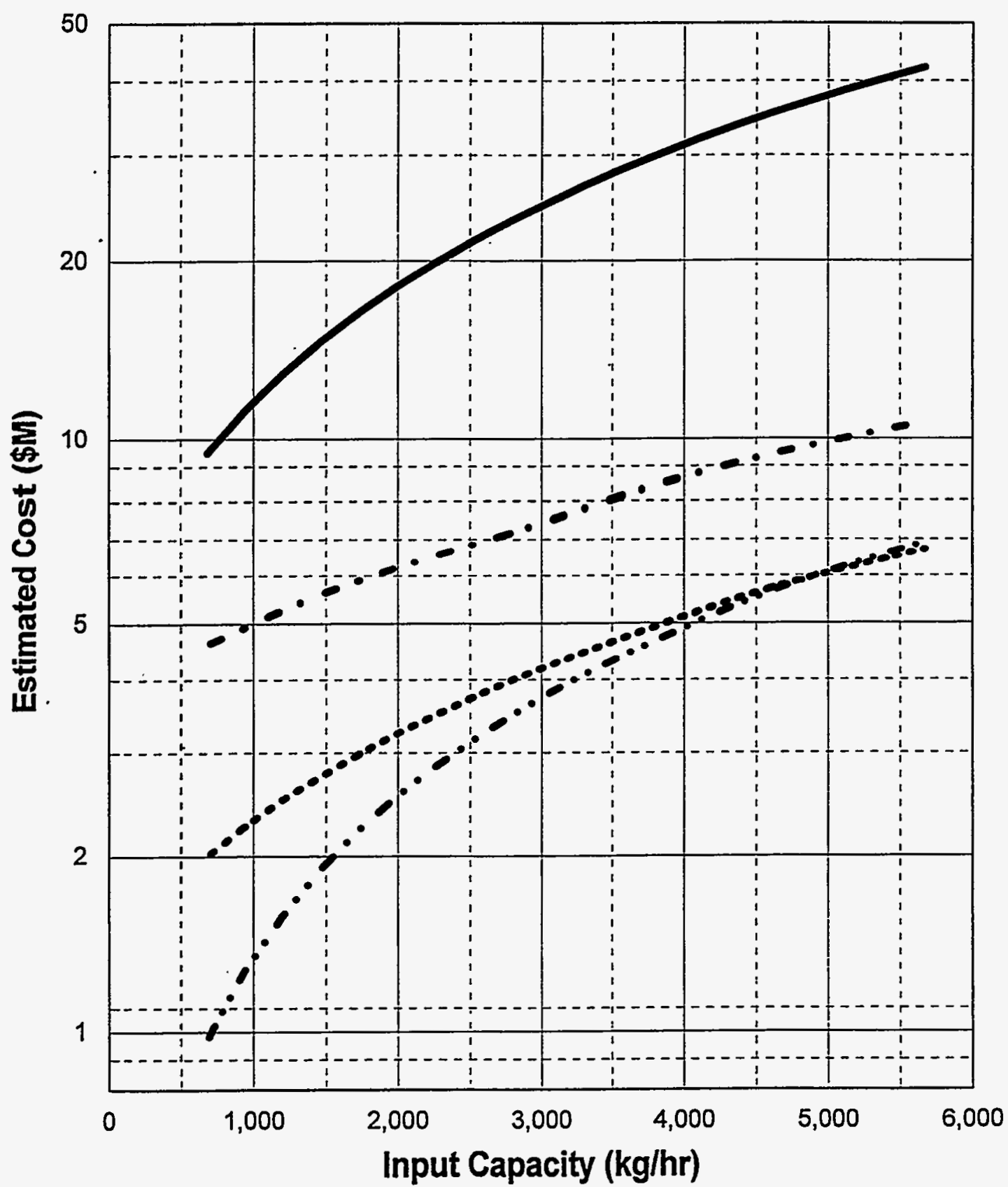

Pre-Operations Construction O\&M (1year) D\&D

Figure 3-5. PLCC versus capacity for the nonalpha receiving and inspection (B-RCINS) module. 


\section{RECEIVING AND INSPECTION}

Cost by Work Breakdown Structure Element

Module: RCINS Waste Type: Alpha and Remote Handled LLW

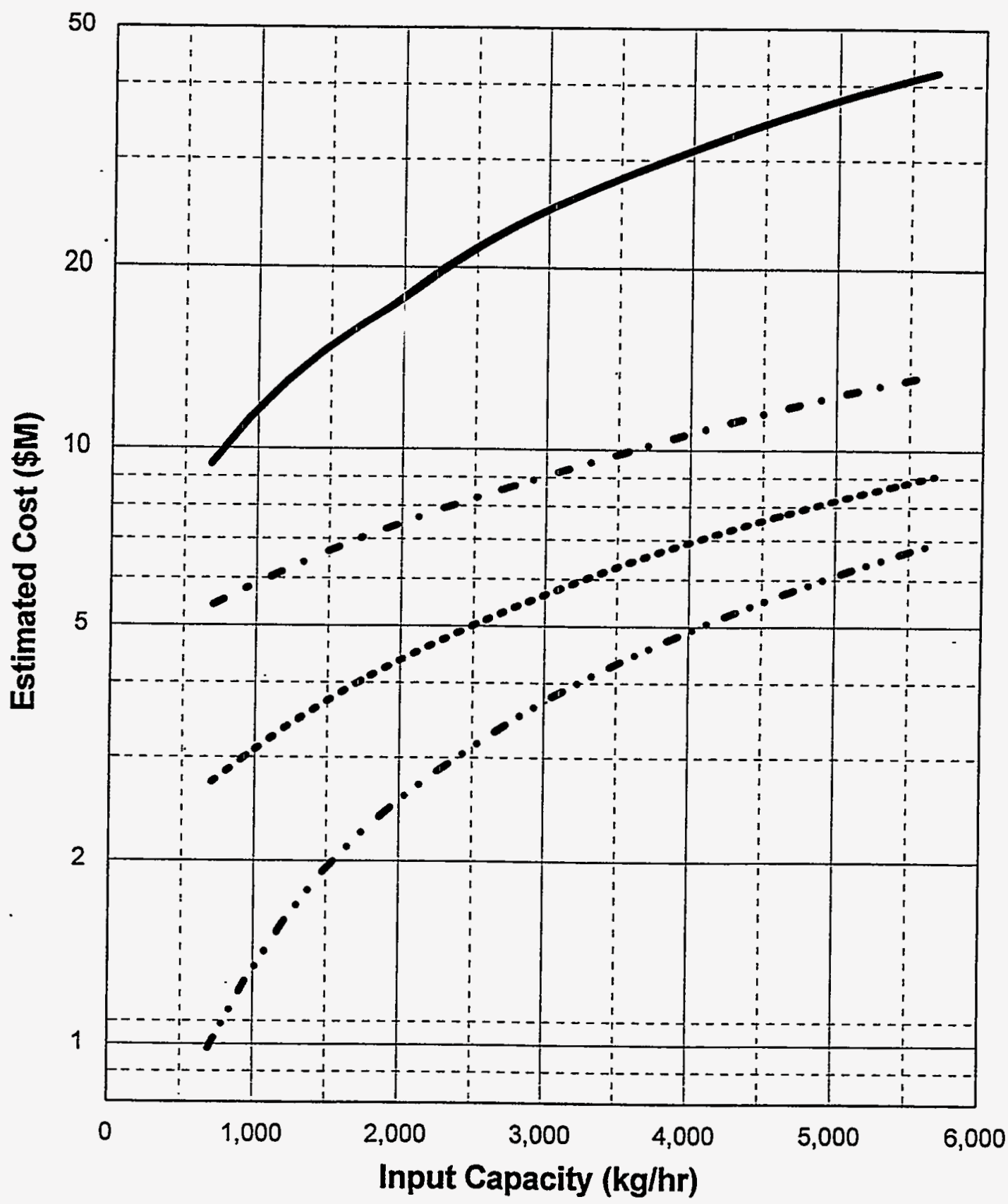

Pre-Operations Construction O\&M (1year) D\&D

Figure 3-6. PLCC versus capacity for the alpha and RH receiving and inspection (A/R-RCINS) module. 


\section{RECEIVING AND INSPECTION}

Total Life Cycle Costs

Module: RCINS Waste Type: Alpha, Nonalphä, and Remote Handled LLW

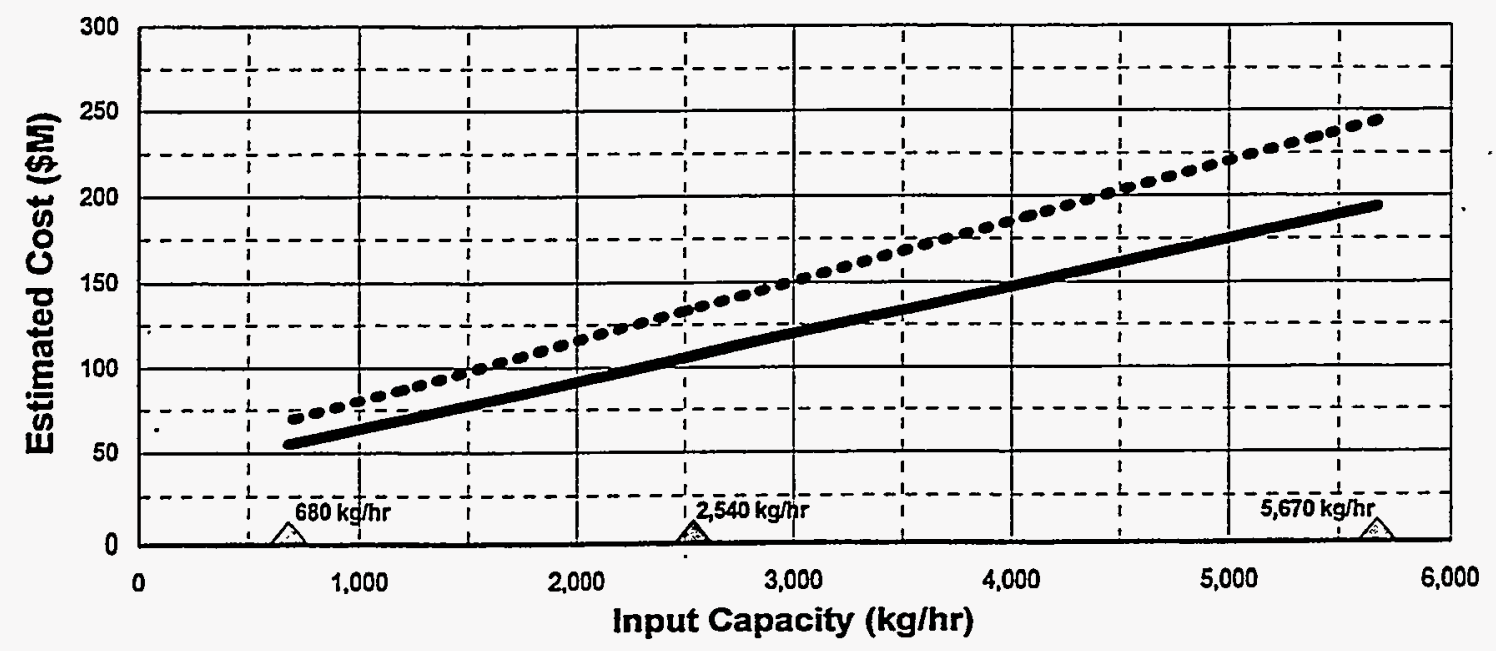

Nonalpha Alpha, Remote Handled

NOTE: Basis includes 20 years O\&M

Triangles indicate capacities where detalled cost estimates were developed.

\section{RECEIVING AND INSPECTION}

Total Life Cycle Unit Costs

Module: RCINS Waste Type: Alpha, Nonalpha, Remote Handled LLW

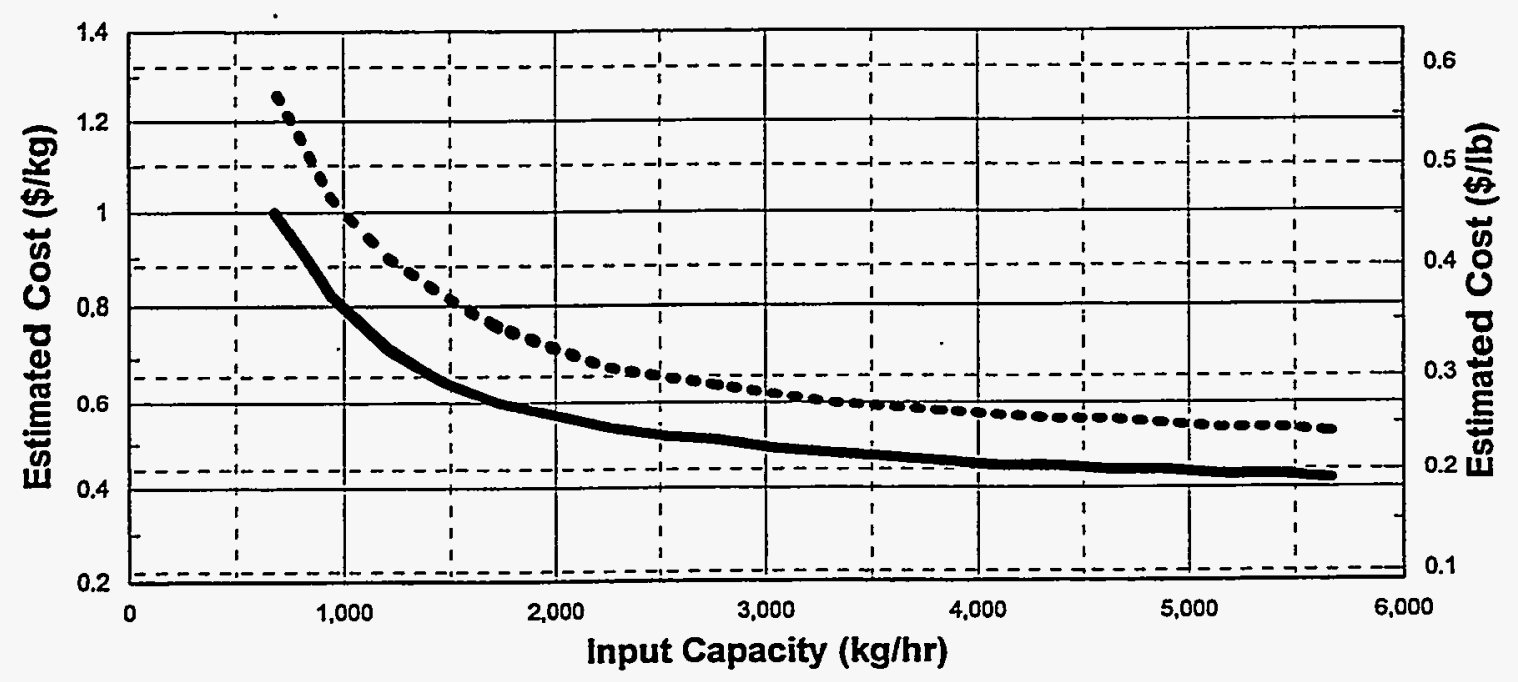

Nonalpha Alpha, Remote Handled

NOTE: Basis includes 20 years O\&M

Figure 3-7. PLCC versus capacity including unit rates for the receiving and inspection (RCINS) module. 


\section{SMALL GENERATOR FRONT-END AND BACK-END SUPPORT (MODULE FBSPT)}

\subsection{Basic Information}

The front-end and back-end support module, shown in Figure 4-1, is the first part of the overall facility needed for treatment of alpha and nonalpha waste at a small generator facility. This module can be used in either a new building or within an existing building at a small generator facility. It is intended only for a small generator, combining the functions of front-end technical and administrative support; receiving and inspection; open, dump, and sort; maintenance; and certification and shipping. For a large generator facility, these functions are distributed among five separate modules (TADMN, RCINS, OSORT, MAINT, and CSHIP). The small generator front-end and back-end support module is intended to be contiguous with the waste-treatment modules. Figure 4-2 shows a PFD of the frontend and back-end support module.

\subsection{Technical Bases and Assumptions}

\subsubsection{Function and Operation of the Module}

The front-end and back-end support module receives incoming untreated waste, which is in the form of a liquid, solid, or sludge. Untreated waste arrives in drums, metal bins, and cardboard boxes shipped to the treatment facility on transport vehicles. Liquid waste is shipped by tank trucks or in special containers carried by transport vehicles. The incoming waste is contact handled (no shipping casks are anticipated) and is transported in enclosed vehicles. A loading and unloading unit operation equipped with an unloading device removes waste containers from the incoming vehicles and places them in a staging and interim (surge) storage area. The storage area is large enough to allow maneuvering the containers during staging operations and provides sufficient surge storage capacity to achieve the desired operational reliability.

An inspect and assay unit operation determines radioactive properties of the waste as needed for safe handling and processing. This unit operation also categorizes the waste by its chemical and physical properties using criteria established for various treatment modules. Radioassay functions may be accomplished by SGS instruments. Chemical characterization may be performed by sampling and analysis. Physical properties may be determined by appropriate instrumentation (e.g., weigh scales may be used to determine waste density). After examination, each container is labeled and the properties are logged and entered into a computer database.

Organic liquid waste is sent for processing by an organic destruction unit (either the organicsolid wet-air oxidation module or incinerator module). Aqueous waste is sent to the aqueous waste treatment module.

Containers holding solid waste acceptable by the alpha and nonalpha waste treatment modules are sent to an opening and emptying unit operation, where the containers are uncapped and the contents are emptied onto a sorting device. There the waste is segregated and placed in transfer bins. Solid process residues are sent for organic destruction (incineration or organic-solids wet-air oxidation); heterogeneous and organic debris are sent for organic destruction (incineration, organic- 
solids wet-air oxidation, or thermal desorption); inorganic debris is sent for stabilization (grouting); metal debris is sent for decontamination; and special, unknown, and inherently hazardous waste is sent for special waste treatment. Some of the bins containing solid waste may be sent first to a size reduction unit operation as needed by the treatment step. For example, inorganic debris may be shredded to small particles to facilitate the stabilization process. Opening, emptying, sorting, size reduction, and transferring may be accomplished manually using appropriate material handling equipment. All unit operations have vent hoods to minimize the spread of dust and contamination.

The module also includes a discarded container packaging unit operation. In this unit operation, containers are either rinsed for reuse or are compacted and sent for disposal.

Another function of the front-end and back-end support module is certification and shipping of waste packaged by the treatment facility. The packaged waste containers brought from the treatment modules are placed in an inspect, assay, and certify unit operation. At this unit operation, the containers are weighed, visually examined, tagged, logged, recorded, and sent to the assay device for classification with regard to gamma radioactivity, in accordance with transportation, storage, and disposal criteria. The presence of material restricted by these criteria is determined using process knowledge. The radioactivity properties are also logged and recorded into the computerized database. The containers are then moved to a temporary storage area until they are ready for shipment to a long-term storage or disposal facility. When ready, the loading and unloading unit operation transfers the container onto enclosed vehicles. Before leaving the module, the vehicles are inspected and certified in accordance with DOE and U.S. Department of Transportation regulations. The testing laboratory provides the capability to sample and analyze to certify that the hazardous component of the waste has been removed, as required for disposal or recycling.

Existing building space required for installation of this module is $613.1 \mathrm{~m}^{2}\left(6,600 \mathrm{ft}^{2}\right)$. The required ceiling height is $7.6 \mathrm{~m}(25 \mathrm{ft})$. The area required for the new building is the same.

\subsubsection{Integration of the Fixed Module}

Input to the front-end and back-end support module consists of containers of untreated waste from storage or generator facilities, and packages of treated waste from the treatment modules. Output from the front-end and back-end support module includes waste that is sorted according to treatment requirements; empty containers, which are recycled or packaged for disposal; and treated waste, which is placed in shipping vehicles going to disposal or long-term storage facilities. Secondary waste generated in this module consists of treated air discharged from high-efficiency particulate air (HEPA) filters and spent rinse water from the washing of empty containers. This module is linked with site communication and alarm systems, including telephone, evacuation, security alarm, and public address systems. This module also serves as the support center for the waste management facility. Consumables, including personal protective equipment, are purchased.

\subsection{Cost Bases, Assumptions, and Results}

Major equipment capital cost items for this module include a testing laboratory, SGS assay system, forklift, shredder, container rinse booth, drum baler, and sorting glove box. All waste is contact handled, and O\&M activities are manual. Sorting will be manual, using glove boxes. Emergency showers, personnel decontamination, breathing air, and maintenance, mechanical, and 
instrument shop equipment are included in the module. Estimated operating staff is based on handling 4.5 drums per day or $36.3 \mathrm{~kg} / \mathrm{hr}$. The relationship between estimated FTE workers and capacity of the module is shown in Table 4-1.

Laboratory analytical equipment for environmental, alpha, and nonalpha waste analysis is estimated to be $\$ 1$ million; this estimate is based on quotes obtained by Eberline Corporation, Santa Fe, New Mexico. The cost to furnish size-reduction equipment is based on prices obtained from Stock Equipment Company of Chagrin Falls, Ohio. The cost to furnish the SGS assay system, rinse booth, and personnel portal monitor is based on a quotation from Atlan-Tech Corporation, Inc., Roswell, Georgia. The cost to furnish the drum baler is based on a quotation from Stock Equipment Company, Chagrin Falls, Ohio. Costs for the small generator front-end and back-end support module are shown in Table 4-2.

The columns in Tables 4-1 and 4-2 reflect the costs of a new building versus building modification costs. 
Table 4-1. FTE workers for the small generator front-end and back-end support module.

\begin{tabular}{lcc}
\hline \multicolumn{1}{c}{ Cost element } & \multicolumn{2}{c}{ Type of module } \\
\cline { 2 - 3 } & $\begin{array}{c}\text { Fixed, in new } \\
\text { building(s) }\end{array}$ & $\begin{array}{c}\text { Fixed, in existing } \\
\text { building(s) }\end{array}$ \\
\hline (1.0) Preoperation & 60 & 59 \\
(2.0) Construction & 54 & 49 \\
(3.0) O\&M (20 years) & 234 & 234 \\
(4.0) D\&D & 13 & 13 \\
All cost elements (total for 20 years O\&M) & 361 & 355 \\
\hline
\end{tabular}

Table 4-2. PLCC $(\$ 1,000)$ for the small generator front-end and back-end support module.

Type of module

\begin{tabular}{lcc}
\multicolumn{1}{c}{ Cost element } & $\begin{array}{c}\text { Fixed, in new } \\
\text { building(s) }\end{array}$ & $\begin{array}{c}\text { Fixed, in existing } \\
\text { building(s) }\end{array}$ \\
\hline (1.0) Preoperation & 9,923 & 9,923 \\
(2.0) Construction & 17,744 & 13,548 \\
(3.0) O\&M (20 years) & 51,560 & 51,560 \\
(4.0) D\&D & 3,279 & 3,279 \\
All cost elements (total for 20 years O\&M) & 82,506 & 78,310 \\
\hline
\end{tabular}



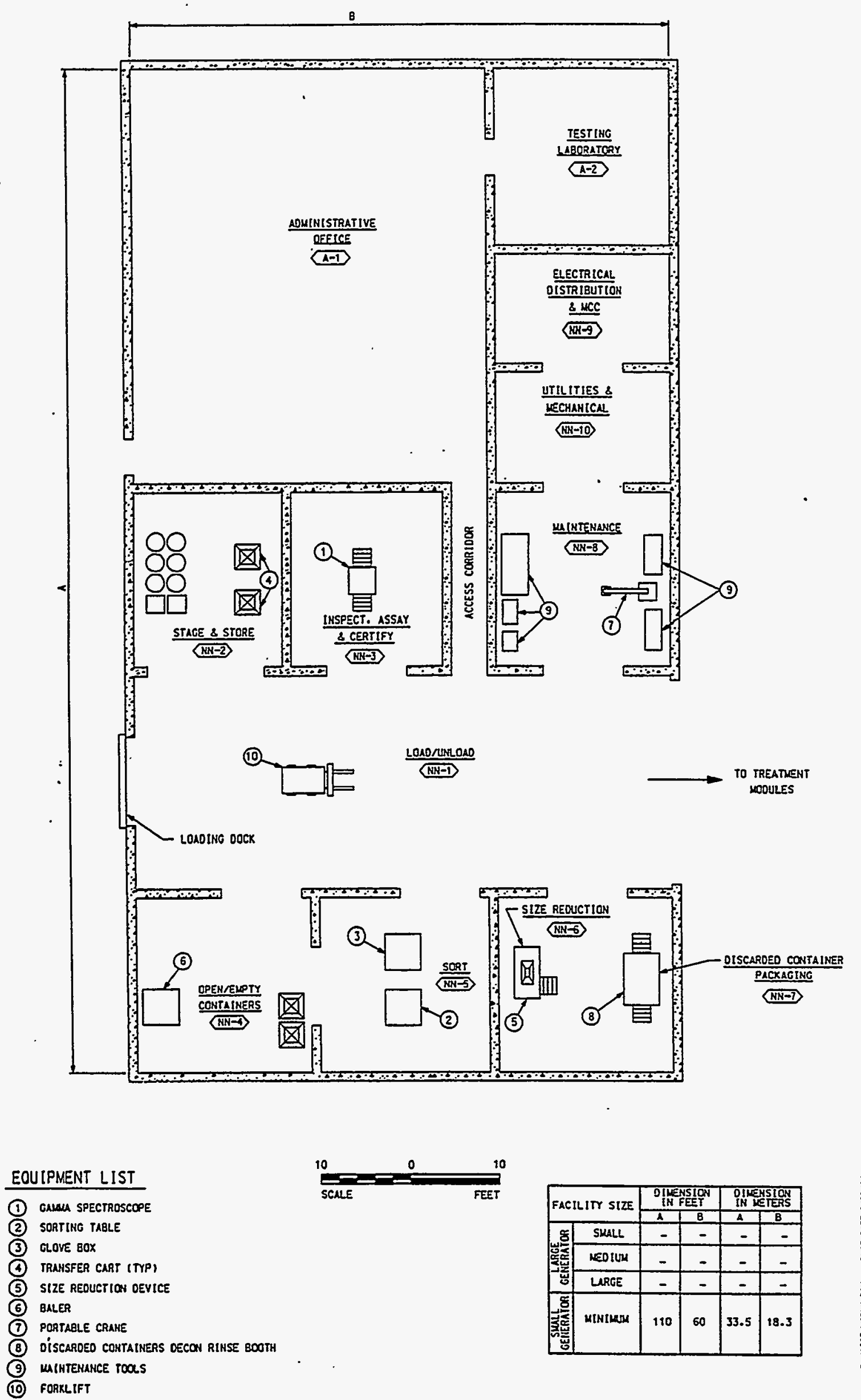

Figure 4-1. Equipment layout for the front-end and back-end support (FBSPT) module. 


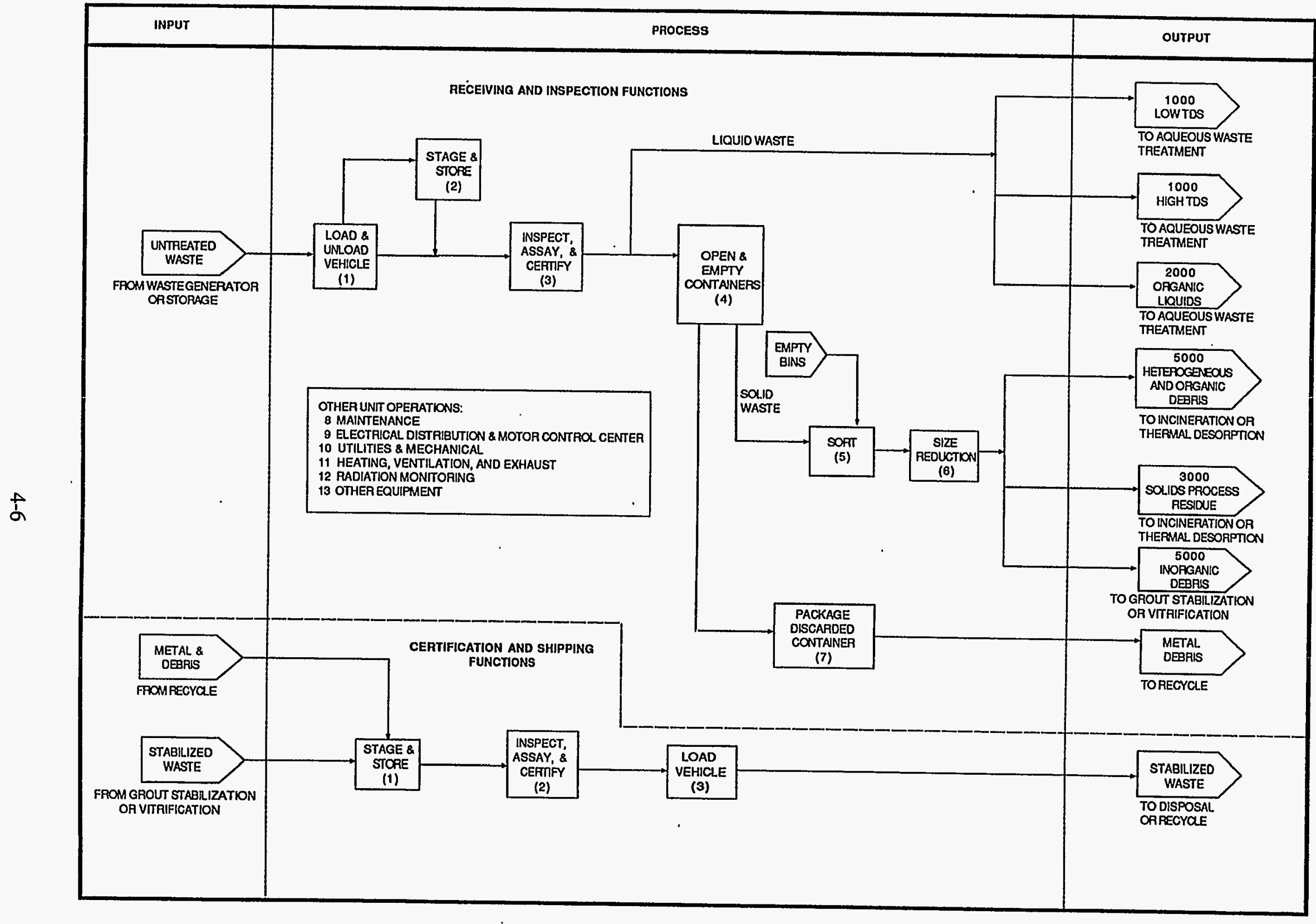

Figure 4-2. Process flow diagram for the front-end and back-end support (FBSPT) module. 


\section{OPEN, DUMP, AND SORT (MODULE OSORT)}

\subsection{Basic Information}

The open, dump, and sort module, shown in Figure 5-1, is designed to be contiguous with the treatment facilities and is ideal for use with an integrated waste management facility that handles multiple waste streams. The module opens and dumps the incoming waste containers and segregates the waste so it can be fed to a combination of treatment processes. The module handles the waste in drums, boxes, or metal bins that are assumed to be properly characterized before they are opened. The module is not needed if the waste arrives presorted. Module OSORT is applicable to nonalpha, alpha, and RH waste. Unit operations are given in the PFD in Figure 5-2.

The module also has the capability to reduce the size of empty nonmetal containers. Metal containers, however, must be transported to other modules for handling, such as a decontamination module for washdown and reuse or a metal melting module for processing.

\subsection{Technical Bases and Assumptions}

\subsubsection{Function and Operation of Large Generator Modules}

At the open, dump, and sort module the waste containers are decapped, and the waste is dumped either onto sorting devices or into transport bins that carry the waste to the treatment operations.

Containers of nonalpha waste are opened manually, while containers of alpha waste are opened by remote means. Containers of both waste types are dumped and sorted remotely by manipulators and robots housed in a cubicle. The cubicle has a controlled environment and multiple barriers. Adequate hoods and supporting ventilation are provided to minimize the spread of dust and contamination. Operations on alpha waste are accomplished in an alpha cell where containers enter the cell through airlock doors. Equipment maintenance is accomplished manually in a controlled environment. In addition, the equipment can be pulled out and decontaminated before performing maintenance.

After the waste containers enter the controlled cubicle environment through airlock doors, they are grouped into two categories: homogeneous waste and heterogeneous waste. Containers of homogeneous waste are opened, dumped, sorted, and sent to treatment modules. Containers of heterogeneous waste are opened, dumped, robot, sorted, manually sorted, packaged, and sent to treatment modules.

The waste in containers that are designated for segregation is dumped onto a sorting station, which removes bulk metal, noncombustibles, semicombustibles, combustibles, special waste, ${ }^{b}$ and gas cylinders. Various sorting technologies, such as robotic assisted sort tables, vibratory screens, and air classifiers, may be used in the sorting station. Any spilled liquid is collected and sent to other unit

h. Special wastes are those materials that are incompatible with the treatment techniques provided in the facility (e.g., mercury). After identification and segregation, special wastes are treated by mobile units provided on a case-by-case basis. 
operations for treatment. The sorted waste material is placed in transfer bins and moved to the treatment modules. Nonmetallic containers are cut into smaller pieces as required for processing.

\subsubsection{Integration of Large Generator Modules}

In addition to general interfaces for all modules, input interfaces to the open, dump, and sort module are waste containers from the receiving and inspection module. The O\&M consumables, including personal protective equipment, are purchased. Output interfaces include sending solid sorted waste to treatment. Reusable empty metal drums and boxes are sent to a decontamination module for cleaning and recycling. Other empty metal containers are sent to the metal melting module. Empty wood and fiberglass boxes are shredded and sent to treatment modules.

\subsubsection{Small Generator Fixed and Portable Module}

For small generator (nonalpha) modules, the open, dump, and sort functions are performed by the front-end and back-end support (FBSPT) module.

\subsection{Cost Bases, Assumptions, and Results}

Major equipment capital cost items for this module are container open, dump, and sort devices and robotics arms. The costs for these items are developed based on consultation with personnel from DOE contractors involved in the Office of Technology Development, Robotic Technology Development Program. Figures 5-3 through 5-5 show the relationship between estimated FTE workers and capacity of the module. Figures 5-6 through 5-9 show the relationship between PLCC and capacity.

Input capacities for the open, dump, and sort modules should be based on the amount of uncharacterized waste to be treated. Presorted and newly generated wastes may already be sufficiently characterized to directly to treatment. Uncharacterized and new "unknown" wastes would utilize this module. 


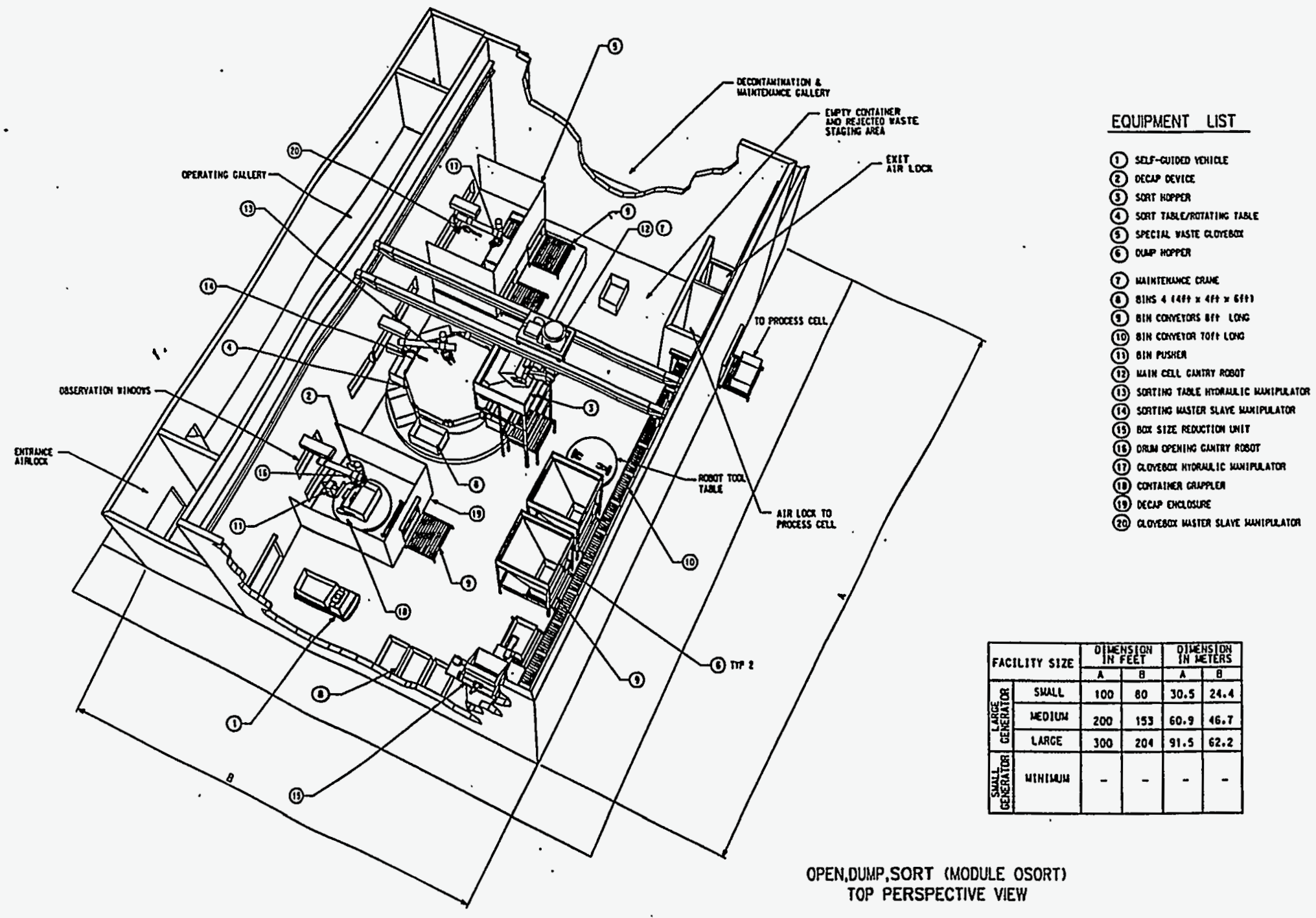

Figure 5-1. Equipment layout for the open, dump, and sort (OSORT) module. 


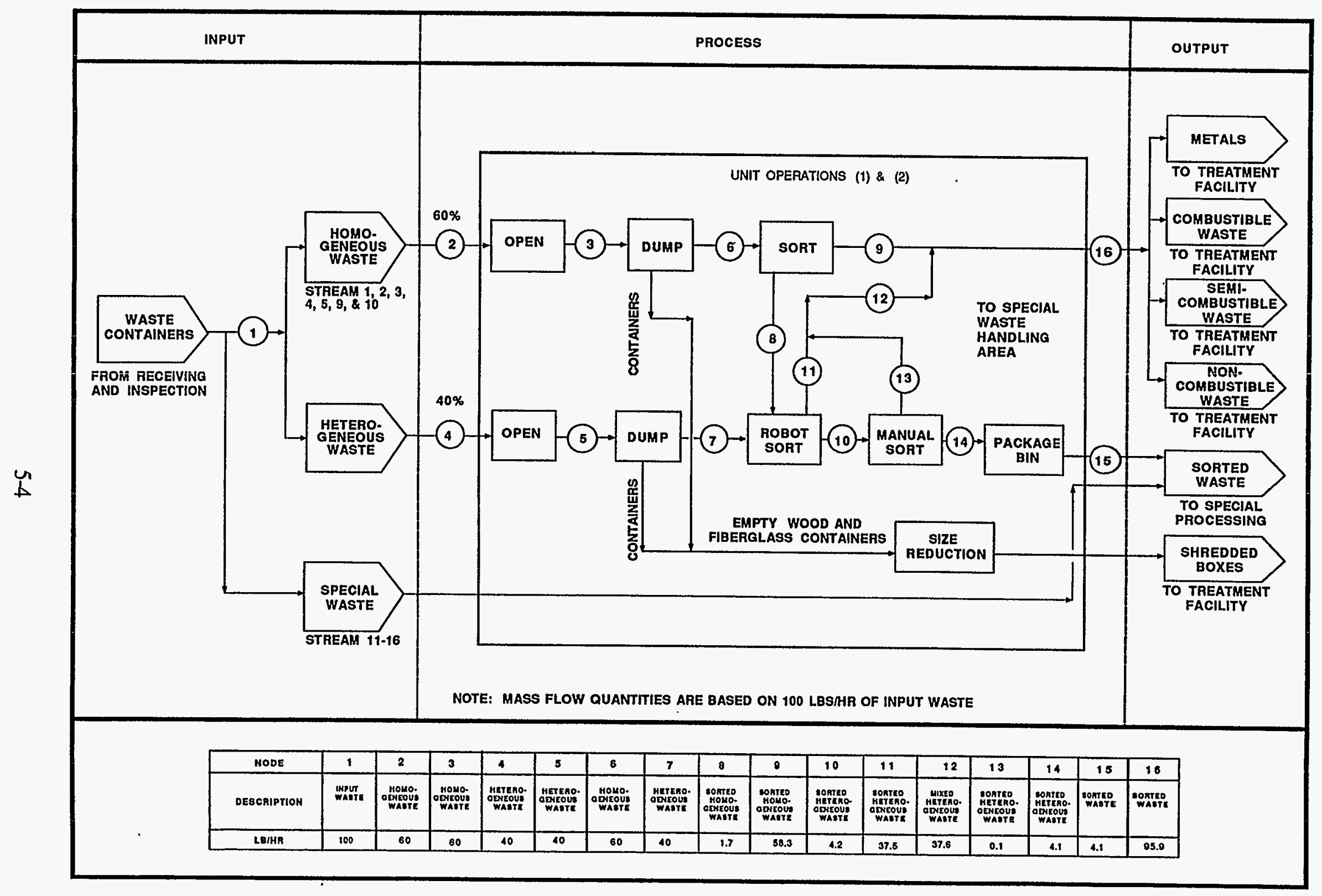

Figure 5-2. Process flow diagram for the open, dump, and sort (OSORT) module. 


\section{OPEN, DUMP, AND SORT}

FTE by Work Breakdown Structure Element Module: OSORT Waste Type: Nonalpha LLW

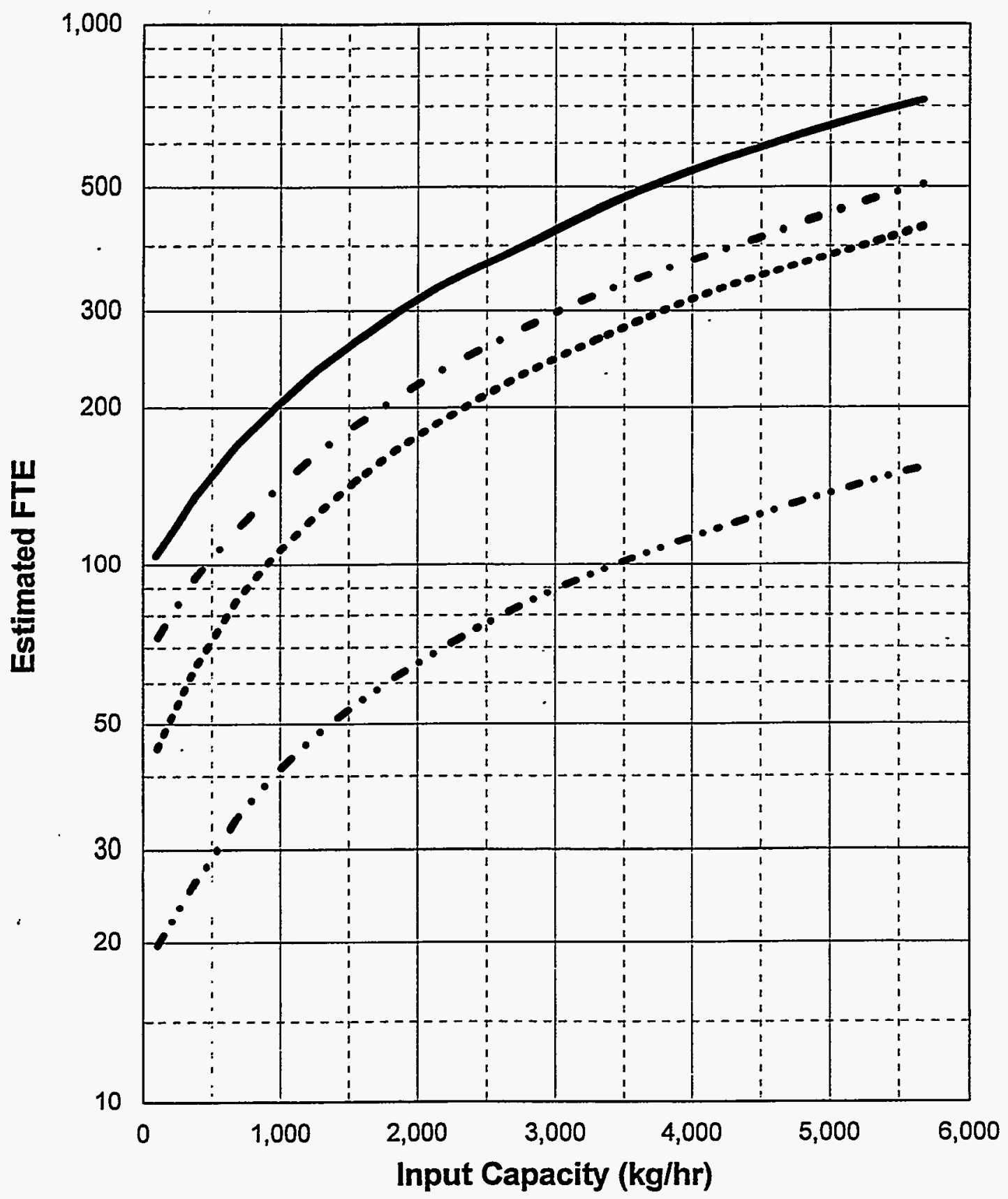

Pre-Operations Construction O\&M (1year) D\&D

Figure 5-3. FTE workers versus capacity for the nonalpha open, dump, and sort (B-OSORT) module. 


\section{OPEN, DUMP, AND SORT}

FTE by Work Breakdown Structure Element

Module: OSORT Waste Type: Alpha LLW

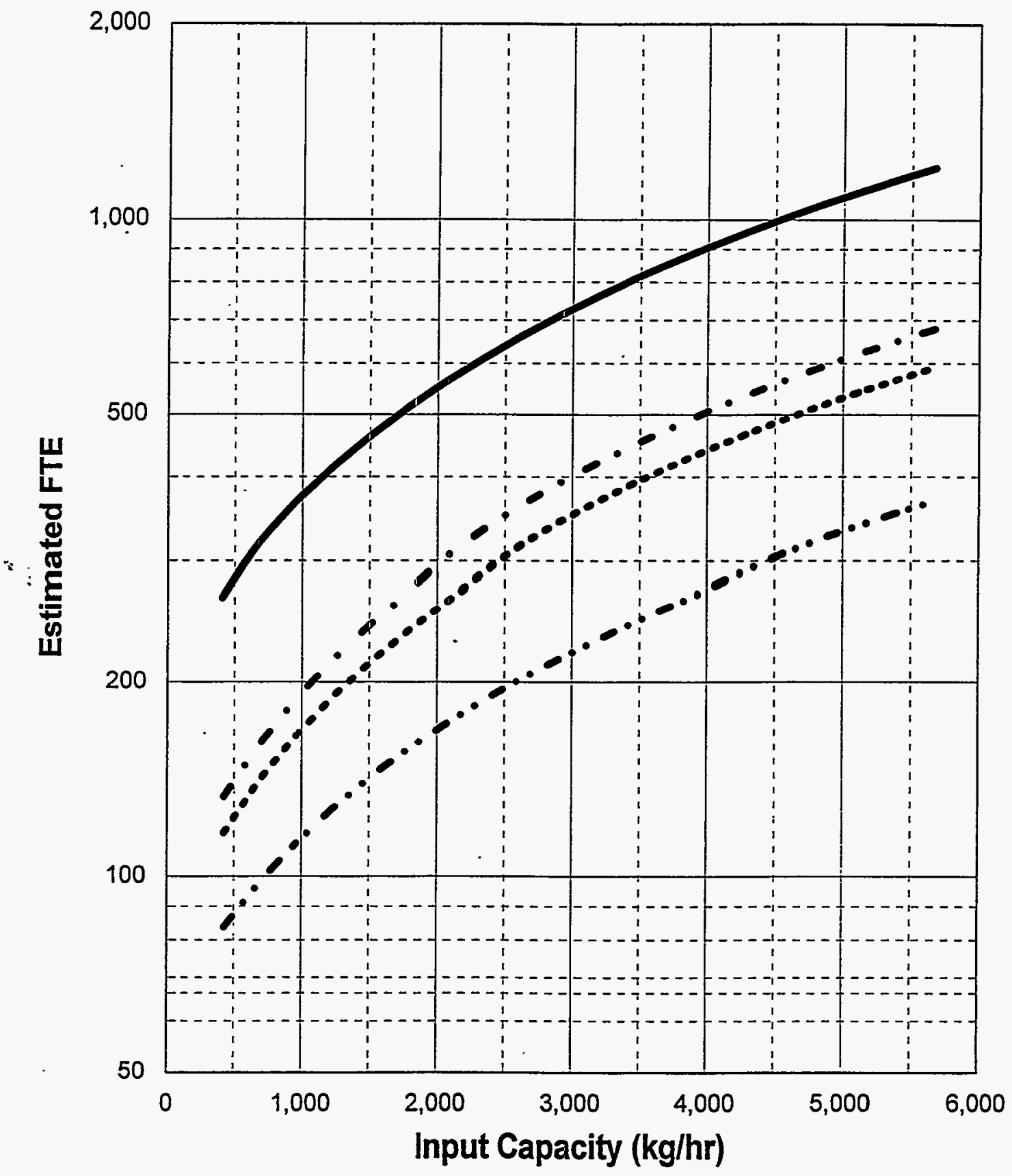

Pre-Operations Construction O\&M (1year) D\&D

Figure 5-4. FTE workers versus capacity for the alpha open, dump, and sort (A-OSORT) module. 


\section{OPEN, DUMP, AND SORT}

FTE by Work Breakdown Structure Element Module: OSORT Waste Type: Remote Handled LLW

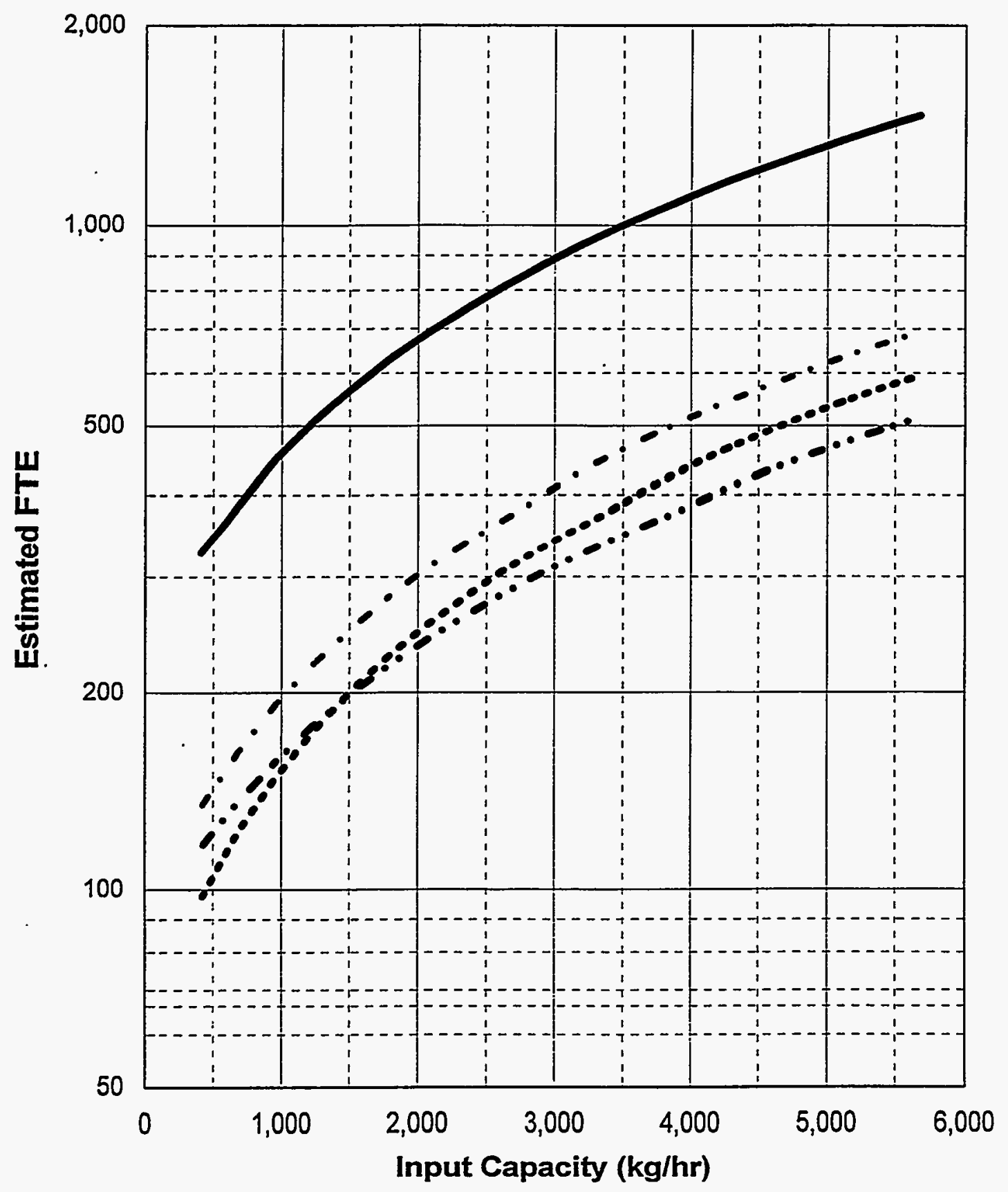

Pre-Operations Construction O\&M (1year) D\&D

Figure 5-5. FTE workers versus capacity for the RH open, dump, and sort (R-OSORT) module. 


\section{OPEN, DUMP, AND SORT}

Cost by Work Breakdown Structure Element Module: OSORT Waste Type: Nonalpha LLW

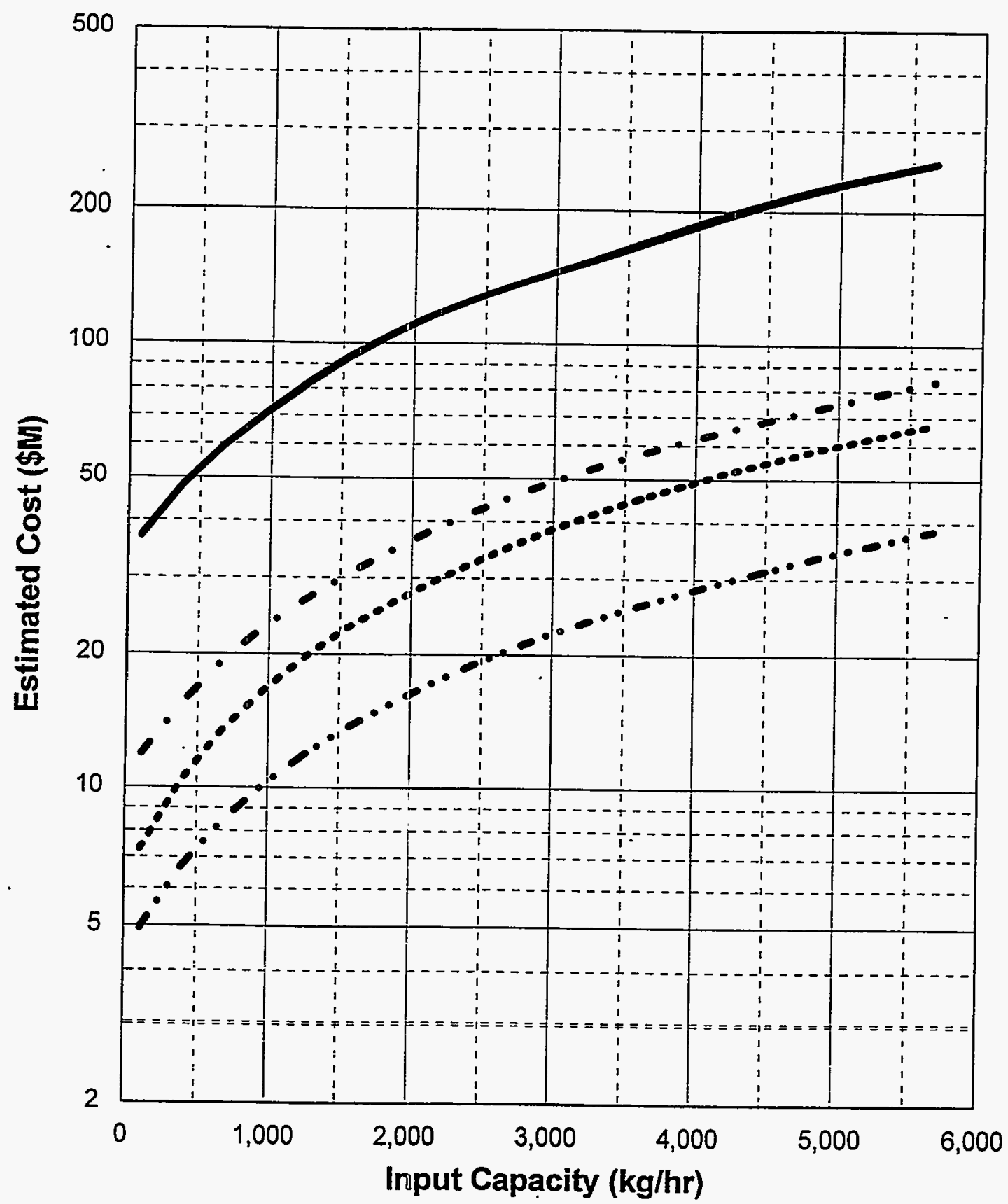

Pre-Operations Construction O\&M (1year) D\&D $\cdots$

Figure 5-6. PLCC versus capacity for the nonalpha open, dump, and sort (B-OSORT) module. 


\section{OPEN, DUMP, AND SORT}

Cost by Work Breakdown Structure Element Module: OSORT Waste Type: Alpha LLW

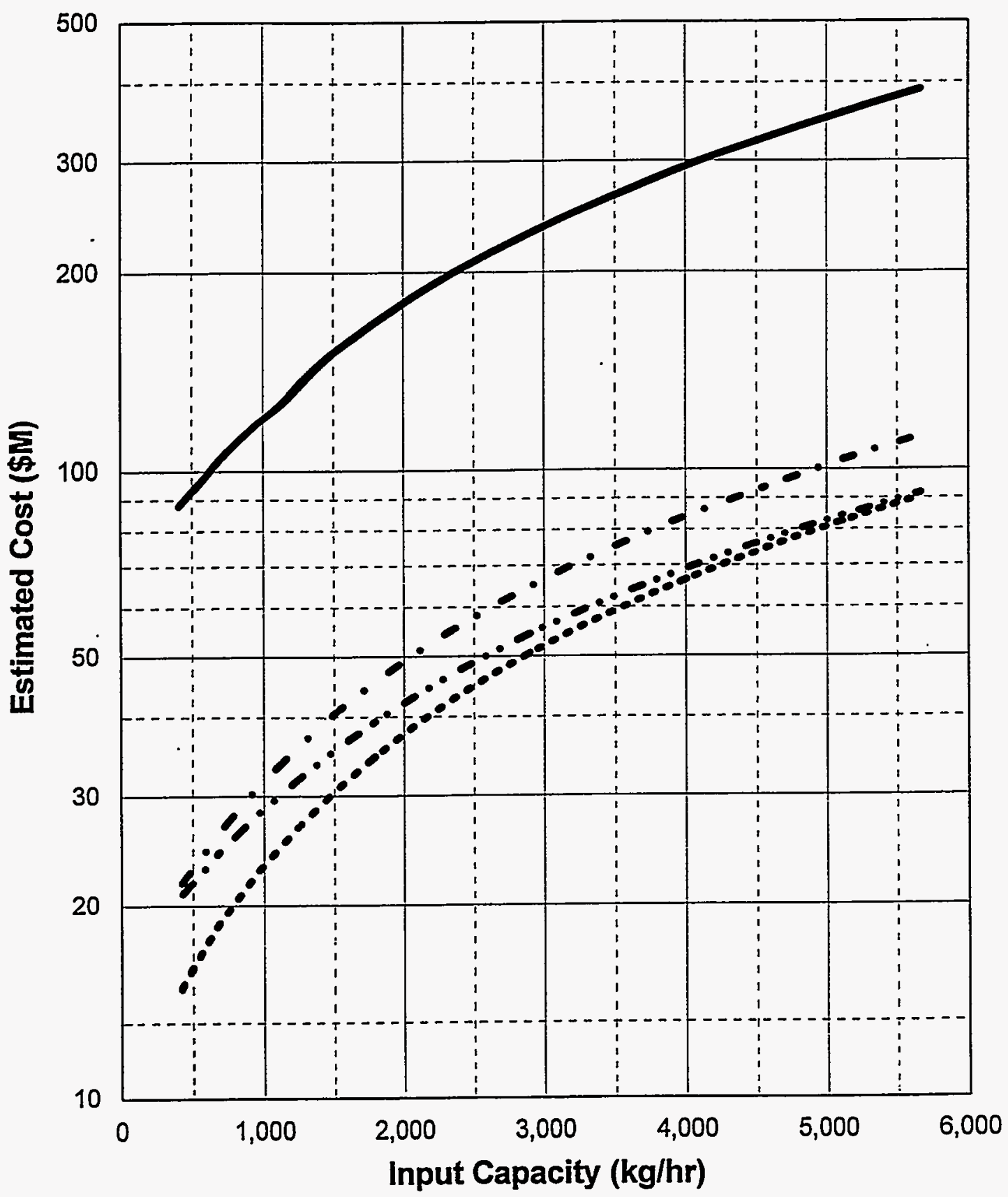

Pre-Operations Construction O\&M (1year) D\&D

Figure 5-7. PLCC versus capacity for the alpha open, dump, and sort (A-OSORT) module. 


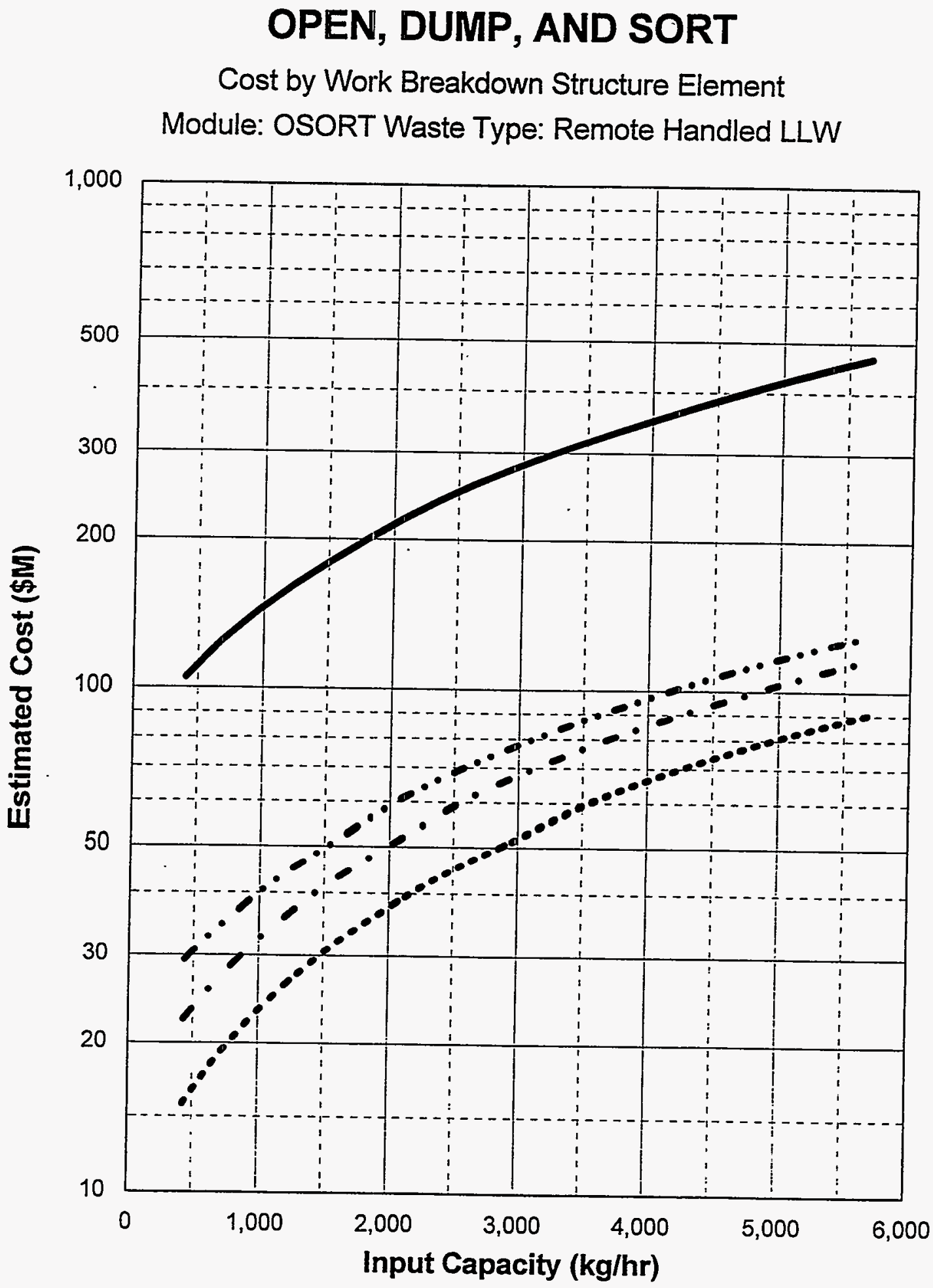

Pre-Operations Construction O\&M (1year) D\&D

Figure 5-8. PLCC versus capacity for the RH open, dump, and sort (R-OSORT) module. 
OPEN, DUMP, AND SORT

Total Life Cycle Costs

Module: OSORT Waste Type: Alpha, Nonalpha, and Remote Handled LLW

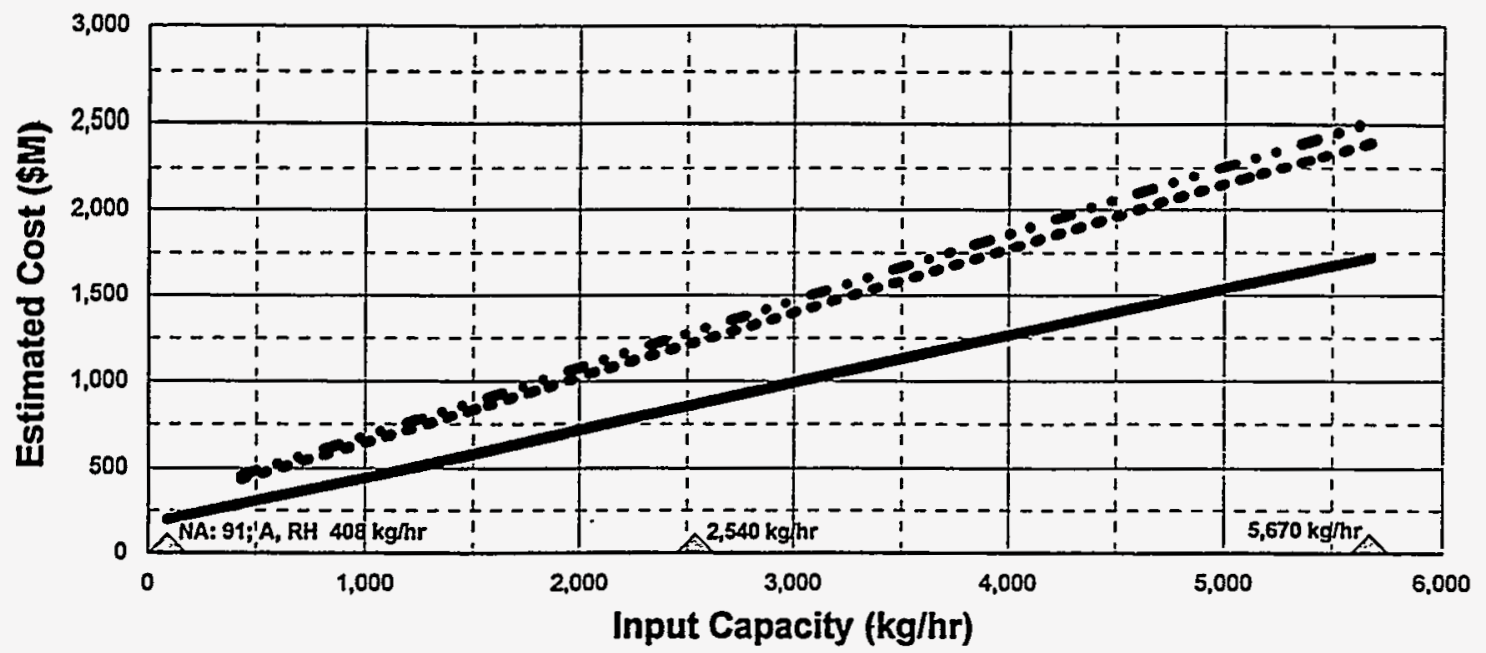

Nonalpha Alpha Remote Handled

NOTE: Basis includes 20 years O\&M

Triangles indicate capacities where detailed cost estimates were developed.

\section{OPEN, DUMP, AND SORT}

\section{Total Life Cycle Unit Costs}

Module: OSORT Waste Type: Alpha, Nonalpha, Remote Handled LLW

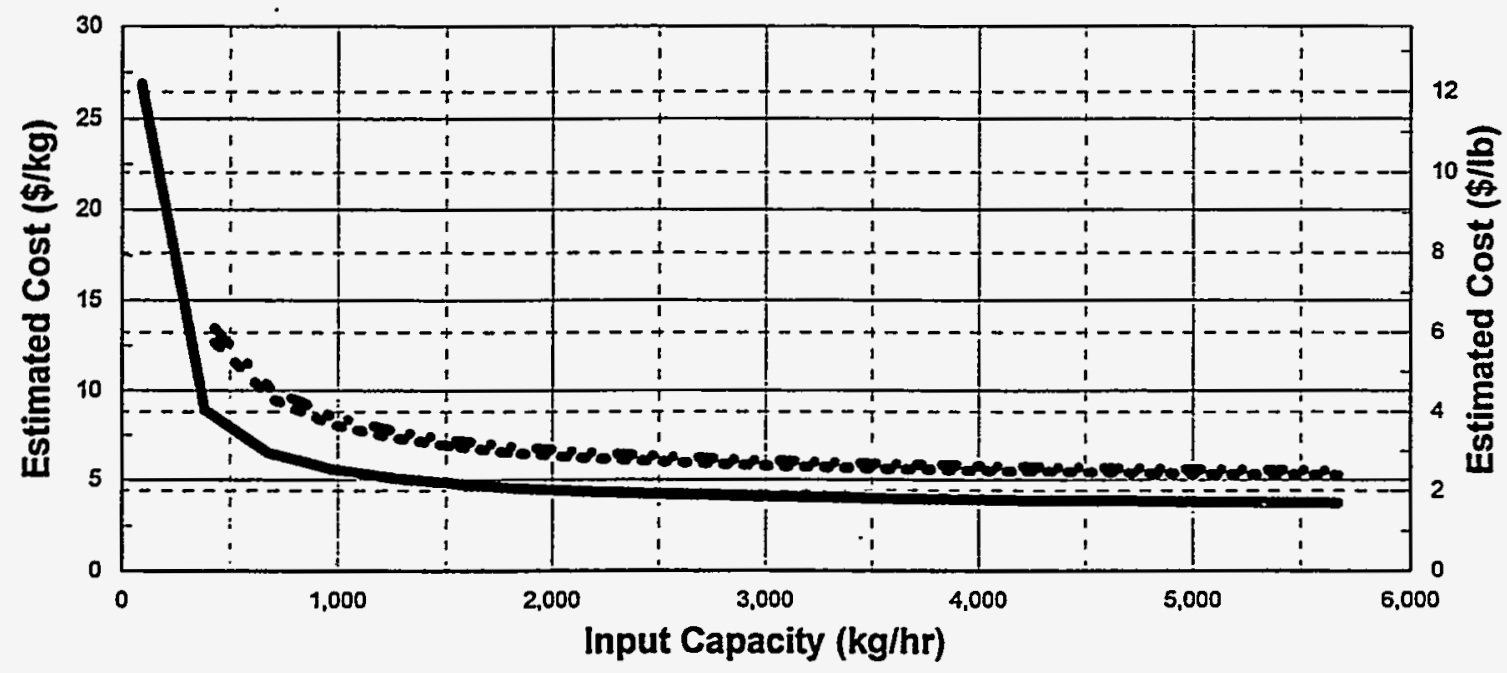

Nonalpha Alpha Remote Handled

NOTE: Basis inciudes 20 years O\&M

Figure 5-9. PLCC versus capacity including unit rates for the open, dump, and sort (OSORT) module. 


\section{MAINTENANCE (MODULE MAINT)}

The maintenance shop is the same for nonalpha and alpha modules except that the alpha waste module includes a mock-up shop. Module MANT is applicable to nonalpha, alpha, and RH waste.

\subsection{Basic Information}

The maintenance module is equipped with a building for receiving and repairing failed equipment. This module is used in conjunction with the treatment modules when such a function is not available at the existing modules. The maintenance shop costs assume that the module will repair components contaminated with low-level radioactivity but not alpha emitters. Components contaminated with alpha particles must be decontaminated in the alpha maintenance galleries before they are brought into the maintenance shop. Module A-MAINT has a remote component mock-up area.

\subsection{Technical Bases and Assumptions}

\subsubsection{Function and Operation of Large Generator Modules}

Contaminated failed equipment and parts arrive at the shop in transfer carts. Parts are removed from the transport carts and placed in a decontamination area where high-pressure spraying or other techniques are used to remove any loose contamination. After cleaning and decontamination, components are moved to maintenance tables. Maintenance machinery and tools are used as needed. The shop includes an overhead crane and a jib crane for material handling. A paint booth is also included.

\subsubsection{Integration of Large Generator Modules}

The module receives failed equipment from the treatment module. The output is repaired equipment. The module has secondary waste containing decontamination solutions, spent oil, and solvent. The O\&M material includes parts, materials, and consumables, which are assumed to be purchased items.

\subsubsection{Small Generator Module}

The maintenance functions for the small generator module are performed by the front-end and back-end support module.

\subsection{Cost Bases, Assumptions, and Results}

Major equipment capital cost items are cranes, milling, sanding, and lathe machinery and tools. Costs for all machinery and equipment including the cranes are based on industrial (nonradioactive) applications. Figures 6-1 and 6-2 show the relationship between estimated FTE workers and capacity of the module. Figures 6-3, 6-4, and 6-5 show the relationship between PLCC and capacity. Table 6-1 lists the plan dimensions of the module. 
Table 6-1. Plan dimensions of the maintenance (MAINT) module.

\begin{tabular}{ccccccc} 
& \multicolumn{2}{c}{$\begin{array}{c}\text { Dimensions } \\
(\mathrm{ft})\end{array}$} & & \multicolumn{2}{c}{$\begin{array}{c}\text { Dimensions } \\
(\mathrm{m})\end{array}$} \\
\cline { 2 - 4 } \cline { 5 - 6 } Module size & Width & Length & & & Width & Length \\
\hline Large generator & 30 & & & & \\
Small & 30 & 250 & & & 9.1 & 26.5 \\
Medium & 30 & 334 & & & 9.1 & 76.2 \\
Large & - & - & & - & 101.8 \\
Small generator & & & & & & - \\
\hline
\end{tabular}




\section{MAINTENANCE}

FTE by Work Breakdown Structure Element Module: MAINT Waste Type: Nonalpha LLW

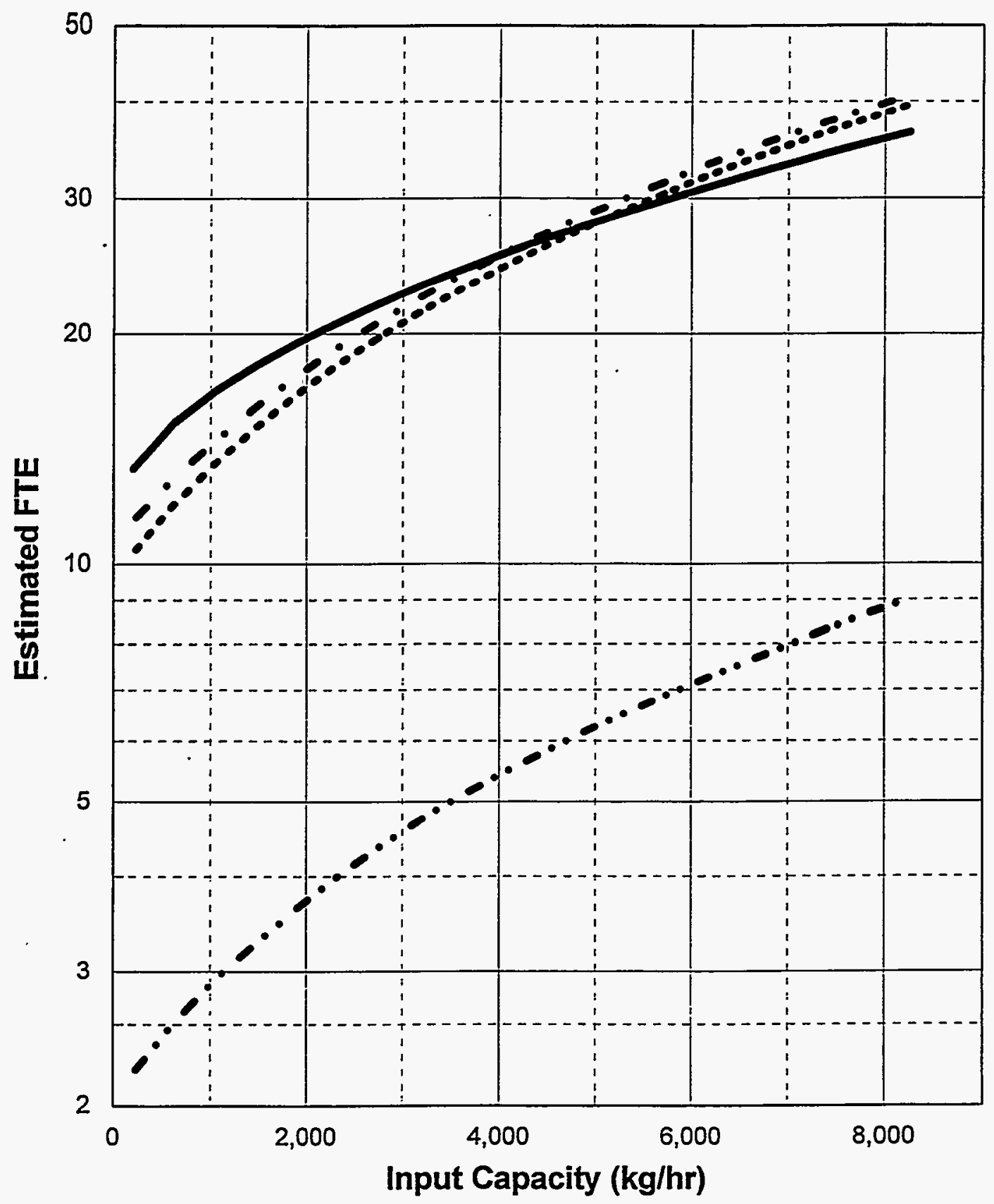

Pre-Operations Construction O\&M (1year) D\&D

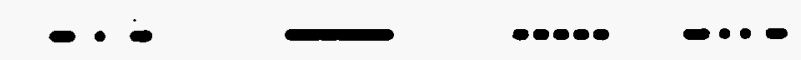

Figure 6-1. FTE workers versus capacity for the nonalpha maintenance (B-MAINT) module. 


\section{MAINTENANCE}

FTE by Work Breakdown Structure Element Module: MAINT Waste Type: Alpha and Remote Handled LLW

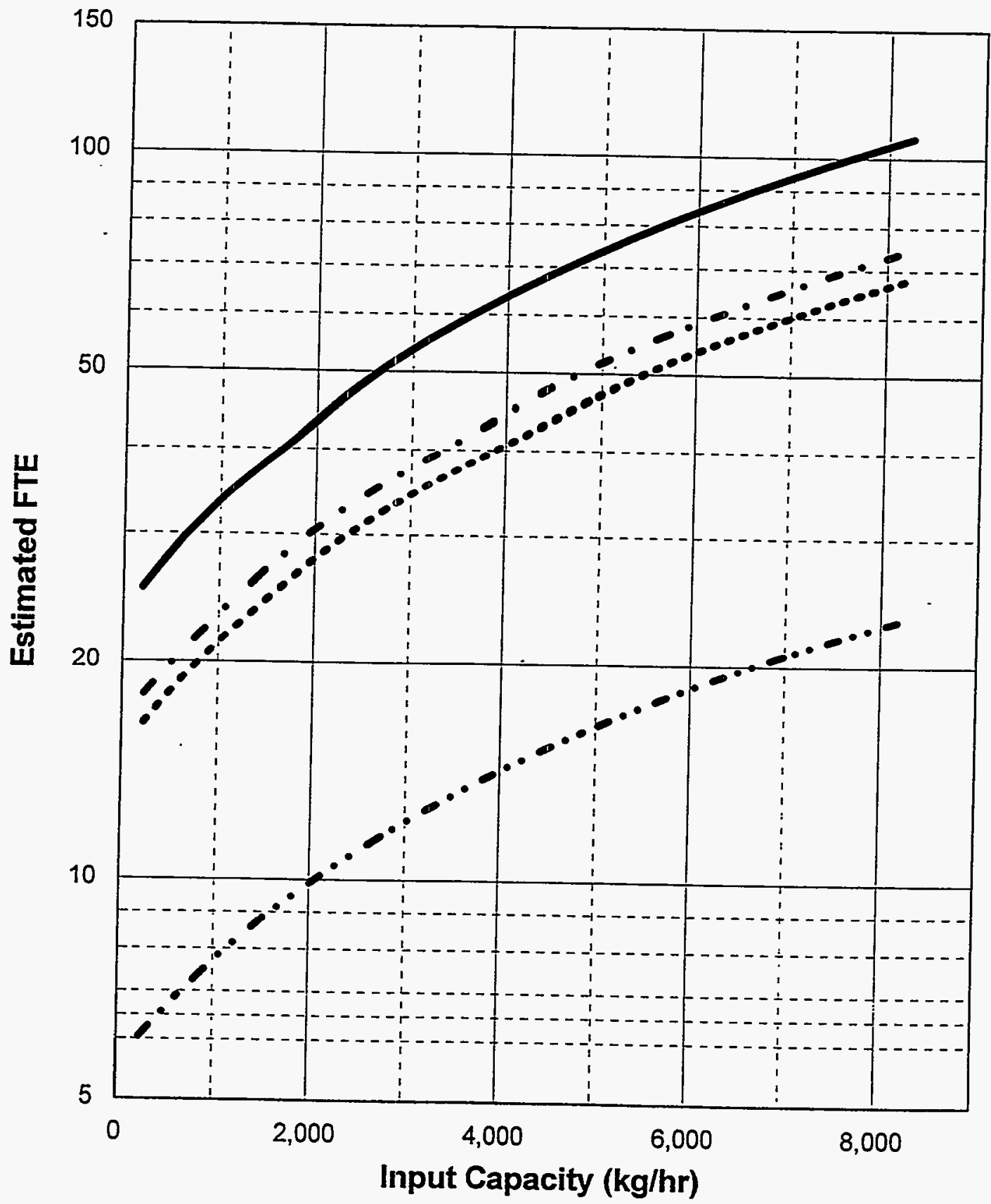

Pre-Operations Construction O\&M (1year) D\&D -

Figure 6-2. FTE workers versus capacity for the alpha and RH maintenance (A/R-MAINT) module. 


\section{MAINTENANCE}

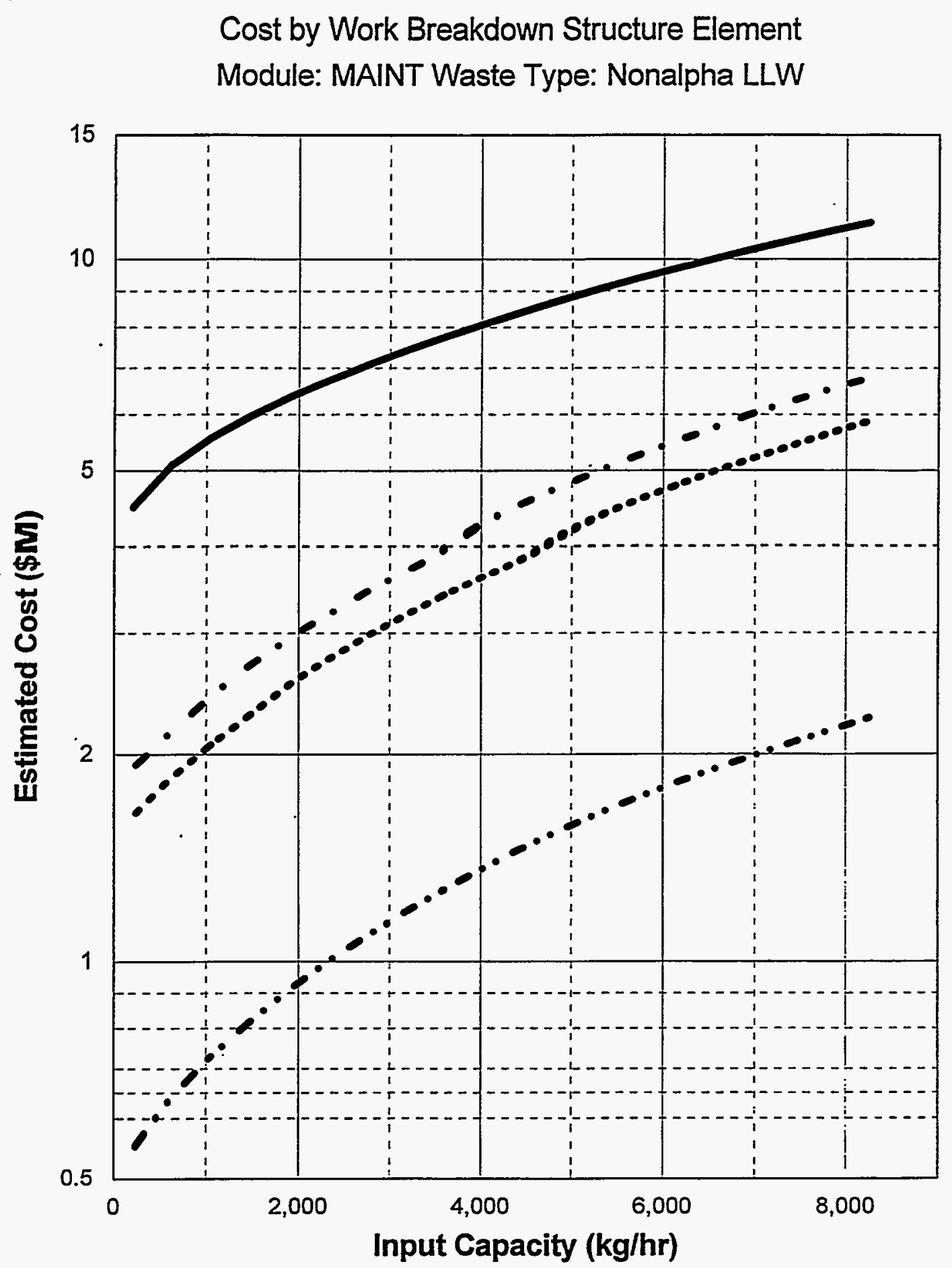

Pre-Operations Construction O\&M (1year) D\&D

Figure 6-3. PLCC versus capacity for the nonalpha maintenance (B-MAINT) module. 


\section{MAINTENANCE}

Cost by Work Breakdown Structure Element

Module: MAINT Waste Type: Alpha and Remote Handled LLW

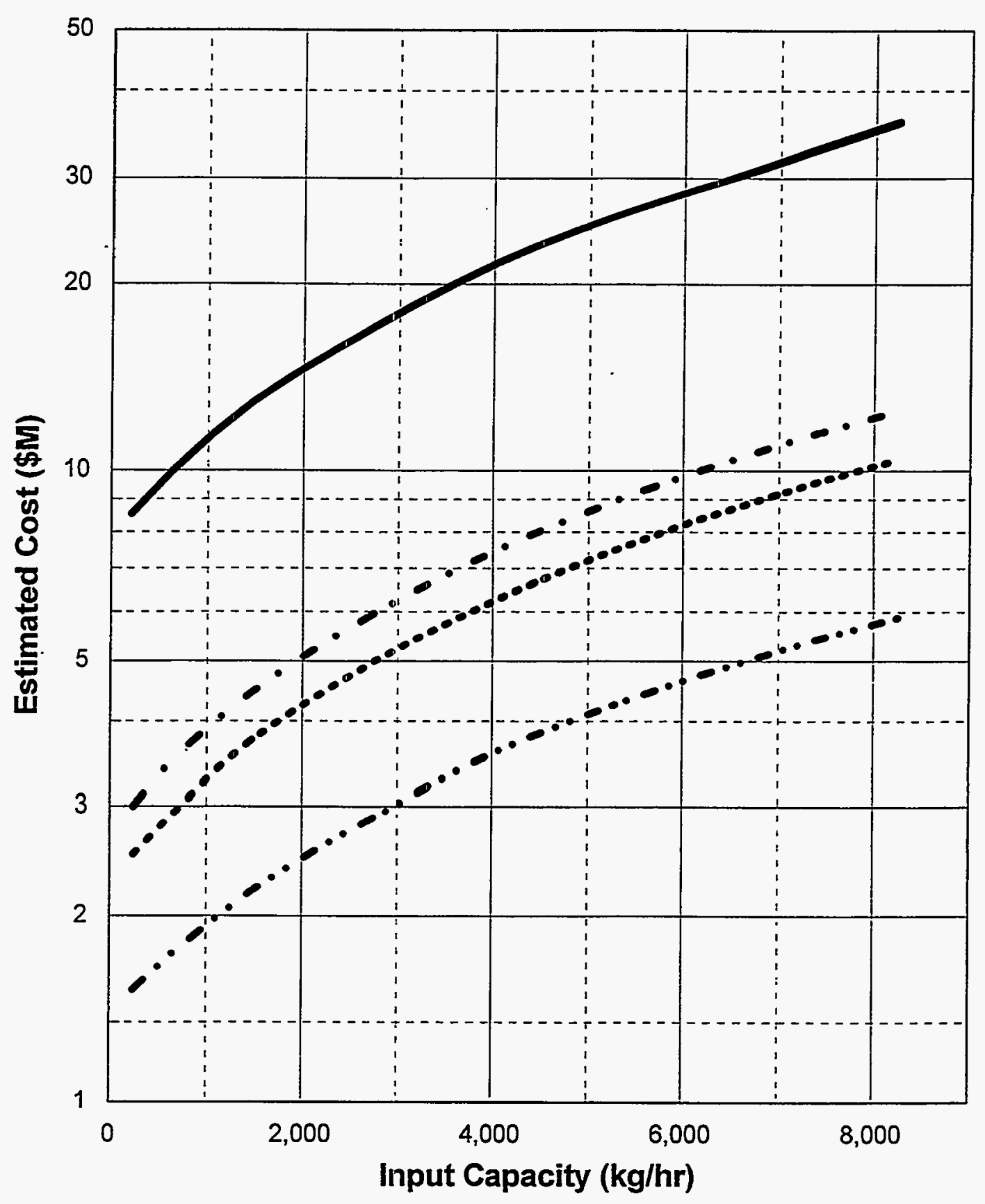

Pre-Operations Construction O\&M (1year) D\&D

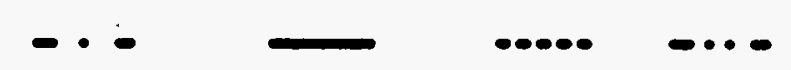

Figure 6-4. PLCC versus capacity for the alpha and RH maintenance (A/R-MAINT) module. 


\section{MAINTENANCE}

Total Life Cycle Costs

Module: MAINT Waste Type: Alpha, Nonalpha, and Remote Handled LLW

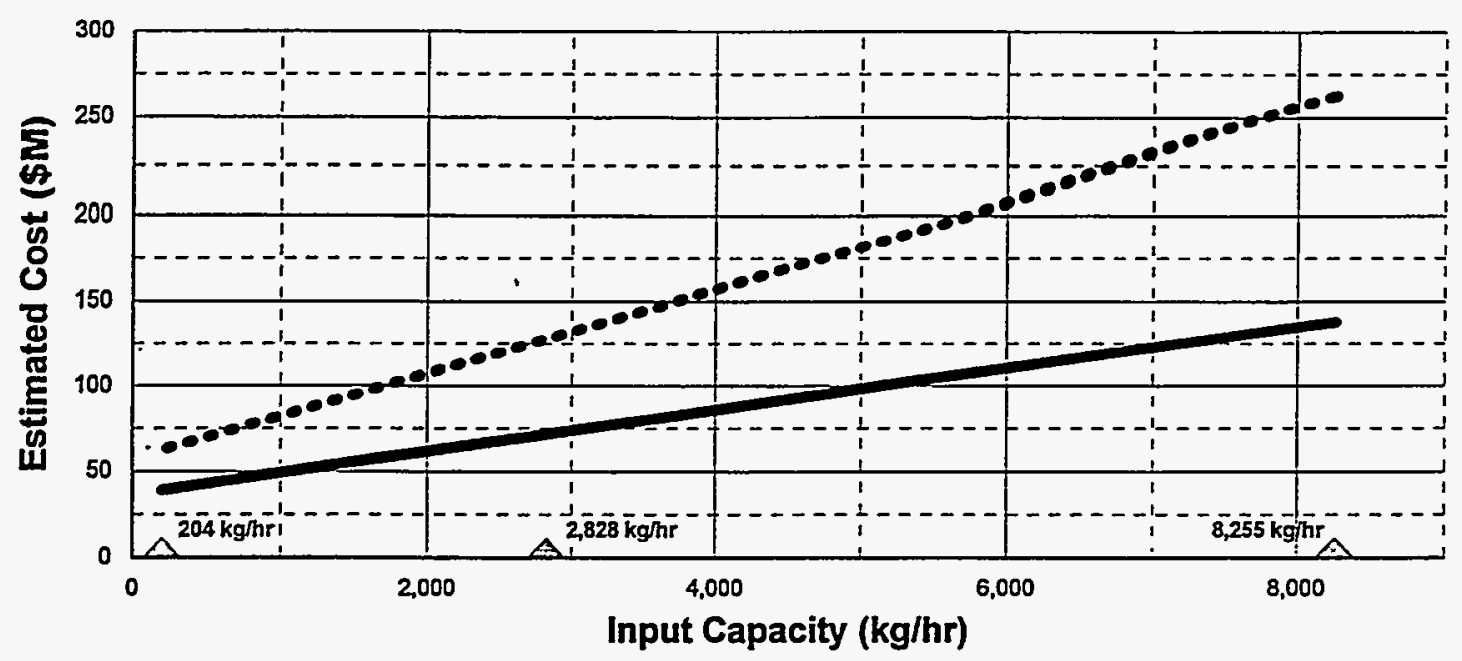

Nonalpha Alpha, Remote Handled

NOTE: Basis includes 20 years O\&M

Triangles indicate capacities where detailed cost estimates were developed.

\section{MAINTENANCE}

Total Life Cycle Unit Costs

Module: MAINT Waste Type: Alpha, Nonalpha, Remote Handled LLW

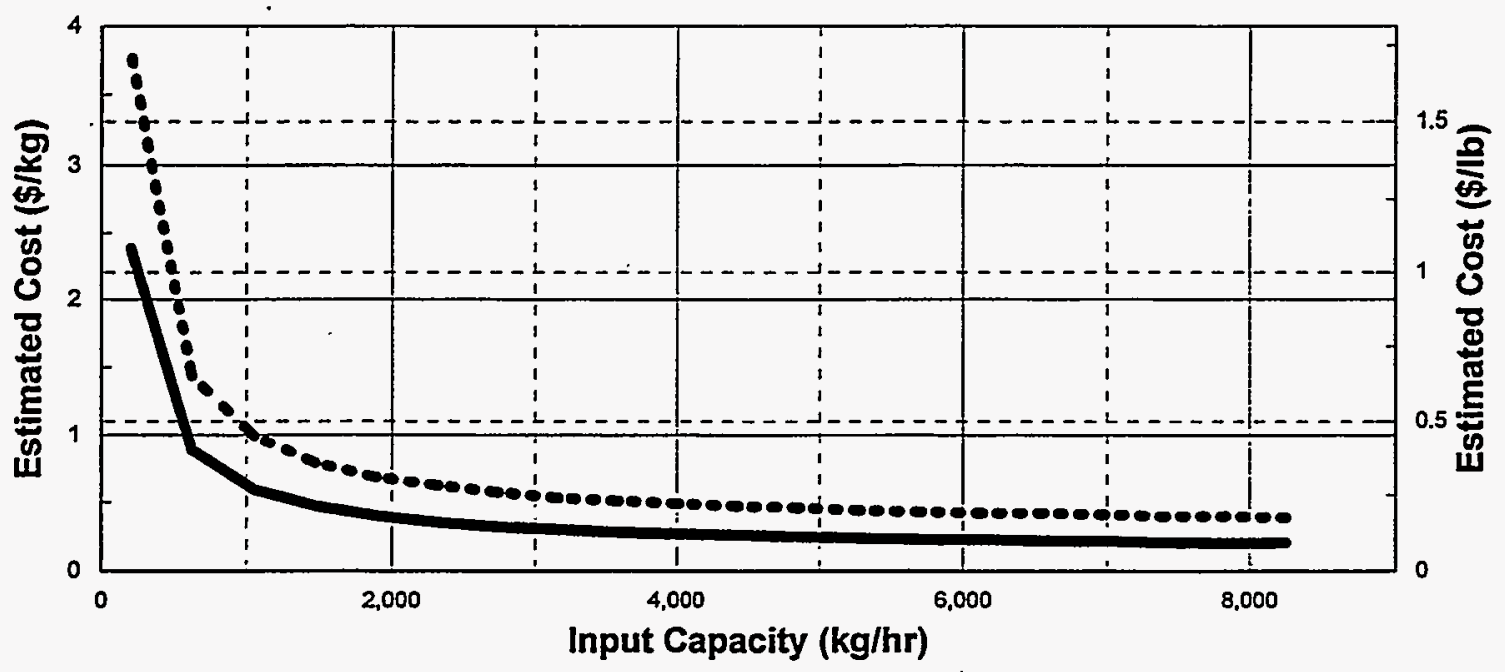

Nonalpha Alpha, Remote Handled

NOTE: Basis indudes 20 years O\&M

Figure 6-5. PLCC versus capacity including unit rates for the maintenance (MAINT) module. 


\section{INCINERATION (MODULE INCIN)}

\subsection{Basic Information}

This module is a thermal (flame) module organic destruction unit. Module INCIN is applicable to nonalpha, alpha, and RH waste. The incineration module, shown in Figure 7-1, must be either used in conjunction with the receiving and inspection (RCINS) module and stabilization (PLYMR) module or installed at a location where similar functions are available in existing facilities. For a small generator facility, the incineration module should be used with the front-end and back-end module devised for small generators (module FBSPT).

The incinerator module receives and treats input combustible waste, including process solid residues and organic and heterogeneous (i.e., combustibles commingled with noncombustibles) debris. Extensive sorting of the combustible and noncombustible material is not necessary, as the incinerator can tolerate a high percentage of incombustible material in the feed.

The Controlled Air Incineration Facility at DOE's Los Alamos National Laboratory in New Mexico has been used as the basis for the small generator module. The incineration concept is similar to this existing facility except that the concept uses the smallest available unit. The TSCA incinerator at Oak Ridge National Laboratory in Tennessee, and the Consolidated Incineration Facility at the Savannah River Site in South Carolina have been used as a basis for the large generator modules.

The waste is sorted at the receiving and inspection (RCINS or FBSPT) module and transferred to the module in transport bins (or combustible boxes). The input waste generally consists of discarded paper, plastics, clothing (textile fabrics), wood, spent ion-exchange resins, spent activated carbon, and other solids produced by typical operations at DOE production or research and development installations.

Treatment units are provided, assuming that the incoming waste contains radioactive constituents regulated under the Atomic Energy Act. The module has a number of unit operations that accomplish the required functions. These unit operations are shown in the PFD in Figure 7-2.

\subsection{Technical Bases and Assumptions}

\subsubsection{Function and Operation of Large Generator Modules}

The incinerator module has all the unit operations needed for treating the incoming solid and oily wastes. The unit operations also have the capability to treat the alpha and nonalpha secondary waste. The incoming solid waste is presorted before it is brought to the incineration module.

The incoming waste is brought to the module in transfer bins (or cardboard boxes) mounted on transport devices. The contents are sorted and thoroughly characterized at the receiving and inspection module. Therefore, the function of the preparation and feed unit operation in the incineration module is merely to convey the solid waste to the incineration chamber. The preparation and feed unit operation has a second feed device that batches and feeds oily liquids to the incinerator. 
The incinerator oxidizes the other combustible material contained in the feed. When sufficient . solid waste is accumulated, the incinerator temperature is raised from the idle temperature (approximately $700-900^{\circ} \mathrm{F}$ ) to the combustion temperature (approximately $1,600-1,800^{\circ} \mathrm{F}$ ). The process begins by gradually charging the incinerator chamber with input waste in solid form. Oil and other petroleum hydrocarbon liquids are injected to the chamber as a fuel supplement, when needed.

After oxidizing the petroleum hydrocarbons and solids, the resulting ash is discharged from the incinerator and placed in containers, which are sent to the stabilization module. The incinerator is designed to completely burn the feed and minimize the amount of carbon in the ash.

Gas generated during the incineration process is the module's first secondary waste stream. To ensure complete destruction of hydrocarbon material, the gas is first heated in a secondary combustion chamber to a temperature of $2,000^{\circ} \mathrm{F}$ with a residence time of at least two seconds. This gas is then sent to an offgas treatment unit operation (or air pollution control unit) that cools and treats the gas to remove particulates, acidic gases, and other regulated elements and compounds before it is released to the atmosphere. This unit operation ensures that the offgas discharged to the atmosphere meets emission standards.

The offgas treatment unit operation has three major phases: dry filtration, wet scrubbing, and monitoring and discharge.

The dry filtration phase removes as much of the particulates (e.g., flyash, and particulates of vaporized toxic metal compounds) as possible to minimize the amount of radioactive particles and toxic metal particles that pass to the wet scrubbing phase. This is done by first cooling the gas using a water quench and then dry filtering the gas using a bag or ceramic candle filters. The filtered gas is then sent to a filter of sulfur-impregnated activated carbon to remove mercury, lead, and other compounds. The final step in the dry phase consists of polishing the gas using a HEPA filter unit. Solid waste from this phase (fly ash, spent activated carbon, and spent HEPA filters) is sent to the stabilization module.

The wet scrubbing phase further removes toxic metal, vapor, and acidic and alkaline gases (including hydrogen chloride and sulfur dioxide) and their salts. A series of wet scrubbing devices using caustic (or lime) solutions accomplishes this function. After scrubbing, the gas is sent to a moisture remover, a reheater, and to the emissions monitoring and discharge unit. Secondary waste from the scrubbing process, which consists of spent slurry, is neutralized and sent to a concentrator unit. The concentrator uses low-temperature evaporation to avoid revaporizing the captured mercury salts. Bottom sludge from the concentrator is sent to the polymer stabilization module. The concentrator distillate is treated and reused.

The monitoring and discharge phase continuously samples the gas and measures the concentration of the elements and compounds as specified by the facility emission control standards. The treated offgas meets the emissions standards as specified by the permit. The module minimizes as much as possible the volume of waste requiring disposal. 


\subsubsection{Integration of Large Generator Modules}

Input waste to the incineration module comes from the container open, dump, and sort; receiving and inspection; and neutralization treatment modules. Incinerator output consists of bottom ash and flyash, spent activated carbon, spent HEPA filters, and wet scrubber sludge, which are sent to the grout stabilization module. Treated water is reused. Materials purchased for O\&M include such consumables as personal protective equipment, fuel, activated carbon, chemicals, and containers.

\subsubsection{Function and Operation of Small Generator Fixed Module in a New or Existing Building}

The function and operation of a fixed small incineration module are essentially the same as that described in Section 7.2.1. The operation can be performed in a new building or within an existing facility of the same area. Costs have been calculated for both, the difference being the cost of a new building versus building modification costs.

Existing building space required for installation of this module is $312.1 \mathrm{~m}^{2}\left(3,360 \mathrm{ft}^{2}\right)$. The required ceiling height is $7.6 \mathrm{~m}(25 \mathrm{ft})$. The area required for a new building is the same.

\subsubsection{Integration of Small Generator Fixed Module in a New or Existing Building}

Input waste to the incineration module comes from the front-end and back-end support and the aqueous waste treatment modules. Incinerator output consists of bottom ash and fly-ash, spent activated carbon, spent HEPA filters, and wet scrubber siudge, which are sent to the grout stabilization module. Treated water is reused. Materials purchased for O\&M include such consumables as personal protective equipment, fuel, activated carbon, chemicals, and containers.

\subsubsection{Function and Operation of Portable Module}

A portable small incineration module has not been developed.

\subsection{Cost Bases, Assumptions, and Results}

The feed preparation, incinerator, secondary combustion chamber, dry offgas filtration, wet scrubber, stack monitors, and concentrator constitute the major equipment capital cost items. The estimate for operating and maintenance manpower of a small generator module is based on the assumption of operating in batch mode and processing about $18.1 \mathrm{~kg} / \mathrm{hr}$. Table 7-1, and Figures 7-3 through and 7-5 show the relationship between estimated FTE workers and capacity of the module.

The cost estimate for the incineration package is based on quotations by Joy Energy Systems of Charlotte, North Carolina and ABB Raymond, Inc. of Lisle, Illinois. The cost estimate for the dry offgas filters is based on the use of a ceramic candle unit as quoted by Pall Advances Separation Systems of Cortland, New York. The cost estimate for the wet scrubbing unit is based on the use of a quencher and scrubbing unit as quoted by Croll-Reynolds Company of Westfield, New Jersey. The cost estimate for the concentrator unit is based on the use of a thin-film evaporator unit as quoted by LCI Corporation of Charlotte, North Carolina. The cost estimate for the air- and area-monitoring unit is based on a quote by Eberline of Santa Fe, New Mexico. The estimate for the stack monitoring 
unit is based on information received from the Eberline Corporation. Cost versus capacity for the incineration module for either a new or existing building is shown in Table 7-2; cost versus capacity is presented in Figures 7-6 through 7-9.

Table 7-1. FTE workers for the small generator incineration module.

\begin{tabular}{lcc}
\hline \multicolumn{1}{c}{ Cost element } & \multicolumn{2}{c}{ Type of module } \\
\cline { 2 - 3 } & $\begin{array}{c}\text { Fixed, in new } \\
\text { building(s) }\end{array}$ & $\begin{array}{c}\text { Fixed, in existing } \\
\text { building(s) }\end{array}$ \\
\hline (1.0) Preoperations & 12 & 12 \\
(2.0) Construction & 77 & 61 \\
(3.0) O\&M (20 years) & 162 & 170 \\
(4.0) D\&D & 9 & 9 \\
All cost elements (total for 20 years O\&M) & 260 & 252 \\
\hline
\end{tabular}

Table 7-2. PLCC $(\$ 1,000)$ for the small generator incineration module.

\begin{tabular}{lcc}
\hline & \multicolumn{2}{c}{ Type of module } \\
\cline { 2 - 3 } Cost element & $\begin{array}{c}\text { Fixed, in new } \\
\text { building(s) }\end{array}$ & $\begin{array}{c}\text { Fixed, in existing } \\
\text { building(s) }\end{array}$ \\
\hline (1.0) Preoperations & 1,971 & 1,915 \\
(2.0) Construction & 20,757 & 17,335 \\
(3.0) O\&M (20 years) & 15,180 & 15,180 \\
(4.0) D\&D & 2,157 & 2,157 \\
All cost elements (total for 20 years O\&M) & 40,065 & 36,587 \\
\hline
\end{tabular}




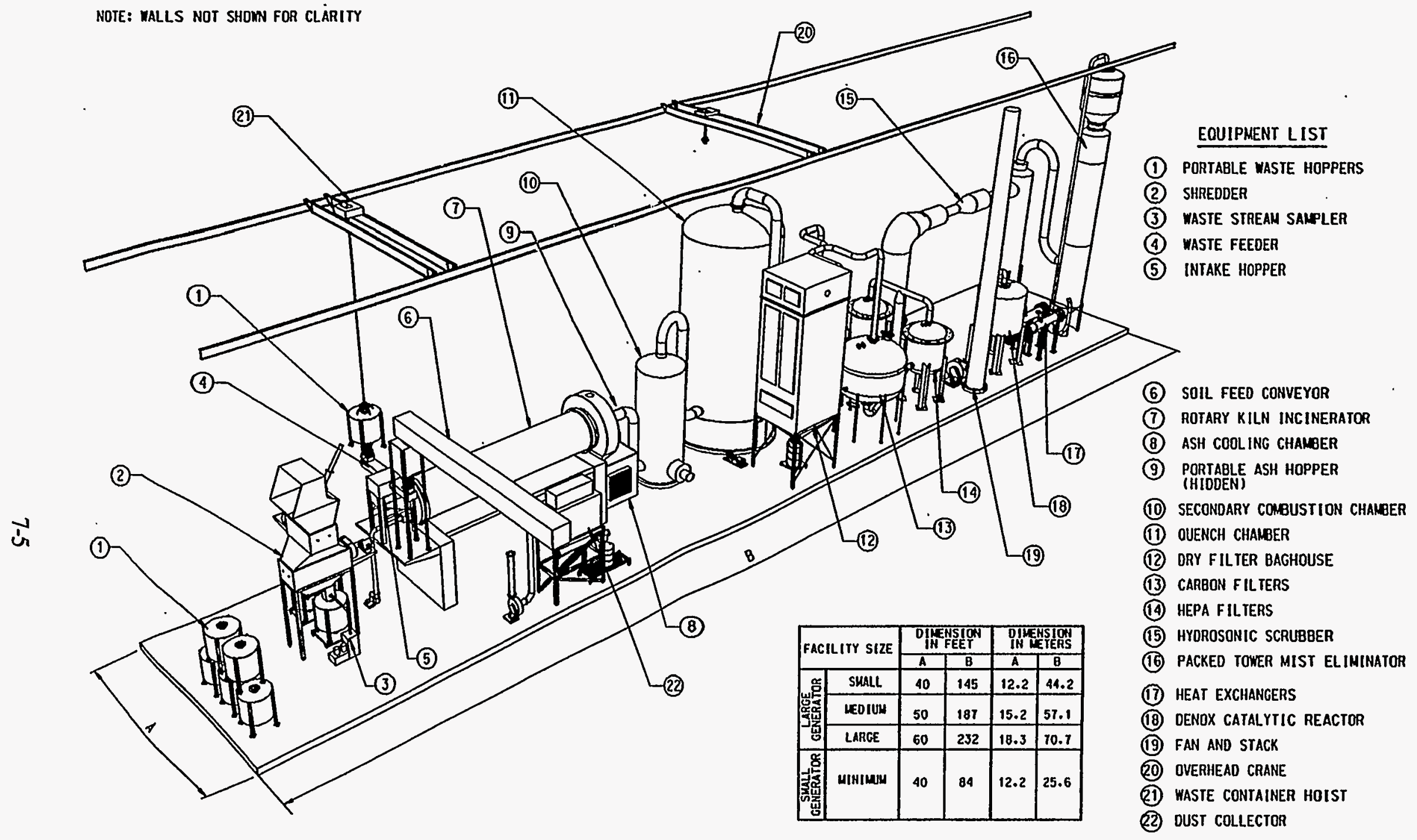

Figure 7-1. Equipment layout for the incineration (INCIN) module. 


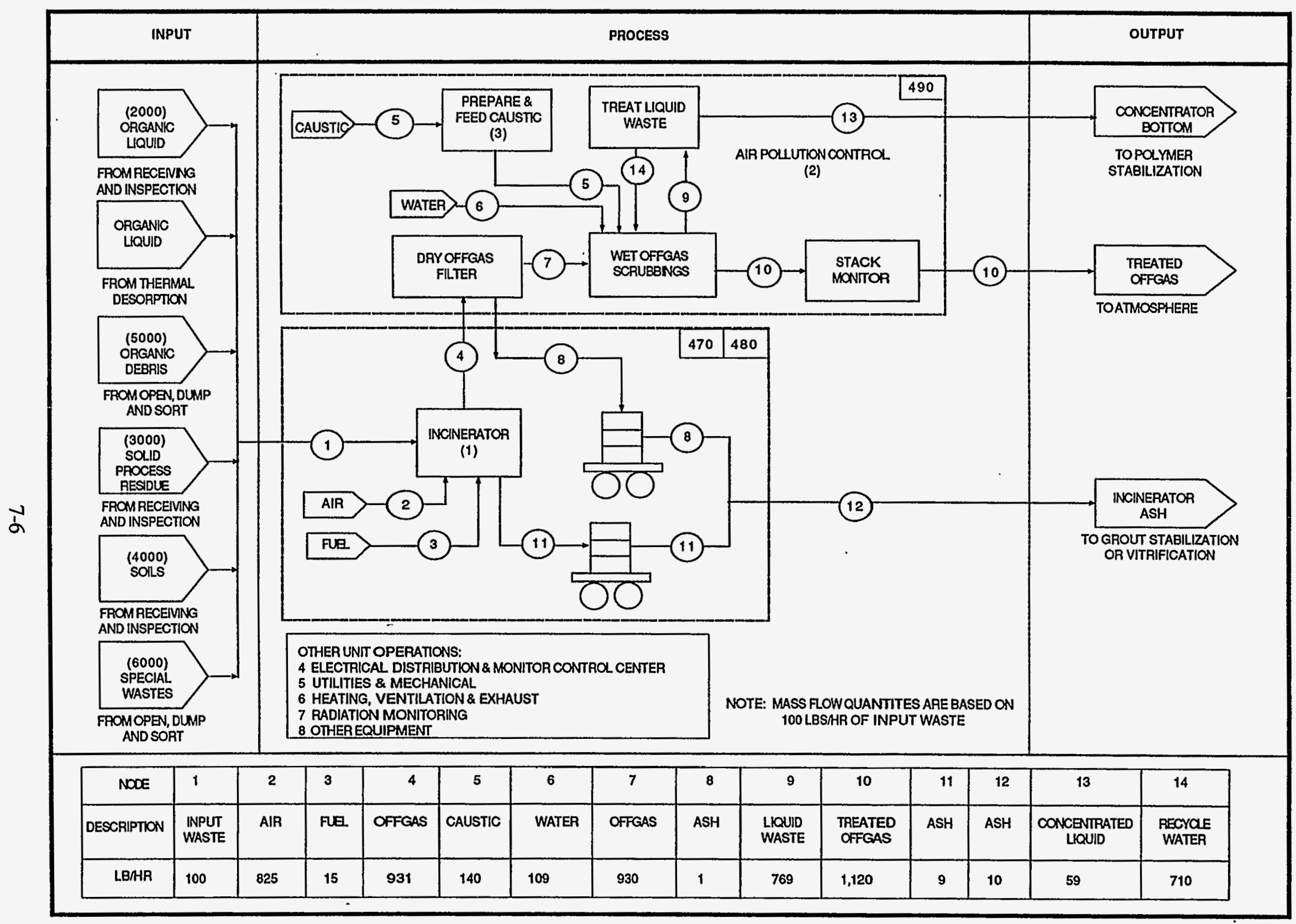

Figure 7-2. Process flow diagram for the incineration (INCIN) module. 


\section{INCINERATION}

FTE by Work Breakdown Structure Element Module: INCIN Waste Type: Nonalpha LLW

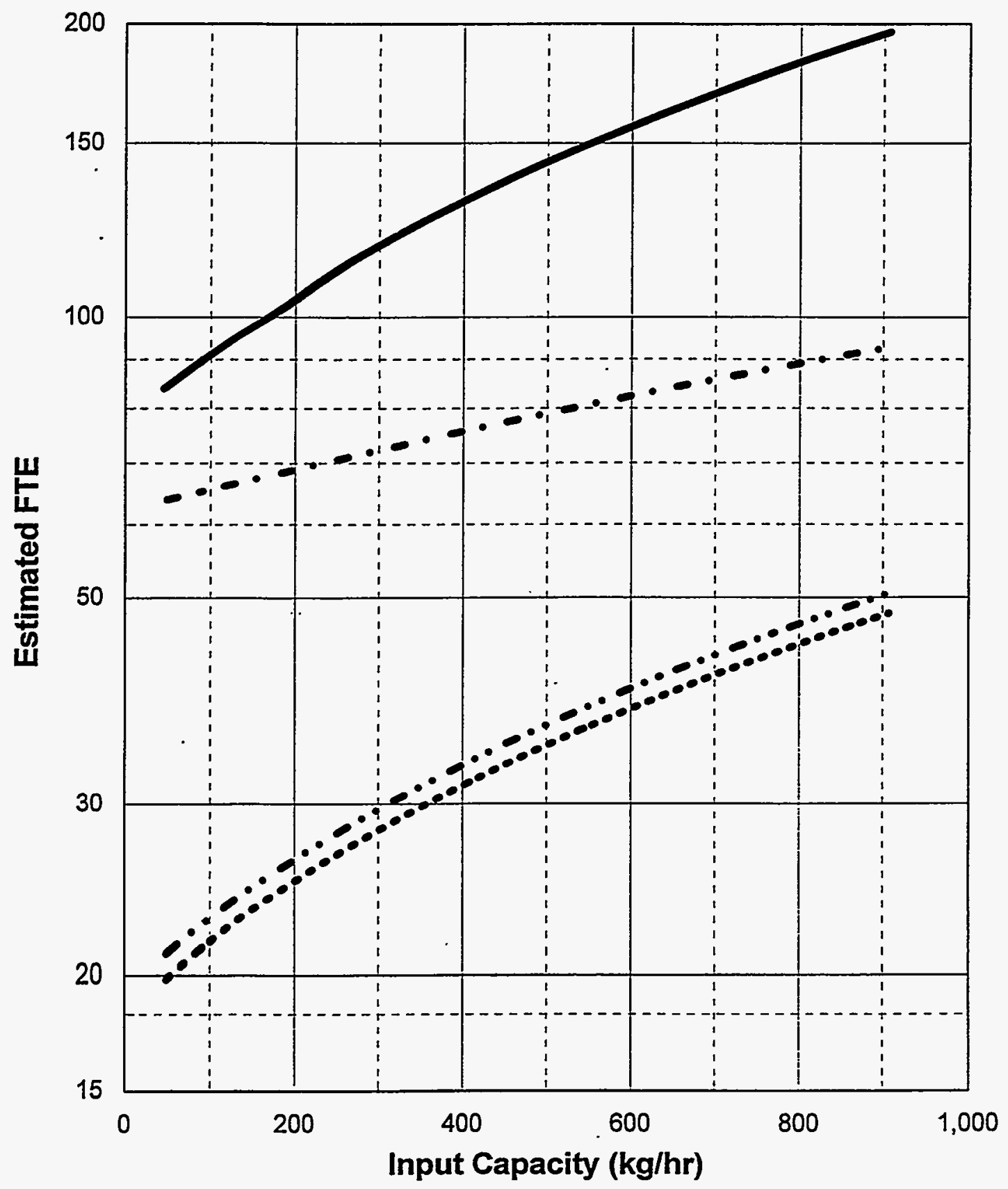

Pre-Operations Construction O\&M (1year) D\&D $-\cdot-$ $\longrightarrow$ -.... -

Figure 7-3. FTE workers versus capacity for the nonalpha incineration (B-INCIN) module. 


\section{INCINERATION}

FTE by Work Breakdown Structure Element

Module: INCIN Waste Type: Alpha LLW

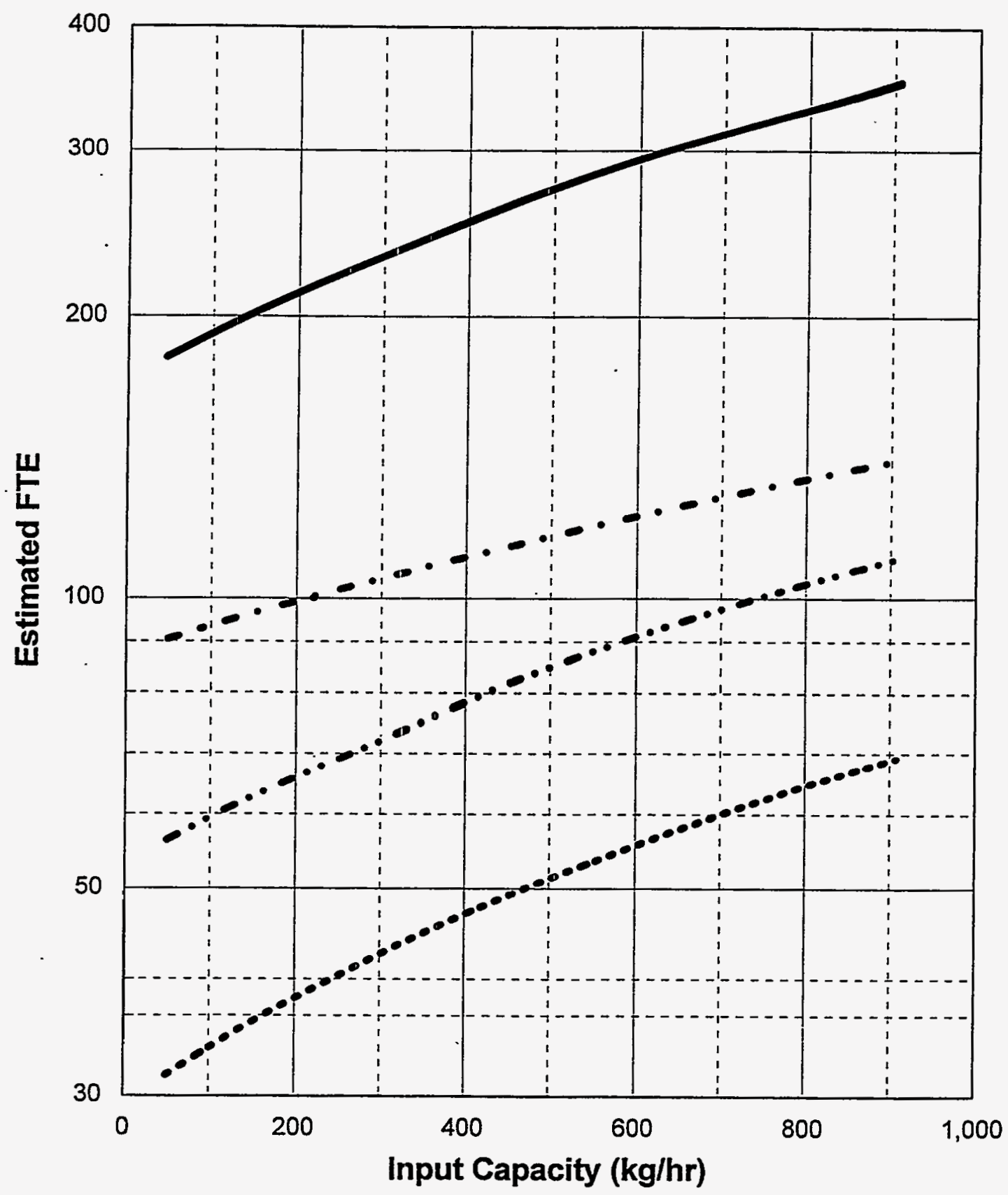

Pre--Operations Construction O\&M (1year) D\&D

Figure 7-4. FTE workers versus capacity for the alpha incineration (A-INCIN) module. 


\section{INCINERATION}

FTE by Work Breakdown Structure Element

Module: INCIN Waste Type: Remote Handled LLW

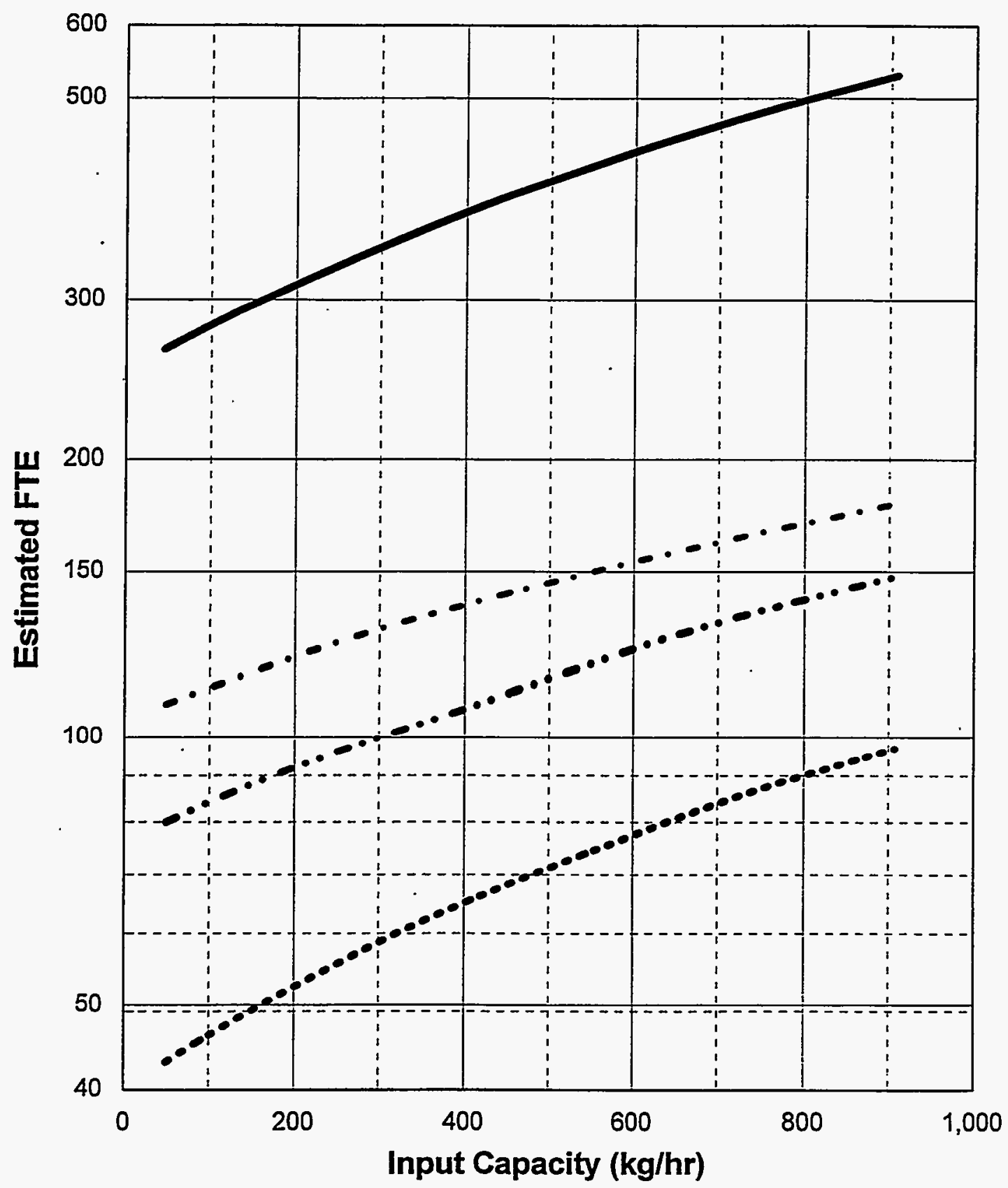

Pre-Operations Construction O\&M (1year) D\&D

Figure 7-5. FTE workers versus capacity for the RH incineration (R-INCIN) module. 


\section{INCINERATION}

Cost by Work Breakdown Structure Element Module: INCIN Waste Type: Nonalpha LLW

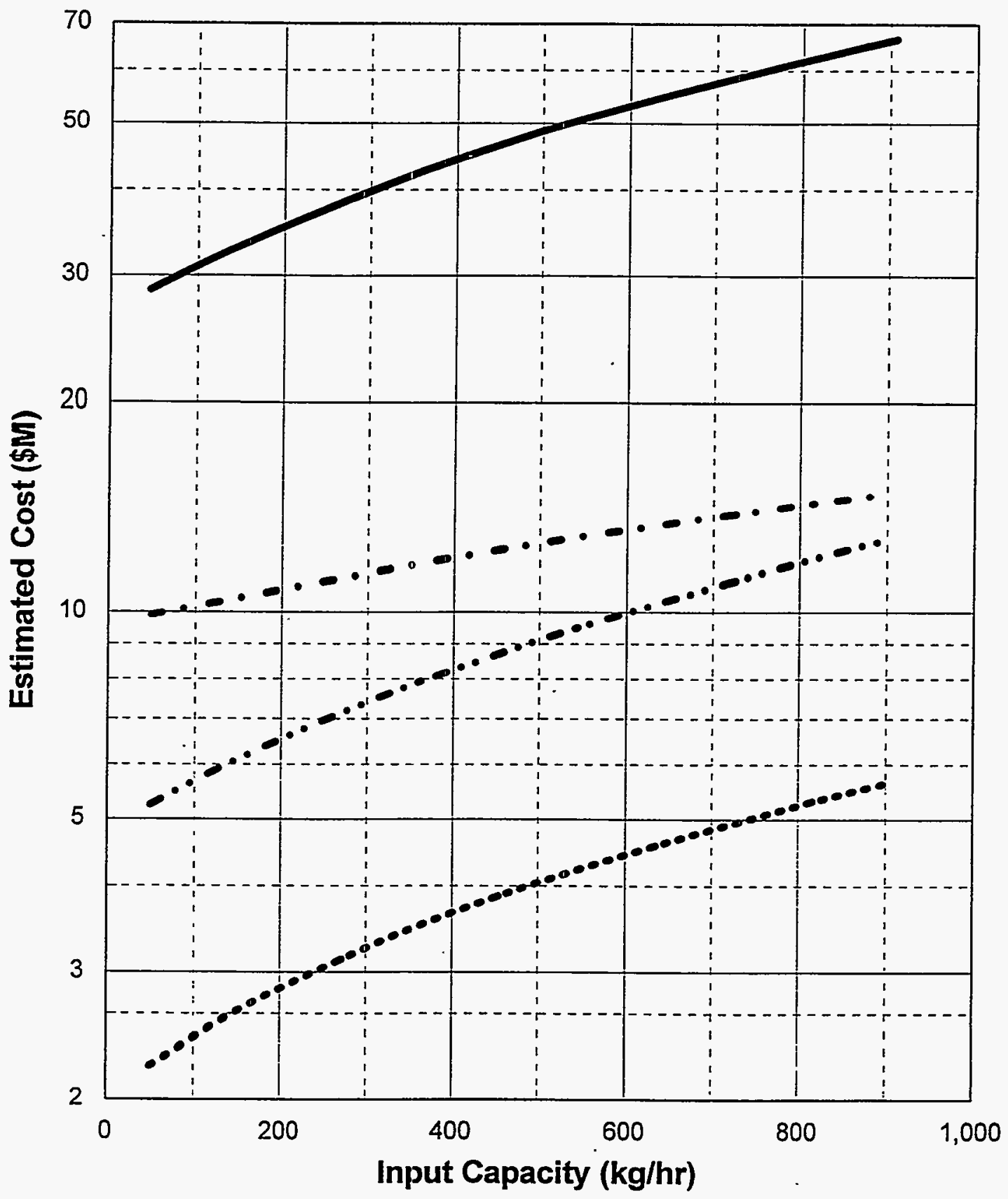

Pre-Operations Construction O\&M (1year) D\&D

Figure 7-6. PLCC versus capacity for the nonalpha incineration (B-INCIN) module. 


\section{INCINERATION}

Cost by Work Breakdown Structure Element

Module: INCIN Waste Type: Alpha LLW

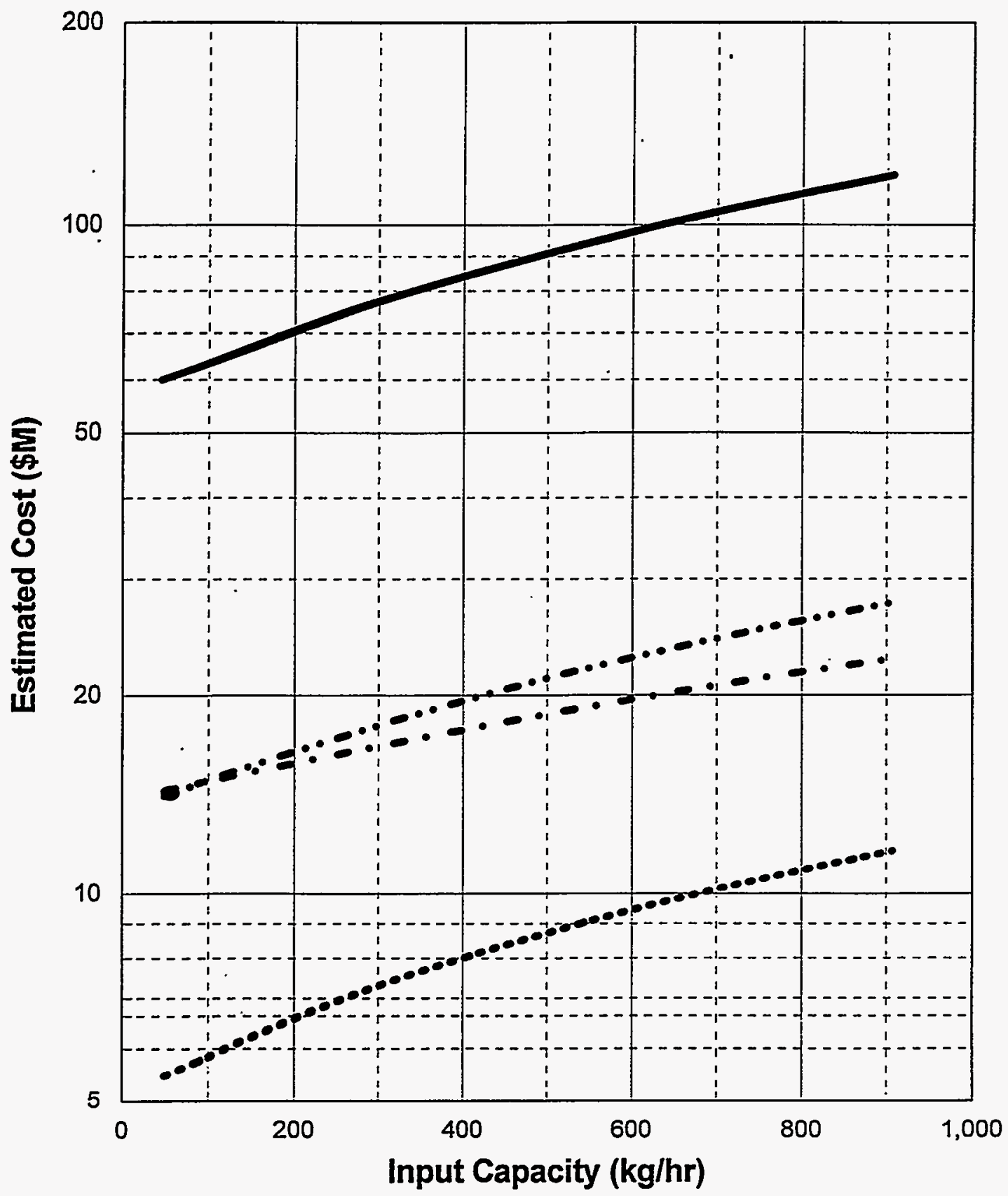

Pre-Operations Construction O\&M (1year) D\&D

Figure 7-7. PLCC versus capacity for the alpha waste incineration (A-INCIN) module. 


\section{INCINERATION}

Cost by Work Breakdown Structure Element Module: INCIN Waste Type: Remote Handled LLW

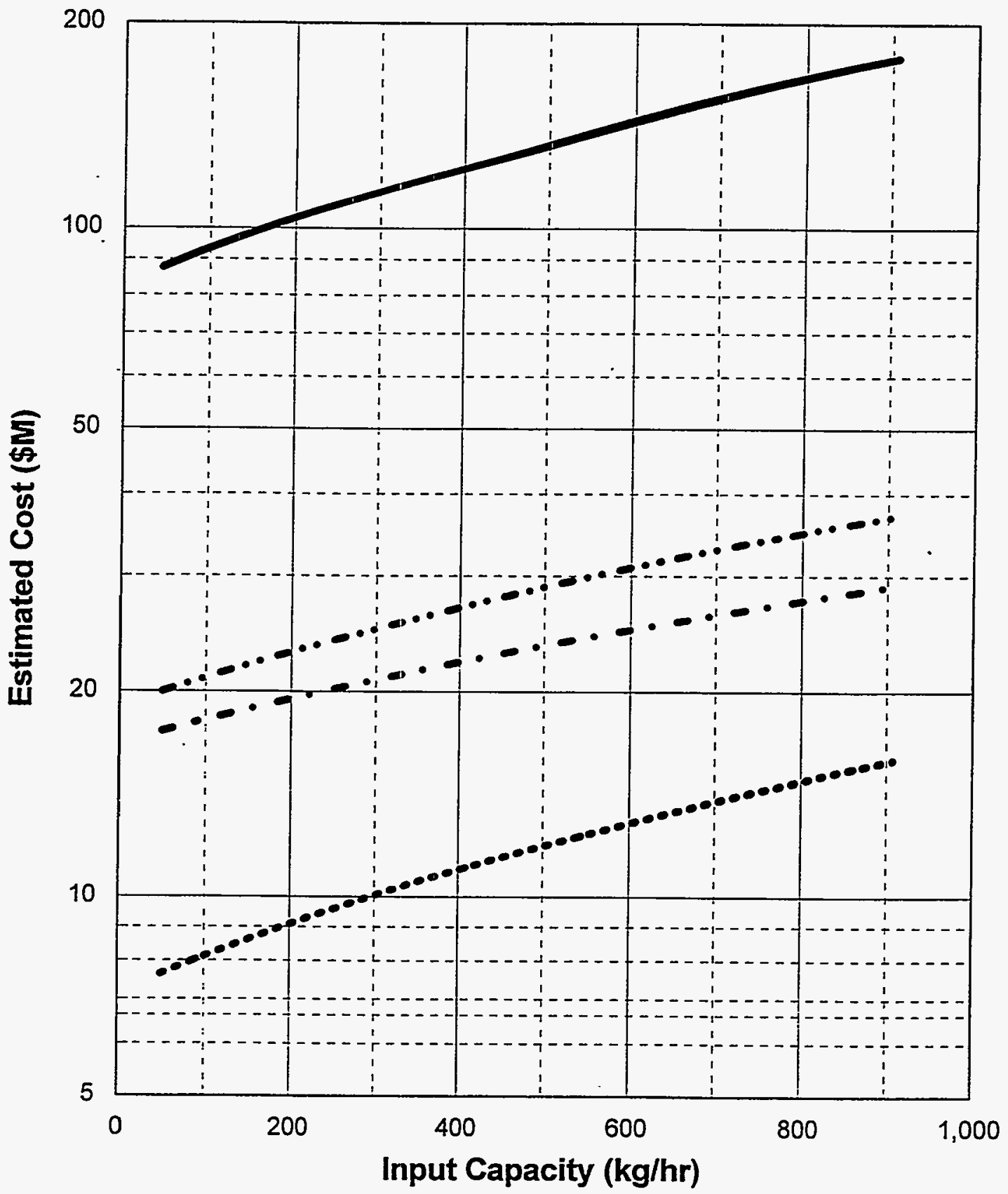

Pre-Operations Construction O\&M (1year) D\&D

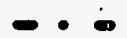

Figure 7-8. PLCC versus capacity for the RH incineration (R-INCIN) module. 


\section{INCINERATION}

Total Life Cycle Costs

Module: INCIN Waste Type: Alpha, Nonalpha, and Remote Handled LLW

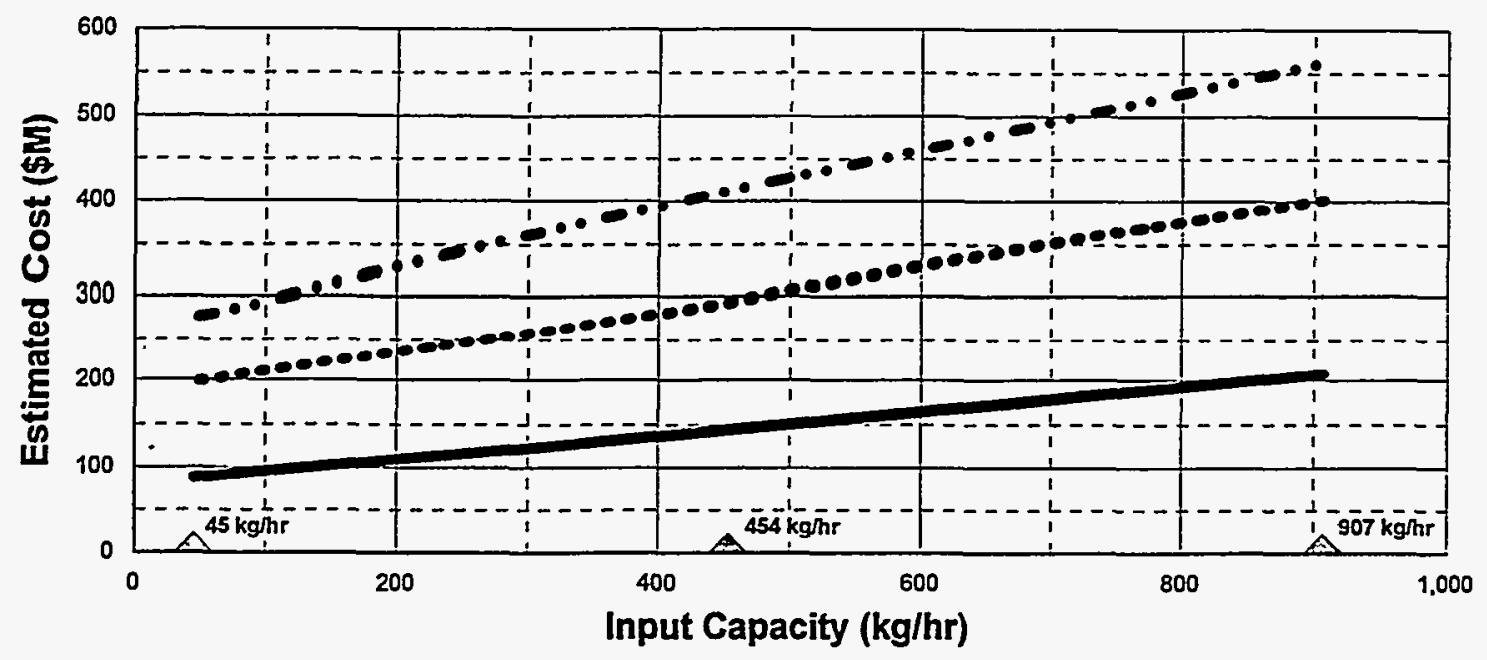

Nonalpha Alpha Remote Handled

NOTE: Basis indudes 20 years O\&M

Triangles indicate capacities where detailed cost estimates were developed.

\section{INCINERATION}

Total Life Cycle Unit Costs

Module: INCIN Waste Type; Alpha, Nonaipha, Remote Handled LLW

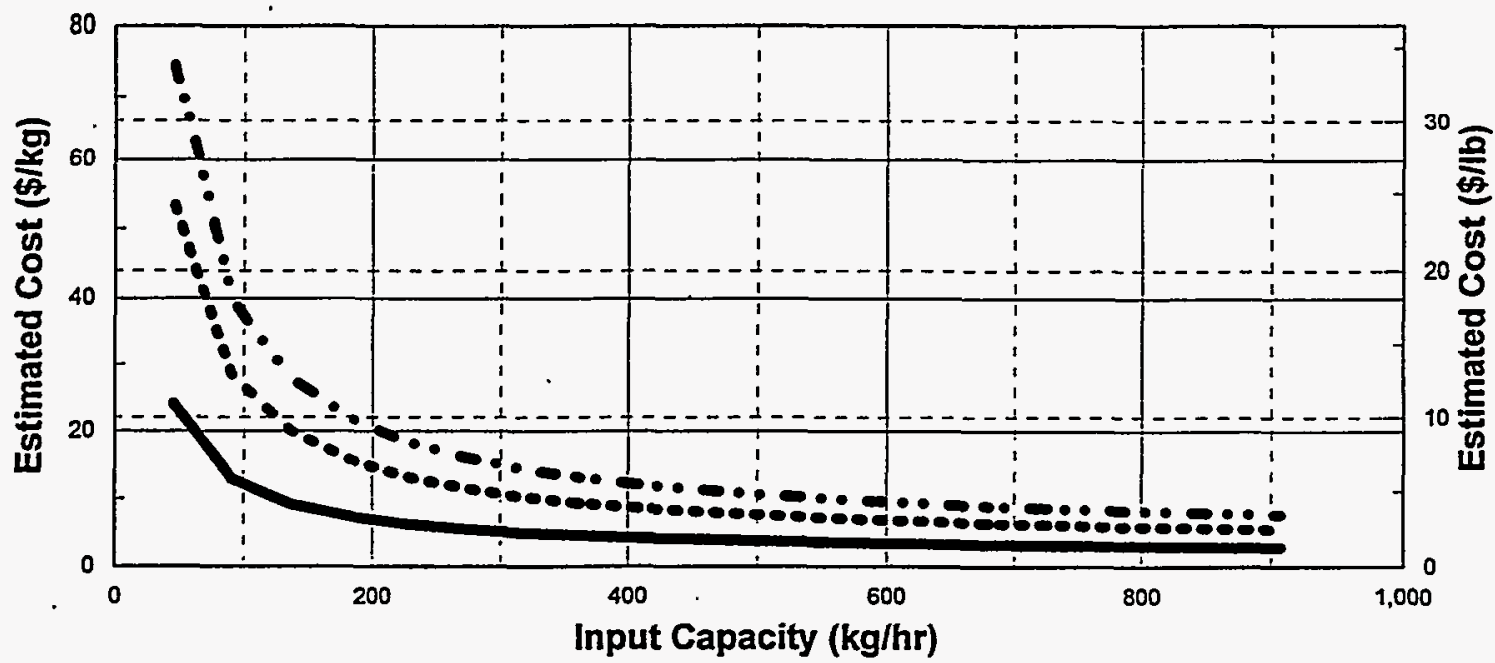

Nonalpha Alpha Remote Handled

NOTE: Basis indudes 20 years O\&M

Figure 7-9. PLCC versus capacity including unit rates for the incineration (INCIN) module. 


\section{METAL MELTING (MODULE MMELT)}

\subsection{Basic Information}

The metal melting module, shown in Figure 8-1, is used either as an addition to an existing facility where similar functions are already available, or in conjunction with the receiving and inspection (RCINS or FBSPT) module. The module involves ten process unit operations that convert incoming contaminated metal into cast metal ingots and cast slag and that treat secondary liquid and gaseous wastes. Secondary waste treatment byproducts, such as offgas scrubber sludge, are solidified and placed in drums. The facility can process ferrous and nonferrous bulk metal of various shapes and forms, such as waste containers, failed equipment, and contaminated scrap structural steel. The module is designed to handle incoming waste containing up to $10 \%$ combustibles. However, this module cannot sort different metal types nor is it equipped to dismantle large pieces of equipment or reduce the size of large components. Metal must arrive at the module presorted and in drums. Module MMELT is applicable to nonalpha, alpha and RH waste. Figure 8-2 contains a PFD showing the unit operations.

\subsection{Technical Bases and Assumptions}

\subsubsection{Function and Operation of the Module}

Drums and transport bins containing contaminated metal are delivered to the feed preparation unit operation where it is staged and size reduced, if needed, in preparation for melting. Drums and transport bins containing waste that needs size reduction are dumped on a size reduction device where metals are cut using remote torches or a shredder. The shredded and size-reduced metal is placed back on transport bins and sent to the melter unit operation.

The melter unit operation is equipped with a bulk material feed system and a drum feed system. Contents of the drums and bins are fed to the melter through a bulk feed system. Alternatively, drums may be fed intact through the melter drum feeder.

In the melter, the metal is melted and accompanying combustible material is thermally destroyed. During the melting process, molten slag containing impurities and most of the radionuclide contamination is separated from the molten metal. The stream of molten metal is sent to the metal casting and cooling unit operation, and the slag stream is directed to the slag casting and cooling unit operation.

In both the metal and slag casting operations, molten materials are poured into water-cooled canisters. After the cool-down operation, the canisters are sealed and sent to a container washing and inspection unit operation. A grouting agent is added to the slag canister before it is sealed. Sealed containers are then staged for disposal.

The unit operations produce two secondary waste streams: liquid and offgas. Secondary liquid waste is processed in the liquid waste treatment unit that removes dissolved and suspended solids (organic and inorganic) from the liquid waste. The facility recycles and reuses the treated wastewater so that there is zero wastewater discharge to the environment. 
The melter offgas system is equipped with a dry treatment train and wet treatment train. The dry treatment train consists of high-temperature HEPA filters with secondary combustion capabilities (such as ceramic filters). In this train, any combustible constituents are thermally destroyed, and particulates are removed from the offgas stream. An induced air blower moves the conditioned effluent through the wet treatment train, which is designed to remove $\mathrm{SO}_{2}, \mathrm{HCl}$, and $\mathrm{NOx}$. A surge tank is provided for offgas retention for reprocessing melter exhaust in case of a process upset.

In the solidification unit operation, liquid waste treatment sludge is mixed with a binder (such as Portland cement) in a drum. A predetermined mixing ratio is used to produce a stabilized waste form. The filled drums are washed with high-pressure water spray jets at the drum capping and washing unit operation.

Drums containing solidified waste, slag containers, and cast metal ingots are the main output from this module. This output is ready for examinations by radioassay and final certification included in the certification and shipping module.

It is assumed that a major portion of the metal ingots have a limited potential for reuse or may be disposed of safely in shallow land disposal units. The anticipated density of the solidified waste is $1,794 \mathrm{~kg} / \mathrm{m}^{3}\left(112 \mathrm{lb} / \mathrm{ft}^{3}\right)$, and the densities for cast metal are the same as their absolute densities. The anticipated density of the slag is $2,755 \mathrm{~kg} / \mathrm{m}^{3}\left(172 \mathrm{lb} / \mathrm{ft}^{3}\right)$.

\subsubsection{Facility Integration}

Major input is contaminated scrap metal in drums and bins from receiving and inspection (module RCINS or FBSPT). Major O\&M purchased materials, such as personal protective equipment, laboratory material, binder, and disposable containers, are assumed to be consumable supplies, and their respective costṣ are estimated accordingly.

Major discharges from the system are canisters of metal ingots, canisters of slag, and drums of solidified waste that are transported to a certification and shipping module. Treated offgas is discharged to the atmosphere.

\subsection{Cost Bases, Assumptions, and Results}

Major equipment capital cost items include the melter, casting, and cooling equipment; offgas treatment and its supporting equipments; and solidification units. Costs for the preparation and feed unit are based on vendor quotes. Melter prices are based on quotes from Ajax Corporation and Retec Corporation. NGK-Locke, Inc., and Callidus Technologies prices were used for the dry and wet offgas treatment trains. The selected solidification unit is manufactured by Stock Equipment Company, Chagrin Falls, Ohio. This supplier provided a quote for a unit similar to that sold to DOE for a facility at the Savannah River Site. Estimated FTEs and cost versus capacity are shown in Figures 8-3 through 8-9. 


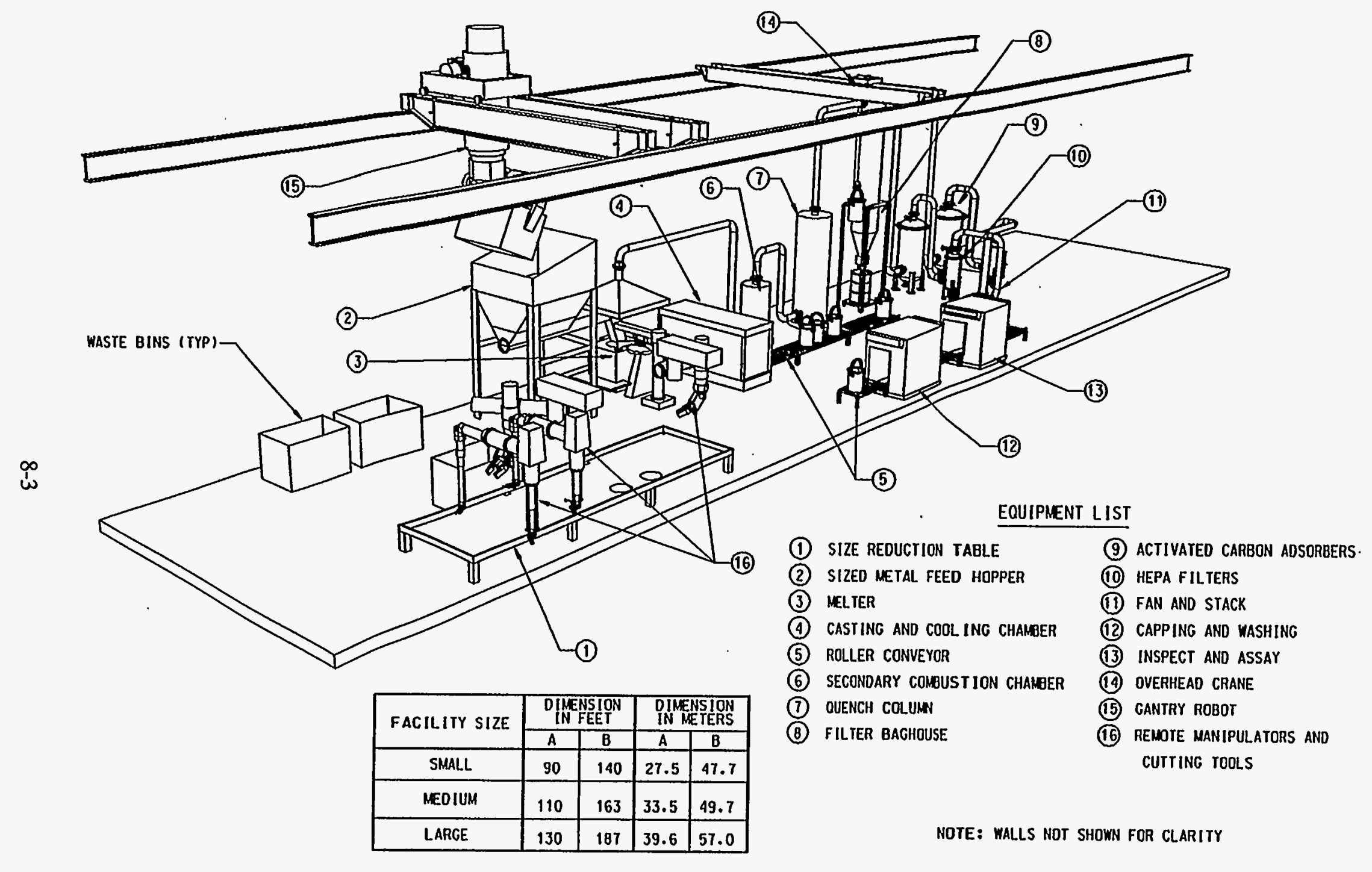

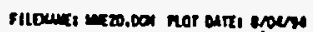

Figure 8-1. Equipment layout for the metal melting (MMELT) module. 


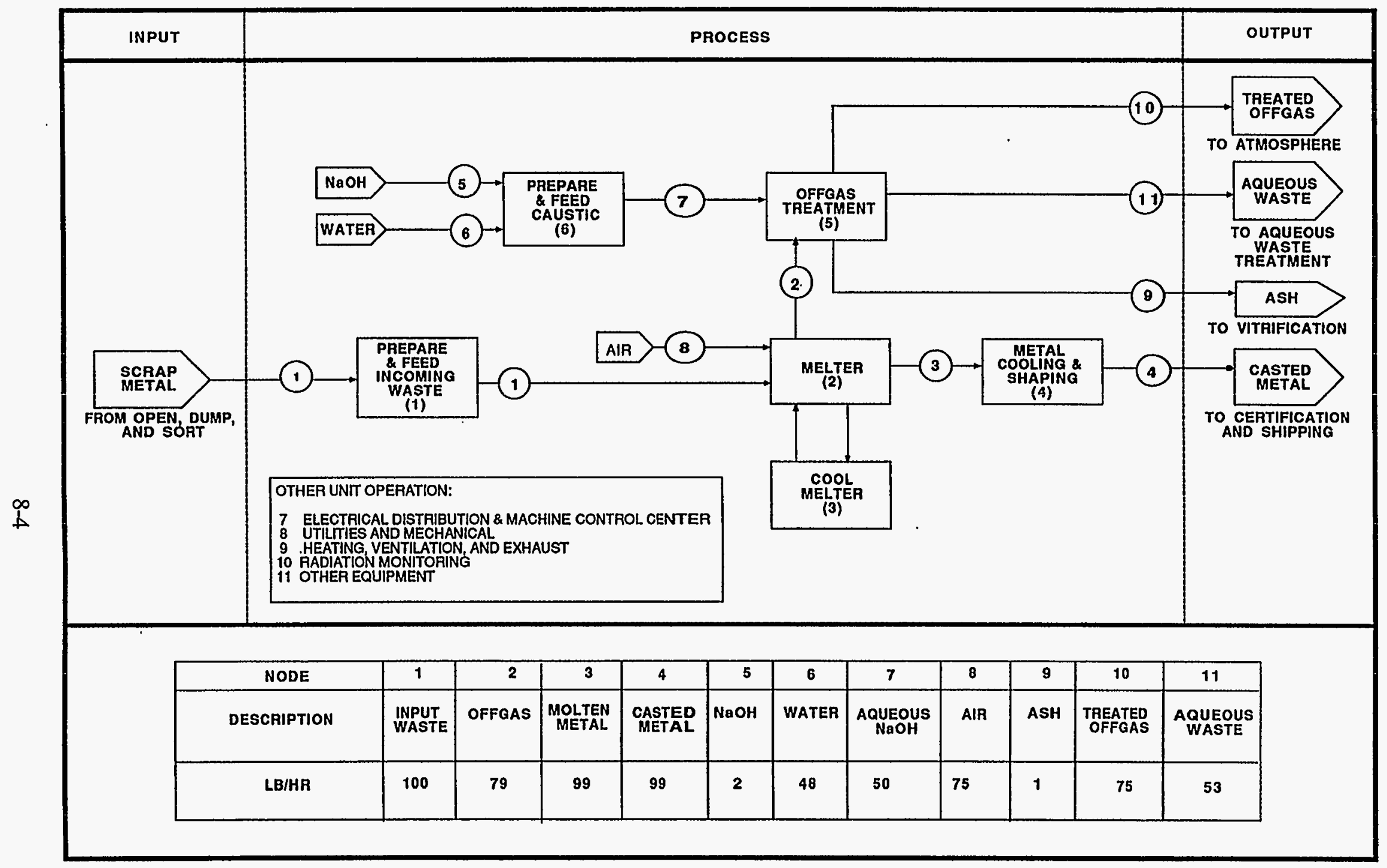

Figure 8-2. Process flow diagram for the metal melting (MMELT) module. 


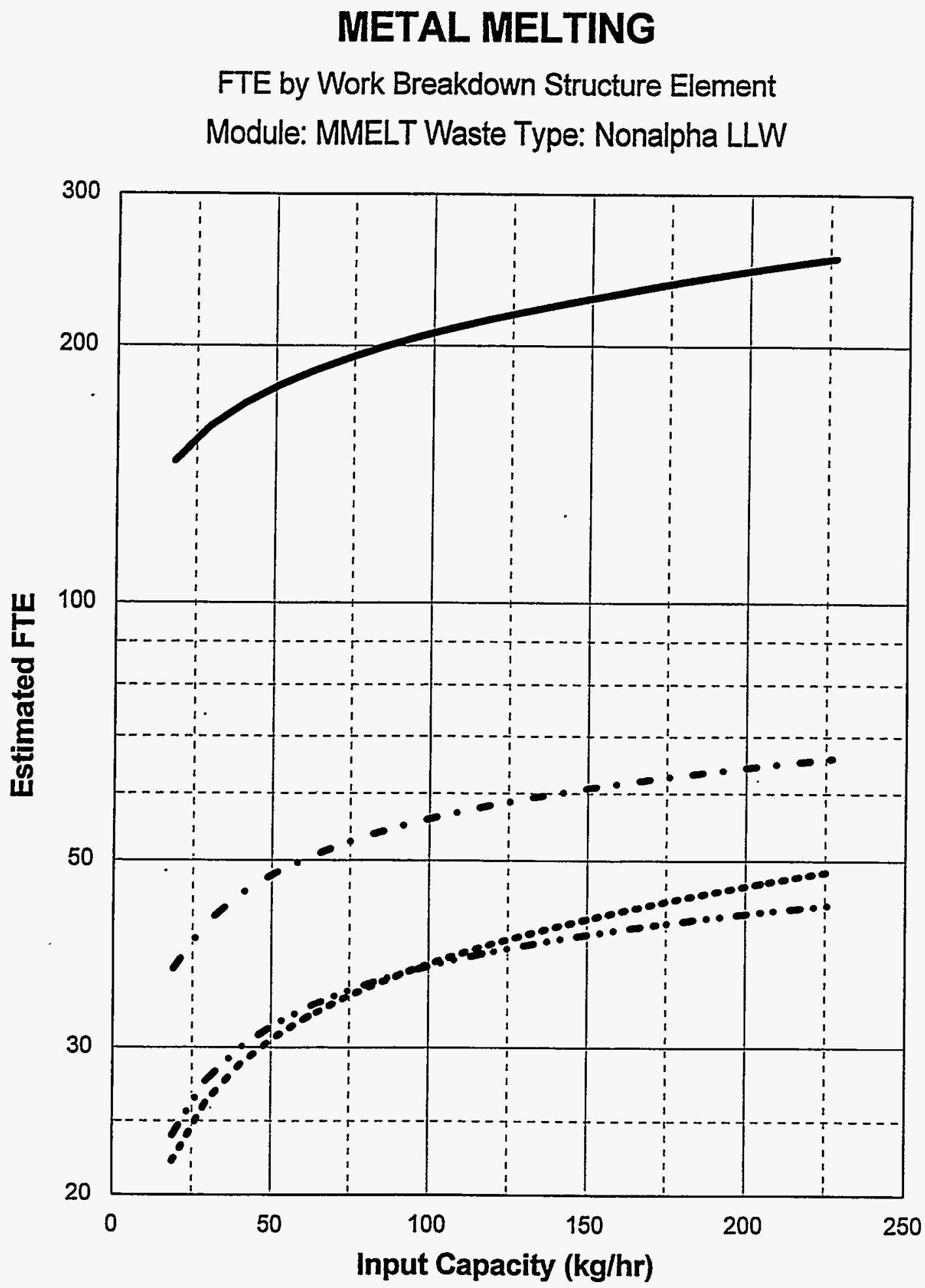

Pre-Operations Construction O\&M (1year) D\&D

Figure 8-3. FTE workers versus capacity for the nonalpha metal melting (B-MMELT) module. 


\section{METAL MELTING}

FTE by Work Breakdown Structure Element

Module: MMELT Waste Type: Alpha LLW

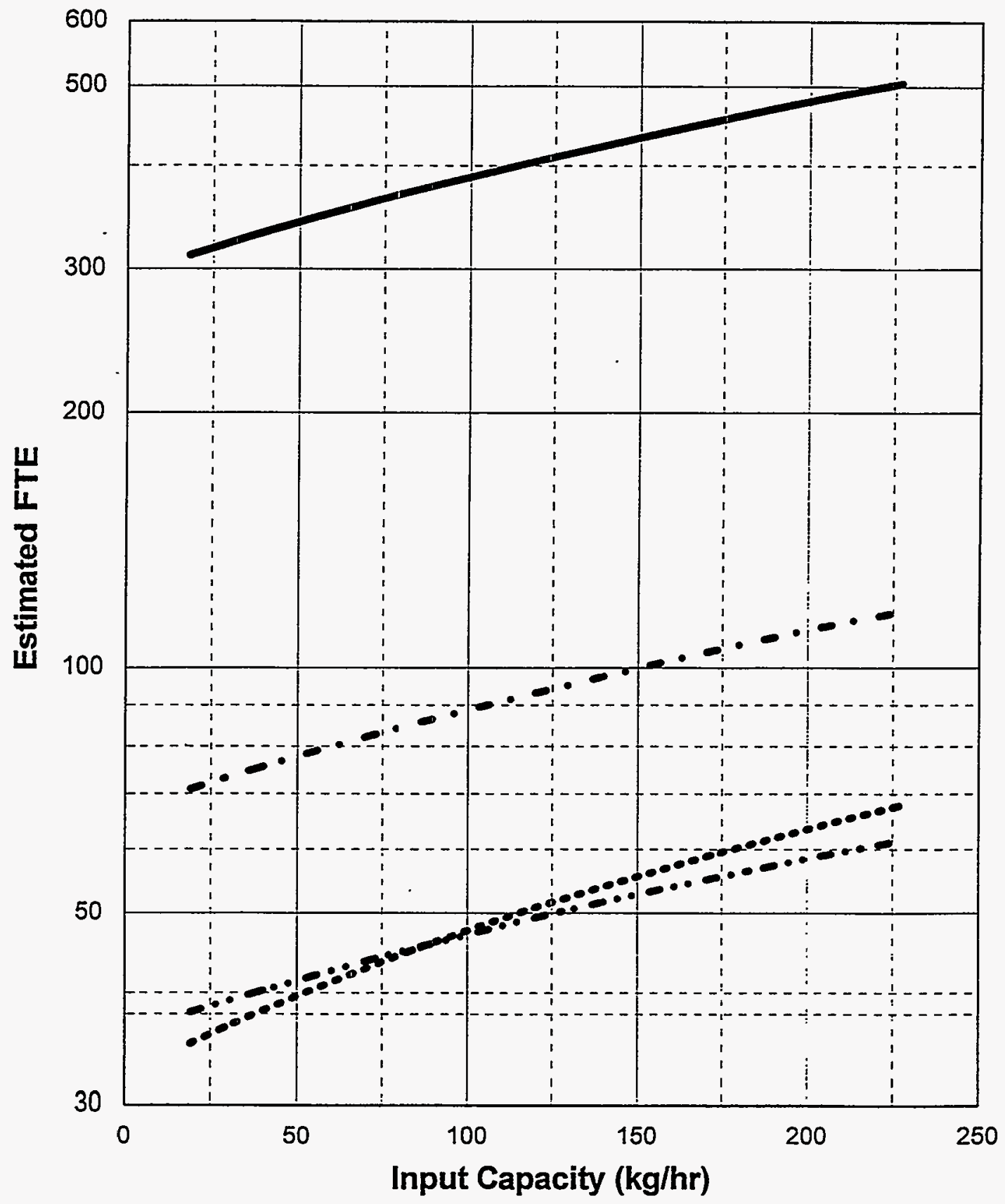

Pre-Operations Construction O\&M (1year) D\&D

Figure 8-4. FTE workers versus capacity for the alpha metal melting (A-MMELT) module. 


\section{METAL MELTING}

FTE by Work Breakdown Structure Element Module: MMELT Waste Type: Remote Handled LLW

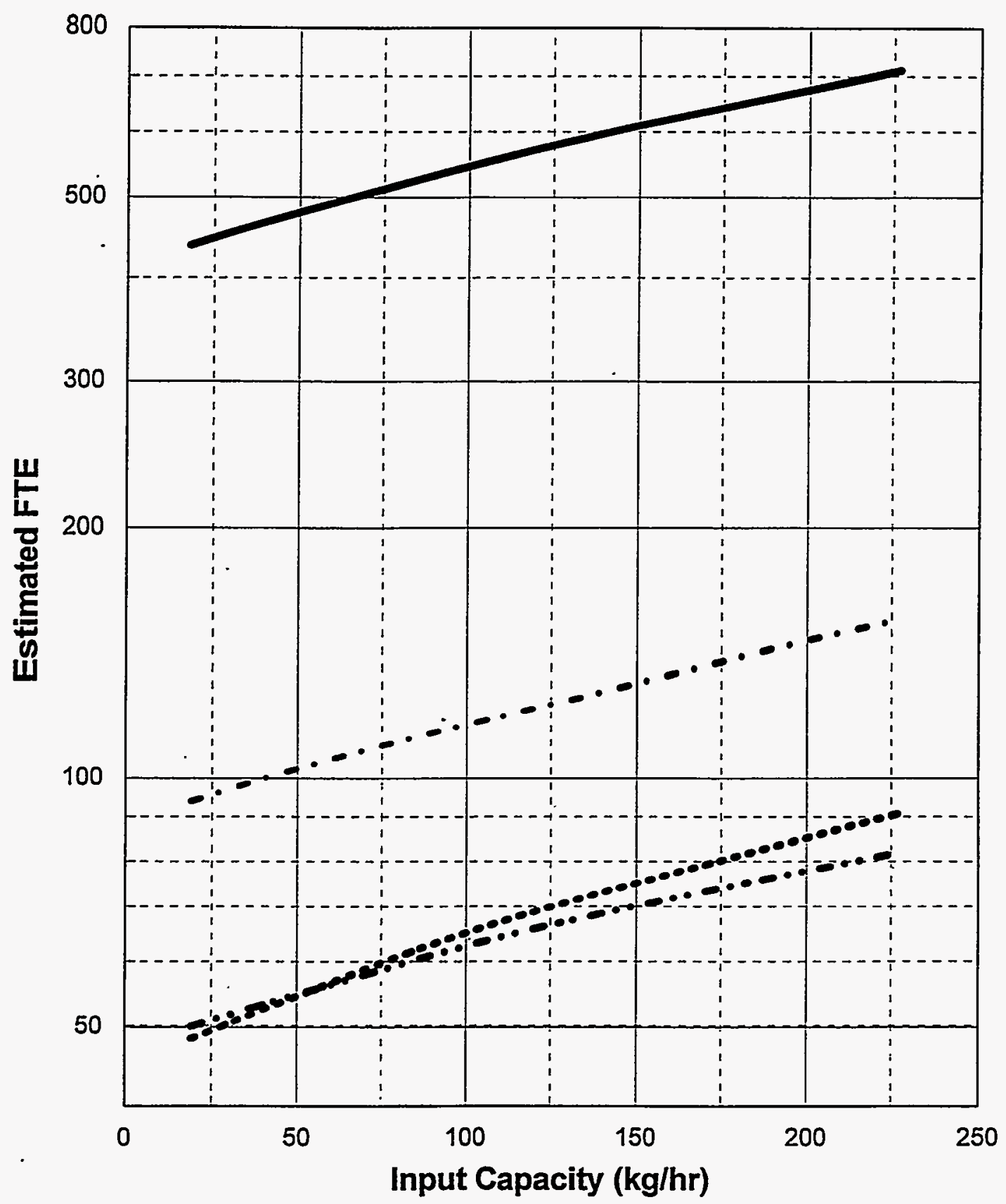

Pre-Operations Construction O\&M (1year) D\&D - -

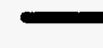

Figure 8-5. FTE workers versus capacity for the RH.metal melting (R-MMELT) module. 


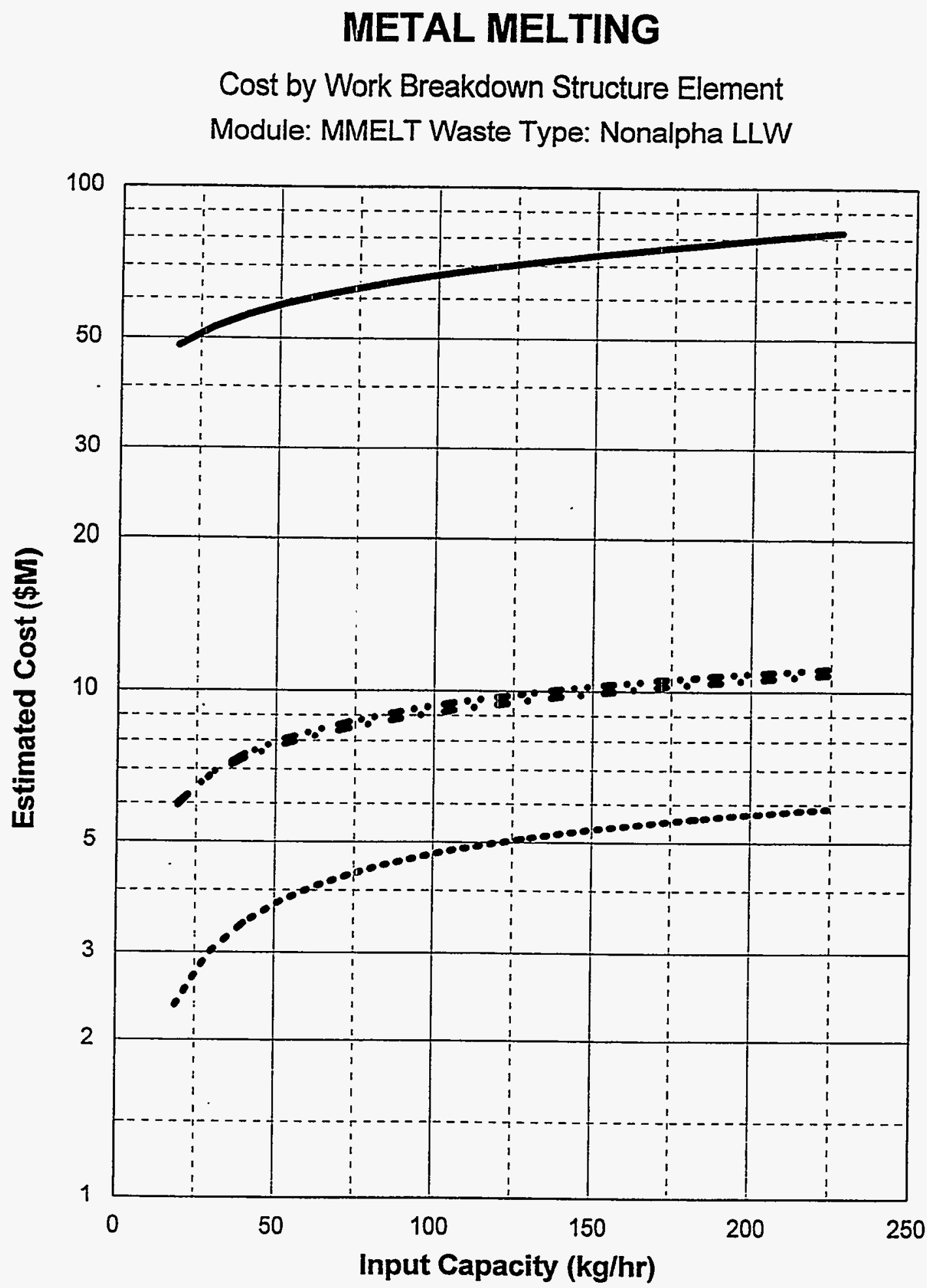

Pre-Operations Construction O\&M (1year) D\&D

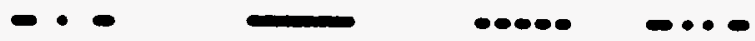

Figure 8-6. PLCC versus capacity for the nonalpha metal melting (B-MMELT) module. 


\section{METAL MELTING}

Cost by Work Breakdown Structure Element Module: MMELT Waste Type: Alpha LLW

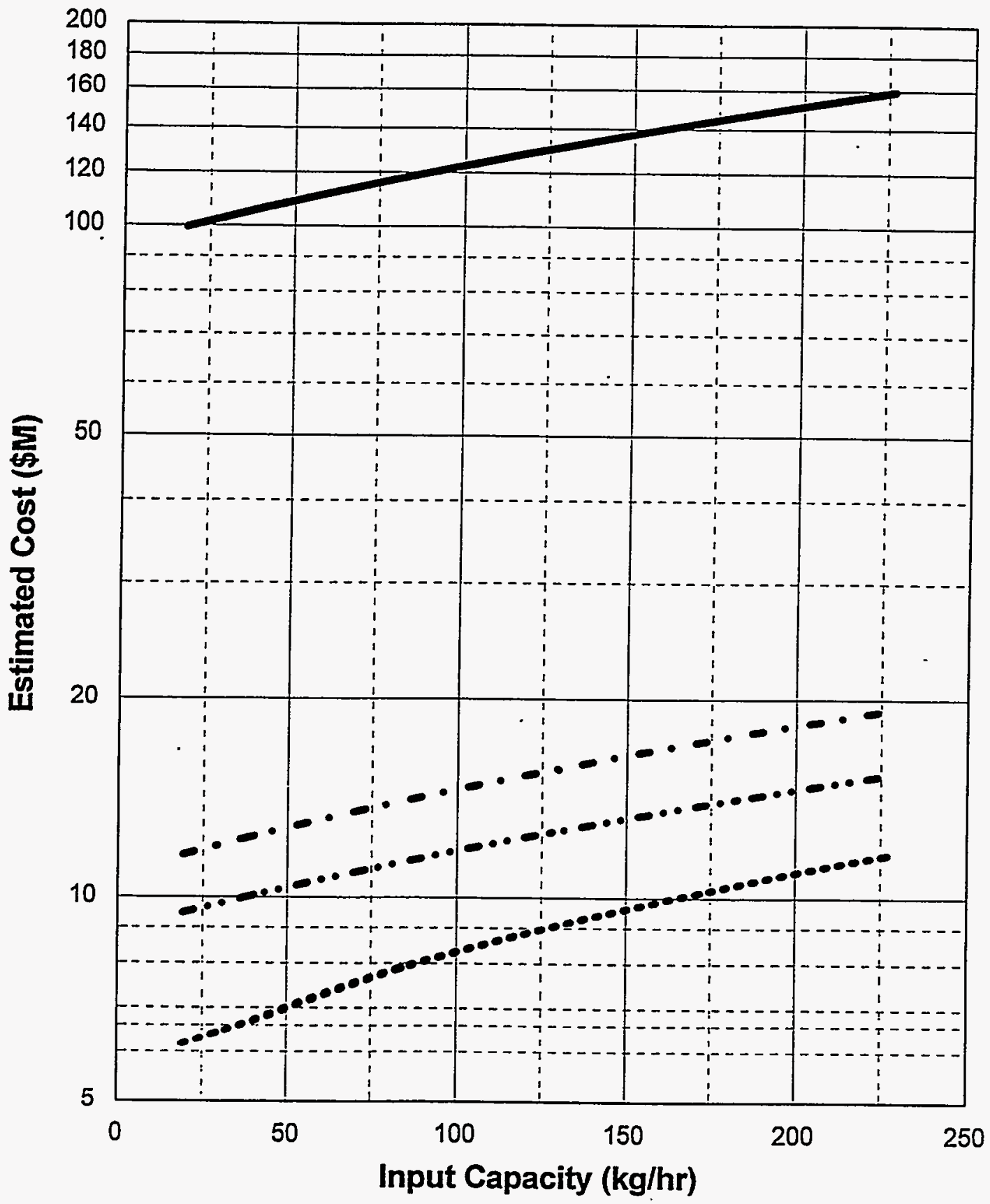

Pre-Operations Construction O\&M (1year) D\&D

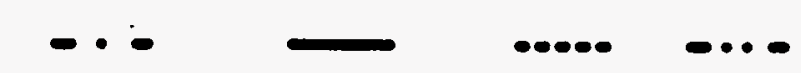

Figure 8-7. PLCC versus capacity for the alpha metal melting (A-MMELT) module. 


\section{METAL MELTING}

Cost by Work Breakdown Structure Element Module: MMELT Waste Type: Remote Handled LLW

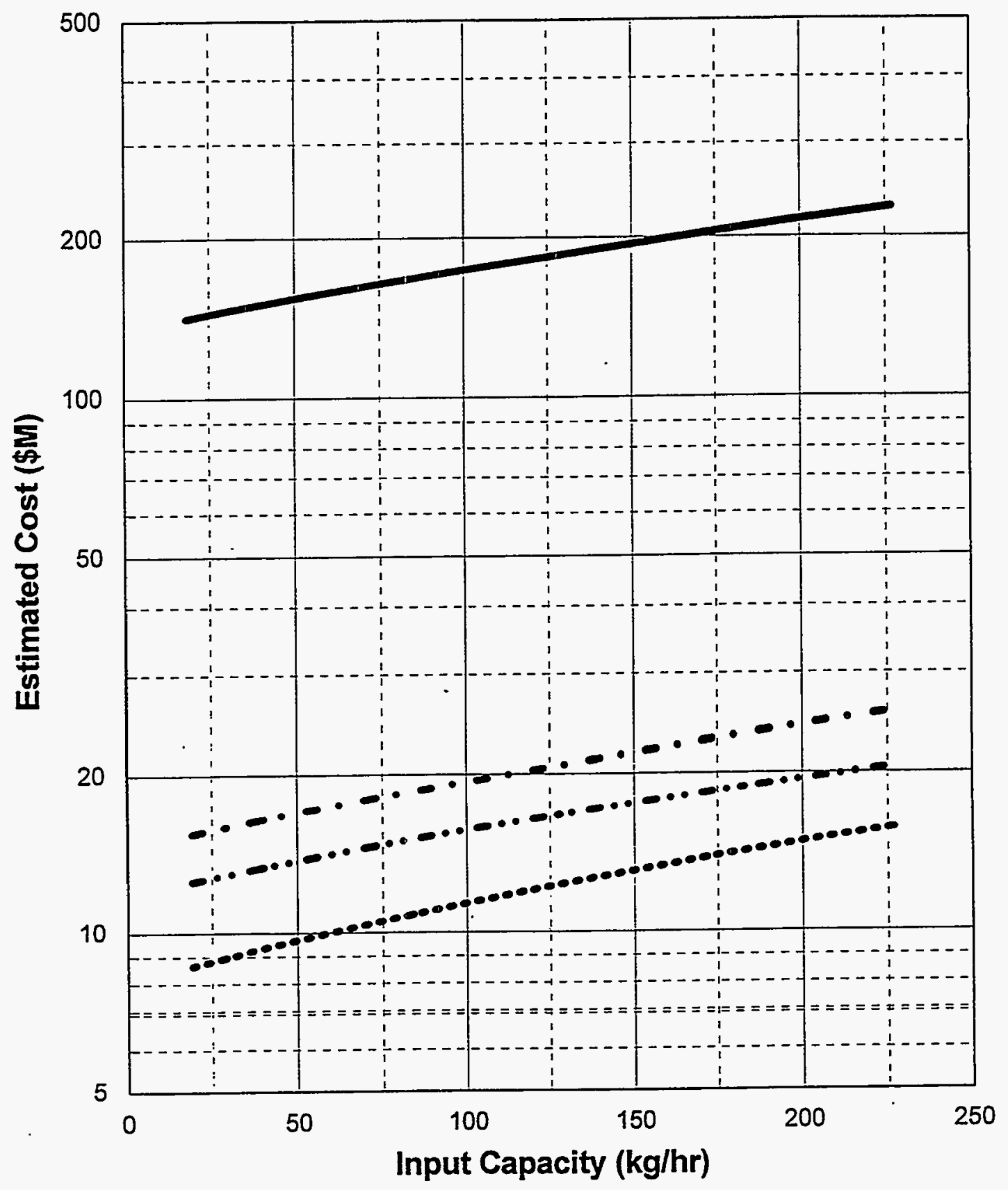

Pre-Operations Construction O\&M (1year) D\&D

Figure 8-8. PLCC versus capacity for the RH metal melting (R-MMELT) module. 


\section{METAL MELTING}

Total Life Cycle Costs

Module: MMELT Waste Type: Alpha, Nonalpha, and Remote Handled LLW

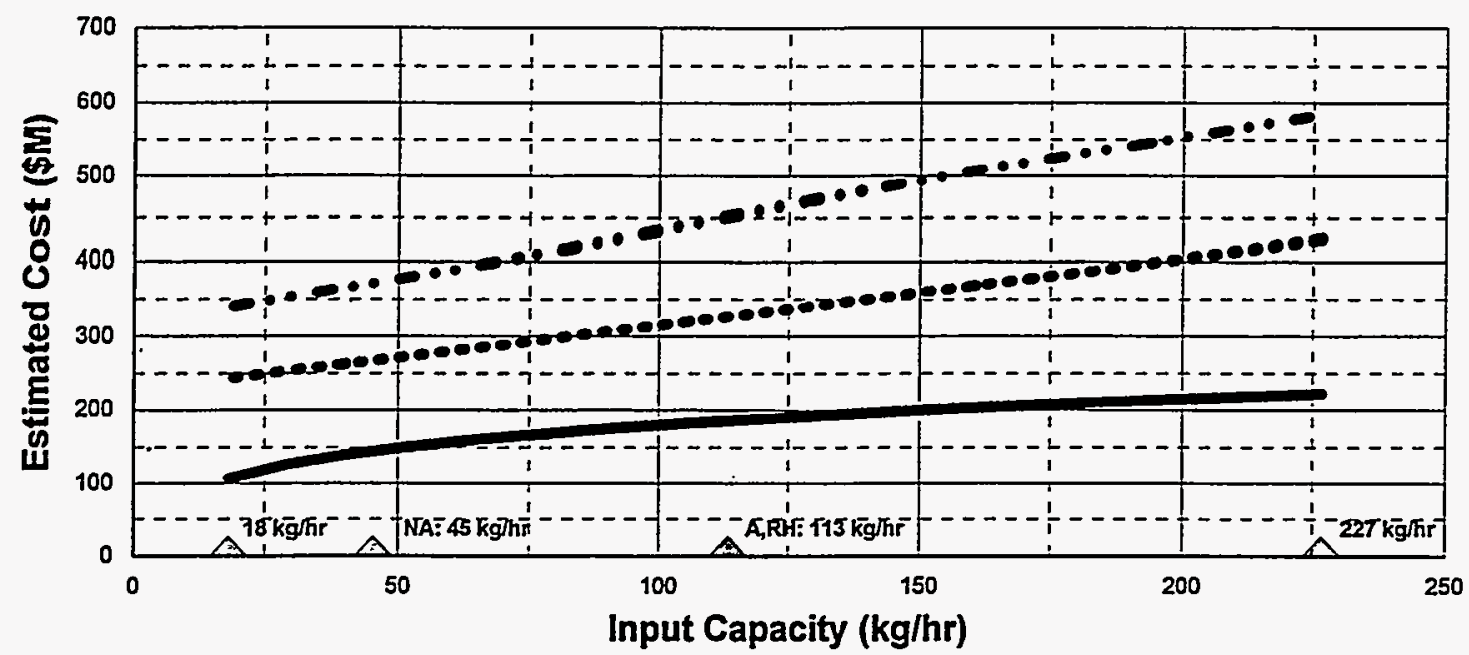

Nonalpha Alpha Remote Handled

NOTE: Basis indudes 20 years O\&M

Triangles indicate capacities where detailed cost estimates were developed.

\section{METAL MELTING}

Total Life Cycle Unit Costs

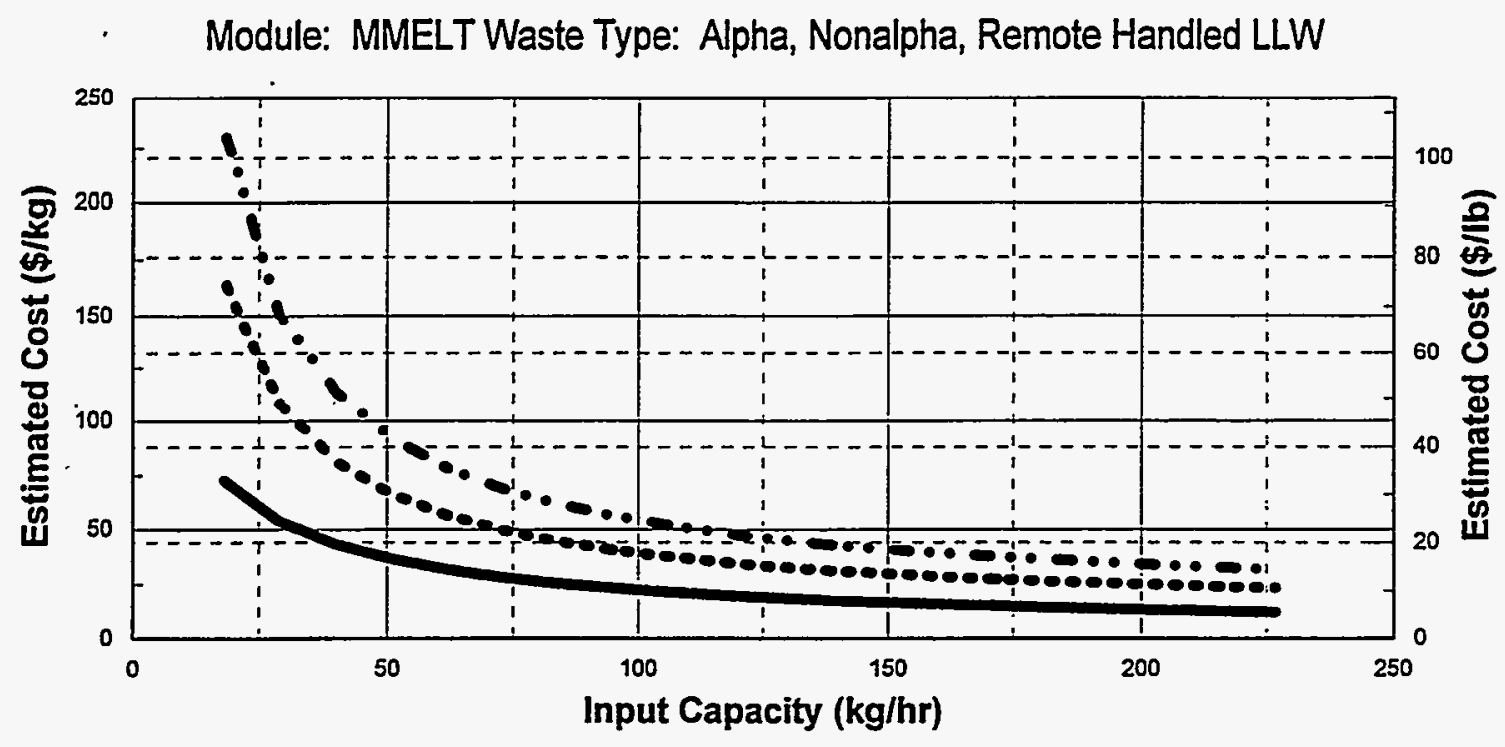

Nonalpha Alpha Remote Handled

NOTE: Basis includes 20 years O\&M

Figure 8-9. PLCC versus capacity including unit rates for the metal melting (MMELT) module. 


\section{SPECIAL WASTE PROCESSING (MODULE SPECL)}

\subsection{Basic Information}

The special waste processing module, shown in Figure 9-1, is designed to treat waste streams that are varied in nature, such as compressed gas cylinders, explosives, and lab packs. This module is designed to accommodate unique waste types on a case-by-case basis. It consists of an area equipped with a number of unit operations that have flexible treatment and handling functions. These unit operations contain material handling equipment, such as master slave manipulators and hydraulic manipulators mounted inside glove boxes. The unit operations are designed to be operated manually or remotely by personnel working in the operator gallery. The area is also equipped with an overhead crane for installing or removing specialized waste treatment unit operations or equipment skids on an as-needed basis. The building space includes all wiring, piping, drains, and ventilation systems required for skid-mounted waste treatment units. The cost of this module includes the building cost, including a lump sum allowance for equipment that must be provided on a case-by-case basis. Figure 9-2 contains a PFD showing unit operations.

\subsection{Technical Bases and Assumptions}

\subsubsection{Function and Operation of the Module}

The special waste processing module receives bins containing waste that cannot be treated by the normal process trains in the treatment facility. When the incoming waste composition is identified, a specific process is developed to treat the waste. The process equipment is skid mounted and installed in the module. After treatment, the skid-mounted equipment is decontaminated and either set aside or removed from the module, making space available for skids needed to treat other special wastes.

\subsubsection{Integration of the Module}

The module input is waste that cannot be treated by other treatment trains. Waste is received from the open, dump, and sort (OSORT) module. The system consumables and output are variable and depend on the waste to be processed.

\subsection{Cost Bases, Assumptions, and Results}

Major fixed equipment include cranes, manipulators, glove boxes, and conveyors. Cost allowances are included for unit operations that have to be provided on a case-by-case basis. For both alpha and nonalpha LLW, process equipment allowances are $\$ 3.5$ million for the small module; $\$ 4.3$ million for the medium module; and $\$ 6$ million for the large module. Facility operations are based on batch processing. Estimated FTEs and cost versus capacity for this module are shown in Figures 9-3 through 9-5. 


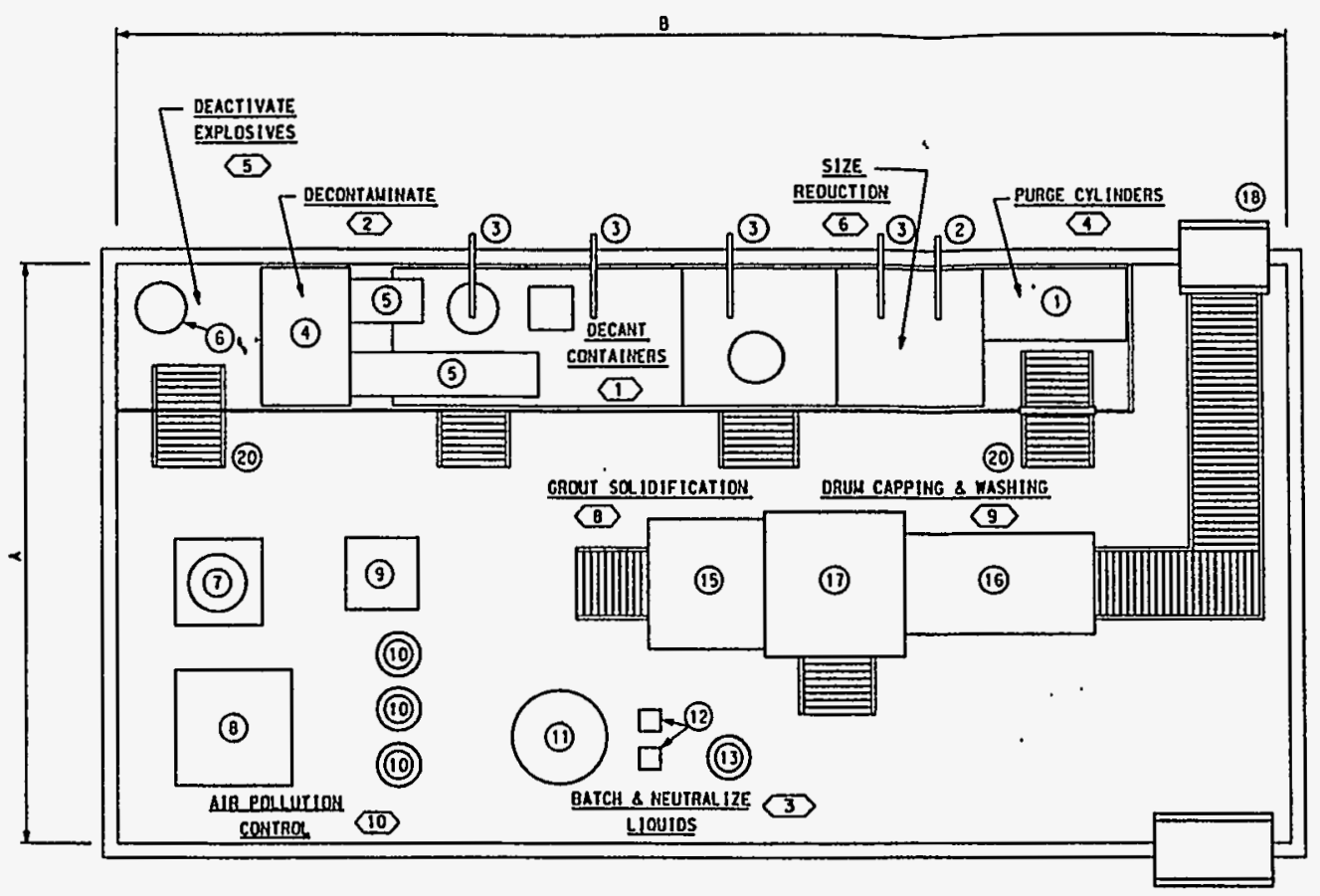

SPECIAL PROCESSING (MODULE SPECL)

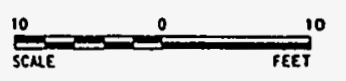

\section{EQUIPMENT LIST}

(1) CYLINOER PIERCING SYSTEM

(2) master slave manipulator

(3) hyoraulic mamipulator

(4) Decontauination godth

(5) Decontauination belt conveyon

(6) DeActivation MeLL

(7) SCRUBBer

(3) HEPA FILTERS

(9) BEPA FILTERS

(10) CARBON FILTERS

(ii) TASTE LIOUIOS BATCH TANX

(13) PUNP

(13) chemical tank

(13) OVEerhead chane *

(15) SOL IDIFICATION UNIT

(16) WASH UNIT

(ii) DRUM CAPPING UNIT

(19) AIRLOCK

(19) GANTAY ROBDT **

(20) ROLLER COHVEYOR

* Irem not visible to the viewer at this angle

\begin{tabular}{|c|c|c|c|c|}
\hline \multirow{2}{*}{ FACILITY SIZE } & \multicolumn{2}{|c|}{$\begin{array}{l}\text { OMEESION } \\
\text { OKEET } \\
\text { FEET }\end{array}$} & \multicolumn{2}{|c|}{$\begin{array}{l}\text { OINENSION } \\
\text { IN KETERS }\end{array}$} \\
\hline & $A$ & 8 & $A$ & 8 \\
\hline SHALL & 30 & 63 & 9.2 & 19.2 \\
\hline MEOLUM & 50 & 89 & 15.3 & 27.2 \\
\hline LARGE & 70 & 90 & 21.4 & 27.5 \\
\hline
\end{tabular}

Figure 9-1. Equipment layout for the special waste processing (SPECL) module. 


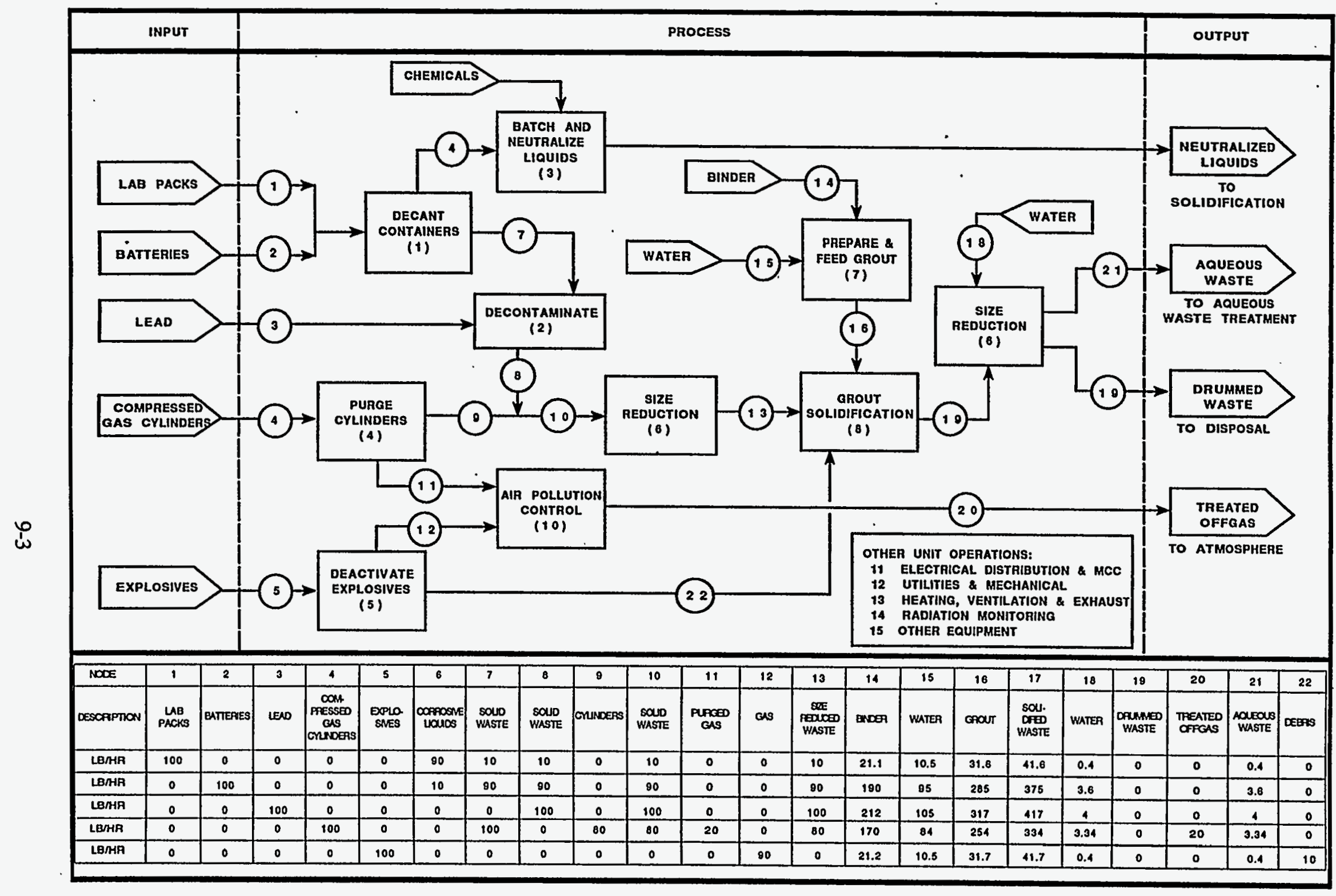

Figure 9-2. Process flow diagram for the special waste processing (SPECL) module. 


\section{SPECIAL WASTE PROCESSING}

FTE by Work Breakdown Structure Element

Module: SPECL Waste Type: Alpha, Nonalpha, and Remote Handled LLW

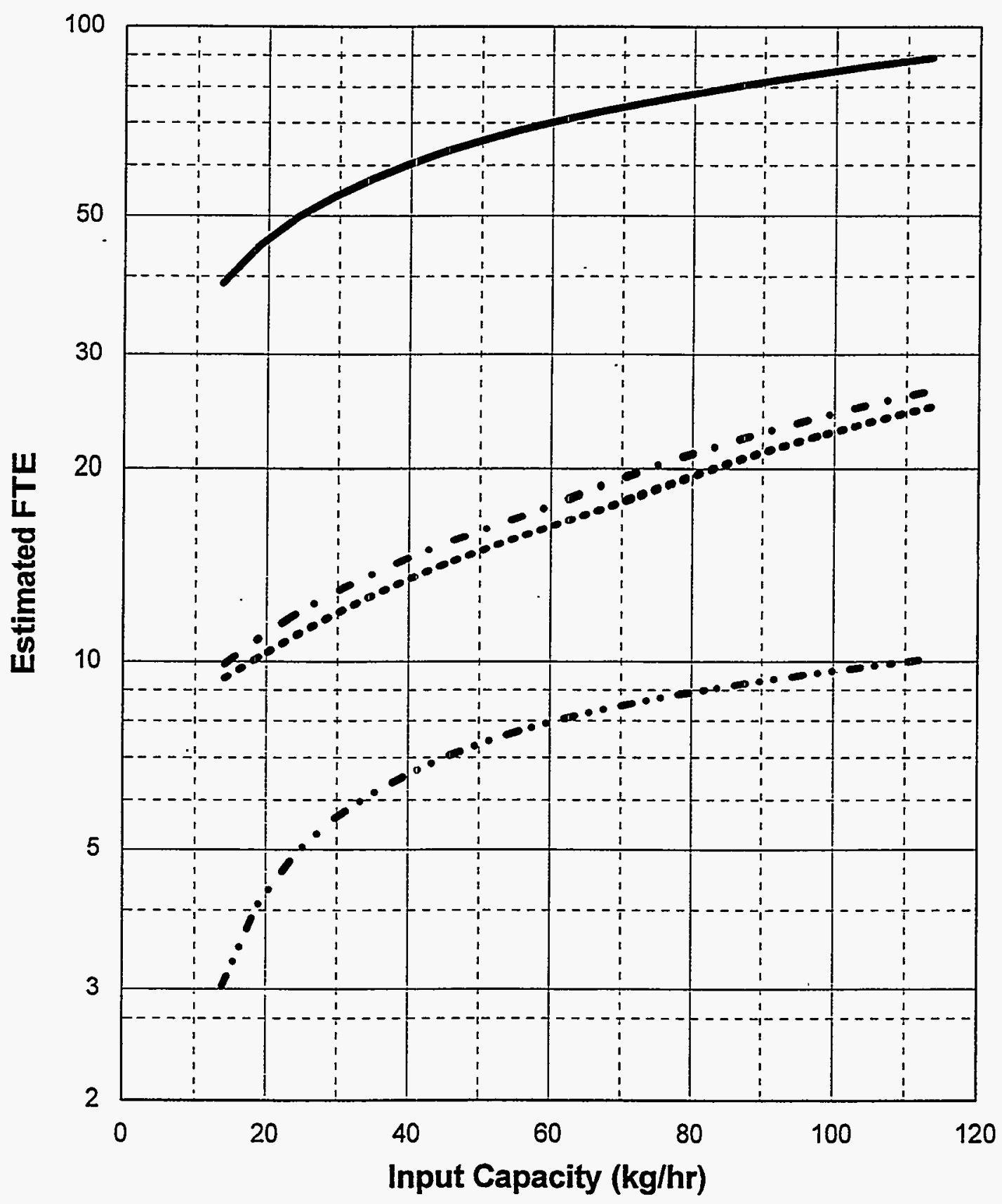

Pre-Operations Construction O\&M (1year) D\&D
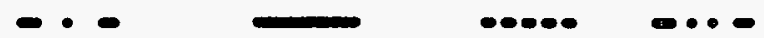

Figure 9-3. FTE workers versus capacity for the special waste processing (SPECL) module. 


\section{SPECIAL WASTE PROCESSING}

Costs by Work Breakdown Structure Element

Module: SPECL Waste Type: Alpha, Nonalpha, and Remote Handled LLW

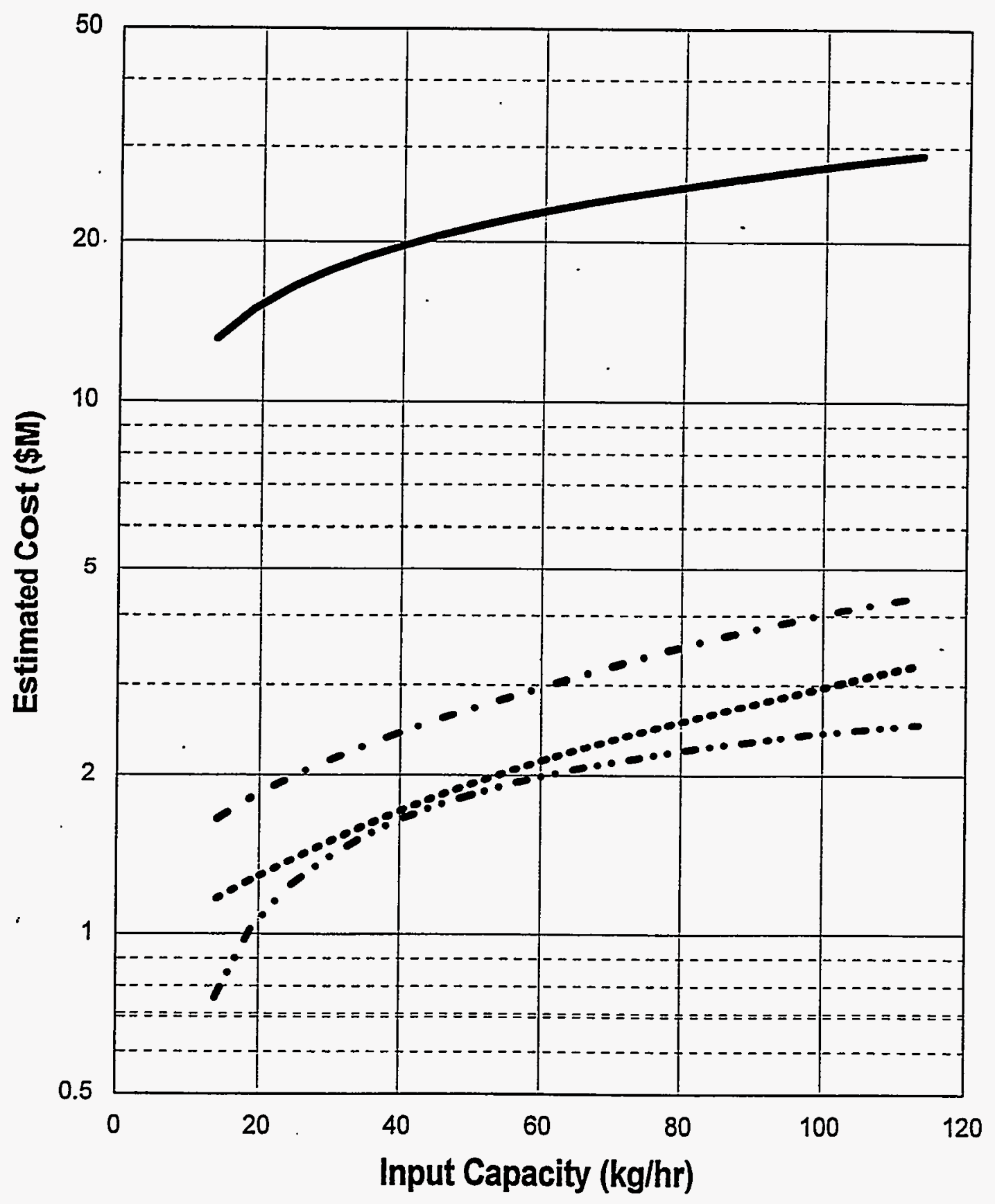

Pre-Operations Construction O\&M (1year) D\&D

Figure 9-4. PLCC versus capacity for the special waste processing (SPECL) module. 
SPECIAL WASTE PROCESSING

Total Life Cycle Costs

Module: SPECL Waste Type: Alpha, Nonalpha, and Remote Handled LLW

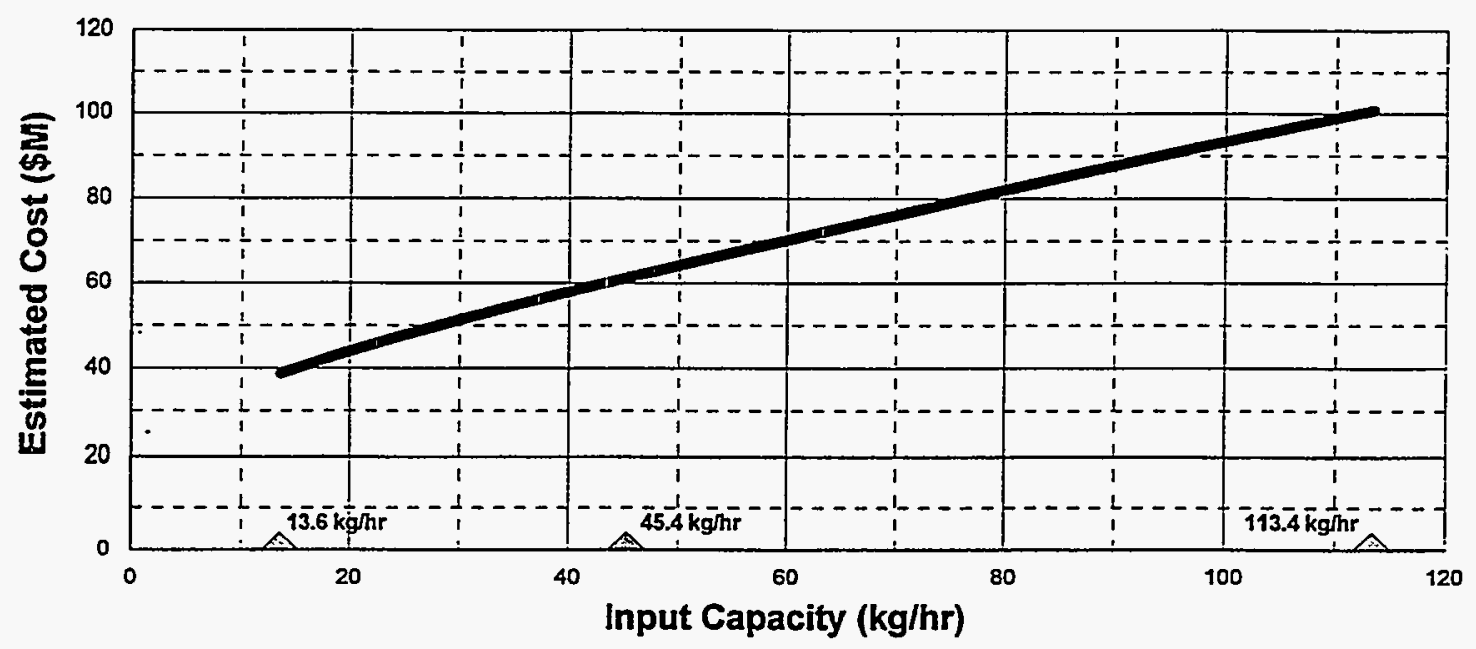

Alpha, Nonalpha, Remote Handled

NOTE: Basis includes 20 years O\&M

Triangles indicate capacities where detailed cost estimates were developed.

\section{SPECIAL WASTE PROCESSING}

Total Life Cycle Unit Costs

Module: SPECL Waste Type: Alpha, Nonalpha, and Remote Handled LLW

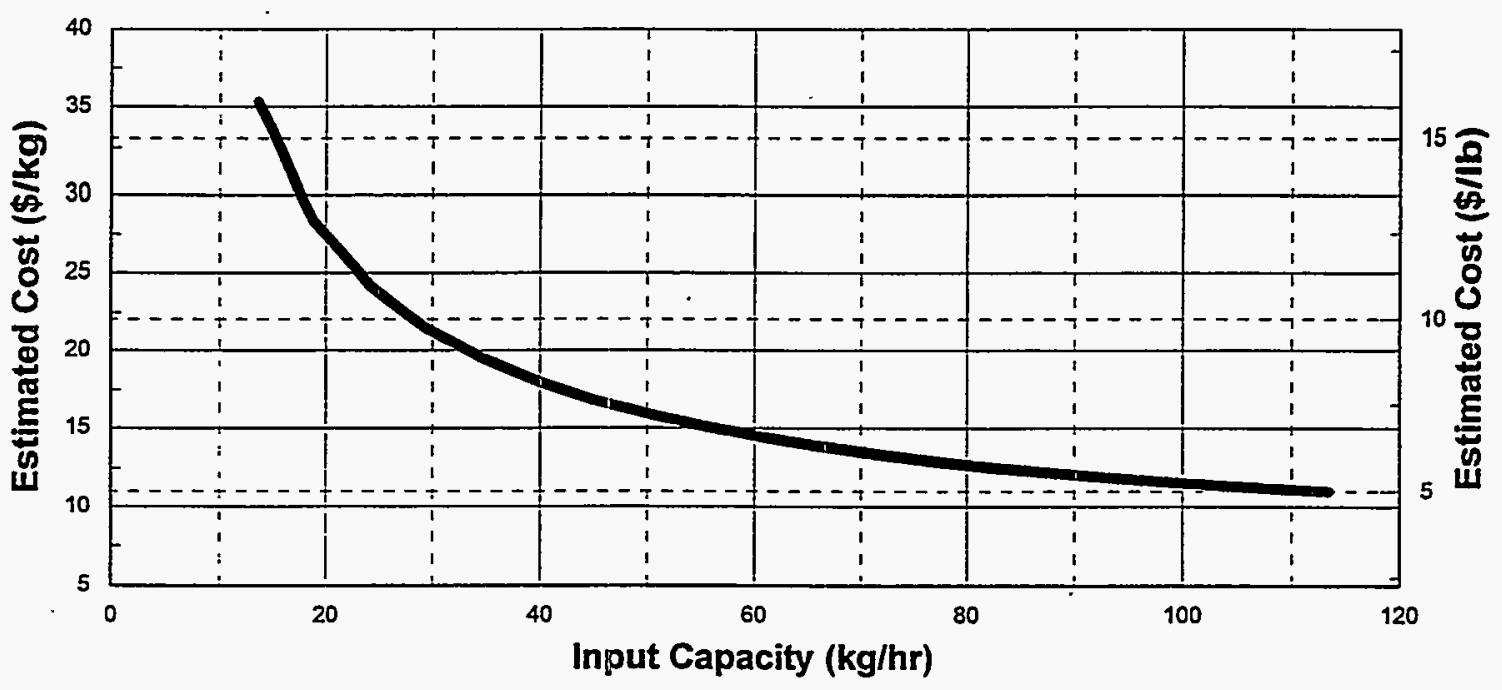

Alpha, Nonalpha, Remote Handled

NOTE: Basis indudes 20 years O\&M

Figure 9-5. PLCC versus capacity including unit rates for the special waste processing (SPECL) module. 


\section{METAL SIZING/DECONTAMINATION FACILITY (MODULE DECON)}

\subsection{Basic Information}

The metal sizing and decontamination large generator facility shown in Figure 10-1, consists of 14 unit operations that are used to pretreat, reduce the size, decontaminate, and package the incoming contaminated bulk metals, loose metals, and empty metal containers. Figure 10-2 shows the equipment layout for the portable, small-, and medium-sized facility. The facility decontaminates LLW/MLLW waste metals to radiation levels acceptable for recycling or disposal in shallow land disposal facilities. The facility must be used in conjunction with either the receiving, preparation, and shipping facility, or must be constructed adjacent to existing facilities where similar functions are already in place. Module DECON is applicable to nonalpha, alpha, and RH waste. Unit operations that accomplish the general functions are shown in Figure 10-3.

\subsection{Technical Bases and Assumptions}

\subsubsection{Function and Operation of the Module}

10.2.1.1 Small, Medium, and Large Facilities. At the facility, the drums are transferred to a pretreatment unit operation that receives the bulk metals and places them in a shielded staging area. Using remote-handling techniques, the bulk metal is cleaned using a high-pressure rinse to remove debris, soil, and other loose contamination. The cleaned waste is then transferred to either a size reduction unit operation or to a metal decontamination unit operation.

At the size reduction unit operation, the material is cut to the desired size. The size reduction unit operation also treats any air containing fugitive dust from shredding and related operations. The size-reduced metals are conveyed via a transfer device to the inspection unit operation. The inspection unit operation is used to identify whether materials have entrained contamination and/or surface contamination. Following the inspection unit operation, the contaminated metals are directed to the appropriate decontamination process in the decontamination unit operation.

The decontamination unit employs chemical and physical decontamination techniques to remove surface and entrained contamination. For surface contamination, abrasive blasting, grinding, and other mechanical techniques are used. For entrained contamination, electro-polishing and acid etching are used.

After decontamination, the material is transferred to the inspect and assay unit operation. This unit operation assays decontaminated metals to ensure that all land disposal restriction controlled components are removed. Metals requiring additional decontamination are returned to the decontamination unit. The assayed materials are placed in 55-gal drums and sent to the compaction and packaging unit operation.

At the compaction and packaging unit operation, a lift device places the filled drums onto press conveyors. The operator selects a drum from one of the conveyors and feeds it to the press through an airlock located in the press negative pressure environmental chamber. A device pierces the drum 
to release any gases that might be trapped in the drum into the confined chamber. A high-pressure compactor (supercompactor) compresses the drum and transfers it to a staging conveyor (or turntable). A lift device picks up the compressed drum and places it into one of several overpacks located on an adjacent conveyor. After each overpack is filled the operator feeds it first to a grouting station and then to a seaming machine where a cap is placed on the overpack and seamed. The operator moves the sealed overpack to a drum washing unit where high-pressure water spray jets remove any loose contamination from the outside surface of the overpack. Any liquid generated during the press operation is directed to a sump and sent to the liquid waste treatment unit operation.

Any liquid produced from the decontamination unit operation is collected and pumped to the liquid waste treatment unit operation, which reduces the volume and detoxifies the waste to meet output criteria. A combination of evaporation, precipitation, filtration, and centrifuge treatment methods are used. The treated clean liquid is received in the decontamination unit operation, and the sludge material is solidified and packaged in the solidification unit operation.

In the solidification unit operation, the waste is mixed with a binder (such as Portland cement) and packaged into disposal containers. The unit operation has remotely operated devices needed for accepting the incoming waste, mixing it with the binder, and packaging the mixture in disposal containers.

After proper mixing, the drum is remotely moved to a capping and washing unit operation. After capping, lose contamination is removed from the container's outer surface by high-pressure spray water jets. This unit operation also provides for solidified matrix sample collection. The containerized waste is transported to the receiving, inspection, and shipping facility.

The anticipated density of the compacted waste is about $3,204 \mathrm{~kg} / \mathrm{m}^{3}\left(200 \mathrm{lb} / \mathrm{ft}^{3}\right)$. The solidified waste density is $1,794 \mathrm{~kg} / \mathrm{m}^{3}\left(112 \mathrm{lb} / \mathrm{ft}^{3}\right)$.

10.2.1.2 Portable Facility. The functional and operational requirements for the minimum facility are identical to the requirements for large, medium and small facilities. The exceptions are as follows:

- Major process equipments are skid mounted, and unit operations are transportable

- Primary and secondary waste processing including feed preparation, decontamination, liquid waste treatment, and solidification are conducted in a single cell.

\subsubsection{Facility Integration}

The facility receives metal waste from the receiving and inspection (RCINS) module. The four major output waste types from this facility include compacted metals, recyclable/reusable metals, and solidified waste in 55-gal drums. The output of this facility is sent to the receiving, preparation, and shipping facility. Any offgas generated is treated and discharged to the atmosphere. Operation and maintenance consumables including empty containers, solidification binder, and personal protective equipment are purchased. 


\subsection{Cost Summaries}

Estimated FTEs and cost versus capacity for this module are shown in Figures 10-4 through 10-10. Costs and FTEs for the small generator facility are shown in Tables 10-1 and 10-2. Costs for the portable metal sizing/decontamination module are $\$ 191,000$ per campaign. Each campaign will require approximately one FTE and will process $2.5 \mathrm{~m}^{3}\left(88.3 \mathrm{ft}^{3}\right)$ of waste. 
Table 10-1. FTE workers for the small generator metal sizing and decontamination module.

\begin{tabular}{lcc}
\hline & \multicolumn{2}{c}{ Type of module } \\
\cline { 2 - 3 } \multicolumn{1}{c}{ Cost element } & $\begin{array}{c}\text { Fixed, in new } \\
\text { building(s) }\end{array}$ & $\begin{array}{c}\text { Fixed, in existing } \\
\text { building(s) }\end{array}$ \\
\hline (1.0) Preoperations & 3 & 3 \\
(2.0) Construction & 20 & 15 \\
(3.0) O\&M (20 years) & 56 & 56 \\
(4.0) D\&D & 2 & 2 \\
All cost elements (total for 20 years O\&M) & 81 & 76 \\
\hline
\end{tabular}

Table 10-2. PLCC $(\$ 1,000)$ for the small generator metal sizing and decontamination module.

\begin{tabular}{lcc}
\hline & \multicolumn{2}{c}{ Type of module } \\
\cline { 2 - 3 } \multicolumn{1}{c}{ Cost element } & $\begin{array}{c}\text { Fixed, in new } \\
\text { building(s) }\end{array}$ & $\begin{array}{c}\text { Fixed, in existing } \\
\text { building(s) }\end{array}$ \\
\hline (1.0) Preoperations & 433 & 414 \\
(2.0) Construction & 5,304 & 4,145 \\
(3.0) O\&M (20 years) & 6,280 & 6,280 \\
(4.0) D\&D & 574 & 574 \\
All cost elements (total for 20 years O\&M) & 12,591 & 11,413 \\
\hline
\end{tabular}




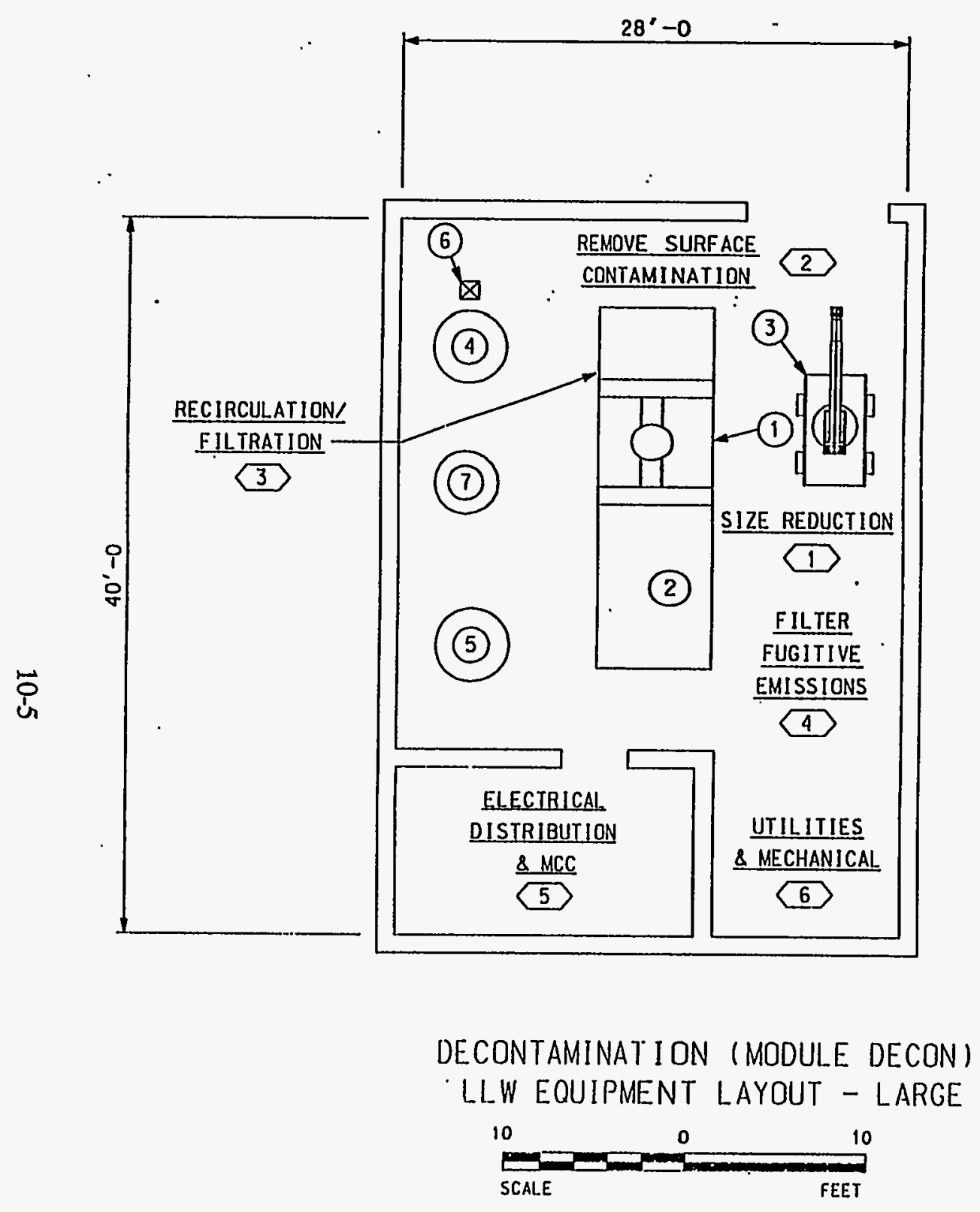




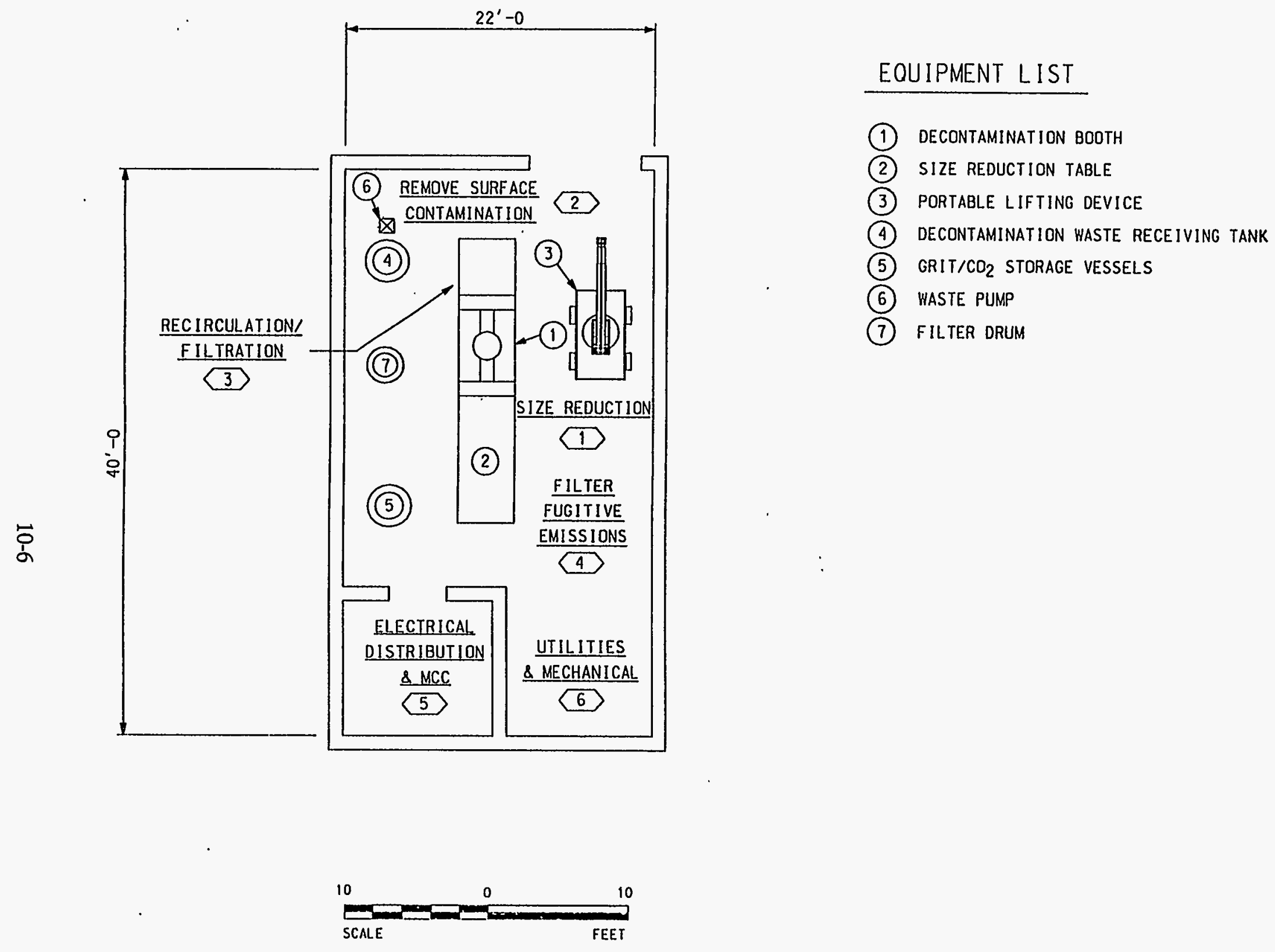

Figure 10-2. Equipment layout for portable, small-, and medium-sized metal sizing/decontamination (DECON) module. 


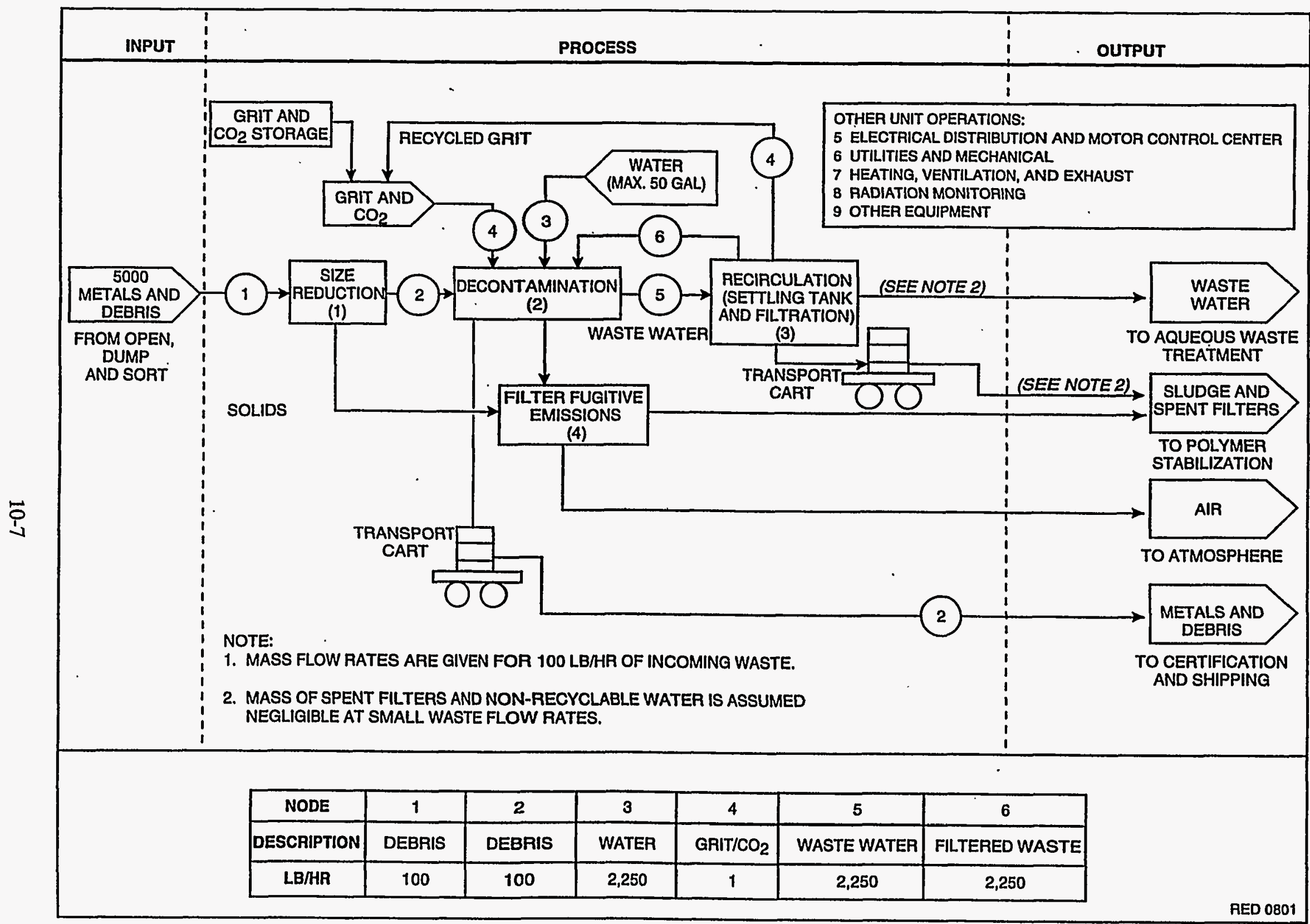

Figure 10-3. Process flow diagram for the metal sizing/decontamination (DECON) module. 


\section{METAL SIZING/DECONTAMINATIONN}

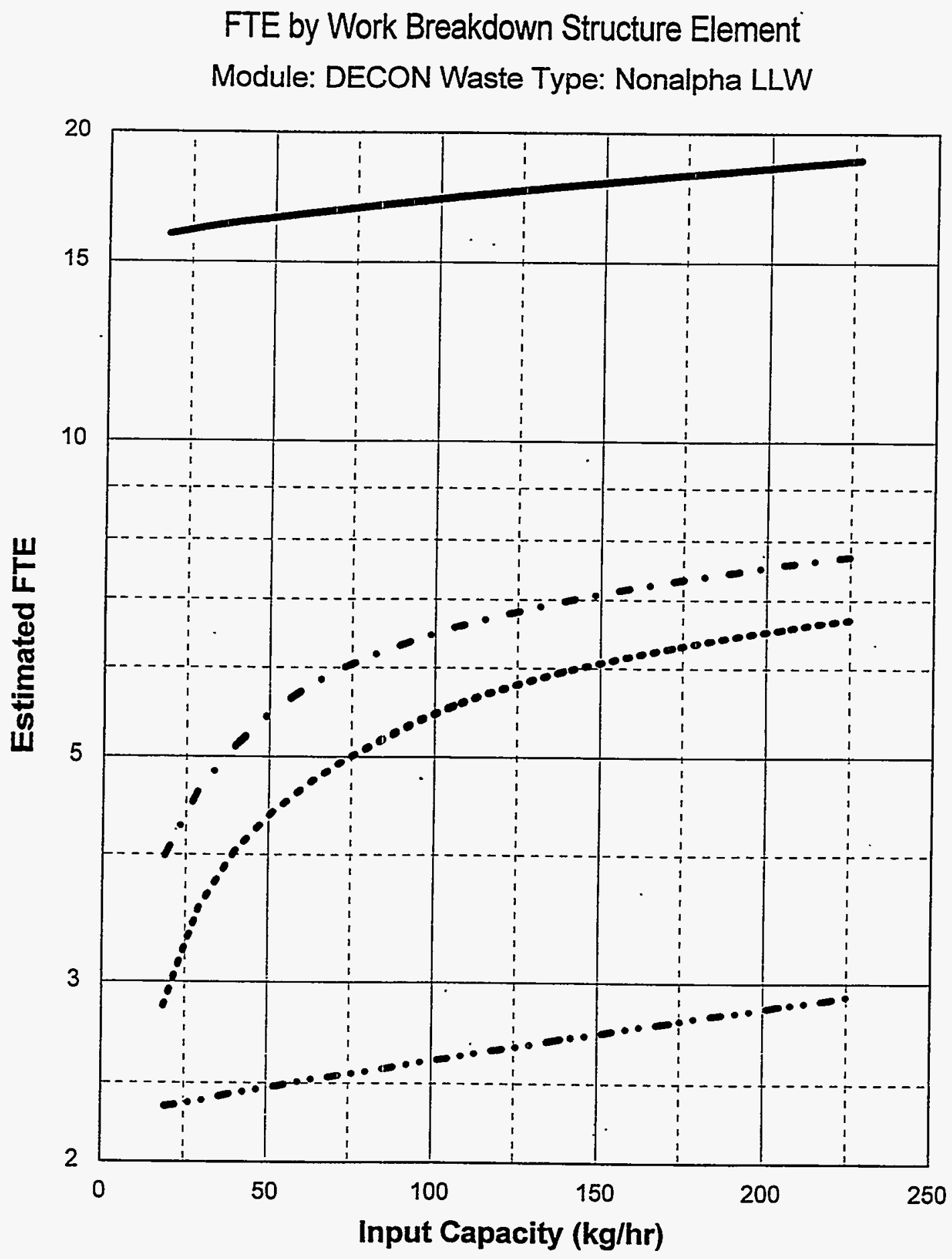

Pre-Operations Construction O\&M (1year) D\&D

Figure 10-4. FTE workers versus capacity for the nonalpha metal sizing/decontamination (B-DECON) module. 


\section{METAL SIZING/DECONTAMINATION}

FTE by Work Breakdown Structure Element Module: DECON Waste Type: Alpha LLW

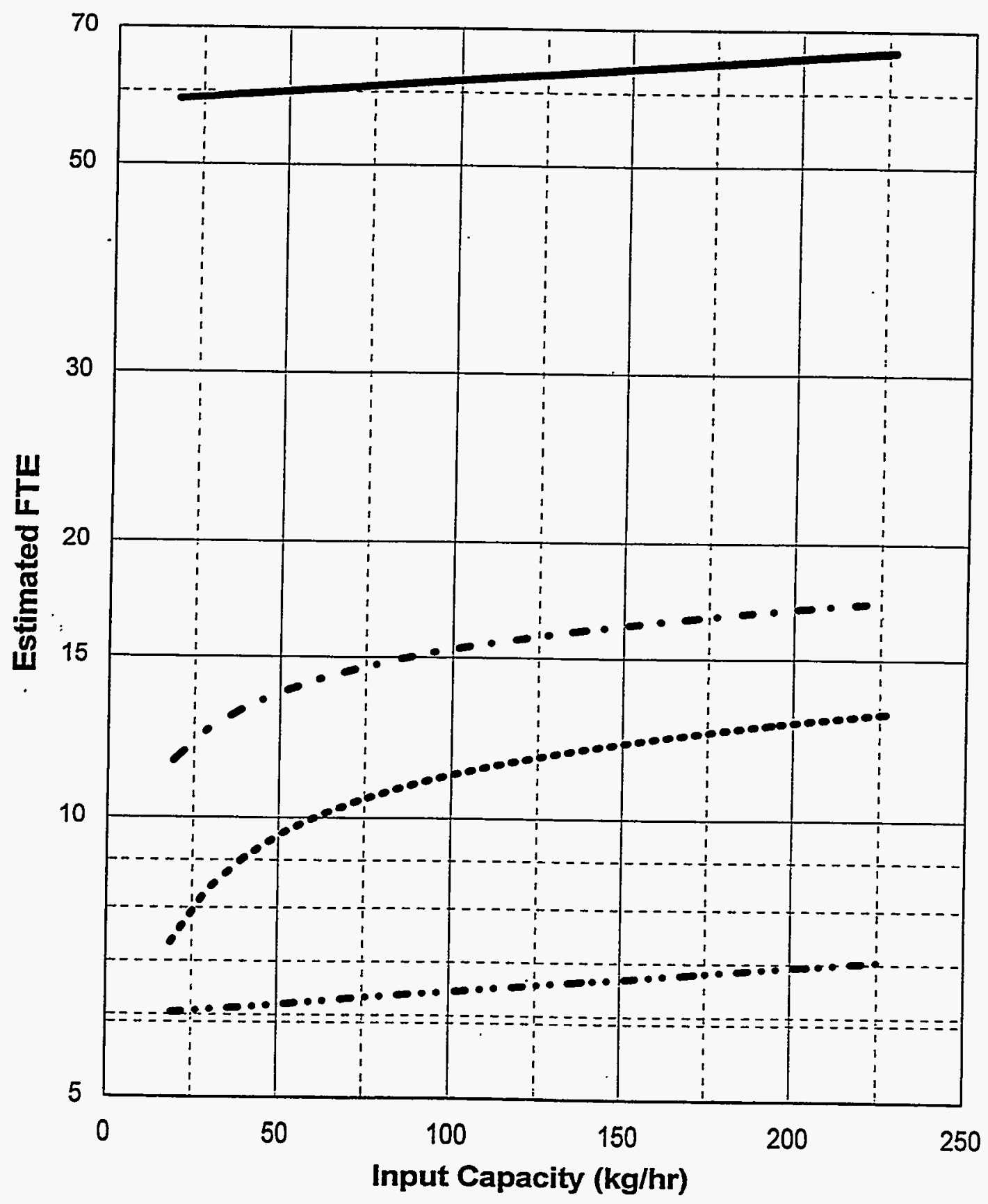

Pre-Operations Construction O\&M (1year) D\&D

Figure 10-5. FTE workers versus capacity for the alpha metal sizing/decontamination (A-DECON) module. 


\section{METAL SIZING/DECONTAMINATION}

FTE by Work Breakdown Structure Element Module: DECON Waste Type: Remote Handled LLW

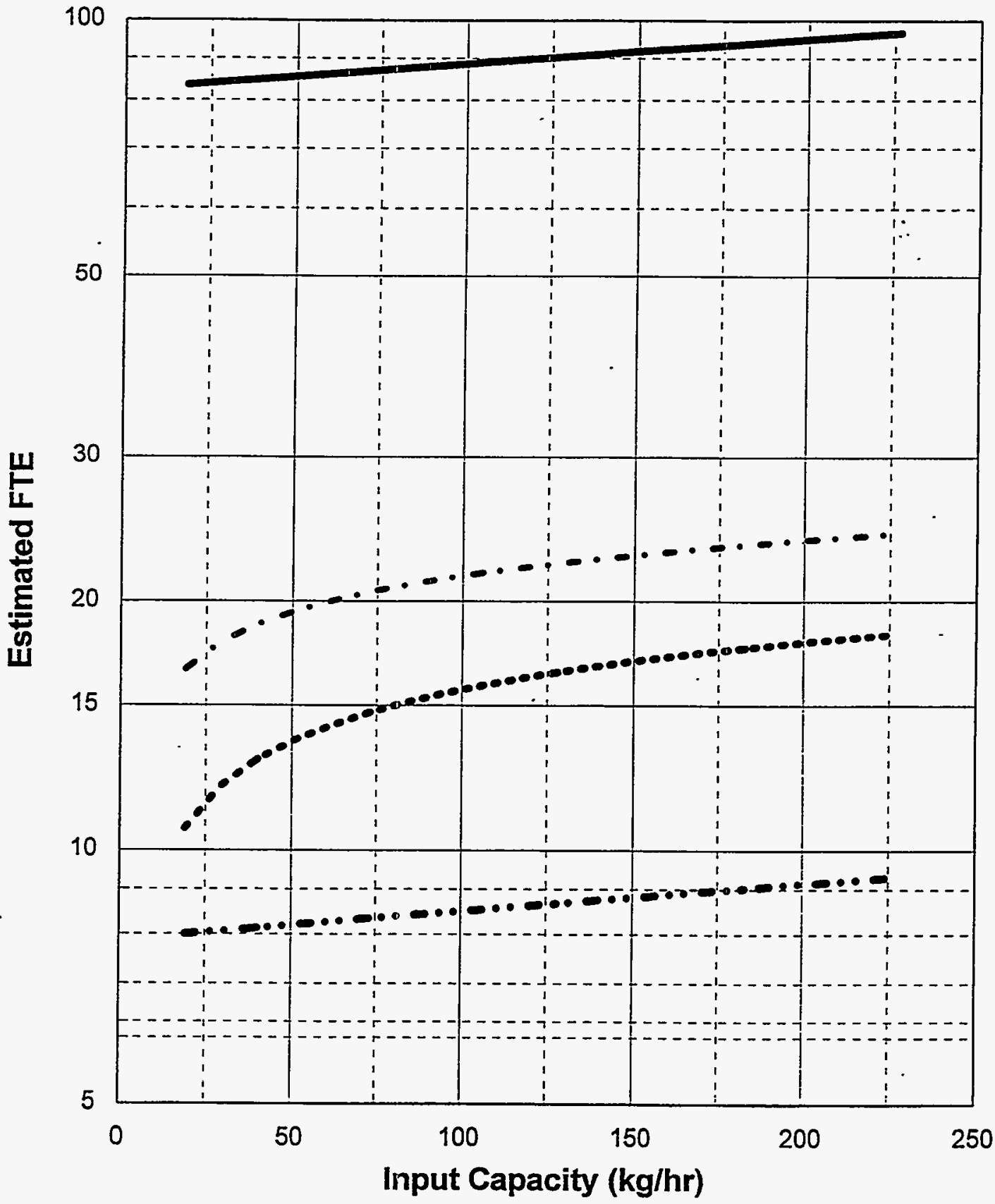

Pre-Operations Construction O\&M (1year) D\&D

Figure 10-6. FTE workers versus capacity for the RH metal sizing/decontamination (R-DECON) module. 


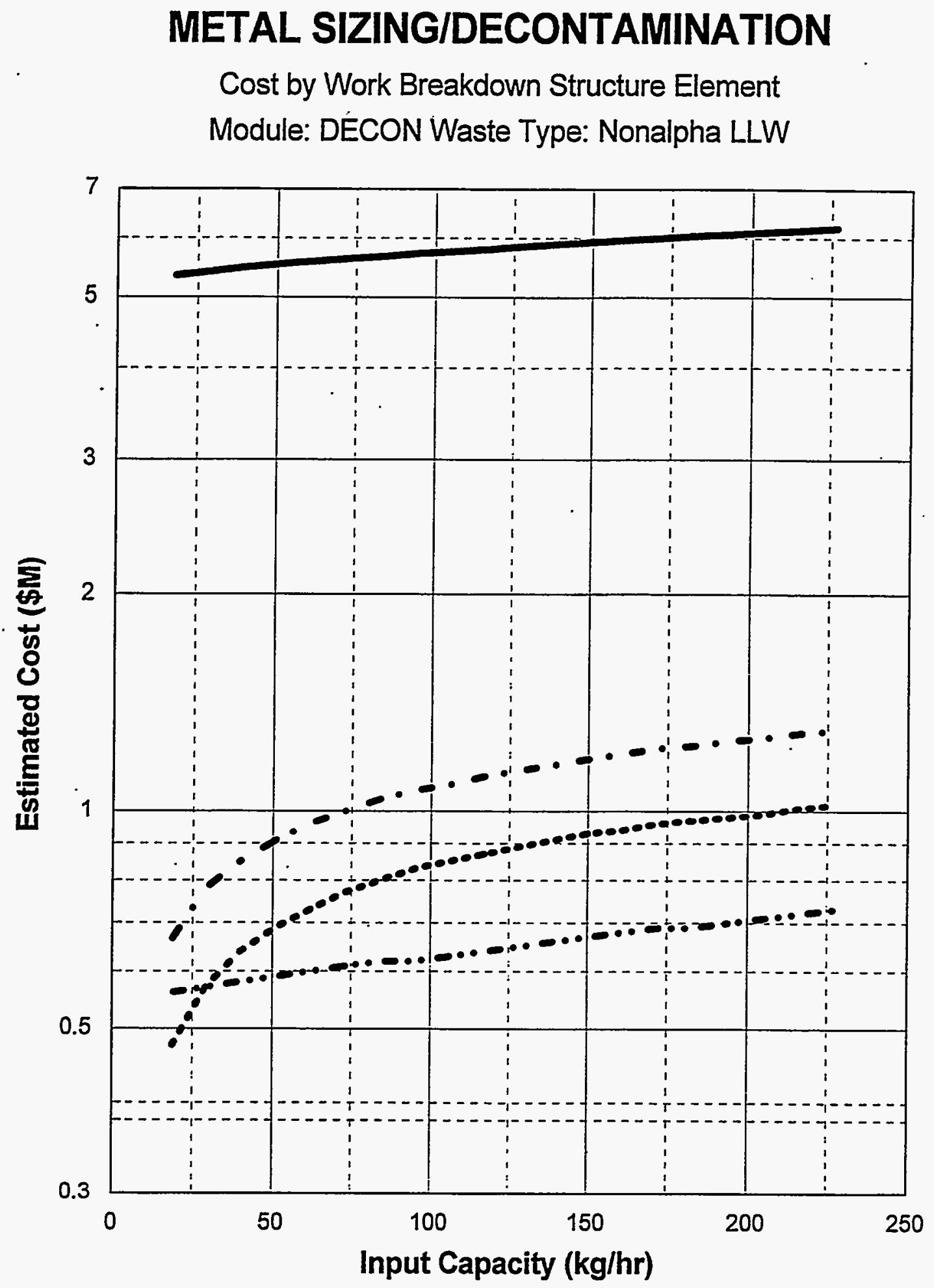

Pre-Operations Construction O\&M (1year) D\&D

Figure 10-7. PLCC versus capacity for the nonalpha metal sizing/decontamination (B-DECON) module. 


\section{METAL SIŻING/DECONTAMINATION}

Cost by Work Breakdown Structure Element Module: DECON Waste Type: Alpha LLW

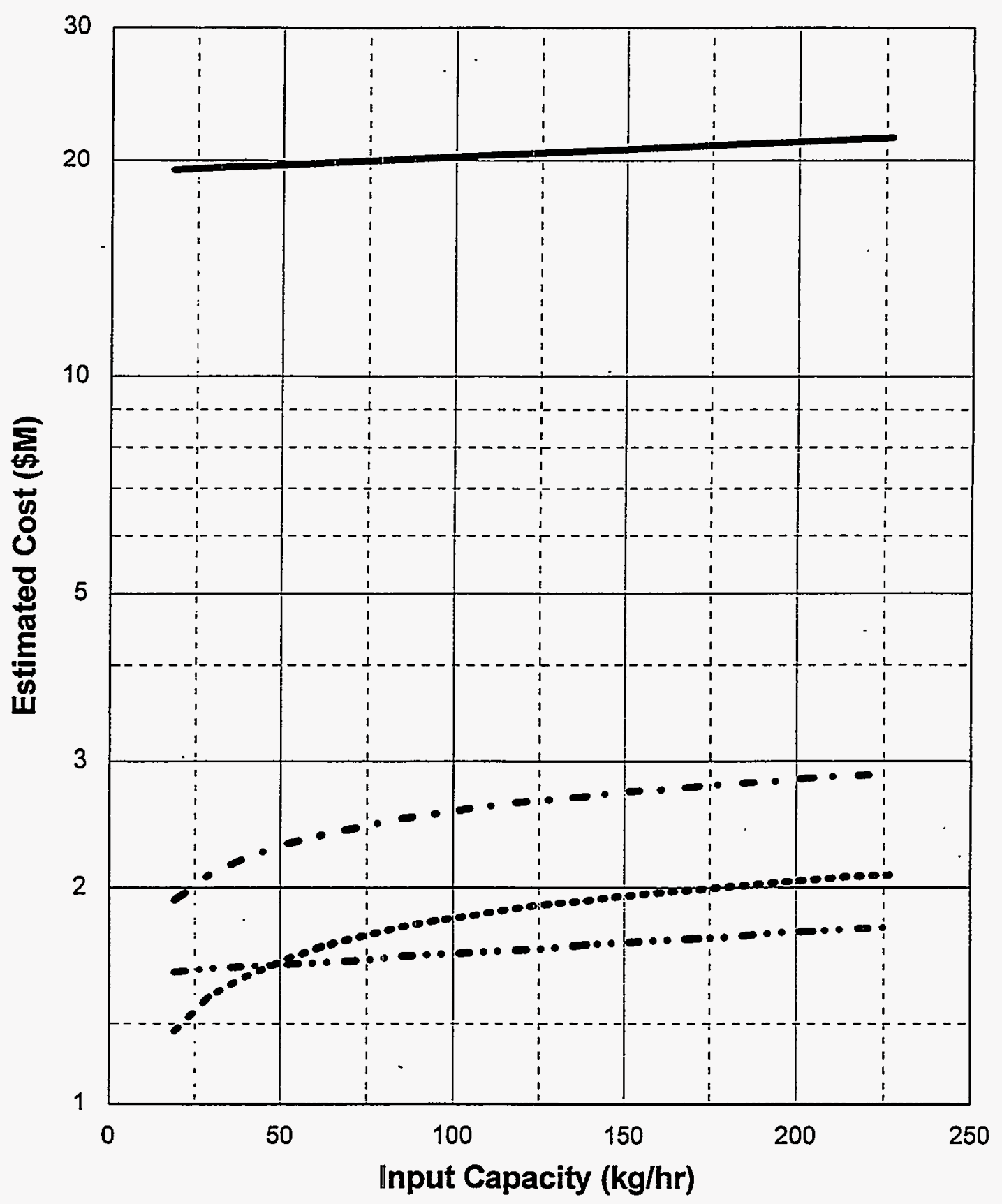

Pre-Operations Construction O\&M (1year) D\&D

Figure 10-8. PLCC versus capacity for the alpha metal sizing/decontamination (A-DECON) module. 


\section{METAL SIZING/DECONTAMINATION}

Cost by Work Breakdown Structure Element Module: DECON Waste Type: Remote Handled LLW

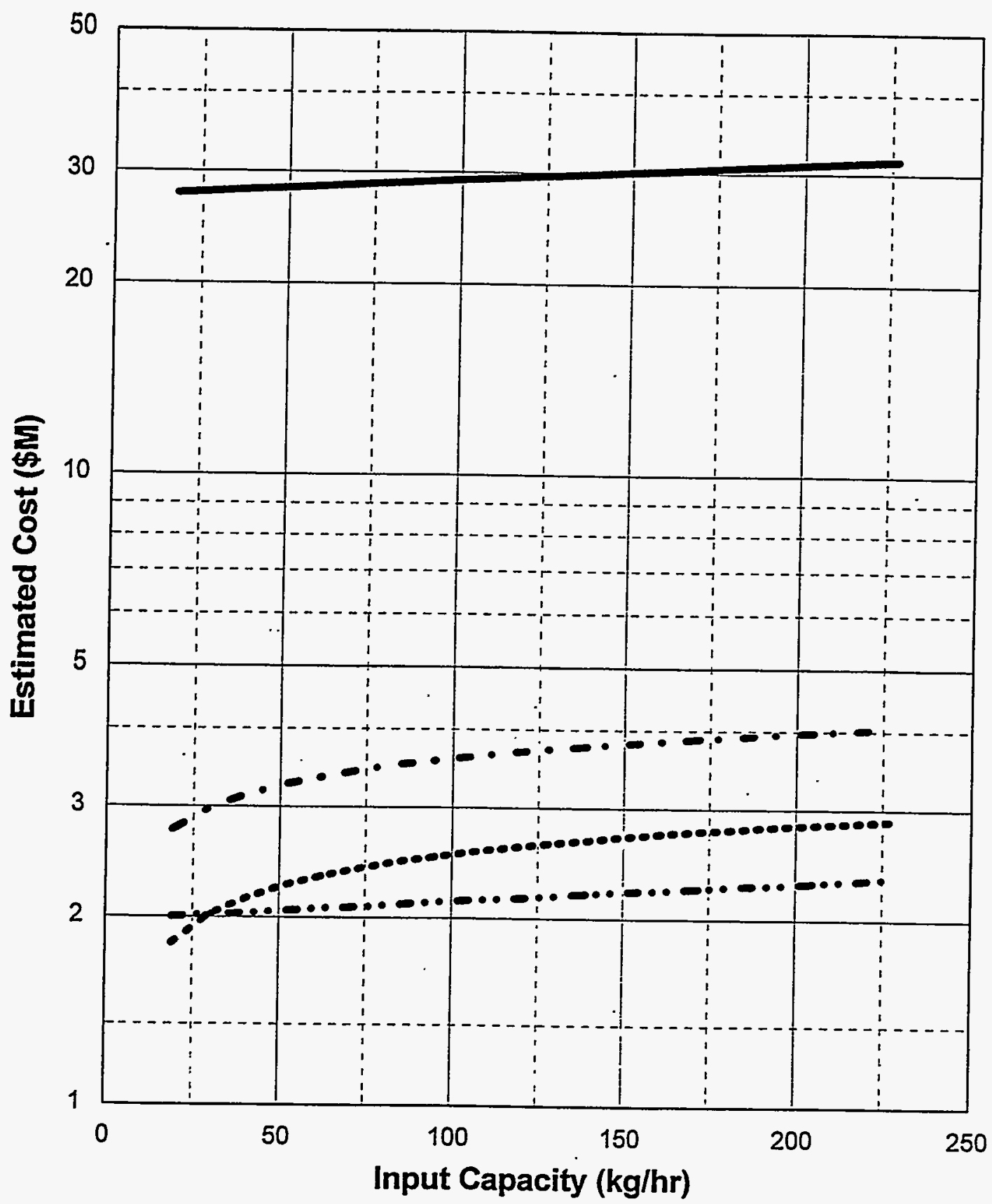

Pre-Operations Construction O\&M (1year) D\&D

Figure 10-9. PLCC versus capacity for the RH metal sizing/decontamination (R-DECON) module. 


\section{METALSIZING/DECONTAMINATION}

Total Life Cycle Costs

Module: DECON Waste Type: Alpha, Nonalpha, and Remote Handled LLW

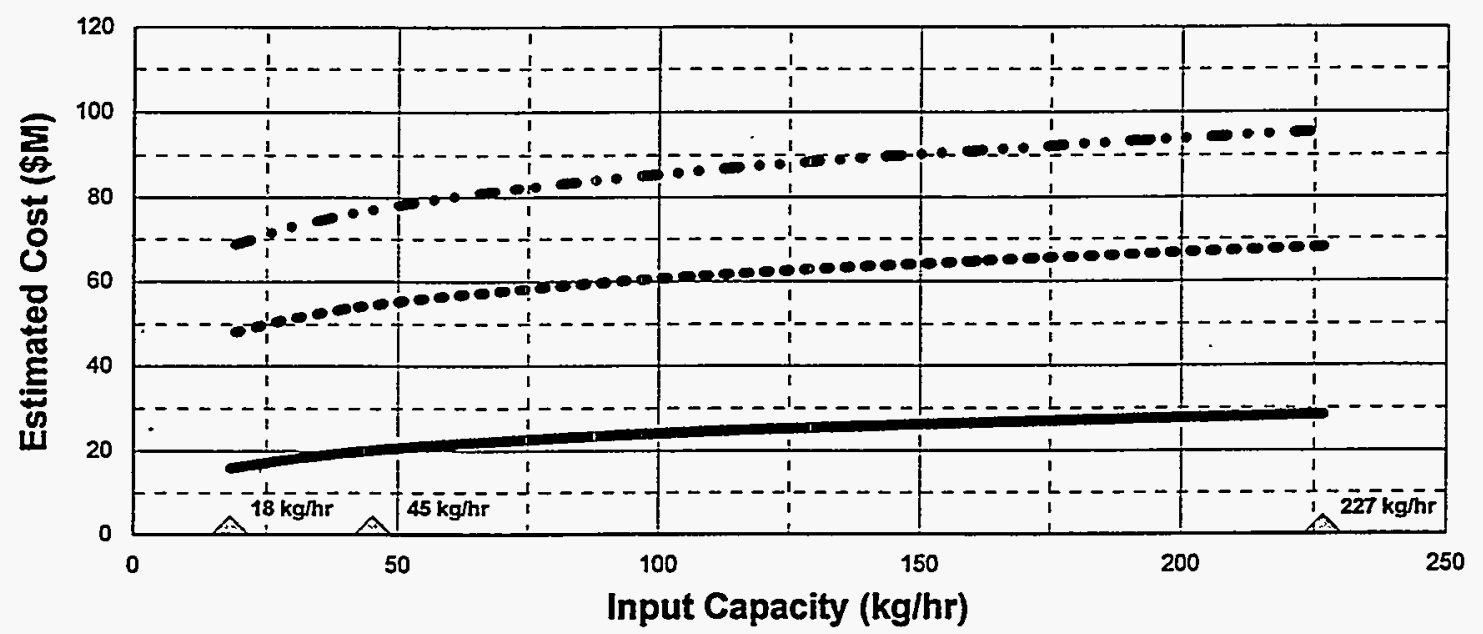

Nonalpha Alpha Remote Handled

NOTE: Basis includes 20 years O\&M

Triangles indicate capacities where detailed cost estimates were developed.

\section{METAL SIZINGIDECONTAMINATION}

Total Life Cycle Unit Costs

Module: DECON Waste Type: Alpha, Nonalpha, Remote Handled LLW

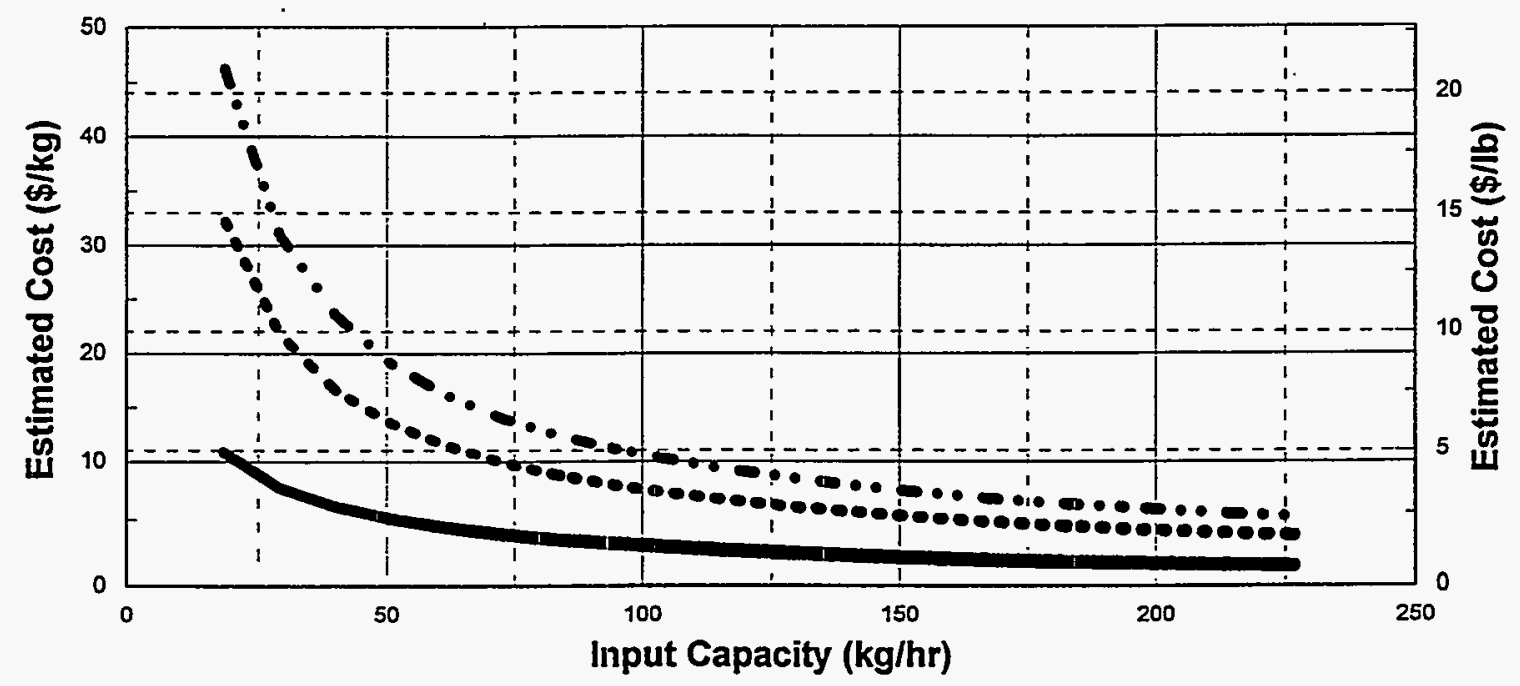

Nonalpha Alpha Remote Handled

NOTE: Basis indudes 20 years O\&M

Figure 10-10. PLCC versus capacity including unit rates for the metal sizing/decontamination (DECON) module. 


\section{NEUTRALIZATION (MODULE NEUTR)}

\subsection{Basic Information}

The neutralization module, shown in Figure 11-1, must be either used in conjunction with the receiving-and-inspection (RCINS or FBSPT) module and stabilization (GROUT) module or installed at a location where similar functions are available. The neutralization module collects and treats input aqueous waste that is corrosive ( $\mathrm{pH}$ below 2.0 or above 10.0 ) or contains inorganic compounds requiring destruction. The corrosive aqueous waste is received at the module in cans, drums, or special transport containers having several different capacities. In addition to treating input aqueous waste, this module treats secondary aqueous waste from the treatment facility, such as from floor drains, equipment drains, and chemical processes. The module has a number of unit operations that accomplish the required functions. Module NEUTR is applicable to nonalpha, alpha, and RH waste. Unit operations are shown in the PFD in Figure 11-2.

\subsection{Technical Bases and Assumptions}

\subsubsection{Function and Operation of the Module}

The neutralization module has all the unit operations needed for treating (neutralizing) incoming liquid waste having a range of non-Resource Conservation and Recovery Act (RCRA)-controlled inorganic contaminants. The unit operations also have the capability to treat secondary liquid waste generated by the waste treatment facility, such as distillate from air pollution control (module INCIN), rinse water from container washdown operations (modules RCINS and PLYMR), and liquid collected from the module equipment and floor drains.

The incoming liquid waste is precharacterized before it is brought to the treatment modules. For bulk operations, the incoming waste is segregated into different groups: liquid with a low $\mathrm{pH}$, liquid with a high $\mathrm{pH}$, and liquid that requires destruction of various inorganic compounds.

The neutralization unit operations have maximum flexibility and can be used in series, in parallel or as stand-alone units. Flexible piping connectors are provided at the iniet and outlet of each treatment device. The waste is transferred from the transport container to appropriate batch tanks or directly to a desired treatment unit operation.

Typical steps for treating bulk quantities of the three waste categories are as follows (refer to Figure 11-2):

Low pH waste. Waste having a low $\mathrm{pH}$ and requiring no treatment other than neutralization is treated with a basic neutralizer compound. Any solids generated are removed by filtration and the aqueous stream is sent for concentration. 
High $\mathbf{p H}$ waste. Waste high in $\mathrm{pH}$ is processed through the neutralization module by adding acidic neutralizer compounds. The final treatment $\mathrm{pH}$ selected is dependent on the type of compounds in the stream and the removal criteria. Any sludge generated from the neutralization process is removed and sent to stabilization. Supernate from the neutralization is sent to concentration.

Inorganic wastes. Waste containing only inorganic compounds requiring destruction are treated by reacting these compounds with various compounds that will convert the toxic compounds into nontoxic or less-toxic compounds. The resulting treated stream is then filtered and the supernate sent to concentration.

\subsubsection{Integration of the Module}

Input waste to the neutralization module comes from the receiving and inspection module or from onsite waste generators. This input waste has been precharacterized. Other input includes secondary waste from incineration, decontamination, and stabilization modules. Output from the neutralization module to the stabilization module includes spent resins, spent carbon, slight amounts of sludge, and the neutral aqueous stream. Materials purchased for O\&M, such as personal protective equipment, ion exchange resins, activated carbon, chemicals and containers are assumed to be consumable supplies, and their costs are estimated accordingly.

\subsection{Cost Bases, Assumptions, and Results}

Input wastes are assumed to be properly characterized to allow a trained operator to anticipate the critical nature of an input, treated, or output stream. The neutralization unit, ion exchange, spent carbon units, filters, and radiation monitors constitute the major equipment capital items. Their costs are based on prices submitted by various vendors. Operating manpower for the module is based on a batch operation with close monitoring of the treatment process at all times.

Estimated FTE and cost versus capacity for this module are shown in Figures 11-3 through 11-9. 


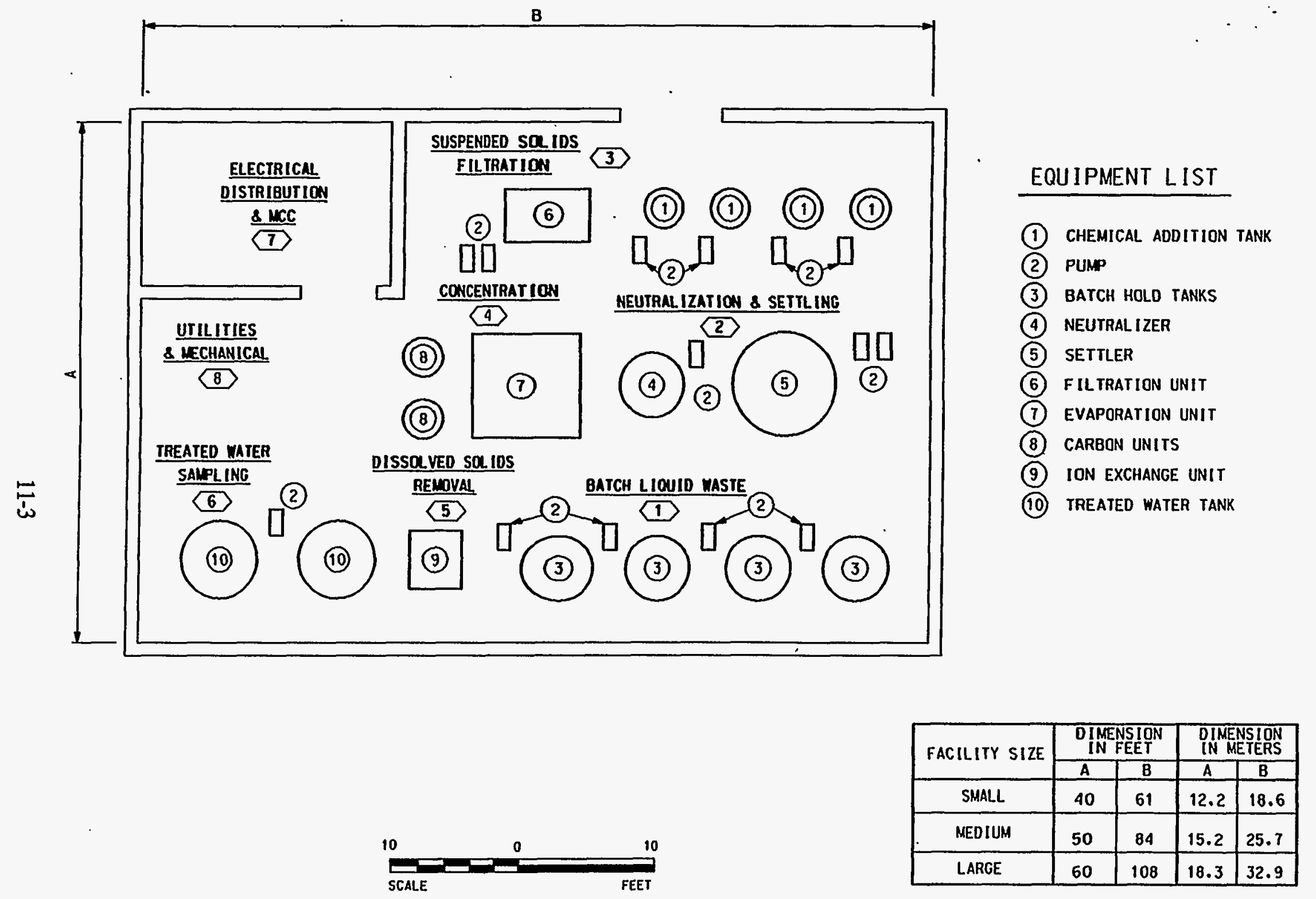

Figure 11-1. Equipment layout for the neutralization (NEUTR) module. 


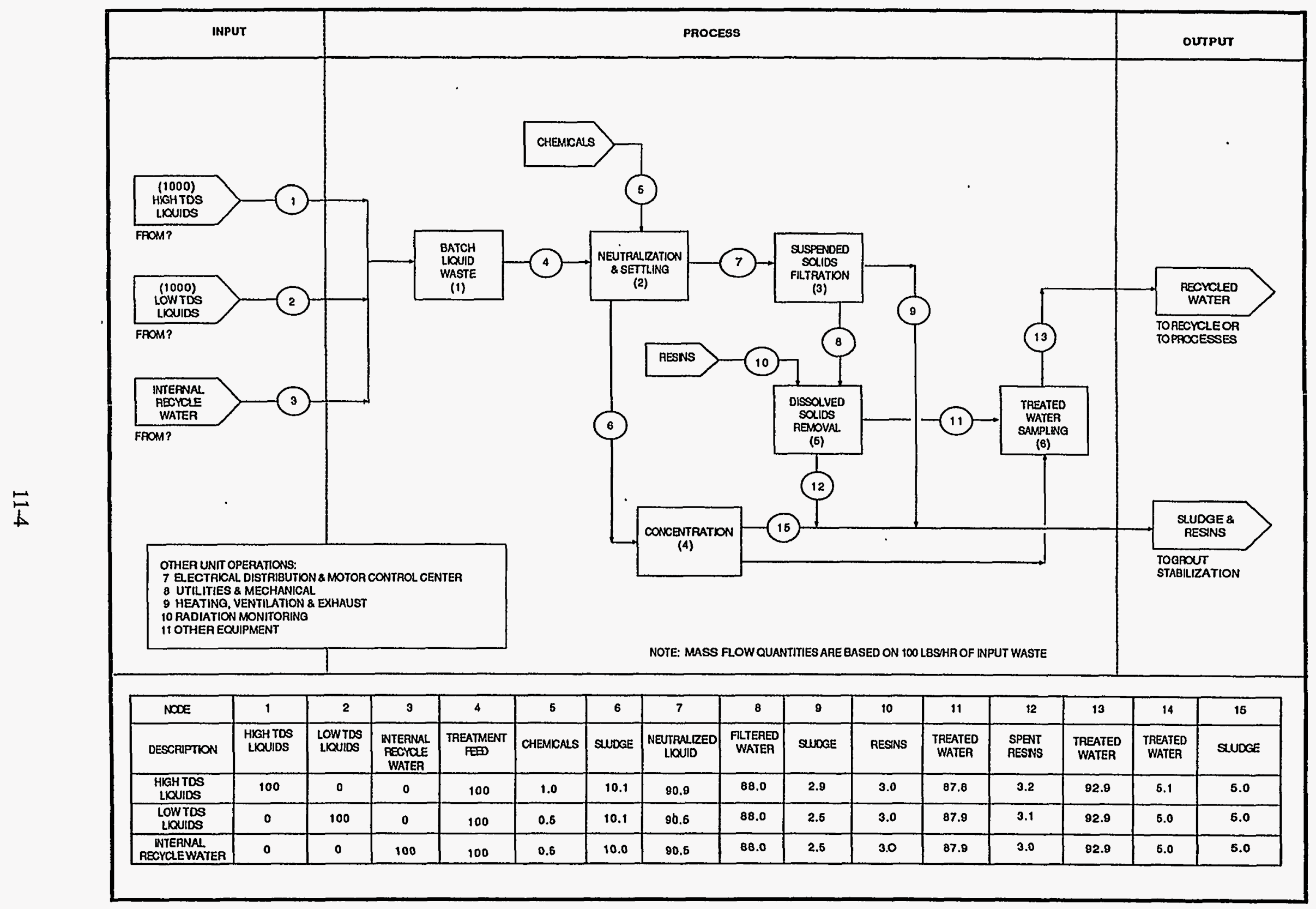

Figure 11-2. Process flow diagram for the neutralization (NEUTR) module. 


\section{NEUTRALIZATION}

FTE by Work Breakdown Structure Element

Module: NEUTR Waste Type: Nonalpha LLW

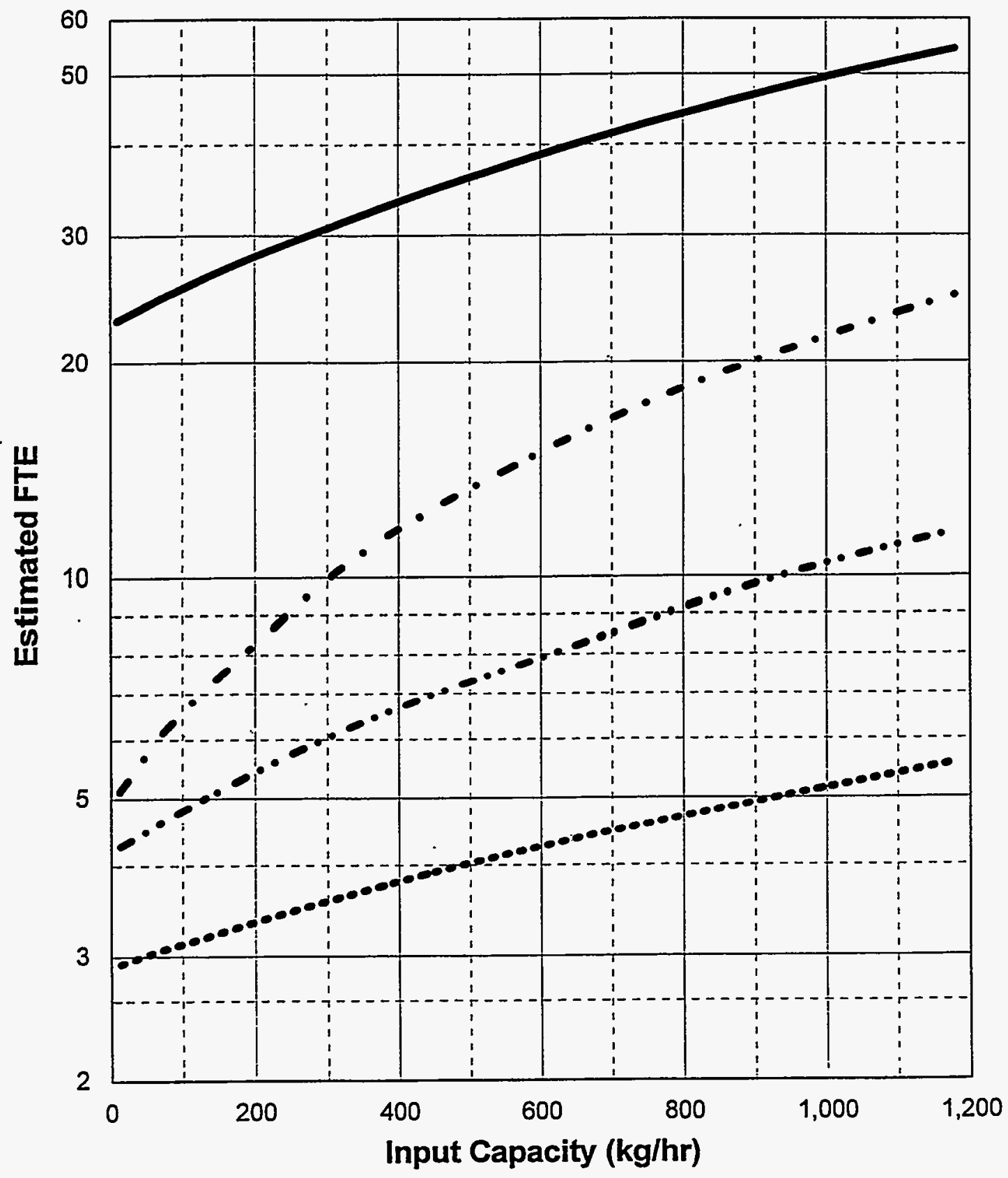

Pre-Operations Construction O\&M (1year) D\&D

Figure 11-3. FTE workers versus capacity for the nonalpha neutralization (B-NEUTR) module. 


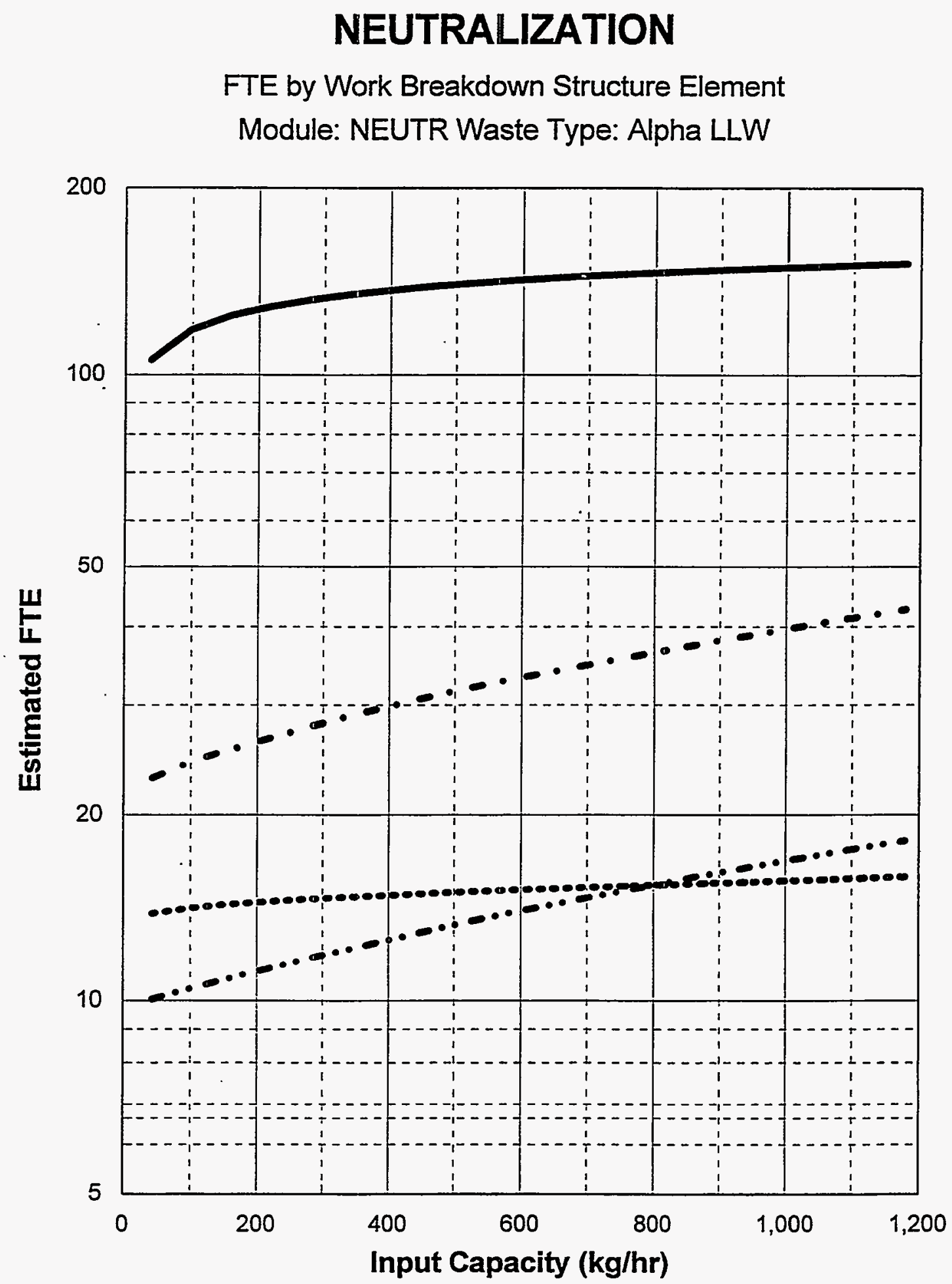

Pre-Operations Construction O\&M (1year) D\&D

Figure 11-4. FTE workers versus capacity for the alpha neutralization (A-NEUTR) module. 


\section{NEUTRALIZATION}

FTE by Work Breakdown Structure Element Module: NETUR Waste Type: Remote Handled LLW

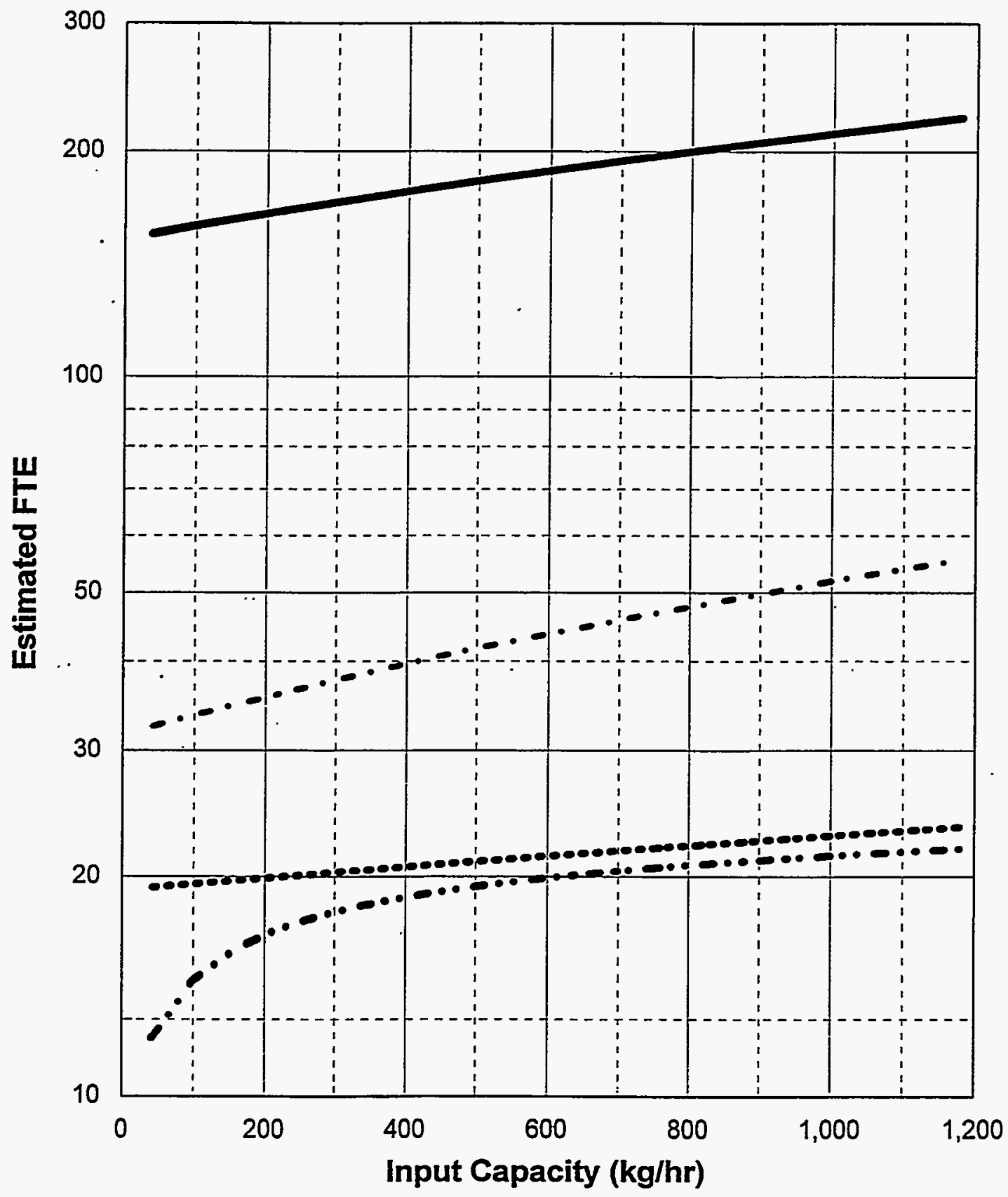

Pre-Operations Construction O\&M (1year) D\&D

Figure 11-5. FTE workers versus capacity for the RH neutralization (R-NEUTR) module. 
NEUTRALIZATION

Cost by Work Breakdown Structure Element

Module: NEUTR Waste Type: Nonalpha LLW

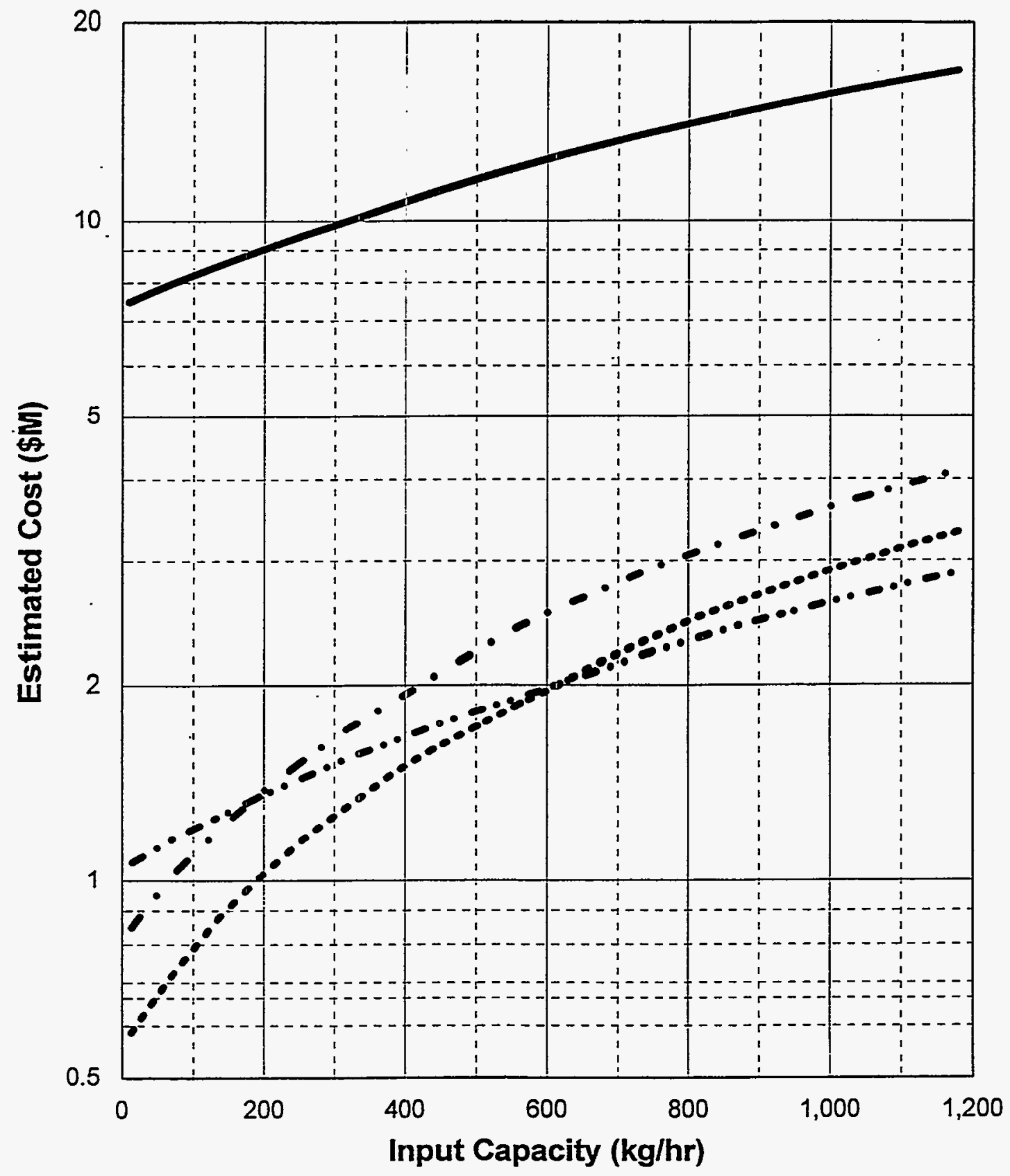

Pre-Operations Construction O\&M (1year) D\&D

Figure 11-6. PLCC versus capacity for the nonalpha neutralization (B-NEUTR) module. 


\section{NEUTRALIZATION}

Cost by Work Breakdown Structure Element Module: NEUTR Waste Type: Alpha LLW

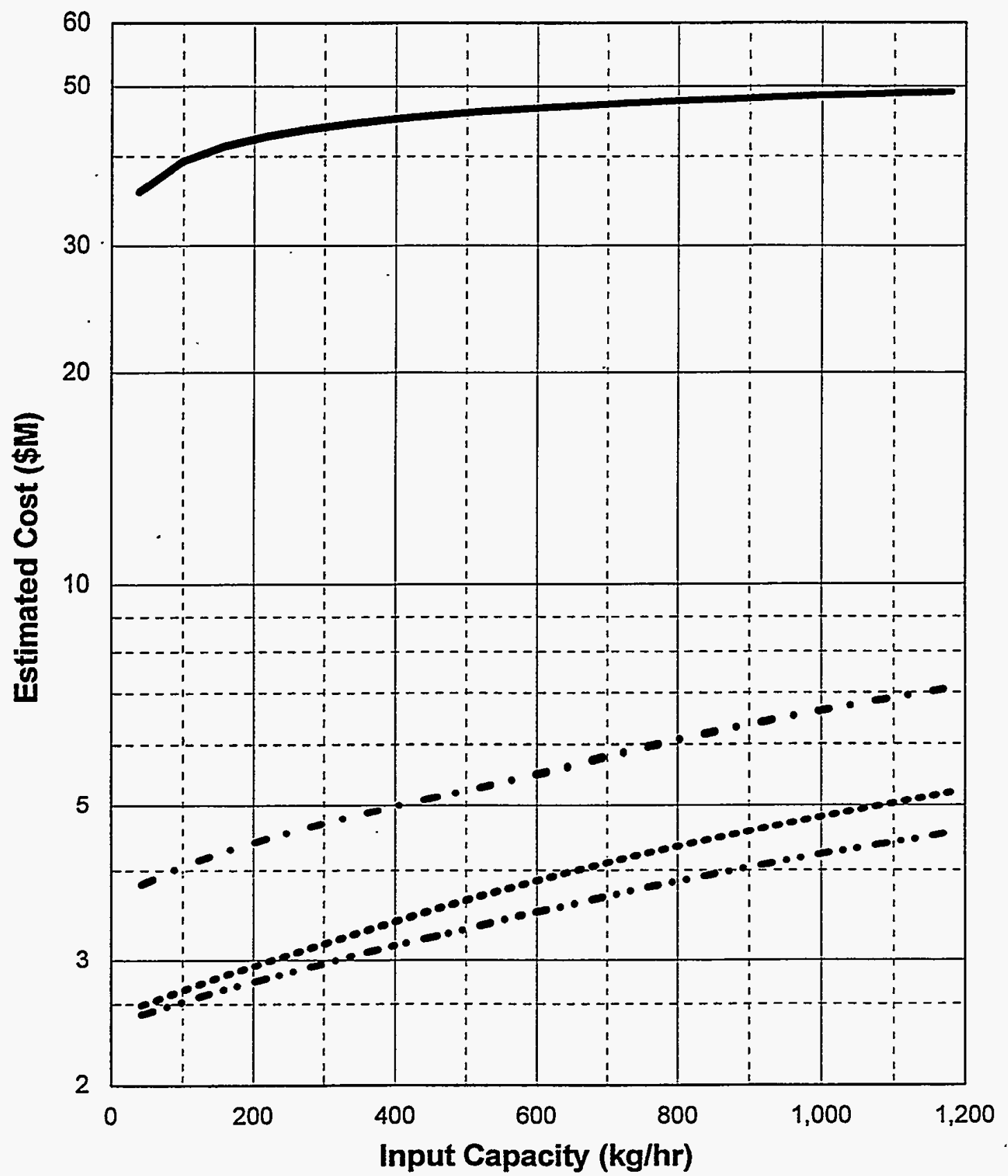

Pre-Operations Construction O\&M (1year) D\&D -.:

Figure 11-7. PLCC versus capacity for the alpha neutralization (A-NEUTR) module. 


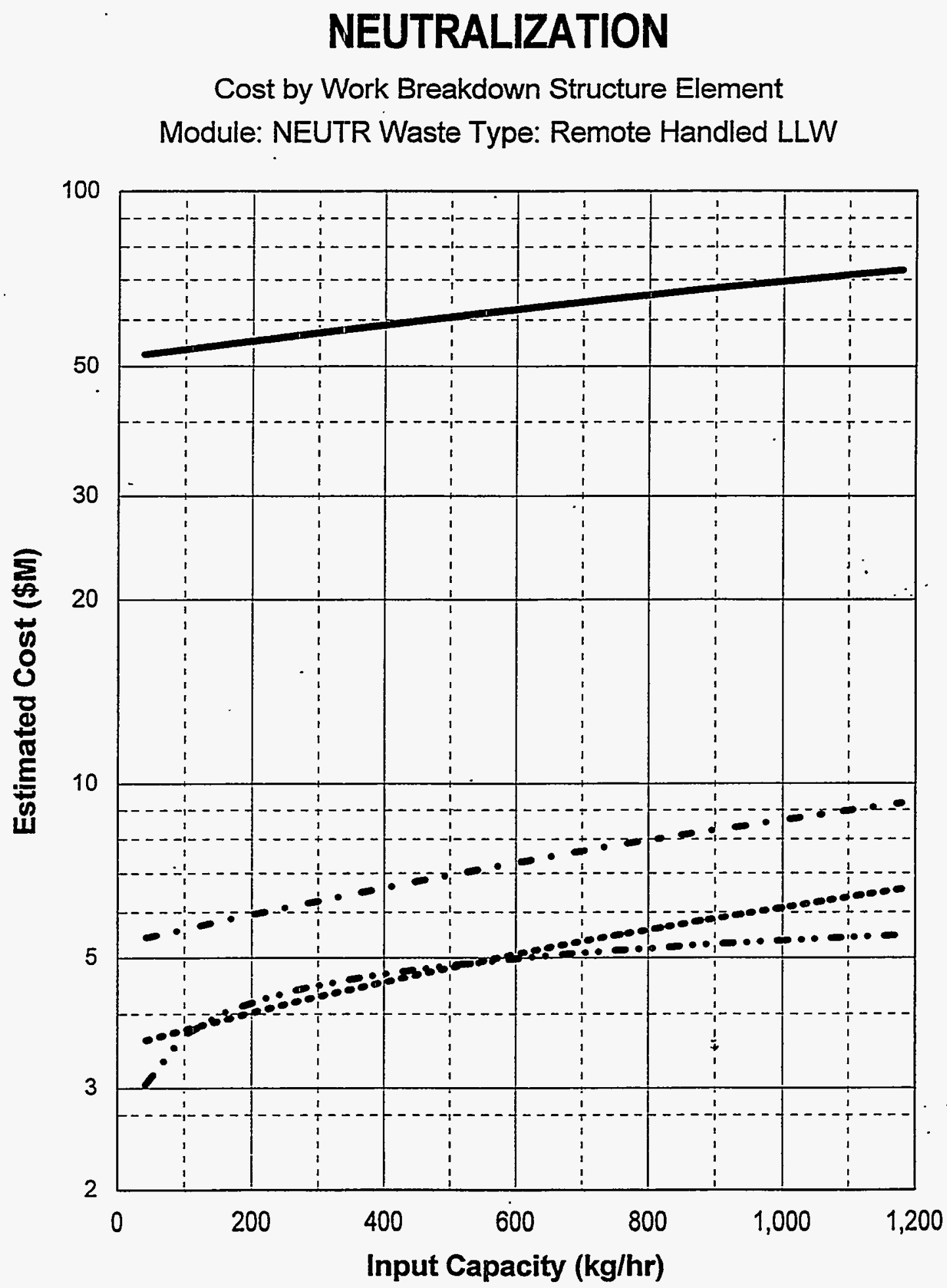

Pre-Operations Construction O\&M (1year) D\&D

Figure 11-8. PLCC versus capacity for the RH neutralization (R-NEUTR) module. 


\section{NEUTRALIZATION}

Total Life Cycle Costs

Module: NEUTR Waste Type: Alpha, Nonalpha, and Remote Handled LLW

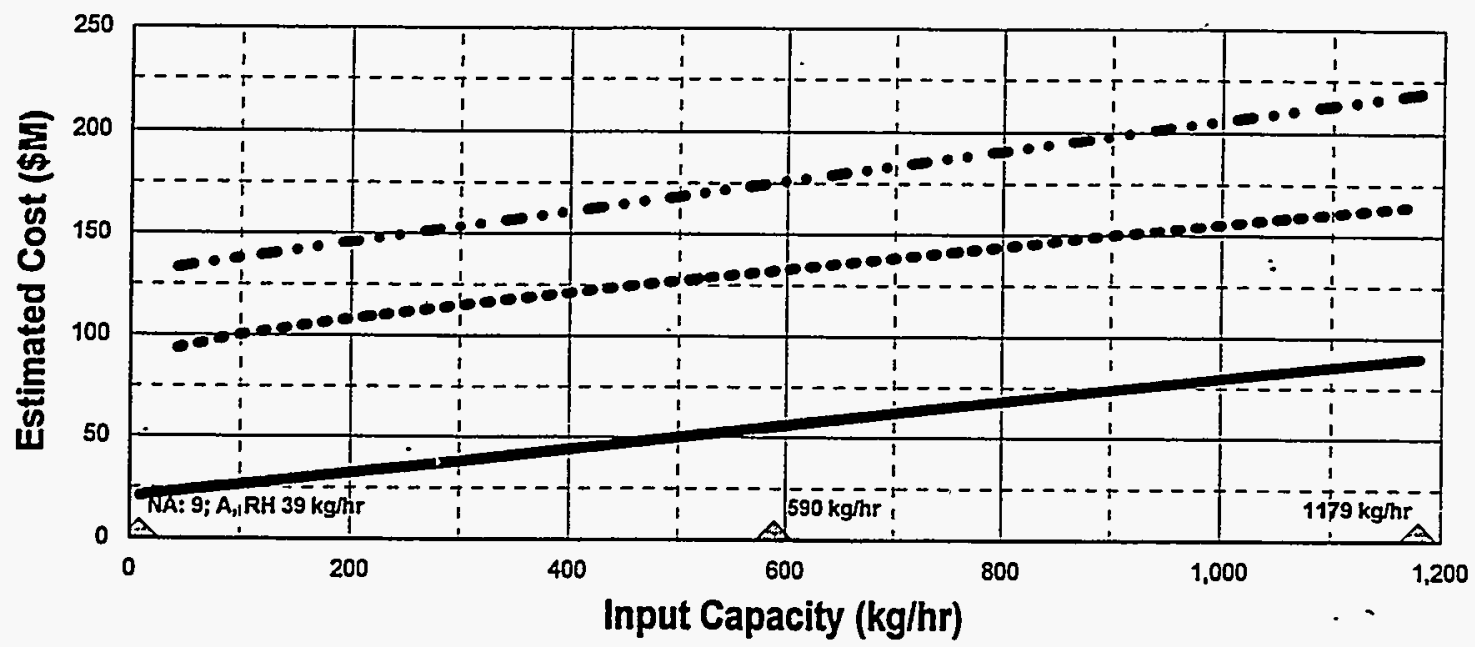

Nonalpha Alpha Remote Handled

NOTE: Basis includes 20 years O\&M

Triangles indicate capacities where detailed cost estimates were developed.

\section{NETURALIZATION}

Total Life Cycle Unit Costs

Module: NEUTR Waste Type: Alpha, Nonalpha, Remote Handled LLW

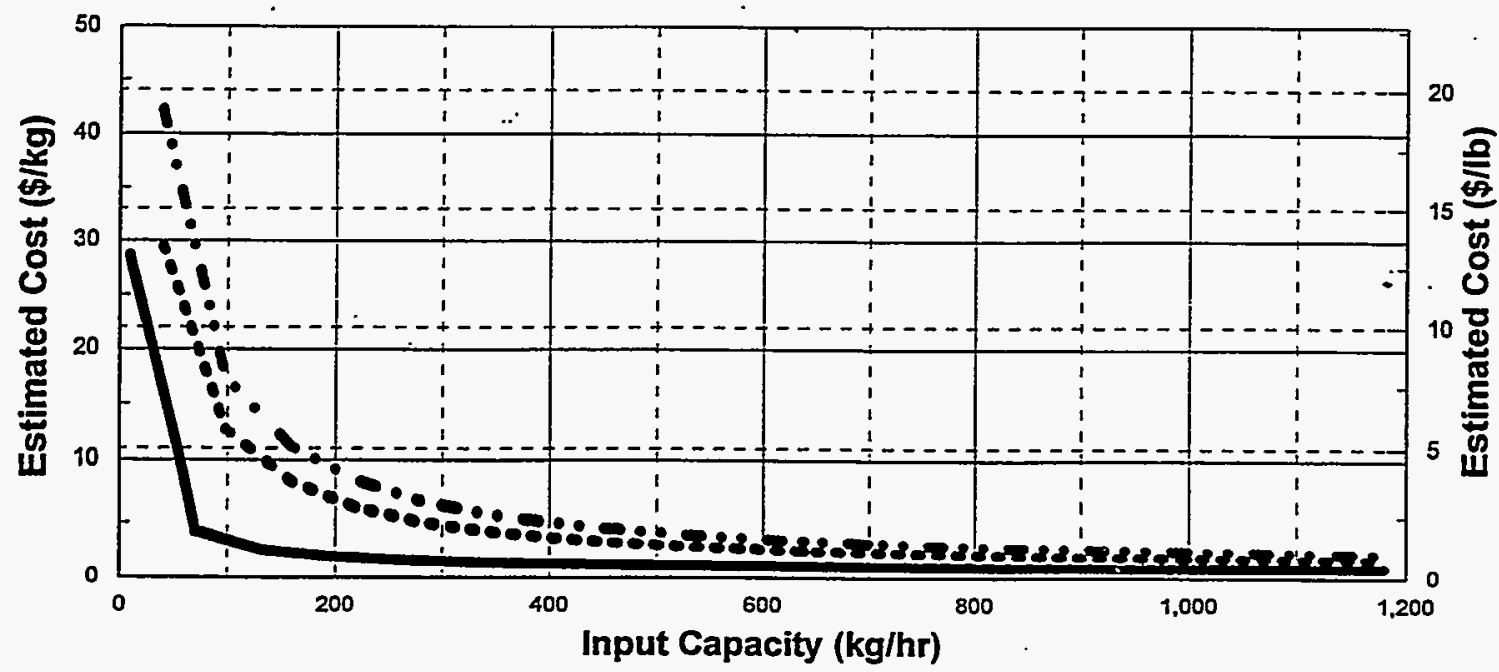

Nonalpha Alpha Remote Handled

NOTE: Basis includes 20 years O\&M

Figure 11-9. PLCC versus capacity including unit rates for the neutralization (NEUTR) module. 


\section{GROUT STABILIZATION (MODULE GROUT)}

\subsection{Basic Information}

The grout stabilization module, shown in Figure 12-1, provides secondary waste treatment capability and is used at the end of the treatment modules. The module output is sent to the certification and shipping (CSHIP or FBSPT) module. The primary purpose of this module is to solidify solid and liquid waste and sludge that arrive from treatment modules, storage facilities, or the generators. Module GROUT is applicable to nonalpha, alpha, and RH waste. Unit operations are shown in the PFD in Figure 12-2.

The module is composed of five main process unit operations that incorporate all buildings, systems, processes, equipment, devices, controls, and accessories required to prepare the incoming waste and stabilize it either by macro or microencapsulation techniques.

\subsection{Technical Bases and Assumptions}

\subsubsection{Function and Operation of Large Generator Modules}

The module receives concentrated liquid waste and sludge via a pipeline. A chemical addition unit is used to adjust the chemistry of the feed before it is fed to the solidification unit operation. A preparation and feed unit crushes and shreds incoming solid waste; the shredded waste is then collected in a storage hopper.

The microsolidification unit operation solidifies concentrated liquid waste, sludge, or a combination of the two. The unit has a remotely operated in-drum solidification assembly equipped with intake tanks and hoppers for sludge, liquid waste, and grout. To accomplish the solidification process, a drum is placed onto a transfer cart. The cart moves the drum to various fill stations where feeders place sludge and liquid waste and binder in the drum. Next, the cart moves the filled drum to a mixing station where the drum is capped and tumbled to achieve the required mixture. The cart moves the drum for a repeat of the filling and mixing steps to maximize the fill efficiency.

The macroencapsulation unit operation solidifies bulkier solids, such as spent filters, shredded solids, and pelletized debris. This waste material and these objects are placed in a drum, and binding agents are added. Macroencapsulation operation is accomplished by placing the solids in a drum, adding grout, and mixing the two components. In large generator modules, a pugmill accomplishes this function.

After encapsulation, the operator remotely moves the filled container to a capping and washing unit. This unit operation provides for sample collection, capping of the container, and removal of loose contamination from the container surface by high-pressure spray water jets. The containerized waste is ready for processing through radioassay and final certification, which are included in the back-end (FBSPT or CSHIP) module. 


\subsubsection{Integration of Large Generator Modules}

Input to the module consists of concentrator bottoms from the neutralization (NEUTR) module; process residues from the open, dump, and sort (OSORT) module; ash from the incinerator (INCIN) module; sludge from wet-air oxidation (WETOX) module; filtration solids from deactivation (DEACT) module; spent filters from miscellaneous treatment modules; and drums, containers, and inorganic debris from the shredding and compaction (CMPCT) module. Major O\&M purchased materials, such as personal protective equipment, laboratory material, binder, and containers, are assumed to be consumable supplies, and their costs are estimated accordingly.

Output consists mainly of drummed, solidified nonalpha and alpha waste, which are moved to a back-end (FBSPT or CSHIP) module. Waste water from drum washing is sent to the neutralization module. Treated offgas is discharged to the atmosphere.

\subsubsection{Function and Operation of Small Generator Fixed Module Installed in a New or Existing Building}

The small generator grout stabilization module was combined with the small generator polymer stabilization module (see Section 13).

\subsection{Cost Bases, Assumptions, and Results}

Incoming waste size reduction and preparation units (shredders) and solidification mixers are the major equipment capital cost items. Costs for the preparation and feed unit are based on vendor quotes for shredders, conveyors, and dust collection equipment. Solidification module assembly prices are based on quotes by Stock Equipment Company. Estimated FTEs and PLCC versus capacity for the large module are shown in Figures 12-3 to 12-9. 


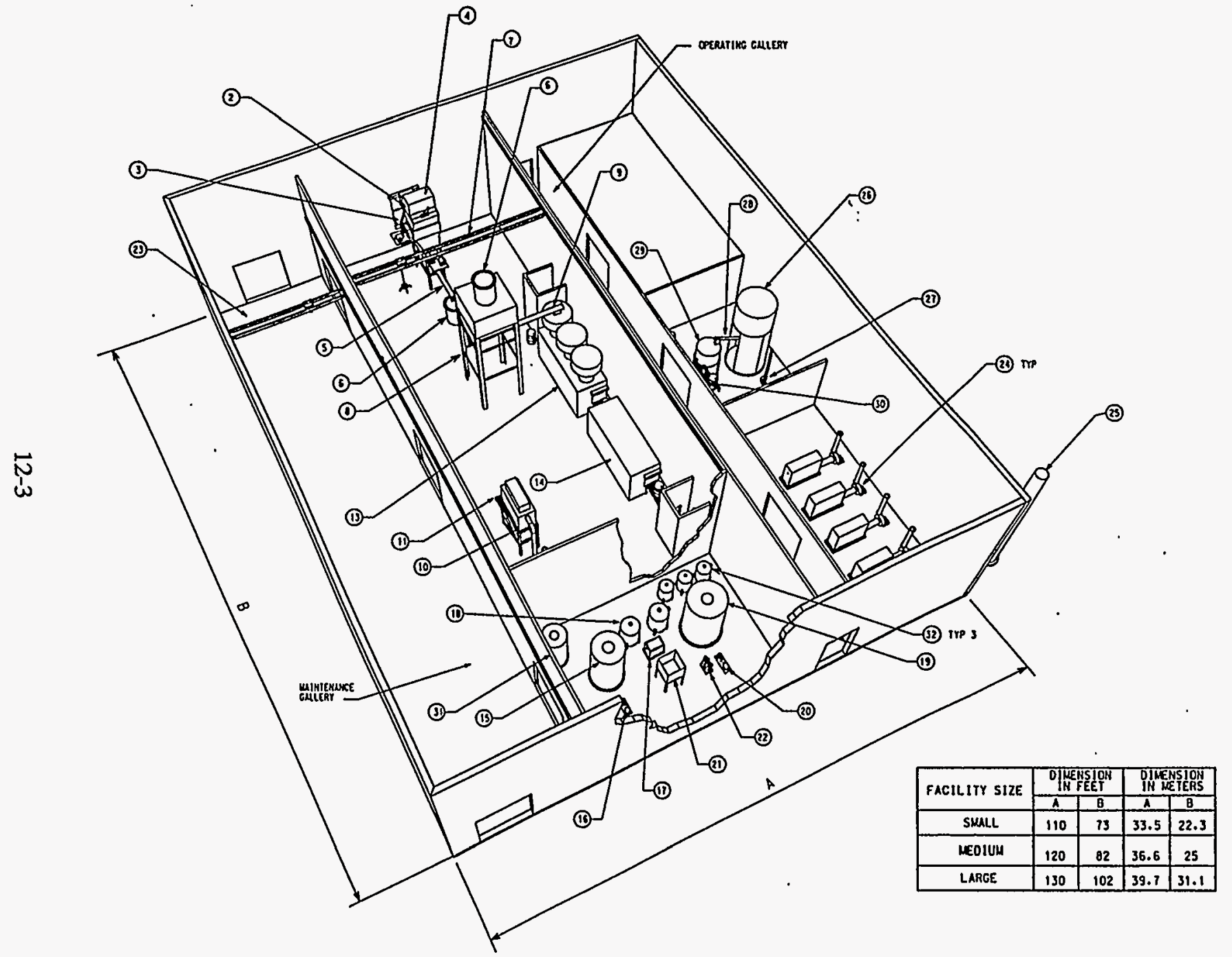

(1) ORLA PUSHER *.

(2) IHCOUIMG MASTE BiH

(3) QIH Hots5

(4) SHREODER (2) VITH FEED HOPPER, OUST HOOO ANO HYORAM IC RAY

(5) NUEER FEEDer

(5)

(6) KASTE TRAMSFER BIM

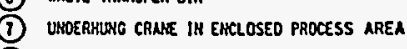

(B) LIVE BOTTON GUXX STORAGE HOPPER

(9) NJGER FEEDER

(10) OUST COLECTRR, FAN AND HEPA FILTER

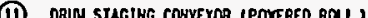

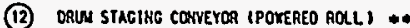

(iD) Salotficarion sYsten

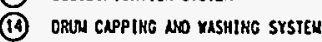

(15) RECEIVIHE takX

(16) PUSP

(18) 1 ox exchance vessels

(19) Treateo wiste taks

(20) PULP

(21) SLUOGE TANX

(22) Puip

(23) UNDERHLAG CRAME IH ERCLOSEO HaINIEHANCE AREA

(24) HEPA FILIER ANO FAM

(23) STACK

(26) BINOER STORACE SILO

(27) BLOKER

(20) PHEUunitic converon

(29) OAY BIS

(30) ORUL STAGIHG COANEROR IGRAVITY

(II) PREciptTATION tRHX

(12) ORGAHIC RELOYYL FILTER VESSELL

-4 Item not visible to the viewer at this angle

GROUT STABILIZATION (MODULE GROUT) TOP PERSPECTIVE VIEW

Figure 12-1. Equipment layout for the grout stabilization (GROUT) module. 


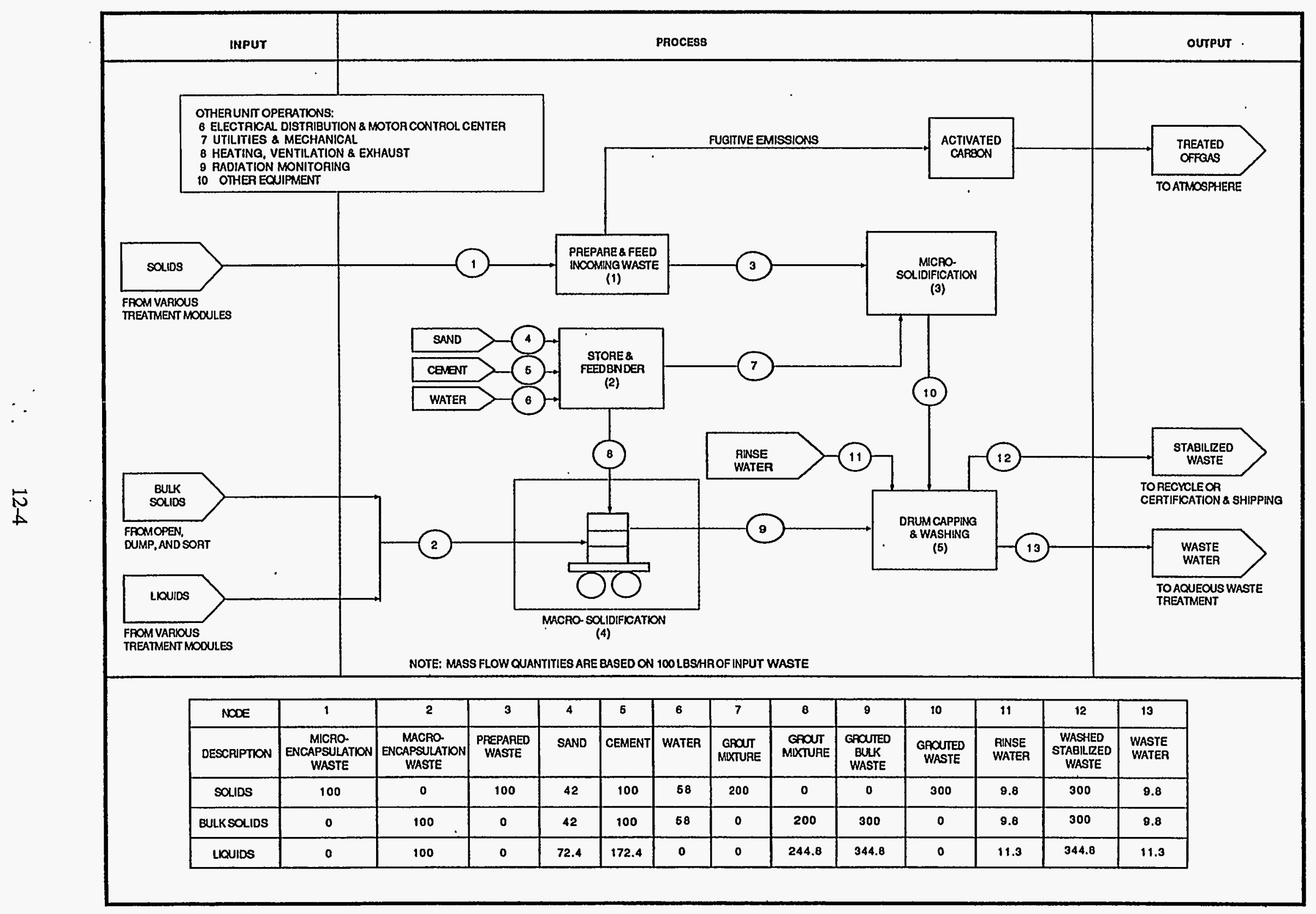

Figure 12-2. Process flow diagram for the grout stabilization (GROUT) module. 


\section{GROUT STABILIZATION}

FTE by Work Breakdown Structure Element

Module: GROUT Waste Type: Nonalpha LLW

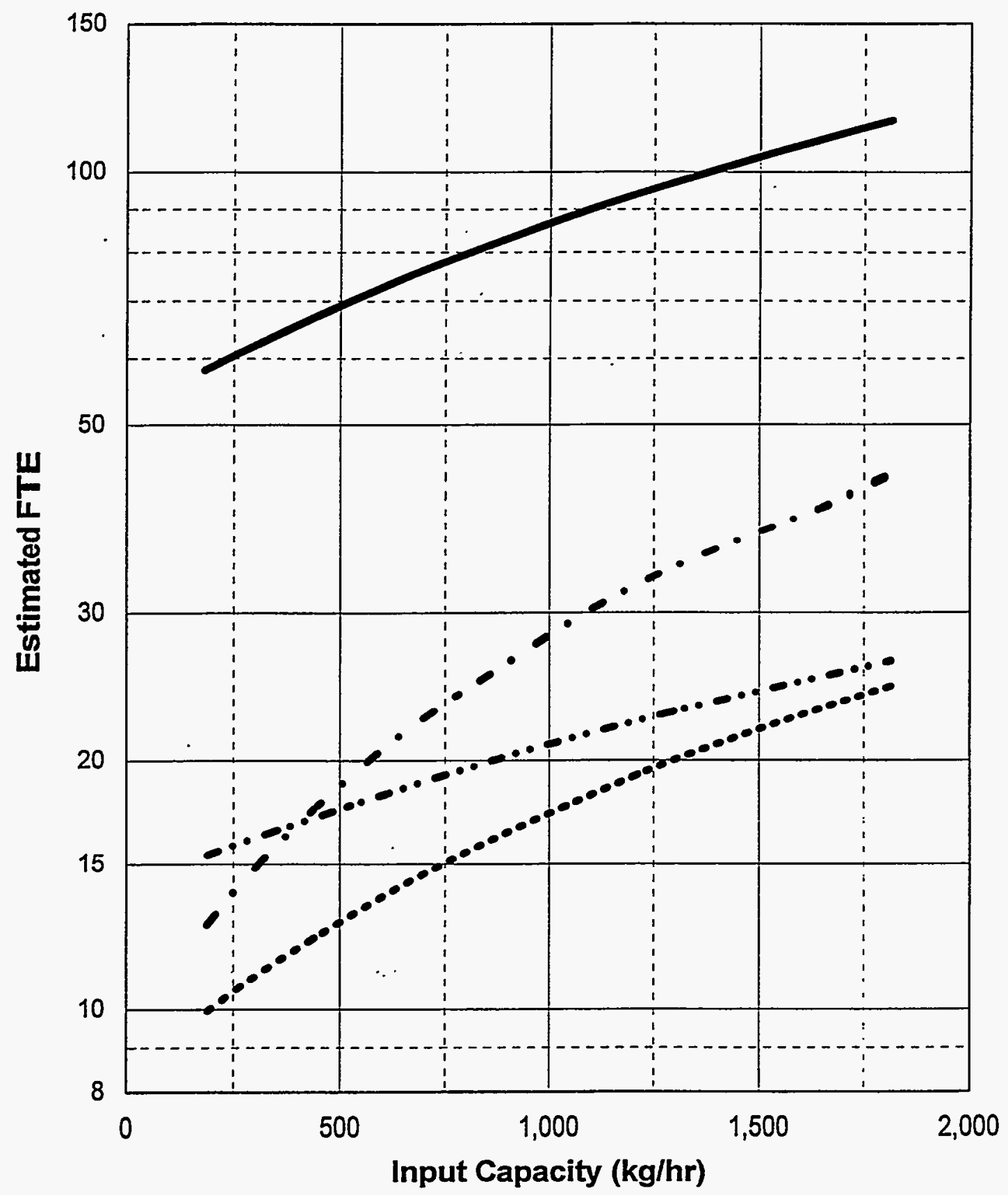

Pre-Operations Construction O\&M (1year) D\&D

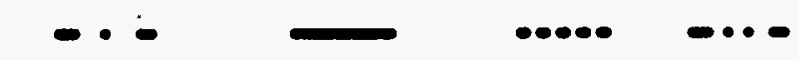

Figure 12-3. FTE workers versus capacity for the nonalpha grout stabilization (B-GROUT) module. 


\section{GROUT STABILIZATION}

FTE by Work Breakdown Structure Element Module: GROUT Waste Type: Alpha LLW

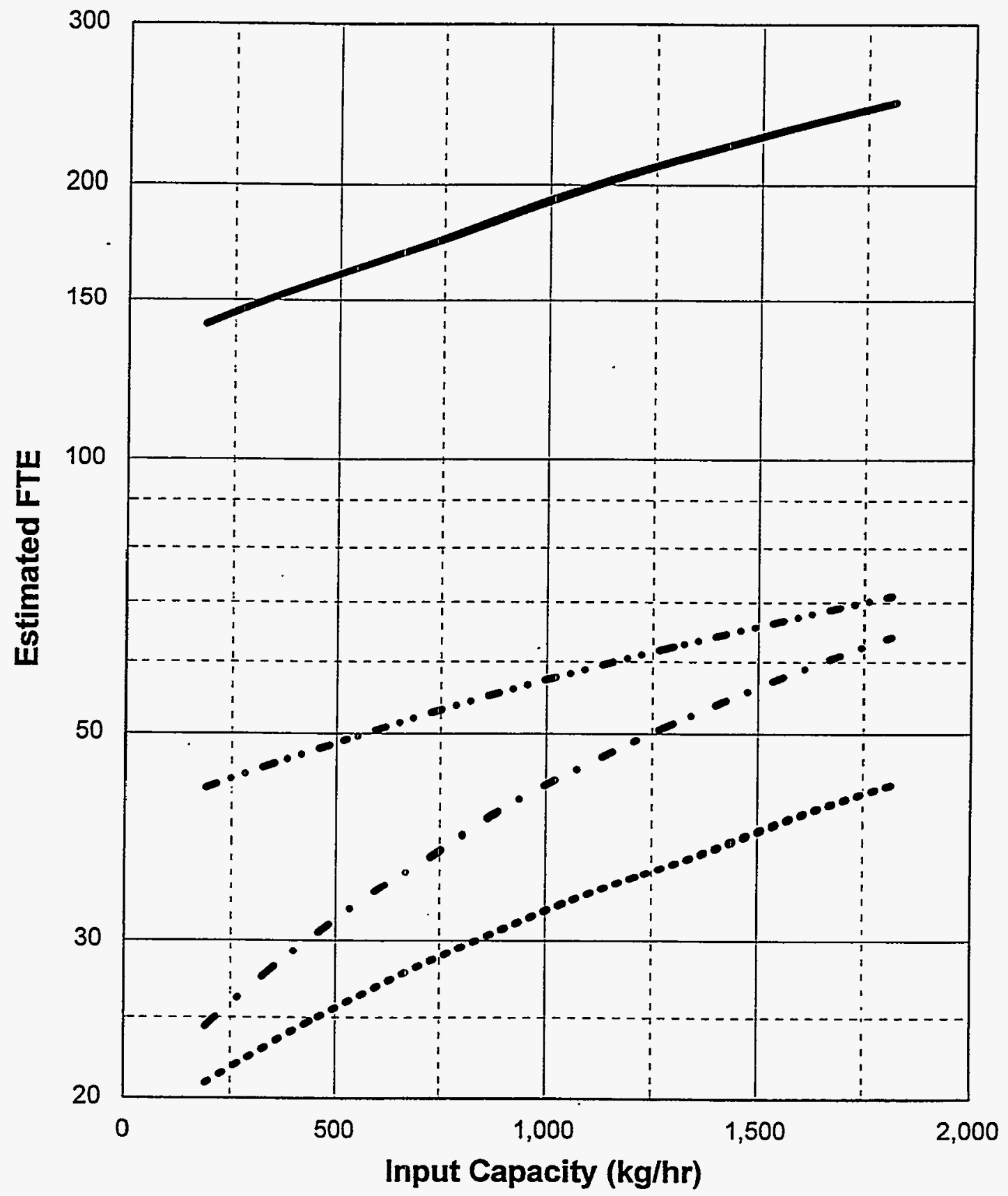

Pre-Operations Construction O\&M (1year) D\&D

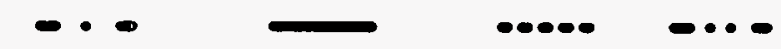

Figure 12-4. FTE workers versus capacity for the alpha grout stabilization (A-GROUT) module. 


\section{GROUT STABILIZATION}

FTE by Work Breakdown Structure Element

Module: GROUT Waste Type: Remote Handled LLW

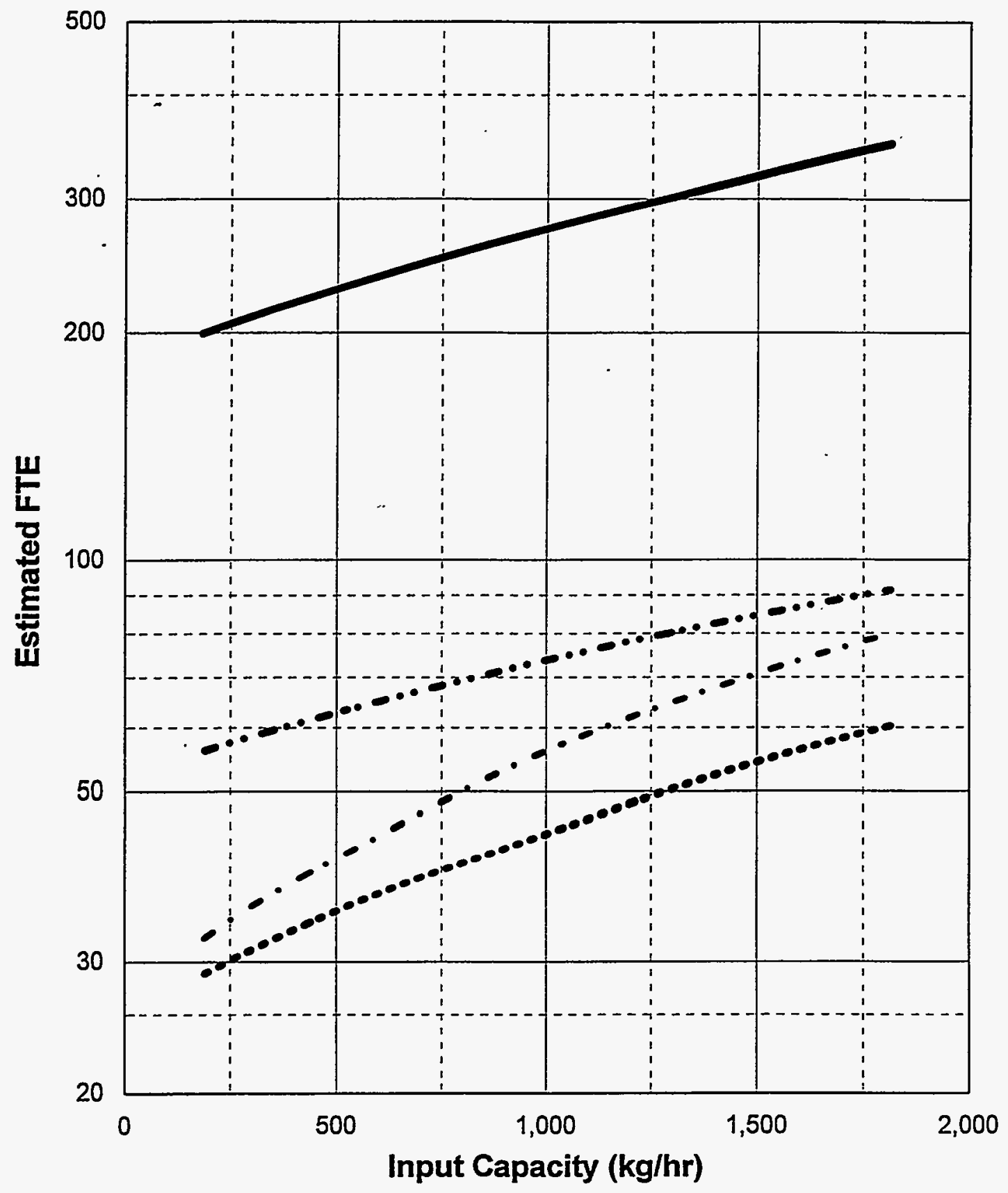

. Pre-Operations Construction O\&M (1year) D\&D

Figure 12-5. FTE workers versus capacity for the RH grout stabilization (R-GROUT) module. 


\section{GROUT STABILIZATION}

Cost by Work Breakdown Structure Element

Module: GROUT Waste Type: Nonalpha LLW

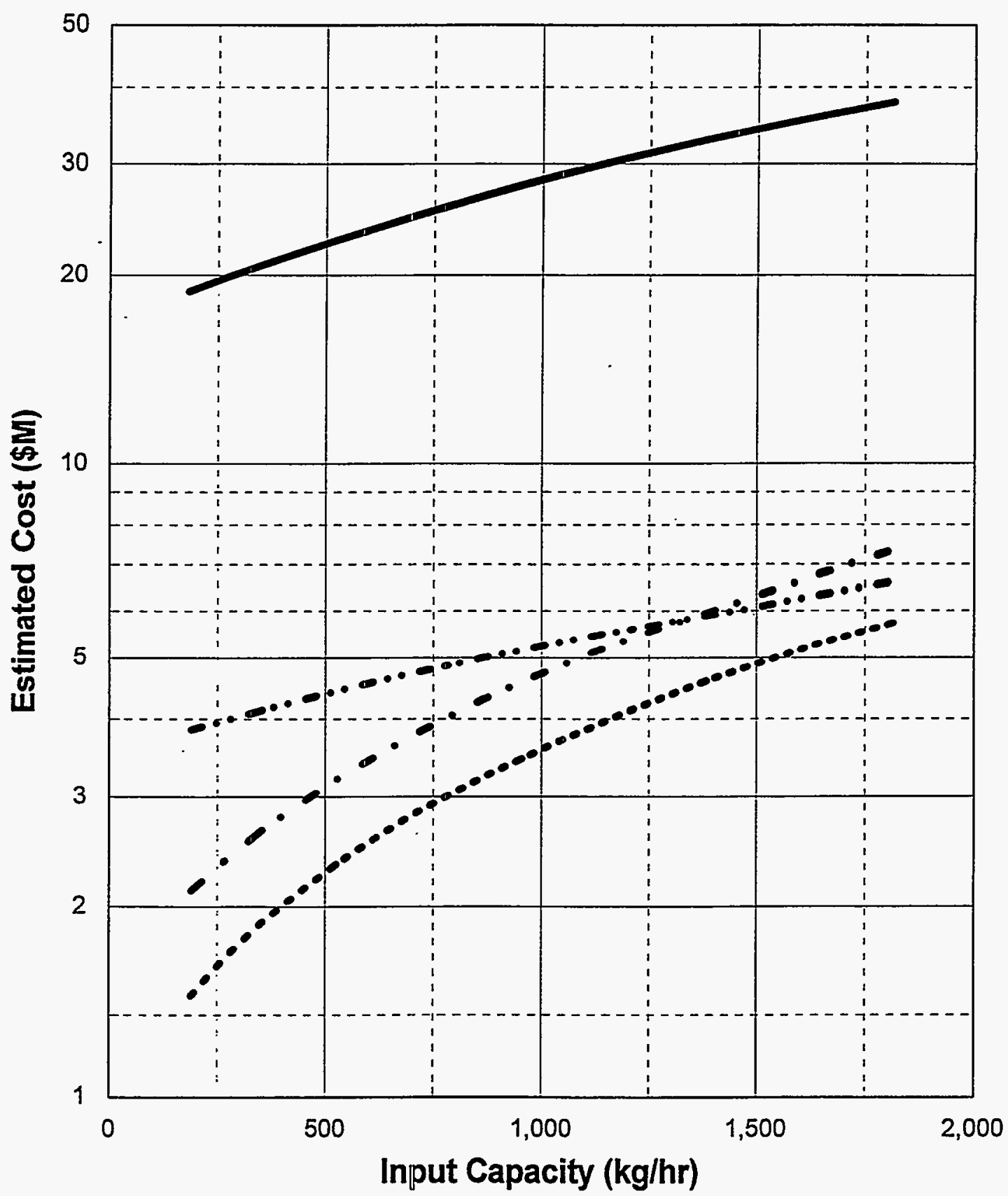

Pre-Operations Construction O\&M (1year) D\&D

Figure 12-6. PLCC versus capacity for the nonalpha grout stabilization (B-GROUT) module. 


\section{GROUT STABILIZATION}

Cost by Work Breakdown Structure Element Module: GROUT Waste Type: Alpha LLW

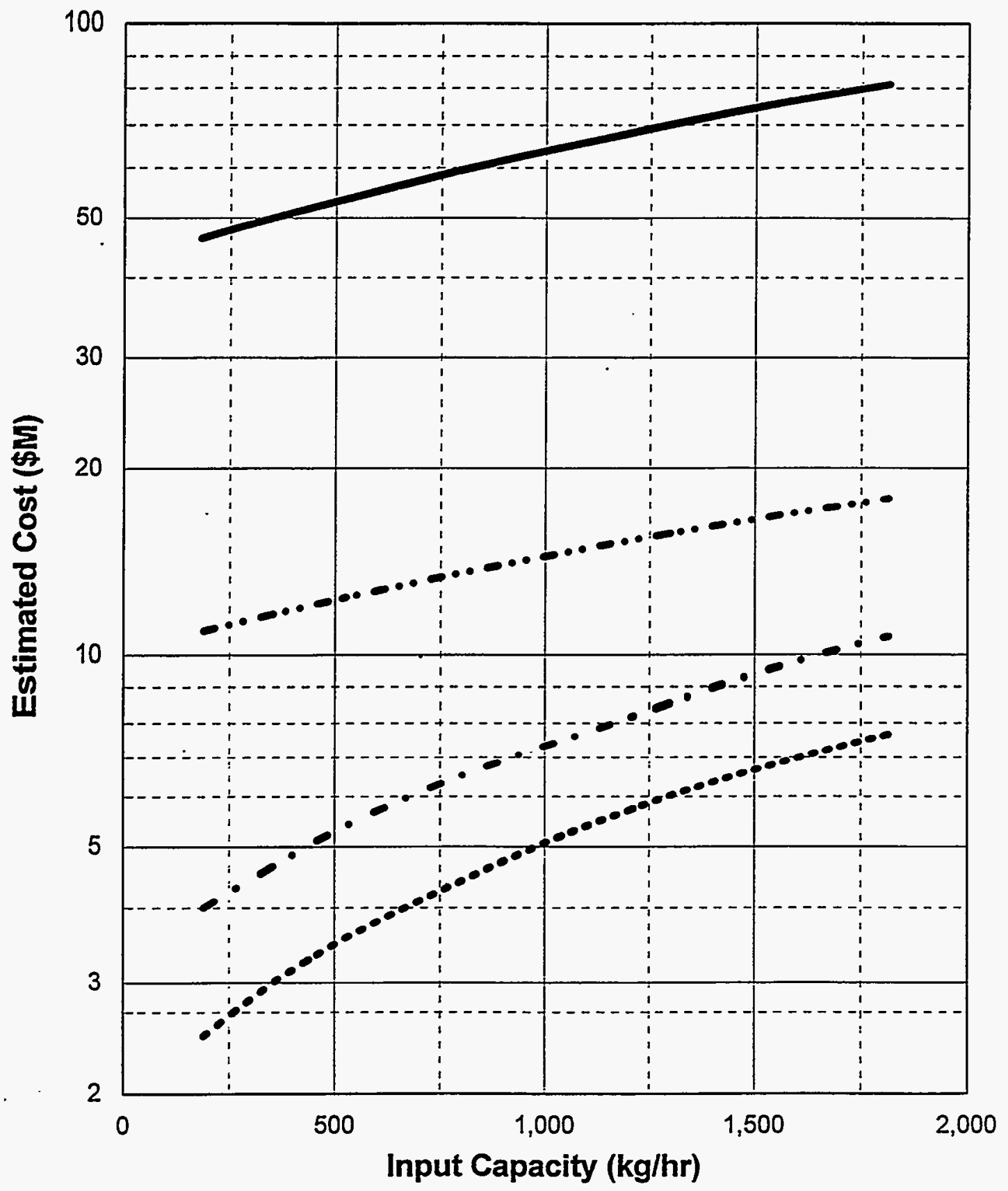

Pre-Operations Construction O\&M (1year) D\&D

Figure 12-7. PLCC versus capacity for the alpha grout stabilization (A-GROUT) module. 


\section{GROUT STABILIZATION}

Cost by Work Breakdown Structure Element

Module: GROUT Waste Type: Remote Handled LLW

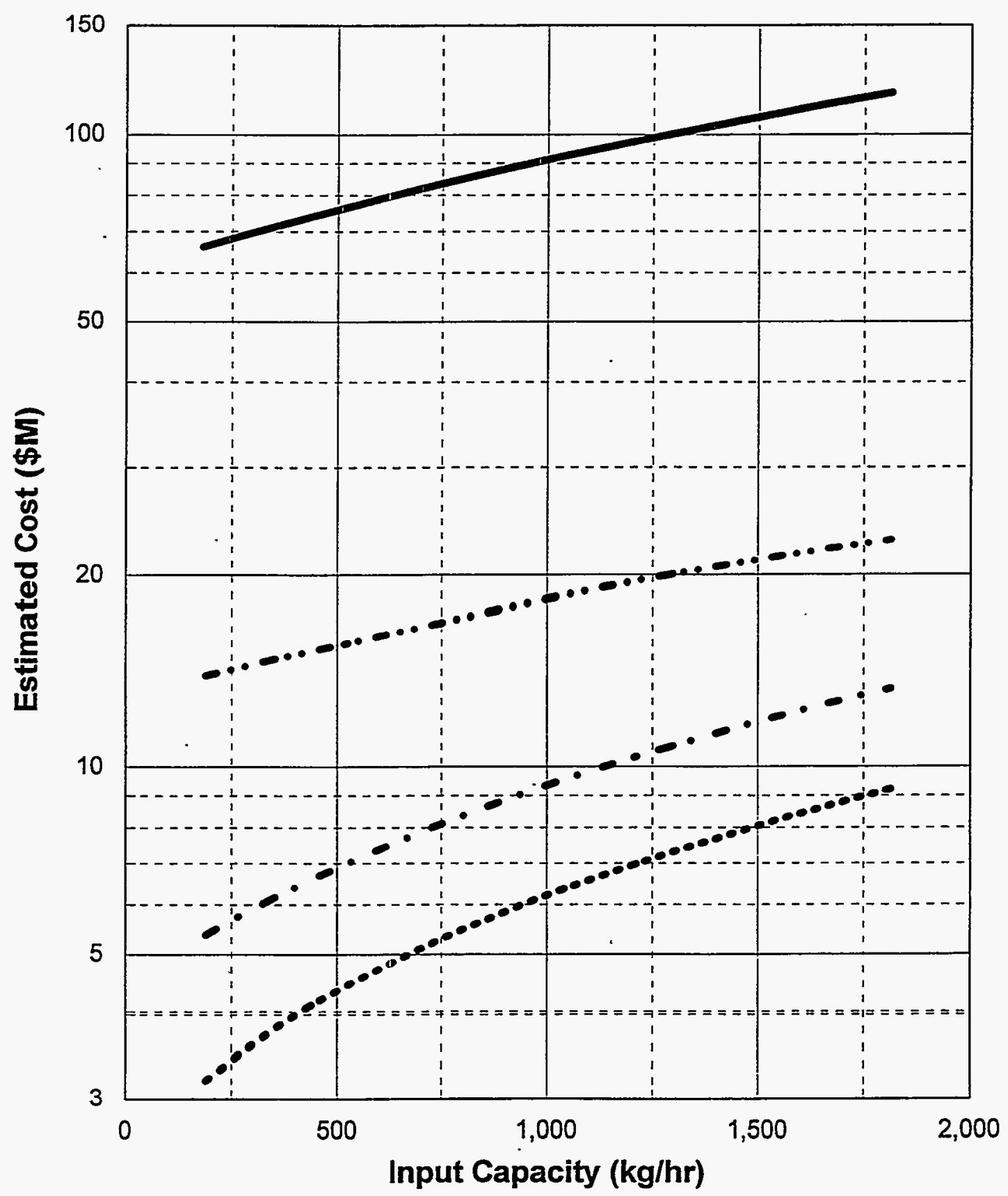

Pre-Operations Construction O\&M (1year) D\&D - -

Figure 12-8. PLCC versus capacity for the RH grout stabilization (R-GROUT) module. 


\section{GROUT STABLIZATION}

Total Life Cycle Costs

Module: GROUT Waste Type: Alpha, Nonalpha, and Remote Handled LLW

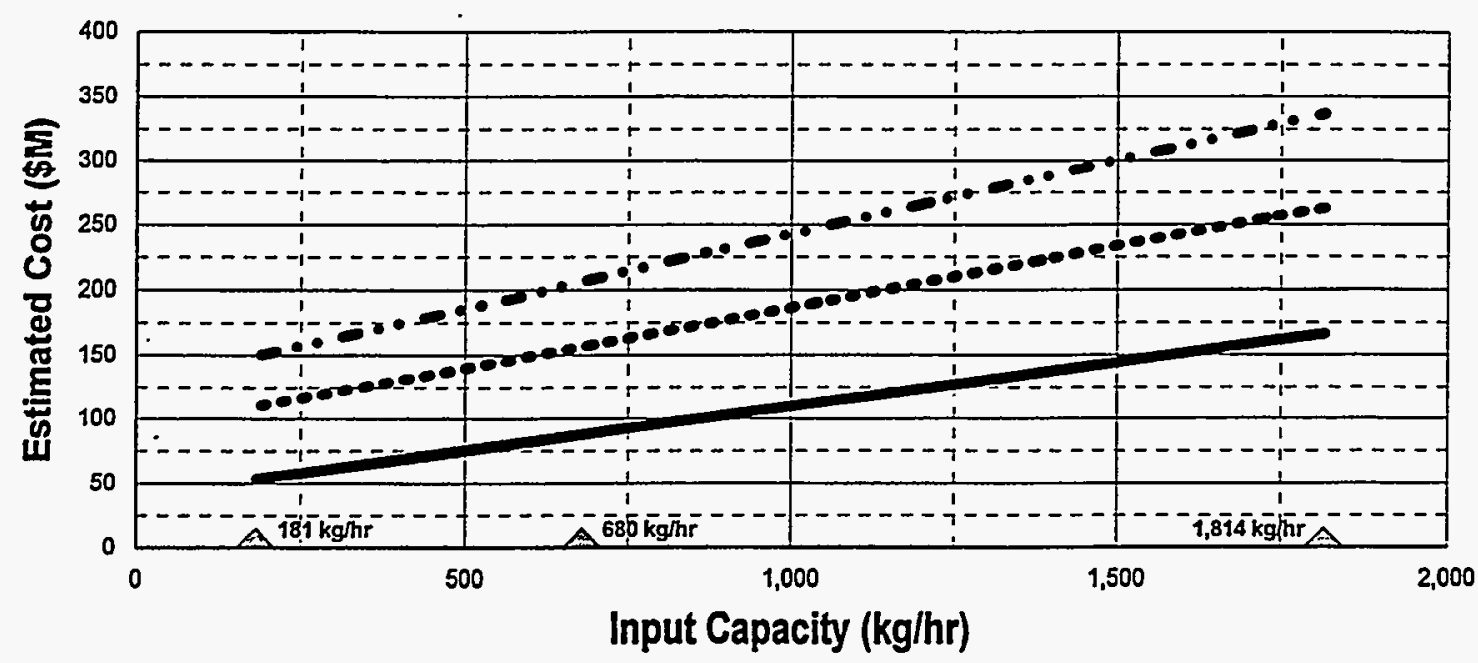

Nonalpha Alpha Remote Handled

NOTE: Basis inciudes 20 years O\&M

Triangles indicate capacities where detailed cost estimates were developed.

\section{GROUT STABILIZATION}

Total Life Cycle Unit Costs

Module: GROUT Waste Type: Alpha, Nonalpha, Remote Handled LLW

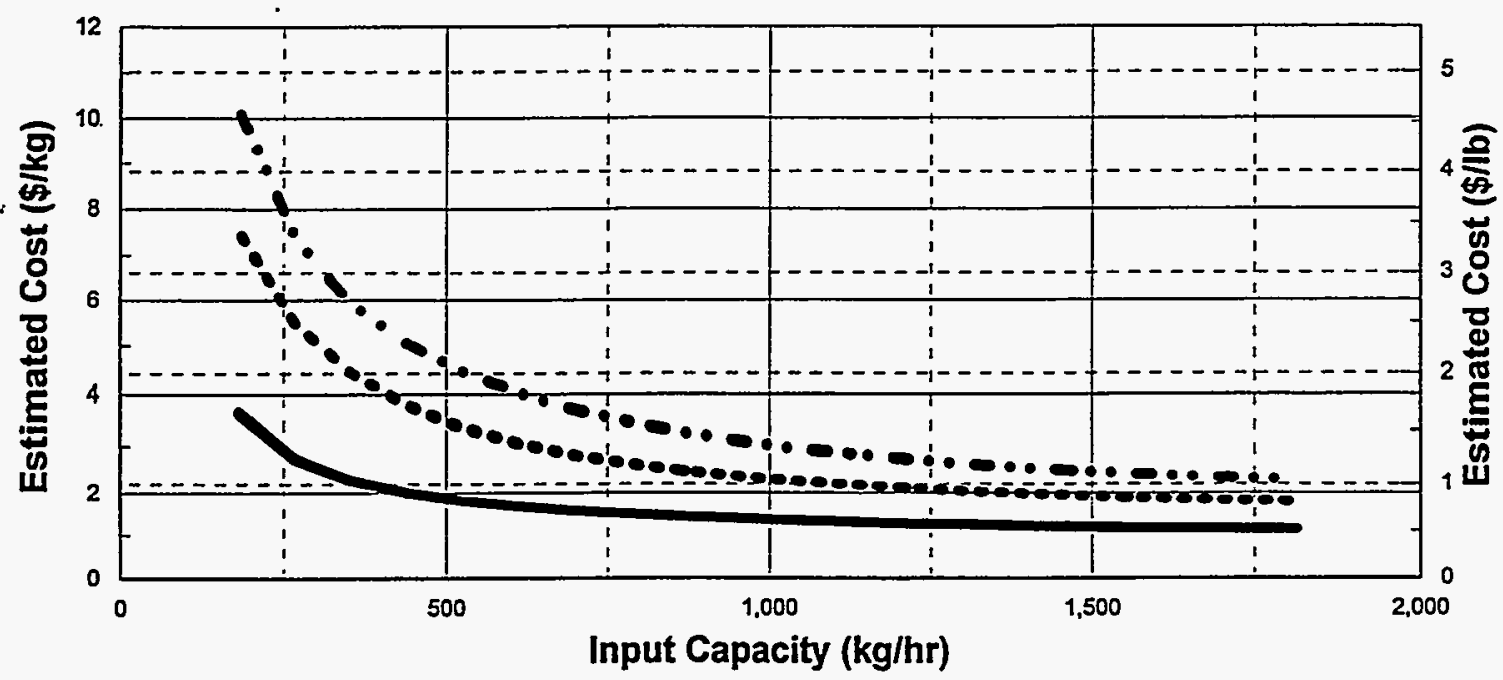

Nonalpha Alpha Remote Handled

NOTE: Basis indudes 20 years O\&M

Figure 12-9. PLCC versus capacity including unit rates for the grout stabilization (GROUT) module. 


\section{POLYMER STABILIZATION (MODULE PLYMR)}

\subsection{Basic Information}

The polymer stabilization module, shown in Figures 13-1 and 13-2, is used for micro or macroencapsulating solids and slurries discharged from the treatment modules in the waste treatment facility. The module consists of several main unit operations that incorporate all systems, processes, equipment, devices, controls, and accessories required to encapsulate the incoming waste. This module must be used in conjunction with the receiving and inspection module (RCINS or FBSPT).

Input waste to this module consists of inorganic debris, spent filters, spent carbon, spent resins, incinerator ash, sludges, and concentrator bottom. All waste input is pretreated to a level that facilitates compliance of the stabilized material with Nuclear Regulatory Commission (NRC) requirements for land disposal.

All stabiliżed and encapsulated waste is packaged in drums and sent to the certification and shipping module for shipment to an appropriate disposal module. Most of the secondary waste is recycled. Distillate from a sludge dryer unit and rinse water from drum cleaning are sent to the neutralization (NEUTR) module. Module NEUTR is applicable to nonalpha, alpha, and RH waste. Figure 13-3 presents a PFD of the module.

\subsection{Technical Bases and Assumptions}

\subsubsection{Function and Operation of Large Generator Modules}

Input waste is sent to a preparation and feed unit operation, after which it goes to a dryer. All waste input is pretreated to a level such that the stabilized material complies with the land disposal restrictions. At a proportioning and blending unit operation, the dried waste and polymer agent are metered into drums and then mixed in a blender. Once blended, the polymer and waste mixture is transferred to the encapsulation unit operation.

The encapsulation unit operation consists of an extruder that melts and pushes the waste and polymer matrix into 55-gal drums. When filled, the drums are transferred to an enclosure where cooling is achieved by forced air ventilation. After cooling, the drum is moved to the drum capping and washing unit operation. Then the drums are moved to the certification and shipping module for final disposal.

\subsubsection{Integration of Large Generator Modules}

The stabilization module receives primary waste (shredded inorganic debris) from the receiving and inspection (RCINS) module and receives secondary waste (concentrator bottom, spent carbon, and spent resins) from the neutralization (NEUTR) module; slag and lead from the lead recovery (PBRCR) module; and salts from the special processing (SPECL); deactivation (DEACT); and the open, dump, and sort (OSORT) modules. All empty transfer containers are returned to the receiving and inspection module for reuse. 
The stabilization module has three secondary waste streams: (a) contaminated air from the process area, which is filtered through active carbon and released to the atmosphere, (b) contaminated distillate from the drying unit operation, which is sent to the neutralization module, and

(c) contaminated rinse water from the drum capping and washing unit operation, which is also sent to the neutralization module.

The major output waste type from this module is stabilized waste. Materials purchased for O\&M include personal protective equipment, laboratory material, polymers for encapsulation, HEPA and carbon filters, and disposal containers, which are assumed to be consumable supplies.

\subsubsection{Function and Operation of Small Generator Fixed Module in a New or Existing Building}

A fixed small generator suitable for installation in a new or existing building space has been cost estimated. Function and operation of the fixed small generator modules are essentially the same as for the large generator modules. The small generator module can also accomplish grout stabilization. Figure 13-4 shows a PFD of the small generator modules.

Existing building space required for installation of this module is $223 \mathrm{~m}^{3}\left(2,400 \mathrm{ft}^{2}\right)$. The

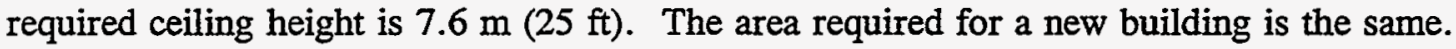

\subsubsection{Integration of Small Generator Fixed Module in a New or Existing Building}

The stabilization module receives waste from the front-end and back-end support module, the aqueous waste treatment or neutralization module, and the lead recovery module. Module input includes spent carbon, spent resins, salts, slag, lead, and concentrator bottom. Materials purchased for O\&M include personal protective equipment, laboratory material, polymers for encapsulation, HEPA and carbon filters, and disposal containers, which are assumed to be consumable supplies. The major output waste type from this module is stabilized waste. Contaminated air, distillate, and rinse water are collected and transferred to the appropriate treatment modules.

\subsubsection{Function and Operation of Portable Module}

The portable stabilization module contains all equipment and support units necessary to stabilize the incoming waste. To accommodate all equipment and support units, four standard roadway trailers are required: three process trailers and one control trailer. Trailer A houses the drying, proportioning, and blending unit operations. Trailer B contains the encapsulation, the drum cooling, and the drum capping and washing unit operations. A control trailer contains the instrumentation and communication equipment necessary for the operation of this module. The portable stabilization module receives waste from the specific sites where the mobile unit is operating. It is assumed that all feed preparation is provided by the host facility. The portable module can also accomplish grout stabilization. 


\subsubsection{Integration of Portable Module}

The portable stabilization module may receive input waste from the following modules if they are located at the host site: storage facilities, front-end and back-end support module, fixed or portable aqueous waste treatment or neutralization module, fixed or portable decontamination module, incineration module, fixed or transportation thermal desorption module, mercury separation module, and fixed or portable wet-air oxidation modules. A portable module layout appears in Figure 13-2. The major type of output waste from this module is stabilized waste. Distillate and rinse water are collected and transferred to the appropriate treatment modules. The portable stabilization module must be accompanied by the portable aqueous waste treatment module when dispatched to sites without this capability.

\subsection{Cost Bases, Assumptions, and Results}

One part of polymer is required for one part of waste. Estimated manpower for small generator module O\&M is based on the assumption that batch operations are used and that incoming waste is stabilized at a rate of about $9.1 \mathrm{~kg} / \mathrm{hr}(20 \mathrm{lb} / \mathrm{hr})$. For the portable stabilization module, a waste process rate of $2.5 \mathrm{~m}^{3}\left(88.3 \mathrm{ft}^{3}\right)$ per campaign is assumed. The portable polymer stabilization module has an estimated cost of $\$ 260,000$ per campaign. Each campaign will require approximately one FTE. Estimated FTE workers versus capacity information is shown in Figures 13-5 through 13-7. Figures 13-8 through 13-11 show the relationship between the PLCC and capacity.

Costs for equipment in this module are based on vendor quotes. The incoming-waste dryer, blender, and extruder are the major equipment capital cost items. The cost estimate for the drying equipment is based on prices obtained from Wyssmont Co., Inc. of Fort Lee, New Jersey. The cost estimate for the blending equipment is based on prices obtained from Velmac Associates, Inc. of Novato, California. The cost estimate for the extruder equipment is based on prices obtained from Sterling Extruders, Davis-Standard Division of Edison, New Jersey. Full-time equivalent estimates and PLCC for small generator fixed modules are shown in Tables 13-1 and 13-2. 
Table 13-1. FTE workers for the small generator polymer stabilization (PLYMR) module.

\begin{tabular}{lcc}
\hline \multicolumn{1}{c}{ Cost element } & \multicolumn{2}{c}{ Type of module } \\
\cline { 2 - 3 } & $\begin{array}{c}\text { Fixed, in new } \\
\text { building(s) }\end{array}$ & $\begin{array}{c}\text { Fixed, in existing } \\
\text { building(s) }\end{array}$ \\
\hline (1.0) Preoperations & 5 & 4 \\
(2.0) Construction & 38 & 25 \\
(3.0) O\&M (20 years) & 80 & 80 \\
(4.0) D\&D & 6 & 6 \\
All cost elements (total for 20 years O\&M) & 129 & 115 \\
\hline
\end{tabular}

Table 13-2. PLCC $(\$ 1,000)$ for the small generator polymer stabilization (PLYMR) module.

\begin{tabular}{lcc}
\hline & \multicolumn{2}{c}{ Type of module } \\
\cline { 2 - 3 } \multicolumn{1}{c}{ Cost element } & $\begin{array}{c}\text { Fixed, in new } \\
\text { building(s) }\end{array}$ & $\begin{array}{c}\text { Fixed, in existing } \\
\text { building(s) }\end{array}$ \\
\hline (1.0) Preoperations & 853 & 769 \\
(2.0) Construction & 9,760 & 6,725 \\
(3.0) O\&M (20 years) & 9,300 & 9,300 \\
(4.0) D\&D & 1,565 & 1,565 \\
\cline { 2 - 3 } All cost elements (total for 20 years O\&M) & 21,478 & 18,359 \\
\hline
\end{tabular}




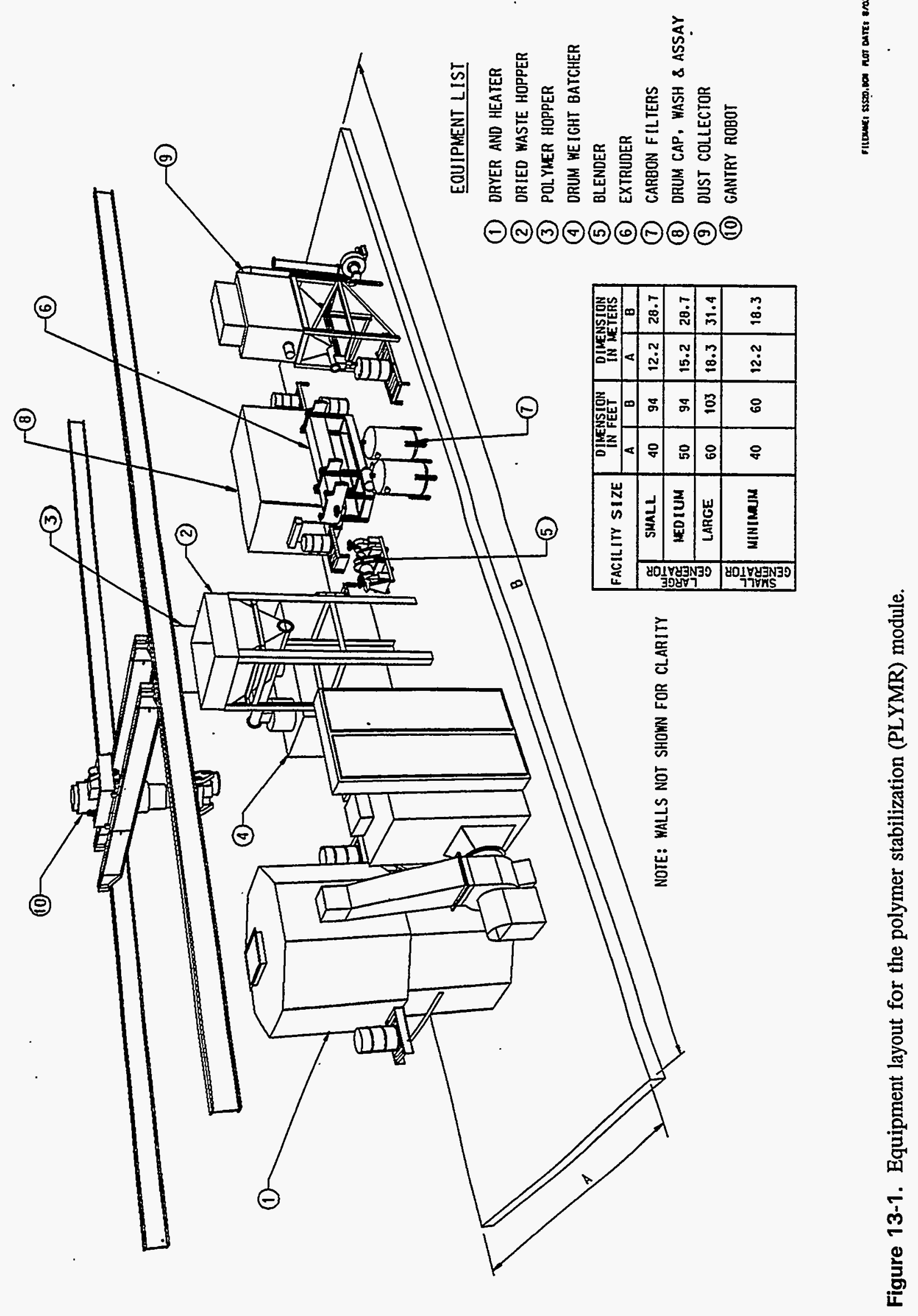



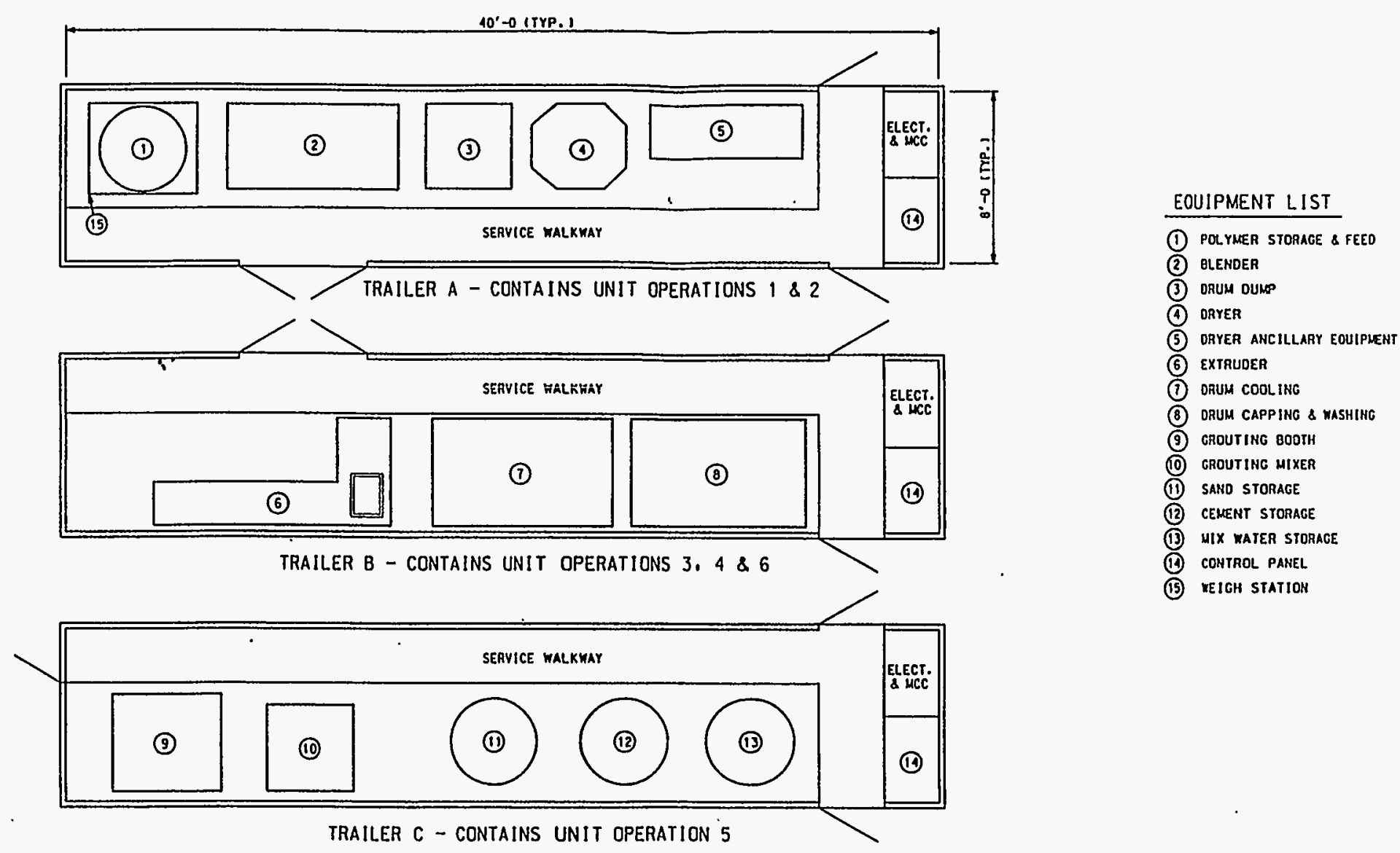

Figure 13-2. Equipment layout for the portable polymer stabilization (PLYMR) module. 


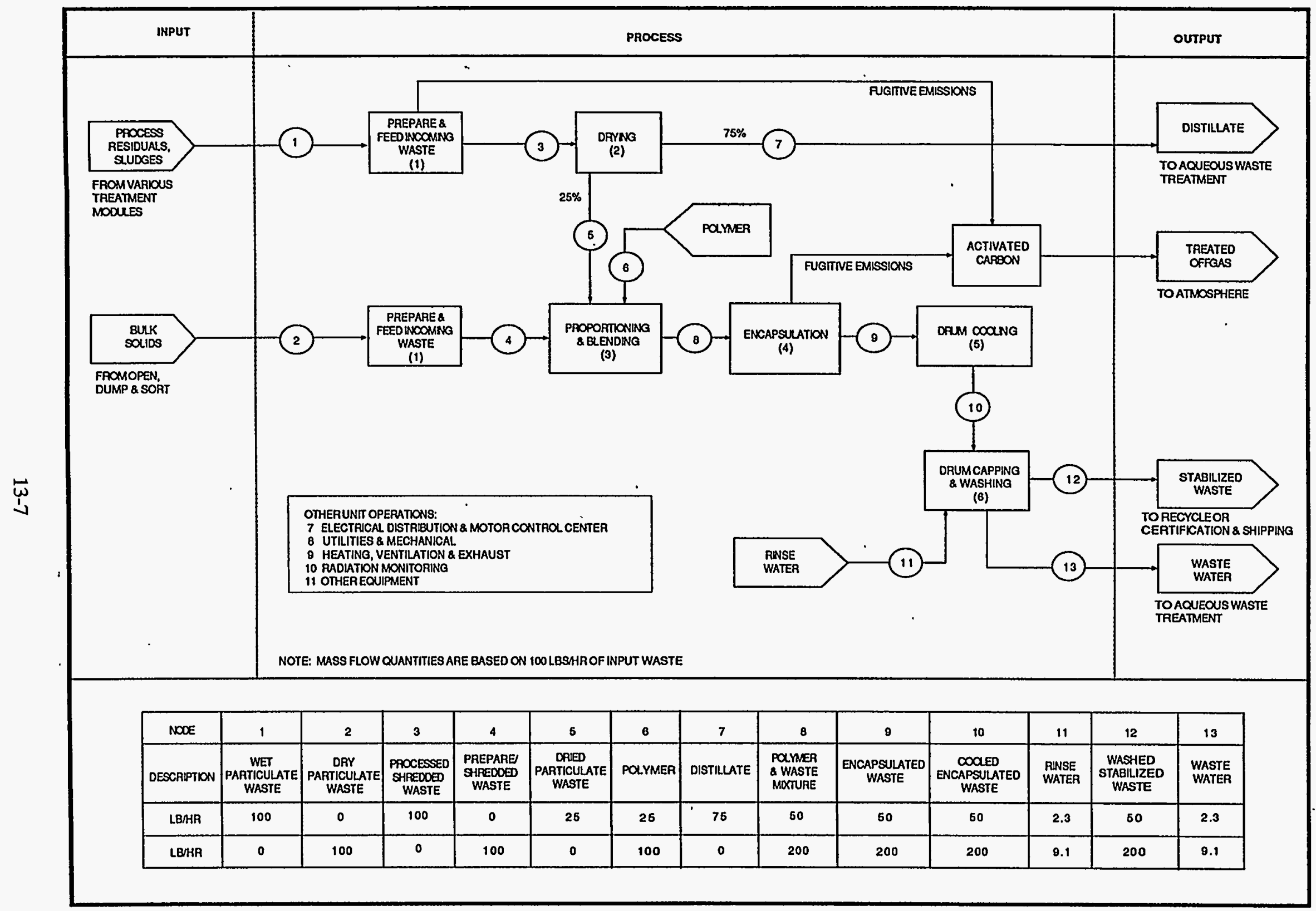

Figure 13-3. Process flow diagram for the large generator polymer stabilization (PLYMR) module. 


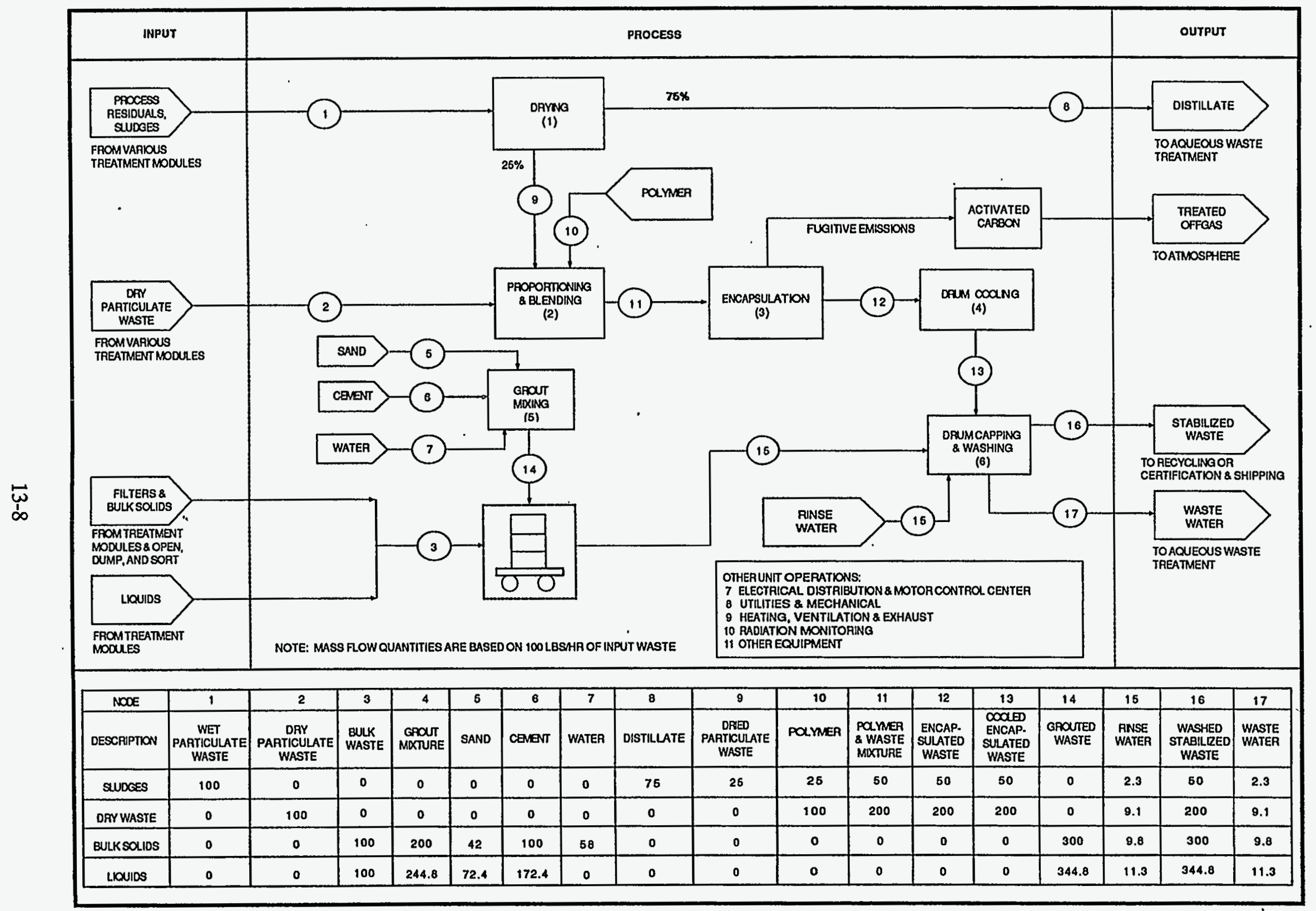

Figure 13-4. Process flow diagram for the small generator polymer stabilization (PLYMR) module. 


\section{POLYMER STABILIZATION}

FTE by Work Breakdown Structure Element Module: PLYMR Waste Type: Nonalpha LLW

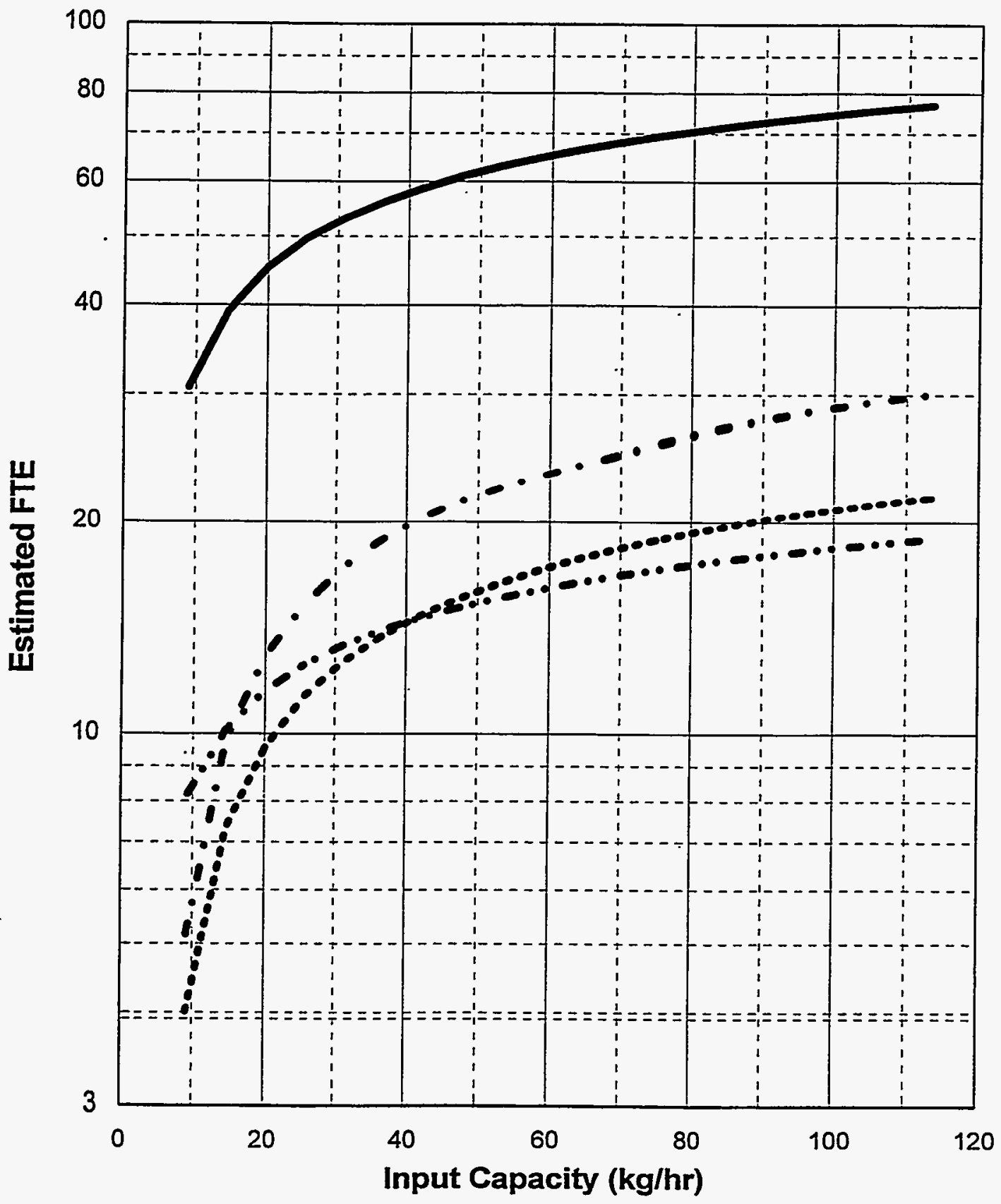

Pre-Operations Construction O\&M (1year) D\&D

Figure 13-5. FTE workers versus capacity for the nonalpha polymer stabilization (B-PLYMR) module. 


\section{POLYMER STABILIZATION}

FTE by Work Breakdown Structure Element

Module: PLYMR Waste Type: Alpha LLW

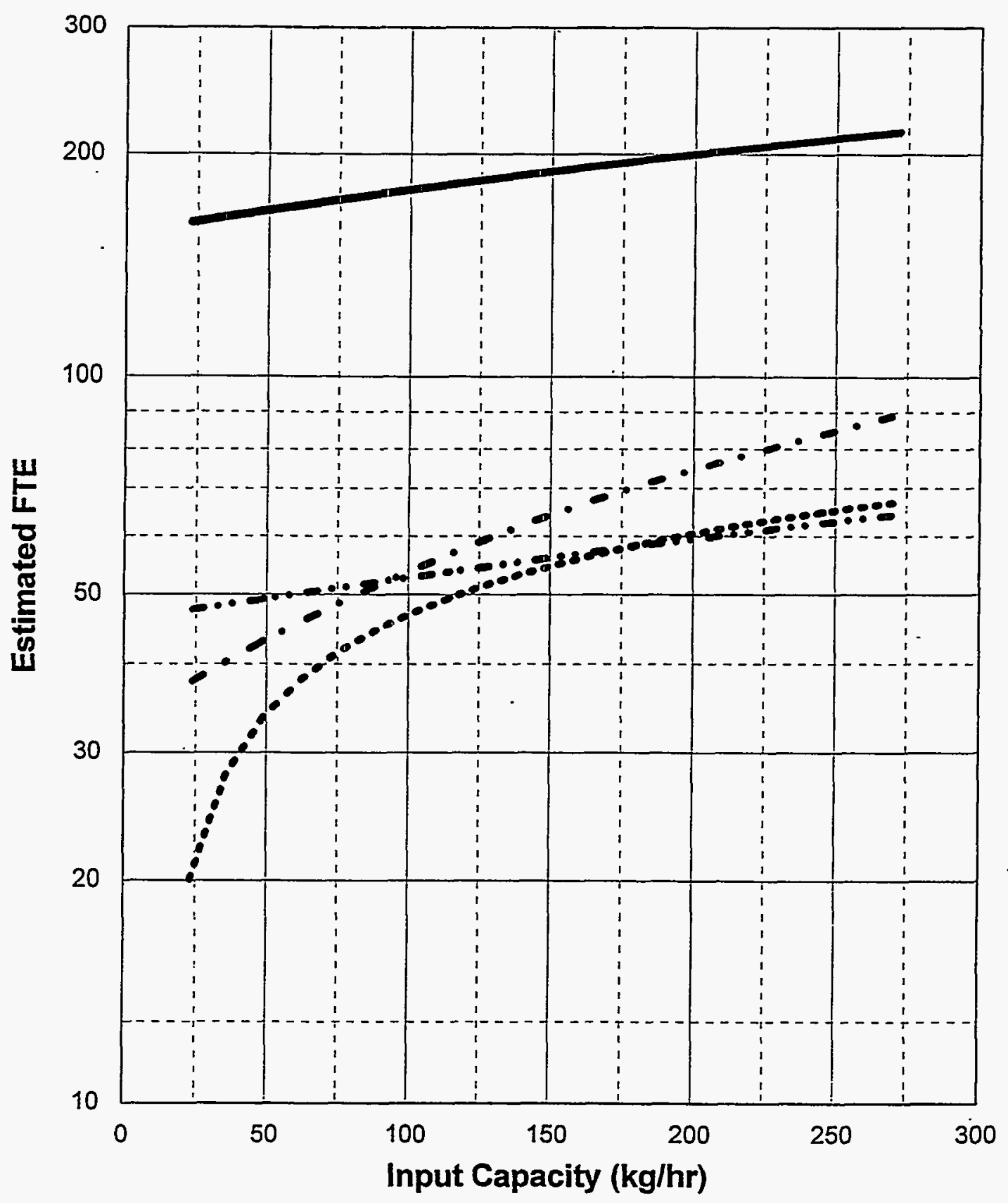

Pre-Operations Construction O\&M (1year) D\&D

Figure 13-6. FTE workers versus capacity for the alpha polymer stabilization (A-PLYMR) module. 


\section{POLYMER STABILIZATION}

FTE by Work Breakdown Structure Element Module: PLYMR Waste Type: Remote Handled LLW

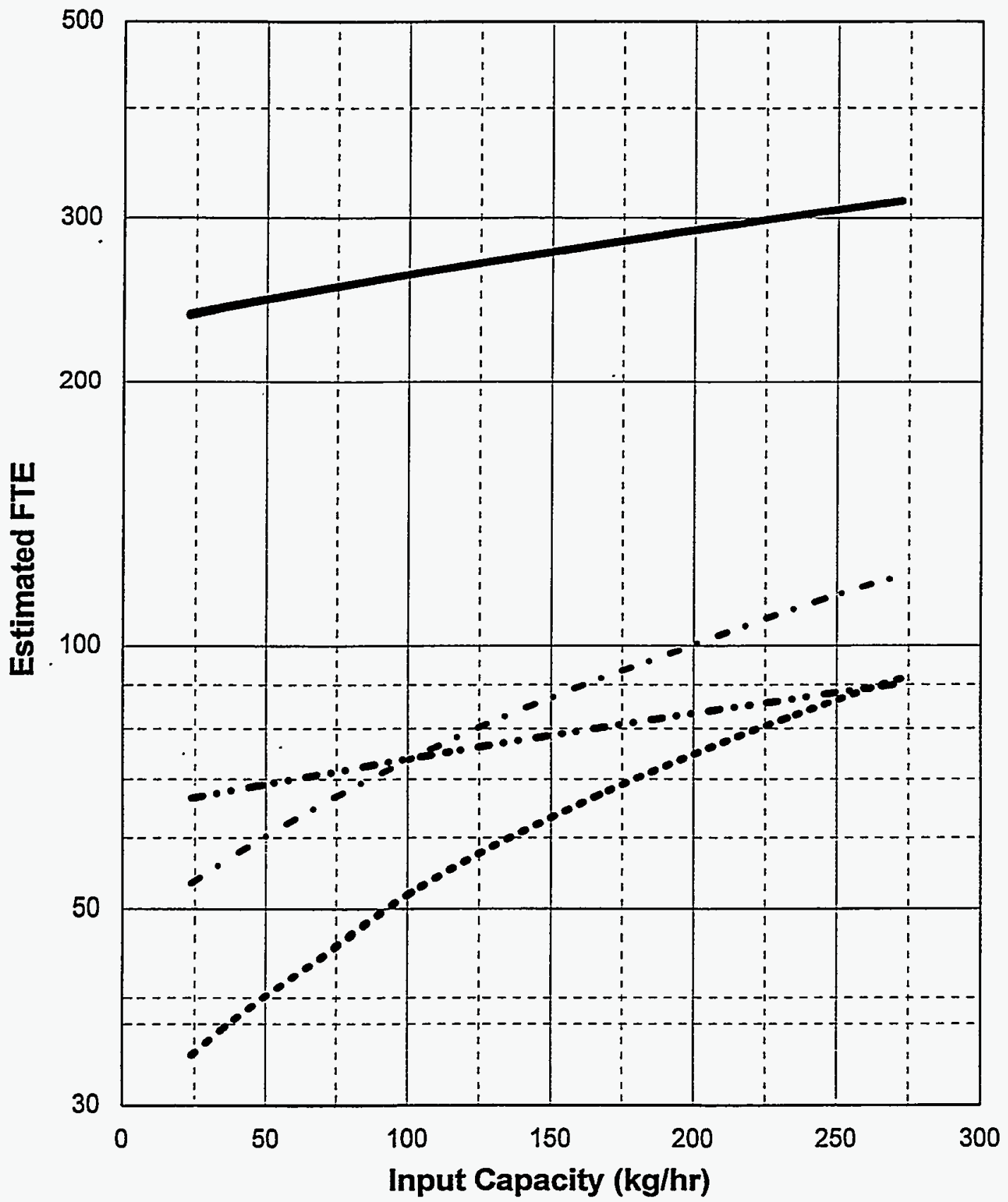

Pre-Operations Construction O\&M (1year) D\&D $\cdot-$

Figure 13-7. FTE workers versus capacity for the RH polymer stabilization (R-PLYMR) module. 


\section{POLYMER STABILIZATION}

Cost by Work Breakdown Structure Element Module: PLYMR Waste Type: Nonalpha LLW

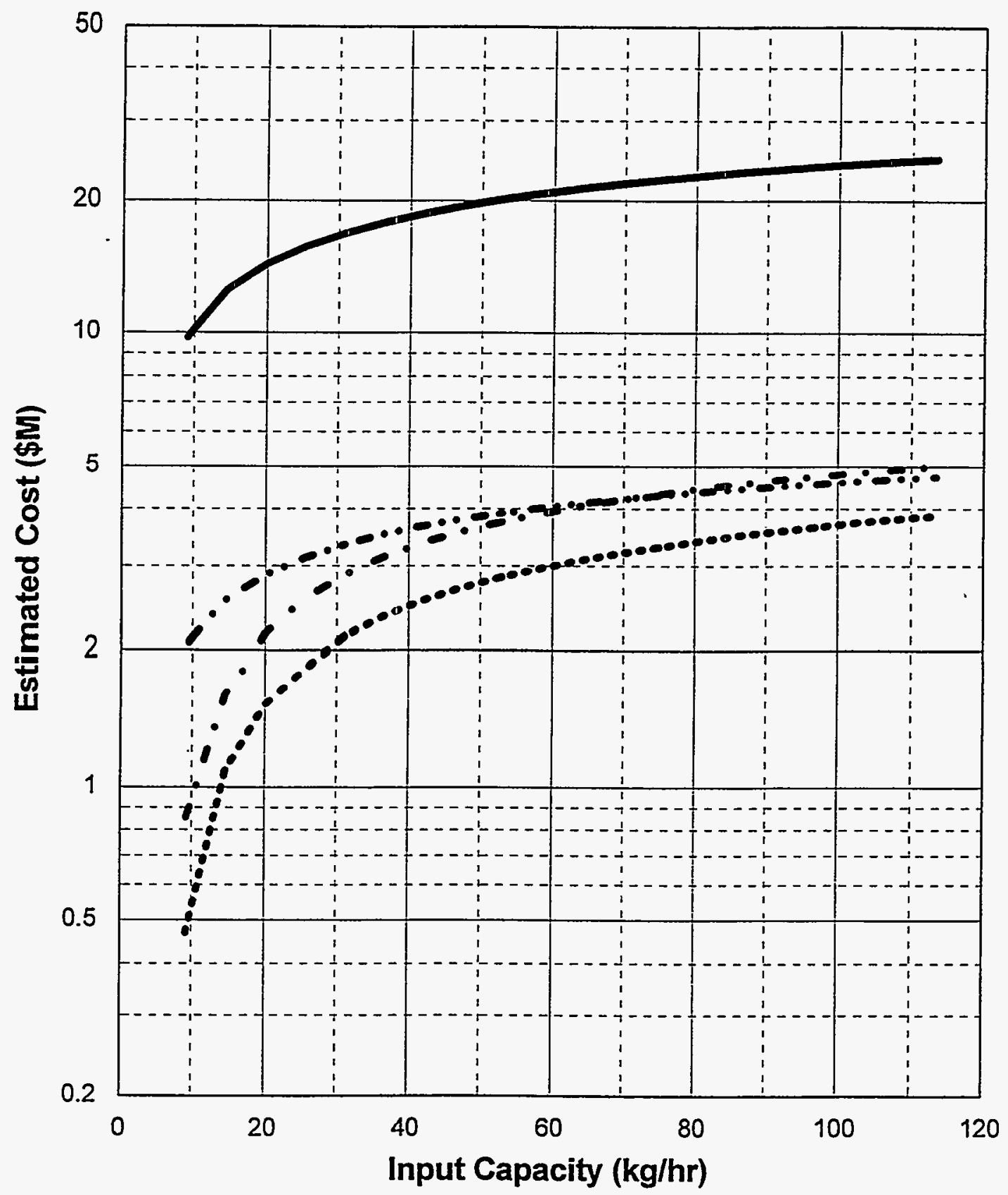

Pre-Operations Construction O\&M (1year) D\&D

Figure 13-8. PLCC versus capacity for the nonalpha polymer stabilization (B-PLYMR) module. 


\section{POLYMER STABILIZATION}

Cost by Work Breakdown Structure Element Module: PLYMR Waste Type: Alpha LLW

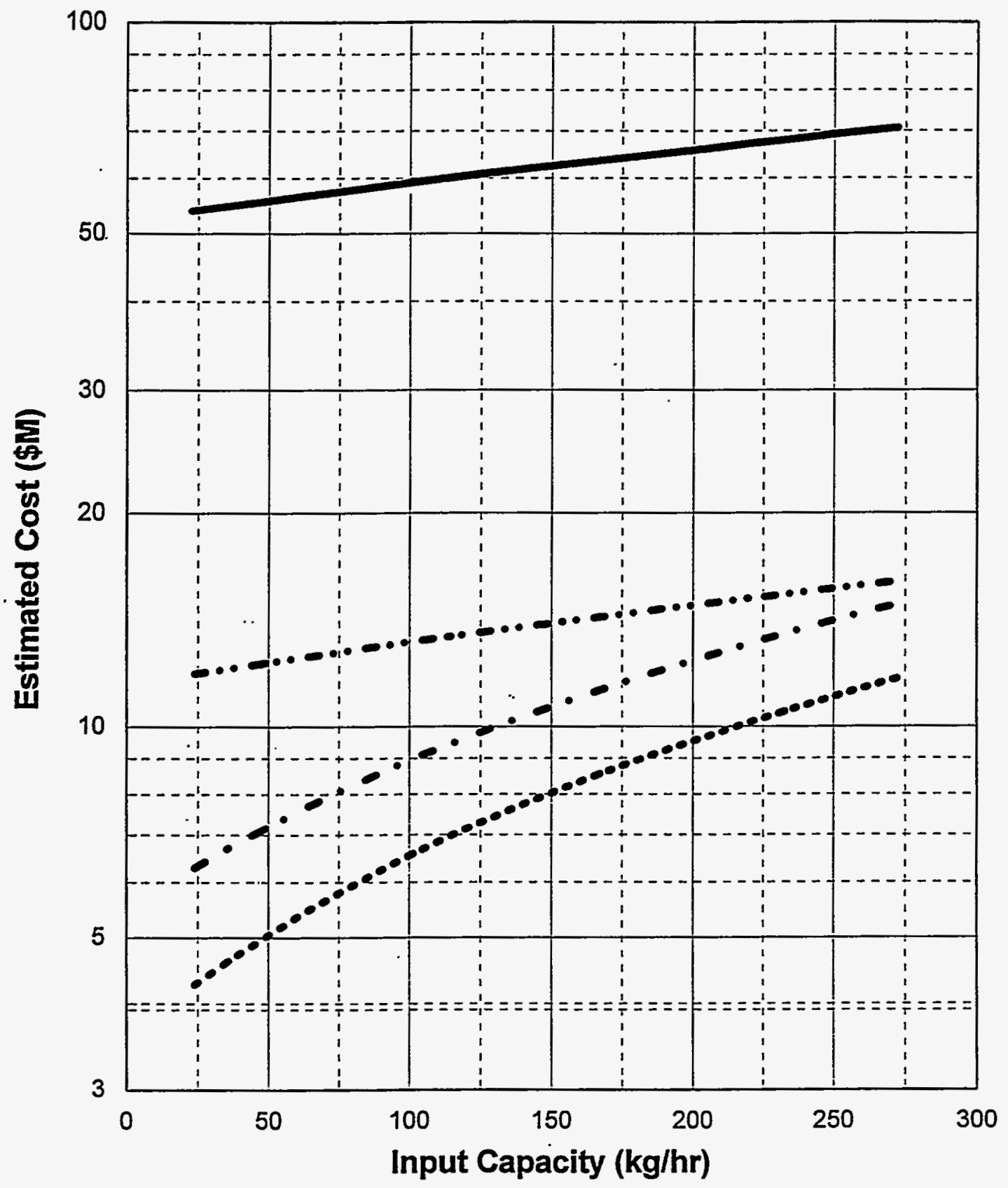

Pre-Operations Construction O\&M (1year) D\&D

Figure 13-9. PLCC versus capacity for the alpha polymer stabilization (A-PLYMR) module. 


\section{POLYMER STABILIZATION}

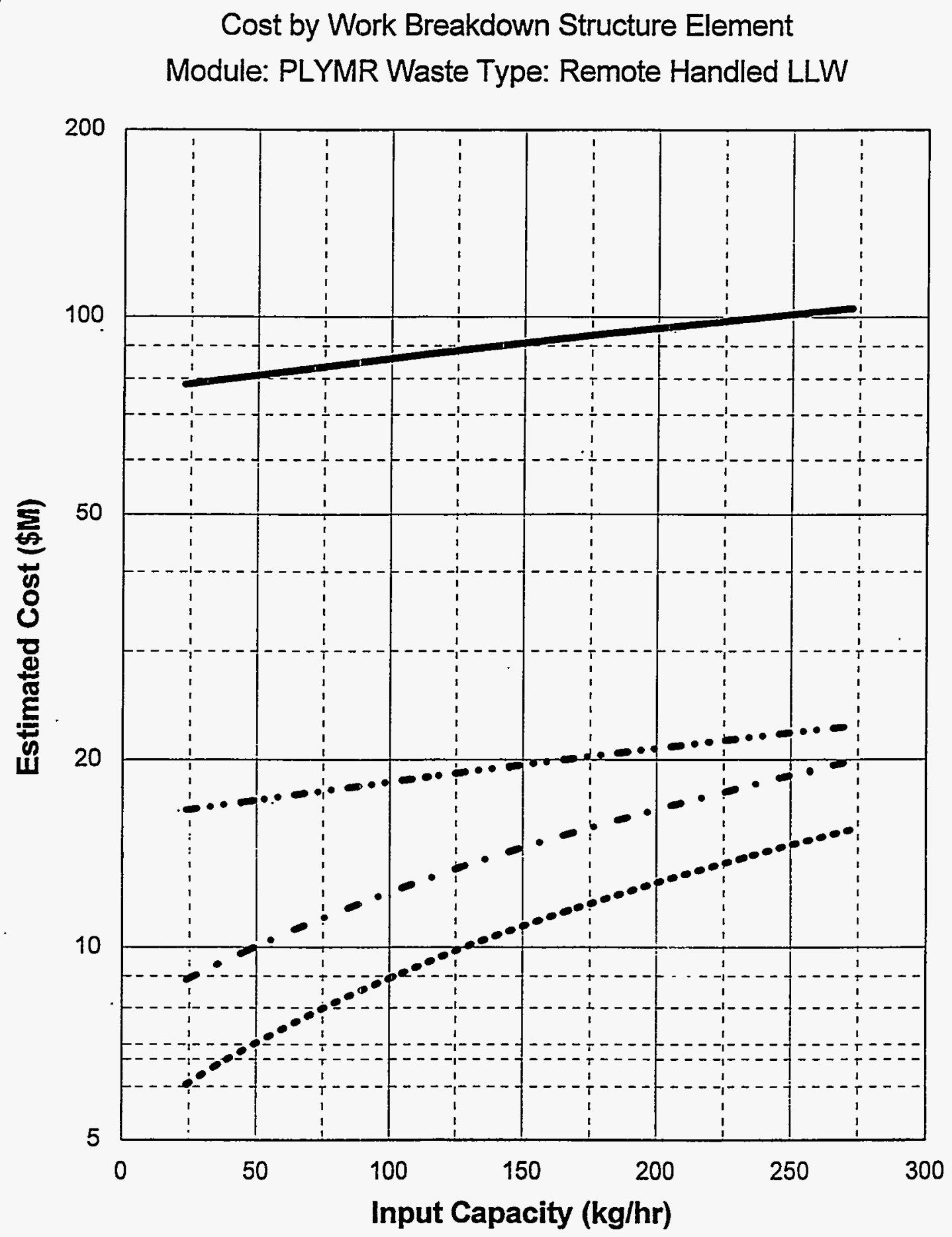

Pre-Operations Construction O\&M (1year) D\&D

Figure 13-10. PLCC versus capacity for the RH polymer stabilization (R-PLYMR) module. 


\section{POLYMER STABLIZATION}

Total Life Cycle Costs

Module: PLYMR Waste Type: Alpha, Nonalpha, and Remote Handled LLW

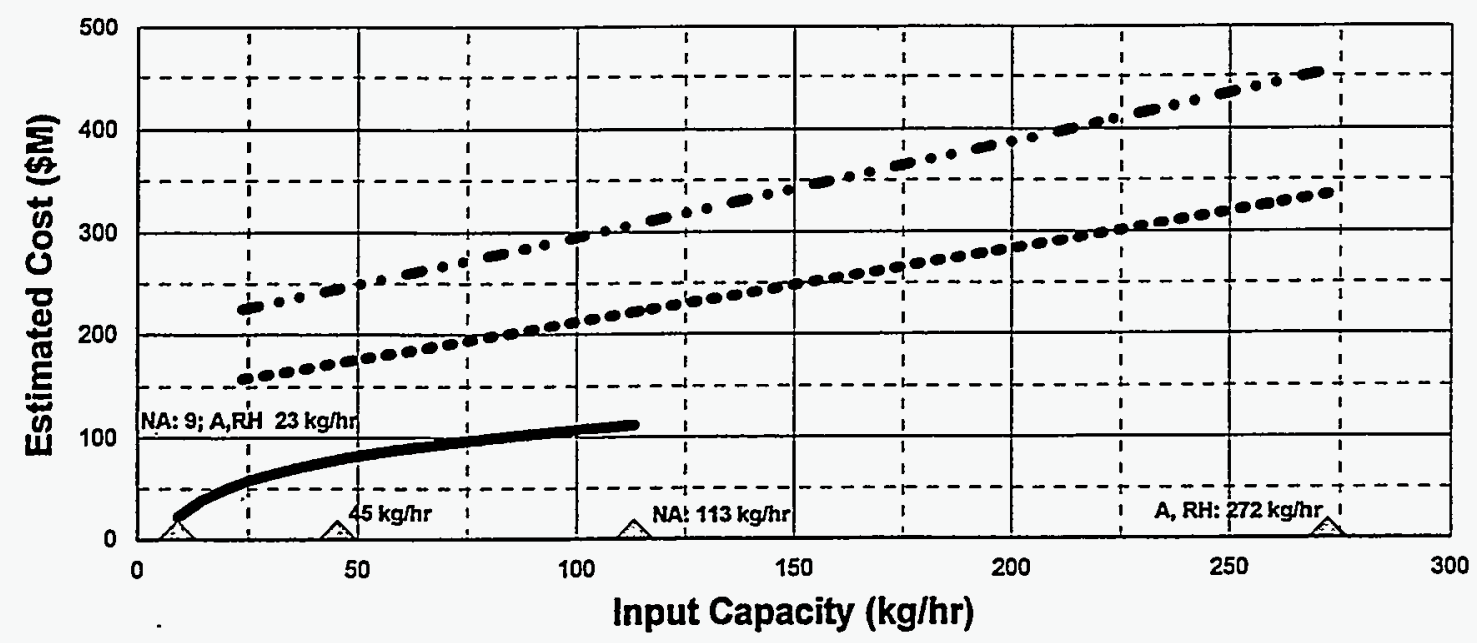

Nonalpha Alpha Remote Handled

NOTE: Basis includes 20 years O\&M

Triangles indicate capacities where detailed cost estimates were developed.

POLYMER STABILIZATION

Total Life Cycle Unit Costs

Module: PLYMR Waste Type: Alpha, Nonalpha, Remote Handled LLW

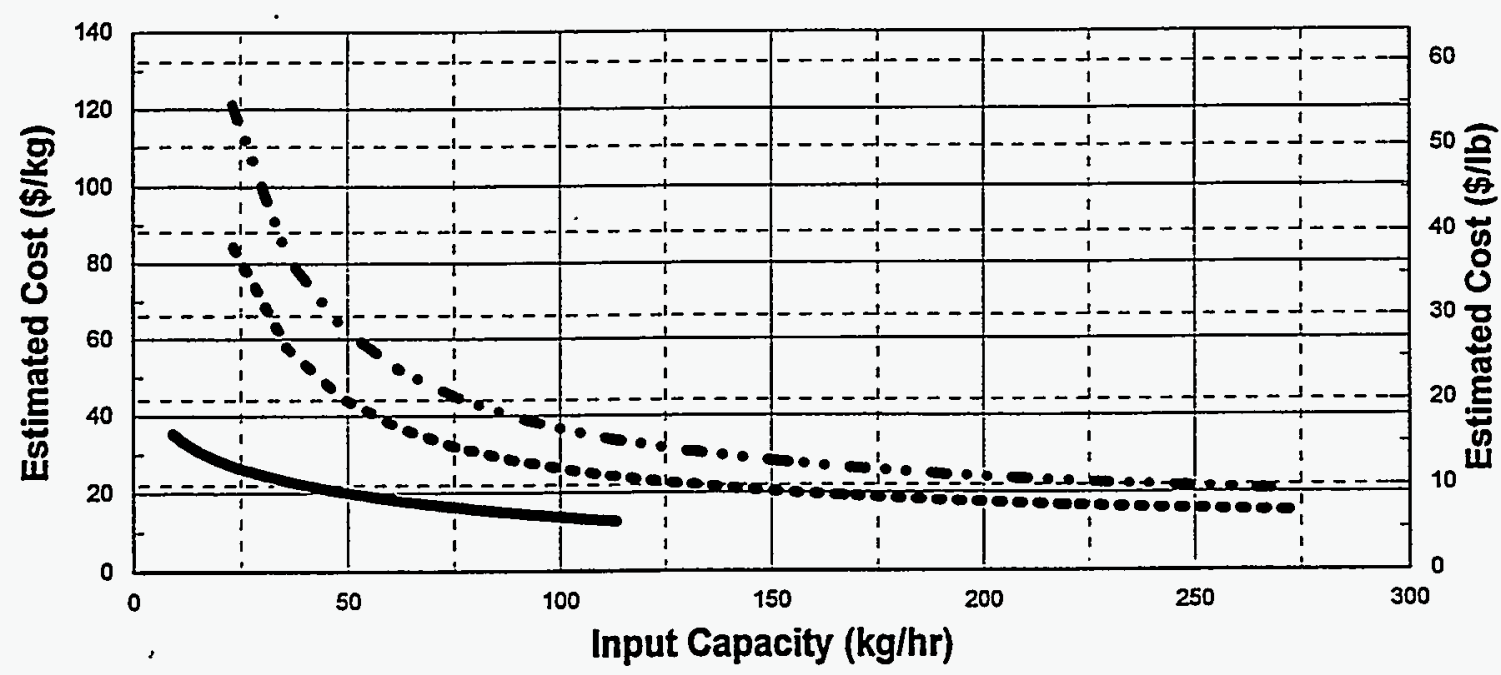

Nonalpha Alpha Remote Handled

NOTE: Basis includes 20 years O\&M

Figure 13-11. PLCC versus capacity including unit rates for the polymer stabilization (PLYMR) module. 


\section{VITRIFICATION (MODULE VITRF)}

\subsection{Basic Information}

The vitrification module, shown in Figure 14-1, consists of 12 operations designed to convert the incoming waste into a leach-resistant, rock- or glass-like material. Vitrified nonalpha, alpha, and $\mathrm{RH}$ waste that is similar in composition to iron-enriched basalt should meet both the land disposal restrictions and DOE disposal requirements (Roads 1992). Secondary liquid is sent to the neutralization (NEUTR) module. Offgas is sent to the offgas treatment unit operation. Secondary waste treatment byproducts, such as offgas scrubber sludge, are sent to the polymer solidification treatment (PLYMR) module. Unit operations are shown in the PFD in Figure 14-2.

The vitrification module processes noncombustible waste such as inorganic sludge, ash, soil, brick, concrete, and other similar material. The module can process solid waste of various shapes and forms. The size limitation imposed by the crusher/shredder is approximately $0.3 \mathrm{~m}^{3}\left(1 \mathrm{ft}^{3}\right)$ and the incoming waste can contain as much as $10 \%$ combustibles. The module is equipped with a predryer for processing wet sludge and solids.

\subsection{Technical Bases and Assumptions}

\subsubsection{Function and Operation of Large Generator Modules}

Specific operations include an input waste preparation and feed unit that crushes and shreds the incoming waste and transfers it to a melter unit operation. At the melter unit operation, a predryer, operating at approximately $300-400^{\circ} \mathrm{F}$, receives, dries, and feeds shredded waste and any sludge that must be vitrified to a vitrification furnace (or melter). Soil is added to the melter through a soil storage and feed unit operation. The furnace melts the soil and waste to form a molten slag. A slag cooling and packaging unit is used to receive the molten slag from the melter and cast it into containers. Containers are then sealed and washed by high-pressure water to remove loose contamination from the container surface. Containers are then sent out of this module to the certification and shipping (CSHIP) module.

The melter is equipped with a secondary combustion unit that completes the volatile gas destruction. An induced air blower moves the secondary combustor effluent through the air pollution control device that is designed to remove particulates. A surge tank retains offgas for reprocessing in the event of a process upset. Secondary liquid waste is sent to the aqueous waste-treatment module.

\subsubsection{Integration of Large Generator Modules}

Major module inputs include waste from the open, dump, and sort (OSORT) module, waste from the generator sites, and soil. Major O\&M purchased materials are consumables, such as personal protective equipment, laboratory material, binder, soil, and disposable containers.

Major module outputs are containerized and vitrified. Nonalpha and alpha wastes are transported to a certification and shipping (CSHIP) module. Treated offgas is discharged into the atmosphere. Secondary liquid waste is sent to the aqueous waste treatment module. 


\subsection{Cost Bases, Assumptions, and Results}

Incoming waste sizing and preparation (shredders) and the melter and its offgas unit are the major equipment capital cost items. Costs for the preparation and feed unit are based on vendor quotes for shredders, conveyors, and dust collection equipment. Melter prices are based on cost quotes received from two vendors, Callidus Technologies and Retec. Callidus Technologies provided cost quotes for the various offgas units. Estimated FTEs and PLCC versus capacity are shown in Figures 14-3 to 14-9. 


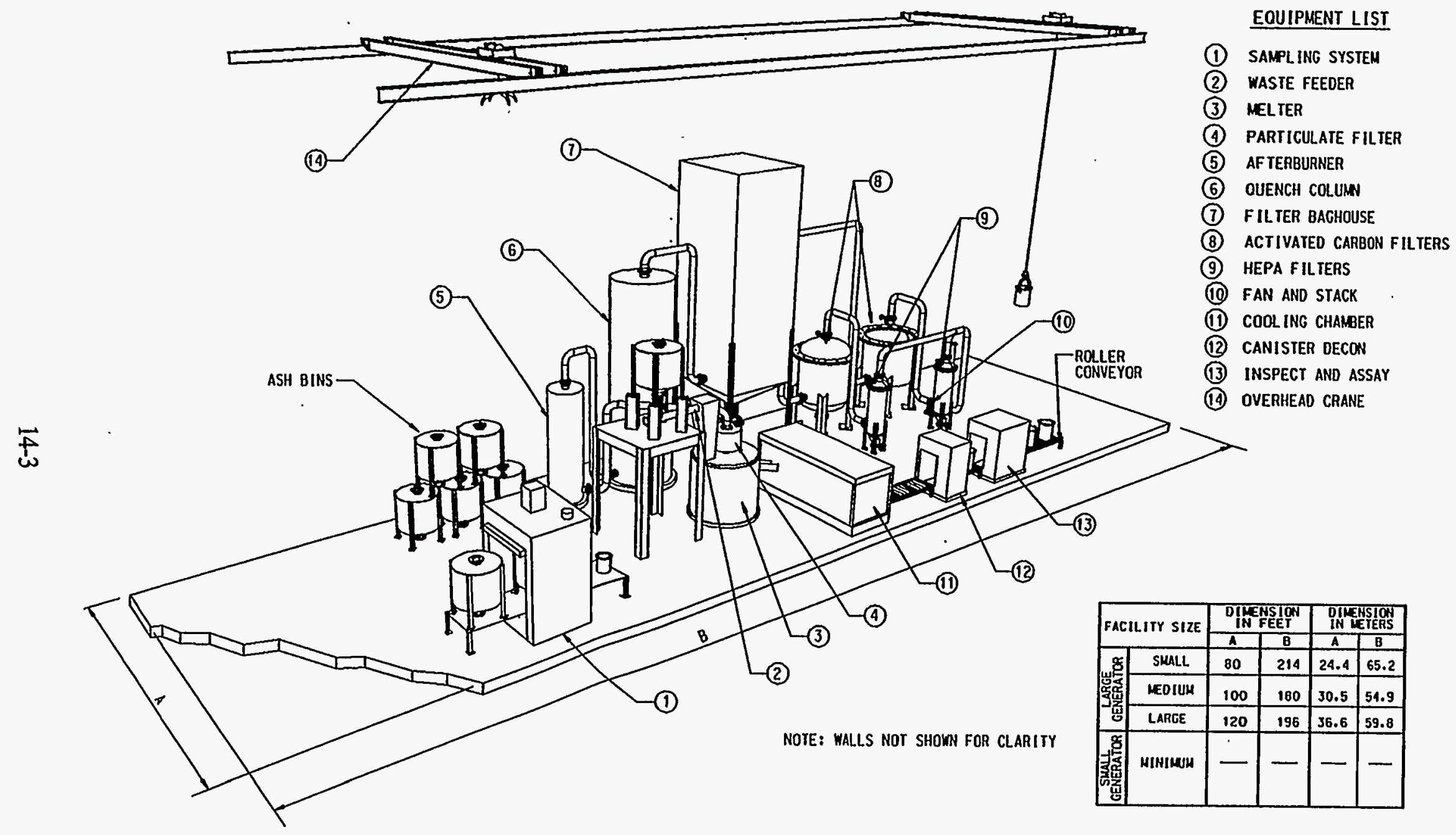

Figure 14-1. Equipment layout for the vitrification (VITRF) module. 


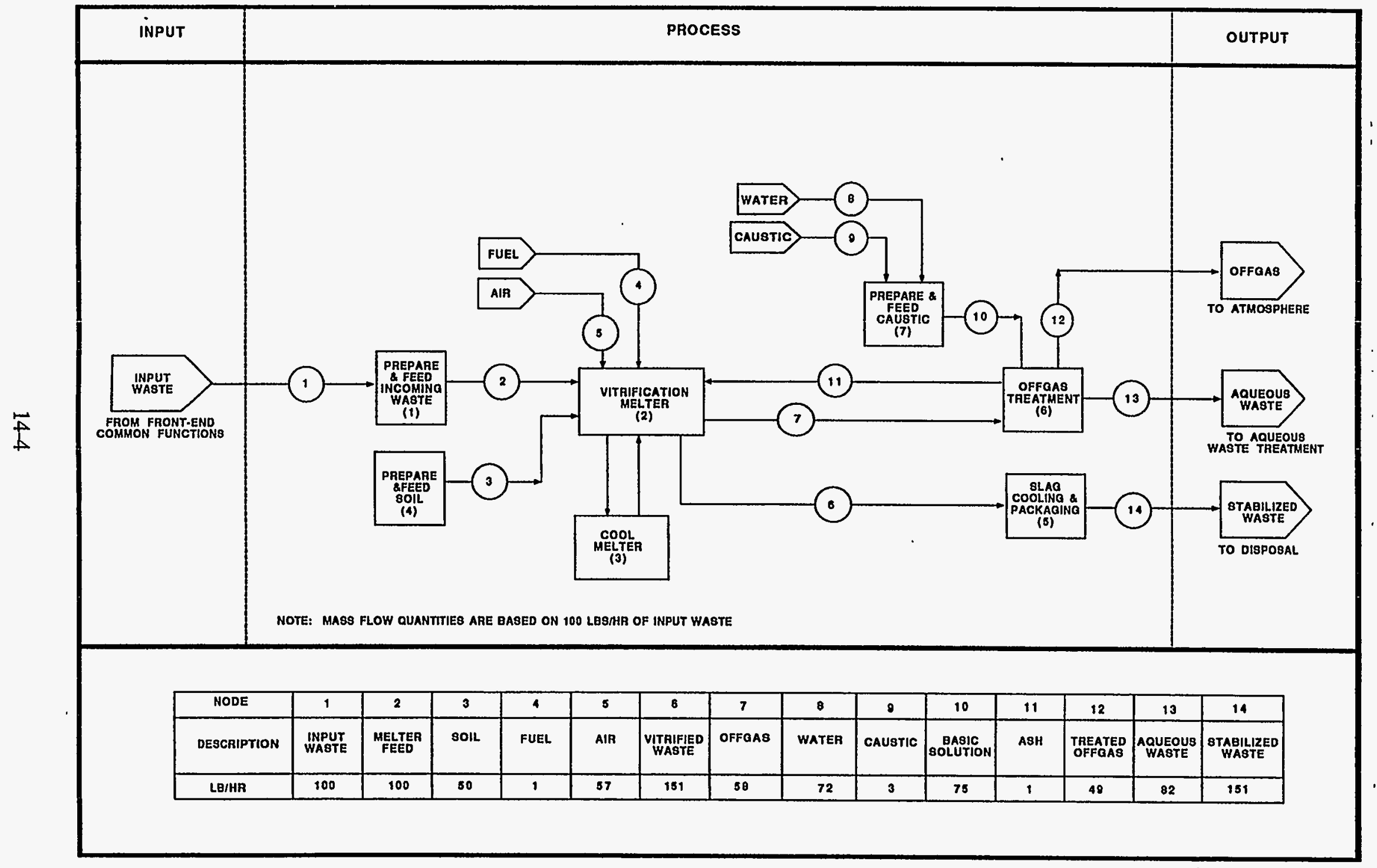

Figure 14-2. Process flow diagram for the vitrification (VITRF) module. 


\section{VITRIFICATION}

FTE by Work Breakdown Structure Element Module: VITRF Waste Type: Nonalpha LLW

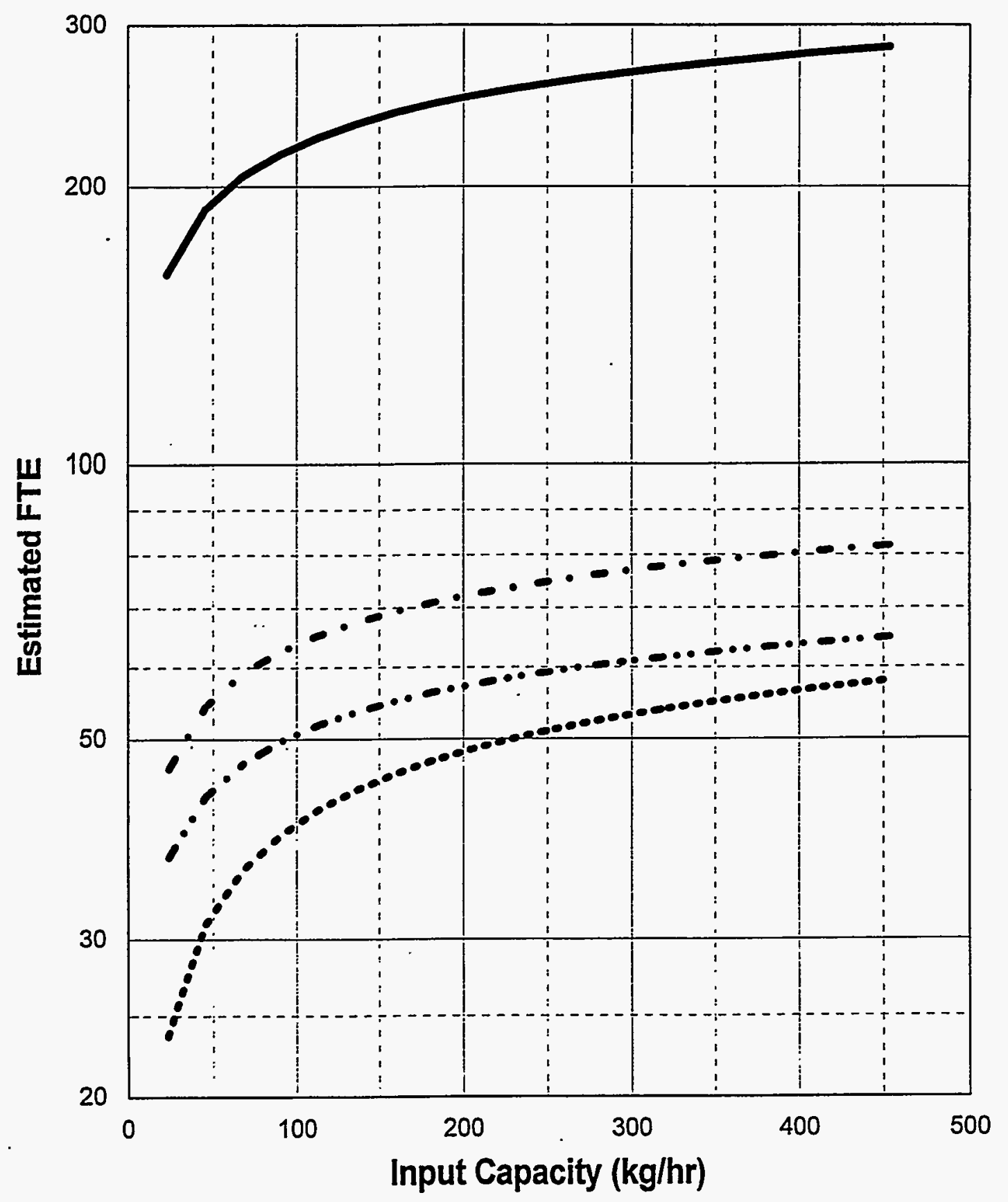

Pre-Operations Construction O\&M (1year) D\&D

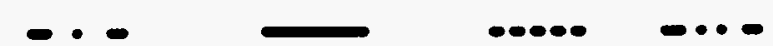

Figure 14-3. FTE workers capacity for the nonalpha vitrification (B-VITRF) module. 


\section{VITRIFICATION}

FTE by Work Breakdown Structure Element Module: VITRF Waste Type: Alpha LLW

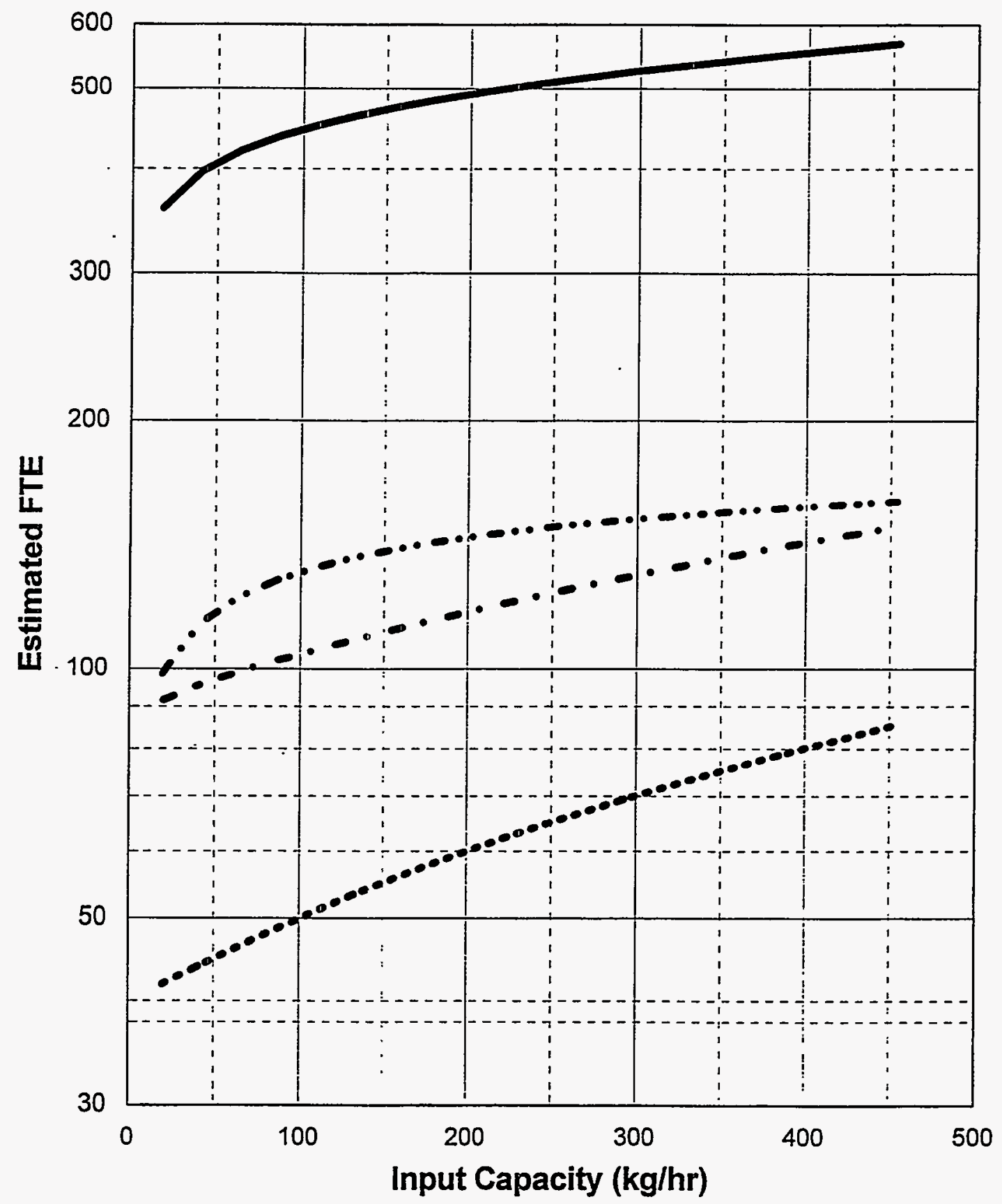

Pre-Operations Construction O\&M (1year) D\&D

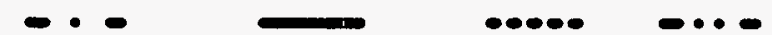

Figure 14-4. FTE workers versus capacity for the alpha vitrification (A-VITRF) module. 


\section{VITRIFICATION}

FTE by Work Breakdown Structure Element

Module: VITRF Waste Type: Remote Handled LLW

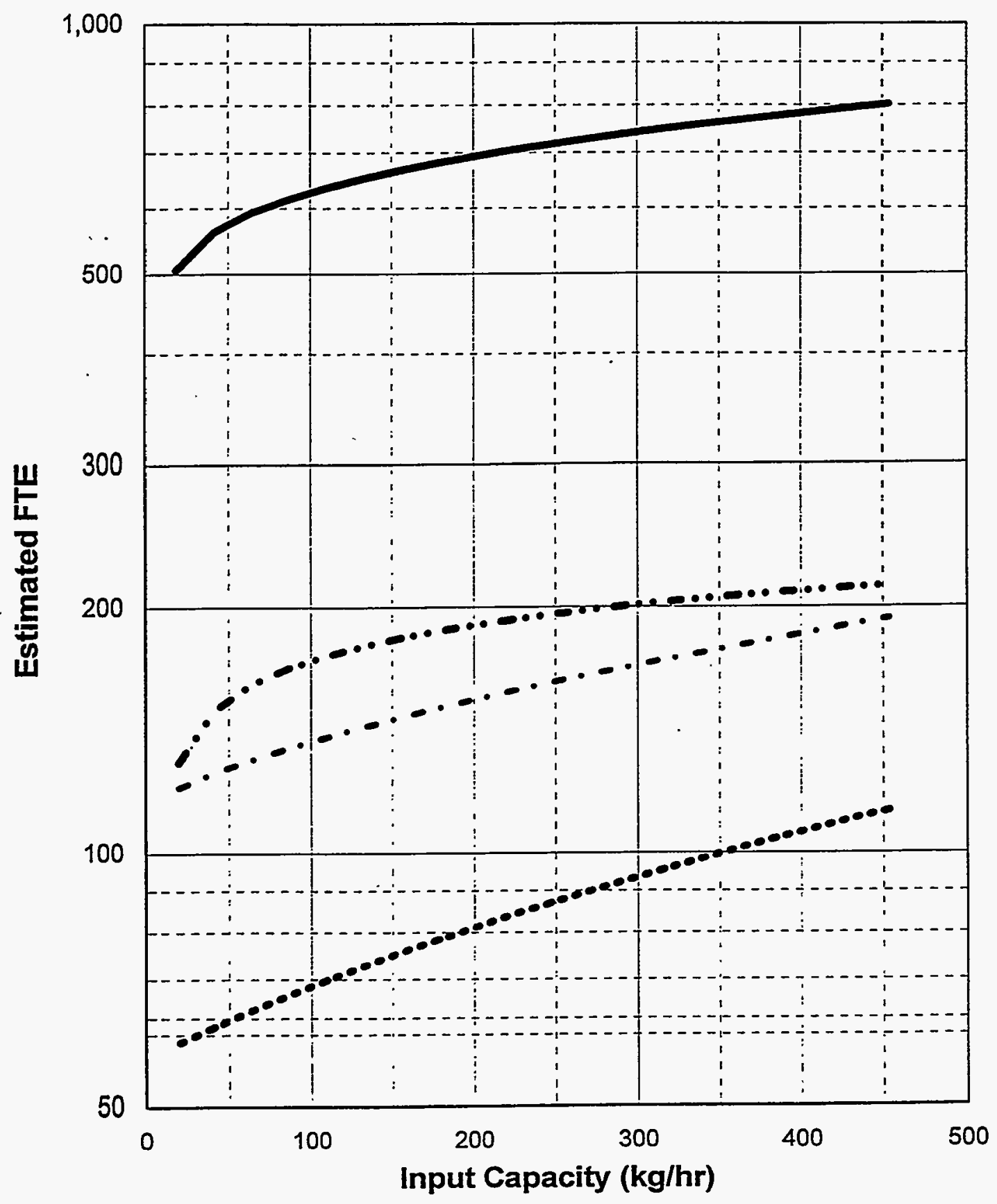

Pre-Operations Construction O\&M (1year) D\&D

Figure 14-5. FTE workers versus capacity for the RH vitrification (R-VITRF) module. 


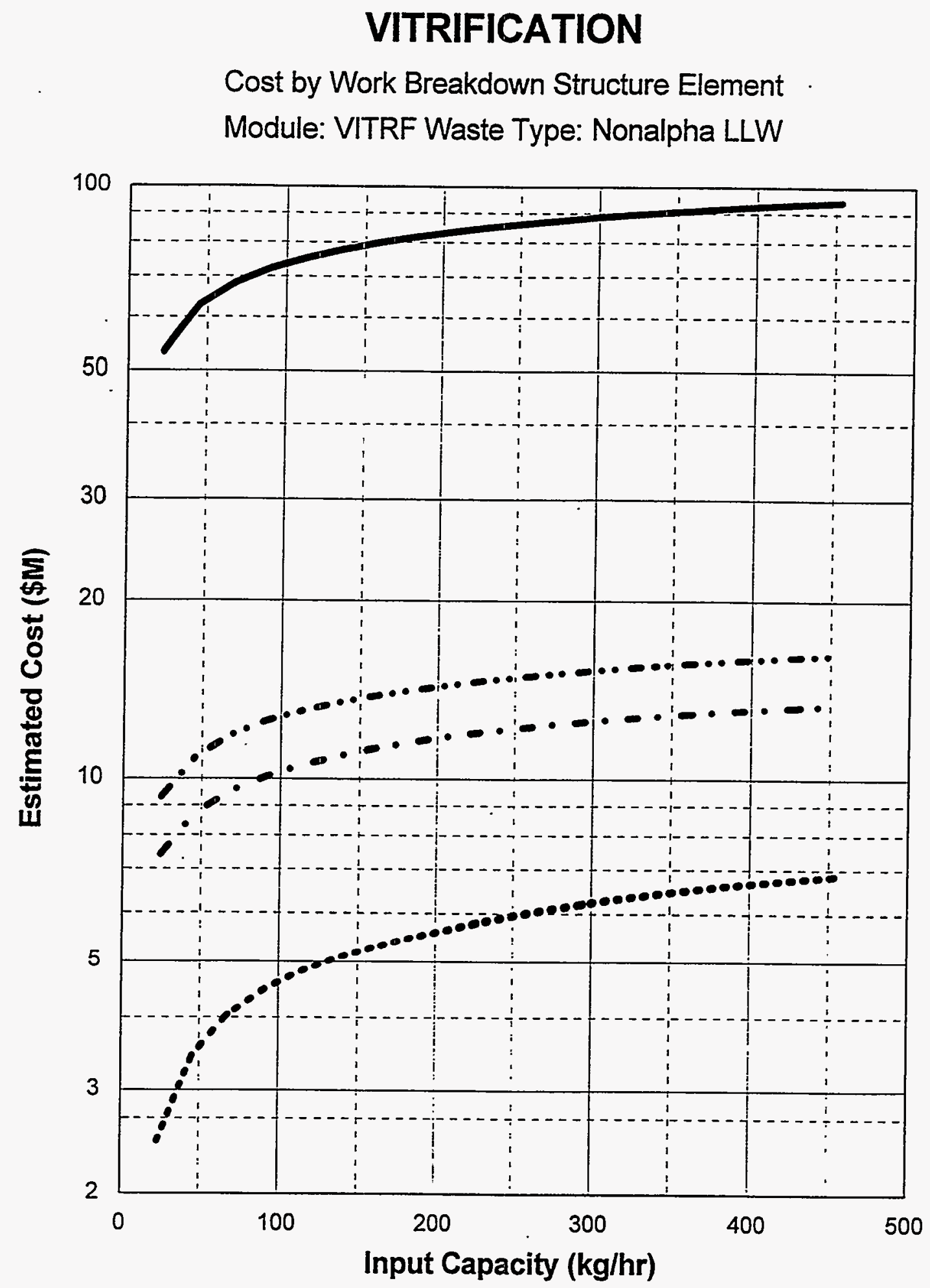

Pre-Operations Construction O\&M (1year) D\&D

Figure 14-6. PLCC versus capacity for the nonalpha vitrification (B-VITRF) module. 


\section{VITRIFICATION}

Cost by Work Breakdown Structure Element Module: VITRF Waste Type: Alpha LLW

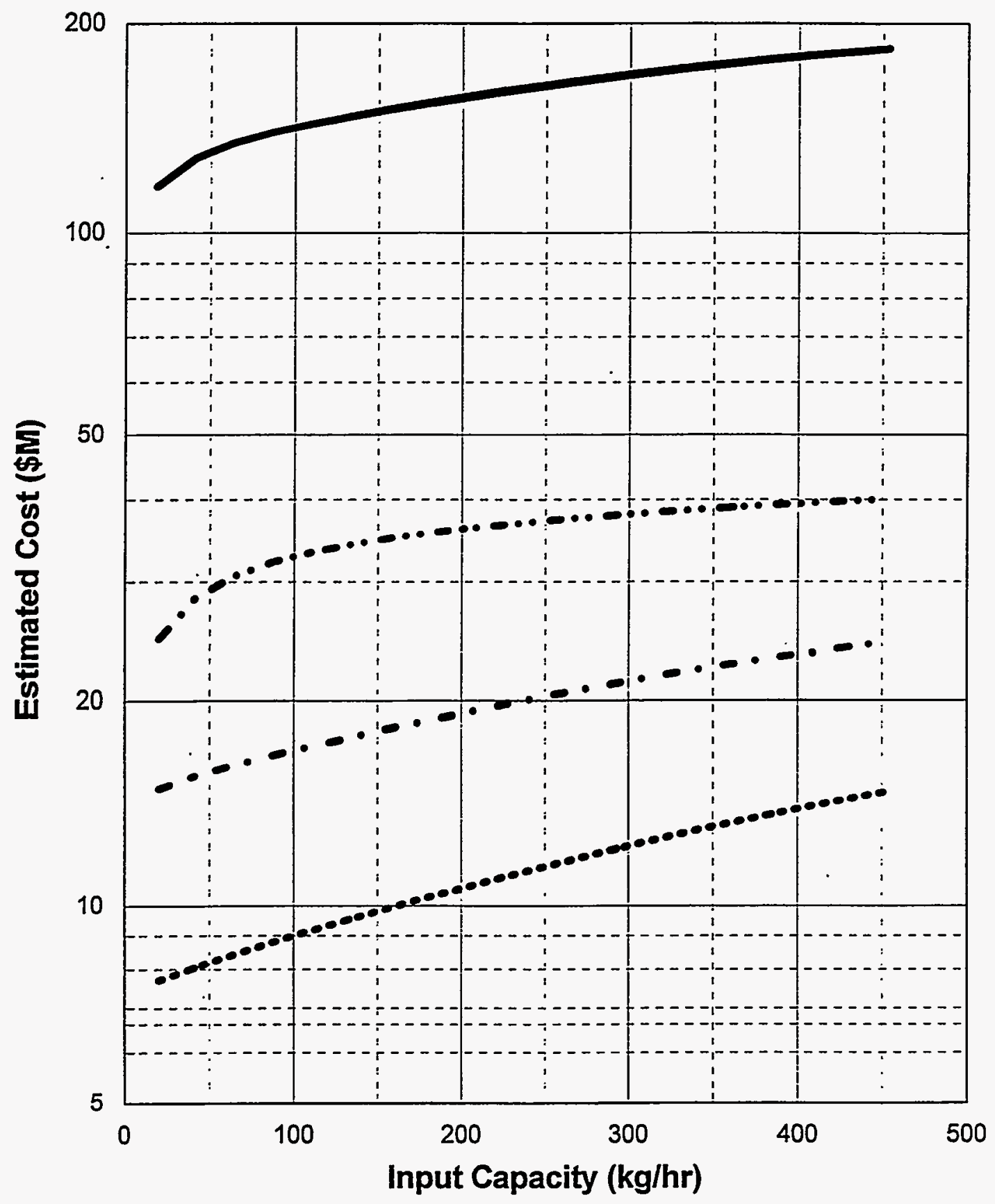

Pre-Operations Construction O\&M (1year) D\&D

Figure 14-7. PLCC versus capacity for the alpha vitrification (A-VITRF) module. 


\section{VITRIFICATION}

Cost by Work Breakdown Structure Element Module: VITRF Waste Type: Remote Handled LLW

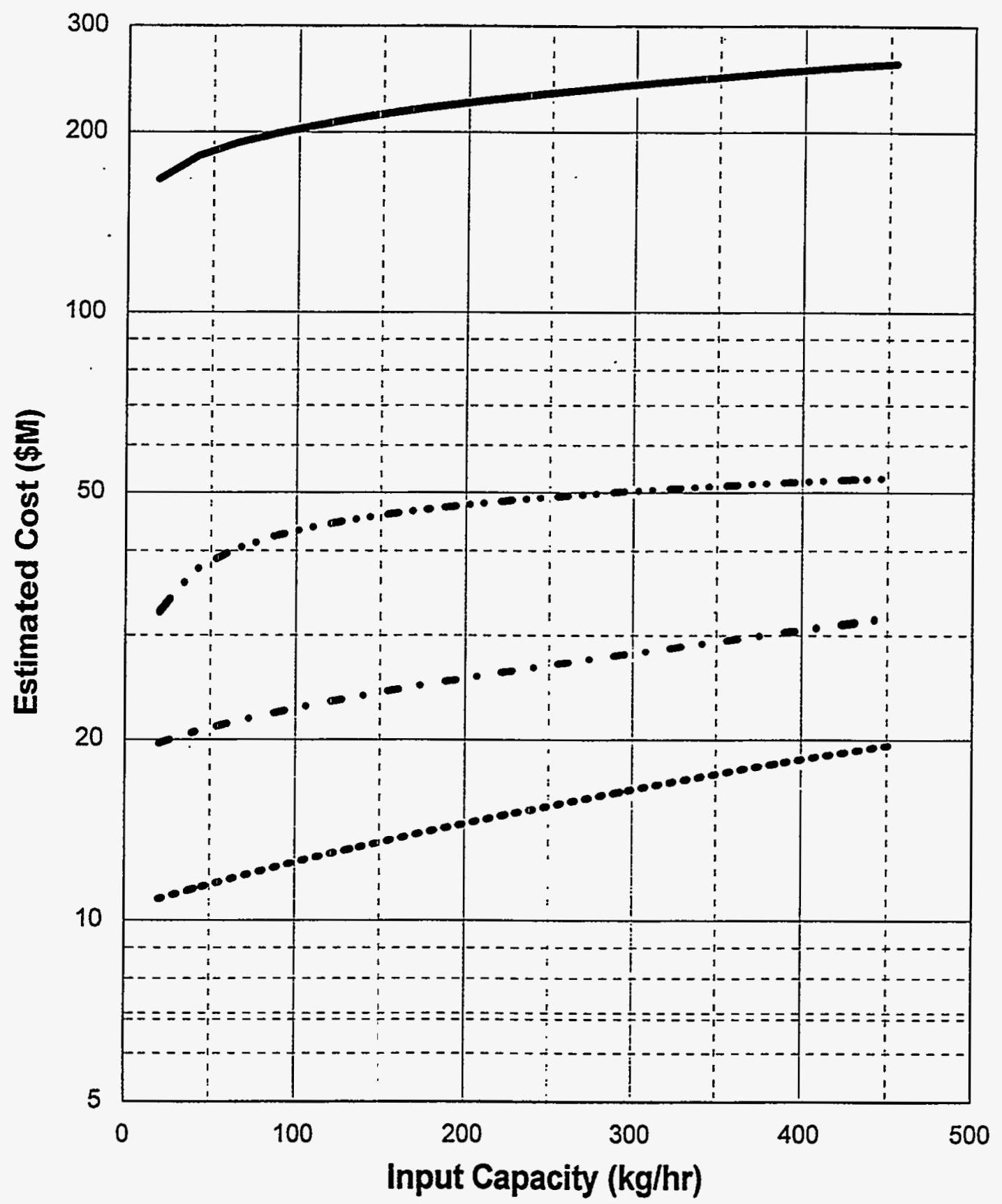

Pre-Operations Construction O\&M (1year) D\&D -.

Figure 14-8. PLCC versus capacity for the RH vitrification (R-VITRF) module. 


\section{VITRIFICATION}

Total Life Cycle Costs

Module: VITRF Waste Type: Alpha, Nonalpha, and Remote Handled LLW

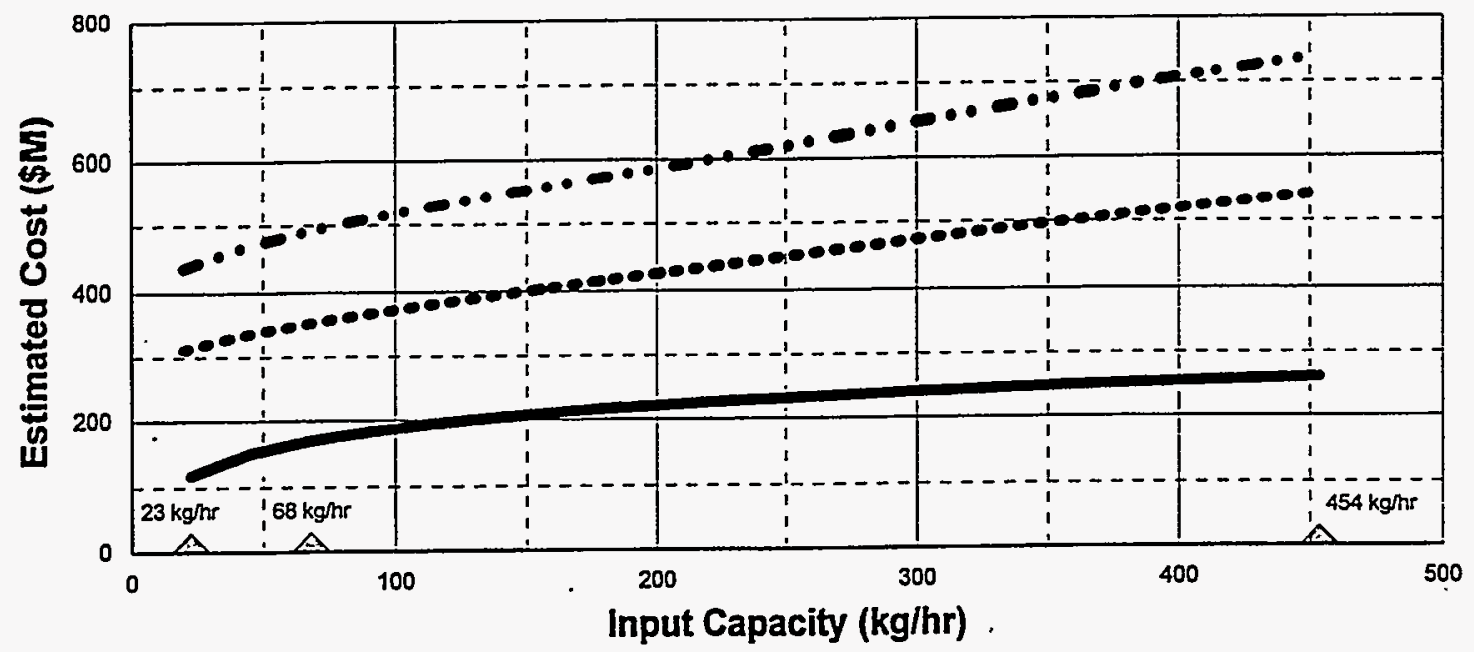

Nonalpha Alpha Remote Handled

NOTE: Basis includes 20 years O\&M

Triangles indicate where detailed cost estimates were developed.

\section{VITRIFICATION}

Total Life Cycle Unit Costs

Module: VITRF Waste Type: Alpha, Nonalpha, Remote Handled LLW

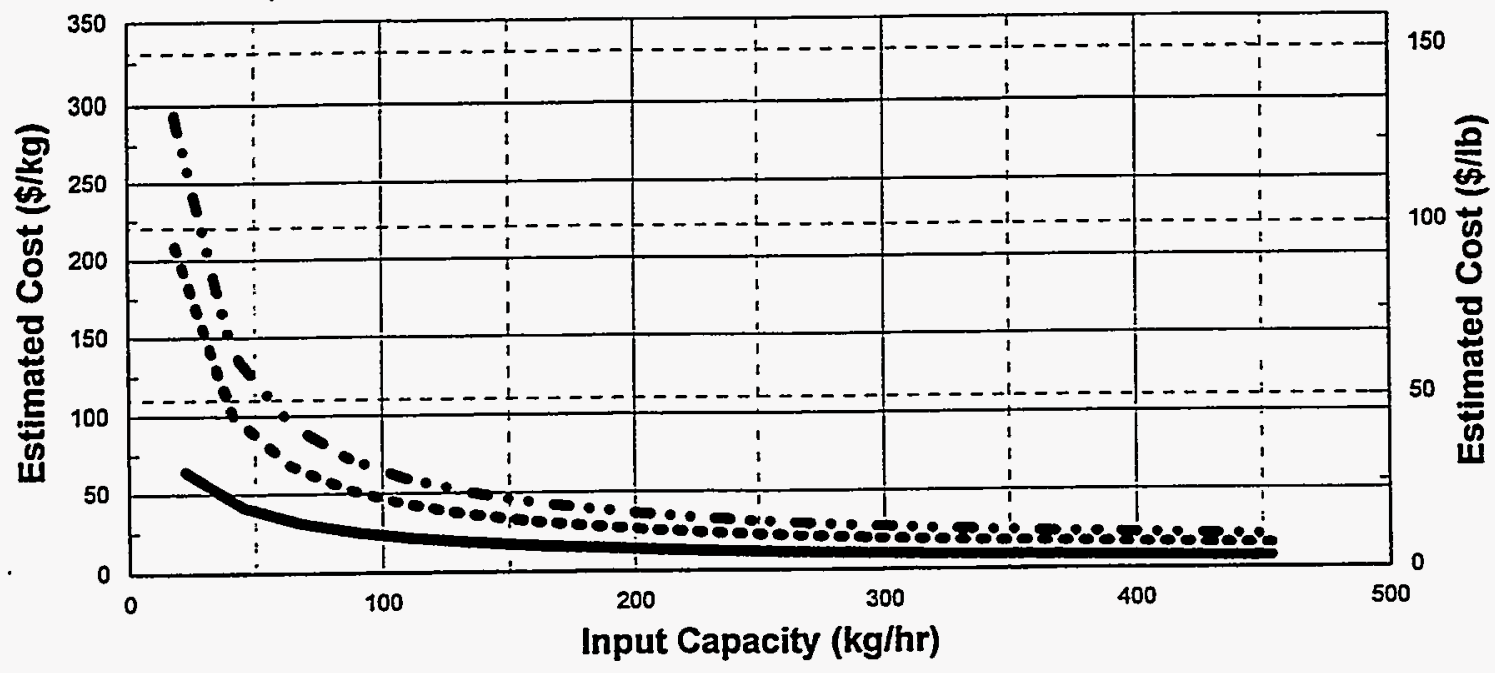

Nonalpha Alpha Remote Handled

NOTE: Basis includes 20 years O\&M

Figure 14-9. PLCC versus capacity including unit rates for the vitrification (VITRF) module. 


\section{PACKAGING (MODULE PACKG)}

\subsection{Basic Information}

The packaging module, shown in Figure 15-1, consists of ten unit operations that incorporate all buildings, systems, processes, equipment, controls, and accessories required to repackage incoming drummed solid waste in overpacks. The modules can process solid waste and metal waste of various shapes and forms. The facility is used in conjunction with modules TADMN, RCINS (or FBSPT), and OSORT, or is constructed adjacent to an existing facility where similar functions are available. Module PACKG is applicable to nonalpha, alpha, and RH waste. Unit operations are shown in the PFD in Figure 15-2.

\subsection{Technical Bases and Assumptions}

\subsubsection{Function and Operation of the Module}

The packaging module is designed to receive drummed waste and to package it in 85-gal overpack containers. In the drum inspection unit operation, drummed waste is inspected for physical integrity. Following inspection, drums that meet the packaging module's acceptance criteria are sent to the overpack, grout, and cap unit operation. Drums that fail are returned to the incoming drum storage area for return to their original location.

In the overpack, grout, and cap unit operation, a lift device picks drums and places them inside 85-gal overpacks. The overpacked drums are then sent to the grouting unit where the void spaces are filled with grout. The overpacks are then capped and sent to the drum washing unit operation, where they are washed and dried before leaving the module.

Liquid waste generated during the operation is collected in a sump and directed to the neutralization module.

\subsubsection{Integration of the Module}

Primary input to the module is waste in drums from the receiving and inspection (RCINS) module or from the open, dump, and sort (OSORT) module. Major O\&M materials, such as personal protective equipment, laboratory material, binders, and overpacks, are assumed to be consumable supplies that must be purchased. Their costs are estimated accordingly.

The overpacks (85-gal drums) containing stabilized 55-gal drums of waste are the main output from this facility. Overpacks are transported to the storage (STORE) module.

\subsection{Cost Bases, Assumptions, and Results}

The major equipment capital cost items include inspection (such as RTR), drum handling, and overpack handling equipment. Estimated FTEs and cost versus capacity for packaging operations are shown in Figures 15-3 through 15-9. 
NOTE: AREAS ALLOCATEO IO SUPPORT UNIT OPERATIONS ARE NOT

SHOWN ON THIS PLAM EECAPSULATING AGENT STOAAGE \&
FEEO. ANO GROUT PREPARAIION UNIT ARE NOT SHOWN
OW THIS PLAN.

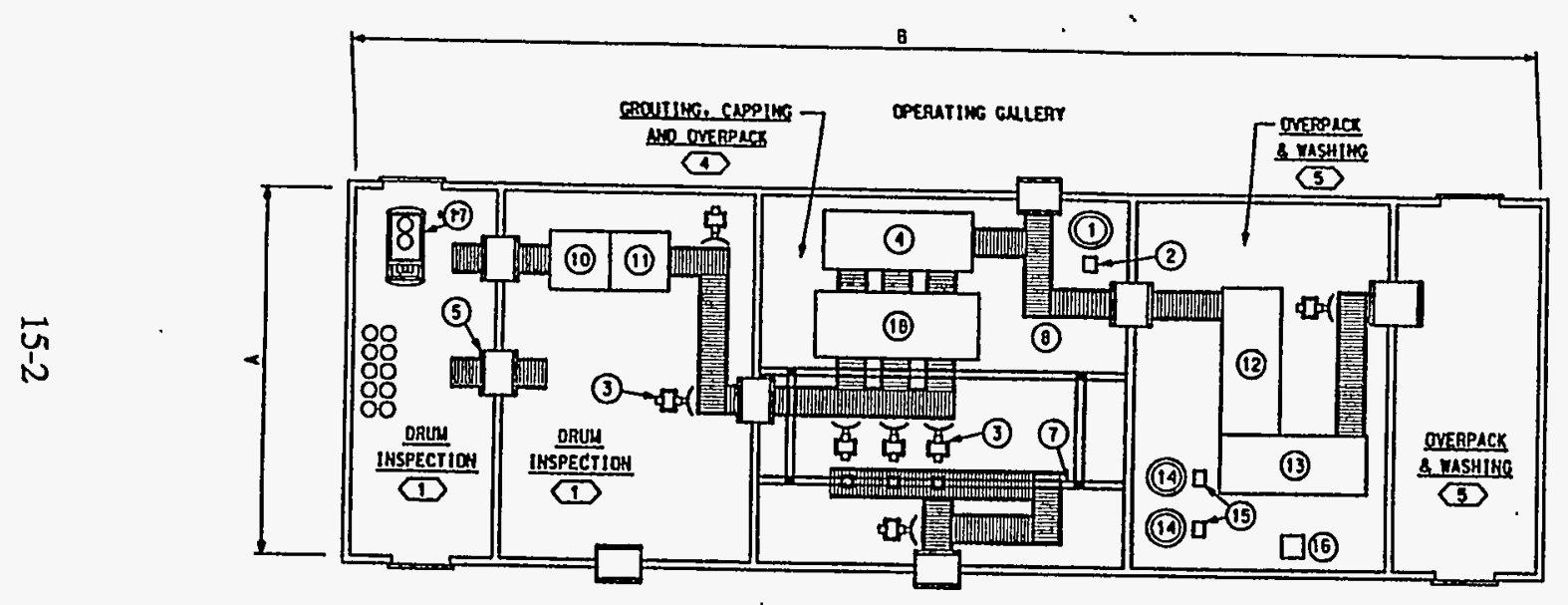

PACKAGING (MODULE PACKG)

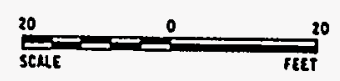

EOUIPMENT LIST

(1) crour oay tarax

(2) GROUT PLP

(3) PRM PUSHER

(4) OVERPACX CAPPING OEYICE

(5) AtRlock ITYP.।

(6) OVERPACK aND GROUTING SYSTEM

(7) overhead crate

(C) holler conveyor

(9) CHEMICAL HIX TANX

(10) contalNer assay Unit

(11) GLOVE gDX ASSAY UNIT

(12) OVERPACX YASH UNIT

(13) ORIER UAIT

(14) chenICal Storage tank

(15) Pusp

(15) PLOXE

(17) SELF-GUIOEO VEHICLE

(18) SOLIOTFICATION UNIT

\begin{tabular}{|c|c|c|c|c|}
\hline \multirow{2}{*}{ FACILITY SIZE } & \multicolumn{2}{|c|}{$\begin{array}{l}\text { OPKESIDIOA } \\
\text { OHFEET }\end{array}$} & \multicolumn{2}{|c|}{$\begin{array}{l}\text { PILEWSION } \\
\text { PN WETESS }\end{array}$} \\
\hline & $a$ & B & $A$ & 8 \\
\hline SLuLLL & 75 & 80 & 22.9 & 24.4 \\
\hline KEDIUY & 120 & 160 & 35.6 & 18.8 \\
\hline LARCE & 150 & 210 & 45.8 & 64.1 \\
\hline
\end{tabular}

Figure 15-1. Equipment layout for the packaging (PACKG) module. 


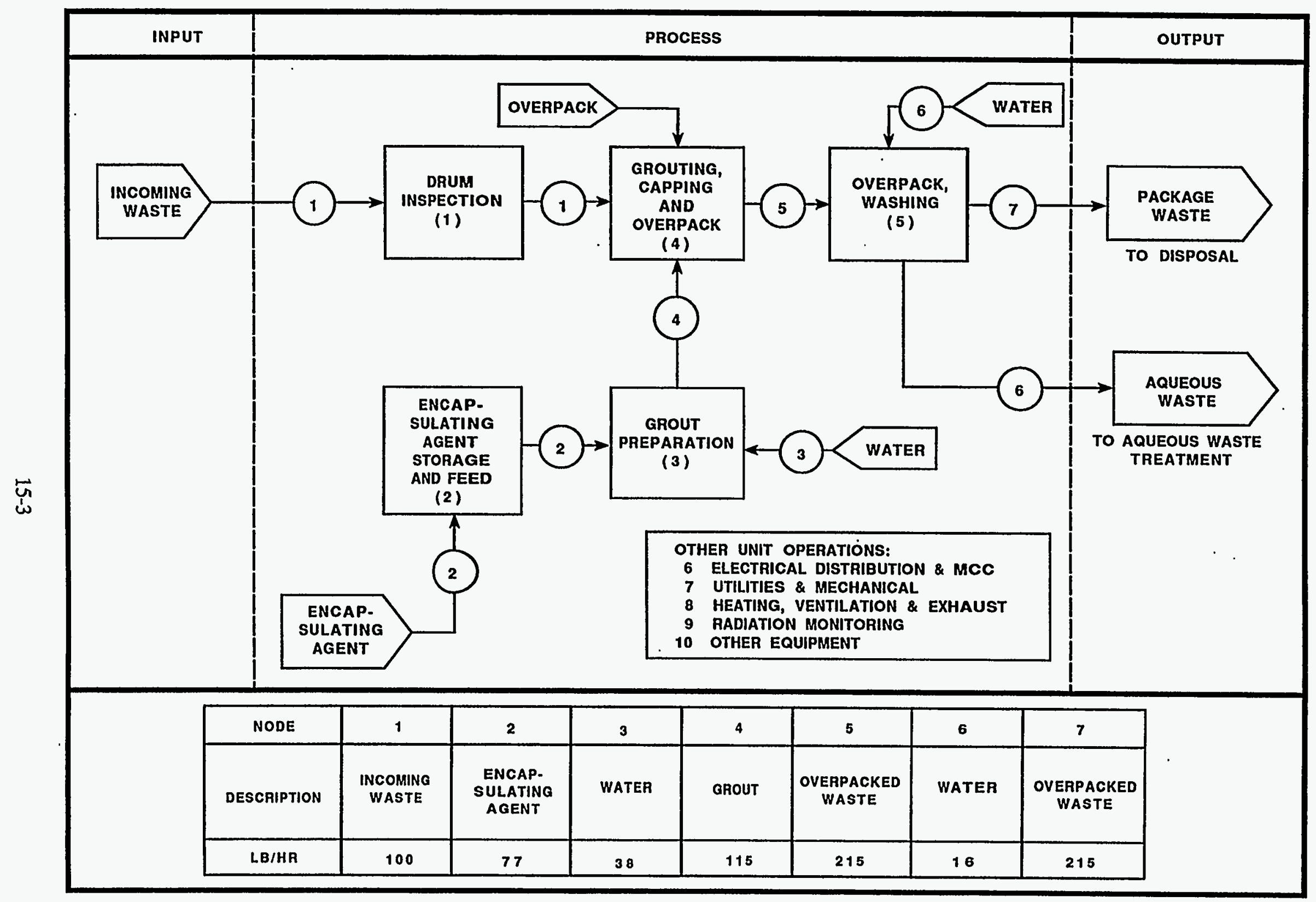

Figure 15-2. Process flow diagram for the packaging (PACKG) module. 


\section{PACKAGING}

FTE by Work Breakdown Structure Element Module: PACKG Waste Type: Nonalpha LLW

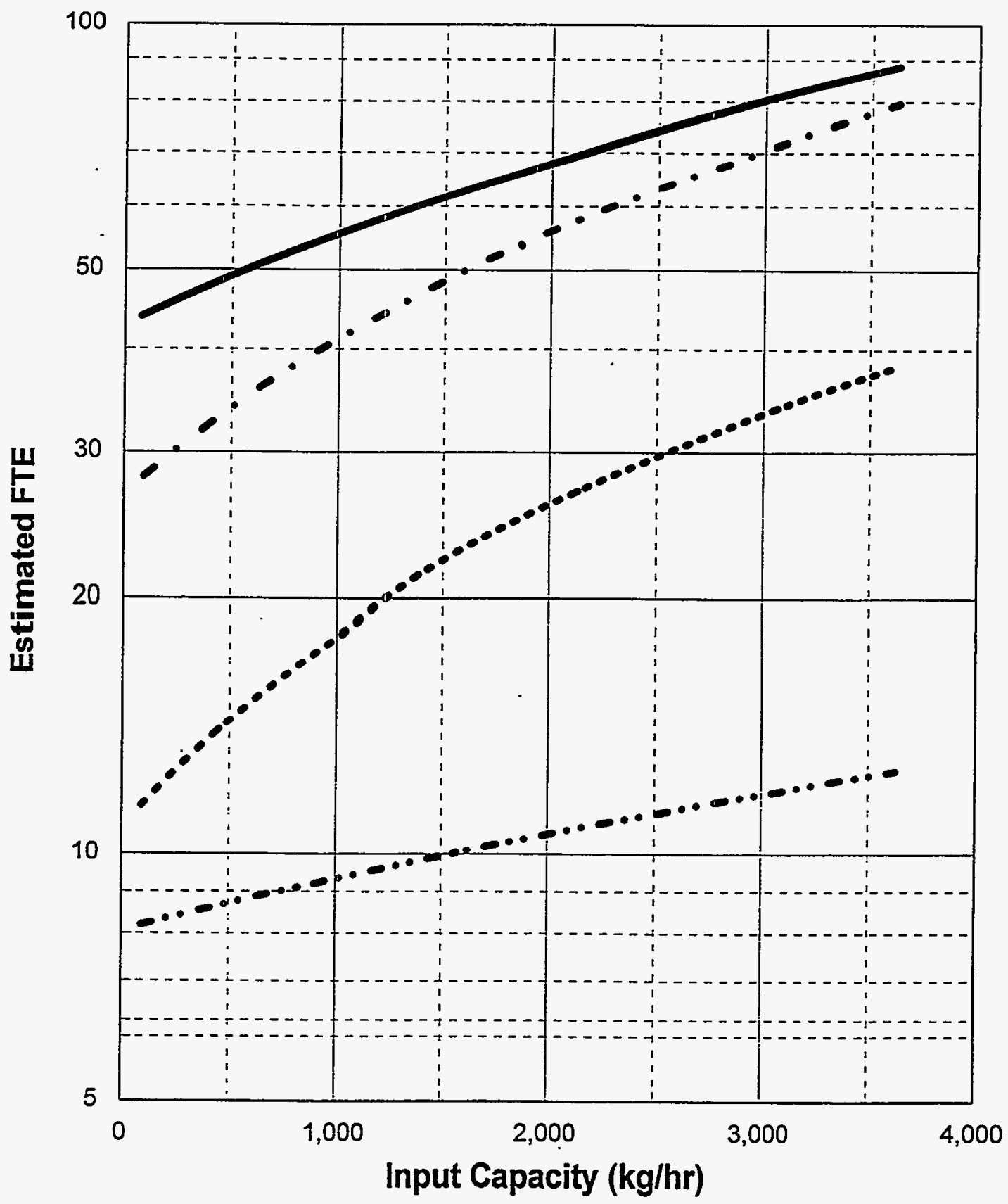

Pre-Operations Construction O\&M (1year) D\&D - $+m$ $\bullet \bullet \bullet-\cdots \bullet$

Figure 15-3. FTE workers versus capacity for the nonalpha waste packaging (B-PACKG) module. 


\section{PACKAGING}

FTE by Work Breakdown Structure Element Module: PACKG Waste Type: Alpha LLW

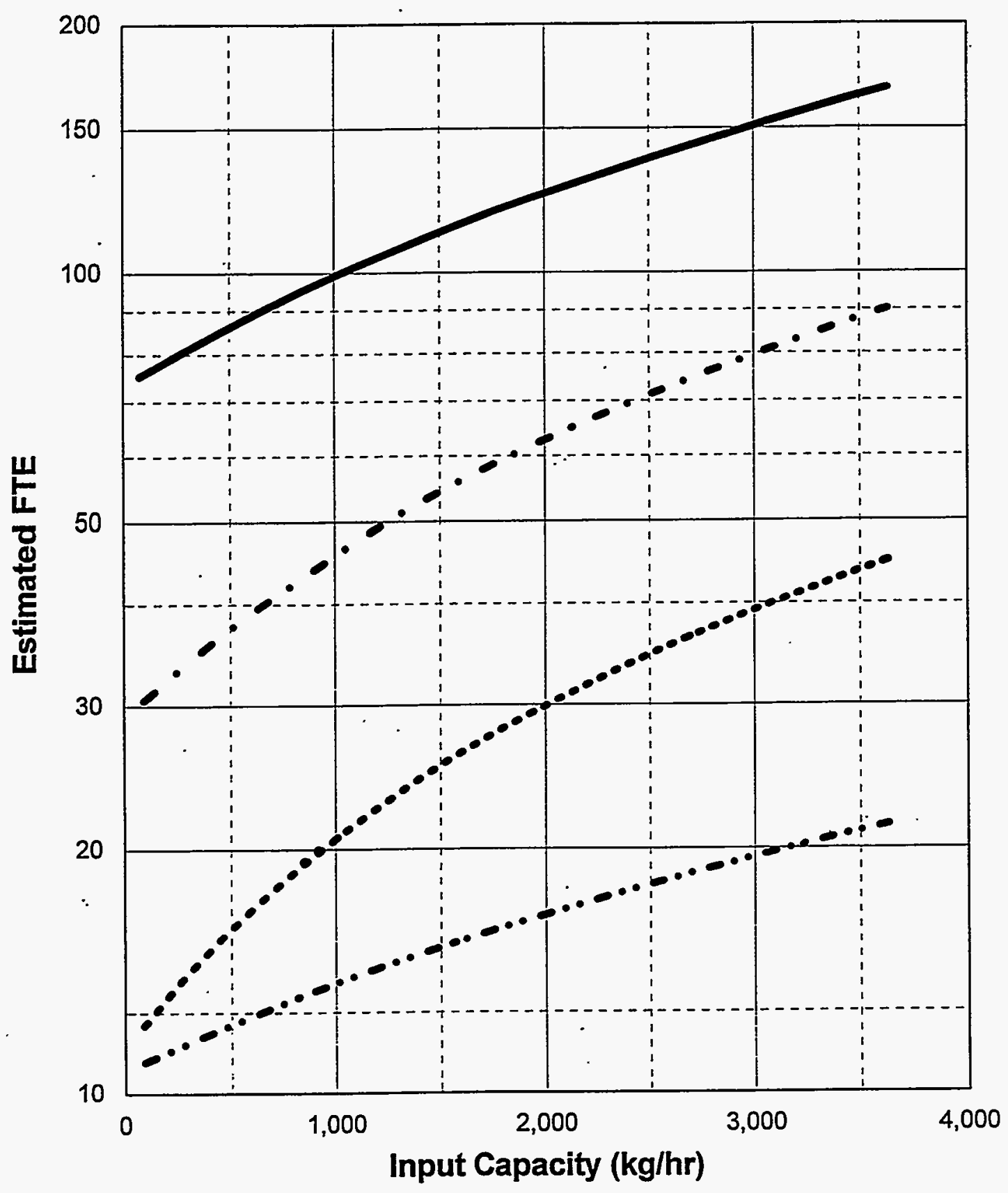

Pre-Operations Construction O\&M (1year) D\&D

Figure 15-4. FTE workers versus capacity for the alpha packaging (A-PACKG) module. 


\section{PACKAGING}

FTE by Work Breakdown Structure Element Module: PACKG Waste Type: Remote Handled LLW

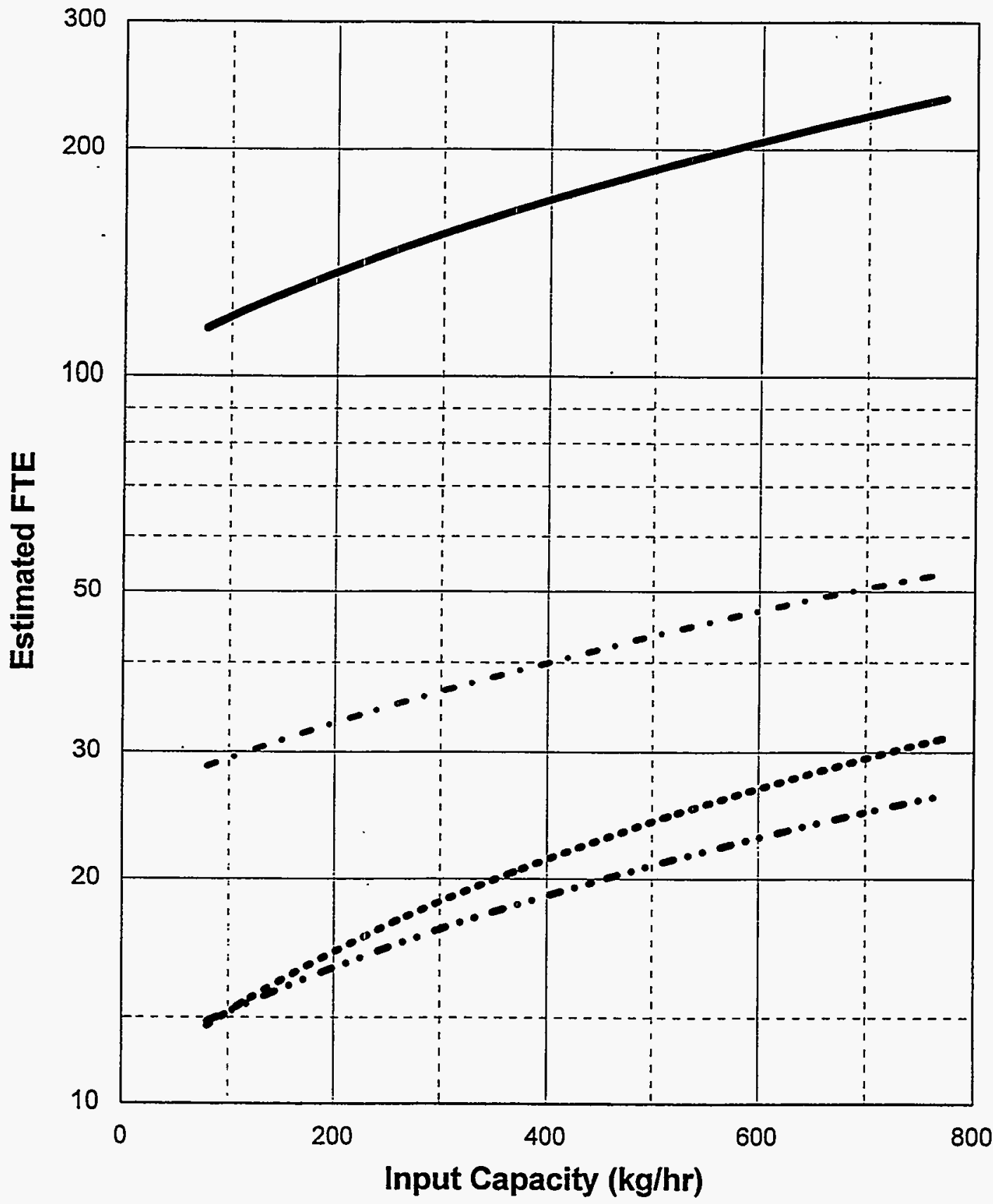

Pre-Operations Construction O\&M (1year) D\&D

Figure 15-5. FTE workers versus capacity for the remote-handled packaging (R-PACKG) module. 


\section{PACKAGING}

Cost by Work Breakdown Structure Element

\section{Module: PACKG Waste Type: Nonalpha LLW}

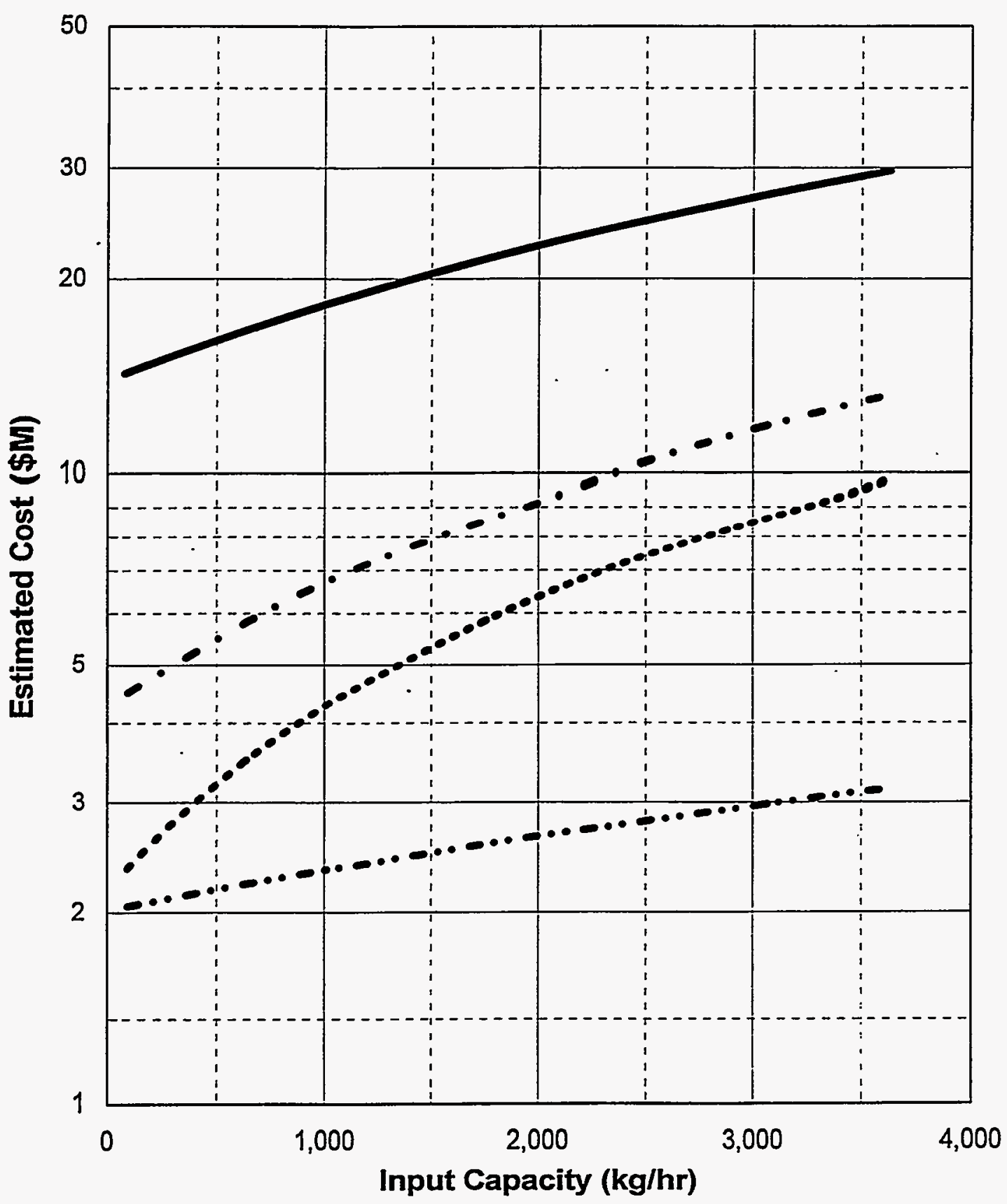

Pre-Operations Construction O\&M (1year) D\&D
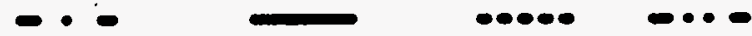

Figure 15-6. PLCC versus capacity for the nonalpha packaging (B-PACKG) module. 


\section{PACKAGING}

Cost by Work Breakdown Structure Element Module: PACKG Waste Type: Alpha LLW

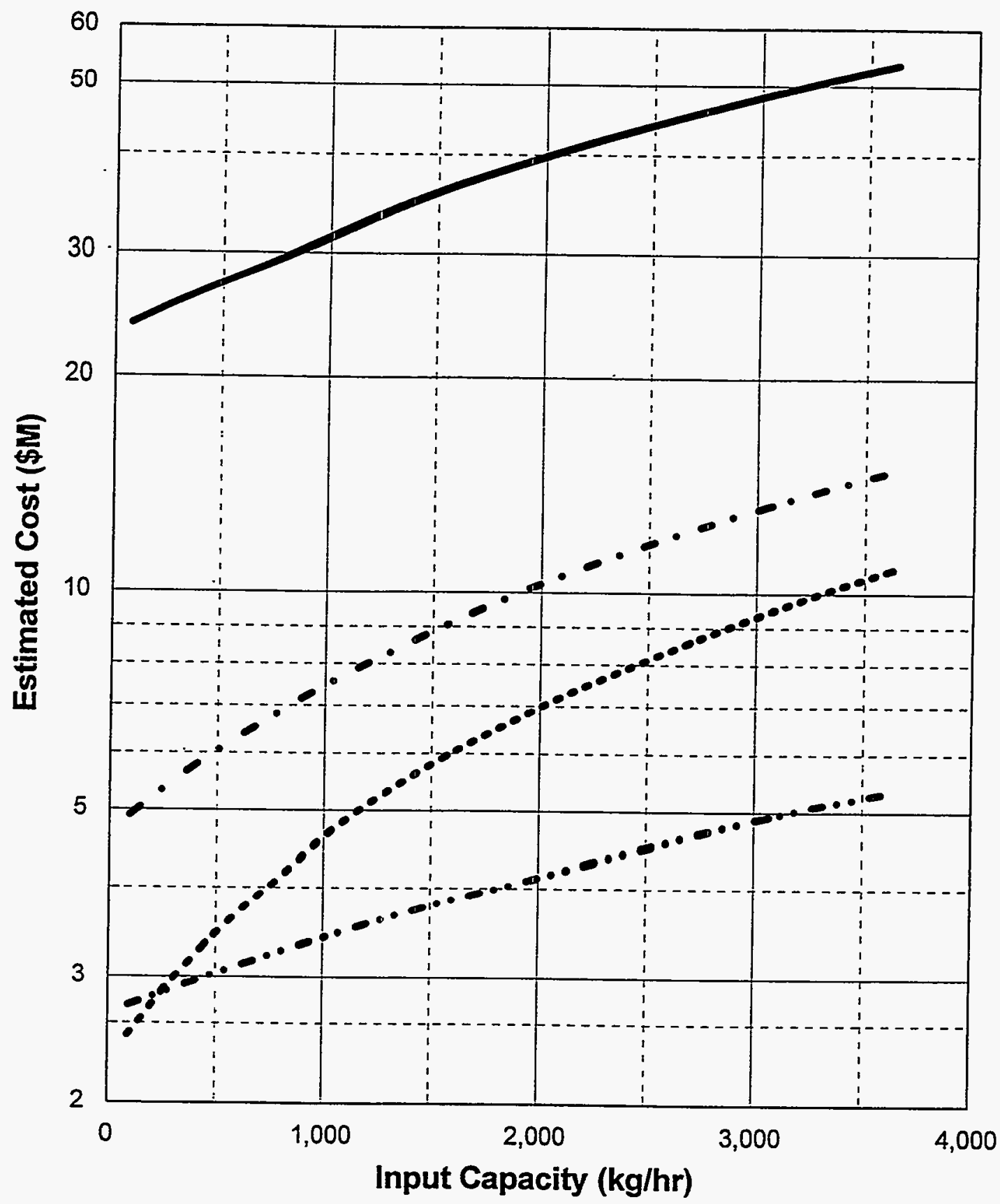

Pre-Operations Construction O\&M (1year) D\&D

Figure 15-7. PLCC versus capacity for the alpha packaging (A-PACKG) module. 


\section{PACKAGING}

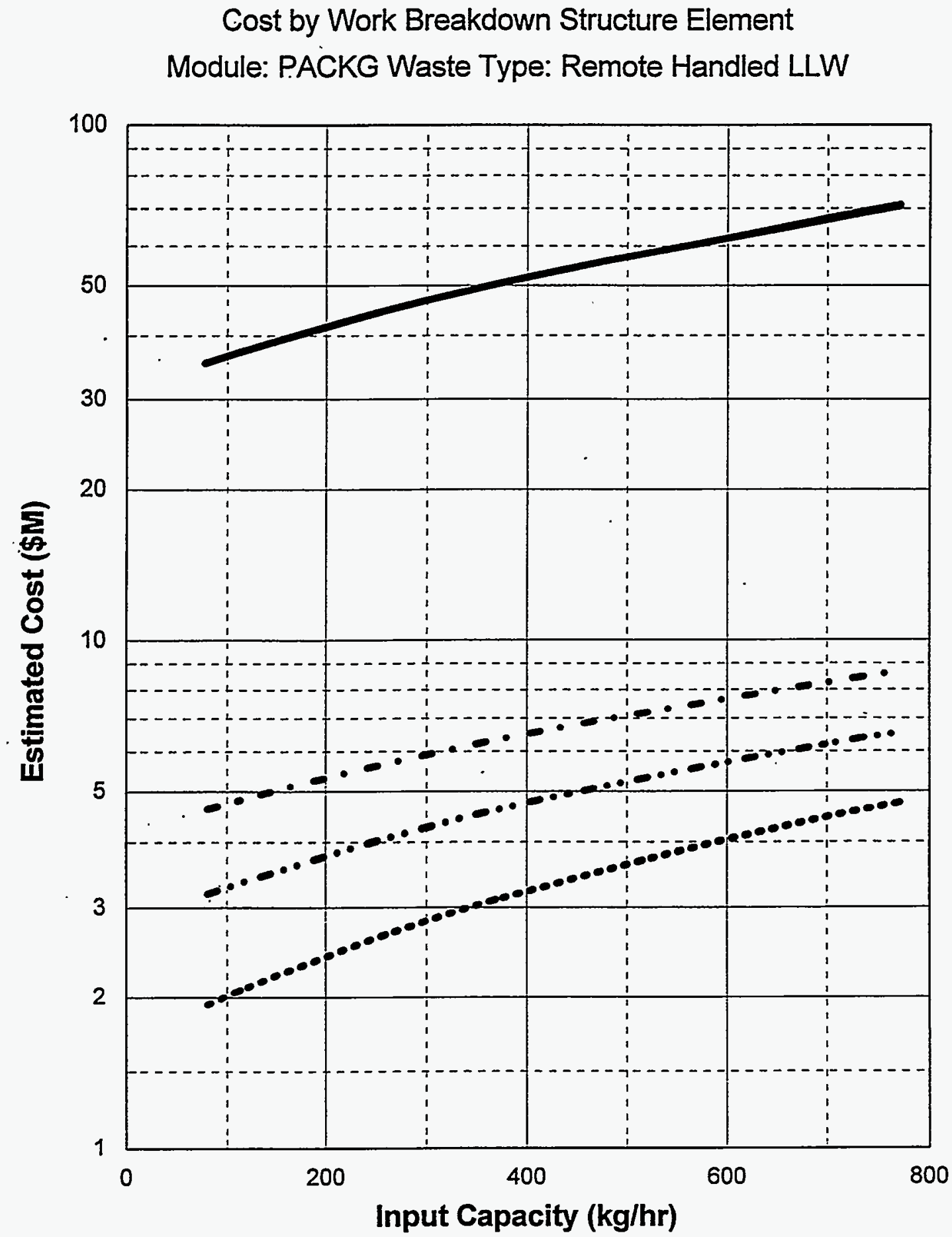

Pre-Operations Construction O\&M (1year) D\&D

Figure 15-8. PLCC versus capacity for the RH packaging (R-PACKG) module. 


\section{PACKAGING}

Total Life Cycle Costs

Module: PACKG Waste Type: Alpha, Nonalpha, and Remote Handled LLW

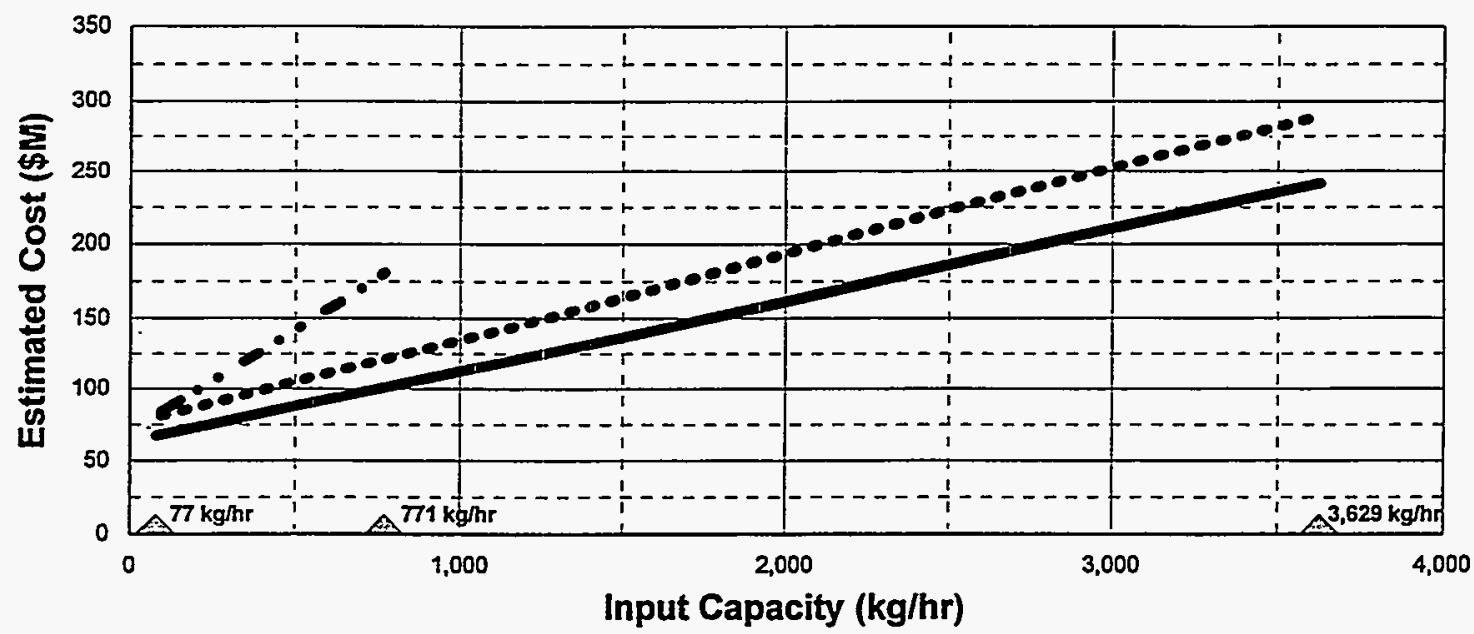

Nonalpha Alpha Remote Handled

NOTE: Basis includes 20 years O\&M

Triangles indicate capacities where detailed cost estimates were developed.

PACKAGING

Total Life Cycle Unit Costs

Module: PACKG Waste Type: Alpha, Nonalpha, Remote Handled LLW

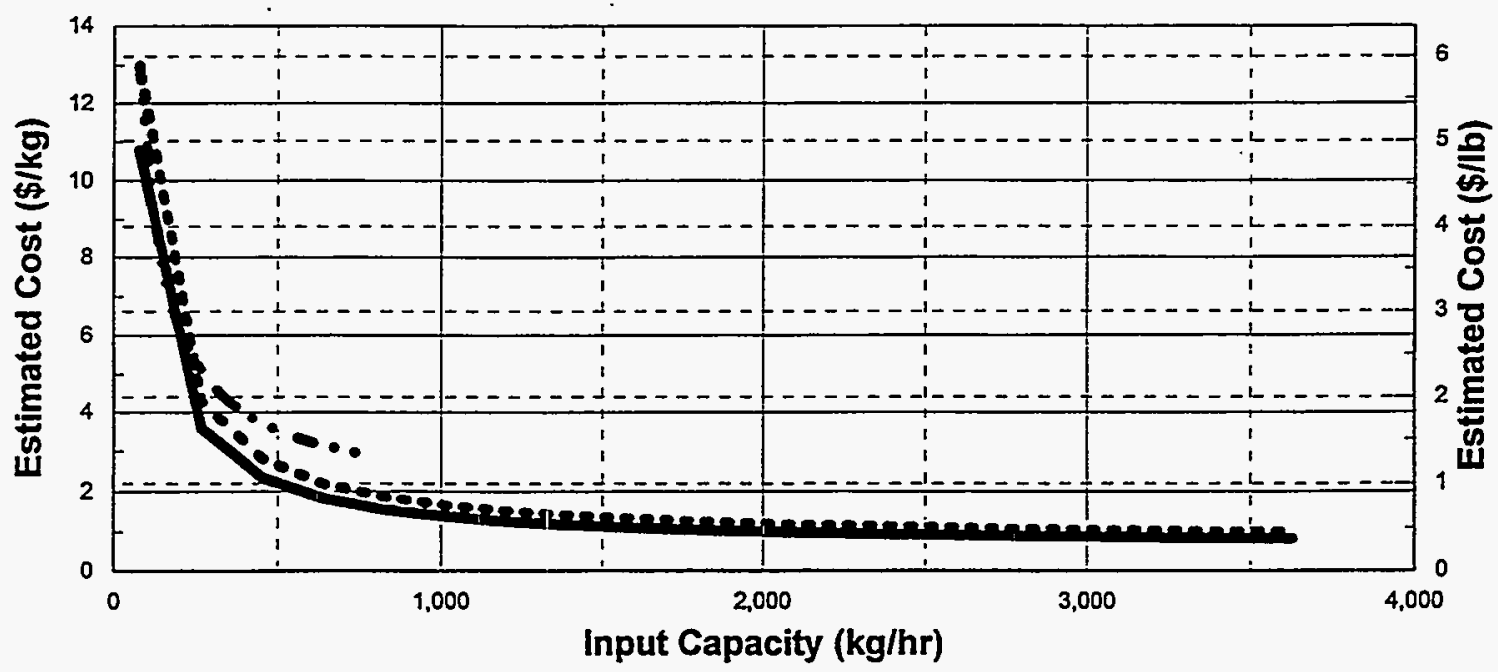

Nonalpha Alpha Remote Handled

NOTE: Basis includes 20 years O\&M

Figure 15-9. PLCC versus capacity including unit rates for the packaging (PACKG) module. 


\section{SHREDDING AND COMPACTION (MODULE CMPCT)}

\subsection{Basic Information}

The shredding and compaction module, shown in Figure 16-1, is used either in conjunction with the treatment administration and back-end support modules (see modules TADMN, RCINS, OSORT, MAINT, and CSHIP) or as an addition to existing facilities where similar functions are already available. Module CMPCT is applicable to nonalpha, alpha, and RH waste and nonalpha waste. Unit operations are shown in the PFD in Figure 16-2.

For LLW, only the shredding portion of this module is applicable and has cost information provided, due to the low capacity requirements.

\subsection{Technical Bases and Assumptions}

\subsubsection{Function and Operation of Large Generator Module}

The large module is designed to shred incoming waste and package it in 55-gal drums. This module is equipped with a dust collection and filtration unit to treat air containing fugitive dust from the shredding operations. The small and medium modules have such low capacities that the expense of a compactor cannot be economically justified and is not included. For the small and medium modules, the waste must be placed into drums before it is further processed.

At the compaction unit operation, a lift device places the filled drums onto press conveyors. The operator selects a drum from one of the conveyors and feeds it to the press through an airlock. A device pierces the drum to release gases that may be trapped in the drum. A high-pressure compactor (supercompactor) compresses the drum and transfers the pressed drum from the press to a staging conveyor (or turntable). A lift device picks up the compressed drum and places it into one of several overpacks located on an adjacent conveyor. After each overpack is filled, the operator feeds it to the grout station where grout is added to fill any spaces in the overpack. The overpack is then sent to the sorting machine where a cap is placed on the overpack and sealed. The operator moves the sealed overpack to a drum washing unit where high-pressure water spray jets remove any loose contamination on the outside surface of the overpack.

Any liquid discharged during press operation is directed to a sump, which pumps it to the aqueous waste treatment module. The compacted waste is ready for radioassay and final certification, which are included in the certification and shipping (CSHIP) module.

\subsubsection{Integration of Large Generator Module}

Primary module inputs are bulk waste from the open, dump, and sort (OSORT) module and directly from generator sites. Major O\&M purchased materials, such as personal protective equipment, laboratory material, and overpacks, are assumed to be consumable supplies and their costs are estimated accordingly. 
Major module outputs are compacted drums containing alpha or nonalpha waste, which are transferred to a back-end support (CSHIP) module. The overpacks (85-gal drums) containing compacted waste are the main output from this module. Treated offgas is discharged into the atmosphere.

\subsection{Cost Bases, Assumptions, and Results}

Waste size reduction and preparation (shredders), and supercompactor are the major equipment capital cost items. Major equipment capital costs are verified against the purchased costs incurred at a U.S. Navy LLW processing facility located in Lynchburg, Virginia. Costs for the preparation and feed unit are based on vendor quotes for shredders, conveyors, and dust collection equipment. Supercompactor prices are based on cost quotes by Stock Equipment Company of Chagrin Falls, Ohio. Estimated FTEs and PLCC versus capacity are shown in Figures 16-3 to 16-7. 


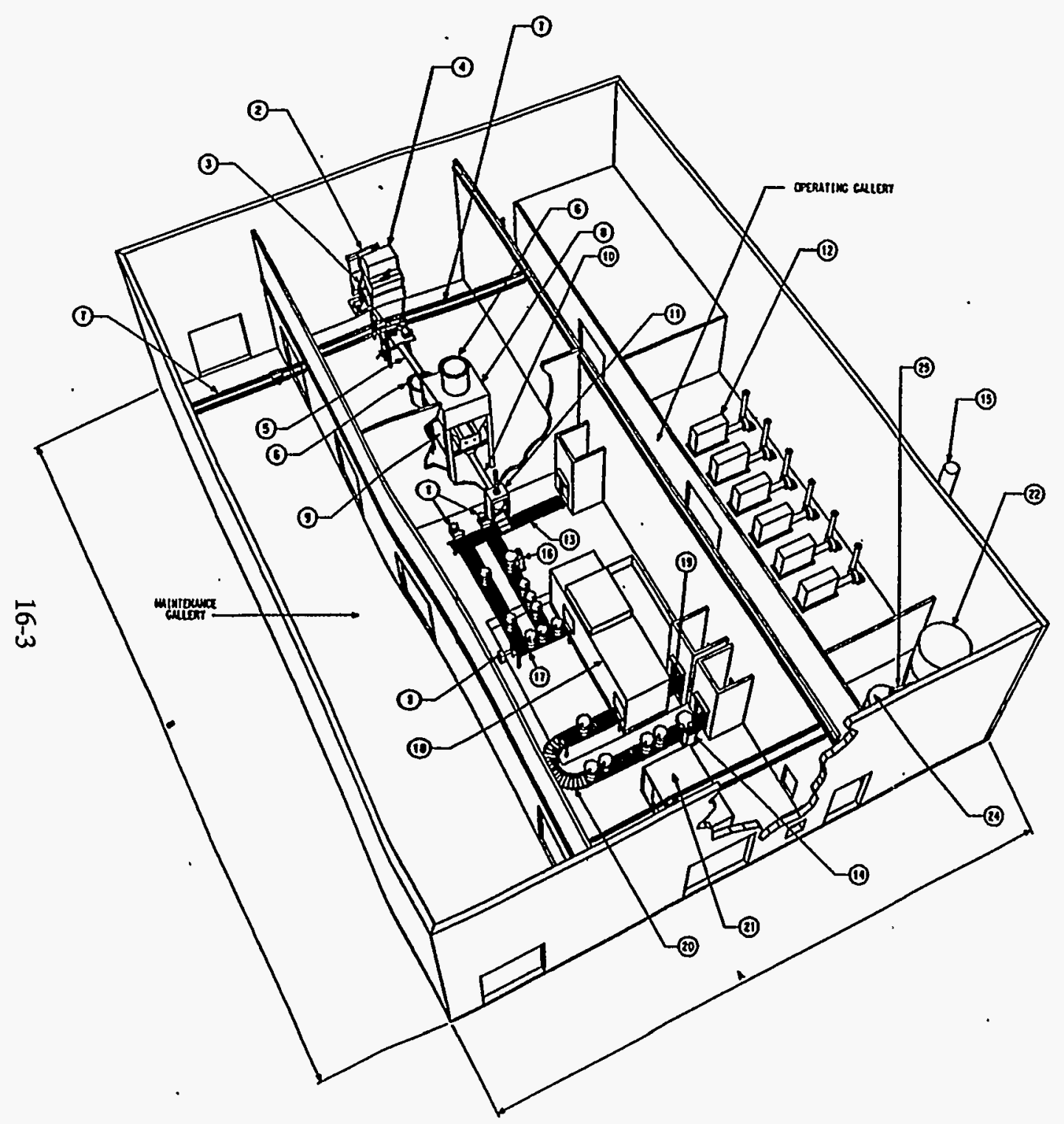

Figure 16-1. Equipment layout for the shredding and compaction (CMPCT) module.

\author{
EQUIPMENT LIST

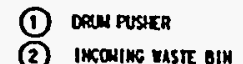 \\ (3) sxip \\ (4) SHFECOER (2) NITH FEEO HOPPER. OUST HOOO NO HTORMUIC RMN \\ (5) NUEER IECOER \\ (6) waste transfer BIN

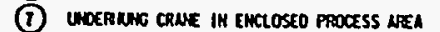 \\ (8) Live Botrou guK storade hopper \\ (9) reatiar sheocer \\ (10) MuCen feEoen \\ (ii) SHAFOXEO MASTE COPACIOR ISO TOH) \\ (12) HEPA :ILTEA NO FAH

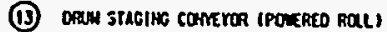 \\ (14) orerpece top senitic station \\ (15) sincx \\ (19) ofu top senine station \\ (ii) SUPERSOPACIOA FECD CONEYOR (POTRED RQLU)

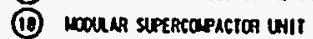

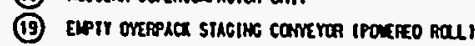

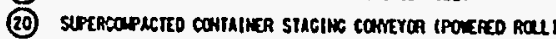 \\ (21) HOVNRR HTORMU IC POKR UIIT \\ (22) Storace olm

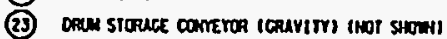 \\ (24) DAr alH \\ (35) preuuric comston
}

\begin{tabular}{|c|c|c|c|c|c|}
\hline \multirow{2}{*}{\multicolumn{2}{|c|}{ FACILITY SIZE }} & \multicolumn{2}{|c|}{ D|FESIO } & \multicolumn{2}{|c|}{$\begin{array}{l}\text { DILENSION } \\
\text { IHETEAS }\end{array}$} \\
\hline & & $A$ & 8 & $\Lambda$ & 8 \\
\hline 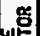 & susele & 40 & 150 & 12.2 & 45.7 \\
\hline 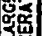 & Letiu & 40 & 150 & 12.2 & 45.7 \\
\hline 8 & LARCE & 50 & 202 & 15.2 & 61.6 \\
\hline $\mathbb{S}^{8}$ & MIMILN & 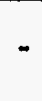 & - & - & - \\
\hline
\end{tabular}




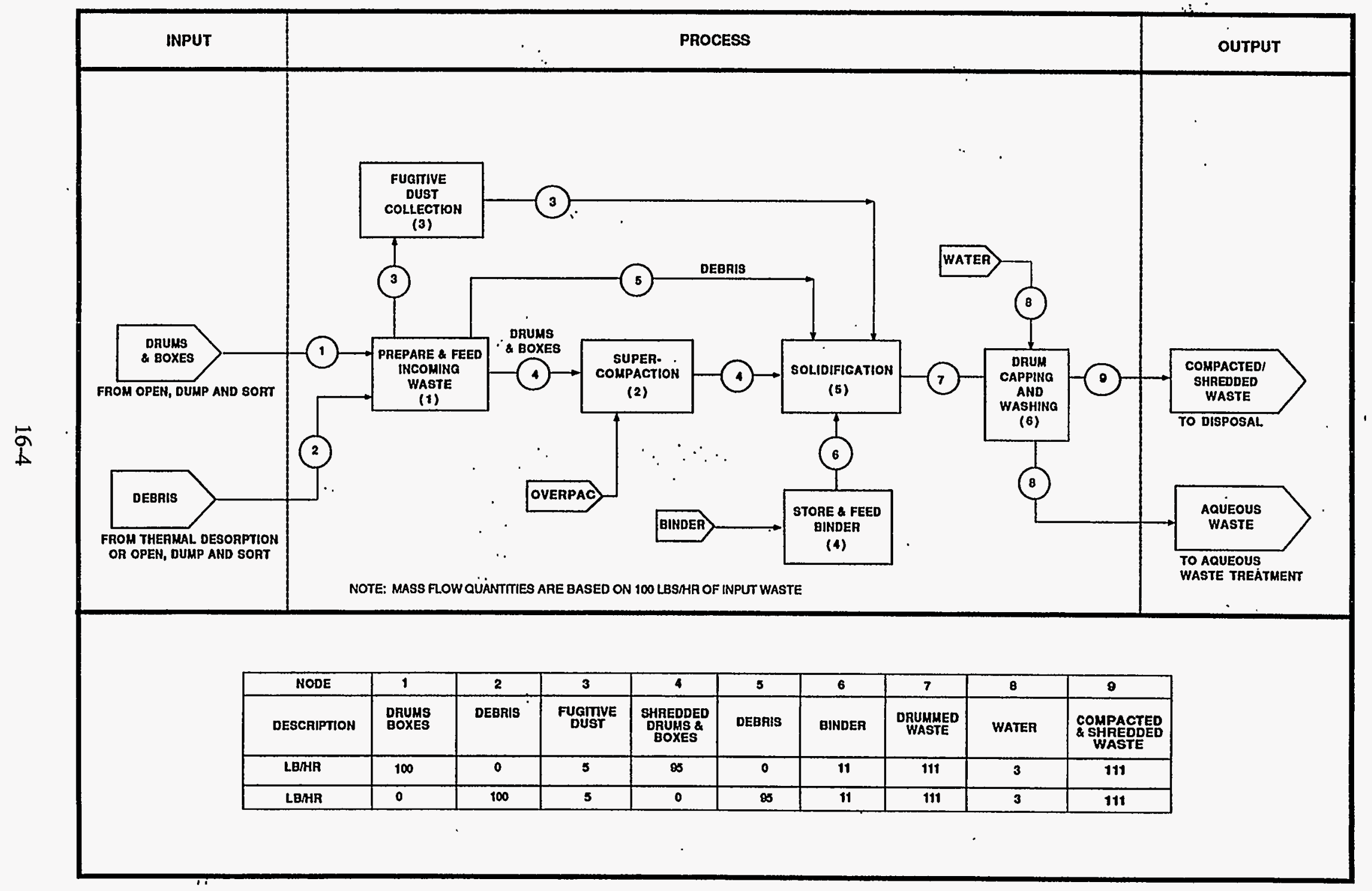

Figure 16-2. Process flow diagram for the shredding and compaction (CMPCT) module. 


\section{SHREDDING/COMPACTION}

FTE by Work Breakdown Structure Element

Module: CMPCT Waste Type: Nonalpha LLW

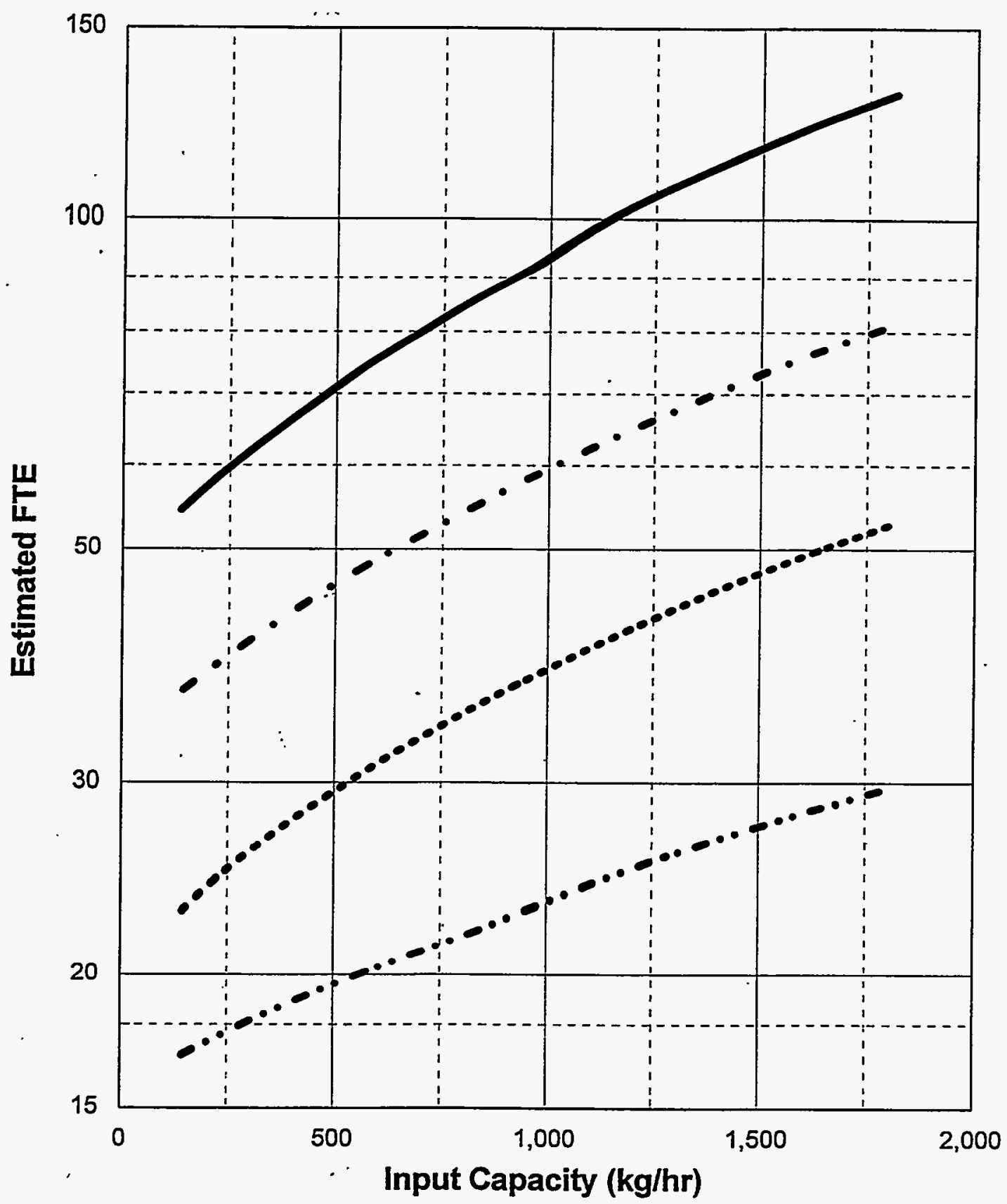

Pre-Operations Construction O\&M (1year) D\&D

Figure 16-3. FTE workers capacity for the nonalpha shredding and compaction (B-CMPCT) module. 


\section{SHREDDING/COMPACTION}

FTE by Work Breakdown Structure Element

Module: CMPCT Waste Type: Alpha and Remote Handled LLW

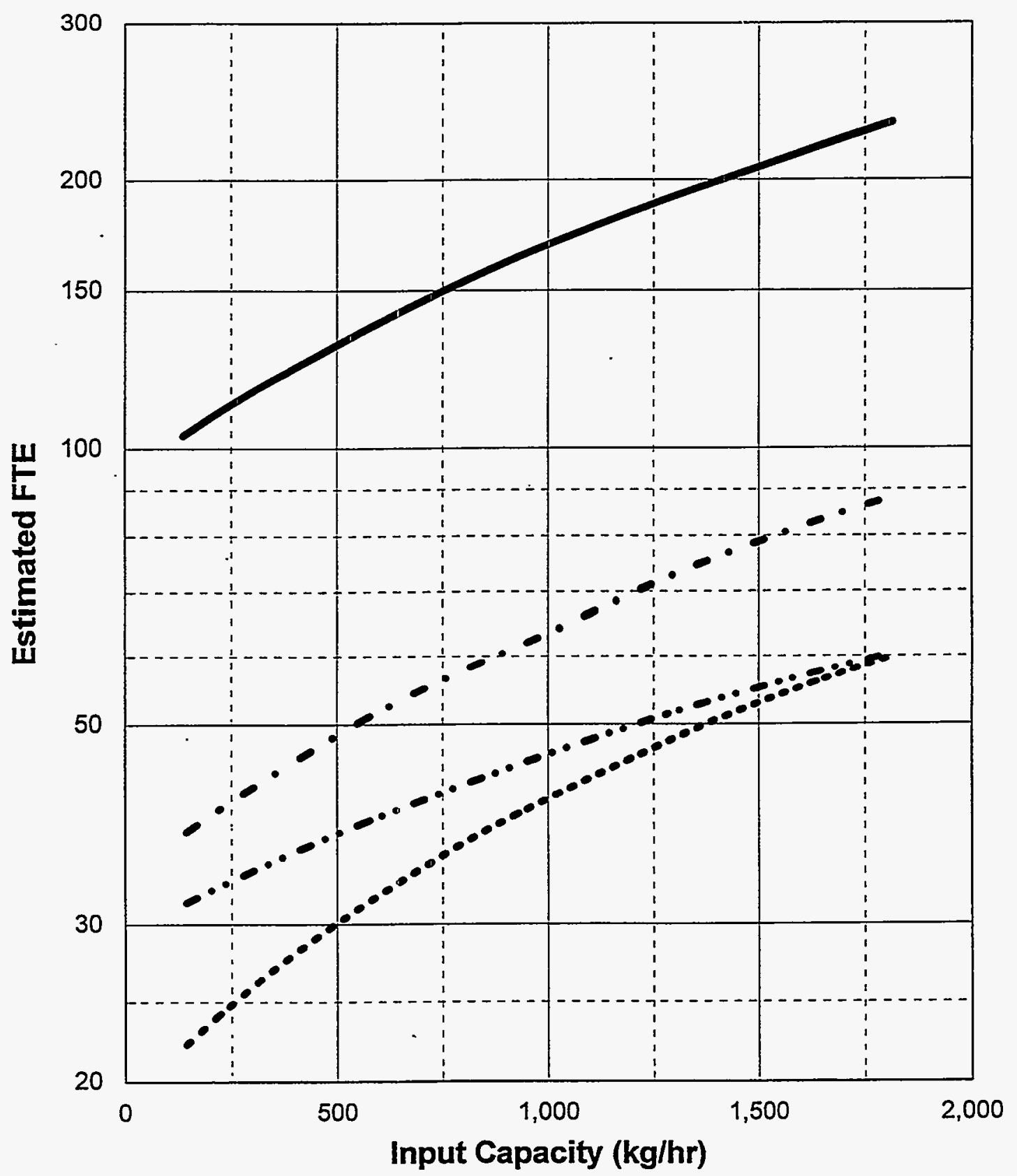

Pre-Operations Construction O\&M (1year) D\&D

Figure 16-4. FTE workers versus capacity for the alpha and RH shredding and compaction (A/R-CMPCT) module. 


\section{SHREDDING/COMPACTION}

Cost by Work Breakdown Structure Element

Module: CMPCT Waste Type: Nonalpha LLW

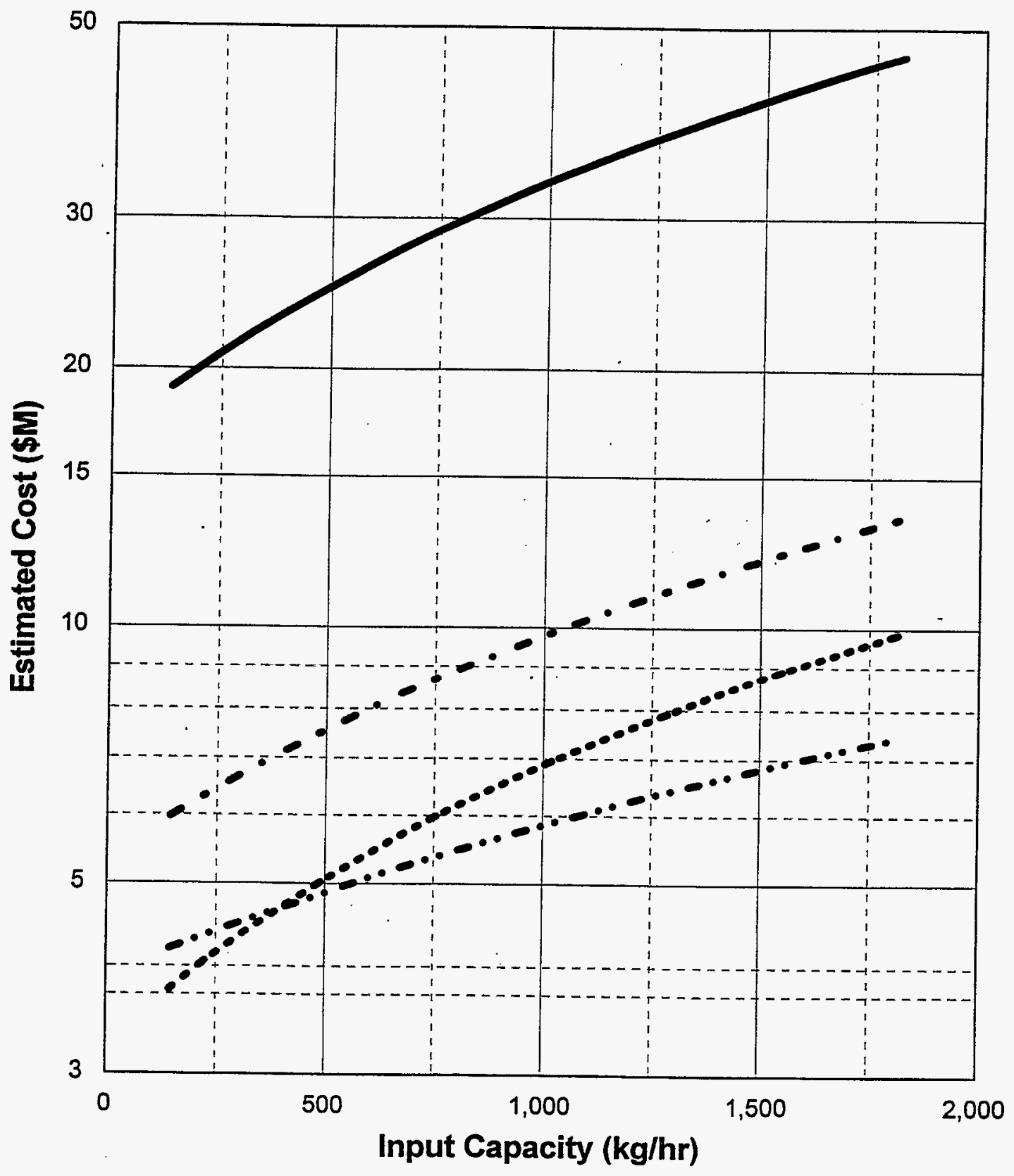

Pre-Operations Construction O\&M (1year) D\&D

Figure 16-5. PLCC versus capacity for the nonalpha shredding and compaction (B-CMPCT) module. 


\section{SHREDDING/COMPACTION}

Cost by Work Breakdown Structure Element

Module: CMPCT Waste Type: Alpha and Remote Handled LLW

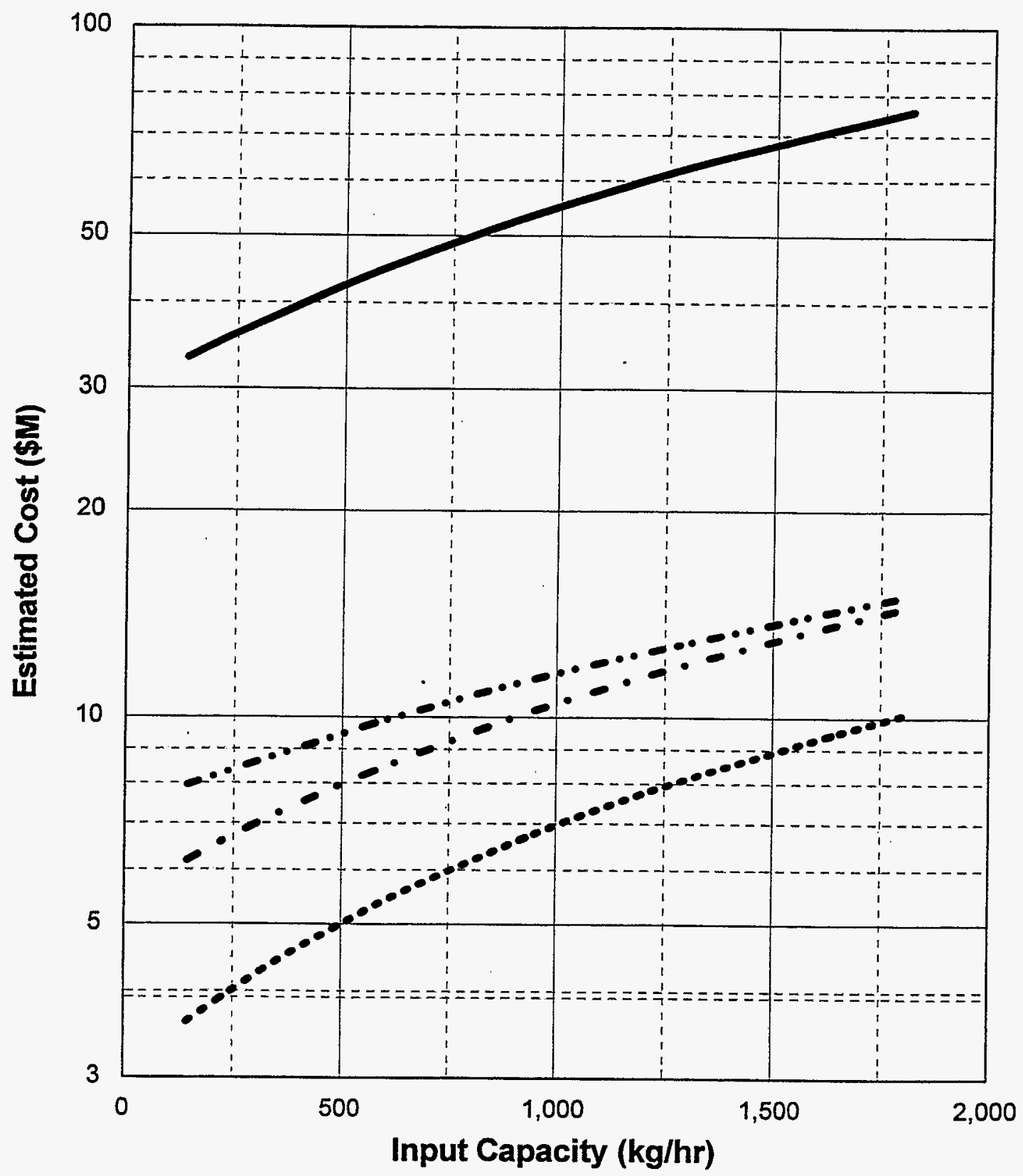

Pre-Operations Construction O\&M (1year) D\&D

Figure 16-6. PLCC versus capacity for the alpha and RH shredding and compaction (A/R-CMPCT) module. 


\section{SHREDDING/COMPACTION}

Total Life Cycle Costs

Module: CMPCT Waste Type: Alpha, Nonalpha, and Remote Handled LLW

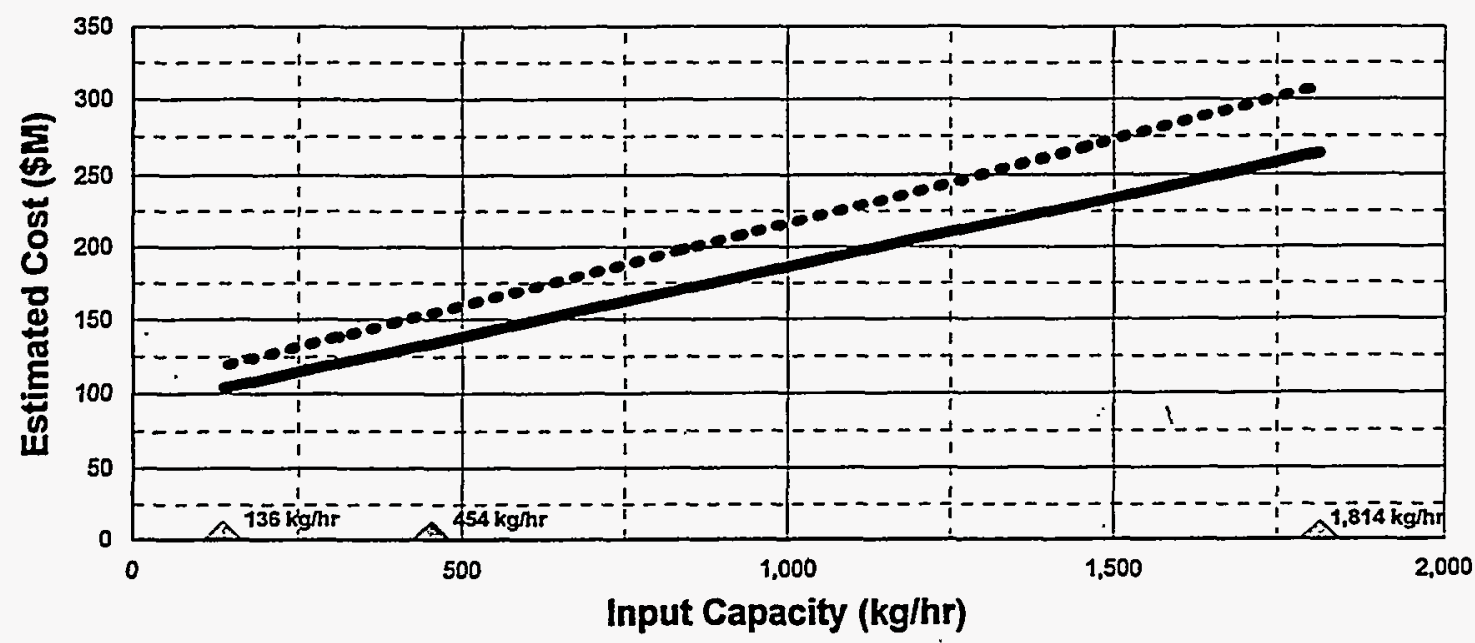

Nonalpha Alpha, Remote Handled

NOTE: Basis indudes 20 years O\&M

Triangles indicate capacities where detailed cost estimates were developed.

\section{SHREDDING/COMPACTION}

Total Life Cycle Unit Costs

Module: CMPCT Waste Type: Alpha, Nonalpha, Remote Handled LLW

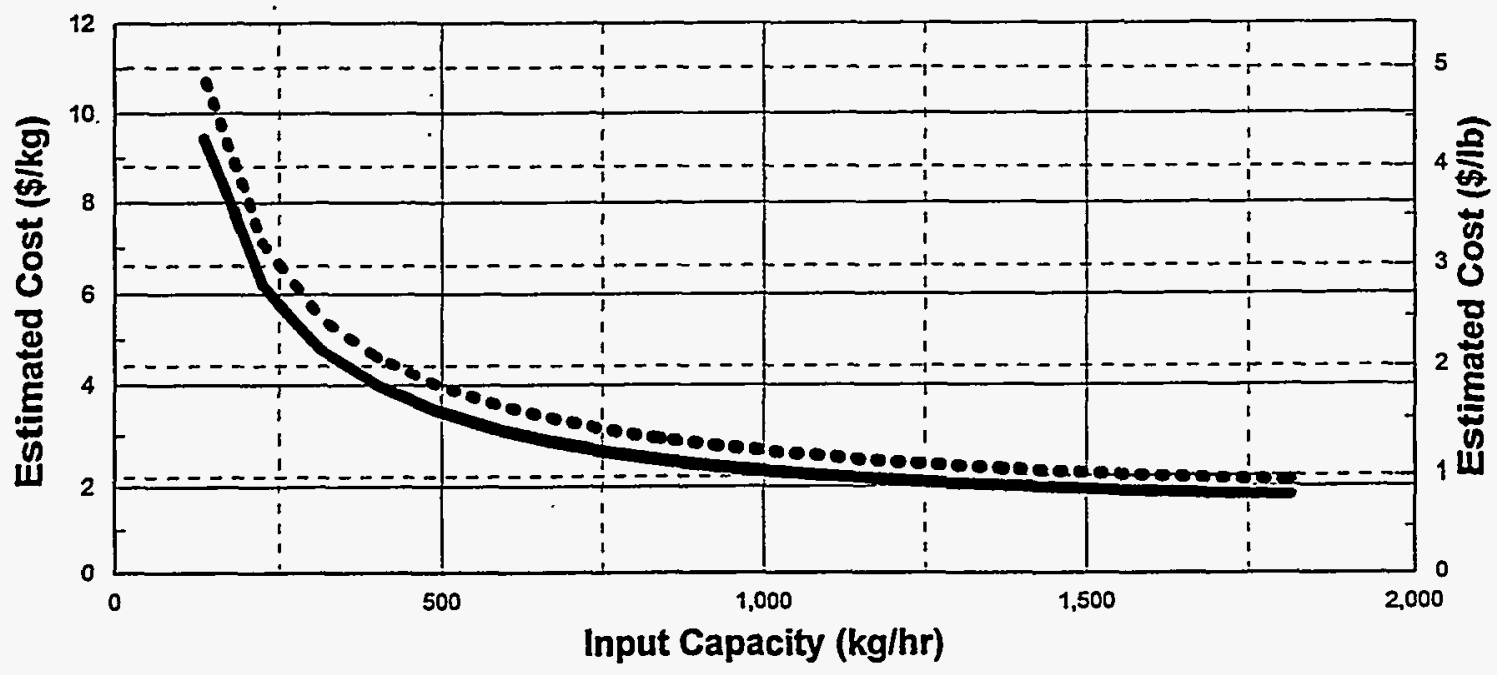

Nonalpha Alpha, Remote Handled

NOTE: Basis includes 20 years O\&M

Figure 16-7. PLCC versus capacity including unit rates for the shredding and compaction (CMPCT) module. 


\section{SUPERCOMPACTION (MODULE SUPER)}

\subsection{Basic Information}

The supercompaction module, shown in Figure 17-1, is used either in addition to existing facilities where similar functions are already available or in conjunction with the treatment administration and back-end support modules (see modules TADMN, RCINS, OSORT, MAINT, and CSHIP). Module SUPER is applicable to nonalpha, alpha, and RH waste. Unit operations are shown in the PFD in Figure 17-2.

\subsection{Technical Bases and Assumptions}

\subsubsection{Function and Operation of the Module}

The supercompaction module is designed to compact incoming waste and package it in 85-gal drums. This module receives waste in 55-gal drums and compacts the drum and its content into a "puck" before repackaging it in 85-gal drum overpacks. No feed preparation is required before compaction. Following overpacking, the void spaces in the overpack container are filled with grout. Grouted overpack is allowed to cure, then is sealed and washed before discharge from this treatment module. Fugitive dust collection equipment are provided to handle dust generated during compaction.

\subsection{Cost Bases, Assumptions, and Assessments}

Cost versus capacity information for the supercompaction module is shown in Figures 17-3 through 17-7. 


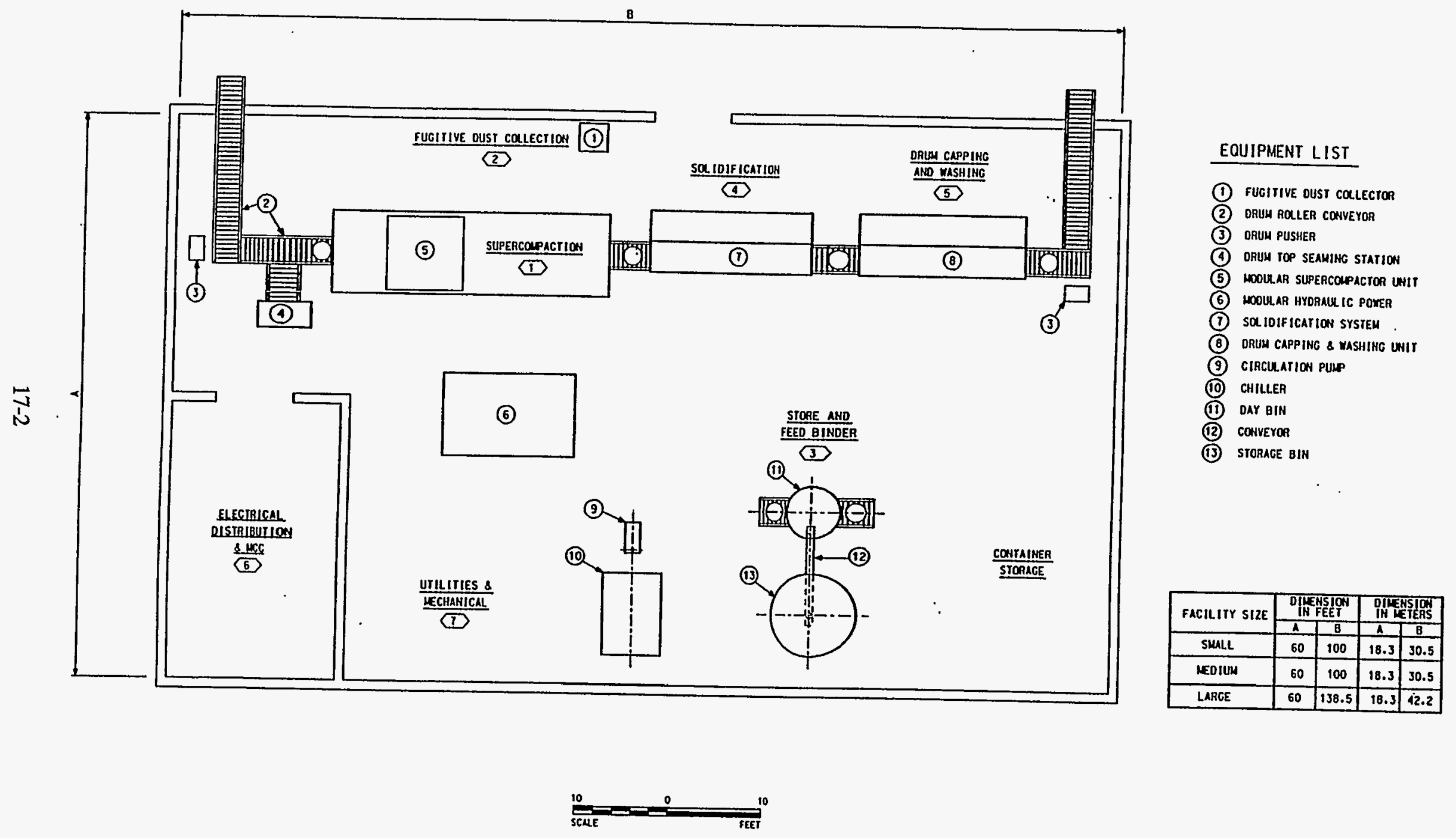

Figure 17-1. Equipment layout for the supercompaction (SUPER) module. 


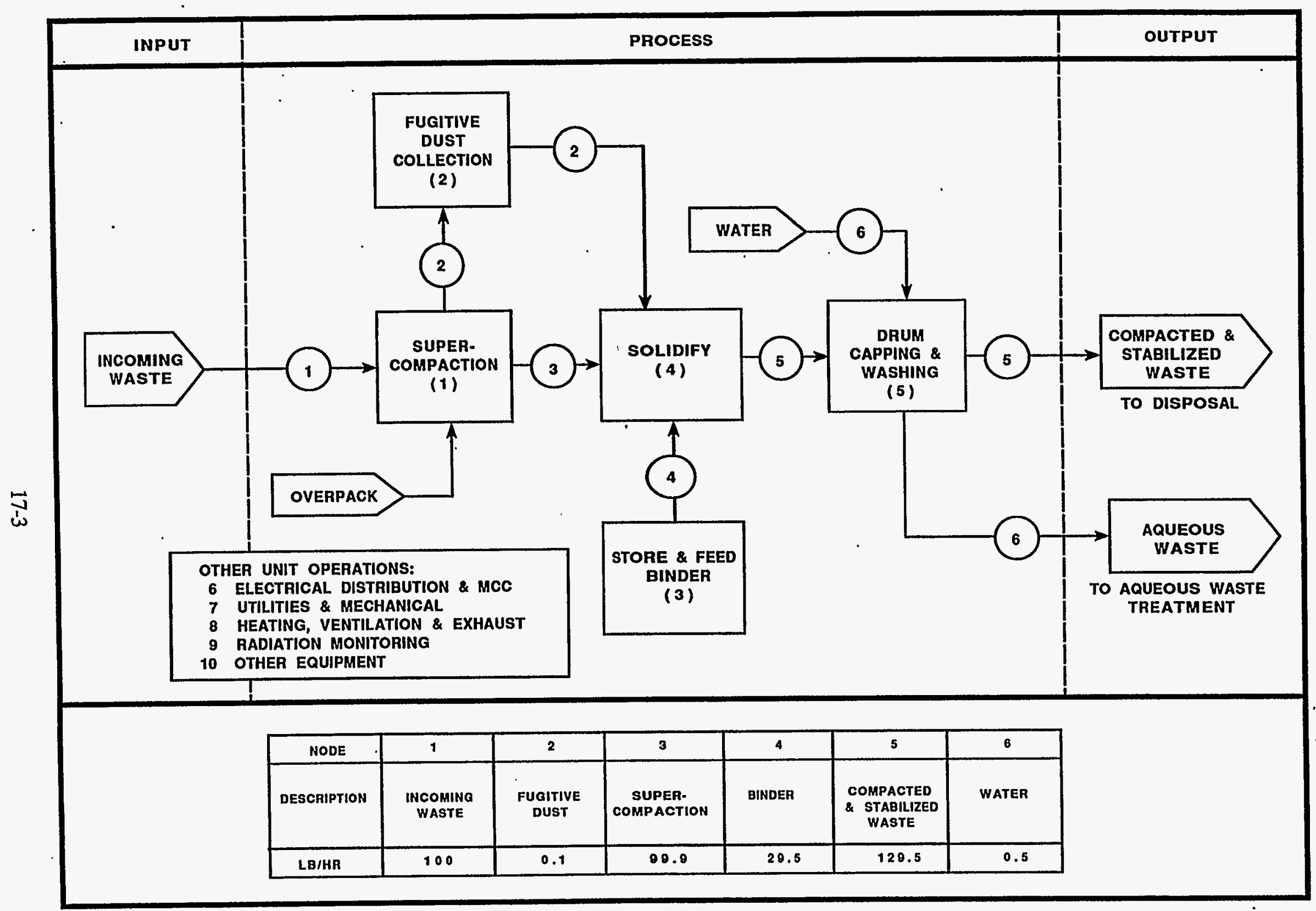

Figure 17-2. Process flow diagram for the supercompaction (SUPER) module. 


\section{SUPERCOMPACTION}

FTE by Work Breakdown Structure Element

Module: SUPER Waste Type: Nonalpha LLW

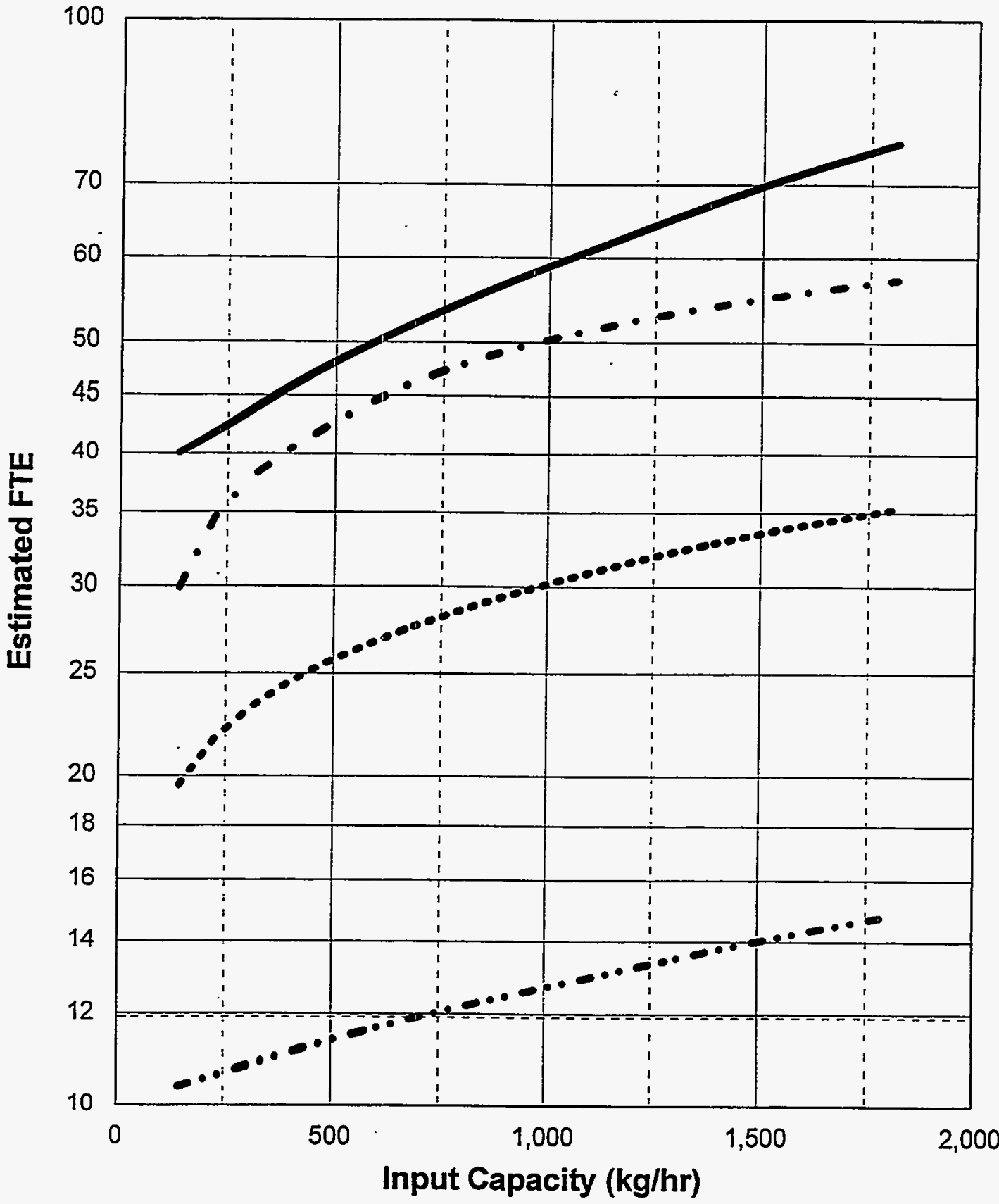

Pre-Operations Construction O\&M (1year) D\&D

Figure 17-3. FTE workers versus capacity for the nonalpha supercompaction (B-SUPER) module. 


\section{SUPERCOMPACTION}

FTE by Work Breakdown Structure Element

Module: SUPER Waste Type: Alpha and Remote Handled LLW

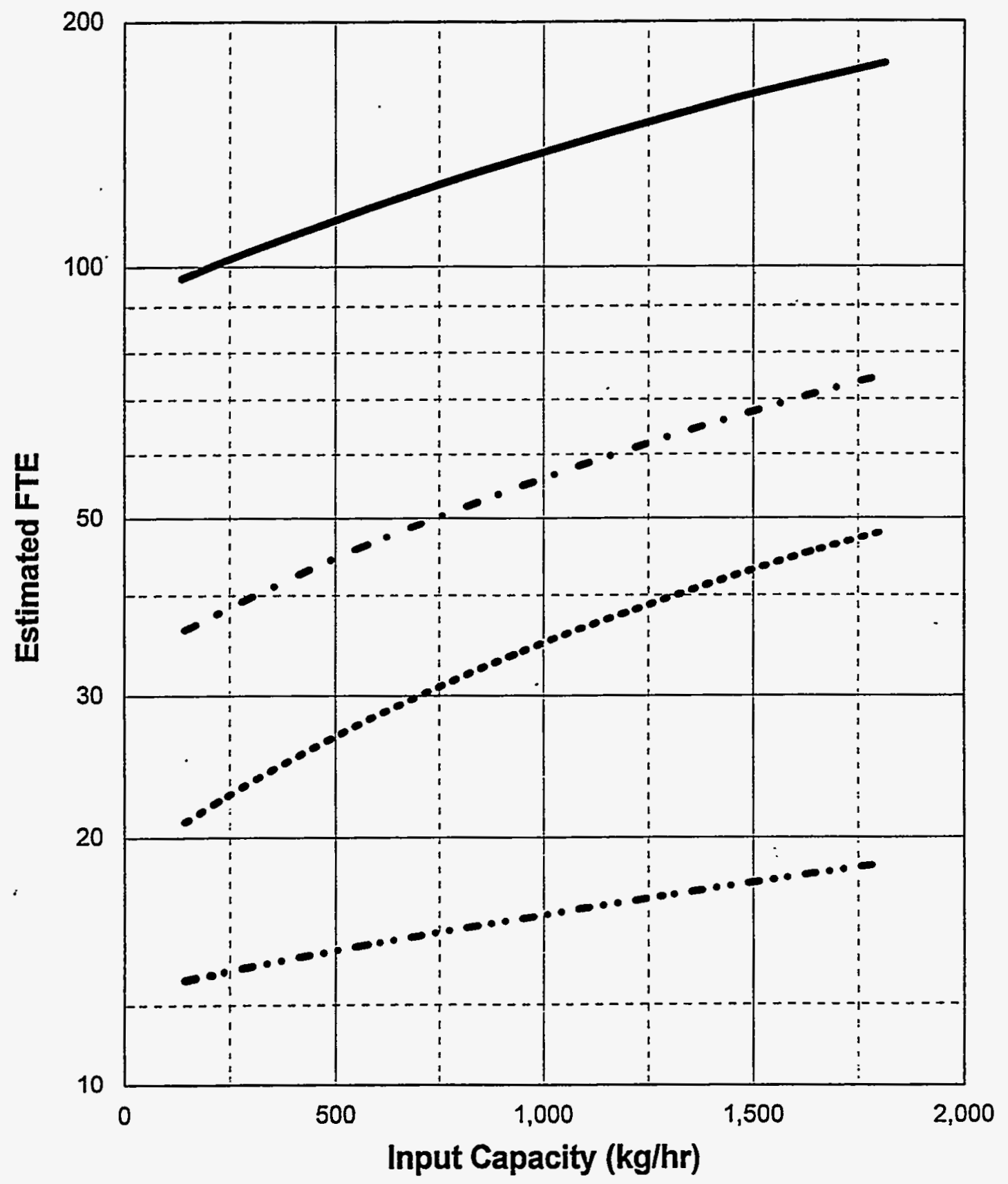

Pre-Operations Construction O\&M (1year) D\&D

$\cdots$

Figure 17-4. FTE workers versus capacity for the alpha and RH supercompaction (A/R-SUPER) module. 


\section{SUPERCOMPACTION}

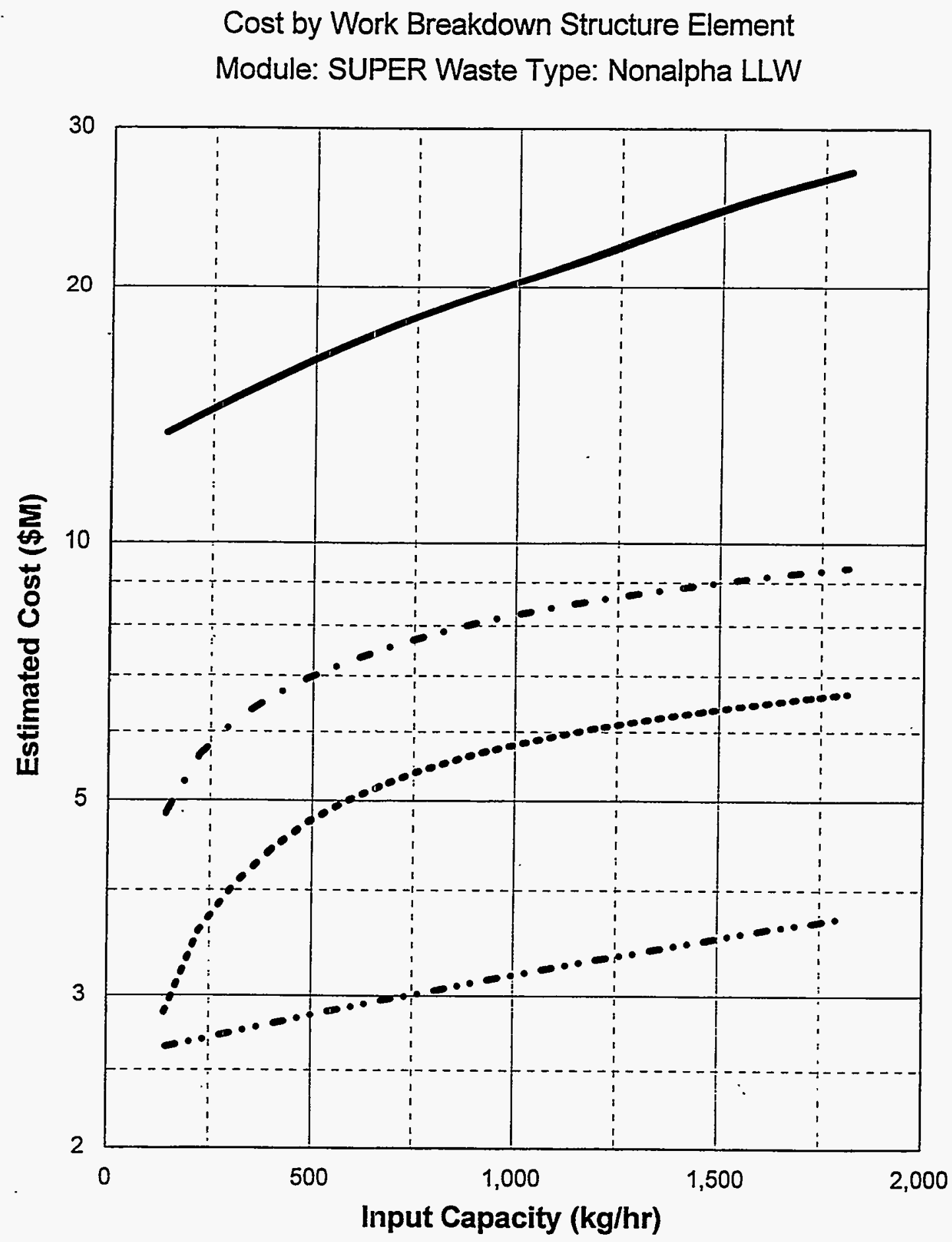

Pre-Operations Construction O\&M (1year) D\&D

Figure 17-5. PLCC.versus capacity for the nonalpha supercompaction (B-SUPER) module. 


\section{SUPERCOMPACTION}

Cost by Work Breakdown Structure Element

Module: SUPER Waste Type: Alpha and Remote Handled LLW

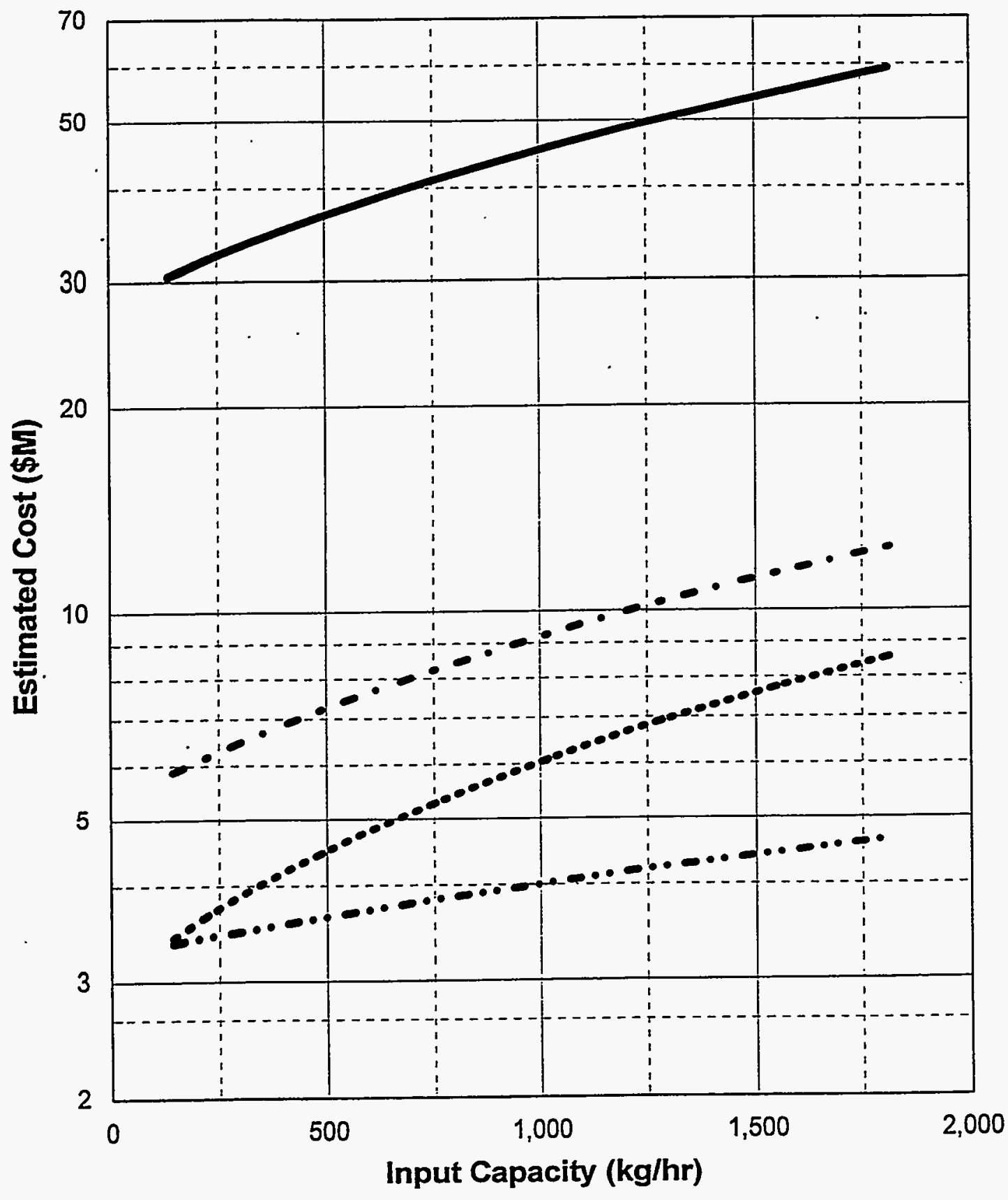

Pre-Operations Construction O\&M (1year) D\&D

Figure 17-6. PLCC versus capacity for the alpha and RH supercompaction (A/R-SUPER) module. 


\section{SUPERCOMPACTION}

Total Life Cycle Costs

Module: SUPER Waste Type: Alpha, Nonalpha, and Remote Handled LLW

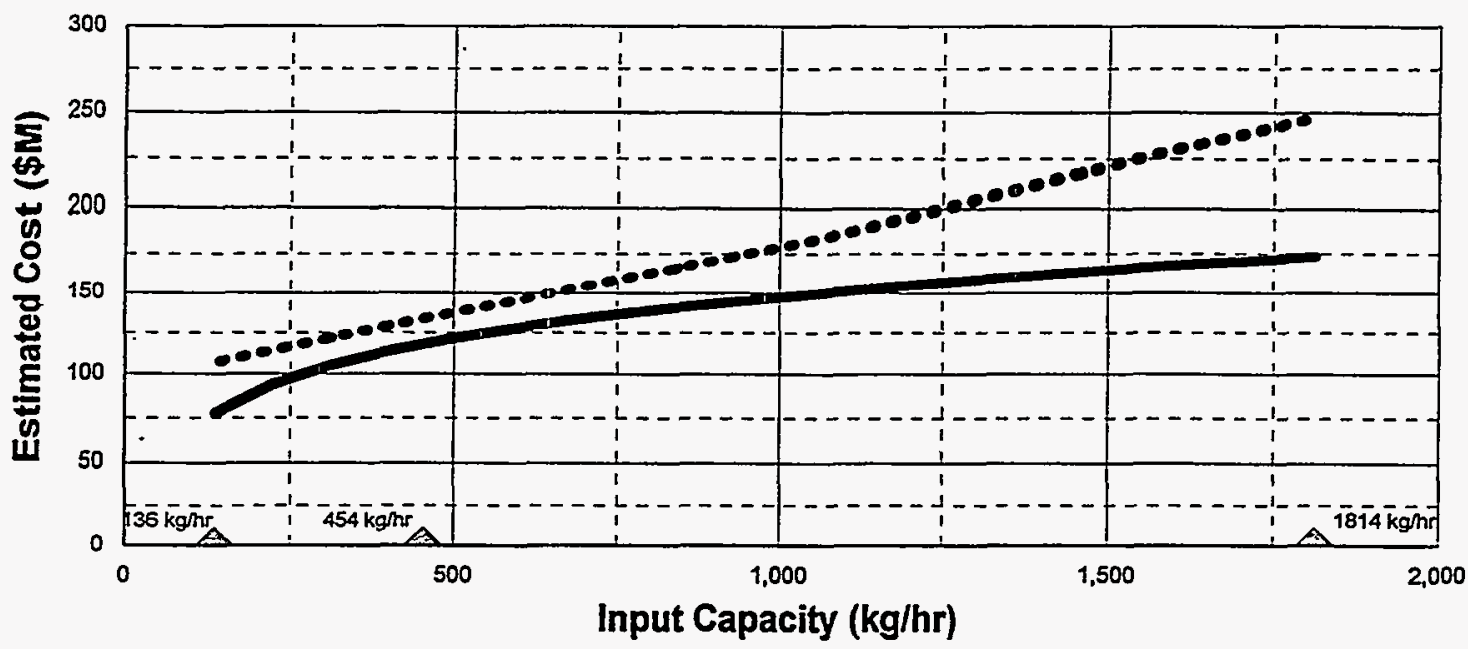

Nonalpha Alpha, Remote Handled

NOTE: Basis indudes 20 years O\&M

Triangles indicate where detailed cost estimates were developed.

\section{SUPERCOMPACTION}

Total Life Cycle Unit Costs

Module: SUPER Waste Type: Alpha, Nonalpha, Remote Handled LLW

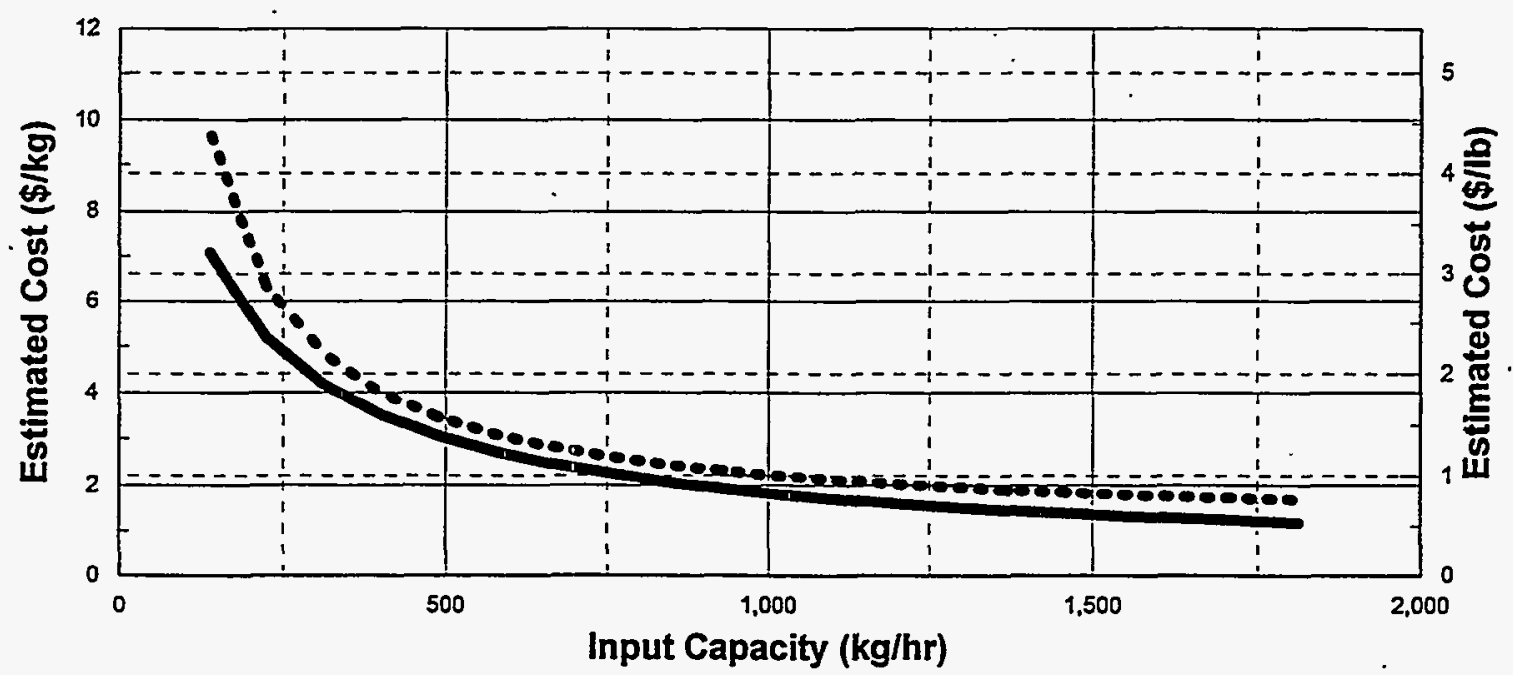

Nonalpha Alpha, Remote Handled

NOTE: Basis includes 20 years O\&M

Figure 17-7. PLCC versus capacity including unit rates for the supercompaction (SUPER) module. 


\section{CERTIFICATION AND SHIPPING (MODULE CSHIP)}

The certification and shipping module, shown in Figure 18-1, is the same for alpha and nonalpha waste. There are only minor differences in the assay and certification equipment that do not affect the overall PLCC estimates. Unit operations are shown in the PFD in Figure 18-2.

\subsection{Basic Information}

The certification and shipping module consists of three unit operations: incoming material storage, assay and certification, and truck loading. This module receives packaged waste containers from treatment modules and provides temporary storage and radiological and physical characterization of the waste and shipment of the containers.

The certification and shipping module is used for large generator facilities only. It is used in conjunction with treatment modules when the required functions are not available at existing facilities. The module includes all equipment needed for certification of the waste in compliance with the transportation, storage, and disposal regulations and requirements.

\subsection{Technical Bases and Assumptions}

\subsubsection{Function and Operation of Large Generator Modules}

Packaged waste containers arrive from treatment modules on conveyors, carts, or other transport devices. Containers are removed from the transport devices and placed in a staging area. The containers are then visually examined, tagged, logged, recorded, and sent to an assay and certification unit operation. In this unit operation, the containers are examined by radioassay devices to allow both alpha and gamma radioactivity classification in accordance with transportation, storage, and disposal criteria. Various devices, such as PAN counting and SGS instruments, may be used.

Next, the containers are weighed and measured to determine waste density. The presence of material restricted by transportation, storage, and disposal criteria is determined by nondestructive examination by ultrasonic instruments or an RTR device. After examination, each container is labeled and its properties are logged and recorded into a computerized database. After inspection, the container is moved to a temporary storage area until readied for shipment to an interim storage or disposal facility. Containers that do not meet the transportation dose criteria are shipped in a truck equipped with shield overpacks.

The shipping and certification module is equipped with a bridge crane and a forklift. Containers can be loaded onto flat-bed trailer or van trucks. Containers can also be loaded into large transportation overpacks (e.g., TRAMPAC). This module is designed to be installed contiguous to a treatment module.

To allow year-round operations and minimize the effects of a potential spill, it is assumed that the certification and shipping operations will take place indoors. 


\subsubsection{Integration of Large Generator Modules}

Module input includes packaged waste from treatment modules. Input from the site includes utilities, service water, normal and emergency power, and communications. Operation and maintenance consumables, including personal protective equipment, must be purchased. Module output includes truck shipments of containerized alpha and nonalpha waste, which are sent to storage and disposal modules.

\subsubsection{Small Generator Fixed and Portable Module}

No separate or portable small generator certification and shipping module has been developed. Module FBSPT includes certification and shipping functions for a portable or small generator facility.

\subsection{Cost Bases, Assumptions, and Results}

- Major equipment capital cost items for this module are a 20-ton bridge crane, alpha assay, gamma assay, and RTR units. The equipment estimates were obtained as discussed in this report's sections describing a receiving/inspection module. Estimated FTE workers versus capacity is shown in Figure 18-3. Cost versus capacity for the certification and shipping module is shown in Figures $18-4$ and 18-5. 


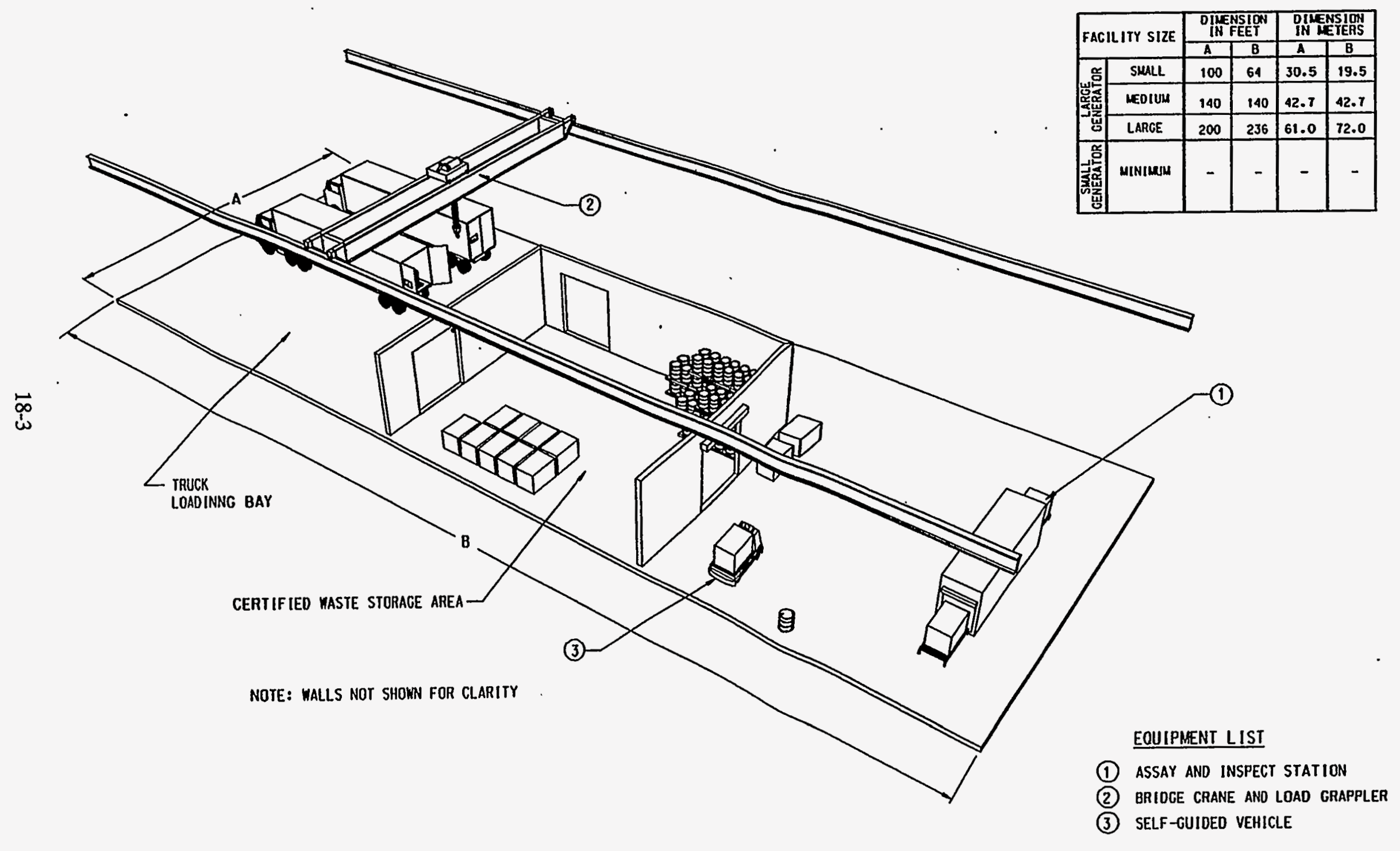

Figure 18-1. Equipment layout for the certification and shipping (CSHIP) module.

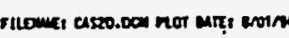




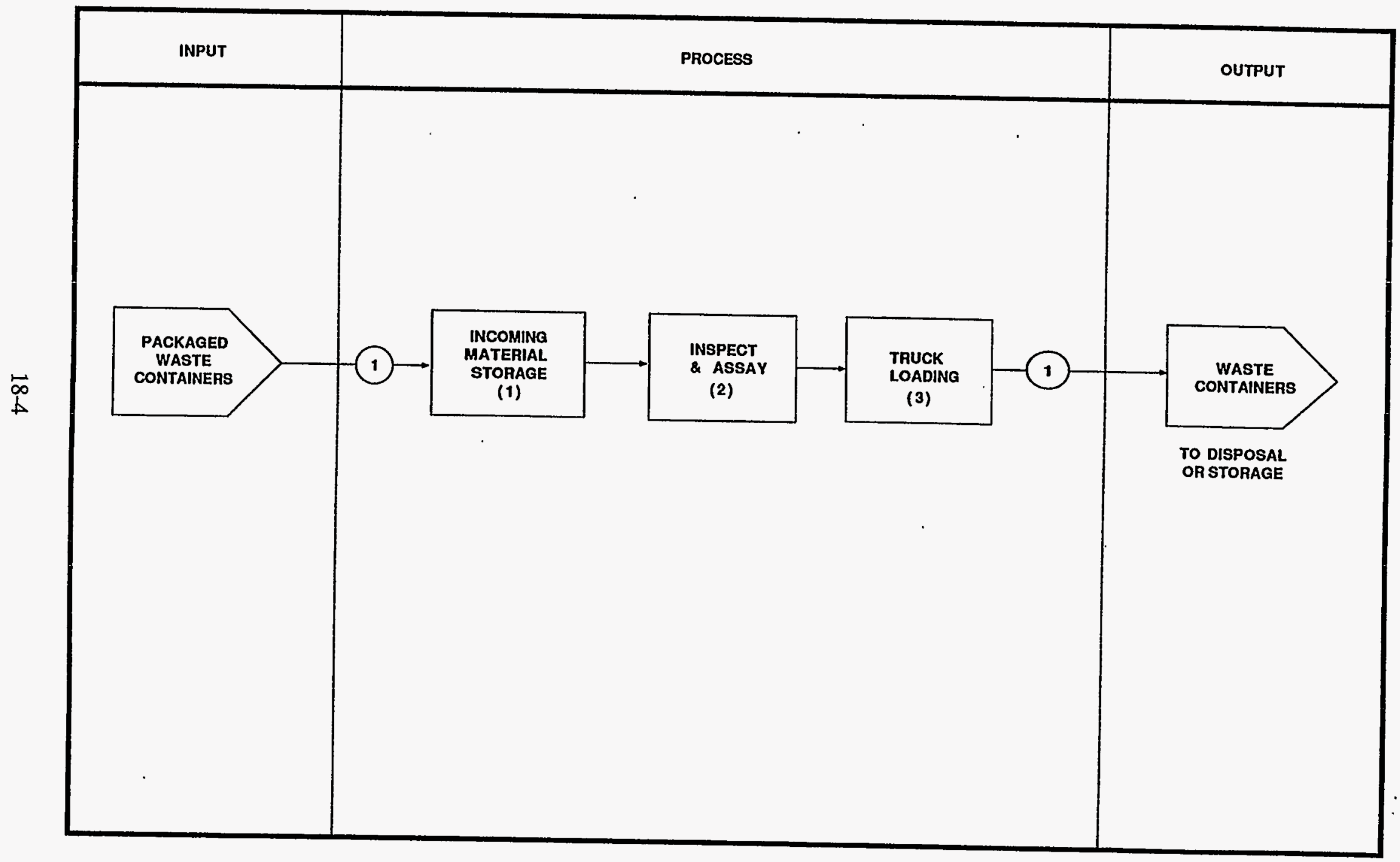

Figure 18-2. Process flow diagram for the certification and shipping (CSHIP) module. 


\section{CERTIFICATION AND SHIPPING}

FTE by Work Breakdown Structure Element

Module: CSHIP Waste Type: Alpha, Nonalpha, and Remote Handled LLW

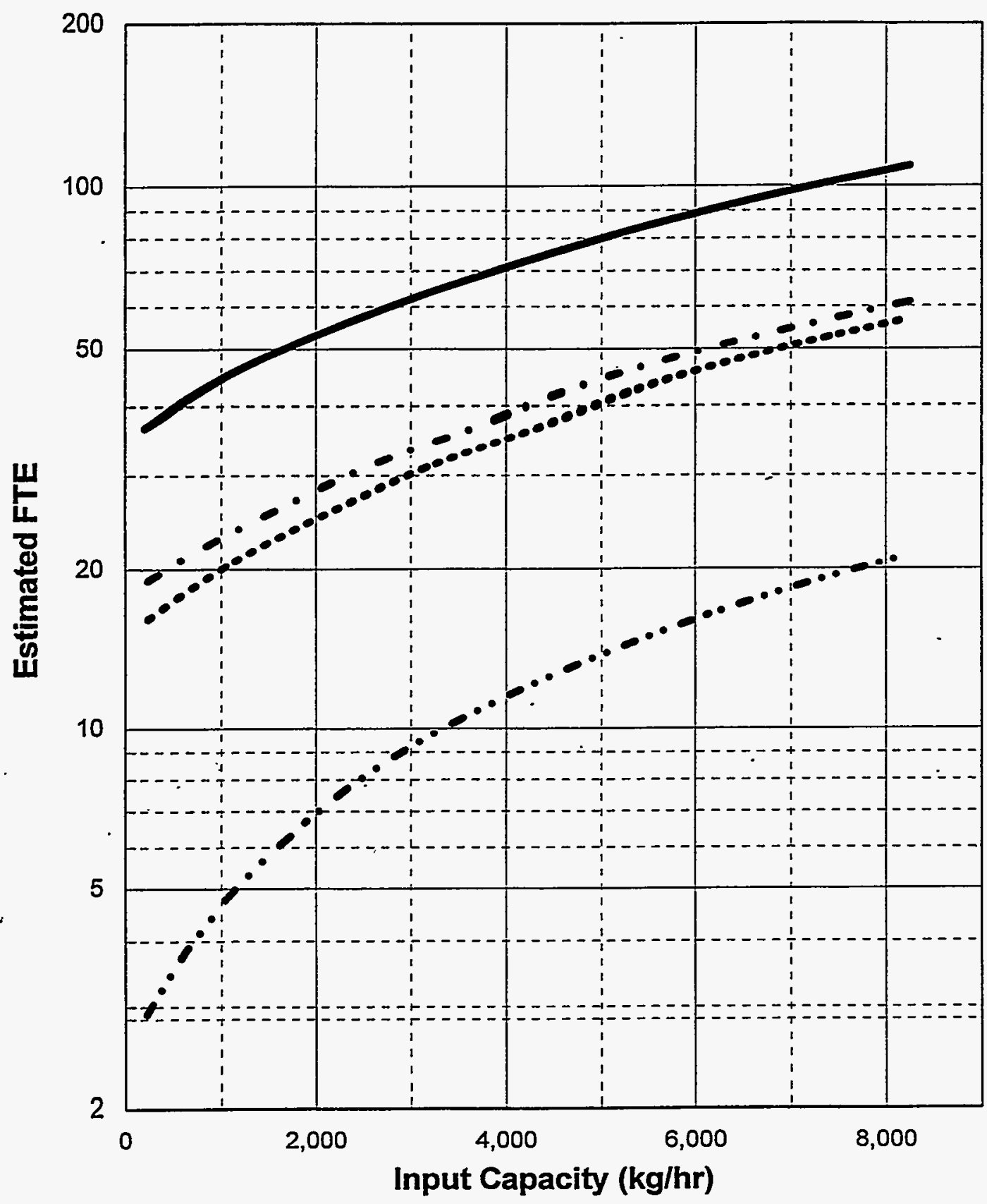

Pre-Operations Construction O\&M (1year) D\&D

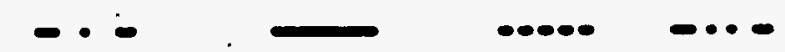

Figure 18-3. FTE workers versus capacity for the certification and shipping (CSHIP) module. 


\section{CERTIFICATION AND SHIPPING}

Cost by Work Breakdown Structure Element

Module: CSHIP Waste Type: Alpha, Nonalpha, and Remote Handled LLW

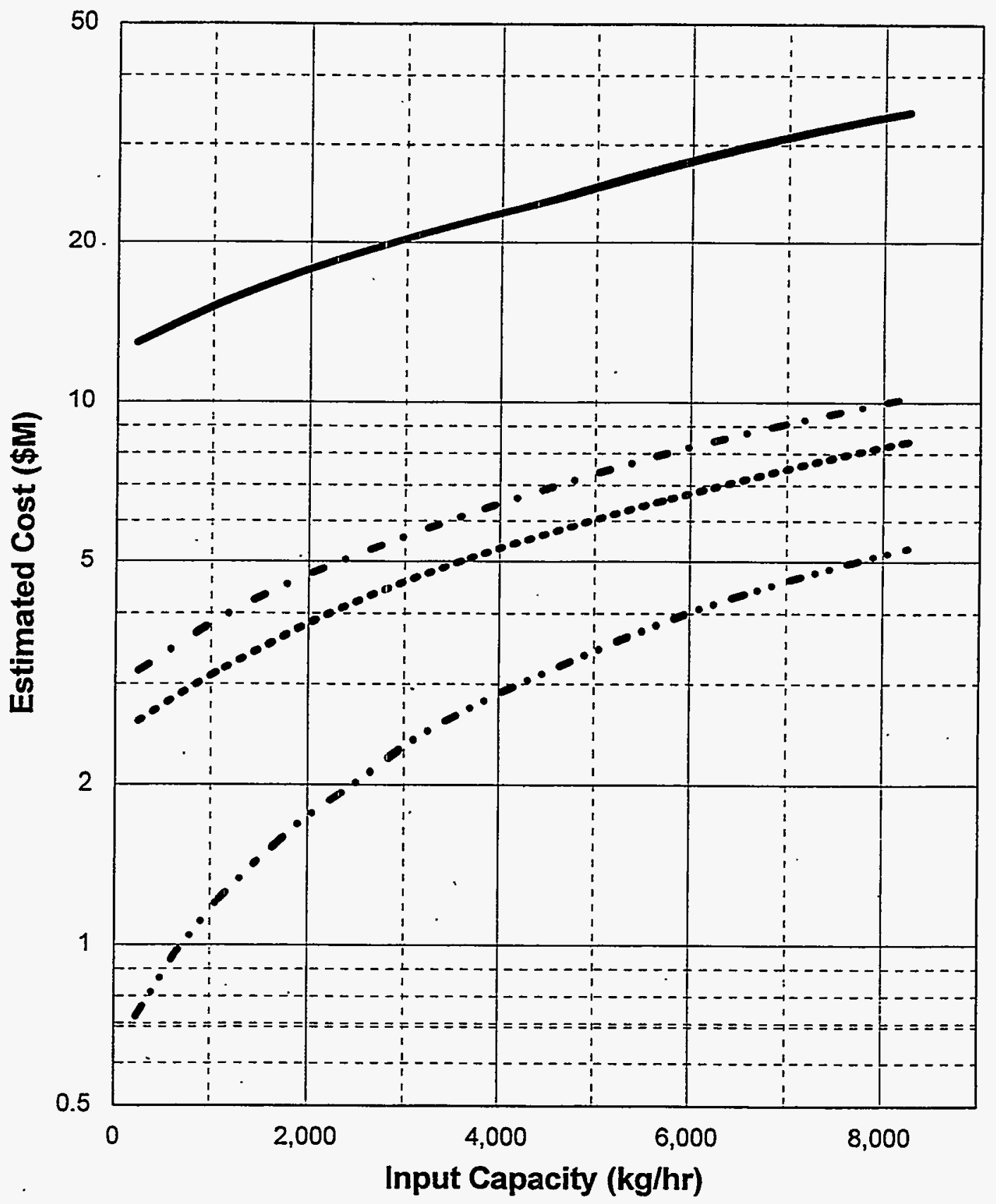

Pre-Operations Construction O\&M (1year) D\&D

Figure 18-4. PLCC versus capacity for the certification and shipping (CSHIP) module. 


\section{CERTIFICATION AND SHIPPING}

Total Life Cycle Costs

Module: CSHIP Waste Type: Alpha, Non-Alpha, and Remote Handled LLW

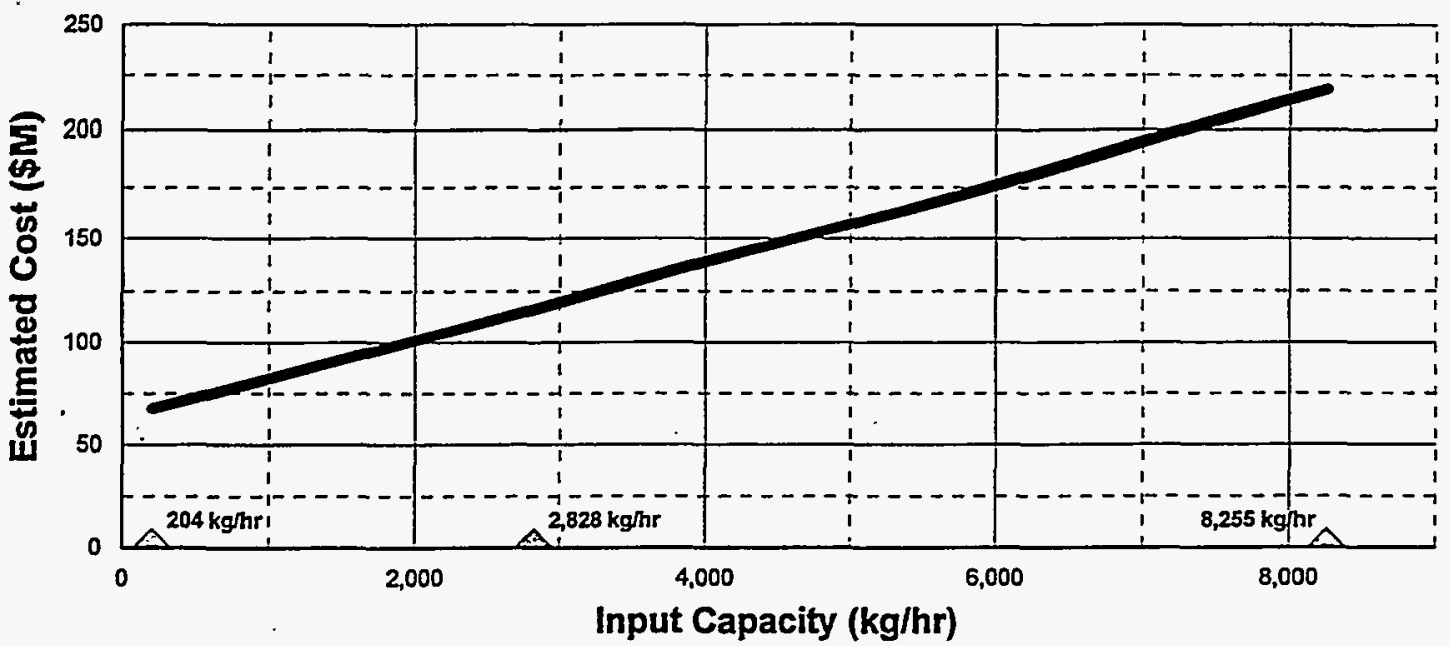

Alpha, Nonalpha, Remote Handled

NOTE: Basis incudes 20 years O\&M

Triangles indicate capacities where detailed cost estimates were developed.

\section{CERTIFICATION AND SHIPPING}

Total Life. Cycle Unit Costs

Module: CSHIP Waste Type: Alpha, Nonalpha, Remote Handled LLW

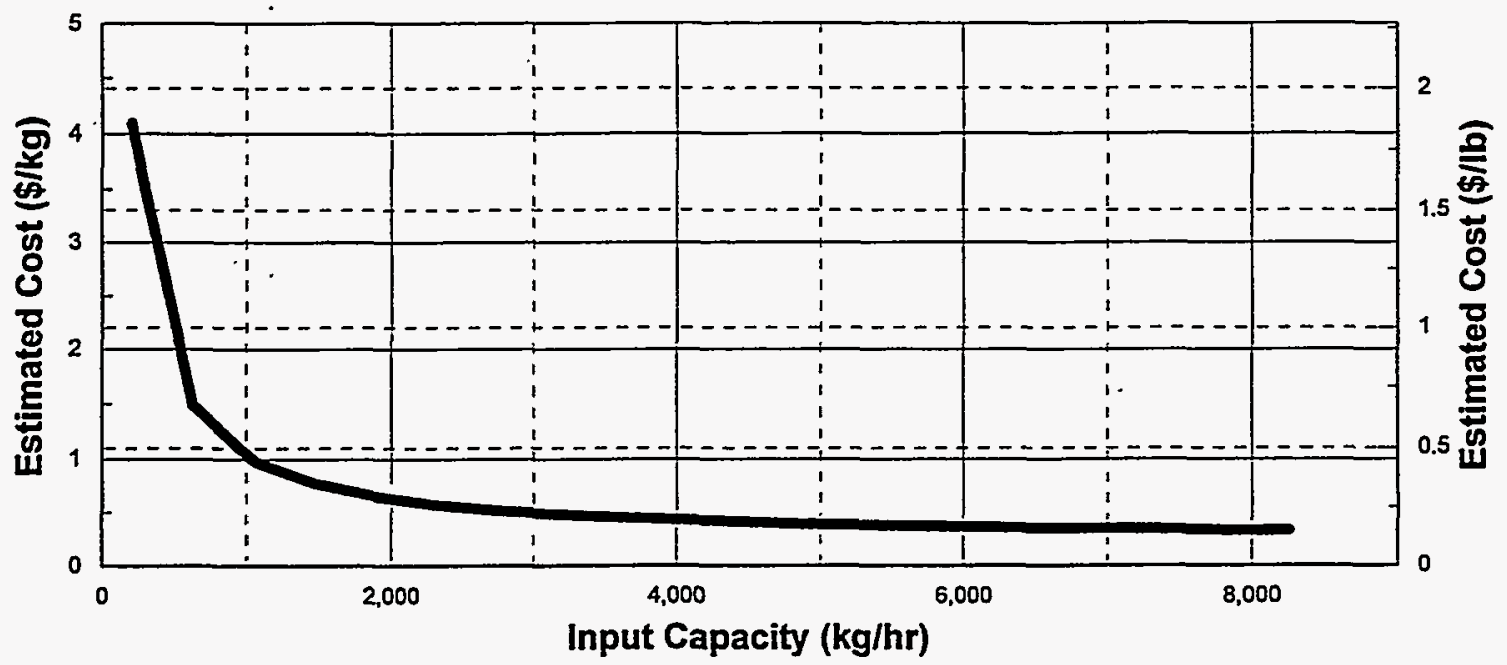

Alpha, Nonalpha, Remote Handled

NOTE: Basis indudes 20 years O\&M

Figure 18-5. PLCC versus capacity including unit rates for the certification and shipping (CSHIP) module. 


\section{STORAGE ADMINISTRATION (MODULE SADMN)}

\subsection{Basic Information}

The storage administration module is used in conjunction with the storage (STORE) module and supplies all the necessary accommodations for storing nonalpha, alpha, and $\mathrm{RH}$ wastes. The module combines receiving and inspection operations with administration, laboratory, unloading, and shipping functions.

\subsection{Technical Bases and Requirements}

\subsubsection{Function and Operation of the Modules}

Containers arrive on a transport vehicle and are unloaded using a forklift or overhead bridge crane and placed in a staging area. The containers are visually examined, labeled, logged, recorded, and sent to inspection and assay. At the inspection and assay operation, the category of the received waste is verified against the results obtained from the back-end treatment module. After inspection, the containers are moved to a storage area. The module is also used for shipping and loading containers that are ready for transport to disposal modules.

The technical bases and requirements for storage administration and storage receiving and shipping modules are the same as those outlined in the treatment administration module, the receiving and inspection module, and the shipping and certification module, except that the assay, inspection, and certification functions are for verification purposes only. In addition, the storage administration and storage receiving and shipping modules are equipped with a computer inventory system that tracks the incoming and outgoing waste, as well as types of sampling and analysis that may be performed at the staging area (nondestructive) or the laboratory. Secondary waste generated by sampling activities is treated and packaged.

\subsubsection{Integration of the Modules}

Module input includes vehicles that carry waste from the treatment module or forklift trucks that carry waste containers from storage areas (STORE) module. Module output includes containerized alpha and nonalpha wastes that are transferred to the storage bays or loaded onto trucks in containers for transport to disposal sites.

\subsection{Cost Bases, Assumptions, and Results}

Staffing levels were estimated based on the number of personnel required to support about ten separate support functions similar to the treatment administration, receiving and inspection, and shipping and certification modules. Staffing levels reflect waste input (unload and inspection) and waste output (certification and shipping) throughput requirements. For a large module, staffing levels could support, as an example, 20 drums per hour input in addition to 20 drums per hour as output. Major equipment capital cost items for this module are the laboratory analytical equipment and overhead bridge crane. An allowance is made for the analytical instruments and components needed for a mixed-waste laboratory. Mixed-waste laboratory vendors have been consulted to ensure that the 
laboratory allowance is adequate. The crane cost is estimated based on vendor quotes. Full-time equivalent and cost summaries for the storage administration module are shown in Figures 19-1 through 19-3. Table 19-1 shows the plan dimensions storage administration module.

Table 19-1. Plan dimensions of the storage administration (SADMN) module.

\begin{tabular}{|c|c|c|c|c|}
\hline \multirow[b]{2}{*}{ Module size } & \multicolumn{2}{|c|}{$\begin{array}{c}\text { Dimensions } \\
\text { (ft) }\end{array}$} & \multicolumn{2}{|c|}{$\begin{array}{l}\text { Dimensions } \\
\text { (m) }\end{array}$} \\
\hline & Width & Length & Width & Length \\
\hline \multicolumn{5}{|l|}{ Large generator } \\
\hline Small & 50 & 50 & 15.2 & 15.2 \\
\hline Medium & 50 & 100 & 15.2 & 30.5 \\
\hline Large & 50 & 156 & 15.2 & 47.5 \\
\hline Small generator & - & - & - & - \\
\hline
\end{tabular}




\section{STORAGE ADMINISTRATION}

FTE by Work Breakdown Structure Element

Module: SADMN Waste Type: Alpha, Nonalpha, and Remote Handled LLW

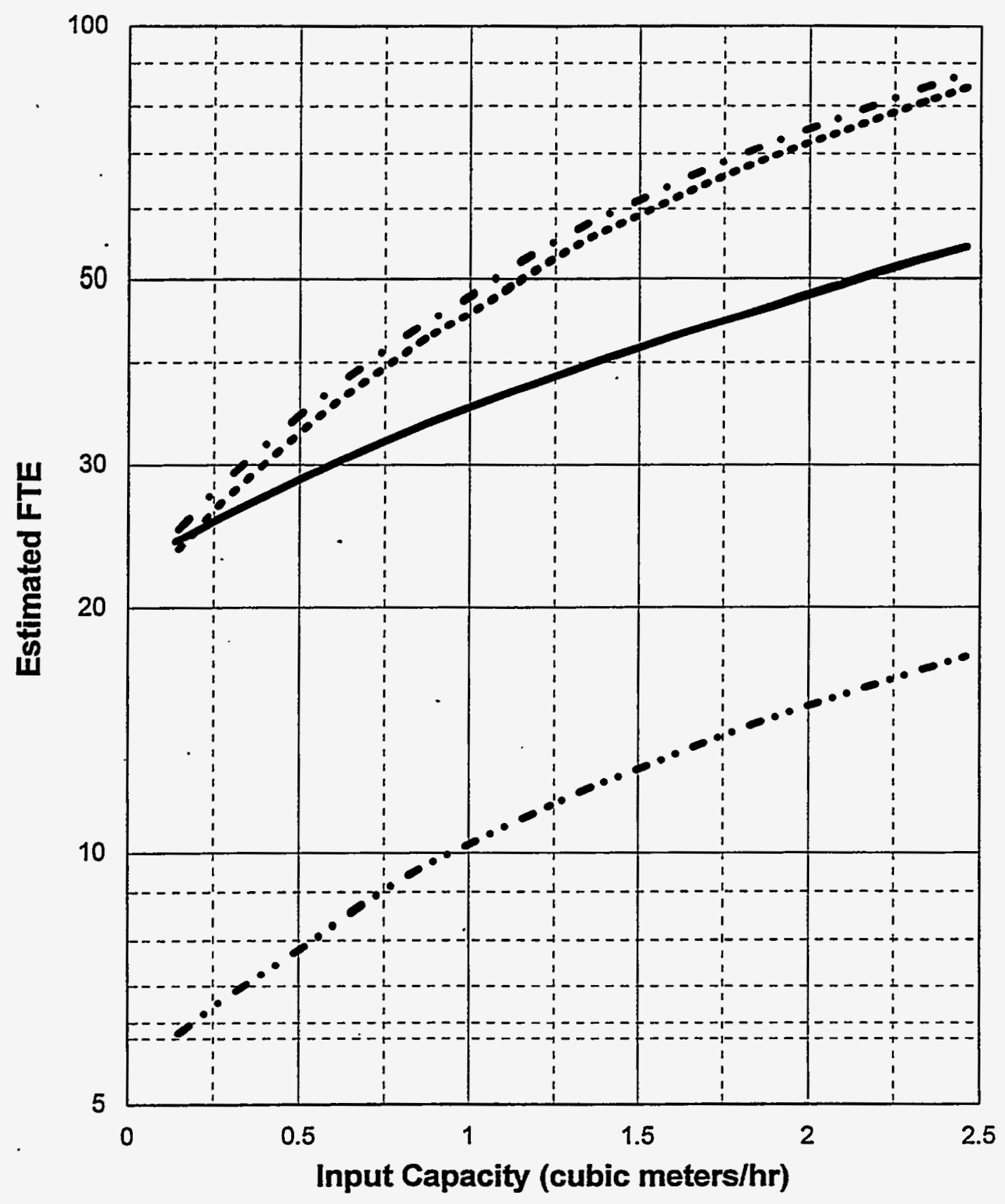

Pre-Operations Construction O\&M (1year) D\&D

Figure 19-1. FTE workers versus capacity for the storage administration (SADMN) module. 


\section{STORAGE ADMINISTRATION}

Costs by Work Breakdown Structure Element Module: SADMN Waste Type: Alpha, Nonalpha, and Remote Handled LLW

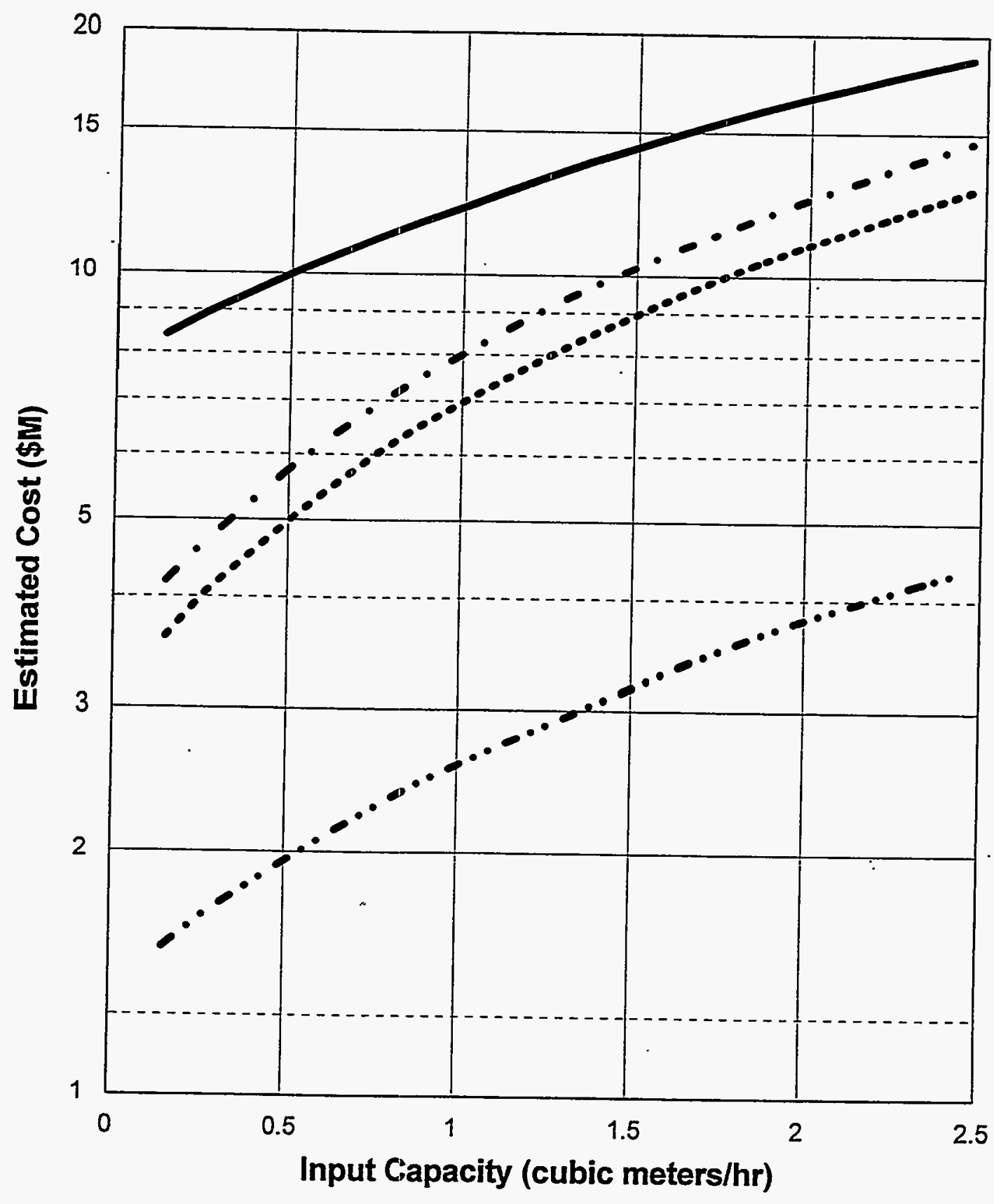

Pre-Operations Construction O\&M (1year) D\&D -

Figure 19-2. PLCC versus capacity for the storage administration (SADMN) module. 


\section{STORAGE ADMINISTRATION}

Total Life Cycle Costs

Module: SADMN Waste Type: Alpha, Nonaipha, and Remote Handled LLW

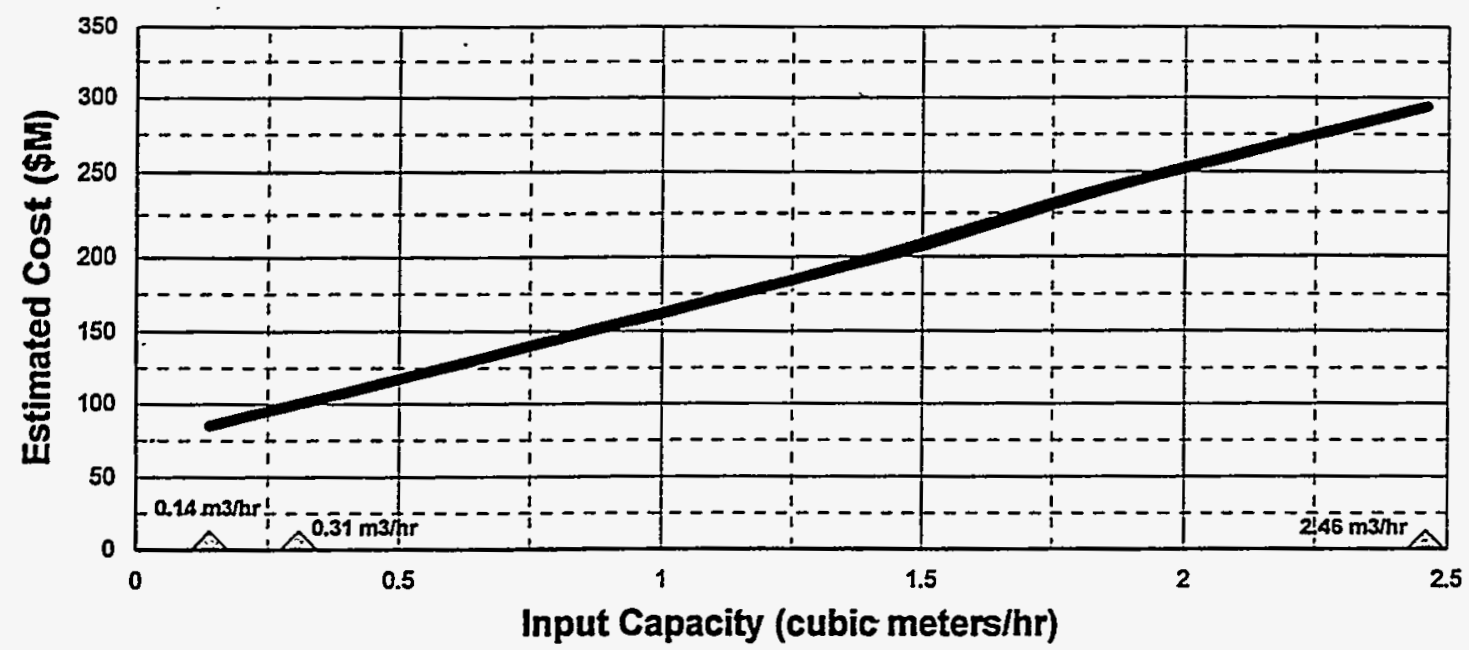

Alpha, Nonalpha, Remote Handled

NOTE: Basis includes 20 years O\&M

Triangles indicate capacities where detailed cost estimates were developed.

\section{STORAGE ADMINISTRATION}

Total Life Cycle Unit Costs

Module: SADMN Waste Type: Alpha, Nonalpha, and Remote Handled LLW

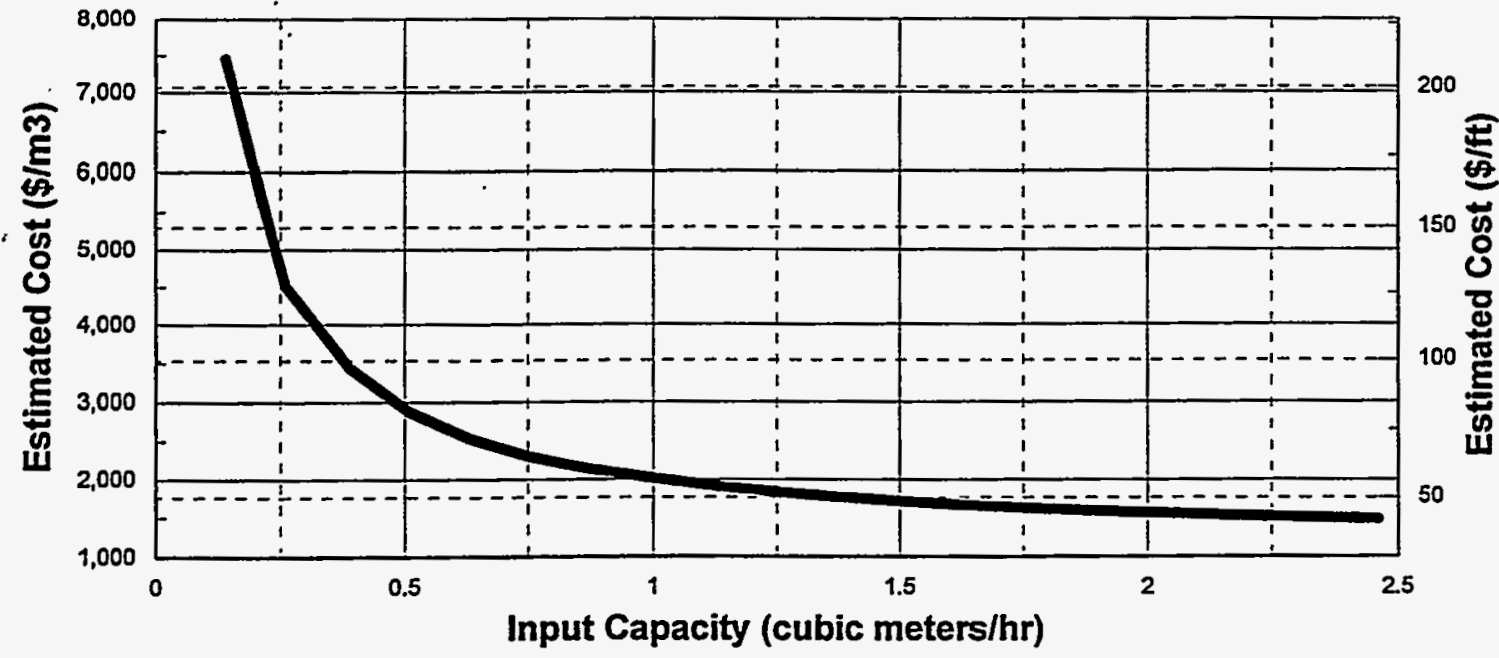

Alpha, Nonalpha, Remote Handled

NOTE: Basis includes 20 years O\&M

Figure 19-3. PLCC versus capacity plus unit rates for the storage administration (SADMN) module. 


\section{STORAGE RECEIVING AND SHIPPING (MODULE SRCSH)}

\subsection{Basic Information}

The storage receiving and shipping module is used in conjunction with the storage (STORE) module and supplies all the necessary accommodations for receiving truck shipments, unloading containers, transporting containers to the storage, and the reverse operations, as needed, for shipping containers out of the storage facility.

\subsection{Technical Bases and Requirements}

\subsubsection{Function and Operation of the Module}

Containers arrive on a transport vehicle and are unloaded using a forklift or overhead bridge crane, and placed in a staging area. The containers are visually examined, labeled, logged, recorded, and transported for inspection and assay. At the inspection and assay operation, the category of the received waste is verified against the results obtained from the storage receiving and shipping module. After inspection, the containers are moved to a storage area. The module is also used for shipping and loading containers that are ready for transport to disposal modules. The loading and shipping operations are the reverse of receiving and unloading steps.

The technical bases and requirements for the storage receiving and shipping module is the same as those outlined in the treatment receiving and inspection, and shipping and configuration modules, except that the assay, inspection, and certification functions are for verification purposes only. In addition, the storage receiving and shipping module is equipped with a computer inventory system that tracks the incoming and outgoing waste, as well as types of sampling and analysis that may be performed at the staging area (nondestructive).

\subsubsection{Integration of the Module}

Module input includes vehicles that carry waste from the treatment module or forklift trucks that carry waste containers from storage areas (STORE) module. Module output is containerized LLW waste that is transferred to the storage bays or loaded onto trucks in containers for transport to disposal sites.

\subsection{Cost Bases, Assumptions, and Results}

Major equipment capital cost items for this module are the equipment and overhead bridge crane. The crane cost is estimated based on vendor quotes. Table 20-1 lists plan dimensions of the storage receiving and shipping module. Estimated FTEs and cost versus capacity data for this module are shown in Figures 20-1 through 20-3. 
Table 20-1. Plan dimensions of storage receiving and shipping (SRCSH) module.

\begin{tabular}{|c|c|c|c|c|}
\hline \multirow[b]{2}{*}{ Module size } & \multicolumn{2}{|c|}{$\begin{array}{c}\text { Dimensions } \\
\text { (ft) }\end{array}$} & \multicolumn{2}{|c|}{$\begin{array}{l}\text { Dimensions } \\
\text { (m) }\end{array}$} \\
\hline & Width & Length & Width & Length \\
\hline \multicolumn{5}{|l|}{ Large generator } \\
\hline Small & 19.5 & 40.9 & 5.9 & 12.5 \\
\hline Medium & 36.6 & 37.8 & 11.1 & 11.5 \\
\hline Large & 73.2 & 42.4 & 22.3 & 12.9 \\
\hline
\end{tabular}




\section{STORAGE RECEIVING AND SHIPPING}

FTE by Work Breakdown Structure Element

Module: SRCSH Waste Type: Alpha, Nonalpha, and Remote Handled LLW

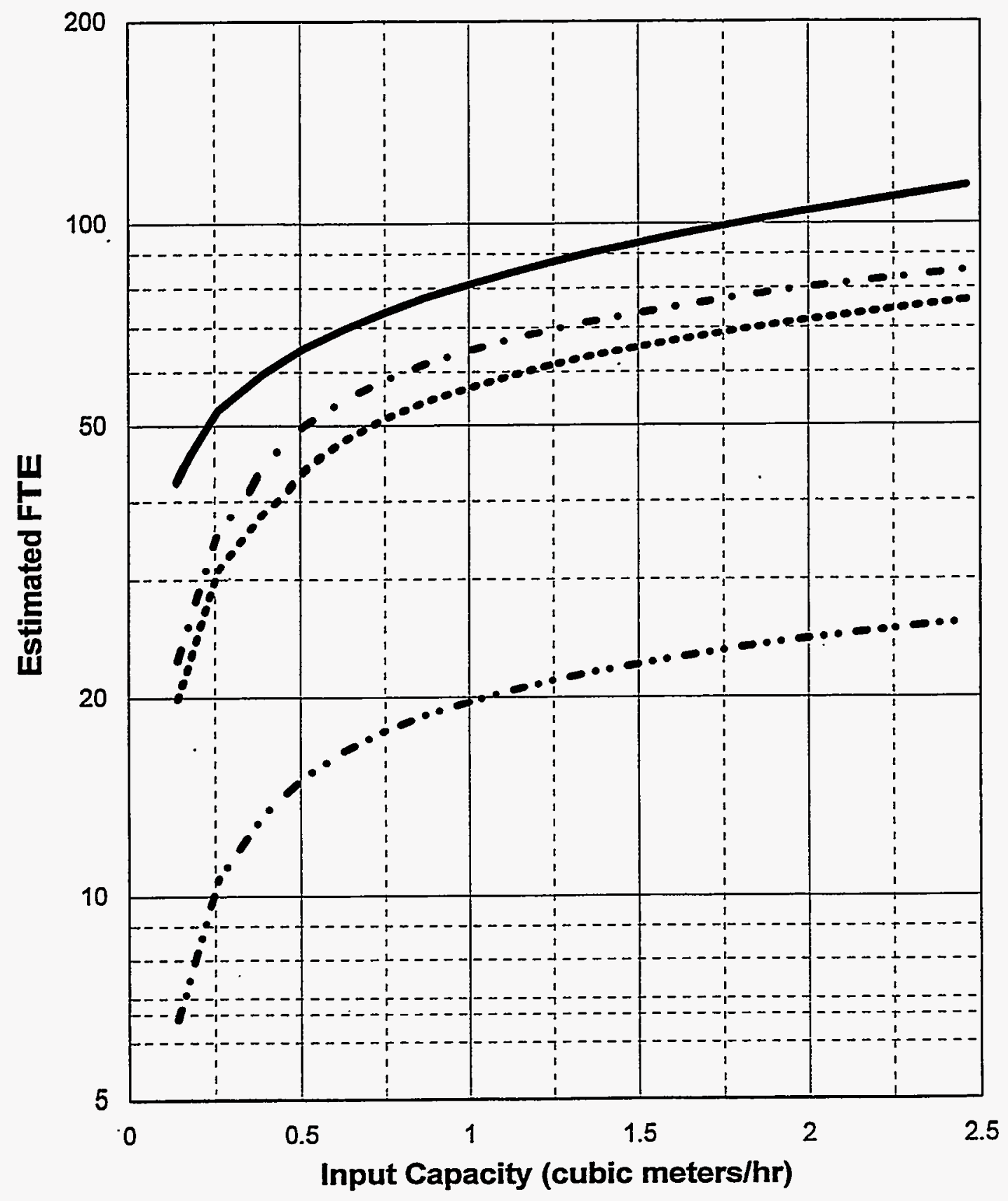

Pre-Operations Construction O\&M (1year) D\&D

Figure 20-1. FTE workers versus capacity for the storage receiving and shipping (SRCSH) module. 


\section{STORAGE RECEIVING AND SHIPPING}

Costs by Work Breakdown Structure Element

Module: SRCSH Waste Type: Alpha, Nonalpha, and Remote Handled LLW

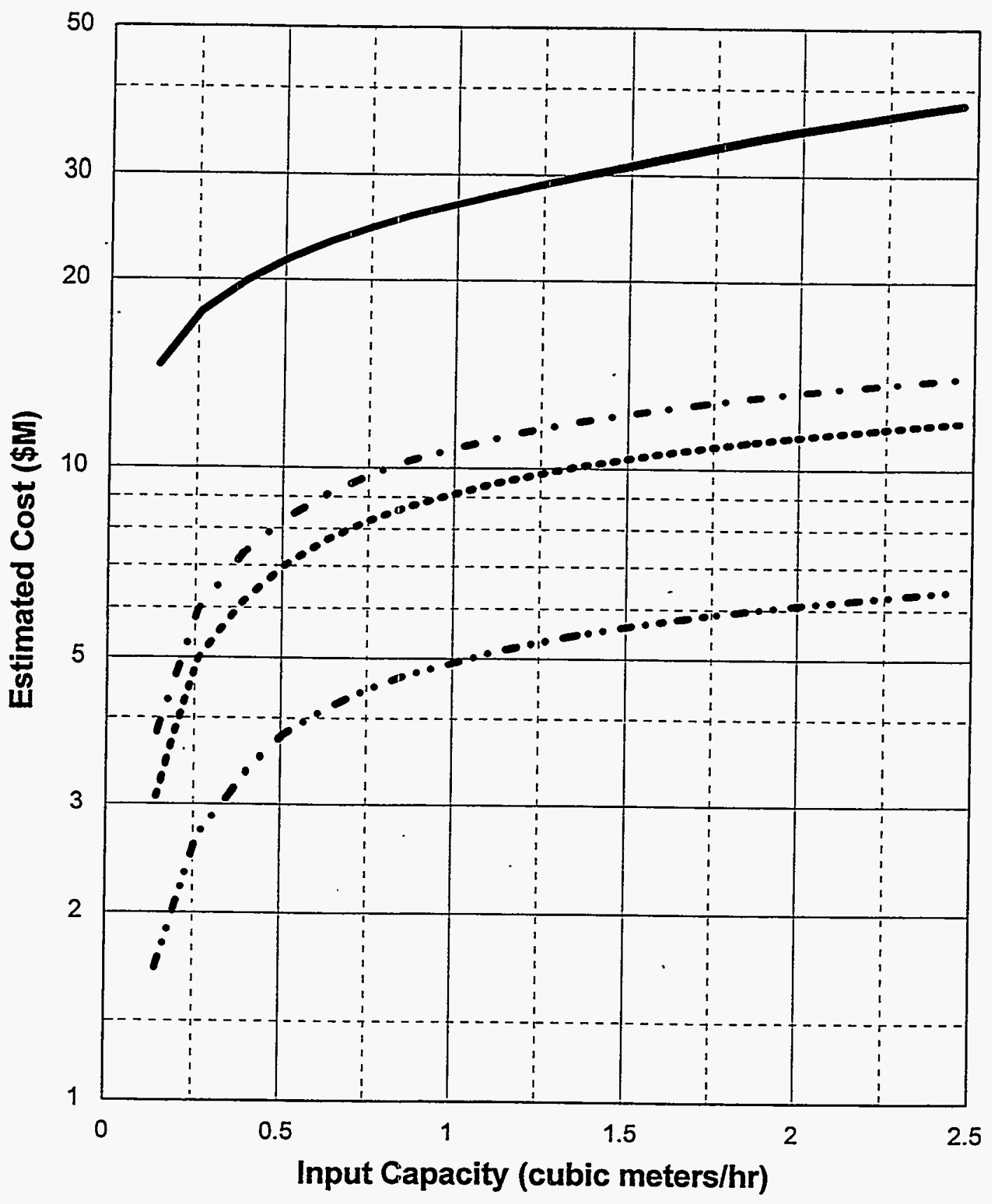

Pre-Operations Construction O\&M (1year) D\&D

Figure 20-2. PLCC versus capacity for the storage receiving and shipping (SRCSH) module. 


\section{STORAGE RECEIVING AND SHIPPING}

Total Life Cycle Costs

Module: SRCSH Waste Type: Alpha, Nonalpha, and Remote Handled LLW

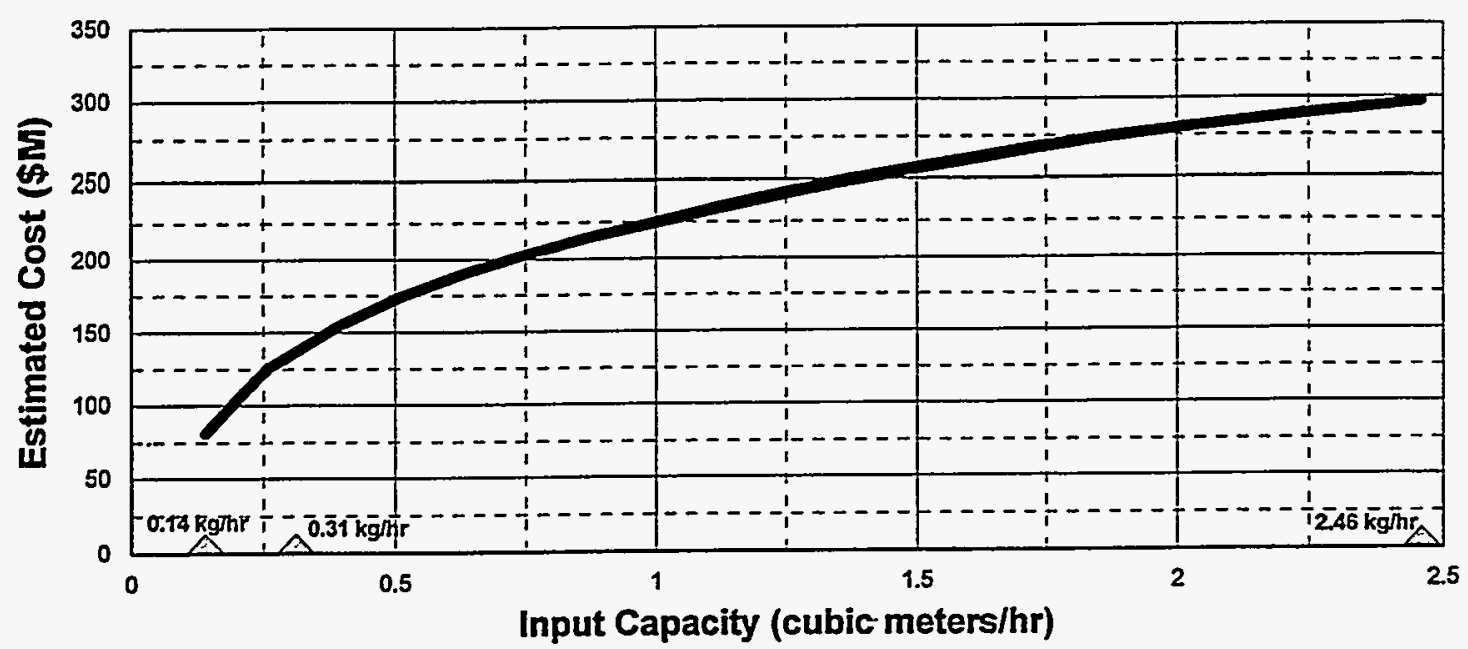

Alpha, Nonalpha, Remote Handled

NOTE: Basis inciudes 20 years O\&M

Triangles indicate capacities where detailed cost estimates were developed.

\section{STORAGE RECEIVING AND SHIPPING}

Total Life Cycle Unit Costs

Module: SRCSH Waste Type: Alpha, Nonalpha, and Remote Handled LLW

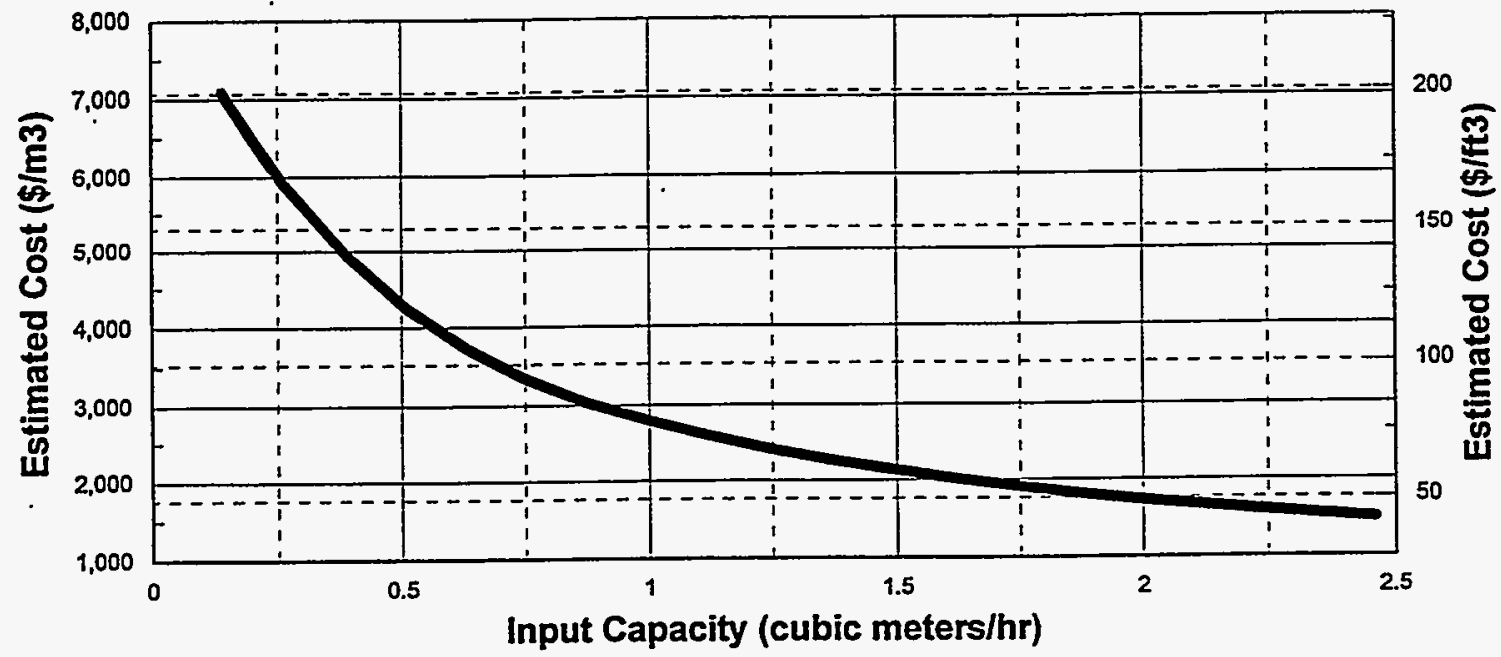

Alpha, Nonaipha, Remote Handled

NOTE: Basis includes 20 years O\&M

Figure 20-3. PLCC versus capacity plus unit rates for the storage receiving and shipping (SRCSH) module. 


\section{STORAGE (MODULE STORE)}

\subsection{Basic Information}

The storage module, shown in Figure 21-1, consists of three unit operations. Waste that arrives from assay and inspection is stored at a specified location. The module is equipped with a cleanup unit operation for responding to potential spills. The module also has permanent monitoring capabilities to ensure the integrity of the stored waste containers. The module should be used in conjunction with the storage administration (SADMN) and storage receiving and shipping (SRCSH) modules or as an addition to an existing facility where similar functions are already available.

\subsection{Technical Bases and Assumptions}

\subsubsection{Function and Operation of the Module}

The storage areas include features, such as spill collection and a combination of sloping floors and sumps, that achieve compliance with the storage requirements of the RCRA. Designated storage areas are separated by 6-in.-high (minimum) concrete berms that extend the length of the storage bays. In bays located along the outside walls, floors slope to the rear of the module. Floors in the remainder of the bays are sloped to the center. Area monitors are included for both gamma and alpha radiation control.

\subsubsection{Integration of the Module}

Module interfaces include packaged waste to and from the staging or inspection and assay area at the storage administration (SADMN) and storage receiving and shipping (SRCSH) modules.

\subsection{Cost Bases, Assumptions, and Results}

The storage capacity has been sized to handle an accumulation of up to 20 years worth of waste input from treatment modules. This module includes no major equipment capital cost items. The storage building is the only major cost element; its size depends on the size of the facility. Accordingly, a preconceptual design of the storage building with concrete walls and concrete roof was developed for several module sizes. These designs were used to generate an estimate. Estimated FTE workers and PLCC versus capacity are shown in Figures 21-2 through 21-6. 


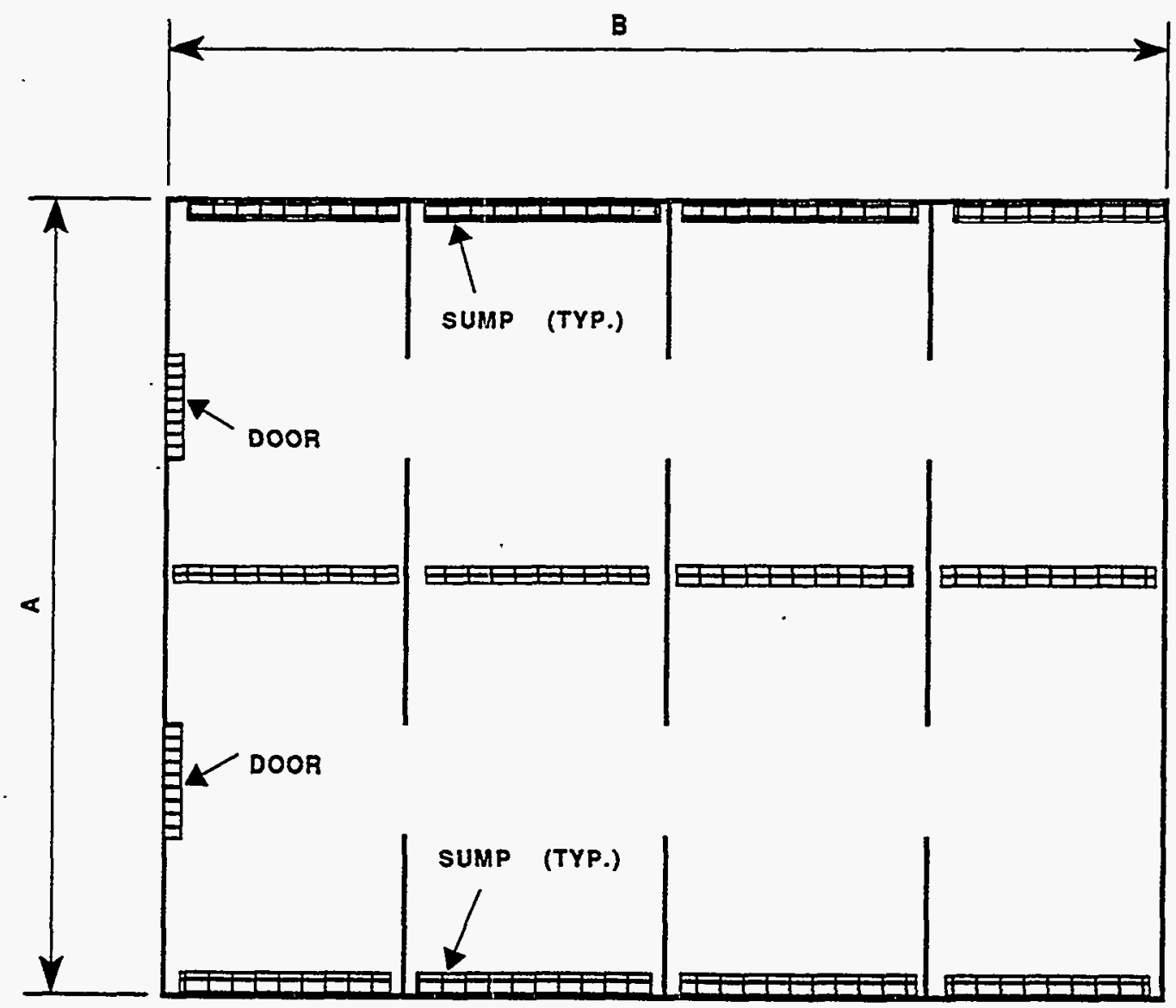

\begin{tabular}{|c|c|c|c|c|c|}
\hline & \multirow{2}{*}{$\begin{array}{l}\text { FACLILTY } \\
\text { SEI }\end{array}$} & \multicolumn{2}{|c|}{ DMEUSIONNFEET } & \multicolumn{2}{|c|}{ DMENSIONNMETERS } \\
\hline & & A & B & A & B \\
\hline \multirow{3}{*}{ 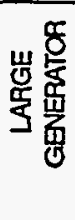 } & SMALL & 64 & 155 & 19.51 & 47.26 \\
\hline & MEDUM & 120 & 157 & 36.58 & 47.86 \\
\hline & LARGE & 240 & 446 & 73.17 & 135.97 \\
\hline 竞 & MINMUM & -- & - & - & - \\
\hline
\end{tabular}

Figure 21-1. Equipment layout for the storage (STORE) module. 


\section{STORAGE}

FTE by Work Breakdown Structure Element Module: STORE Waste Type: Nonalpha LLW

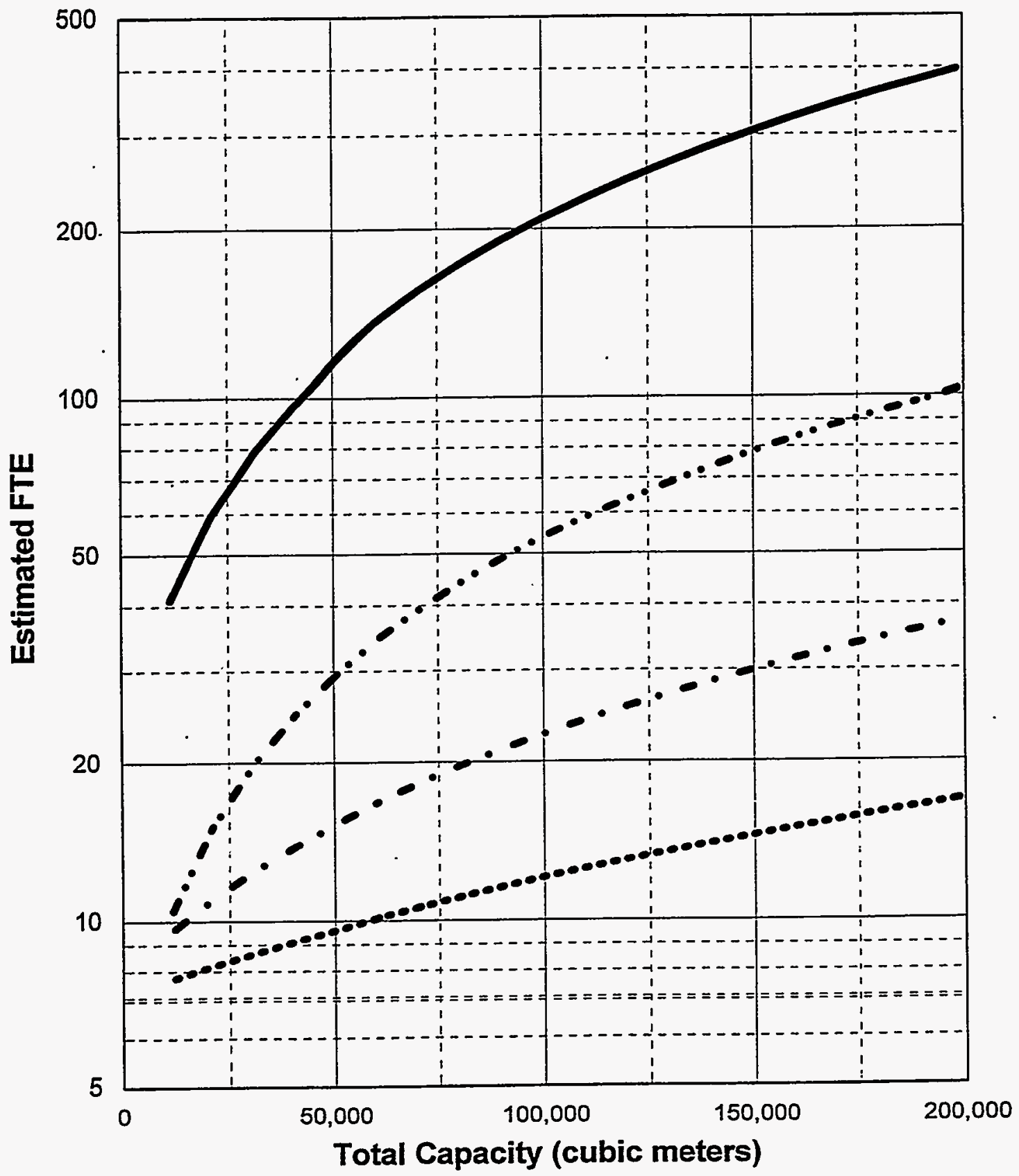

Pre-Operations Construction O\&M (1year) D\&D

Figure 21-2. FTE workers versus capacity for the nonalpha storage (B-STORE) module. 


\section{STORAGE}

FTE by Work Breakdown Structure Element

Module: STORE Waste Type: Alpha and Remote Handled LLW

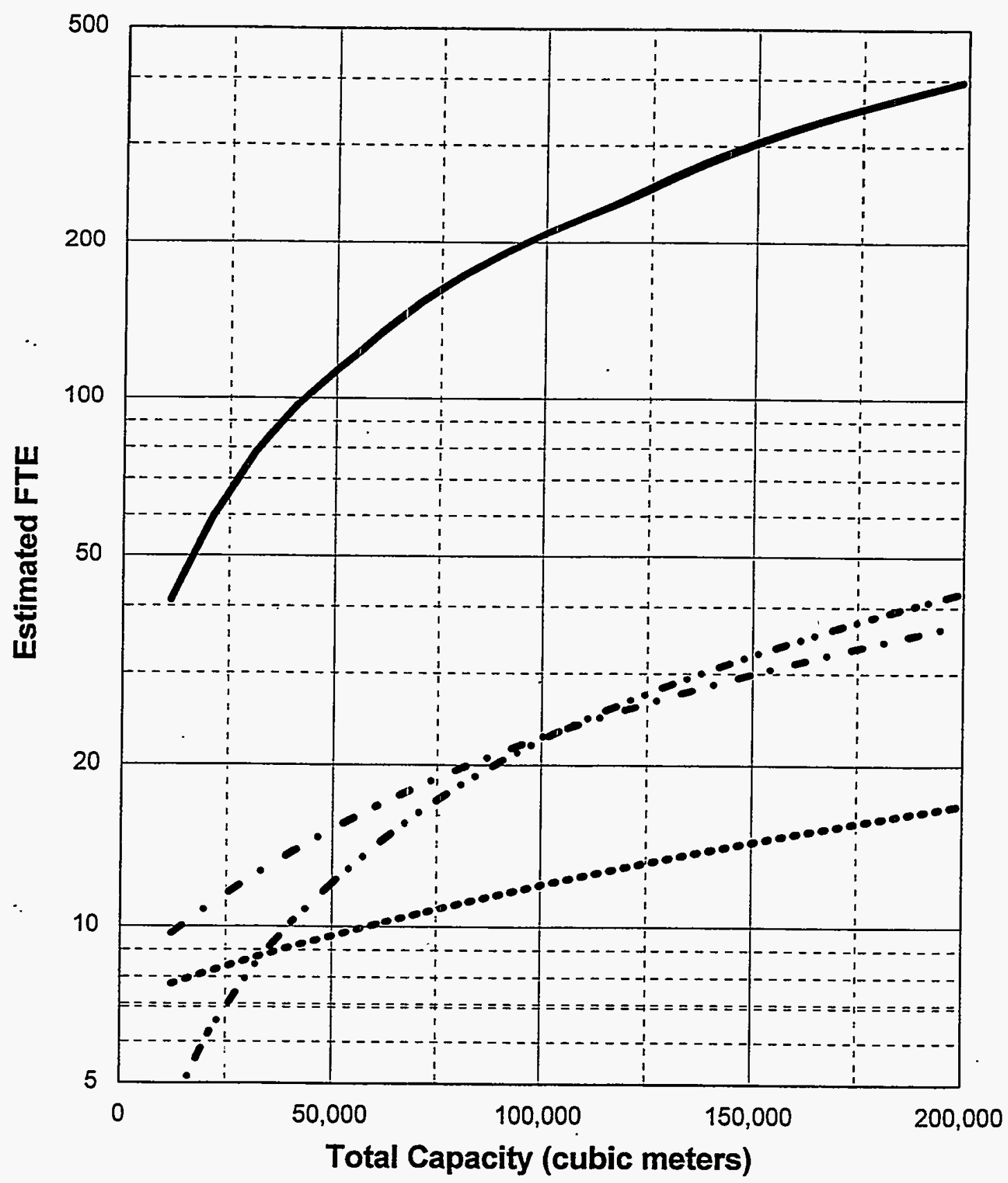

Pre-Operations Construction O\&M (1year) D\&D

Figure 21-3. FTE workers versus capacity for the alpha and RH storage (A/R-STORE) module. 


\section{STORAGE}

Costs by Work Breakdown Structure Element Module: STORE Waste Type: Nonalpha LLW

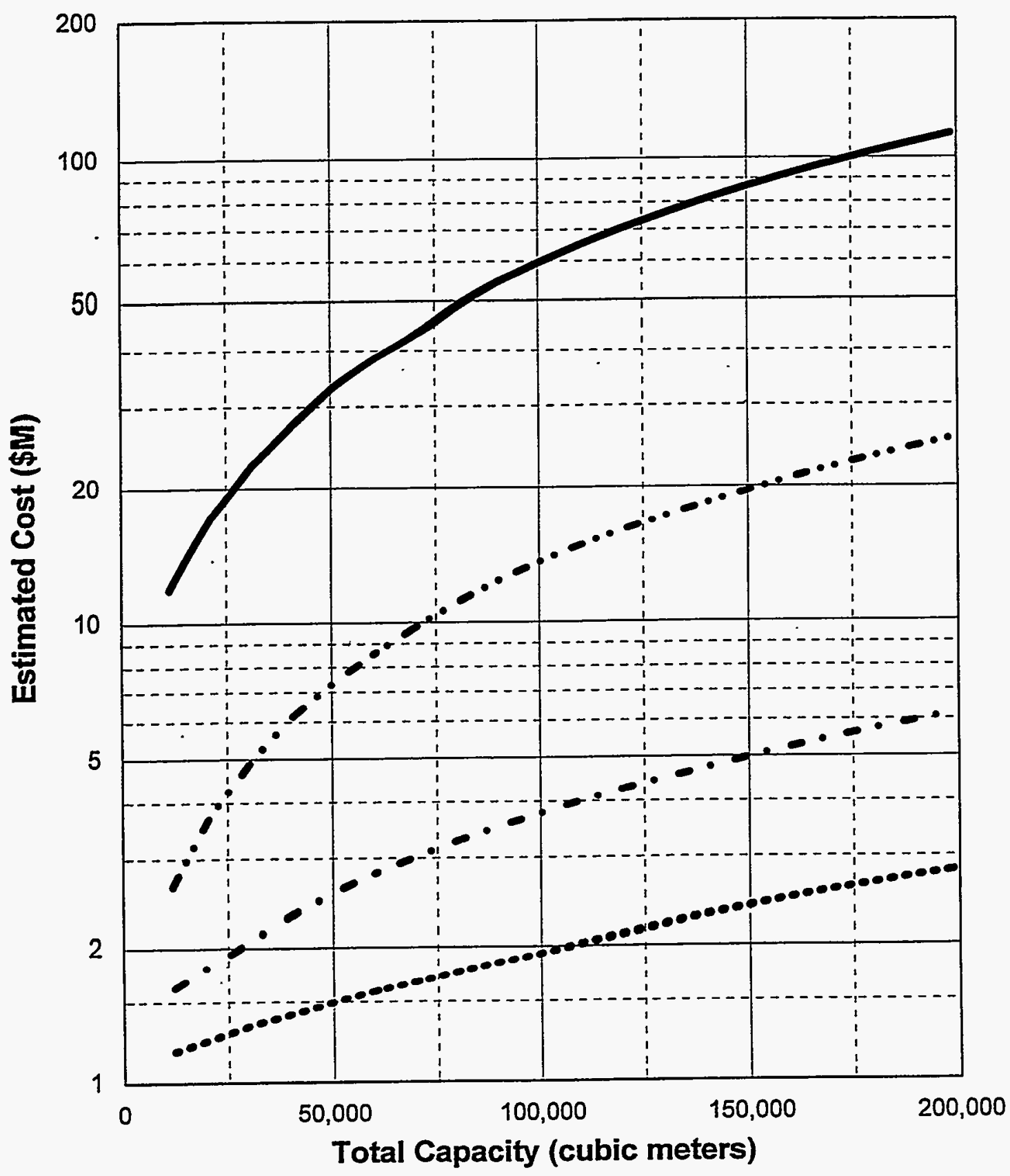

Pre-Operations Construction O\&M (1year) D\&D

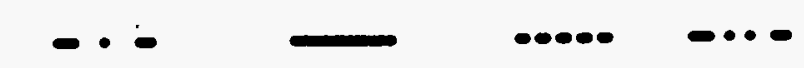

Figure 21-4. PLCC versus capacity for the nonalpha storage (B-STORE) module. 


\section{STORAGE}

Cost by Work Breakdown Structure Element

Module: STORE Waste Type: Alpha and Remote Handled LLW

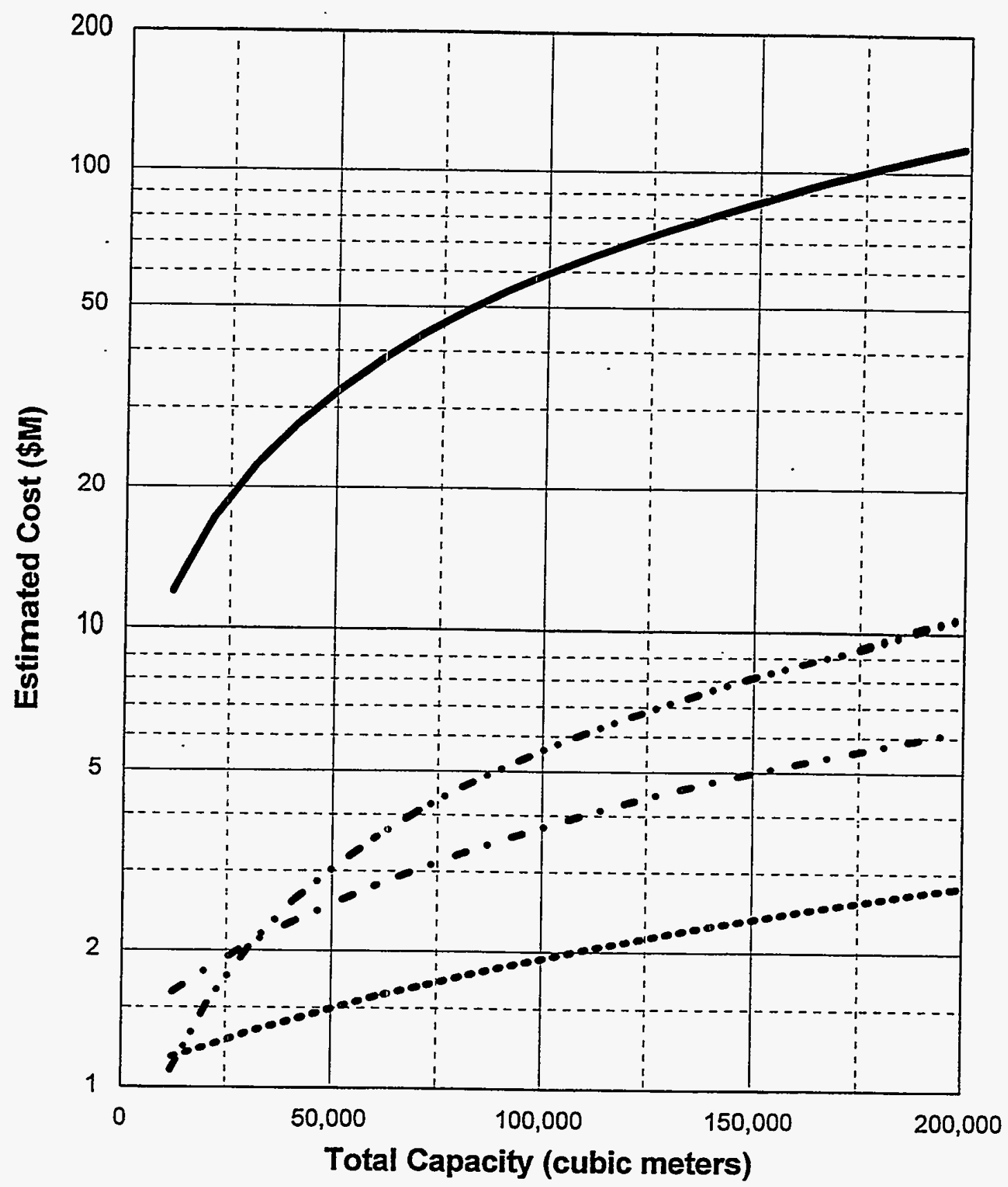

Pre-Operations Construction O\&M (1year) D\&D

Figure 21-5. PLCC versus capacity for the alpha and RH storage (A/R-STORE) module. 
STORAGE

Total Life Cycle Costs

Module: STORE Waste Type: Alpha, Nonalpha, and Remote Handled LLW

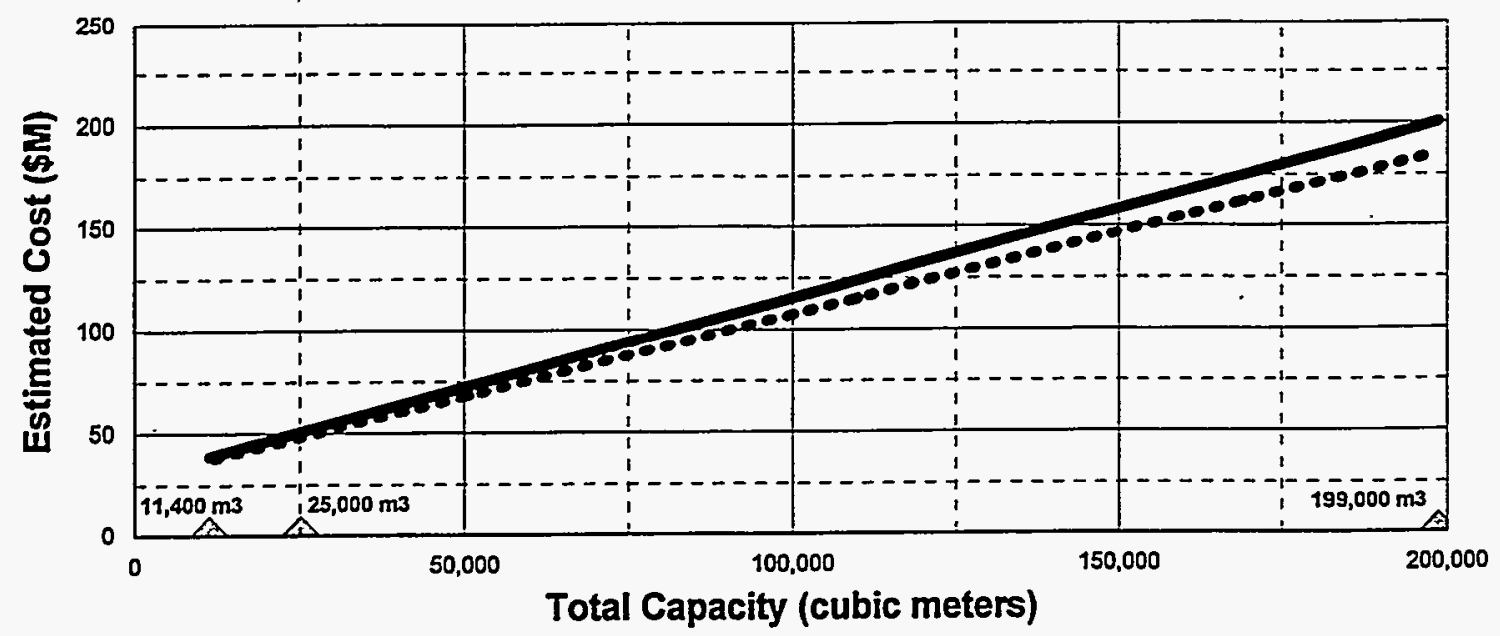

Nonalpha Alpha, Remote Handled

NOTE: Basis includes 20 years O\&M

Triangles indicate where detailed cost estimates were developed.

\section{STORAGE}

Total Life Cycle Unit Costs

Module: STORE Waste Type: Alpha, Nonalpha, and Remote Handled LLW

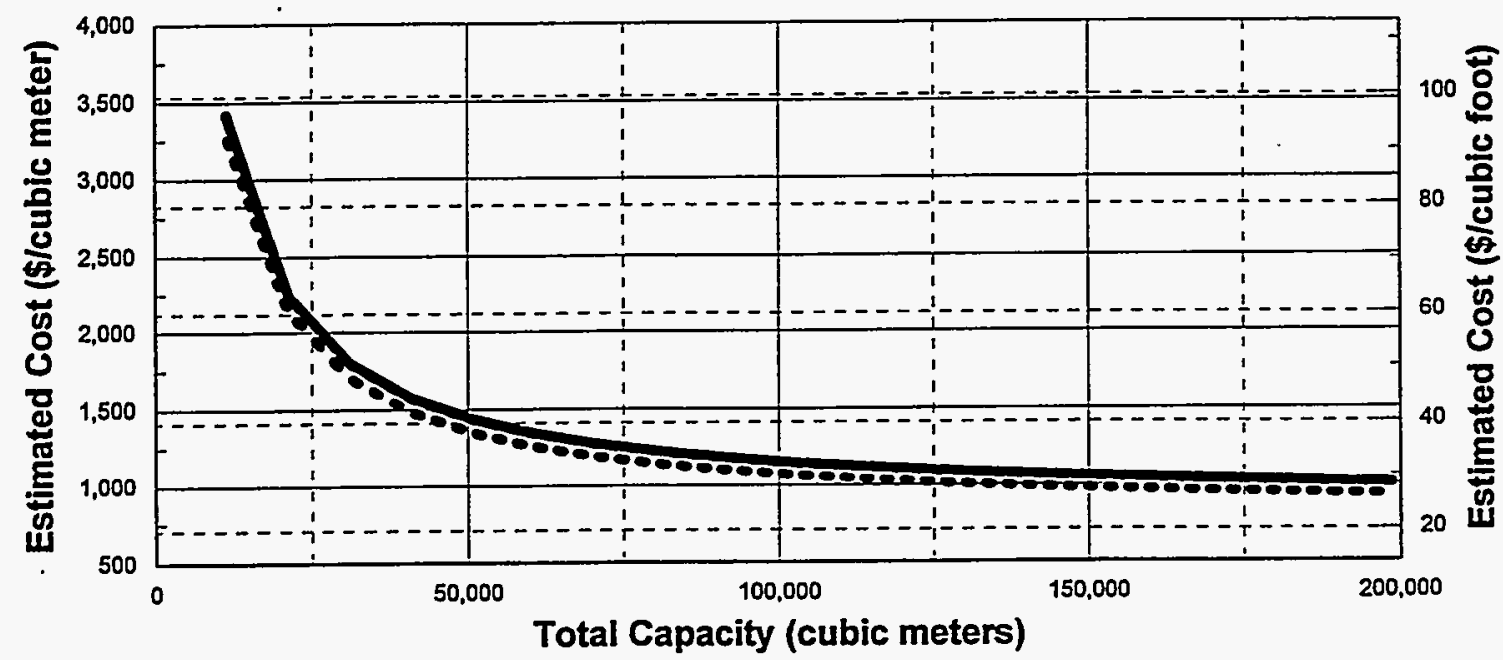

Nonalpha Alpha, Remote Handled

NOTE: Basis includes 20 years O\&M

Figure 21-6. PLCC versus capacity including unit rates for the storage (STORE) module. 


\section{SILO STORAGE (MODULE STOSI)}

\subsection{Basic Information}

The silo storage facility, shown in Figure 22-1, is used in conjunction with the storage administration and the storage receiving and shipping modules. In addition, the facility can accept packaged waste from generators or other sources. The facility receives RH LLW waste in metal drums and holds them in shielded storage silos for long-term storage. The unit operations that accomplish these functions are shown in the PFD in Figure 22-2.

\subsection{Technical Bases and Assumptions}

\subsubsection{Function and Operation of the Module}

A transport vehicle brings drums loaded in a radiation shielding cask to the storage yard where. prefabricated storage silos are located. The designated storage silo is prepared in advance to accept the drums.

At the storage yard, an unloading and staging unit operation receives and inspects the transportation vehicle and shield cask and removes the cask cover. Using remote-handling techniques, the waste drum is transferred from the transportation cask to a storage pallet. When a drum removal operation is completed, the pallet is remotely placed inside the silo. The empty cask and trailer is then inspected, the cask lid is attached, and the trailer is transported either to the parking area or back to the treatment facility.

The vault safely stores the drums for the desired period. A monitoring unit operation continuously monitors the storage confinement system and drum leakage. It will be able to determine when corrective action needs to be taken to maintain safe storage conditions.

Operation steps for shipment of the drums out of the storage facility are the reverse of the incoming drum operation steps discussed above. The storage facility does not generate secondary waste.

\subsubsection{Integration of the Module}

This facility interfaces directly with the LLW storage administration (SADMN) module; the LLW storage receiving and shipping facility (SRCSH) module; and the waste generator facilities. Operations and maintenance consumables, including personal protective equipment, must be purchased. Facility input is the incoming RH LLW drums in casks mounted on transport devices. The output is the same as the input. The facility includes security fence, monitoring, and security and access control features. 


\subsection{Cost Bases, Assumptions and Results}

Each storage silo holds 16 drums in four pallets. It is assumed that prefabricated silos will be a complete package supplied by vendors. Hence, design cost is estimated at $6 \%$ of the silo construction costs. Inspection cost is $2 \%$. Decommissioning costs are estimated at $\$ 1,500$ per fabricated concrete silo. Estimated FTEs and cost versus capacity data for this module are shown in Figures 22-3 through 22-5. 

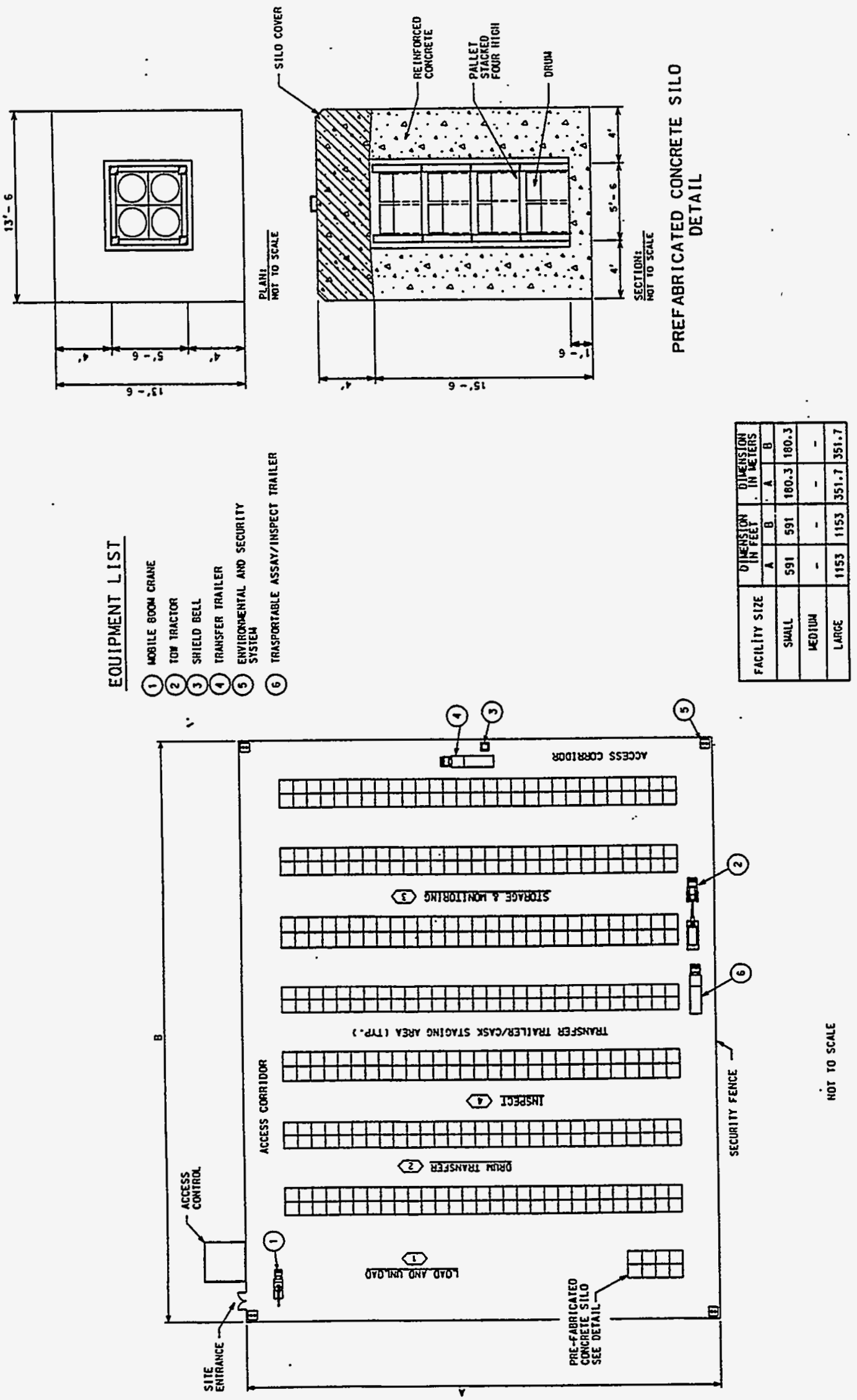

을 


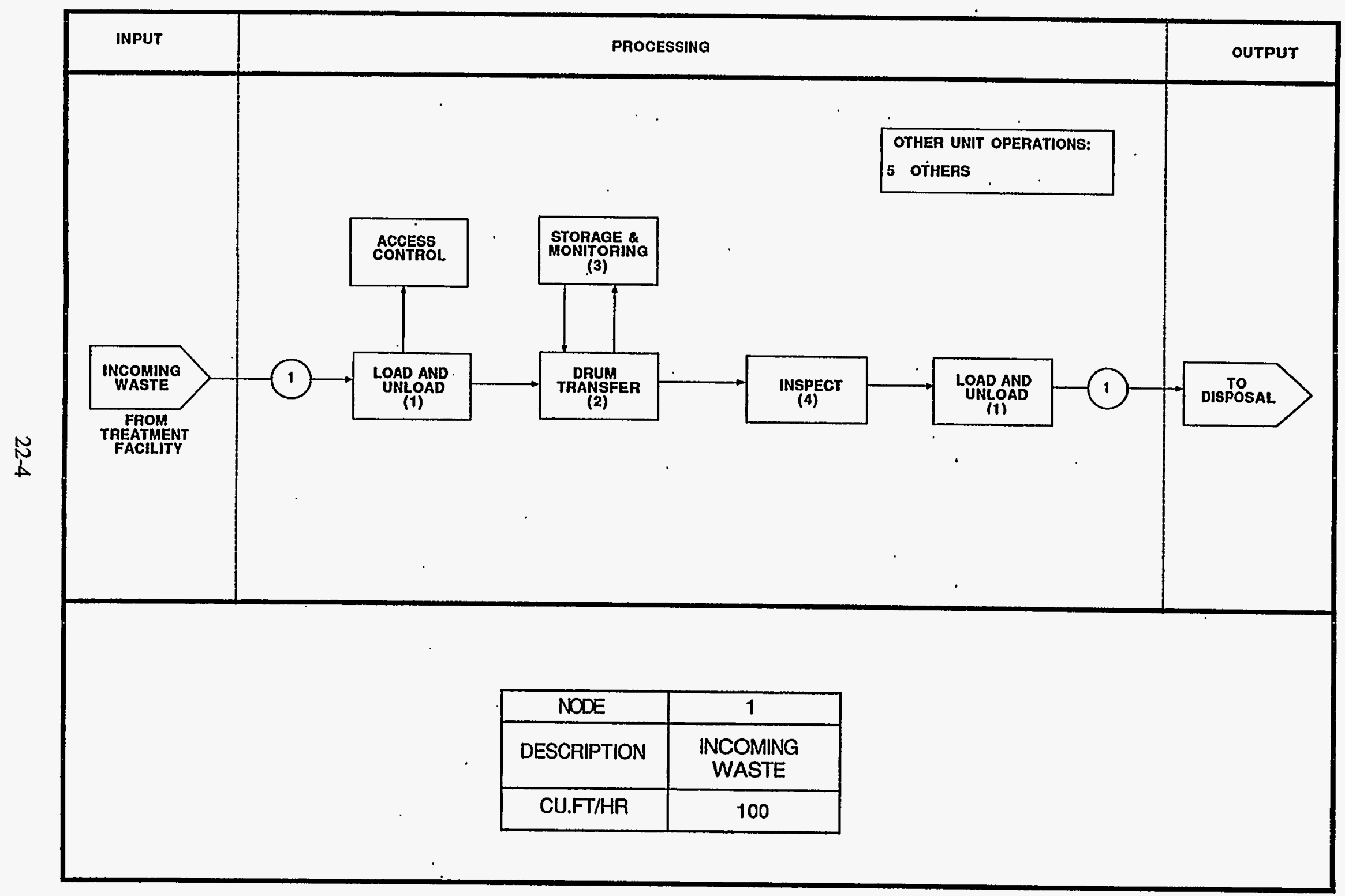

Figure 22-2. Process flow diagram for the silo storage (STOSI) module. 


\section{SILO STORAGE}

FTE by Work Breakdown Structure Element Module: STOSI Waste Type: Remote Handled LLW

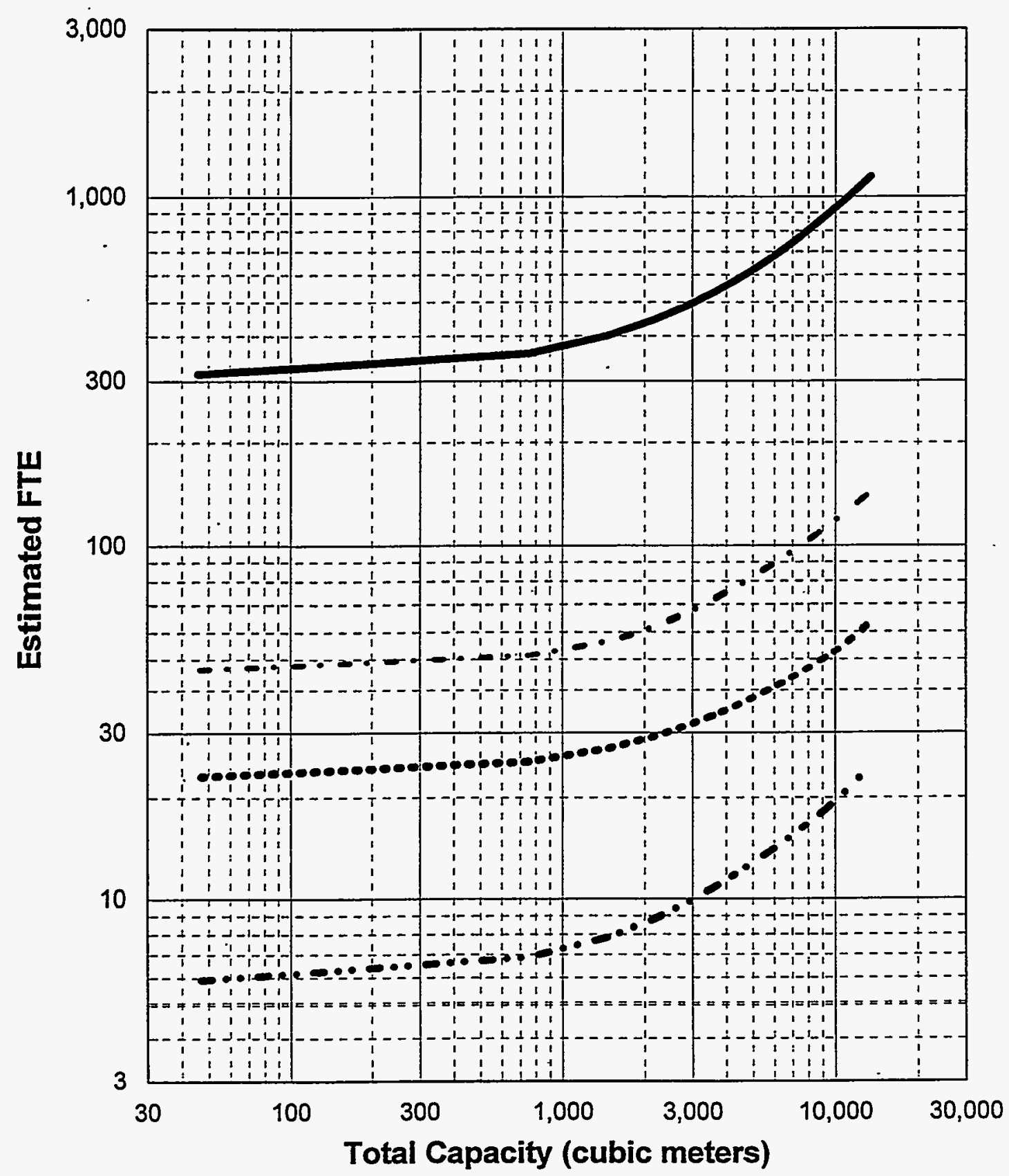

Pre-Operations Construction O\&M (1year) D\&D

Figure 22-3. FTE workers versus capacity for the RH silo storage facility (R-STOSI) module. 


\section{SILO STORAGE}

Cost by Work Breakdown Structure Element Module: STOSI Waste Type: Remote Handled LLW

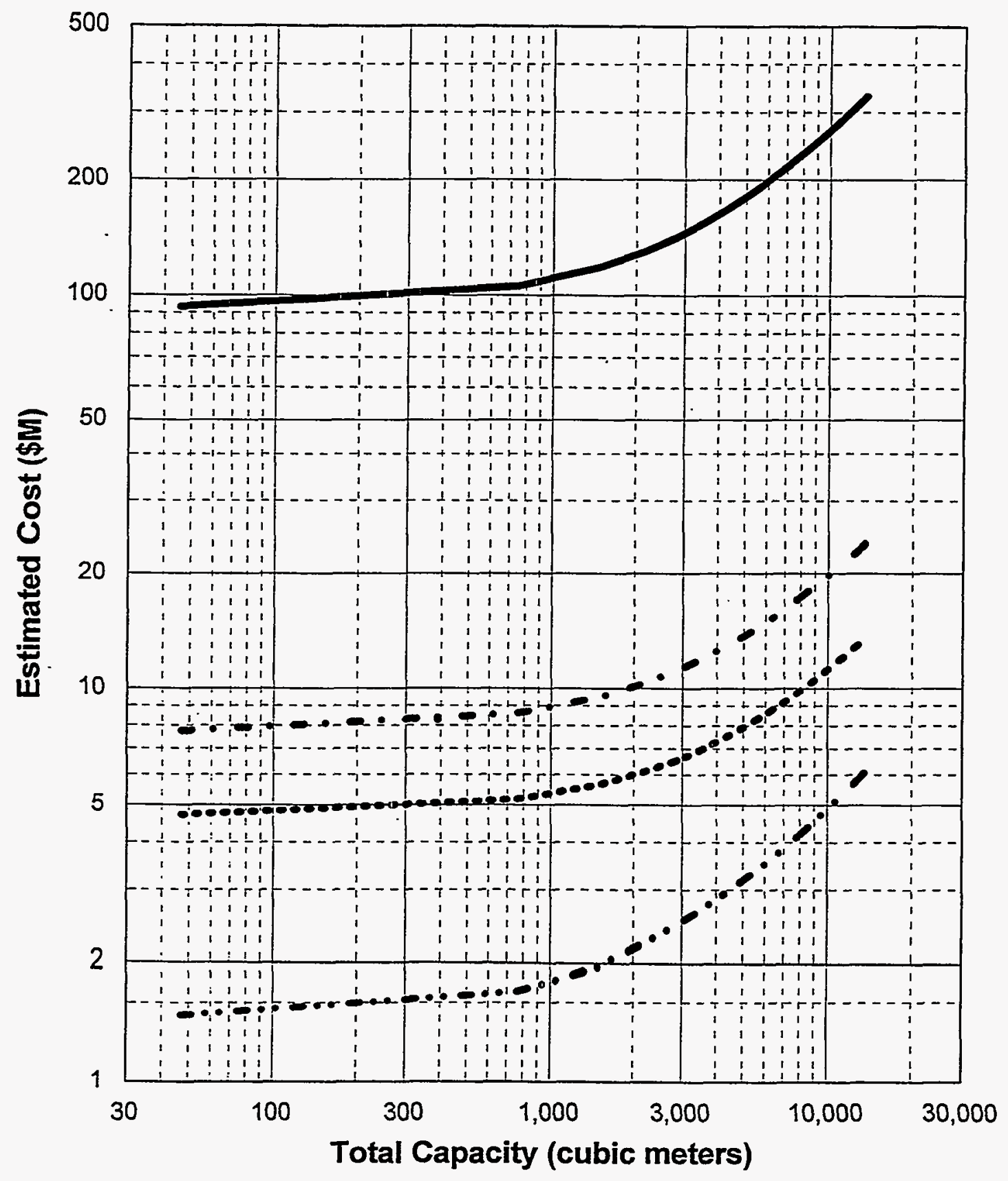

Pre-Operations Construction O\&M (1year) D\&D

Figure 22-4. PLCC versus capacity for the RH silo storage facility (R-STOSI) module. 


\section{SILO STORAGE}

Total Life Cycle Costs

Module: STOSI Waste Type: Remote Handled LLW

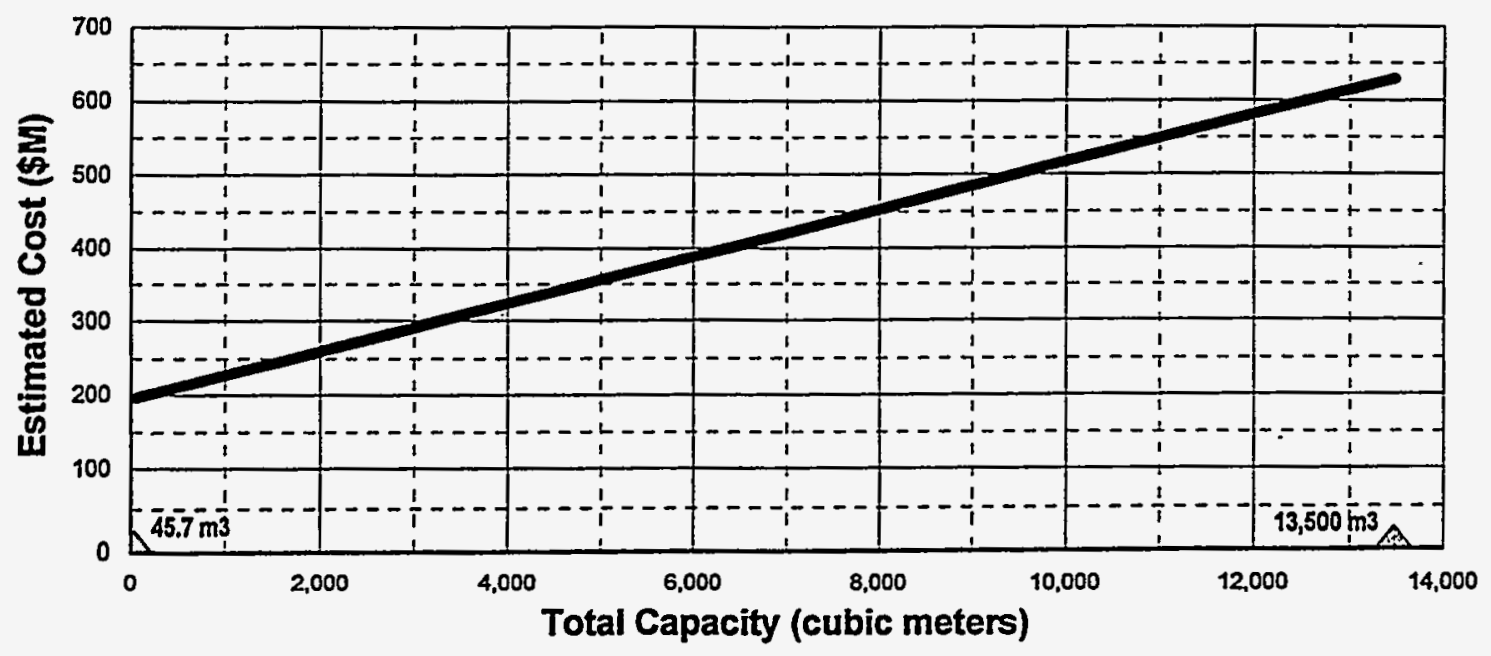

Remote Handled

NOTE: Basis includes 20 years O\&M

Triangles indicate where detailed cost estimates were developed.

\section{SILO STORAGE}

Total Life Cycle Unit Costs

Module: STOSI Waste Type: Remote Handled LLW

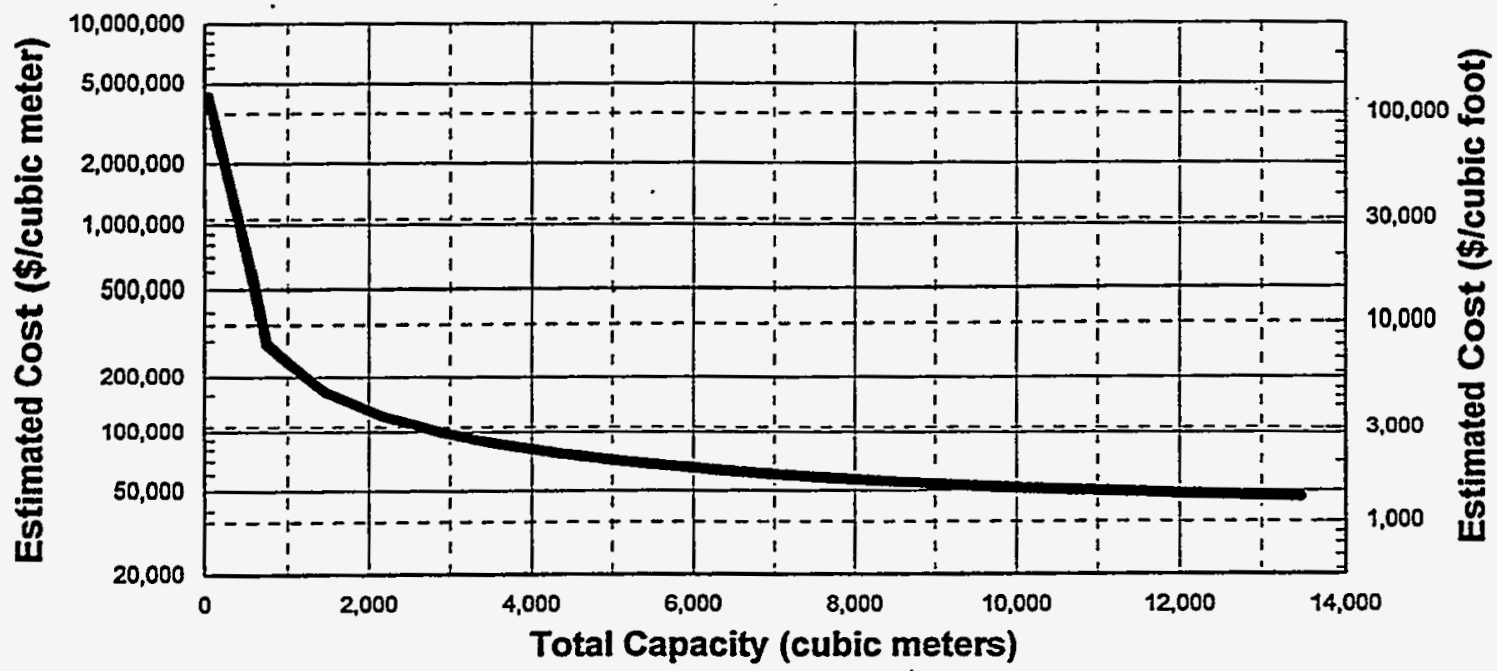

Remote Handled

NOTE: Basis indudes 20 years O\&M

Figure 22-5. PLCC versus capacity including unit rates for the RH silo storage facility (R-STOSI) module. 


\section{DISPOSAL ADMINISTRATION (MODULE DADMN)}

\subsection{Basic Information}

The disposal administration module is used in conjunction with the disposal (AGDSP, SLDSP, SIDSP, and BHDSP) modules and provides all the necessary common functions for disposal of alpha and nonalpha waste. The disposal administration module unit operations include truck loading and unloading areas, administrative offices, analytical laboratory facilities, and truck inspection and washdown.

\subsection{Technical Bases and Assumptions}

\subsubsection{Function and Operation of the Modules}

The containers arrive in a transport vehicle, are unloaded using a forklift or overhead bridge crane, and are placed in a staging area. The containers are visually examined, labeled, logged, and sent to inspection and assay. At the inspection and assay unit, the category of the received waste is verified against the results obtained from the back-end treatment or storage modules. After inspection, the drums are sent to the disposal module.

The technical bases and requirements for all disposal administration modules are the same as those outlined in the treatment receiving and inspection and administration modules except that the inspection, assay, and certification functions are for verification purposes only.

\subsubsection{Integration of the Modules}

Module input includes packaged waste brought from the treatment or storage modules. The O\&M consumables include personal protective equipment, which must be purchased. Module output consists of certified containers that are transferred to the disposal modules.

\subsection{Cost Bases, Assumptions, and Results}

The cost and design of the module are based on several simplifying assumptions and information gathered from a variety of sources. Major equipment and module cost items for this module are based on data obtained from the Illinois LLW Disposal Facility (Morrison Knudsen/Chem Nuclear Services 1991). Staffing levels were estimated based on the number of personnel required for support of approximately ten separate support functions similar to those identified in the treatment administration and receiving/inspection modules.

FTE staffing levels are based on data obtained from the Illinois LLW Disposal Facility (Morrison Knudsen/Chem Nuclear Services 1991). A \$1 million allowance is made for the analytical instruments and components needed for a mixed-waste laboratory. Full-time equivalent and cost summaries for the disposal administration module are shown in Figures 23-1 through 23-3. Table 23-1 shows the plan dimensions of disposal administration module. 
Table 23-1. Plan dimensions of disposal administration (DADMN) module.

\begin{tabular}{cccccc} 
& \multicolumn{2}{c}{$\begin{array}{c}\text { Dimensions } \\
(\mathrm{ft})\end{array}$} & & \multicolumn{2}{c}{$\begin{array}{c}\text { Dimensions } \\
(\mathrm{m})\end{array}$} \\
\cline { 2 - 4 } \cline { 5 - 6 } Module size & Width & Length & & Width & Length \\
\hline Large generator & 100 & 92.5 & & 30.5 & 28.2 \\
Small & 100 & 172.5 & & 30.5 & 52.6 \\
Medium & 150 & 176 & & 45.7 & 53.6 \\
Large & - & - & & - & - \\
Small generator & & & & & \\
\hline
\end{tabular}




\section{DISPOSAL ADMINISTRATION}

FTE by Work Breakdown Structure Element

Module: DADMN Waste Type: Alpha, Nonalpha, and Remote Handled LLW

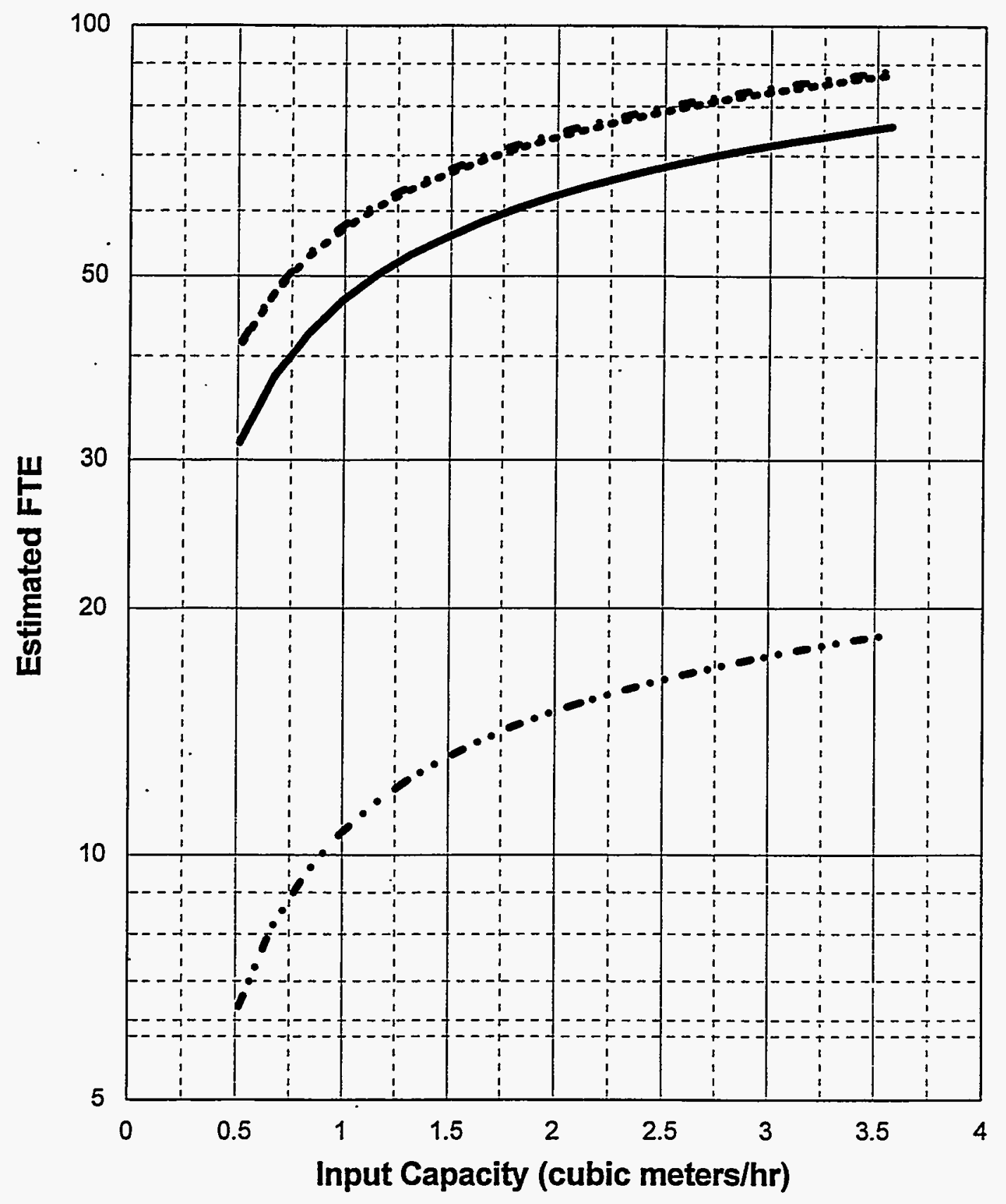

Pre-Operations Construction O\&M (1year) D\&D

Figure 23-1. FTE workers versus capacity for the disposal administration (DADMN) module. 


\section{DISPOSAL ADMINISTRATION}

Cost by Work Breakdown Structure Element

Module: DADMN Waste Type: Alpha, Nonalpha, and Remote Handled LLW

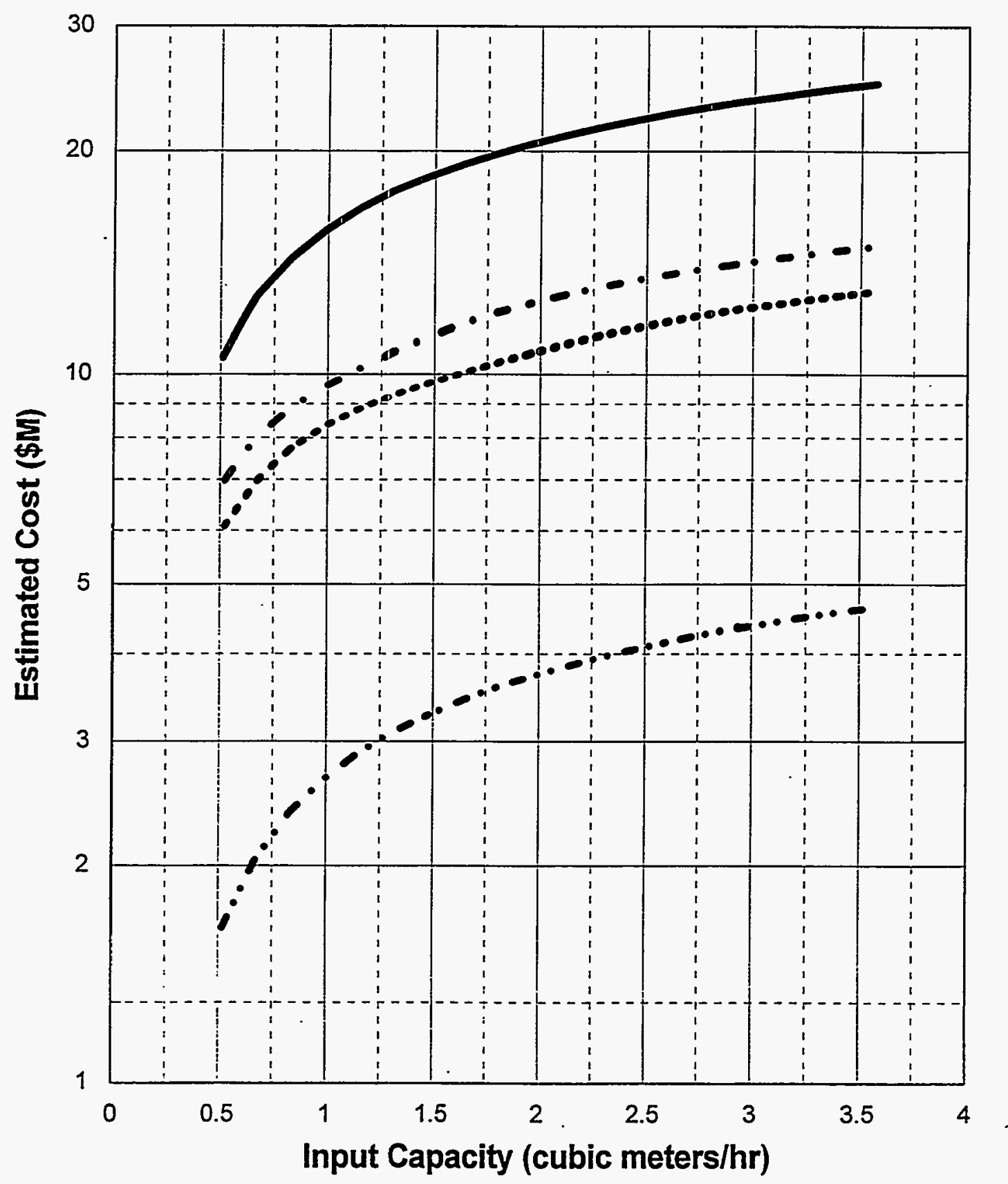

Pre-Operations Construction O\&M (1year) D\&D

Figure 23-2. PLCC versus capacity for the disposal administration (DADMN) module. 


\section{DISPOSAL ADMINISTRATION}

Total Life Cycle Costs

Module: DADMN Waste Type: Alpha, Nonalpha, and Remote Handled LLW

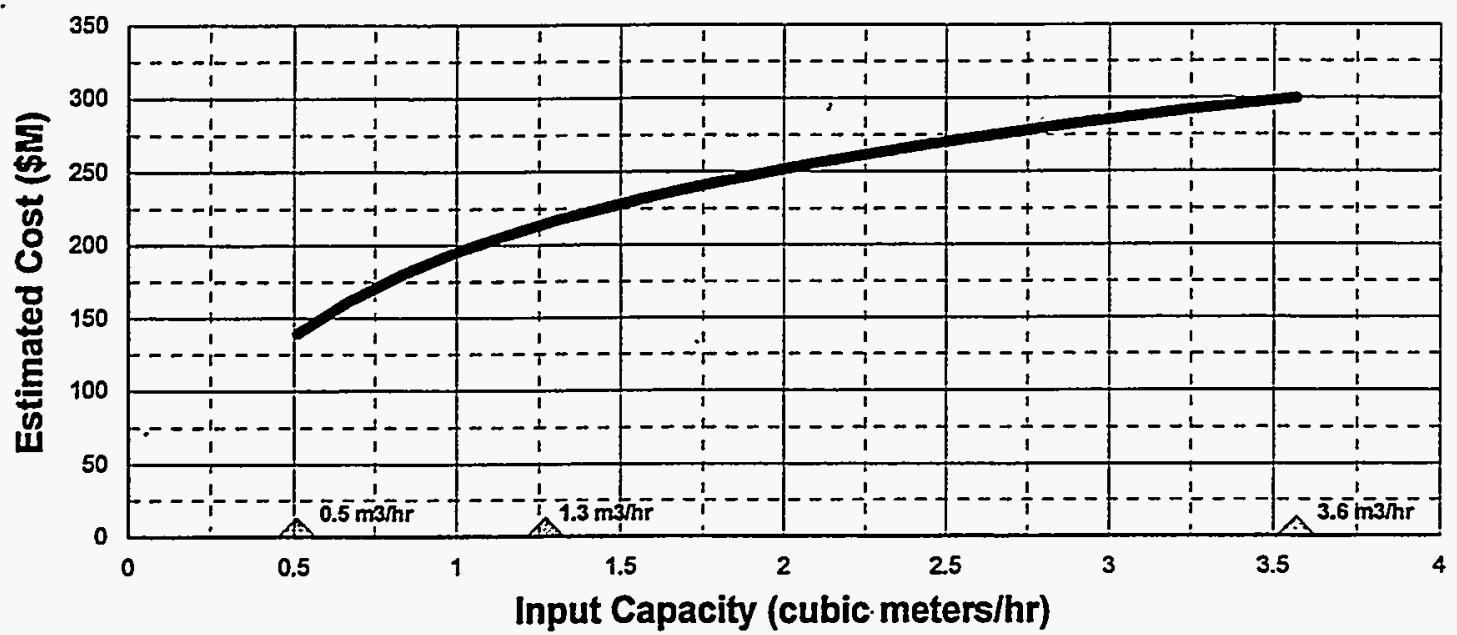

Alpha, Nonalpha, Remote Handled

NOTE: Basis includes 20 years O\&M

Triangles indicate capacities where detailed cost estimates were developed.

\section{DISPOSAL ADMINISTRATION}

Total Life Cycle Unit Costs

Module: DADMN Waste Type: Alpha, Nonalpha, Remote Handled LLW

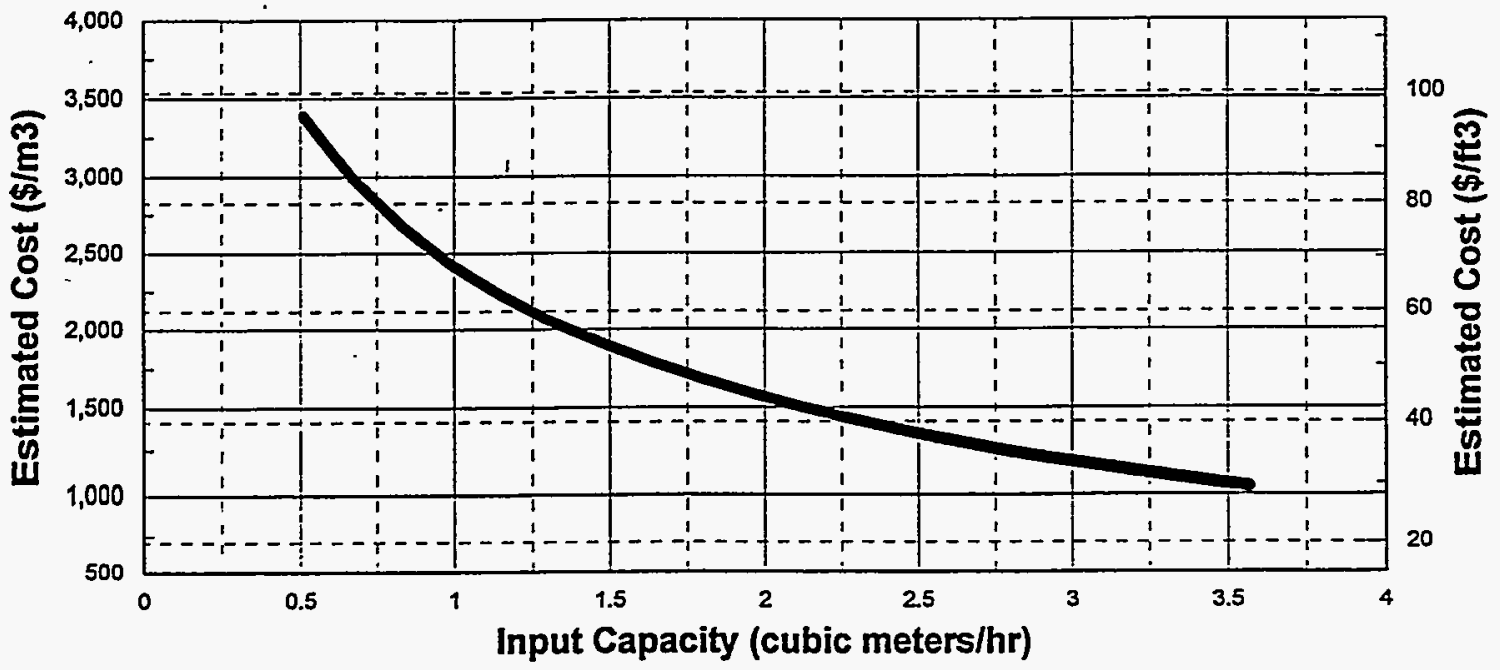

Alpha, Nonalpha, Remote Handled

NOTE: Basis includes 20 years $08 M$

Figure 23-3. PLCC versus capacity plus unit rates for the disposal administration (DADMN) module. 


\section{DISPOSAL RECEIVING (MODULE DRECV)}

\subsection{Basic Information}

The disposal receiving module, shown in Figure 24-1, is effectively the same for nonalpha, alpha, and RH waste. There are minor differences in the assay and inspection equipment that are negligible at a PLCC estimate level. Unit operations are shown in the PFD in Figure 24-2.

The disposal receiving module is intended to receive waste from treatment modules and to inspect waste prior to disposal. It consists of two unit operations: (a) unload and stage, and (b) inspect and assay. The containers of waste arrive at the receiving and inspection module on a transport vehicle. Containers are removed from the transport vehicle and placed in a staging or storage area. The containers are visually examined, labeled, logged, recorded, and sent to inspection and assay.

The purpose of the inspect and assay unit operation is to physically and radiologically characterize the waste ensure compliance with the disposal facility waste acceptance criteria. Based on the inspection and assay results, the waste containers are accepted or rejected. Accepted waste containers are sent to the disposal modules and rejected waste is sent back to the generating site.

The receiving and unloading area is equipped with a bridge crane and a forklift truck. It is designed to receive and unload containers from flat-bed trailers or van trucks.

\subsection{Technical Bases and Assumptions}

\subsubsection{Function and Operation of Large Generator Modules}

Transportation vehicles are used to ship the containers (in overpacks, if necessary) from the generators to the receiving module. These vehicles are not included in the module. In the unloading and staging unit operation, the transportation vehicles are unloaded, and containers are placed in the staging area. Surge storage is also provided. Containers may be moved within the unloading, staging, and surge storage areas.

Containers are unloaded in an enclosed truck bay and placed in an indoor staging area. The area is large enough to maneuver the containers and provide sufficient surge storage capacity to meet the desired operational reliability.

The inspect and assay unit operation determines the radioactivity, physical properties, and other parameters needed to categorize the containerized waste before processing in accordance with the criteria established for the processing unit operations. Various devices, such as PAN counting instruments, may be used. Containers holding waste classified as other than alpha and nonalpha LLW, or wastes not acceptable to the ultimate disposal site, are returned to the generator. After examination, each container is labeled and its contents are logged and entered into a computerized database. 
To allow year-round operations and to minimize the effects of a potential spill, it is assumed that loading, unloading and staging operations will take place indoors.

\subsubsection{Integration of Large Generator Modules}

In addition to general interfaces typical for all modules, waste from treatment facilities becomes input to the disposal receiving module. The O\&M consumables, including personal protective equipment, must be purchased. Module output consists of containers of alpha and nonalpha waste that are moved to the open, dump, and sort module or to treatment modules.

\subsection{Cost Bases, Assumptions, and Results}

Cost bases and assumptions were derived from a variety of sources. Major equipment capital cost items for this module include alpha assay, gamma assay, 20-ton bridge crane, and RTR units. The crane cost is based on vendor quotations. The inspection and assay units are based on conceptual designs and cost estimates for a radiological and hazardous material measurement system provided by Lockheed Martin. Budget estimate for an inspection and assay system is $\$ 2$ million. Figure 24-3 shows the relationships between estimated FTE workers and capacity of the module. Figures 24-4 and 24-5 show the relationship between PLCC and capacity. 


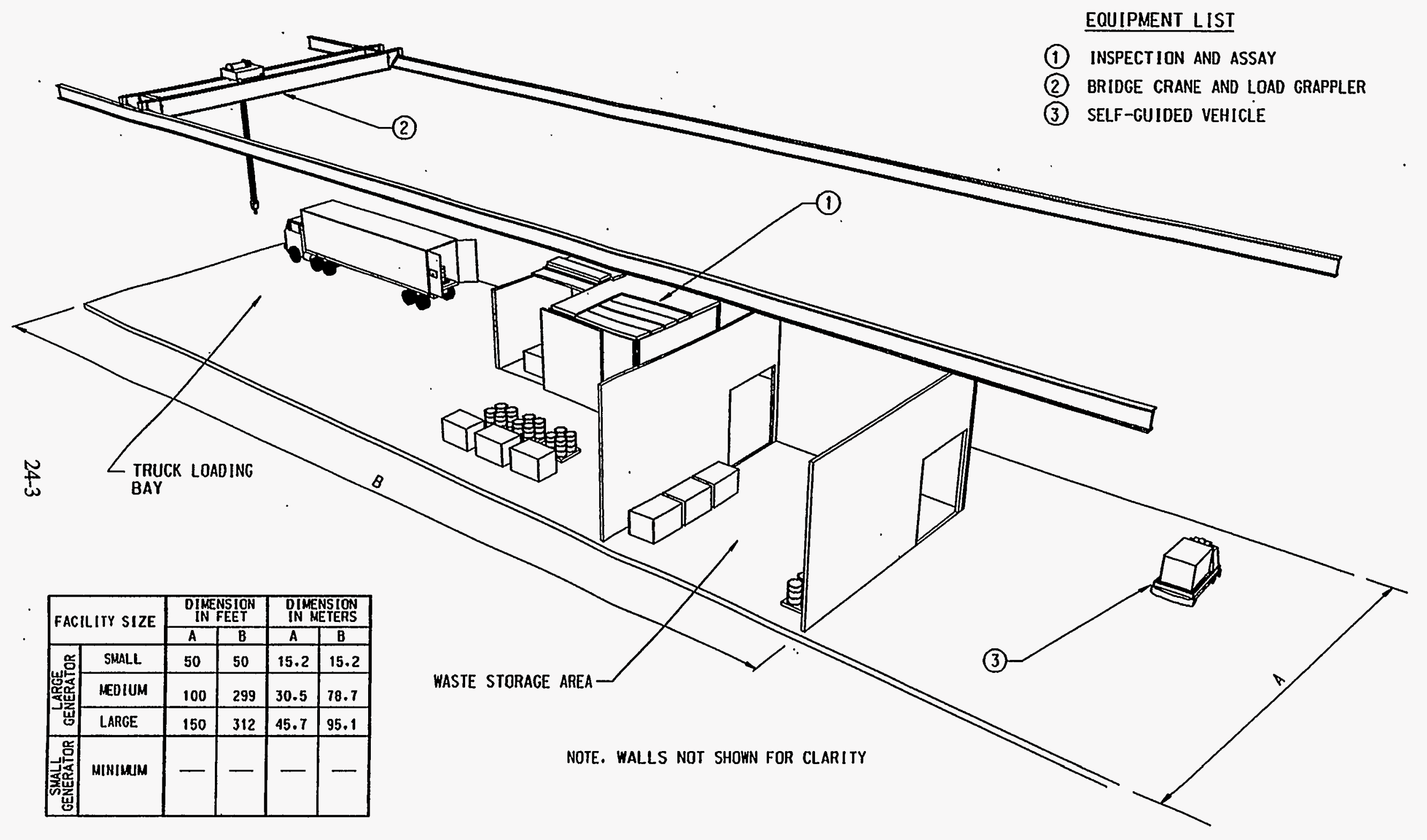

Figure 24-1. Equipment layout for the disposal receiving (DRECV) module. 


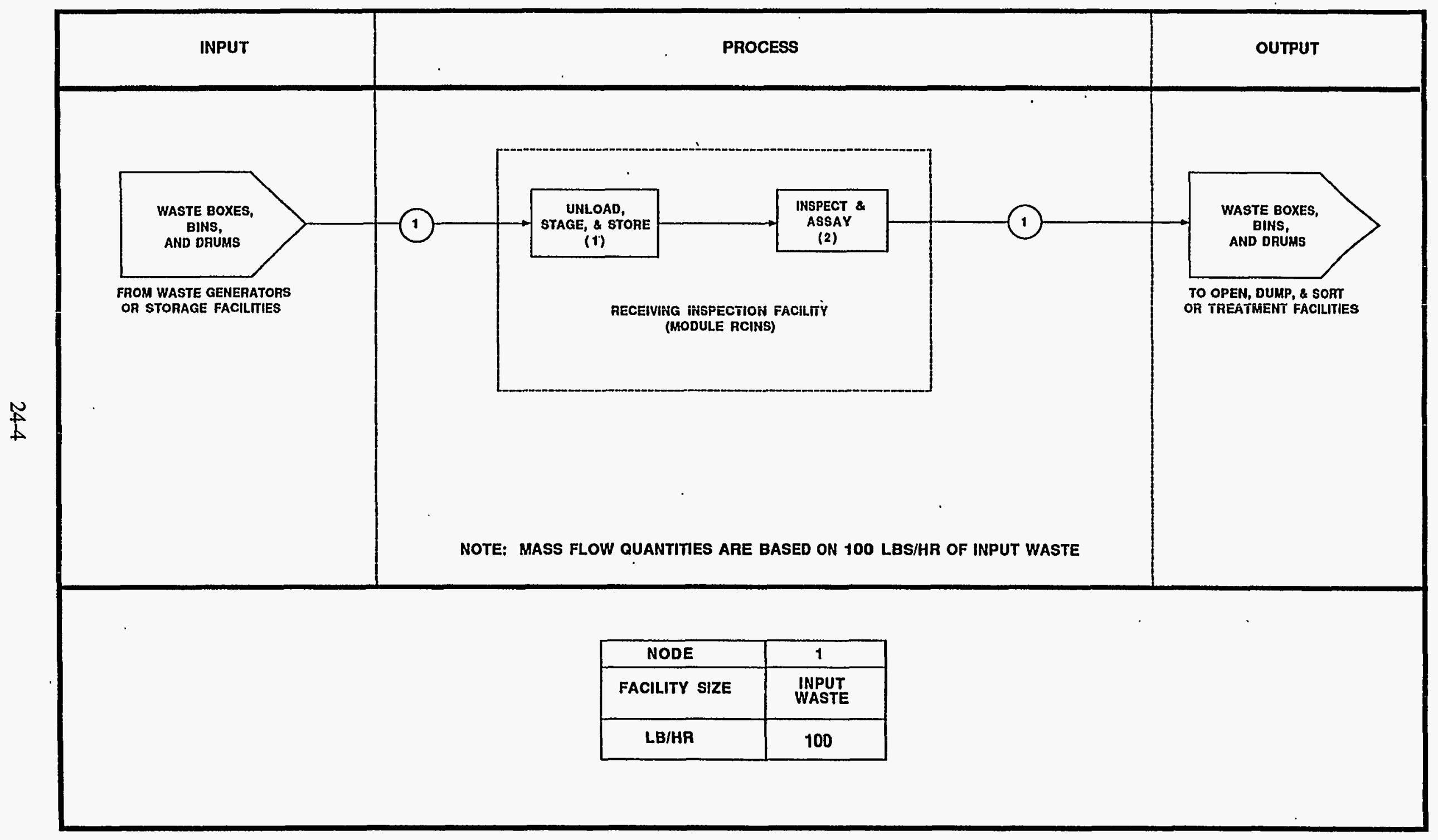

Figure 24-2. Process flow diagram for the disposal receiving (DRECV) module. 


\section{DISPOSAL RECEIVING}

FTE by Work Breakdown Structure Element

Module: DRECV Waste Type: Alpha, Nonalpha, and Remote Handled LLW

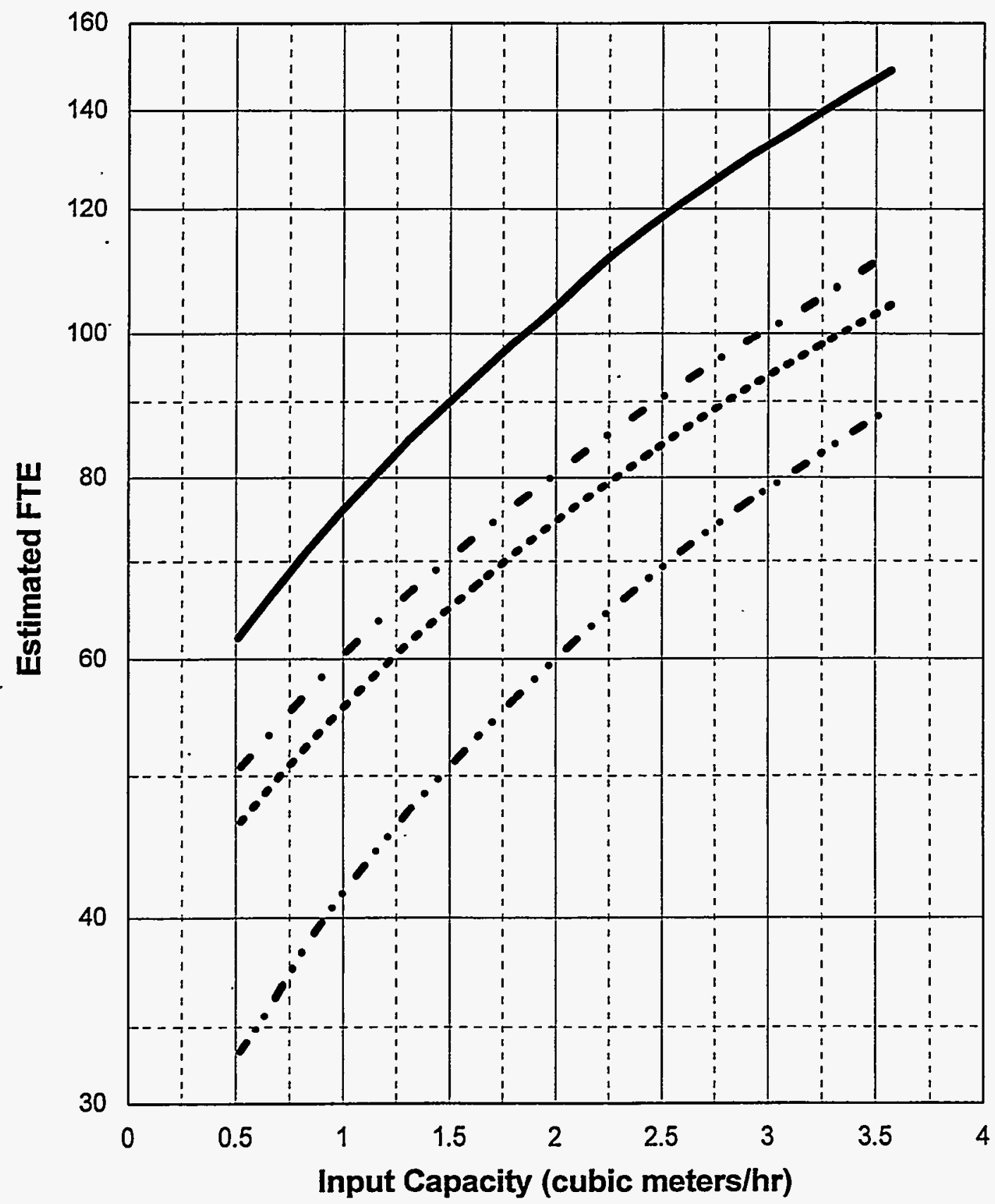

Pre-Operations Construction O\&M (1year) D\&D

Figure 24-3. FTE workers versus capacity for the disposal receiving (DRECV) module. 


\section{DISPOSAL RECEIVING}

Cost by Work Breakdown Structure Element

Module: DRECV Waste Type: Alpha, Nonalpha, and Remote Handled LLW

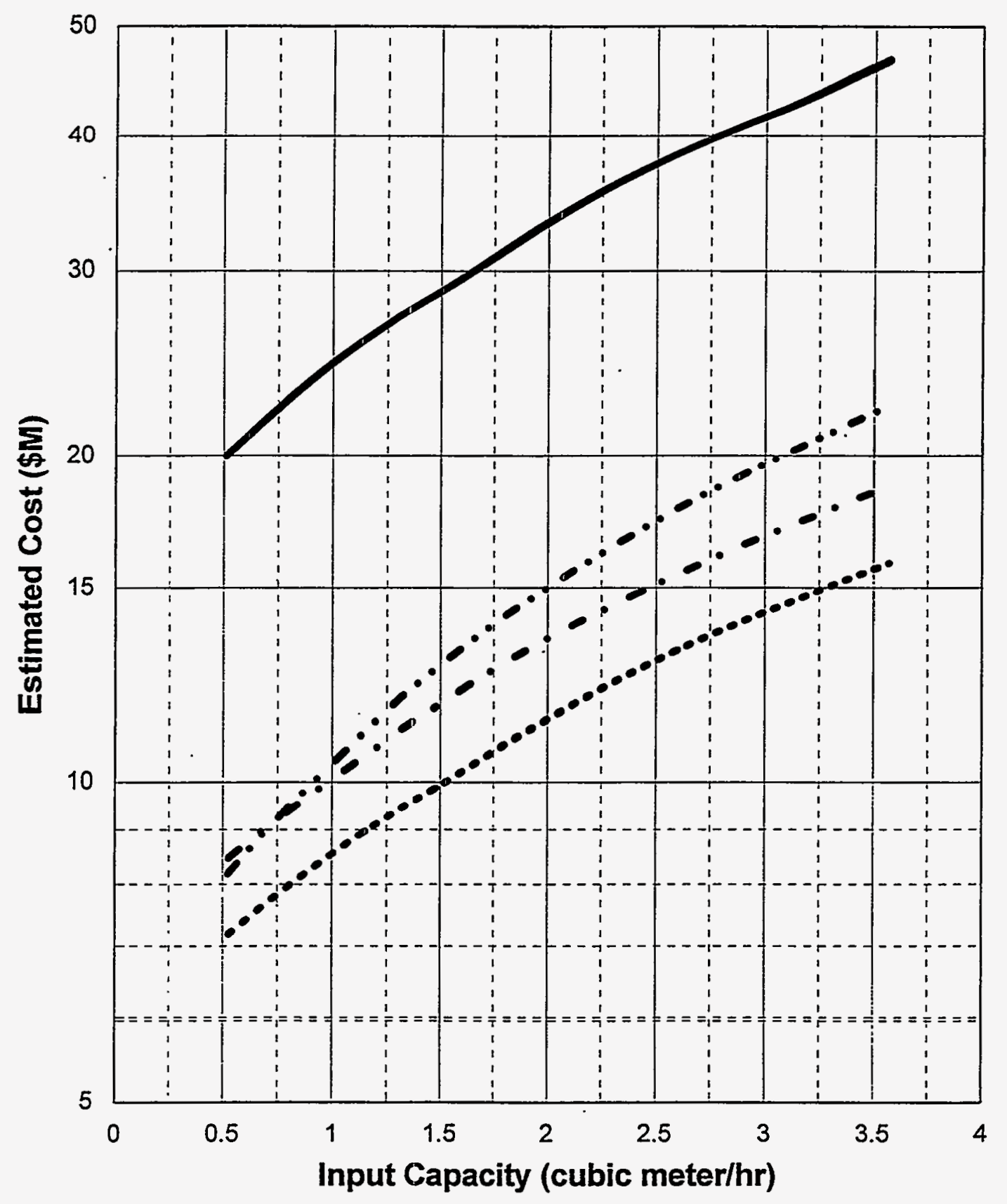

Pre-Operations Construction O\&M (1year) D\&D

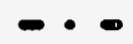

Figure 24-4. PLCC versus capacity for the disposal receiving (DRECV) module. 


\section{DISPOSAL RECEIVING}

\section{Total Life Cycle Costs}

Module: DRECV Waste Type: Alpha, Non-Alpha, and Remote Handled LLW

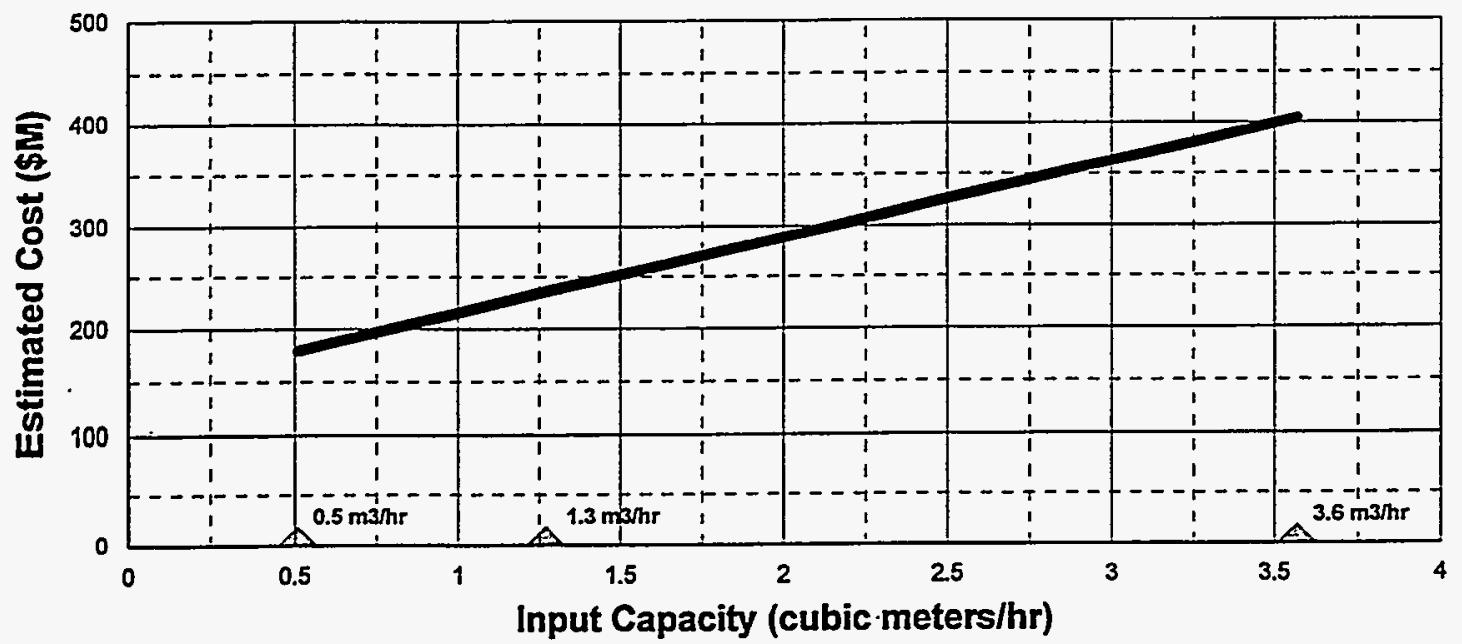

Alpha, Nonalpha, Remote Handled

NOTE: Basis includes 20 years O\&M

Triangles indicate capacities where detailed cost estimates were developed.

\section{DISPOSAL RECEIVING}

Total Life Cycle Unit Costs

Module: DRECV Waste Type: Alpha, Nonalpha, Remote Handled LLW

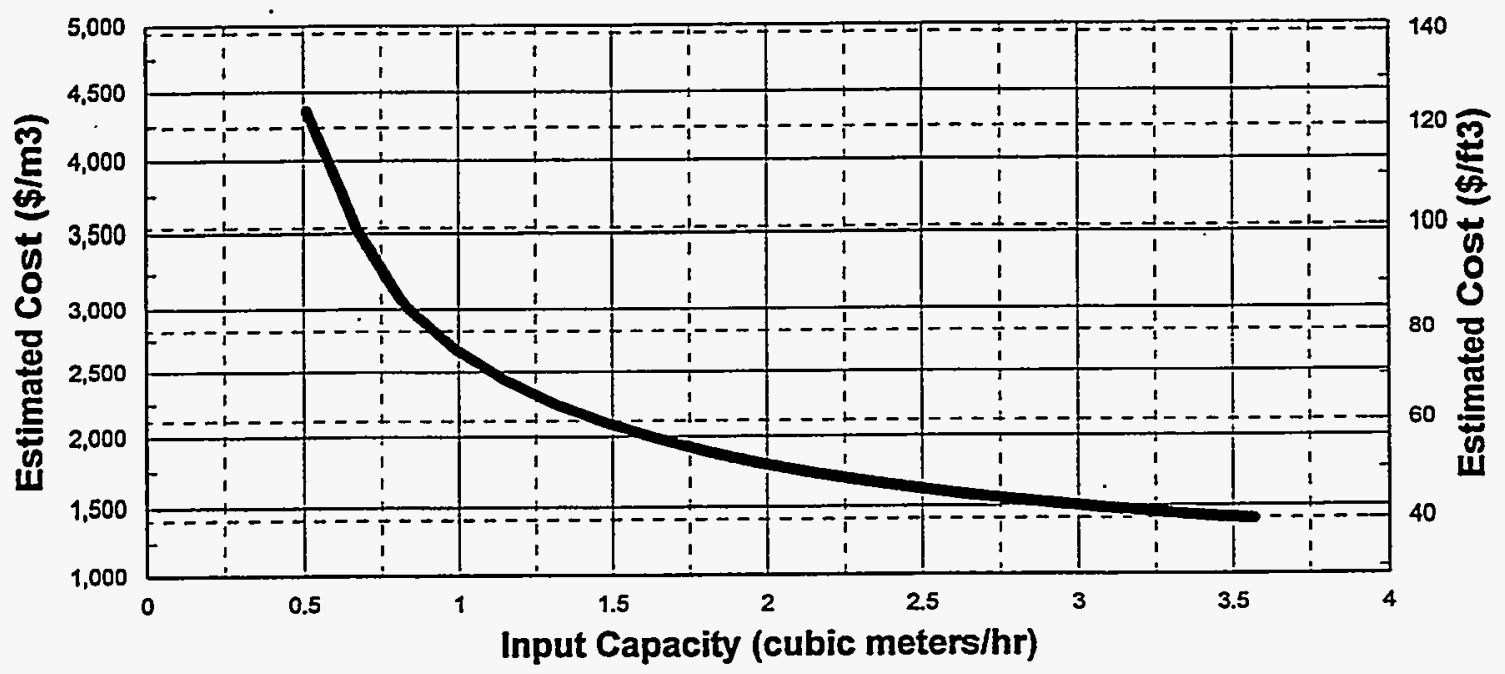

Alpha, Nonalpha, Remote Handled

NOTE: Basis includes 20 years $O \& M$

Figure 24-5. PLCC versus capacity including unit rates for the disposal receiving (DRECV) module. 


\section{ENGINEERED DISPOSAL (MODULE AGDSP)}

\subsection{Basic Information}

The engineered disposal module, shown in Figure 25-1, should be used in conjunction with the disposal administration (DADMN) module or as an addition to existing facilities where similar functions are already available. The module consists of engineered disposal units that are based on the Illinois LLW disposal module design, shown in Figure 25-1, which uses an earth mound and concrete cell concept (Morrison Knudsen/Chem Nuclear Services 1991). Engineered disposal modules for non-RCRA waste and RCRA waste are essentially the same except that a RCRA disposal unit has a double leachate collection system in compliance with the RCRA requirements. Unit operations are shown in the PFD in Figure 25-2.

The unit operations include receiving the inspected drums from the front-end module, placing the drums into concrete canisters, and constructing the disposal units that will house incoming concrete waste canisters. Disposal unit construction includes foundation, leachate collection system, and monitoring system, concrete vaults, and earth covers. Construction of the modules is intended to be a continuous process concurrent with the placement of the canisters.

\subsection{Technical Bases and Assumptions}

\subsubsection{Function and Operation of the Module}

The containers received from the disposal administration module are packaged into concrete canisters that are then sealed with grout. The canisters are transported to the disposal units for placement. Each disposal unit is made of a double row of concrete cells with an access aisle between the rows. Concrete canisters that arrive from the packaging area are placed in a cell by overhead crane or forklift from the access aisle and stacked three canisters high. Once the cell is full, it is backfilled with sand and a concrete cover is concurrently constructed to seal the cells.

The cells are capped with an earth layer that is engineered to withstand long-term environmental and weathering effects. The layered cap consists of sandy drain layers placed directly over the cells, an impervious clay layer, a high density polyethylene liner, and another drain layer to deter seepage into the cells. The top layer consists of either subsoil and vegetative material or subsoil, bedding, and riprap. The monitoring system includes sensors that will detect any leakage from the cells.

Decontamination and decommissioning includes module demolition and disposal unit maintenance. Disposal unit maintenance is planned in two stages, each with two substages: (a) short-term maintenance, which consists of closure and post-closure periods, and (b) long-term maintenance, which consists of active and passive institutional care.

Closure activities take place during the first two years after the facility ceases to accept waste. Closure includes decontamination of the modules, initial demolition of buildings, site development, closure of the cells, site remediation, and monitoring of the cell performance and groundwater. Years 1 through 10 after the facility ceases to accept waste are designated as the post-closure period. During this period monitoring of the groundwater and cell performance will continue, as will site 
remediation and restoration. Active institutional care is planned for 11 to 100 years following the post-closure period. During this stage, any buildings not previously demolished are torn down and all site services are removed; monitoring activities will also be ongoing. The last stage, passive institutional care, extends from 101 to 300 years after the facility ceases to accept waste. Passive institutional care includes closing the center aisles of the vaults, completing the earth caps and site grading, removing the retention ponds and retaining walls, and installing passive drains. Site maintenance is discontinued after 300 years.

\subsubsection{Integration of the Modules}

Input interfaces include waste drums received from the disposal administration (DADMN) module. The O\&M consumables, including empty concrete canisters, grout, sand, and personal protective equipment, must be purchased. The module is intended for permanent disposal of the waste and designed for site maintenance and monitoring as described above. No module output is anticipated for the post-closure period (at least 300 years).

\subsection{Cost Bases, Assumptions, and Results}

Major equipment capital cost items are a forklift and an overhead crane for placement of the drums into canisters and placement of filled canisters into the concrete cells. Costs for these items are based on vendor quotes.

Estimated FTE workers versus capacity information is shown in Figure 25-3. This staffing is based on data on the Illinois LLW Disposal Facility (Morrison Knudsen/Chem Nuclear Services 1991) and a DOE conceptual design report (DOE 1987).

Construction of the disposal units is a major cost item. A preconceptual design of one disposal unit that applies to all modules, including the concrete cell and cover design, was developed based on the design of the Illinois LLW Disposal Facility. A unit cost per cell was developed based on data from the Illinois facility, and an estimate was generated according to the rate of incoming waste and number of cells required for each small, medium, and large module. Minimum size capacity is provided as a lower bound for the smallest economical engineering designed facility. Estimates are based on a disposal facility in accordance with DOE and NRC criteria, but a NRC license is not assumed. Cost versus capacity information for the engineered disposal module is shown in Figures 25-4 and 25-5. 


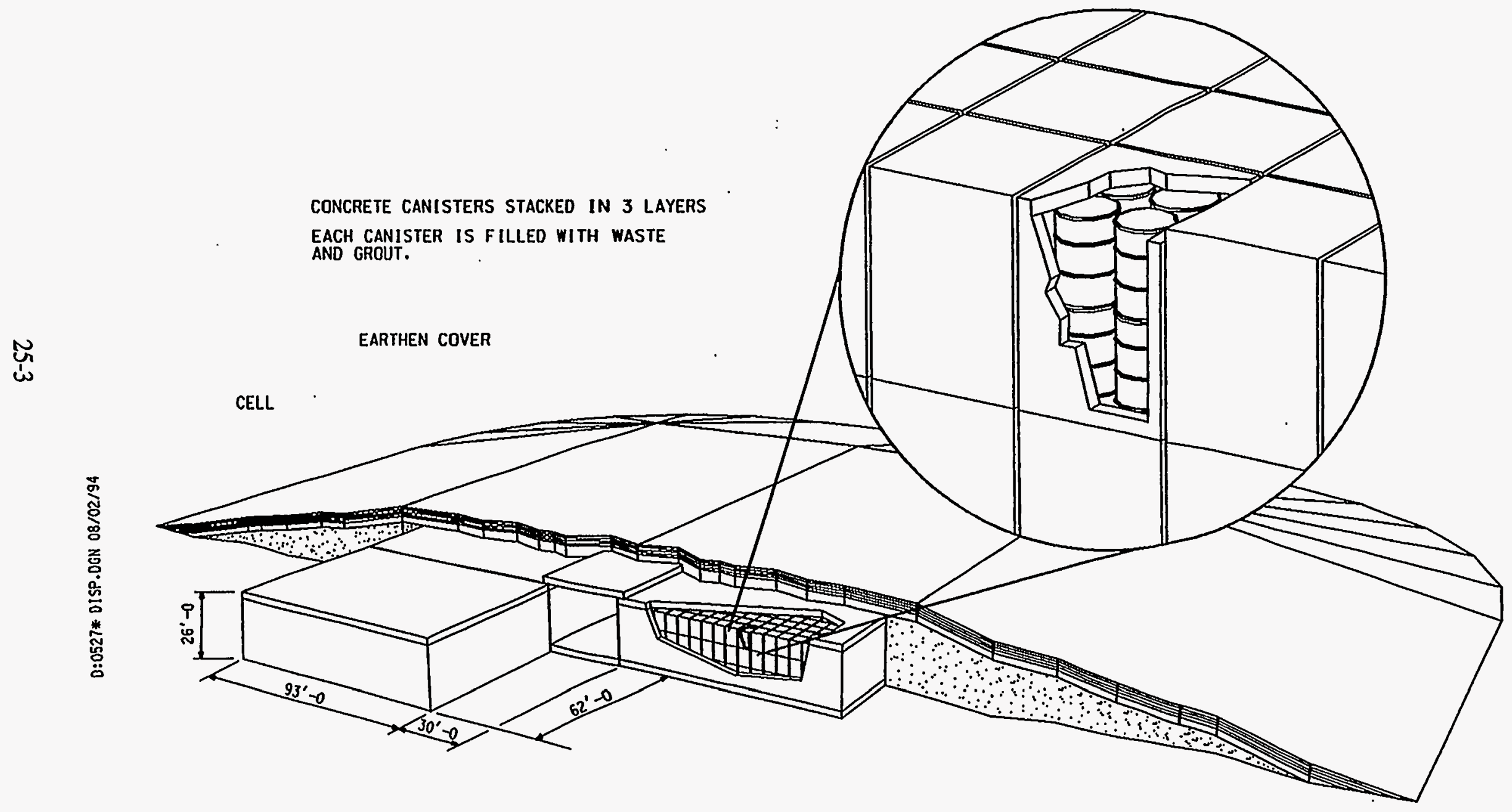

Figure 25-1. Equipment layout for the engineered disposal (AGDSP) module. 


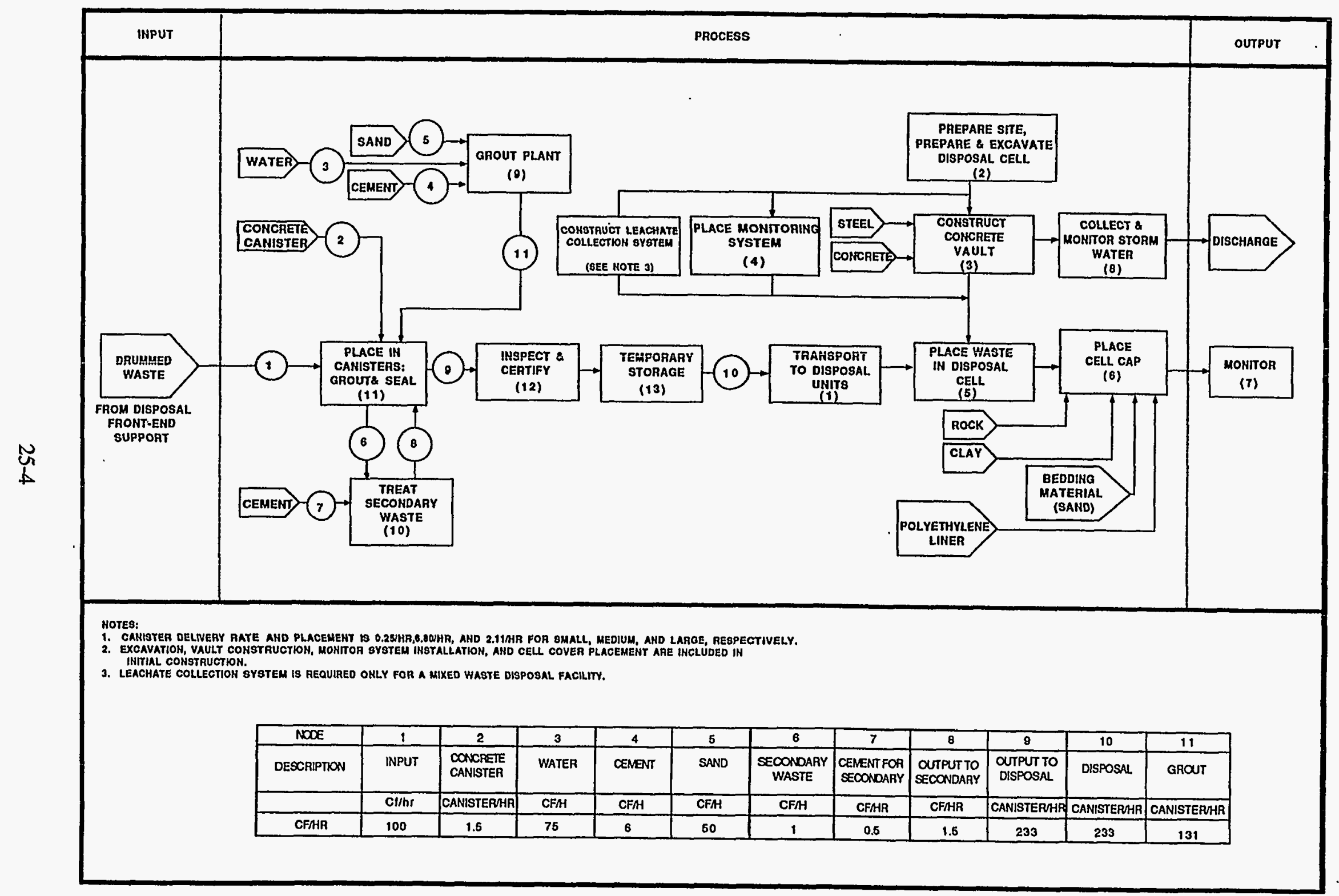

Figure 25-2. Process flow diagram for the engineered disposal (AGDSP) module. 


\section{ENGINEERED DISPOSAL}

FTE by Work Breakdown Structure Element Module: AGDSP Waste Type: Alpha, Nonalpha, Remote Handled LLW

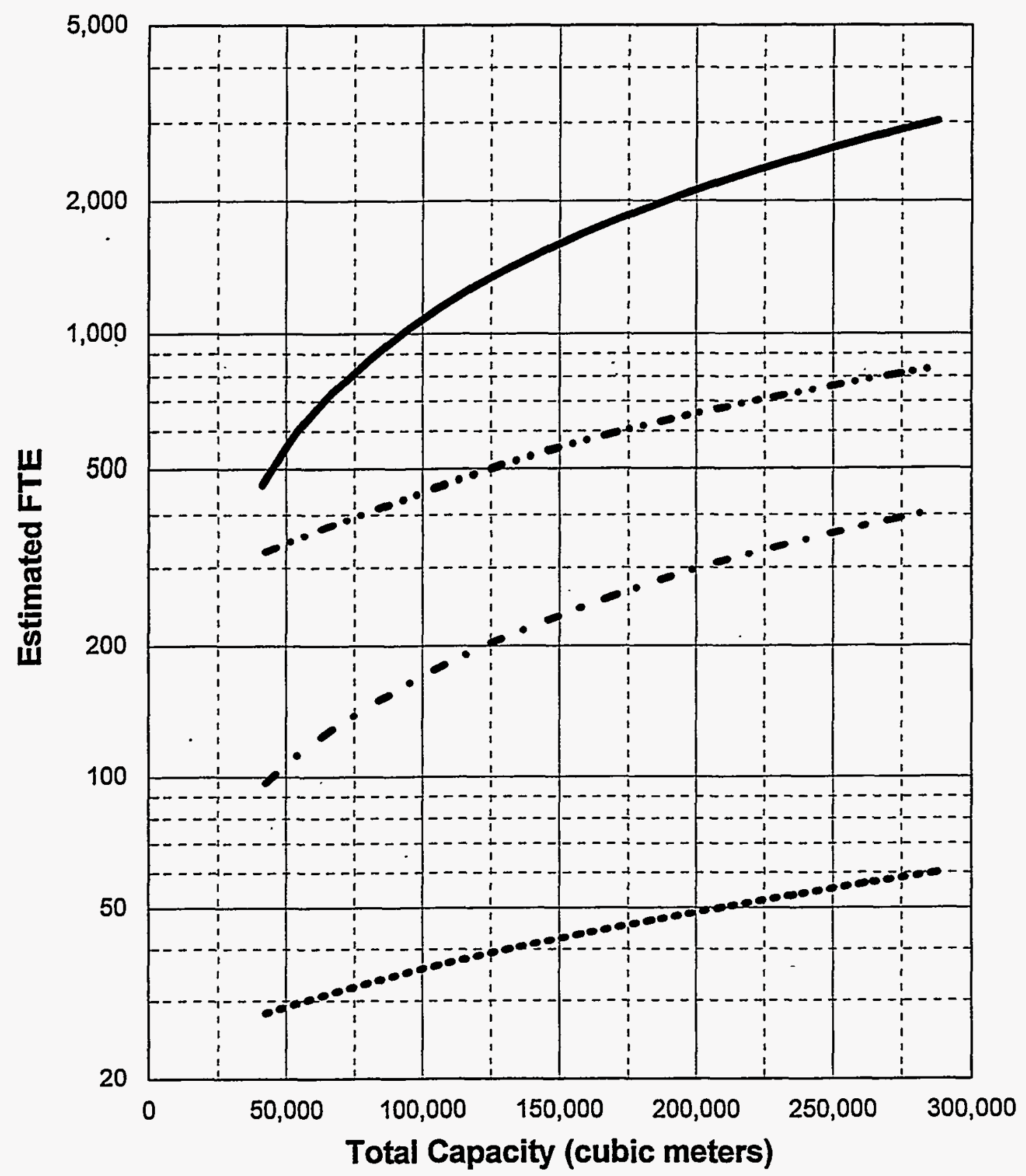

Pre-Operations Construction O\&M (1year) S\&M

Figure 25-3. FTE workers versus capacity for the engineered disposal (AGDSP) module. 


\section{ENGINEERED DISPOSAL}

Cost by Work Breakdown Structure Element Module: AGDSP Waste Type: Alpha, Nonalpha, Remote Handled LLW

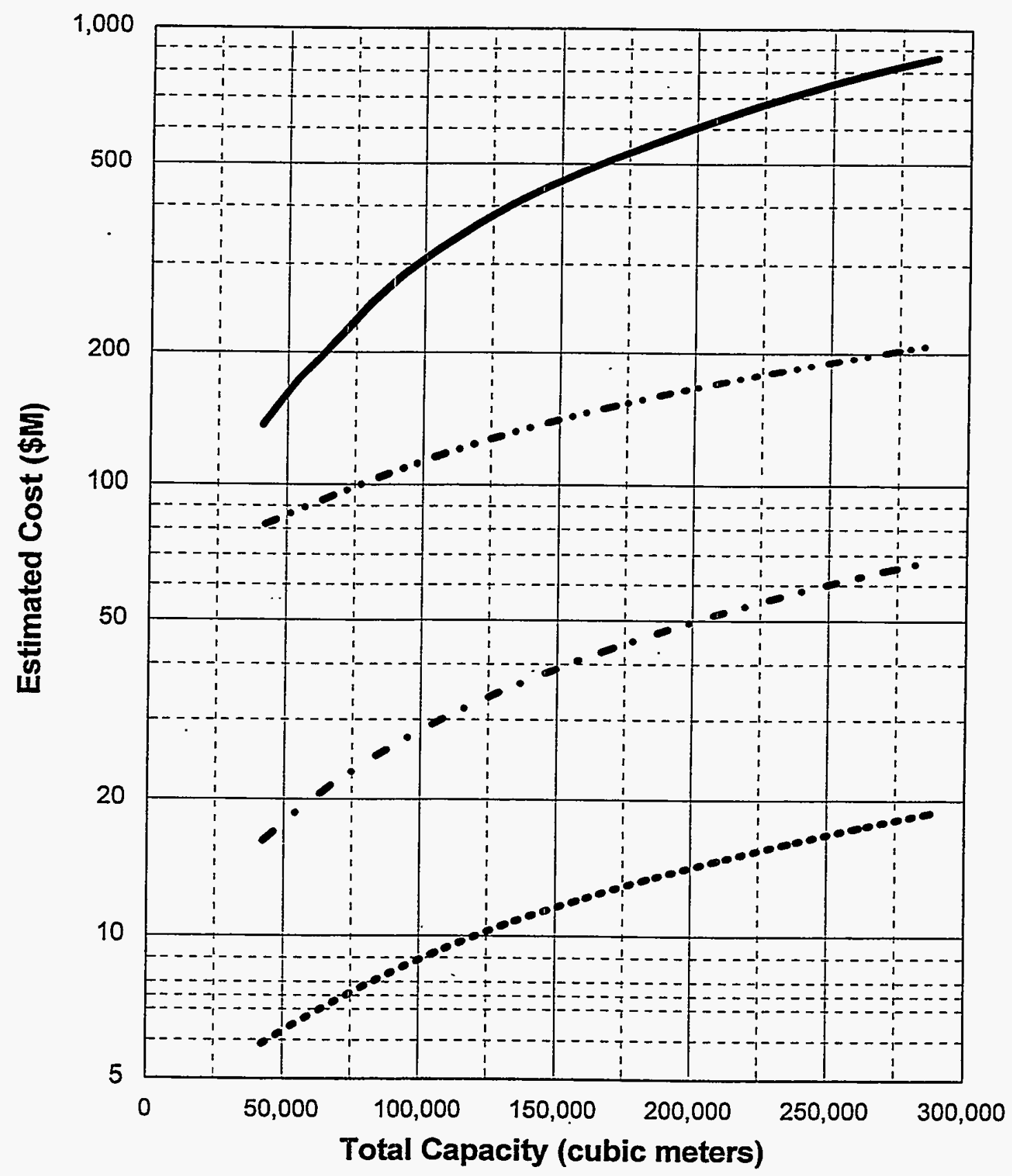

Pre-Operations Construction O\&M (1year) S\&M

Figure 25-4. PLCC versus capacity for the engineered disposal (AGDSP) module. 


\section{ENGINEERED DISPOSAL}

Total Life Cycle Costs

Module: AGDSP Waste Type: Alpha, Nonalpha, and Remote Handled LLW

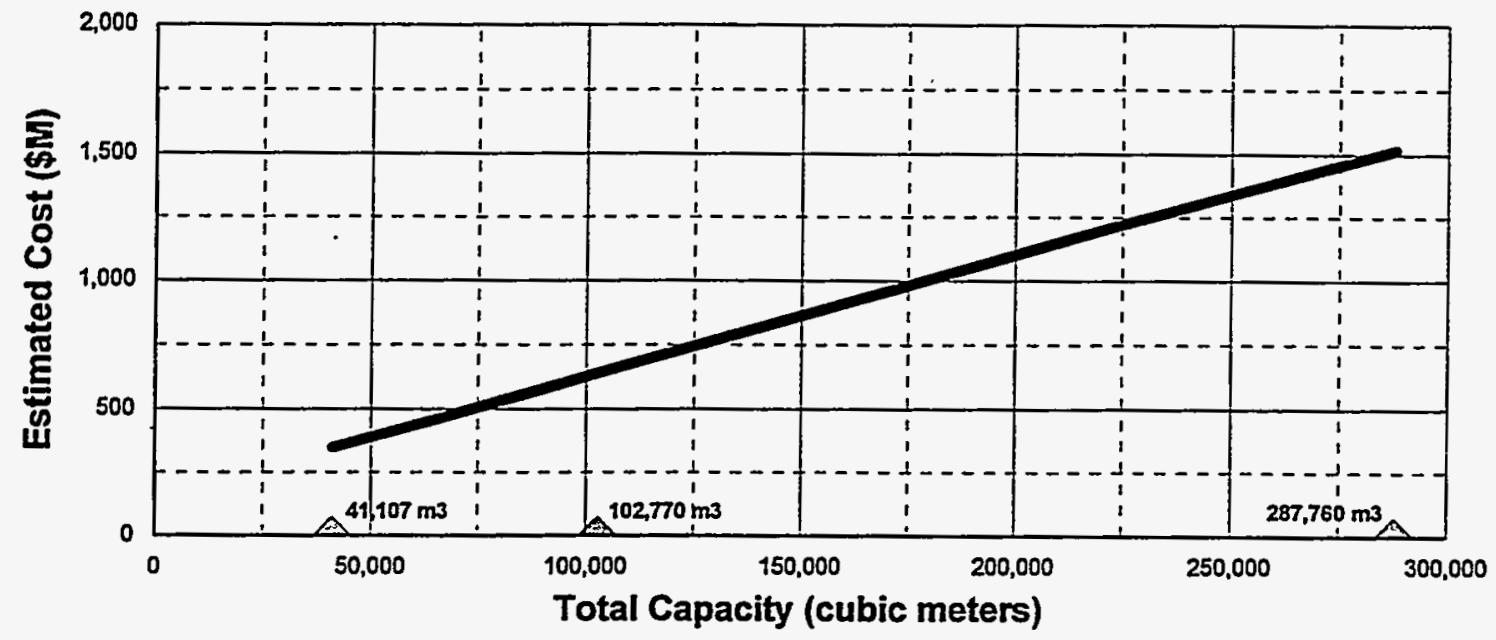

Alpha, Nonalpha, Remote Handled

NOTE: Basis includes 20 years O\&M

Triangles indicate capacites where detailed cost estimates were developed.

\section{ENGINEERED DISPOSAL}

Total Life Cycle Unit Costs

Module: AGDSP Waste Type: Alpha, Nonalpha, Remote Handled LLW

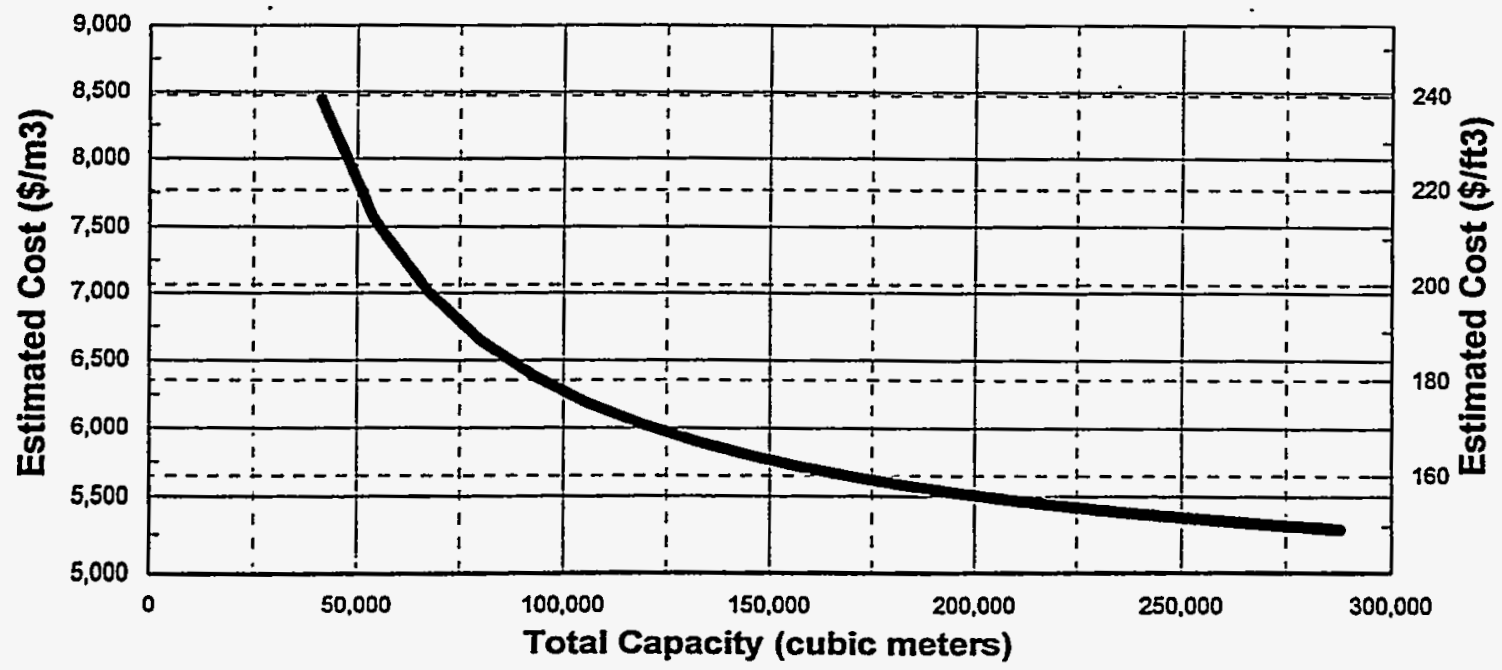

Alpha, Nonalpha, Remote Handled

NOTE: Basis includes 20 years O\&M

Figure 25-5. PLCC versus capacity including unit rates for the engineered disposal (AGDSP) module. 


\section{SHALLOW LAND DISPOSAL (MODULE SLDSP)}

\subsection{Basic Information}

The shallow land disposal module essentially consists of trench disposal without engineered features. The cost for a shallow land disposal consists of three components: disposal administration module capital cost, disposal O\&M cost, and site closure cost. Disposal administration module capital cost is discussed in module DADMN and should be added only if a new disposal module is under consideration. Since shallow land trench disposal units are commonly used by both the DOE and the commercial nuclear industry, a preconceptual design of disposal units to develop capital and O\&M costs was not necessary.

\subsection{Technical Bases and Assumptions}

\subsubsection{Function and Operation of the Module}

Containers received from the disposal administration module are transported to a disposal unit. Each disposal unit consists of an excavated trench. The containers are stacked in the bottom of the trench using a boom crane. After one row is completed, a layer of fill is placed on top of the containers. The cap consists of at least seven feet of engineered fill dirt and clay. The disposal site includes all of the appropriate storm drainage collection and discharge equipment. Site monitoring includes both groundwater and air sampling systems.

\subsubsection{Integration of the Module}

Input interfaces include waste drums received from the disposal administration (DADMN) module. The O\&M consumables, including personal protective equipment, must be purchased. No module output is anticipated for a post-closure period (at least 230 years).

\subsection{Cost Bases, Assumptions, and Assessments}

The cost for disposal of contact-handled waste at INEL has historically ranged from $\$ 1.42 / \mathrm{m}^{3}$ $\left(\$ 50 / \mathrm{ft}^{3}\right)$ for $2,832 \mathrm{~m}^{3} /$ year $\left(100,000 \mathrm{ft}^{3} /\right.$ year) to $\$ 4 / \mathrm{m}^{3}\left(\$ 150 / \mathrm{ft}^{3}\right)$ for $708 \mathrm{~m}^{3} /$ year $\left(25,000 \mathrm{ft}^{3} /\right.$ year $){ }^{\mathrm{i}}$ Disposal costs have varied considerably because of varying annual disposal volumes. Site closure costs should be added to the shallow land disposal costs to obtain the total module SLDSP cost. As an alternative, shallow land disposal costs can be compared to rates from commercial disposal sites. Disposal fees at commercial sites include all three cost elements. Full-time equivalent and cost versus capacity information for the shallow land disposal module are shown in Figures 26-1 through 26-3.

i. Based on Radioactive Waste Management Complex (RWMC) contact-handled alpha and nonalpha waste disposal costs calculated by Darris Bright of Lockheed Martin, and on a memorandum (JAL-5-92) by J. A. Logan, regarding costs of waste disposal. 


\section{SHALLOW LAND DISPOSAL}

FTE by Work Breakdown Structure Element

Module: SLDSP Waste Type: Alpha, Nonalpha, and Remote Handled LLW

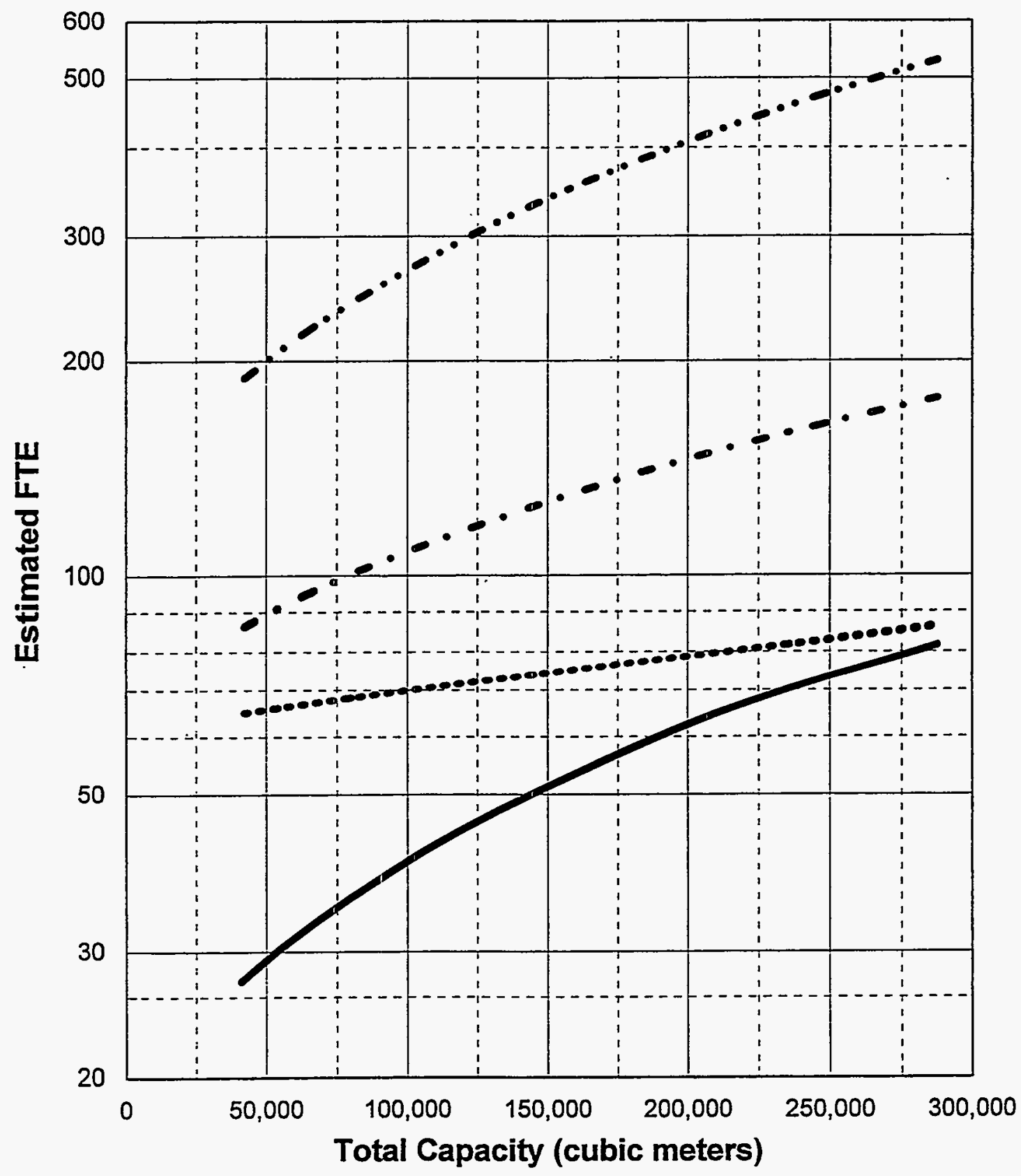

Pre-Operations Construction O\&M (1year) S\&M

Figure 26-1. FTE workers versus capacity for the shallow land disposal (SLDSP) module. 


\section{SHALLOW LAND DISPOSAL}

Costs by Work Breakdown Structure Element Module: SLDSP Waste Type: Alpha, Nonalpha, and Remote Handled LLW

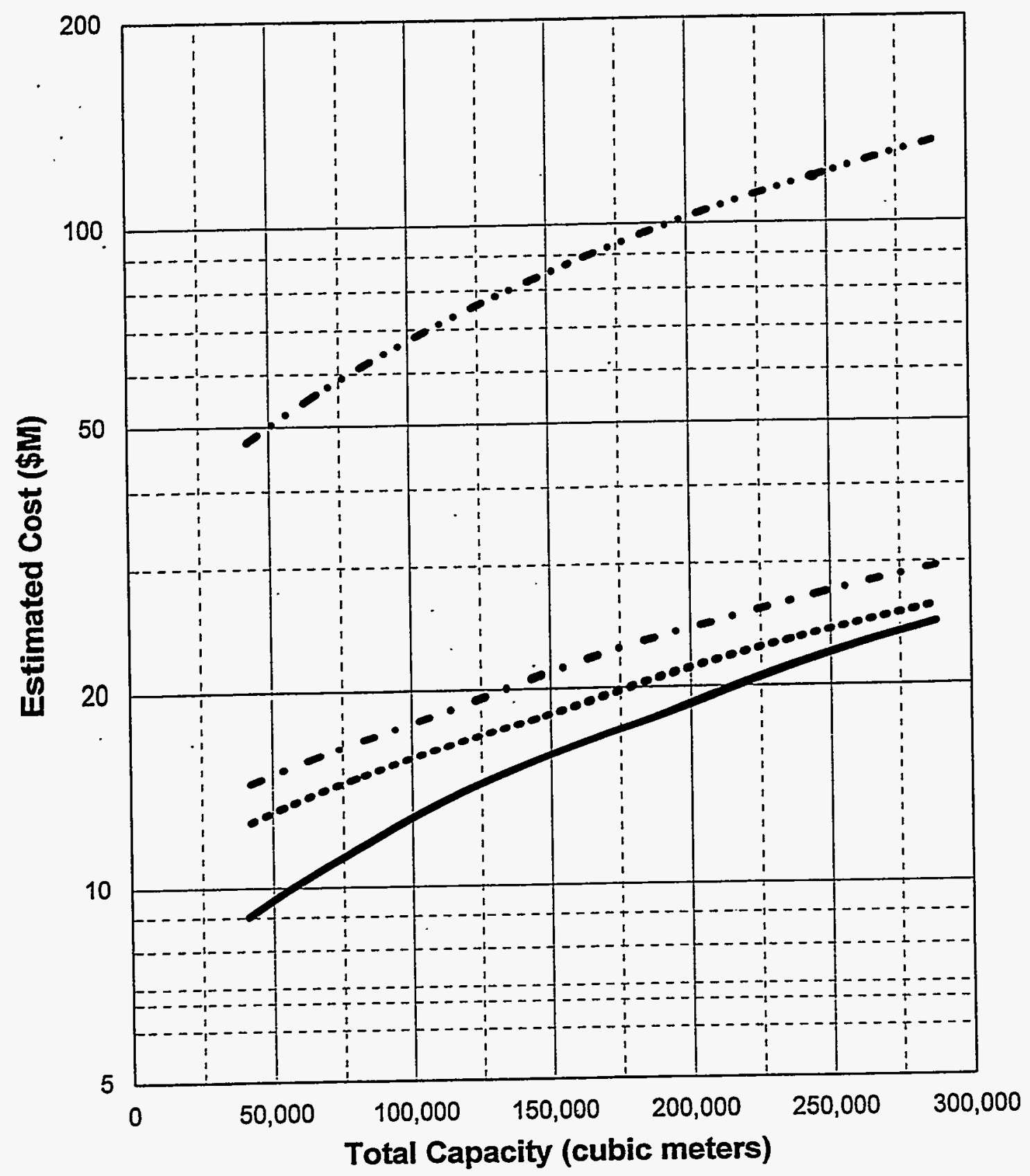

Pre-Operations Construction O\&M (1year) S\&M

Figure 26-2. PLCC versus capacity for the shallow land disposal (SLDSP) module. 


\section{SHALLOW LAND DISPOSAL}

Total Life Cycle Costs

Module: SLDSP Waste Type: Alpha, Nonalpha, and Remote Handled LLW

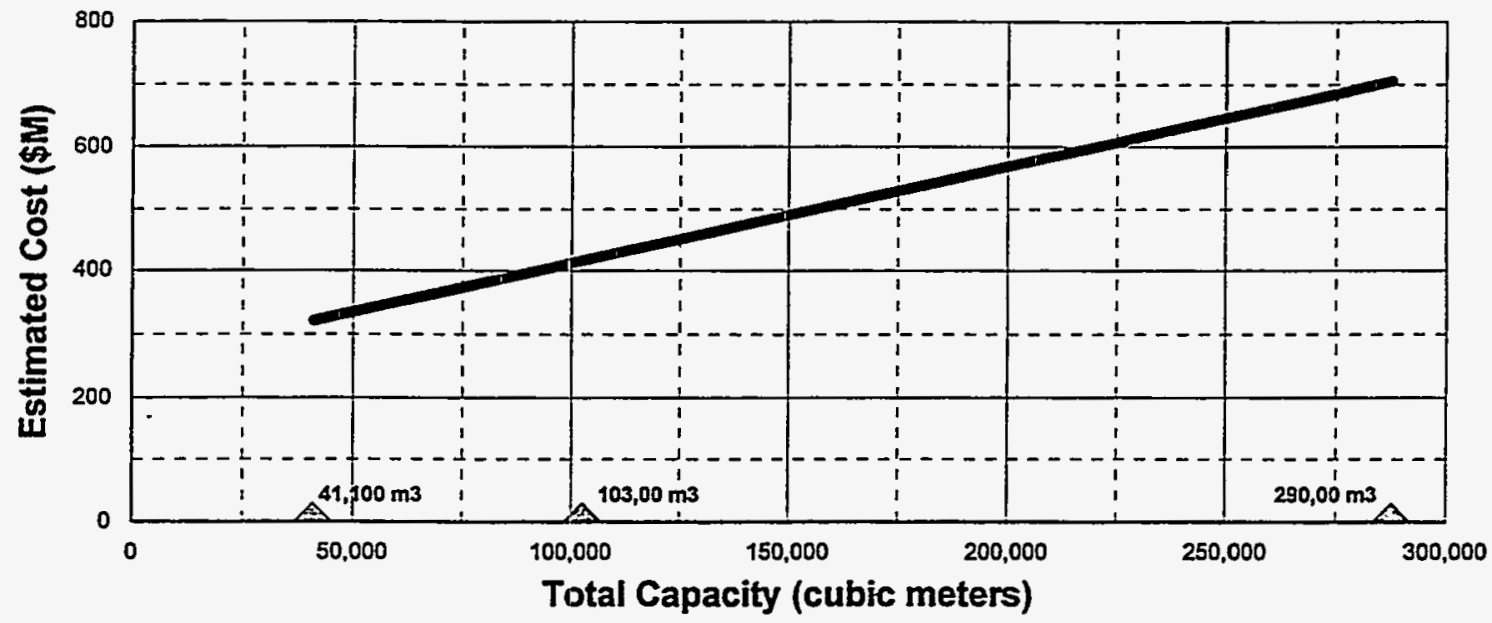

Alpha, Nonalpha, Remote Handled

NOTE: Basis includes 20 years O\&M

Triangles indicate capacities where detailed cost estimates were developed.

\section{SHALLOW LAND DISPOSAL}

Total Life Cycle Unit Costs

Module: SLDSP Waste Type: Alpha, Nonalpha, and Remote Handled LLW

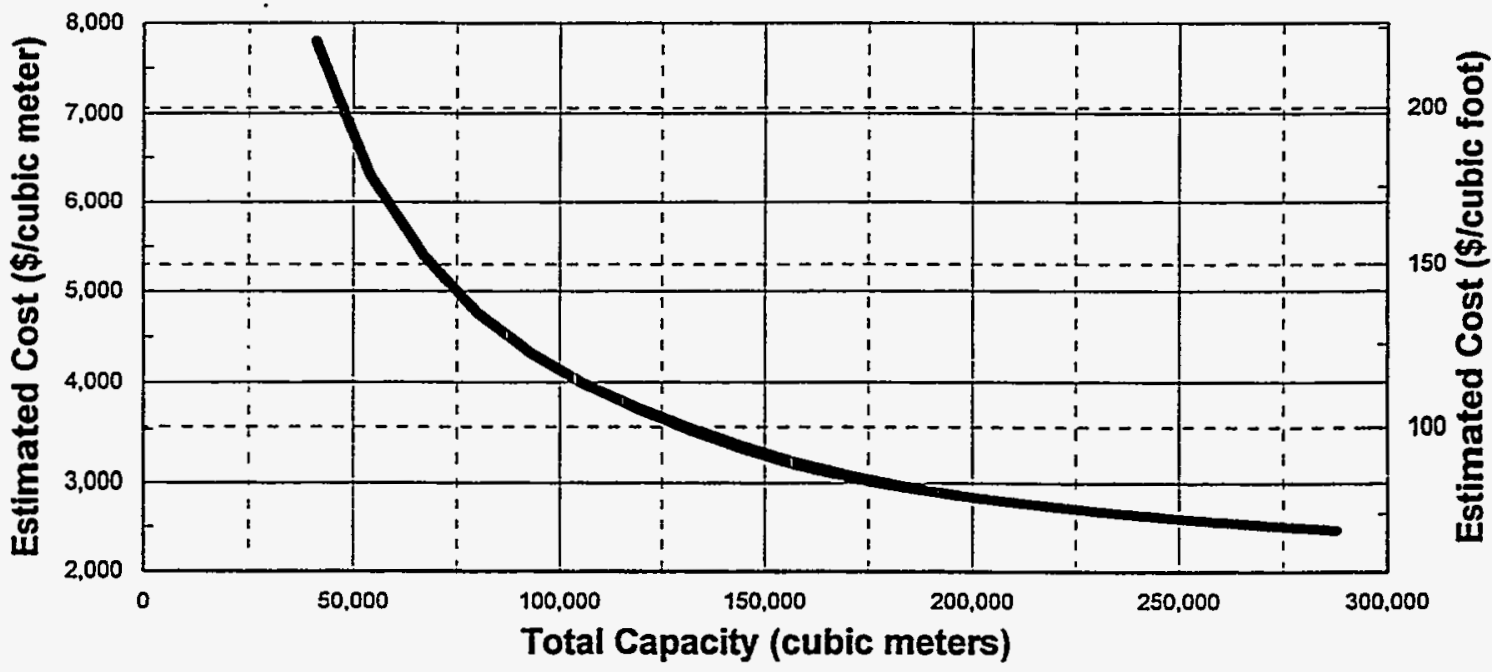

Alpha, Nonalpha, Remote Handled

NOTE: Basis includes 20 years O\&M

Figure 26-3. PLCC versus capacity including unit rates for the shallow land disposal (SLDSP) module. 


\section{SILO DISPOSAL (MODULE SIDSP)}

\subsection{Basic Information}

The silo disposal module, shown in Figure 27-1, is used in conjunction with the storage receiving and shipping module. This module should be used for sites requiring disposal of a small quantity of waste. In addition, the module can directly accept packaged waste from generators or other sources. The unit operations are shown in the PFD in Figure 27-2.

\subsection{Technical Bases and Assumptions}

\subsubsection{Function and Operation of the Module}

Waste material arrives in 55-gal drums placed in the transportation casks mounted on flat-bed trailers. Drums are removed by an overhead bridge crane or boom crane and transported to the silo area. Silos are constructed in place with reinforced concrete on a concrete pad and underlying liner and leachate collection system. Drums are placed by boom crane five drums in a row and seven drums high. Silos are backfilled with sand, and a reinforced concrete cap seals the silo. A multi-layered earth materials mound covers all silo areas.

\subsubsection{Integration of the Module}

Input includes waste drums received from the generators. The O\&M consumables, including personal protective equipment, must be purchased. No module output is anticipated for the post-closure (at least 300 years).

\subsection{Cost Bases, Assumptions, and Results}

Full-time equivalent and cost versus capacity information for the silo disposal module are shown in Figures 27-3 through 27-5. 

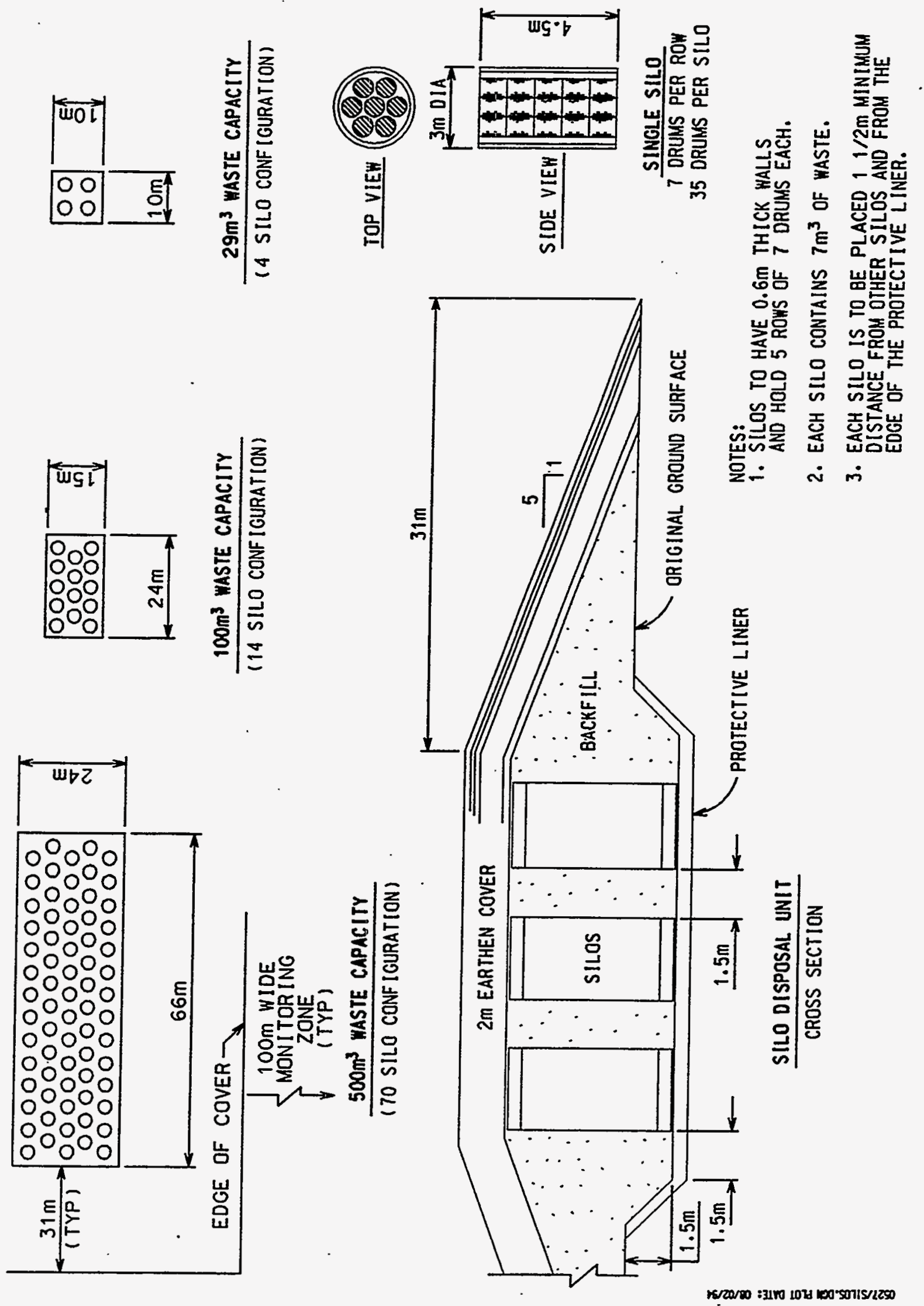

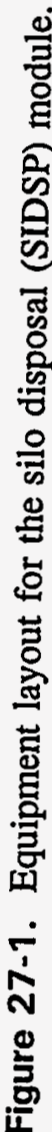




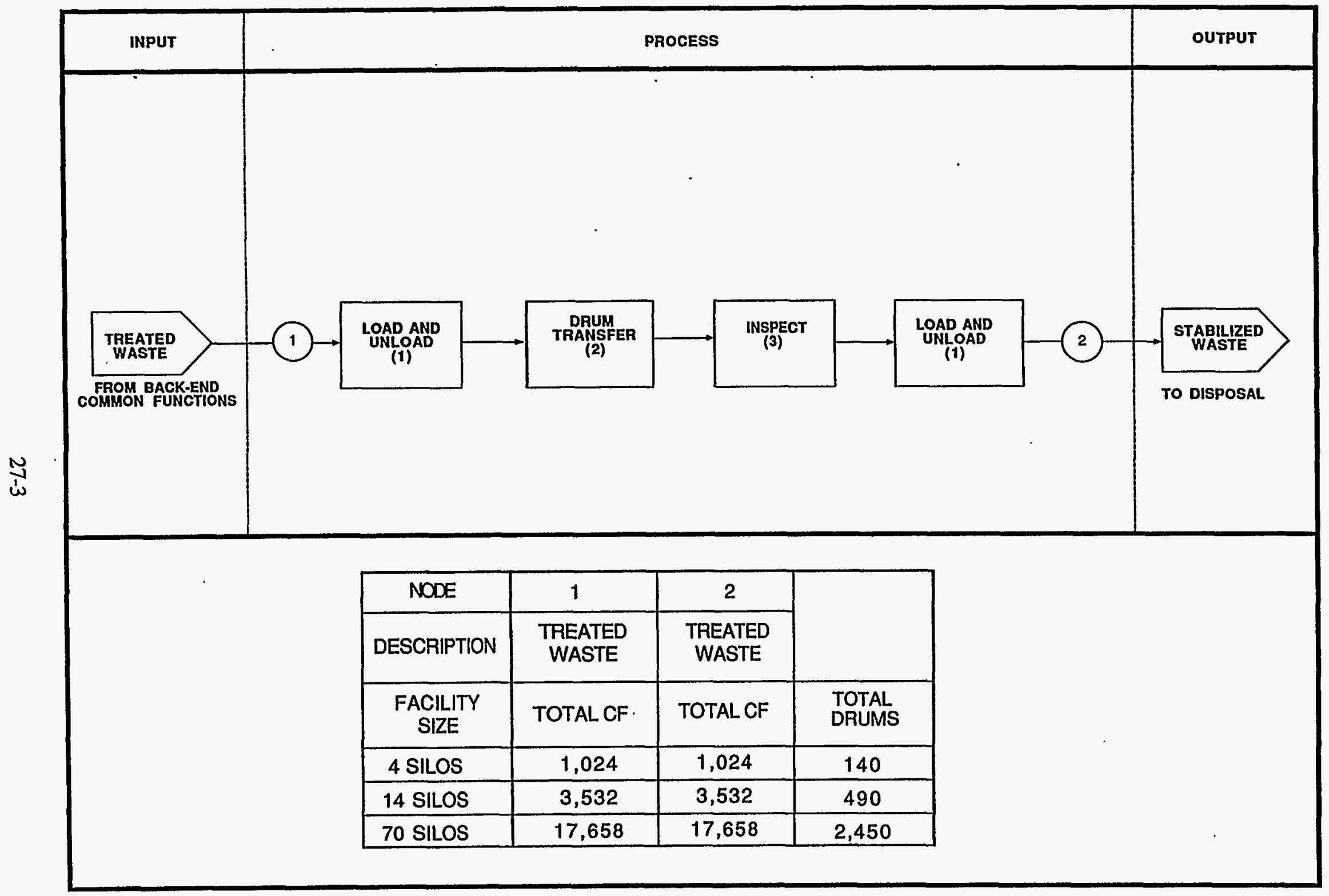

Figure 27-2. Process flow diagram for the silo disposal (SIDSP) module. 


\section{SILO DISPOSAL}

FTE by Work Breakdown Structure Element Module: SIDSP Waste Type: Alpha, Nonalpha, and Remote Handled LLW

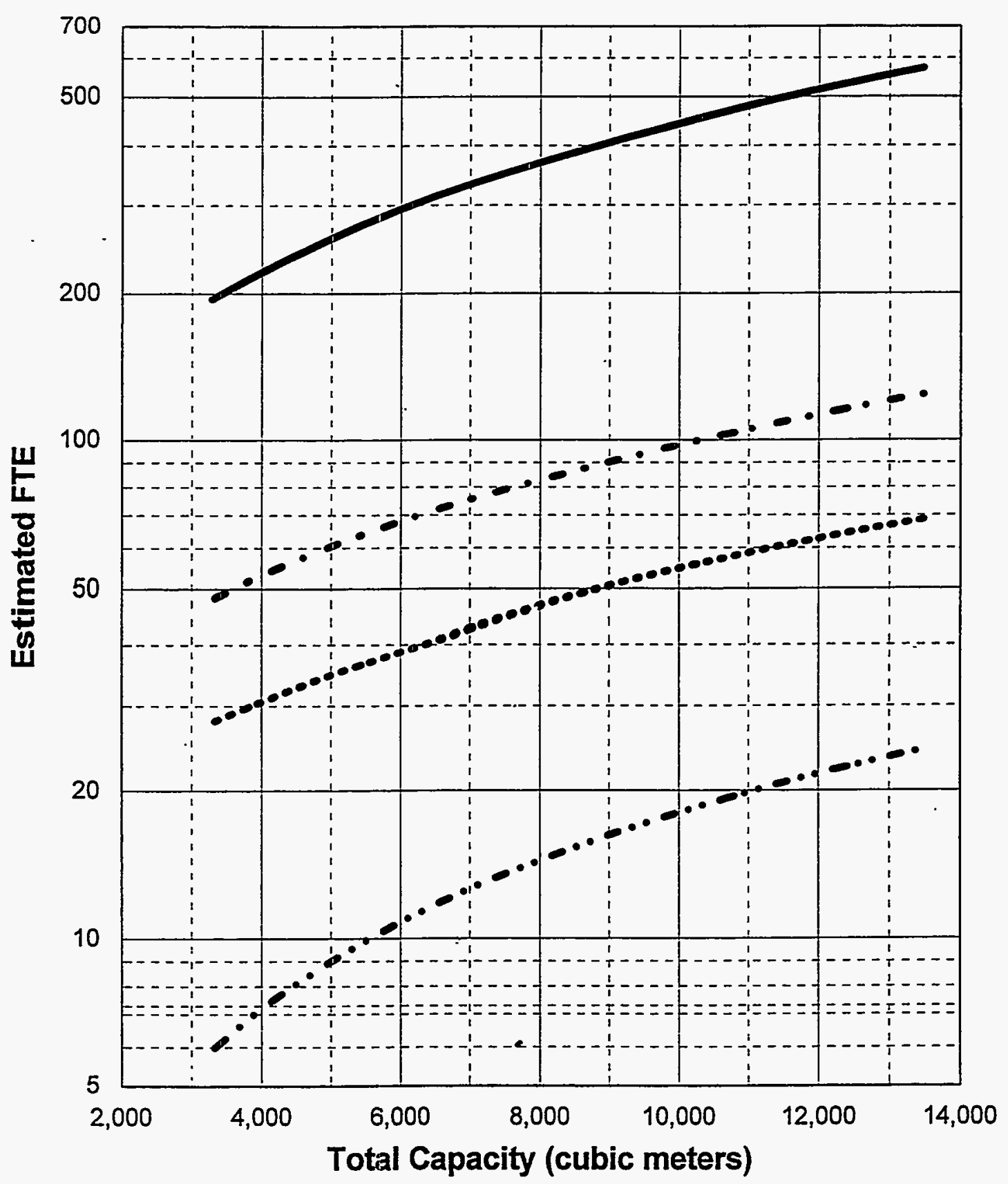

Pre-Operations Construction O\&M (1year) S\&M

Figure 27-3. FTE workers versus capacity for the silo disposal (SIDSP) module. 


\section{SILO DISPOSAL}

Costs by Work Breakdown Structure Element Module: SIDSP Waste Type: Alpha, Nonalpha, and Remote Handled LLW

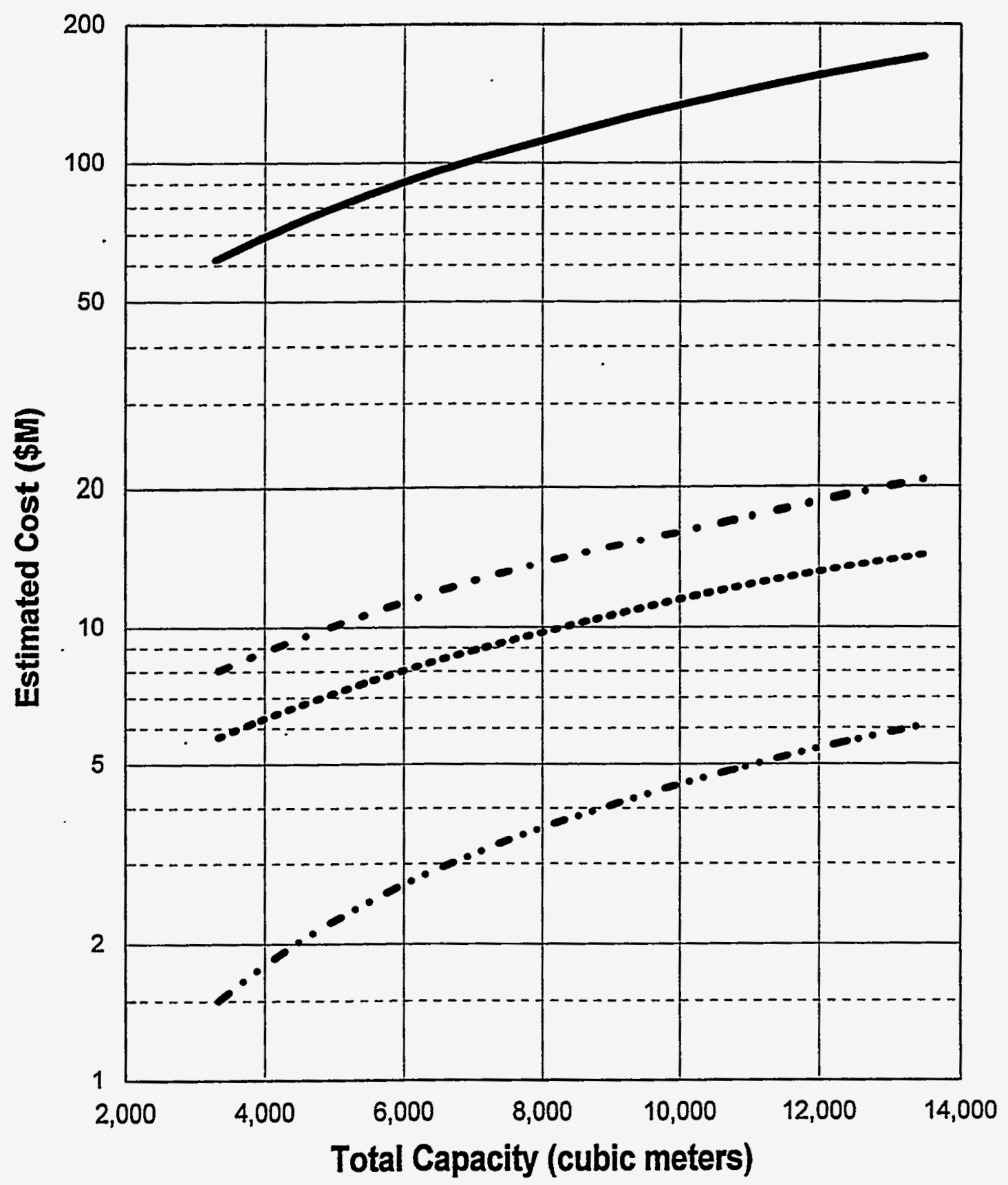

Pre-Operations Construction O\&M (1year) S\&M

Figure 27-4. PLCC versus capacity for the silo disposal (SIDSP) module. 


\section{SILO DISPOSAL}

Total Life Cycle Costs

Module: SIDSP Waste Type: Alpha, Nonalpha, and Remote Handled LLW

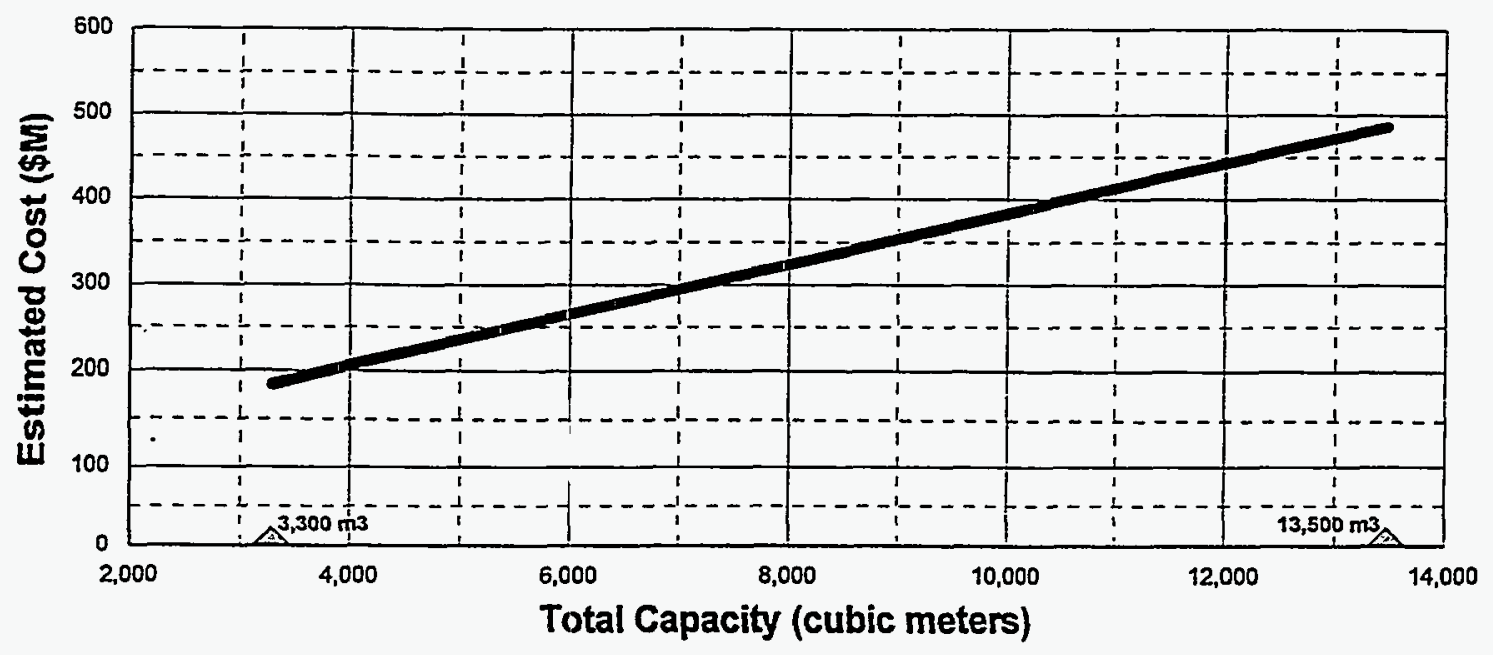

Alpha, Nonalpha, Remote Handled

NOTE: Basis includes 20 years O\&M

Triangles indicate capacities where detailed cost estimates were developed.

\section{SILO DISPOSAL}

Total Life Cycle Unit Costs

Module: SIDSP Waste Type: Alpha, Nonalpha, and Remote Handled LLW

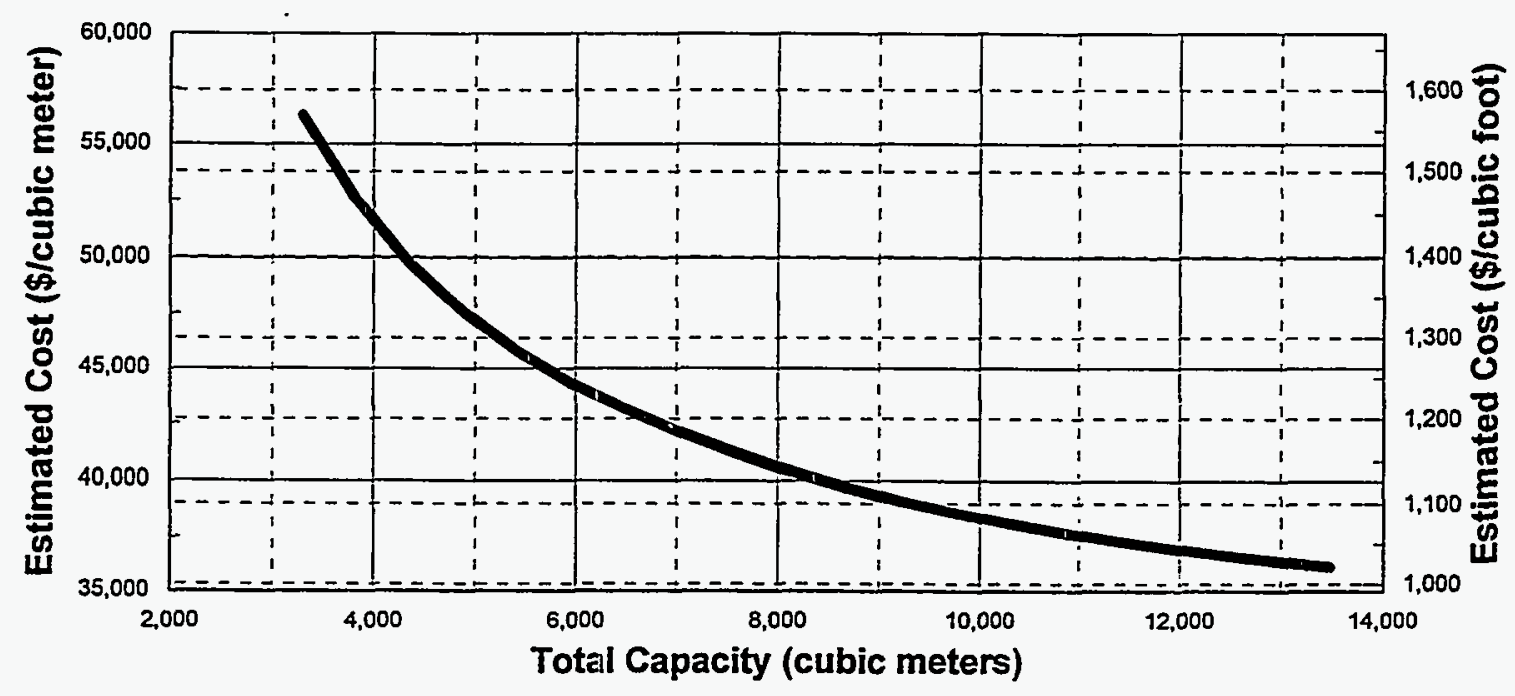

Alpha, Nonalpha, Remote Handled

NOTE: Basis includes 20 years O\&M

Figure 27-5. PLCC versus capacity including unit rates for silo disposal (SIDSP) module. 


\section{BOREHOLE DISPOSAL (MODULE BHDSP)}

\subsection{Basic Information}

The borehole concept, shown in Figure 28-1, is considered an alternative disposal method for small generator installations. A single borehole allows disposal of $1.0 \mathrm{~m}^{3}\left(35.3 \mathrm{ft}^{3}\right)$ of waste. This disposal concept may not meet the RCRA requirement for a double liner leachate collection system. Also, the borehole may not be acceptable where groundwater is within $0.85 \mathrm{~m}(2.8 \mathrm{ft})$ of the ground surface.

\subsection{Technical Bases and Assumptions}

\subsubsection{Function and Operation of the Module}

A borehole is drilled $0.91 \mathrm{~m}(3 \mathrm{ft})$ in diameter and $7.6 \mathrm{~m}(25 \mathrm{ft})$ deep. Concrete is placed in the

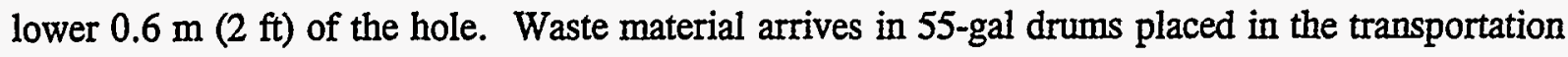
casks mounted on flat-bed trailers. Five drums are lowered into the hole, stacked one on top of another. The hole is grouted around the drums to the surface. A cover, consisting of a 2.4-m (8-ft) thick concrete slab, is constructed atop the borehole. A 2-m (7-ft) thick engineered earth cover is constructed on top of the concrete cover. Boreholes installed in low-versus high-sensitivity areas would be constructed in a similar manner. Additional site characterization would be required at highsensitivity areas.

In low-sensitivity areas, such as at remote existing DOE sites, which are well above the water table, and with borehole installation associated with the installation of other modules for which NEPA permitting activities have been included, the borehole would require minimal attention.

In high-sensitivity areas, such as a non-DOE facility that is near a populated area, close to the water table, and requiring NEPA permitting activities or front-end support, a much higher level of attention throughout its life term would be necessary.

\subsubsection{Integration of the Module}

Input includes waste drums received from storage. The O\&M consumables, including personnel protective equipment, must be purchased. No module output is anticipated for a long time period (at least 300 years).

\subsection{Cost Bases, Assumptions, and Results}

The major capital cost item is the drill rig if subcontracting the drilling is not feasible. Costs for excavating and completing the borehole for use in disposal is based on past experience with similar excavations and wells used for other purposes. Table 28-1 presents estimates of FTE workers and PLCC for each borehole at both low- and high-sensitivity areas. Data shown in Table 28-1 do not include site characterization, NEPA, for the low-sensitivity area but do include it, plus front-end support, for the high-sensitivity area. If detailed site characterization and NEPA are required for the low-sensitivity area, an estimated cost of $\$ 7.4$ million should be added to the operation-funded 
activities. The cost for 100 years of active monitoring and 200 years of inactive monitoring is included in the $\$ 14.77$ million for D\&D.

Table 28-1. FTE workers and PLCC $(\$ 1,000)$ per excavation for the borehole disposal module.

\begin{tabular}{lcccccc}
\hline & \multicolumn{2}{c}{ Low-sensitivity } & & \multicolumn{2}{c}{ High-sensitivity } \\
\cline { 2 - 3 } \cline { 6 - 7 } \multicolumn{1}{c}{ Cost element } & PLCC & $\begin{array}{c}\text { FTE } \\
\text { workers }\end{array}$ & & PLCC & $\begin{array}{c}\text { FTE } \\
\text { workers }\end{array}$ \\
\hline (1.0) Preoperations & 32 & 0 & & 7,059 & 42 \\
(2.0) Construction & 52 & 1 & & 437 & 8 \\
(3.0) O\&M (20 years) & 568 & 4 & & 8,200 & 52 \\
(4.0) D\&D & 1,757 & 7 & & 14,770 & 59 \\
All cost elements (total for 20 years O\&M) & 2,409 & 12 & & 30,466 & 161 \\
\hline
\end{tabular}




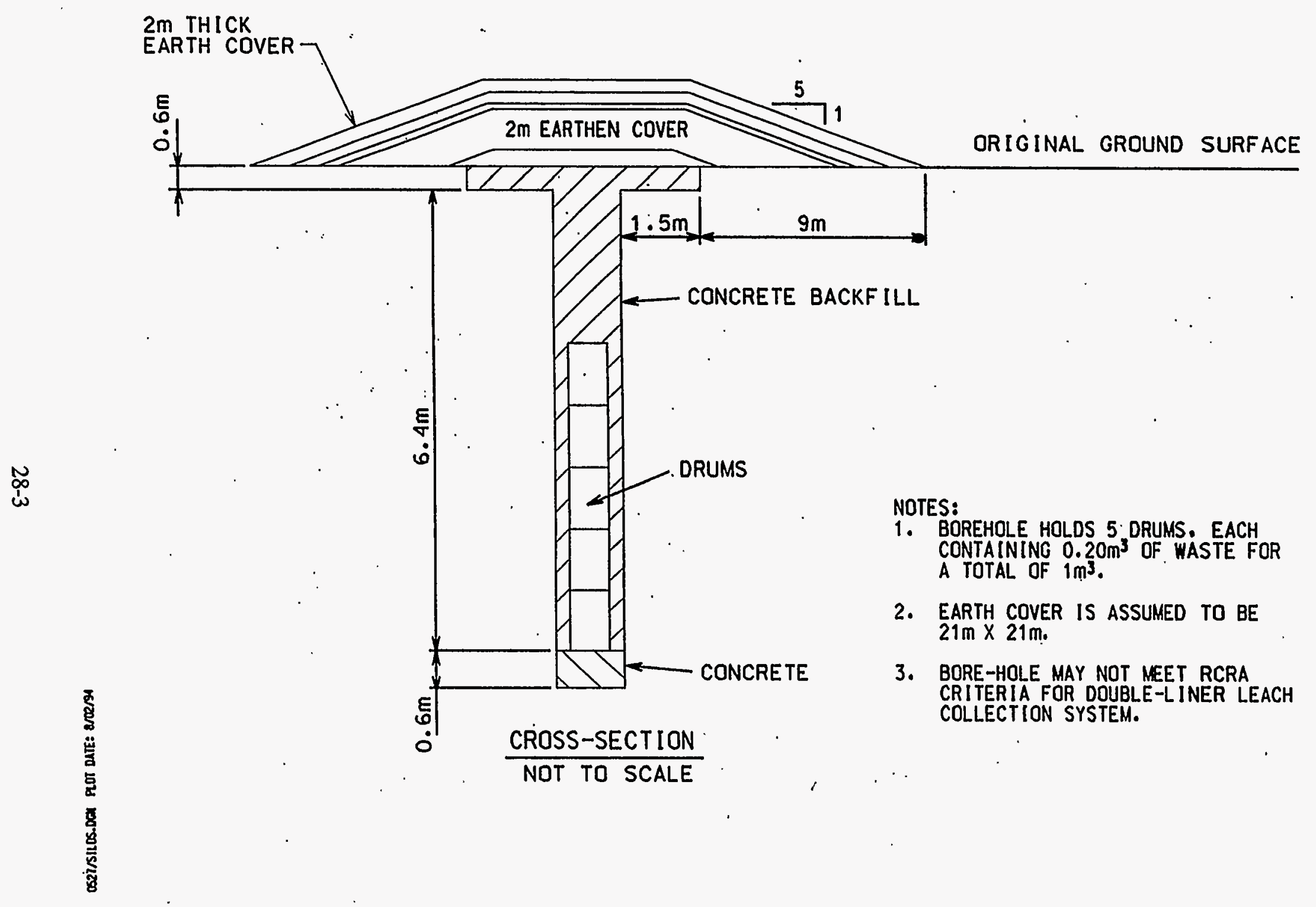

Figure 28-1. Equipment layout for the borehole disposal (BHDSP) module. 


\section{COST ESTIMATION PROCEDURE}

\subsection{Overview}

To this point this report describes how the costs and FTEs of the various TSD modules were estimated. These costs and FTEs were estimated over a wide range of input capacities. These data were used to define cost and FTE versus capacity relationships for large generator modules, represented by curves on a graph. For fixed small generator and portable modules, tables containing a single cost and FTE data are presented. The data in these tables are applicable to a limited capacity range of the lowest end of the given treatment modules. From either a curve or a table, one can estimate the costs and FTEs of a module given its capacity. From a group of such curves and tables, one can estimate the FTEs and cost for treating, storing, and disposing of a given inventory of any combination of nonalpha, alpha, and RH LLW. A combination of modules that treats, stores, and disposes of a given inventory of such waste is referred to as a treatment scenario. Figure 29-1 shows how modules can be combined to create a treatment facility based on a minimum treatment approach for LLW. Figure 29-2 shows a layout of an integrated facility designed to achieve maximum volume reduction of LLW. Figure 29-3 shows a layout of an integrated facility that combines maximum volume reduction with vitrification to produce a more robust final waste form.

The cost estimation procedure in this section has been developed to allow the reader to estimate the total cost for a scenario for treating, storing, and disposing of this waste. The scenario estimation procedure essentially consists of three major steps which are discussed in the following subsections.

\subsection{Waste Loads Definition}

In the waste loads definition step, the capacity requirement for each module is defined. To use the WMFCI cost and FTE data, the total capacity requirements need to be converted into the appropriate processing rate (e.g., $\mathrm{kg} / \mathrm{hr}, \mathrm{m}^{3} / \mathrm{hr}$ ) or total storage or disposal capacities (e.g., $\mathrm{m}^{3}$ ) by developing operating assumptions. An estimator may need three basic calculations to establish treatment processing rates, storage and disposal input/throughput rates, and storage and disposal total volumetric requirements. The basic calculations and examples are as follows:

1. Front-end and treatment modules. The total unprocessed waste volume $\left(\mathrm{m}^{3}\right) \mathrm{can}$ be converted to a treatment input capacity processing rate $(\mathrm{kg} / \mathrm{hr})$ by the following calculations. The total volume in cubic meters $\left(\mathrm{m}^{3}\right)$ is multiplied by the unprocessed waste density $(\mathrm{kg} / \mathrm{hr})$ to obtain the total mass in kilograms $(\mathrm{kg})$. This mass is divided by the total hours of facility (module) operation. An example is as follows: $\left(1,000 \mathrm{~m}^{3} \times 1,242 \mathrm{~kg} / \mathrm{m}^{3}\right.$ (density of soil) $/(4,032 \mathrm{hrs} /$ year $\times 20$ years of operation) $=15.4 \mathrm{~kg} / \mathrm{hr}$ processing rate for 20 years.

2. Storage administration, storage receiving and shipping, and disposal administration. The total processed waste $(\mathrm{kg} / \mathrm{hr})$ can be converted to a post-treatment storage or disposal throughput capacity $\left(\mathrm{m}^{3} / \mathrm{hr}\right)$ by the following calculations. The processed waste rate $(\mathrm{kg} / \mathrm{hr})$ is divided by the processed waste density $\left(\mathrm{kg} / \mathrm{m}^{3}\right)$ to obtain the throughput capacity 
rate for storage or disposal. An example is as follows: $1,000 \mathrm{~kg} / \mathrm{hr} / 2,013 \mathrm{~kg} / \mathrm{m}^{3}$ (density of soils that have been processed and grouted) $=0.50 \mathrm{~m}^{3} / \mathrm{hr}$ storage input/output (or disposal input) capacity.

3. Storage and disposal modules. The storage administration, storage receiving and shipping, and disposal administration throughput rates $\left(\mathrm{m}^{3} / \mathrm{hr}\right.$ ) can be converted into total volumes $\left(\mathrm{m}^{3}\right)$ for storage or disposal by the following calculations. The storage input/output (or disposal input) capacity is multiplied by the total hours of facility (module) operations. An example is as follows: $\left(0.50 \mathrm{~m}^{3} / \mathrm{hr} \times 4,032 \mathrm{hrs} /\right.$ year $\times 20$ years of operation) $=40,320 \mathrm{~m}^{3}$ total volume for storage (or disposal).

These calculations would need to be completed for existing or new facilities. The existing facility capacities are used for estimating O\&M and D\&D costs and FTEs only. New facility capacities are used to define the preoperations, facility construction, O\&M and D\&D costs, and FTEs.

Treatment, storage, and disposal modules are covered in the WMFCI report. Processing rates for each type of module may be defined as described in the following sections.

\subsubsection{Large Generator Facility Treatment Waste Loads}

Large generator facility treatment waste loads may be documented in a data sheet similar to that shown in Figure 29-4. As shown, the treatment modules are separated into four categories, which are discussed as follows.

1. Treatment front-end modules. To estimate cost and FTEs for the front-end modules, the total processing rate of the treatment facility must be defined. The processing rate of the treatment facility is used to size the treatment front-end modules even though some of the modules (e.g., the maintenance module) do not process the input waste per se. For large generator facilities, there are four front-end modules: treatment administration (analytical laboratory and administration building); receiving and inspection; open, dump, and sort; and maintenance. The user must define both the existing and new module loads for each of the four modules.

2. Primary treatment modules. The total treatment processing rate must be subdivided according to the processing needs. The treatment modules in this report are designed to satisfy the processing needs of 32 waste matrix categories. ${ }^{j}$ The waste matrix categories are defined in Kirkpatrick 1995. Primary treatment modules are selected based on the processing requirements and the contaminants present in the waste. Processing rates for each module identified in the treatment train need to be specified.

3. Secondary treatment and stabilization modules. The processing rate for the secondary treatment and stabilization modules must be defined by considering two sources. The first source is the input unprocessed waste that bypasses the primary treatment modules. For

j. The waste matrix categories are not all applicable to non-mixed LLW. 
example, the vitrification module will receive both the ash from an incinerator plus inorganic solids that do not need primary treatment. The second source is the secondary waste from the primary treatment systems. For example, the concentrated waste discharged from the neutralization module will have to be treated by a stabilization module. The secondary waste generation rates can be determined from the mass balance data depicted on the PFDs.

4. Treatment back-end module. The waste load for the back-end module is defined by summing the output waste from the secondary treatment and stabilization modules. There are also some wastes that do not require secondary treatment that must be added to the sum of the output from the secondary treatment and stabilization modules.

\subsubsection{Small Generator Facility and Portable Treatment Waste Loads}

The fixed small generator treatment facility and the portable treatment trailer concept are useful for installations requiring an overall processing rate of less than approximately $19.8 \mathrm{~m}^{3} / \mathrm{yr}$ (700 $\mathrm{ft}^{3} /$ year). The FTEs and cost data in this report are included for estimating a fixed small generator module either in an existing building space or in a new building. The fixed small generator and portable treatment waste loads may be documented in a data sheet similar to that shown in Figure 29-5. As shown, the small generator facility has three categories of modules because all of the frontend and back-end functions are combined into a single module (FBSPT). There are also fewer primary and secondary treatment modules than with a large generator facility because of the expectation that a more limited variety of waste will be treated at a small generator facility.

The processing rate for the small generator modules can be determined the same way as for the large generator modules (see Section 29.2.1). The portable module capacity is defined by determining the number of treatment campaigns.

\subsubsection{Storage and Disposal Waste Loads}

Unlike the treatment modules, which use mass feed rates like waste loads, storage and disposal capacities are expressed in volumetric feed rates or as total volumes (i.e., storage, disposal). Figure 29-6 may be used to document the storage and disposal feed rates. As shown, the are six storage and disposal module categories: storage administration, storage receiving and shipping, storage, disposal administration, disposal receiving, and disposal. As with treatment, the existing and new capacities must be defined for each of the six categories.

\subsection{Estimating TSD Facility Costs and FTEs}

Estimates of FTEs and PLCC for TSD facilities are prepared based on the processing requirements developed in the waste load definition step. The corresponding FTEs and costs for each module are developed by referring to the FTEs and cost versus capacity curves and tables given in this report. For existing capacities, operating costs (which consists of O\&M and D\&D costs) must be defined. For new capacity needs, the facility construction and preoperation estimates must be added to the facility O\&M and D\&D costs. To obtain total TSD facilities cost, a sum of the cost or FTEs from all TSD modules must be prepared. 


\subsection{Transportation Costs}

Transportation costs can be estimated by defining the total volume of waste to be transported and the distance in each of the potential transport segments (e.g., from generator to treatment facility, from treatment facility to storage facility, or from storage facility to disposal facility). Once the volumes and mileages are defined for each transportation segment, the cost data presented in Feizollahi et al. 1994 can be used to calculate the number of shipments and the associated transportation costs. 


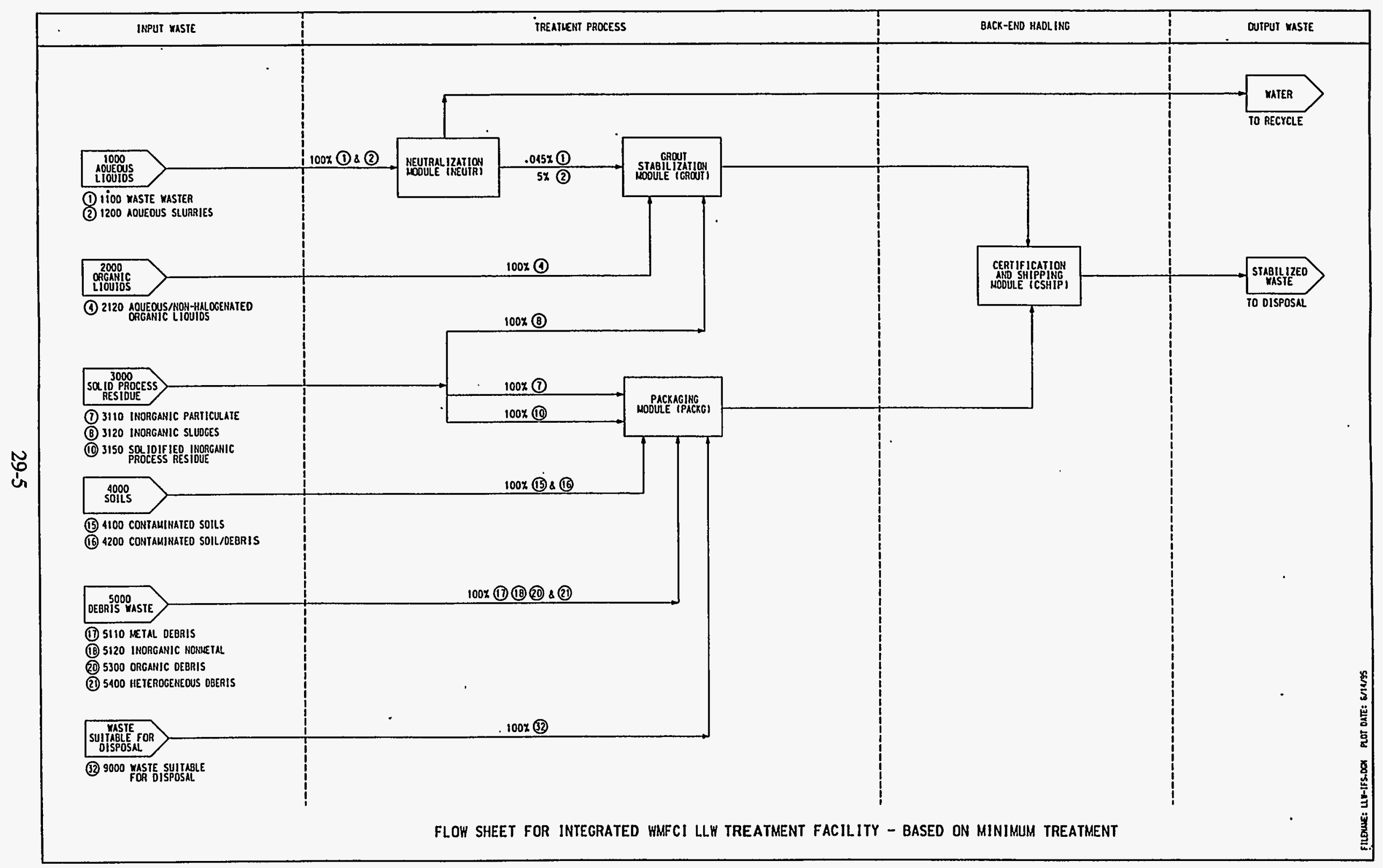

Figure 29-1. Layout for integrated treatment facility based on a minimum treatment approach for LLW. 


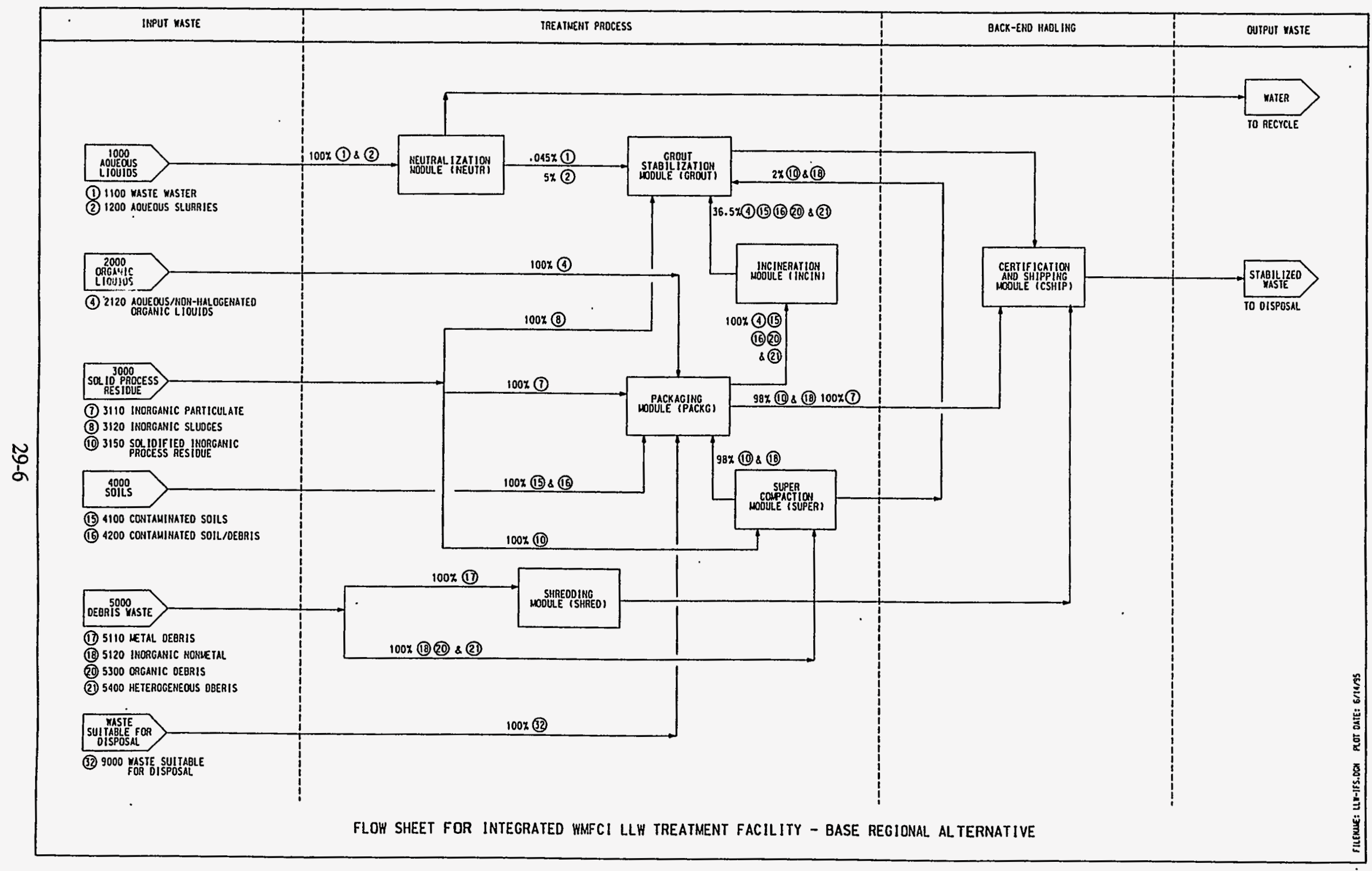

Figure 29-2. Layout of an integrated facility designed to achieve maximum volume reduction of LLW. 


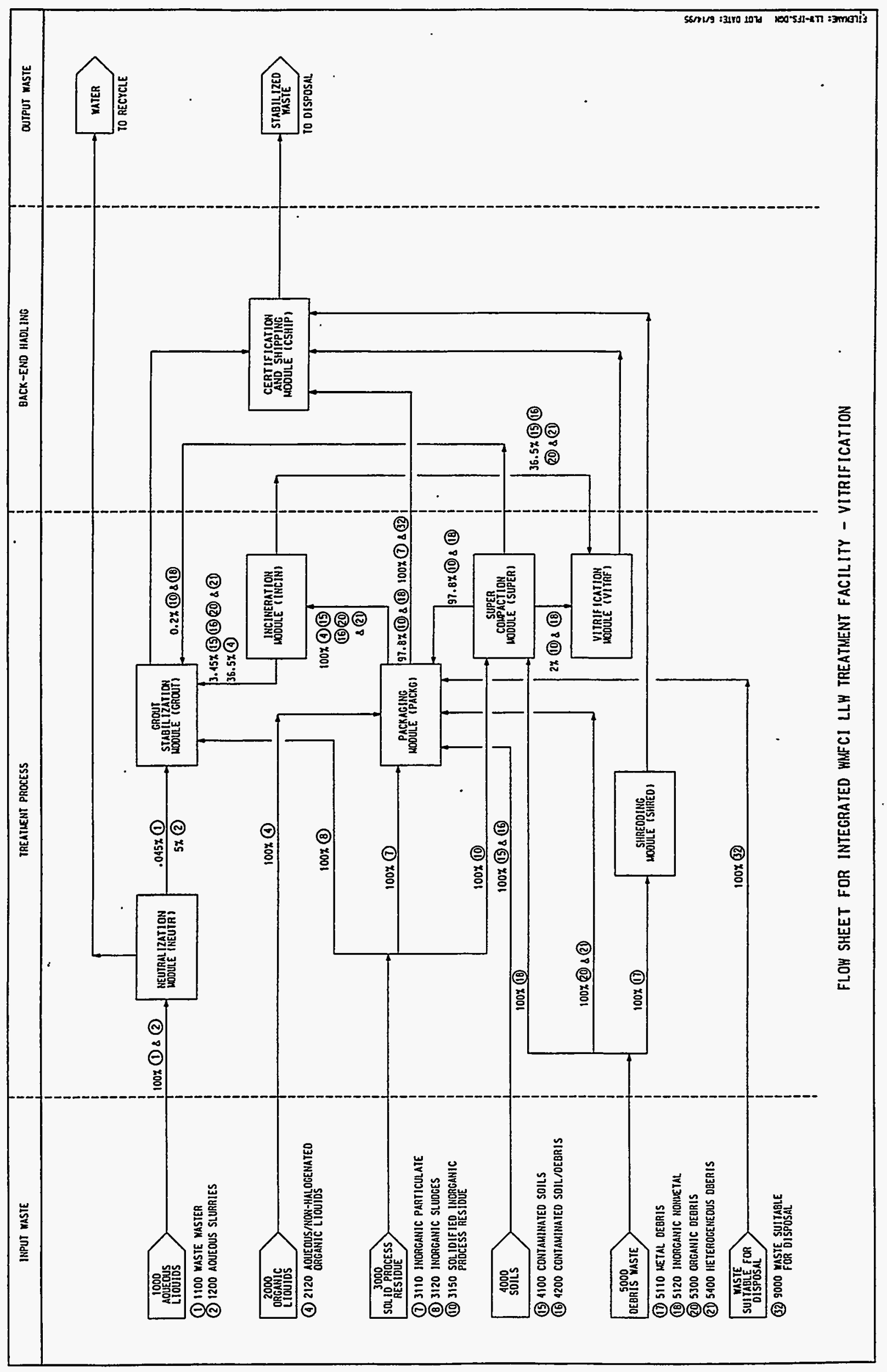

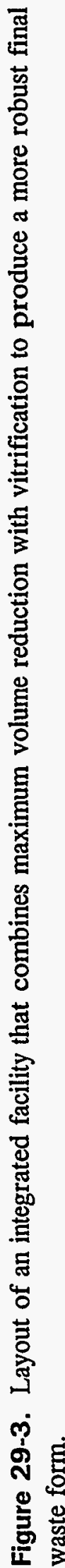




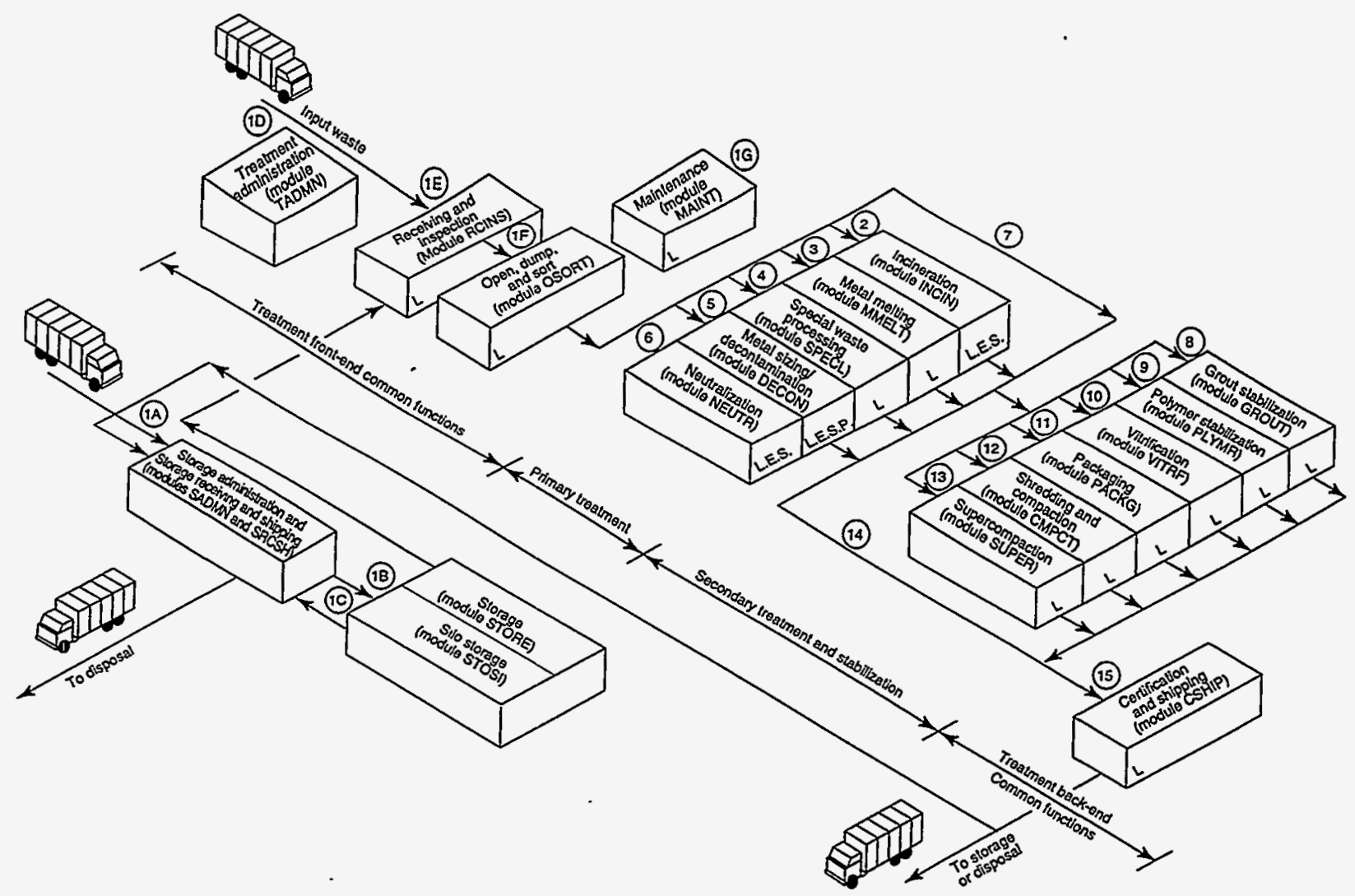

RED 0809

\begin{tabular}{|c|c|c|c|c|}
\hline Modules & Unit & $\begin{array}{c}\text { Total } \\
\text { capacity }\end{array}$ & $\begin{array}{l}\text { Existing } \\
\text { capacity }\end{array}$ & $\begin{array}{c}\text { New } \\
\text { capacity }\end{array}$ \\
\hline \multicolumn{5}{|l|}{ 1. Storage front-end and back-end support } \\
\hline (1A) Storage administration and Storage receiving and shipping & $\mathrm{m}^{3} \mathrm{mr}$ & & & \\
\hline \multicolumn{5}{|l|}{ 11. Storage } \\
\hline (1B) Storage & $\mathrm{m}^{3}$ & & & \\
\hline \multicolumn{5}{|l|}{ (19) Slo storage } \\
\hline \multicolumn{5}{|l|}{ III. Treatment front-end } \\
\hline (1D) Treatmens administration & $\mathrm{kg} / \mathrm{hr}$ & & & \\
\hline (11) Receiving and inspoction & $\mathrm{kg} / \mathrm{hr}$ & & & \\
\hline (1) Open, dump and sort & $\mathrm{kg} / \mathrm{hr}$ & & & \\
\hline (16) Maintenance & $\mathrm{kg} / \mathrm{hr}$ & & & \\
\hline \multicolumn{5}{|l|}{ N. Primary treatment } \\
\hline (2) Incineration & $\mathrm{kghr}$ & & & \\
\hline (3) Metal meting & $\mathrm{kg} / \mathrm{hs}$ & & & \\
\hline (4) Special waste processing & kghs & & & \\
\hline (5) Metal sizing/decontamination & kg/hs & & & \\
\hline (6) Neutralizetion & $\mathrm{kg} / \mathrm{hr}$ & & & \\
\hline (7) Bypass primary (not a nodúle) & $\mathrm{kg} / \mathrm{hr}$ & & & \\
\hline \multicolumn{5}{|l|}{ V. Secondary treatment and stabilization } \\
\hline (8) Grout stabifization & $\mathrm{kg} / \mathrm{hr}$ & & & \\
\hline (9) Polymer stabification & $\mathrm{kghhs}$ & & & \\
\hline (10) Varification & $\mathrm{kg} / \mathrm{hr}$ & & & \\
\hline (11) Packaging & $\mathrm{kght}$ & & & \\
\hline (12) Shrodding and compaction & $\mathrm{kghr}$ & & & \\
\hline (13) Supercompaction & $\mathrm{kg} / \mathrm{hr}$ & & & \\
\hline (14) Bypass secondary (not a module) & kghr & & & \\
\hline \multicolumn{5}{|l|}{ v. Treatment back-end } \\
\hline (15) Centification and shipping & $\mathrm{kg} / \mathrm{hr}$ & & & \\
\hline
\end{tabular}

Figure 29-4. Treatment waste load data sheet for the large generator facility. 


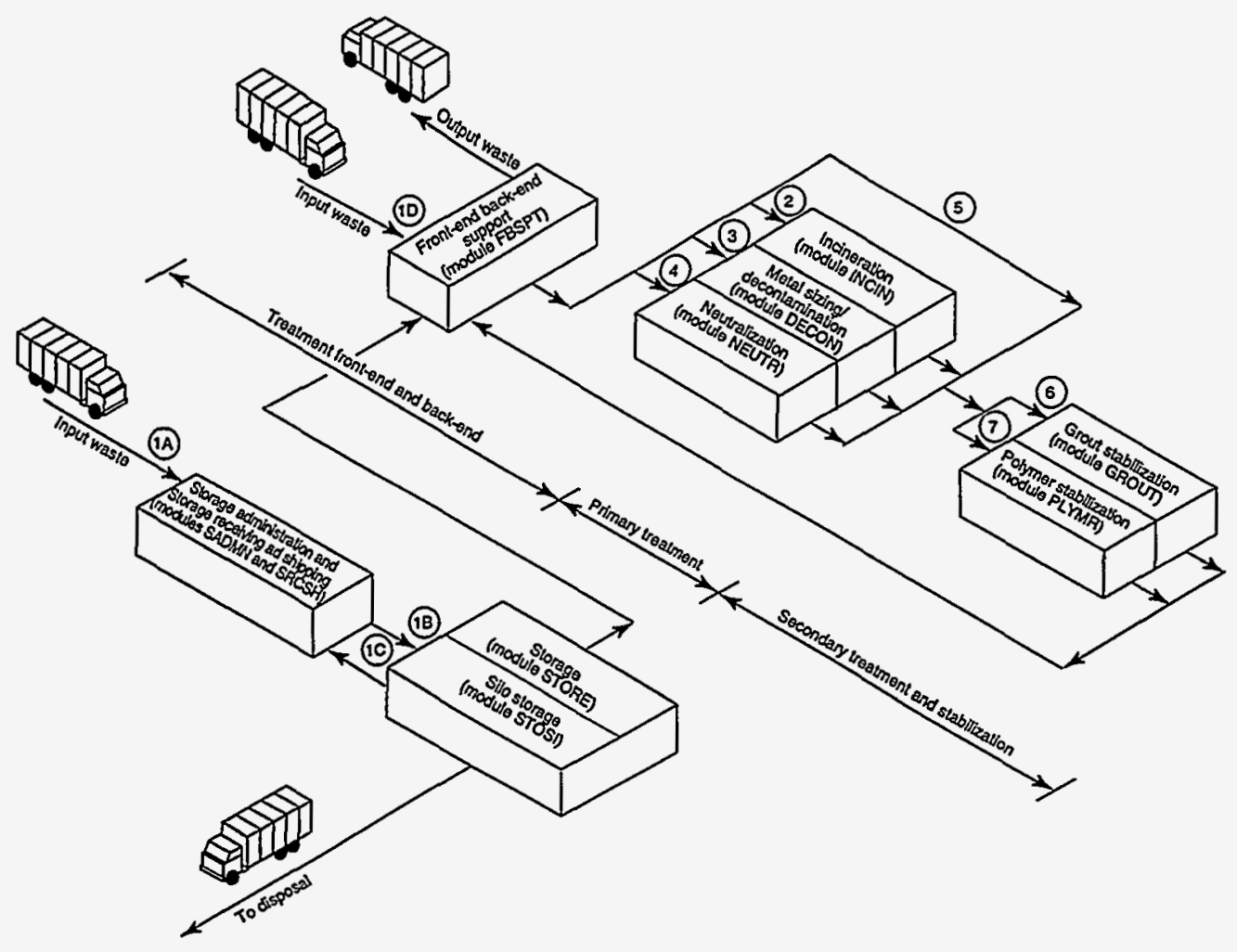

RED 0808

\begin{tabular}{|c|c|c|c|c|c|}
\hline Modules & Unit & $\begin{array}{c}\text { Total } \\
\text { capacity }\end{array}$ & $\begin{array}{l}\text { Existing } \\
\text { capacity }\end{array}$ & $\begin{array}{c}\text { New } \\
\text { capacity } \\
(")\end{array}$ & $\begin{array}{c}\text { Portable } \\
\text { module } \\
\text { capacity } \\
(* *)\end{array}$ \\
\hline \multicolumn{6}{|l|}{ 1. Storage front-end and back-end support } \\
\hline (1A) Storage administration and Storage recenving and shipping & $\mathrm{m}^{3} \mathrm{mr}$ & & & & \\
\hline \multicolumn{6}{|l|}{ II. Storage } \\
\hline (19) Storage & $m^{3}$ & & & & \\
\hline (1C) Sito storage & $m^{3}$ & & & & \\
\hline \multicolumn{6}{|l|}{ 11I. Treatment front-end and back-end } \\
\hline (1D) Front-end and back-end support & kghr & & & & $\therefore$ \\
\hline \multicolumn{6}{|l|}{ IV. Primary treatment } \\
\hline (2) Incineration & $\mathrm{kghr}$ & & & & 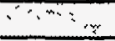 \\
\hline (3) Metal sizing/decontaminztion & $\mathrm{kghrs}$ & & & & \\
\hline (4) Nestralization & $\mathrm{kg} / \mathrm{hr}$ & & & & \\
\hline (5) Primary bypass (not a module) & $\mathrm{kghr}$ & & & & \\
\hline \multicolumn{6}{|l|}{ V. Secondary treatment and stabilization } \\
\hline (6) Grout stabiteation & $\mathrm{kghr}$ & & & . & . \\
\hline (7) Polymer stabilization & $\mathrm{kg} / \mathrm{hr}$ & & & & $x=?$ \\
\hline
\end{tabular}

(1) This column may bo futher drided to include new equipment in existing building of new equipment in new buakding (") Unit is number of campaigns

Figure 29-5. Treatment waste load data sheet for the small generator facility. 


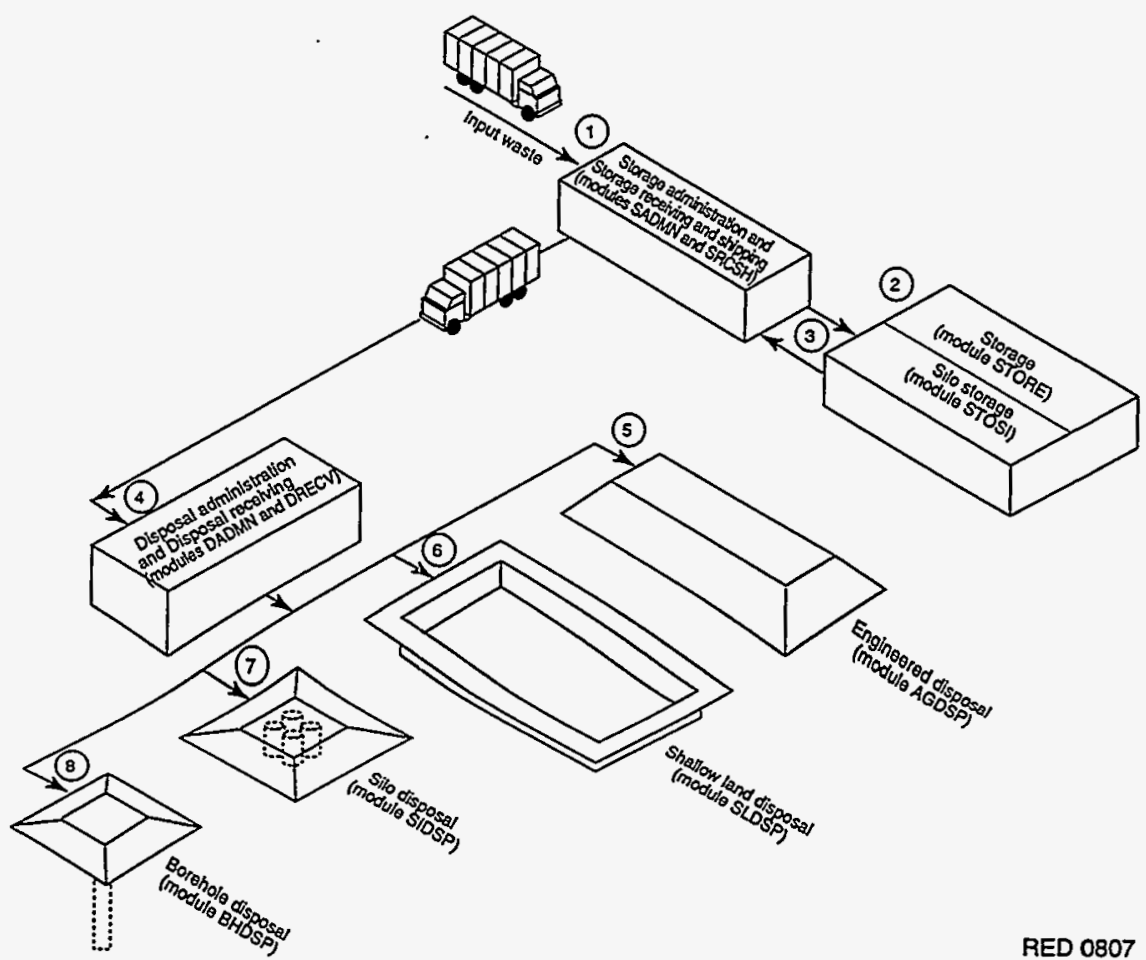

\begin{tabular}{|l|c|c|c|c|}
\hline Modules & Unit & $\begin{array}{c}\text { Total } \\
\text { capacity }\end{array}$ & $\begin{array}{c}\text { Existing } \\
\text { capacity }\end{array}$ & $\begin{array}{c}\text { New } \\
\text { capacity }\end{array}$ \\
\hline L. Storage front-end and back-end support & & & & \\
\hline (1) Storage administration and Storage receiving and shipping & $\mathrm{m}^{3} \mathrm{~ms}$ & & & \\
\hline II. Storage & & & & \\
\hline (2) Storgge & $\mathrm{m}^{3}$ & & & \\
\hline (3) silo storage & $\mathrm{m}^{3}$ & & & \\
\hline II. Disposal front-end & & & & \\
\hline (4) Disposal administration and Disposal recerving & $\mathrm{m}^{3} \mathrm{hr}$ & & & \\
\hline N. Disposal & & & & \\
\hline (5) Engineered disposal & $\mathrm{m}^{3}$ & & & \\
\hline (6) Stablow land disposal & $\mathrm{m}^{3}$ & & & \\
\hline (7) Silo disposal & $\mathrm{m}^{3}$ & & & \\
\hline (8) Borehole disposal & $\mathrm{m}^{3}$ & & & \\
\hline
\end{tabular}

Figure 29-6. Storage and disposal waste load data sheet. 


\section{REFERENCES}

DOE, 1987, Conceptual Design Report-Alternative Concepts for Low-Level Radioactive Waste Disposal, National Low-Level Waste Management Program, DOE/LLW-60T, June.

Feizollahi, F., and D. Shropshire, 1992, Waste Management Facilities Cost Information Report, EGG-WTD-10443.

Feizollahi, F., D. Shropshire, and D. Burton, 1995, Waste Management Facilities Cost Information for Transportation of Radioactive and Hazardous Materials, INEL-95/0300, Rev. 1, (formerly EGG-WM-10877, Rev. 1), June.

Kirkpatrick, T. D., 1995, DOE Waste Treatability Group Guidance, DOE/LLW-217, Rev. 0, January.

Morrison Knudsen/Chem Nuclear Services, 1991, Chapter 3: Illinois Low-Level Radioactive Waste Disposal Facility; Design, Construction and Capital Cost, from Illinois Low-Level Radioactive Waste Disposal Facility Application, May.

Roads, A. S., 1992, "Performance Assessment of Radioactive Waste Encapsulated in Iron-Enriched Basalt and Disposed at the Idaho National Engineering Laboratory's Radioactive Waste Management Complex," Proceedings of Spectrum 92 International Topical Meeting, Nuclear and Hazardous Waste Management, v. 2, p. 1442, Boise, Idaho, August 23-27.

Shropshire, D., M. Sherick, and C. Biagi, 1995a, Waste Management Facilities Cost Information for Hazardous Waste, INEL-95/0016, Rev. 1, (formerly EGG-WM-11432), June.

Shropshire, D., M. Sherick, and C. Biagi, 1995b, Waste Management Facilities Cost Information for Mixed Low-Level Waste, INEL-95/0014, Rev. 1, June.

Shropshire, D., M. Sherick, and C. Biagi, 1995c, Waste Management Facilities Cost Information for Transuranic Waste, INEL-95/0015, Rev. 1, (formerly EGG-WM-11274), June. 